
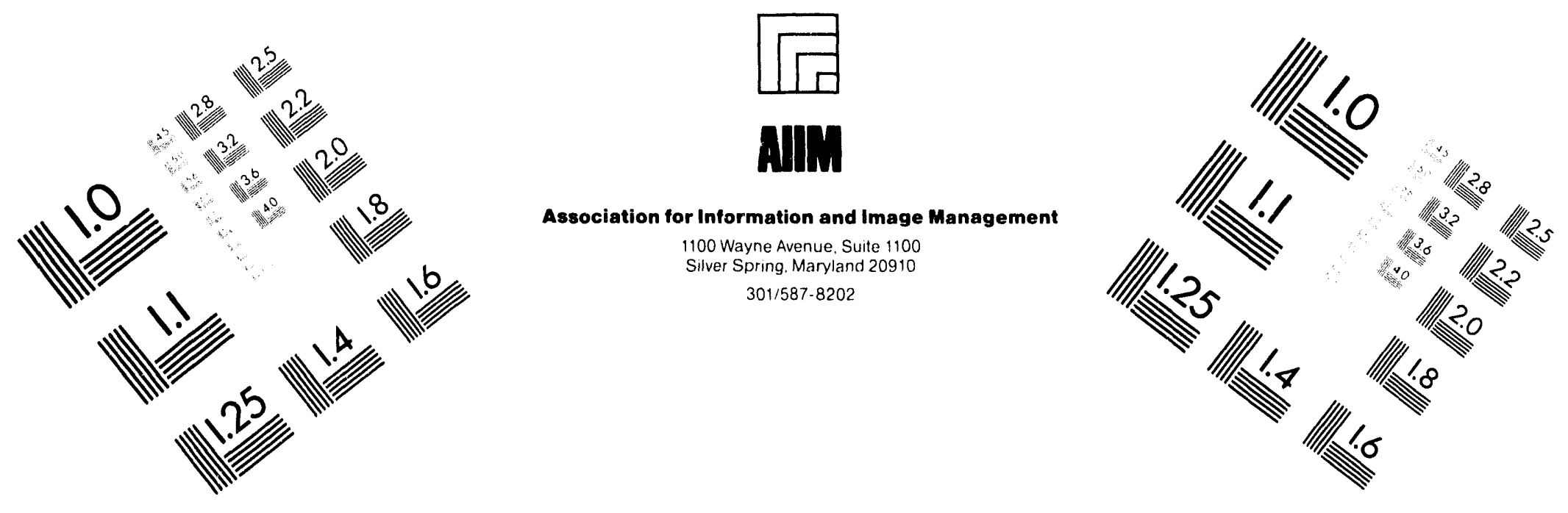

\title{
Centimeter
}

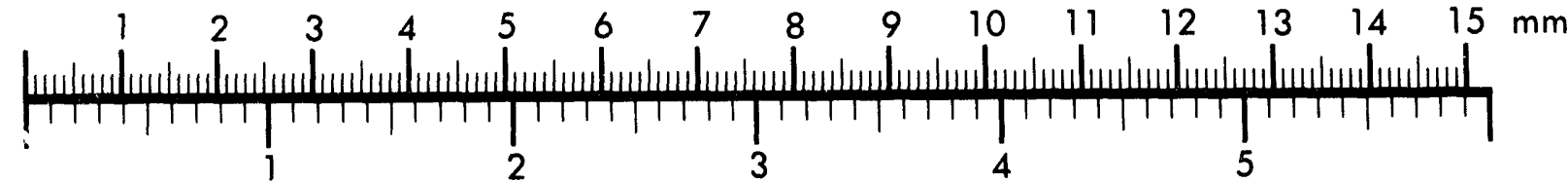

Inches
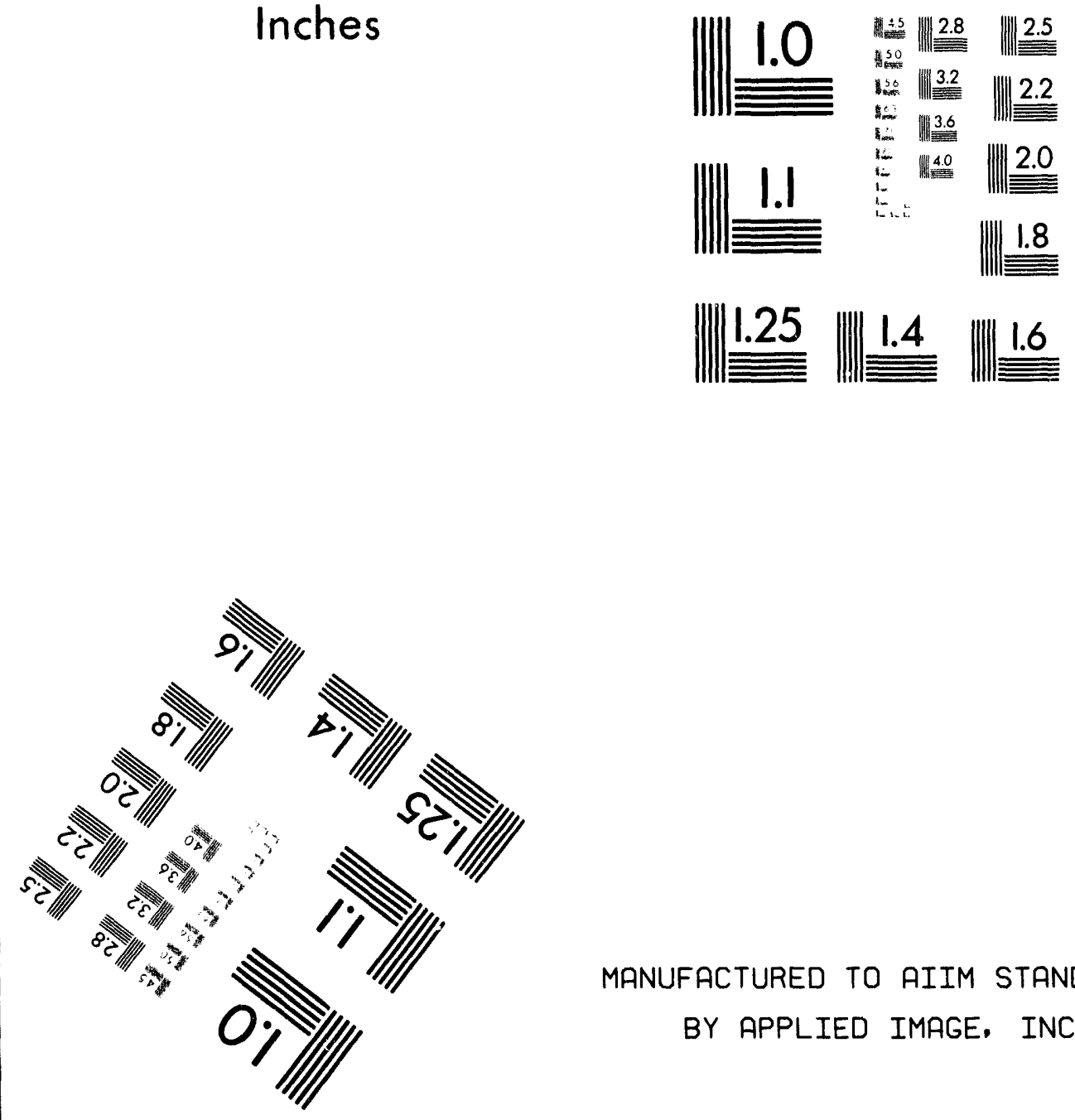

MANUFACTURED TO AIIM STANDARDS

BY APPLIED IMAGE. INC.

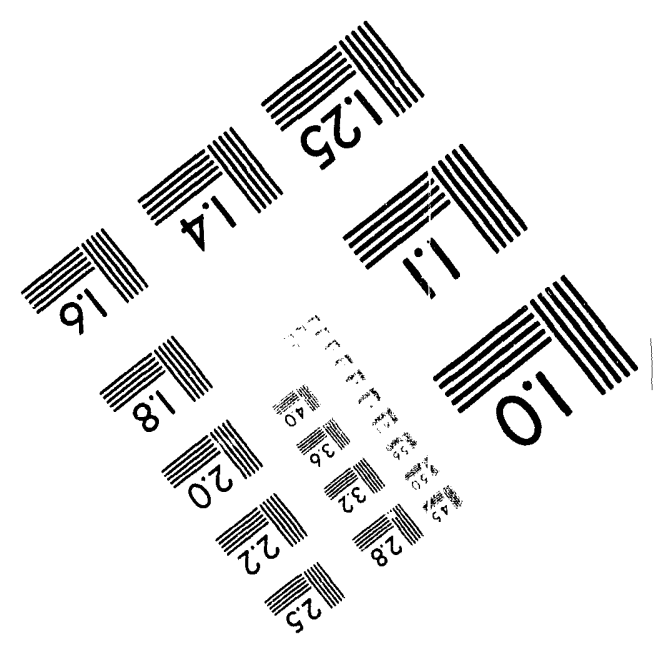



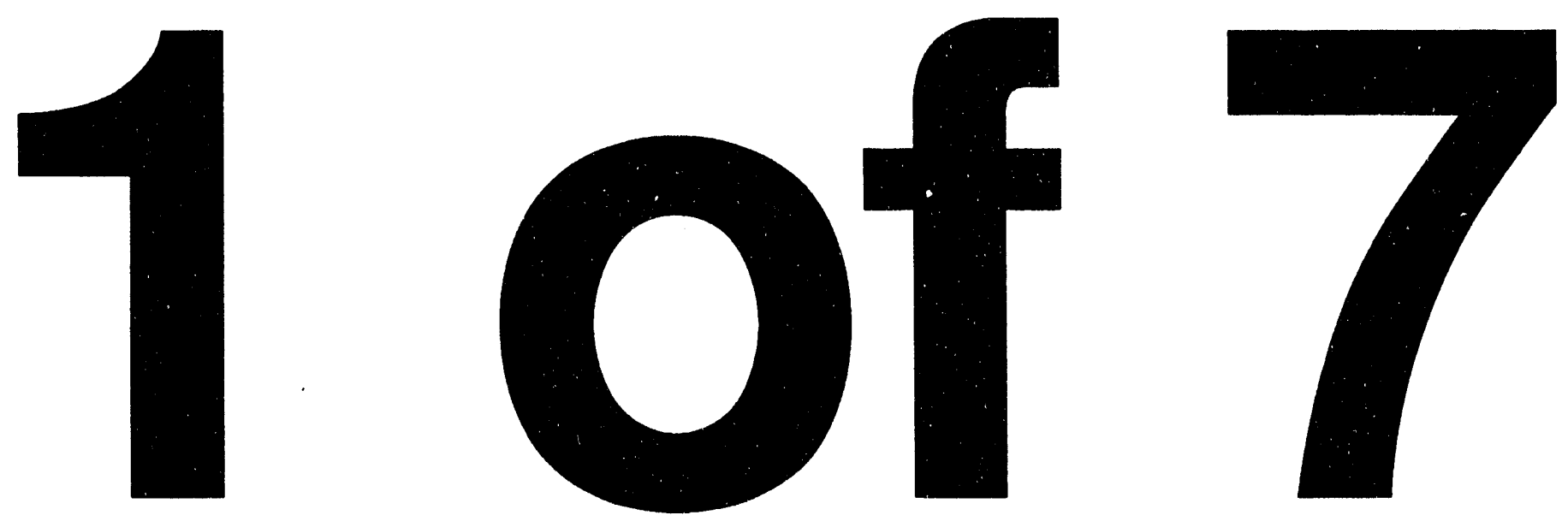


\section{RADIOLOGICAL PERFORMANCE ASSESSMENT FOR THE Z-AREA DISPOSAL FACILITY (U)}

by

J. R. Cook

Westinghouse Savannah River Company

Savannah River Site

Aiken, South Carolina 29808

J. R. Fowler

DOE Contract No. DE-AC09-89SR18035

This paper was prepared in connection with work done under the above contract number with the U.S.

Department of Energy. By acceptance of this paper, the publisher and/or recipient acknowledges the U. S. Government's right to retain a nonexclusive, royalty-free license in and to any copyright covering this paper, along with the right to reproduce and to authorize others to reproduce all or part of the copyrighted paper. 


\section{DISCLAIMER}

This report was prepared as an account of work sponsored by an agency of the United States Government. Neither the United States Government nor any agency thereof, nor any of their employees, makes any warranty, express or implied, or assumes any legal liability or responsibility for the accuracy, completeness, or usefulness of any information. apparatus, product, or process disclosed, or represents that its use would not infringe privately owned rights. Reference herein to any specific commercial product. process, or service by trade name, trademark. manufacturer, or otherwise does not necessarily constitute or imply its endorsement, recommendation, or favoring by the United States Government or any agency thereof. The views and opinions of authors expressed herein do not necessarily state or reflect those of the United States Government or any agency ihereof.

This report has been reproduced directly from the best available copy.

Available to DOE and DOE contractors from the Office of Scientific and Technical Information, P. O. Box 62. Oak Ridge. TN 37831; prices available from (615) $576-8401$.

Available to the public from the National Technical Information Service, U. S. Deparmeat of Commerce, 5285 Port Royal Rd., Springfield. VA 22161 
iSOLVE for $50.0 \mathrm{yr}$ in steps of $2 . \mathrm{e}-2$ increase by $1.0 \mathrm{max} 100 \mathrm{~min} 1 \mathrm{e}-10$ ISAVE U. V.P. S NOW

ISOLVE for $100.0 \mathrm{yr}$ in steps of $2.5 \mathrm{e}-2$ factor $1.0 \mathrm{max} 100 \mathrm{~min} 1 \mathrm{e}-101.1100000$

ISAVE U, V. P, S NOW

/SOLVE for 200.0 yr by $3 . e-2$ factor $1.0 \mathrm{max} 100 \mathrm{~min} 1 \mathrm{e}-101.1100000$

ISAVE U, V, P, S

END 


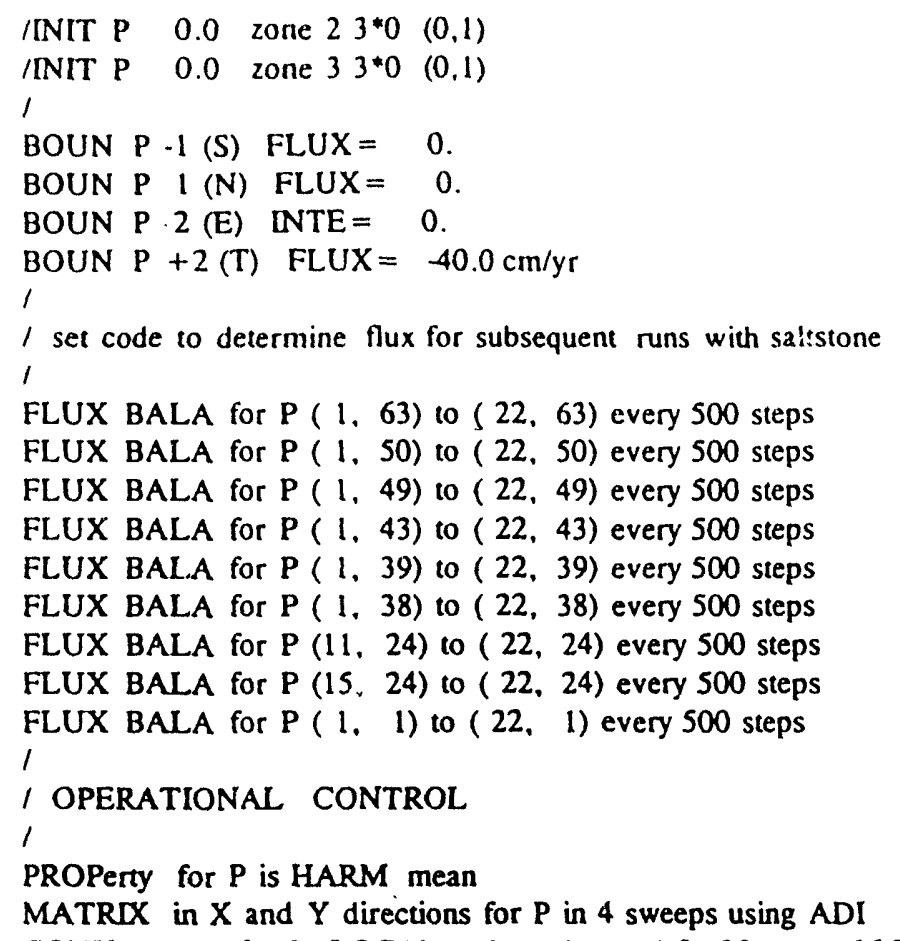


$0.55 \quad 3.2039 \mathrm{E}-02$

$0.56 \quad 3.6102 \mathrm{E}-02$

$0.57 \quad 4.0541 \mathrm{E}-02$

$0.58 \quad 4.5377 \mathrm{E}-02$

$0.59 \quad 5.0632 \mathrm{E}-02$

0.6 5.6332E-02

$0.61 \quad 6.2500 \mathrm{E}-02$

$0.62 \quad 6.9161 \mathrm{E}-02$

0.63 7.634IE-02

$0.64 \quad 8.4066 \mathrm{E}-02$

$0.65 \quad 9.2362 \mathrm{E}-02$

$0.66 \quad 1.0126 \mathrm{E}-01$

0.67 1.1078E-01

$0.68 \quad 1.2096 \mathrm{E}-01$

$0.69 \quad 1.3183 \mathrm{E}-01$

$0.7 \quad 1.4341 \mathrm{E}-01$

$0.71 \quad 1.5574 \mathrm{E}-01$

$0.72 \quad 1.6885 \mathrm{E}-01$

$0.73 \quad 1.8277 \mathrm{E}-01$

$0.74 \quad 1.9753 \mathrm{E}-01$

$0.75 \quad 2.1317 \mathrm{E}-01$

$0.76 \quad 2.2972 \mathrm{E}-01$

0.77 2.4721E-01

$0.78 \quad 2.6569 \mathrm{E}-01$

$0.792 .8518 \mathrm{E}-01$

$0.8 \quad 3.0573 \mathrm{E}-01$

$0.81 \quad 3.2736 \mathrm{E}-01$

$0.82 \quad 3.5013 \mathrm{E}-01$

$0.83 \quad 3.7406 \mathrm{E}-01$

$0.84 \quad 3.9920 \mathrm{E}-01$

$0.85 \quad 4.2558 \mathrm{E}-01$

0.86 4.5325E-01

0.87 4.8225E-01

$0.88 \quad 5.1262 \mathrm{E}-01$

$0.895 .4440 \mathrm{E}-01$

$0.9 \quad 5.7764 \mathrm{E}-01$

$0.91 \quad 6.1238 \mathrm{E}-01$

$0.92 \quad 6.4865 \mathrm{E}-01$

$0.93 \quad 6.8652 \mathrm{E}-01$

$0.947 .2602 \mathrm{E}-01$

0.95 7.6721E-01

0.96 8.1012E-01

$0.978 .5480 \mathrm{E}-01$

0.98 9.0131E-01

$0.999 .4970 \mathrm{E}-01$

$11.00008+00$

1

FOR zone 2 SGRAVEL

ROCK bulk den $2.60 \mathrm{e} 6 \mathrm{gm} / \mathrm{cub} / \mathrm{me}$, neff $=.380$, ntot $=0.380$, ndif $=0.380$

HYDRaulic prop. ss $=0.01 \mathrm{Kx} *=1.577 \mathrm{E}+7 \mathrm{Ky} *=1.577 \mathrm{E}+7 \mathrm{~cm} / \mathrm{yr} \mathrm{Kz}=1.577 \mathrm{E}+7 \mathrm{~cm} / \mathrm{yr}$ MULTiphase flow: VAN, $\mathrm{n}=3.70,0.0819 / \mathrm{cm}, \mathrm{Swr}=0.0263$

1

FOR zone 3 SCLAY

ROCK bulk den $2.60 \mathrm{e} 6 \mathrm{gm} / \mathrm{cub} \mathrm{me}$, neff $=.386, \mathrm{ntot}=0.386$, ndif $=0.386$

HYDRaulic prop. ss $=6 . \mathrm{E}-4, \mathrm{Kx} *=2.4 \mathrm{E}-1 \mathrm{Ky} \mathrm{y}^{*}=2.4 \mathrm{E}-1 \mathrm{~cm} / \mathrm{yr} \mathrm{Kz}=2.4 \mathrm{E}-1 \mathrm{~cm} / \mathrm{yr}$

MULTiphase flow: VAN, $n=1.33,8.18 E-4 / \mathrm{cm}$, Swr $=0.2974$

1

/ assign initial conditions based upon unit gradient calculation with $38.1 \mathrm{~cm} / \mathrm{yr}$ INIT P -51.0 zone $13^{*} 0(0,1)$ 


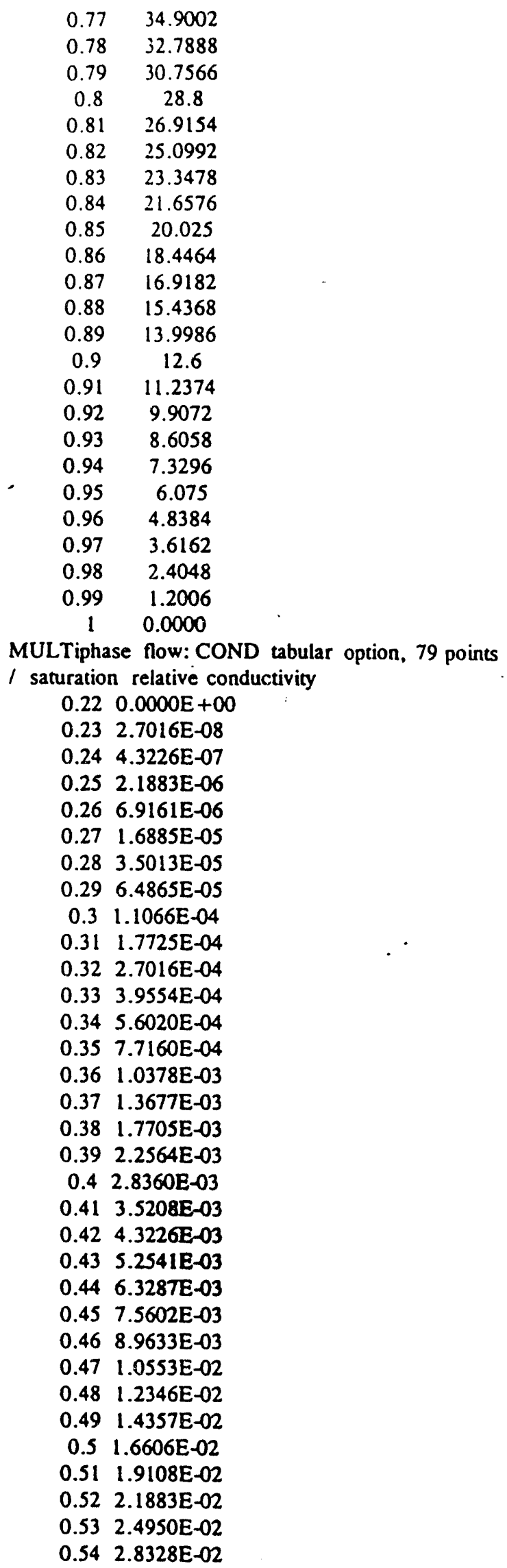


ROCK bulk den $1.60 \mathrm{gm} / \mathrm{cc}$. neff $=.439, \mathrm{ntot}=0.439$. ndif $=0.439$

HYDRaulic prop. ss $=1 . e-3, \mathrm{Kx}=332.6 \mathrm{Ky}=332.6 \mathrm{~cm} / \mathrm{yr}$

MULTiphase flow: tabular option. 79 points

I saturation matric potential in $\mathrm{cm}$
$0.22 \quad 378.3312$
$0.23 \quad 366.3198$
$0.24 \quad 354.5856$
$0.25 \quad 343.125$
$0.26 \quad 331.9344$
$0.27 \quad 321.0102$
$0.28 \quad 310.3488$
$0.29 \quad 299.9466$
$0.3 \quad 289.8$
$\begin{array}{ll}0.31 & 279.9054\end{array}$
$0.32 \quad 270.2592$
$0.33 \quad 260.8578$
$0.34 \quad 251.6976$
$0.35 \quad 242.775$
$0.36 \quad 234.0864$
$0.37 \quad 225.6282$
$0.38 \quad 217.3968$
0.39209 .3886
$0.4 \quad 201.6$
$0.41 \quad 194.0274$
$0.42 \quad 186.6672$
$0.43 \quad 179.5158$
$0.44 \quad 172.5696$
$0.45 \quad 165.825$
$0.46 \quad 159.2784$
$0.47 \quad 152.9262$
$0.48 \quad 146.7648$
$0.49 \quad 140.7906$
$0.5 \quad 135$
$0.51 \quad 129.3894$
$\begin{array}{ll}0.52 & 123.9552\end{array}$
$0.53 \quad 118.6938$
$0.54 \quad 113.6016$
$0.55 \quad 108.675$
$0.56 \quad 103.9104$
$0.57 \quad 99.3042$
$0.58 \quad 94.8528$
0.5990 .5526
$0.6 \quad 86.4$
$0.61 \quad 82.3914$
$0.62 \quad 78.5232$
$0.63 \quad 74.7918$
0.6471 .1936
$0.65 \quad 67.725$
$0.66 \quad 64.3824$
$0.67 \quad 61.1622$
$0.68 \quad 58.0608$
$0.69 \quad 55.0746$
$0.7 \quad 52.2$
$0.71 \quad 49.4334$
$0.72 \quad 46.7712$
$0.73 \quad 44.2098$
$0.74 \quad 41.7456$
$0.75 \quad 39.375$
$0.76 \quad 37.0944$ 


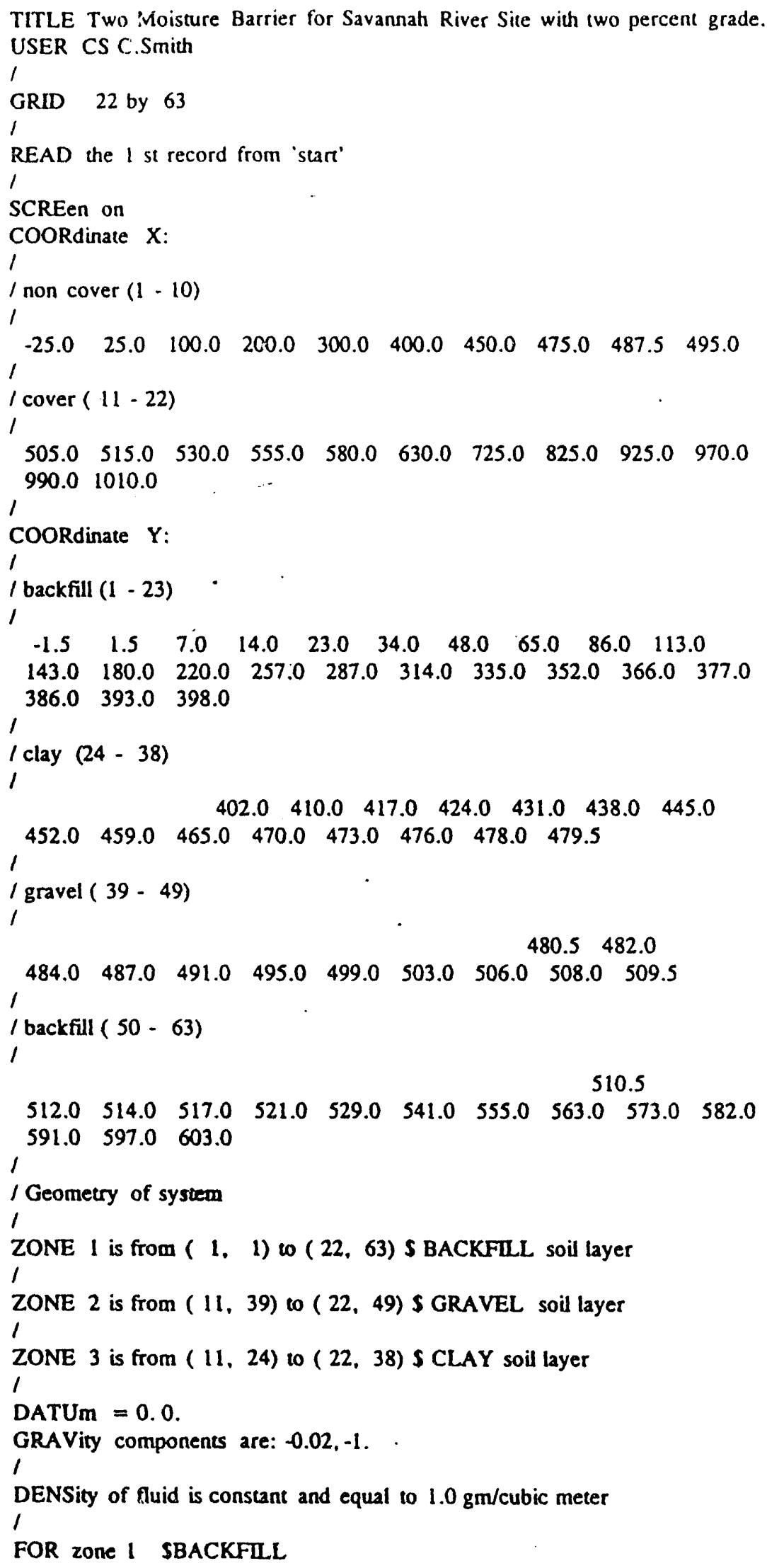


Attachment 1

PORELOW-3

Input Eile

Upper Moisture Barrier

Simulation 
- On page E-9, in Section E.2.3, in the second line of the second paragraph, "are based" should be "is based". In the last line, delete the comma after "groundwater flow".

- On page E-13, in the top paragraph, in the second sentence, insert "adjacent" before "to z-Area".

- On page E-16, in the top paragraph, in the fourth line, delete "Eig. E.2-4" just before "Zone 6".

- On page E-25, in Eigure E.2-10, the x-axis label should say "moisture", rather than "moiture".

- On page F-2, under PORrLOW-3D, in the second line, replace "of" with "and". Under SOETWARE VAIIDATION, in the first line, replace "resting" with "testing".

- On page $F-6$, in section 6.2.2, change the last line to read: "uniquely identifies each data set and corresponding simulation results."

- On page F-7, in Section 8.0 , in the fourth line, replace "such and Idaho" with "such as Idaho".

- On page F-8, in the last reference, in the second line, replace "Mustifluid" with Multifluid".

- On page $F-9$, in the upper righthand corner of the page, replace "EGG-EELS-003" with "EGG-EELS-10666"; in the center of the page, replace "1992" with "March, 1993".

- On page $\mathrm{H}-2$, in the caption for Figure $\mathrm{H} .1-2$, replace "Fractionan" with "Fractional", and.replace "of a function" with "as a function".

- On page $\mathrm{H}-3$, in the titles for the first, third and fourth graphs, delete the first occurrence of "to".

- On page $\mathrm{H}-20$, the last sentence of the footnote to Table H.2-1 should read: "To the right of the near-field uncertainty run number are thirteen numbers, representing the thirteen nitrate fractional fluxes at thirteen points in time, used for the saturated flow runs." 
- At the bottom of page c-5, in footnote c, the word "ration" should be "ratio".

At the bottom of page $\mathrm{C}-5$, the following two footnotes should be added:

d "...+ d" indicates there are daughters in equilibrium. Activity reported is that of the parent.

- Total activity includes the activity of radioactive daughters in secular equilibrium with the parent (indicated by "...+ $d^{n}$ ).

- On page C-17, at the bottom of the page, in the second line of the caption, the parentheses should be closed at the end of the sentence.

- On page c-65, in the table at the bottom of the figure, the maximum concentration of $4.4 \mathrm{pCi} / 1$, as a result of fractures, occurs at 1.5 $\times 10^{4}$ years rather than $1.4 \times 10^{4}$ years.

- On page D-2, in section D.1.2, in the first paragraph, in the last sentence, insert "the runs showed" after "Further," .

- On page D-5, in the Title for Table D.3-1, in the second 11ne, change "formation" to "formulation". The second compound listed should be "Al2O3" rather than "A1203"; the eleventh compound listed should be "SO3" rather than "SO3".

- On page $D-10$, in the top paragraph, in the fourth line, "cement ore fluids" should be "cement pore fluids".

- On page D-13, in the title of Table D.4-1, "interstitual" should be "interstitial".

- On page D-14, in Table D.4-2, in the left column, the first entry for $\mathrm{Na}$ species should be "Na+" rather than "Na"; the first entry for $K$ species should be " $K+n$ rather than " $K " ;$ the third entry for $\mathrm{SO}_{4}{ }^{2-}$ species should be " $\mathrm{KSO}_{4}^{-"}$ rather than "KSO $4 "$; the first entry for $\mathrm{NH}_{4}$ species should be " $\mathrm{NH}_{4}{ }^{+\infty}$ rather than "NH4"; the entry for $\mathrm{NO}_{2}$ species should be " $\mathrm{NO}_{2}^{-"}$. racher than "NO $2^{\prime}$. In the right column, the first entry for $\mathrm{NO}_{3}$ species should be "NO $3^{-n}$ rather than "NO $3^{\prime \prime}$; the first entry for $\mathrm{CO}_{3}$ - species should be "NaHCO 3 , aq" rather than "NaHCO $3, \mathrm{aq}^{-"}$; the first entry for $\mathrm{Fe}^{+3}$ species should be "Fe(OH) $4^{-"}$ rather than " $\mathrm{FeOH}_{4}^{-n}$, the second entry should be "Fe(OH) $2^{+ \text {" }}$ rather than "FeOH2n, the third entry should be "Fe(OH) $3^{n}$ rather than "EeOH 3 ".

- On page E-1, in Section E.1.1, in the third paragraph, in the sixth line, "south-eastern" should be "southeastern". 
- On page A-49, in Section A.3.1.3, in the second line, the 222 Rn flux value should be $0.1 \mathrm{pCi} \mathrm{m} \mathrm{m}^{-2} \mathrm{~s}^{-1}$ rather than $7.3 \times 10^{-1}$.

- On page A-51, in Section A.3.2.3, in the first line, the reference should be to equation A.3.5, rather than to equation A.3.12. In the third line, the reference should be to equation A.3.6 rather than to equation A.3.13.

- On page A-52, In Section A.3.2.4, equation A.3.7 should be rewritten as follows:

$$
\begin{aligned}
& Q_{s s}=\frac{\frac{R}{K_{r}+K_{V}}}{V_{r}} \\
& R=J_{i} A_{b}
\end{aligned}
$$

Where

$$
\begin{aligned}
& Q_{s s}=\text { steady-state room concentration }\left(\mathrm{pCi} \mathrm{m}^{-3}\right) \\
& R=\text { radionuclide input rate }\left(\mathrm{pCi} \mathrm{s}^{-1}\right) \\
& \mathrm{K}_{r}=\text { radionuclide decay constant }\left(\mathrm{s}^{-1}\right) \\
& \mathrm{K}_{\mathrm{V}}=\text { room ventilation rate constant }\left(\mathrm{s}^{-1}\right) \\
& \mathrm{v}_{r}=\text { volume of room }\left(\mathrm{m}^{3}\right) \\
& \left.\mathrm{J}_{1}=\text { radionuclide flux (pCi } \mathrm{cm}^{-2} \mathrm{sec}^{-1}\right) \\
& \mathrm{A}_{\mathrm{b}}=\text { floor area of the room }\left(\mathrm{cm}^{2}\right)
\end{aligned}
$$

In equation A.3.8 and in the following definition of terms, "Q" should be "Qss".

- On page A-60, in Table A.4-2, under the line containing "Sb-126", the following line should be inserted (this line should be indented just as the line for $(5-126)$ :

$$
\begin{array}{ll}
\mathrm{Sb}-126 \mathrm{~m} & 0.1 \\
& 7.3 \times 10^{-5}
\end{array}
$$

- On pages C-2 through C-5, in Table C.1-1, each nuclide which is followed by "+ $d^{n}$ should have a reference to footnote $d$ added. For example, "Ru-106 + d" should be "Ru-106 + ddn.

- On page C-5, the "Total Activity" entry should reference footnote $e$; i.e., the entry should be "Total Activity".

The value for Total Activity of the Nominal Blend should be $2.90 \mathrm{x}$. $10^{-4} \mathrm{Ci} / \mathrm{liter}$ rather than $2.81 \times 10^{-4}$. 
- On page A-22, in Table A.1-3, the initial pore concentration of Nitrate should be $" 2.3 \times 10^{5}$ " rather than $" 1.6 \times 10^{5 "}$.

- On page A-29, in the definition of terms for the first equation, the last two terms $z_{0}$ and $x_{0}$ should be upper case to refer to the numerators in the first two equations after "where". In the definition of $\lambda_{j}$, the " $z_{0}$ " term should be lower case.

- On page $A-33$, in the second equation (which defines $H_{2}(\lambda)$ ), in the numerator, the sign between the hyperbolic sine and the sine terms should be minus instead of plus. In other words, the equation should be:

$\mathrm{H}_{2}(\lambda)=\lambda\left(\frac{\sinh 2 \lambda-\sin 2 \lambda}{\cosh 2 \lambda-\cos 2 \lambda}\right)$

In the equation above "where the solution depends upon these dimensionless variables that follow:" the "aCf $f$ in the numerator should be " $\alpha C_{f}$ ".

- On page A-35, in Table A.1-5, the value used for $\phi_{f}$, the fracture porosity, should be $11.7 \times 10^{-5}$ " rather than $1.0 "$.

- On page A-39, in section A.2.1.2, in the fourth line replace "Zone $5 b$ (the Congaree Formation)" with "zone $5 a$ (the Congaree Formation)".

- On page A-40, in Table A.2-1, the values for vertical hydraulic conductivity for zones $6 / 7 / 8$ and 5 b should be $n 4 \times 10^{-6 n}$ and $" 2 x$ 10-9". In Section A.2.1:4, in the last paragraph, in the first. line, the units for the effective diffusion coefficient should be $" \mathrm{~cm}^{2} / \mathrm{s} "$ rather than $" \mathrm{~cm} / \mathrm{s} "$.

- On page A-43, in section A.2.2.2, in the first paragraph, in the seventh line, delete "of". In the second paragraph, in the last line, change "are" to "1s".

- On page A-45, In the second paragraph, in the fourth line, delete "were obtalned"; in the sixth line, change "setting" to "settings".

- On page A-47, in section A.3.1, in the fourth line, insert " $/ \mathrm{cm}^{3} "$ after "g". In Section A.3.1.1, in the second line, the reference should be to "Subpart Q", rather than to "Subpart O".

- On page A-48, equation A.3.1 should be written as follows:

$J_{S}=10^{4} R P E \sqrt{\lambda D_{S}} \tanh \left[\sqrt{\frac{\lambda}{D_{S}}}\left(x_{S}\right)\right]$ 
- On page 5-2, in Table 5.1-1, for the Degraded Saltstone/Vault Scenarios, the maximum predicted concentration for nitrate should be $53 \mathrm{mg} / \mathrm{L}$ rather than $38 \mathrm{mg} / \mathrm{L}$. The column headings "Maximum predicted dose or concentration" under Intact Saltstone/Vault Scenarios and Degraded Saltstone/Vault Scenarios should be deleted. Insert new headings as follows: Insert "Best estimate dose" just above the dose results of "0.6 mrem per year" and "50 - 110 mrem per year" for the inadvertent intruder; Insert "Maximum predicted dose or concentration" just above the results for the groundwater pathway.

- On page 7-1, in the first reference, in the first line, replace "Date" with "Data". In the sixth reference, in the first line, replace "Celisum" with "Cesium".

- On page 7-2, in the seventh reference, in the first line, delete "24".

- On page 7-3, in the fifth reference, in the first line, change "S. T." to "S. J.".

- On page 7-4, in the ninth reference, in the second line, insert "DP1493 " after "Ground.".

- On page 7-8, in the sixth reference, in the second line, delete "24" before "Savannah River Site".

- On page 7-9, in the sixth reference, in the second line, change "DOE/E15/0082" to DOE/EIS/0082".

- On page 7-10, in the eighth reference, in the second line, insert "DPST-85-417" after "Saltstone.".

- On page 7-11, in the.first reference, in the fourth line, replace "Chase T. Main" with "Chas. T. Main".

- On page A-9, in Figure A.1-4, the legend for the fourth set of values, denoted by triangles, should be "Coarse Sand" rather than "Course Sand".

- On page A-12, in the first paragraph, in the fifth line, insert "for" after "empirically". In the second paragraph, in the fourth line, change "assume" to. "assumes".

- On page A-13, in Table A.1-2, in the Title, replace "assumed" with "used": the entries for Nitrate under Clay and Gravel should be "O.".

- On page A-16, in the last sentence of the top paragraph, it is stated that a copy of the input file for the PORFLOW simulations of the upper moisture barrier is in Appendix C.2. This input file was inadvertently omitted from Appendix C.2. A copy is attached to this errata.

- On page A-19, in the fifth line of the top paragraph, change "all to" to "ail of". 
- On page 3-59, in the second paragraph, in the last sentence, replace "assumed" with "used".

- On page 3-60, in Table 3.3-1, in the title, replace "assumed" with "used". In the heading of the second column from the left, insert "Saturated Hydraulic Conductivity" above $K_{S}$. In the fifth column from the left, the reference to footnote a should follow $\alpha$ rather than $\left(\mathrm{cm}^{-1}\right)$. Footnote $c$ should be deleted.

- On page 3-61, in the second paragraph, in the eighth line, insert "vault" before "fractures"; in the tenth line, insert "saltstone" before "pours".

- On page 3-64, in the last sentences of the first and last paragraphs, replace "assumed" with "used".

- On page 3-65, in the heading for the second column, change "Assumed property value" to "Eroperty value used".

- On page 3-86, in section 3.4.4, in the fifth line, replace "DOE Order 5820.2a" with "DOE Order 5820.2A".

- On page 4-2, in the last line of the last paragraph, delete "Table".

- On page 4-5, in Table 4.1-3, the time of peak flux for tritium when infiltration is $2 \mathrm{~cm} /$ year should be " $9.1 \times 10^{1 "}$ rather than $" 9.1 \times 10^{-1 "}$.

- On page 4-6, in Table 4.1-4, the peak flux for nitrate should be $" 4.9 \times 10^{9}$ rather than $" 3.4 \times 10^{9}$ "

- On page 4-9, in Table 4.1-6, the peak concentration for nitrate should be $" 5.3 \times 10^{1 /}$ rather than $" 3.6 \times 10^{1 "}$. The peak concentration for C14 should be $" 6.0 \times 10^{-5}$ " rather than $" 6.0 \times 10^{-6 "}$.

- On page 4-26, in section 4.1.4.3, in the fourth paragraph, in the third line, change "Sect. 4.1.4.2" to "Sect. 4.1.4.1".

- On page 4-35, in section 4.2.1.2, in the second paragraph, in the seventh line, insert "and technetium" after "nitrate".

- On page 4-43, In the second paragraph, in the fourteenth line, delete "from"; in the fifteenth line, delete the first occurrence of "and the".

- On page 4-50, in section 4.3.1, in the last sentence, change "(38 $\mathrm{mg} / \mathrm{L}$ at 1400 years)" to " $(53 \mathrm{mg} / \mathrm{L}$ at 1400 years)"; change "is close to" to "exceeds".

- On page 4-55, in section 4.3.3, in the fourth line, change "are 84\% of" to "exceeds". 


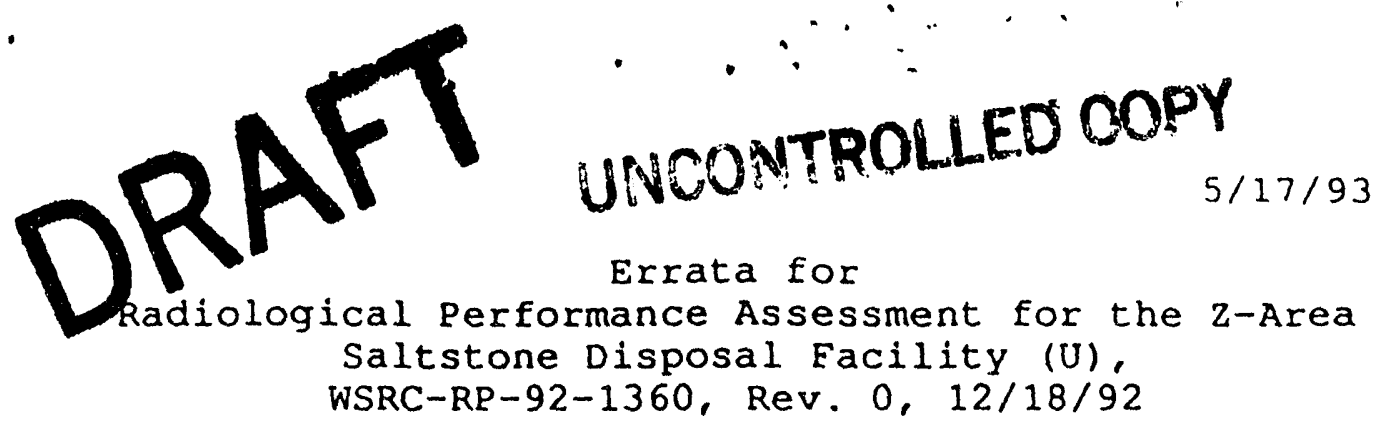

- On page $v$, for Sections 4.1 .3 and 4.1.4, "Doses" should be "Dose".

- On page vii, for Appendix F, insert "QA" after "SOFTWARE".

- On page $x$, for C.2-4, close the parenthesis at the end of the second line.

- On page xvii, for D.3-1, replace "formation" with "formulation".

- On page $x x$, insert the following after "SSHT Salt Solution Hold Tank": "TDS Total Dissolved Solids".

- On page $x \times i i$, in the eleventh line, replace "complies with" with "exceeds"; in the thirteenth line, replace "38 $\mathrm{mg} / \mathrm{L}$ " with "53 $\mathrm{mg} / \mathrm{L}$ "; in the fourteenth line, replace "approaches" with "exceeds".

- On page 1-8, in the first paragraph after the performance objectives, in the second line, delete "usually" and insert "at SRS" after "has" been interpreted":

- On page 1-9, in the next-to-the-last paragraph, in the third and seventh lines, replace "effective dose equivalent" with "effective dose"

- On page 2-1, in the second paragraph, in the eighth line, omit "(chemical and radiochemical)".

- On page 2-7, in section 2.1.4.1, in the second paragraph, in the fifth line, insert a comma before "the Pen Branch fault".

- On page 2-9, in section 2.1.4.2, in the second paragraph, in the second line, "200 year" should be "200 years".

- On page 2-13, in section 2.1.6, in the last sentence of the last paragraph, replace "with an average velocity of approximately $3 \mathrm{~m} \mathrm{~s}$ corresponding to a flow of $1200 \mathrm{~m}^{3} \mathrm{~s}^{-1 \text { n }}$ with "with an average flow of approximately $160 \mathrm{~m}^{3} \mathrm{~s}^{-1 n}$.

- On page 2-17, in Section 2.1.10, in the first line of the second paragraph, replace "number" with "member".

- On page 2-30, in section 2.2.4, in the first line of the first paragraph, replace "are" with "is".

- On page 2-33, in Table 2.2-3, the seventh Parameter listed should be "Suspended Solids" rather than "Suspended soils".

- On page 2-37, in section 2.3.1.1, in the second paragraph, in the fifth line, replace "TBP" with "TPB". 
- On page 2-41, insert an asterisk after the Table itle bottom of the page, insert the following before the ist of footnotes: "* Density of solutions is $1.25 \mathrm{~g} / \mathrm{mL} "$.

- On page 2-53, in Figure 2.4-1, in the legend for the two upper curves, "Ref" should be "non-slag".

- On page 2-54, in Figure 2.4-2, the legend for the solid circle symbol should be "No Cap non-slag Saltstone Lysimeter" rather than "No Cap Reference Saltstone Lysimeter". In the title for the figure, replace "Slag- and Cement-Based" with "Slag and non-slag".

- On page 2-60, in the fourth paragraph, in the seventh'line, replace "composition of these steams" with "compositions of these streams".

- On page 2-64, in section 2.6.4.1, in the sixth line, replace "1984" with "1983".

- On page 2-67, in Table 2.6-2, add the following to footnote $b$ : "ITP waste was assumed to be aged 15 years".

- On page 2-70, in Table 2.6-4, the entry for Total alpha for Cell A should be $" 1.6 \times 10^{-3 n}$ rather than $" 2.5 \times 10^{-5 n}$.

- On page 2-71, in section 2.7.1, in the first paragraph, in the eleventh line, replace "sysem" with "system".

- On page 2-75, in Table 2.7-1, the hydraulic conductivity of Backfill should be $1 \times 10^{-4} \mathrm{~cm} / \mathrm{s}$.

- On page 3-3, in the third paragraph, in the third line, "(sect. $1.2)$ " should be "(Sect. 1.3)".

- On page 3-5, in the second paragraph, in the fifth line, change "is" to "are".

- On page 3-9, under sulfate attack, in the second paragraph, in the second and third lines, replace "groundwater" with "soil water".

- On pages 3-16 and 3-17, in Figures 3.1-6 and 3.1-7, the label for the vertical axis should be "Percent Rebar Remaining".

- On page 3-20, in the title for Table $3.1-1$, replace "Langton $(1989 \mathrm{~b})$ " with "(Langton 1989b)". In the heading for the second column insert "In salt solution" after "Concentration limit".

- On page 3-22, in the second paragraph, in the third line, change "indivi-dual" to "individual".

- On page 3-56, in section 3.3.1, in the second paragraph, in the second line, insert "was" after "analysis".

- On page 3-58, in the first paragraph, in the fourth line, insert "out" after "carried". 


\section{CONTENTS}

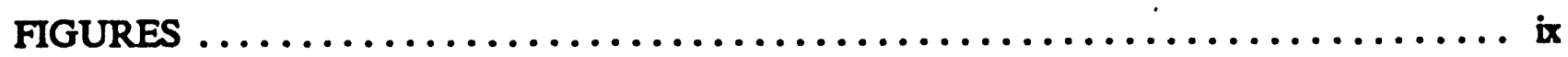

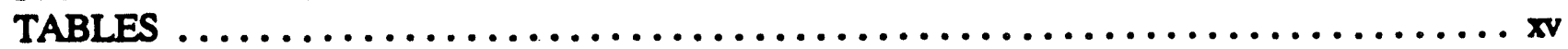
ACRONYMS AND ABBREVIATIONS $\ldots \ldots \ldots \ldots \ldots \ldots \ldots \ldots \ldots \ldots \ldots \ldots \ldots$ xix EXECUTIVE SUMMARY $\ldots \ldots \ldots \ldots \ldots \ldots \ldots \ldots \ldots \ldots \ldots \ldots \ldots \ldots \ldots \ldots$

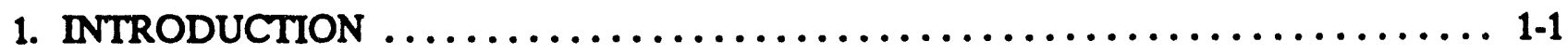

1.1 PURPOSE AND SCOPE $\ldots \ldots \ldots \ldots \ldots \ldots \ldots \ldots \ldots \ldots \ldots \ldots \ldots$

1.2 SOURCE OF WASTEWATER TO BE TREATED AND

DISPOSED IN Z-AREA $\ldots \ldots \ldots \ldots \ldots \ldots \ldots \ldots \ldots, 1-4$

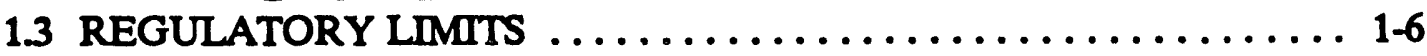

1.3.1 Regulatory Radiological Limits .............. 1-7

1.3.2 Operational Radiological Limits $\ldots \ldots \ldots \ldots \ldots \ldots \ldots$ 1-7

1.3.3 Chemical Composition Limits .............. 1-7

1.4 PERFORMANCE OBJECTIVES $\ldots \ldots \ldots \ldots \ldots \ldots \ldots \ldots \ldots \ldots, 1-8$

2. DISPOSAL FACILITY DESCRIPTION $\ldots \ldots \ldots \ldots \ldots \ldots \ldots \ldots \ldots \ldots \ldots \ldots \ldots \ldots \ldots \ldots$

2.1 REGIONAL CHARACTERISTICS $\ldots \ldots \ldots \ldots \ldots \ldots \ldots \ldots \ldots . \ldots \ldots$

21.1 Geography of the Region $\ldots \ldots \ldots \ldots \ldots \ldots \ldots \ldots .2-1$

21.2 Demography....................... 2-3

2.3 Meteorology $\ldots \ldots \ldots \ldots \ldots \ldots \ldots \ldots \ldots \ldots \ldots 2-6$

2.1 .4 Seismicity $\ldots \ldots \ldots \ldots \ldots \ldots \ldots \ldots \ldots \ldots \ldots, 2-7$

2.5 Hydrogeology ...................... 2-10

2.1.6 Surface Water Hydrology $\ldots \ldots \ldots \ldots \ldots \ldots \ldots \ldots .2-13$

21.7 Water Quality and Usage $\ldots \ldots \ldots \ldots \ldots \ldots \ldots \ldots .2-13$

21.8 Soils $\ldots \ldots \ldots \ldots \ldots \ldots \ldots \ldots \ldots \ldots \ldots \ldots \ldots .2-14$

21.9 Ecology $\ldots \ldots \ldots \ldots \ldots \ldots \ldots \ldots \ldots \ldots \ldots . \ldots \ldots . \ldots \ldots$

2.1.10 Existing Radiological Environment ........... 2-17

2.2 Z-AREA SITE DESCRIPTION .................... 2-21

221 Z-Area Location, Description, and Land Use ...... 2-21

2.2 .2 Hydrogeology of Z-Area $\ldots \ldots \ldots \ldots \ldots \ldots \ldots .2-23$

22.3 Surface Water in the Vicinity of Z-Area ......... 2-30

2.24 Water Quality and Usage in the Z-Area Vicinity .... 2-30

2.2.5 Existing Radiation Environment at Z-Area ........ 2-32

2.3 DESCRIPTION OF Z-AREA OPERATIONS, FACILITIES, AND

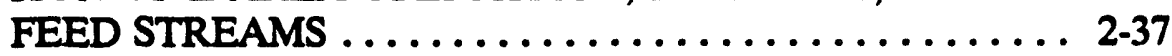

2.3.1 Description of the Salt Solution Feed to Z-Area

(Design Basis) $\ldots \ldots \ldots \ldots \ldots \ldots \ldots . \ldots .2-37$

2.3.2 Description of Dry Materials $\ldots \ldots \ldots \ldots \ldots \ldots \ldots . \ldots .2-42$

2.3.3 Saltstone Production and Disposal $\ldots \ldots \ldots \ldots \ldots .2-42$

Rev. 0

iii 
24 SALTSTONE WASTE FORM $\ldots \ldots \ldots \ldots \ldots \ldots \ldots \ldots \ldots \ldots .2-46$

2.4.1 History of Saltstone Development $\ldots \ldots \ldots \ldots \ldots \ldots .2-46$

24.2 Physical Characteristics of Saltstone $\ldots \ldots \ldots \ldots \ldots$ 2-55

24.3 Chemical Composition $\ldots \ldots \ldots \ldots \ldots \ldots \ldots \ldots$ 2-56

2.5 DESCRIPTION OF THE SALTSTONE DISPOSAL LANDFILL SITE 2.58

25.1 Site Layout and Capacity $\ldots \ldots \ldots \ldots \ldots \ldots \ldots .2 .58$

2.5 .2 Vault Description ..................... 2-61

2.6 PROJECTED SDF WASTE INVENTORY $\ldots \ldots \ldots \ldots \ldots \ldots \ldots, 2-62$

26.1 Disposal Capacity in the SDF $\ldots \ldots \ldots \ldots \ldots \ldots$ 2-63

2.6.2 Projected Minimum Saltstone Inventory in the SDF ... 2-63

2.6.3 Projected Inventory of Components $\ldots \ldots \ldots \ldots \ldots .2-63$

2.6.4 Existing Inventory in the SDF $\ldots \ldots \ldots \ldots \ldots \ldots \ldots 2-64$

27 SDF CLOSURE CONCEPT $\ldots \ldots \ldots \ldots \ldots \ldots \ldots \ldots \ldots \ldots \ldots .2-68$

27.1 Physical Description of the SDF Closure Concept .... 2-71

2.7.2 Functional Description of the SDF Closure Concept .. 2-74

2.8 SUMMARY OF DISPOSAL FACILITY DESCRIPTION ........ $2-74$

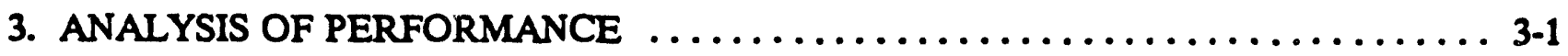

3.1 SOURCE TERM $\ldots \ldots \ldots \ldots \ldots \ldots \ldots \ldots \ldots \ldots \ldots \ldots \ldots \ldots, 3.1$

3.1.1 Chemical and Radionuclide Inventories $\ldots \ldots \ldots \ldots \ldots$ 3-3

3.1.2 Release Mechanisms ................... 3-3

3.1.3 Engineered Barriers Degradation and Failure ........ 3-6

3.1.4 Non-Radioactive Constituents $\ldots \ldots \ldots \ldots \ldots \ldots \ldots$ 3-19

3.2 PATHWAYS AND SCENARIOS $\ldots \ldots \ldots \ldots \ldots \ldots \ldots \ldots \ldots \ldots, 3-21$

3.2.1 Time Periods of Concern ................ 3-21

3.22 Transport Pathways $\ldots \ldots \ldots \ldots \ldots \ldots \ldots \ldots .3 .23$

3.2.3 Exposures of Off-Site Members of the Public and

Protection of Groundwater ............ 3-30

3.2.4 Exposure Scenarios for Inadvertent Intruders ....... 3-41

3.3 MODELS AND ASSUMPTIONS $\ldots \ldots \ldots \ldots \ldots \ldots \ldots \ldots \ldots, 3.55$

3.3.1 Near-Field Model $\ldots \ldots \ldots \ldots \ldots \ldots \ldots \ldots \ldots \ldots, 3-56$

3.3.2 Groundwater Transport Model ............. 3-62

3.3.3 Models for Dose Estimation ................. 3-66

3.4 PERFORMANCE ANALYSIS METHODOLOGY .......... 3-68

3.4.1 Near-Field Model Analysis ............... 3-68

3.4.2 Groundwater Flow and Mass Transport .......... 3-77

3.4.3 Methods for Dose Analysis ................. 3-85

3.4.4 Quality Assurance .................... 3.86

3.5 SUMMARY OF ANALYSIS OF PERFORMANCE ........... 3.89

Rev. 0

iv 


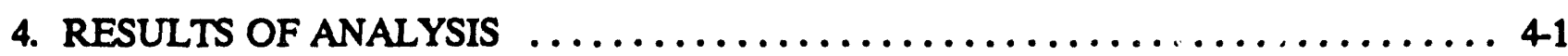

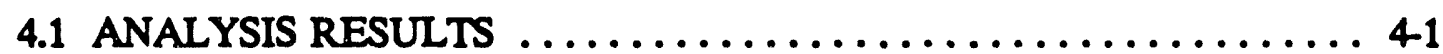

4.1.1 Near-Field Results ................... 4-1

4.1.2 Groundwater Concentrations ............. 47

4.1.3 Doses Analysis for Off-Site Releases of Radionuclides . 4-10

4.1.4 Doses Analysis for Inadvertent Intruders ........ 4-13

4.2 SENSITTVITY AND UNCERTAINTY ANALYSES .......... 4-31

4.2. Analysis for Intact and Degraded Vaults ......... 4-31

4.22 Analysis for Groundwater Transport .......... 4-40

4.2.3 Analysis of Dose Model from Off-Site Releases ..... 4 4-45

4.2. Analysis of Dose Models for Inadvertent Intruders ... 4 4-46

4.3 INTERPRETATION OF RESULTS ................. 4-50

4.3.1 Off-Site Doses and Groundwater Protection ....... 4-50

4.3.2 Inadvertent Intruders $\ldots \ldots \ldots \ldots \ldots \ldots \ldots \ldots, 4.53$

4.3.3 Conclusions $\ldots \ldots \ldots \ldots \ldots \ldots \ldots \ldots \ldots \ldots, 455$

5. PERFORMANCE EVALUATION $\ldots \ldots \ldots \ldots \ldots \ldots \ldots \ldots \ldots \ldots \ldots \ldots \ldots \ldots \ldots \ldots$. 5 -1

5.1 COMPARISON TO PERFORMANCE OBJECTIVES .......... 5-1

5.2 DESIGN CHANGES REQUIRED TO MEET PERFORMANCE OBJECTTVES $\ldots \ldots \ldots \ldots \ldots \ldots \ldots \ldots \ldots \ldots \ldots, 5,2$

5.3 DATA AND RESEARCH NEEDS $\ldots \ldots \ldots \ldots \ldots \ldots \ldots \ldots \ldots, 5,3$

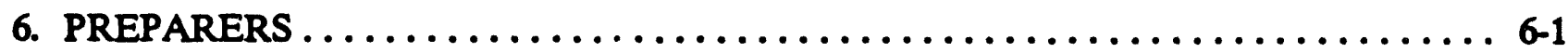

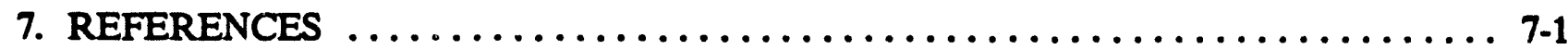

-

APPENDIX A DETAIIS OF MODELS AND ASSUMPTIONS

A.1 NEAR-FIELD MODEL $\ldots \ldots \ldots \ldots \ldots \ldots \ldots \ldots \ldots \ldots \ldots \ldots \ldots$ A-1

A.1.1 Infiltration .......................... A-1

A.1.2 Flow and Mass Transport Through Intact Vaults ...... A-5

A.1.3 Flow and Mass Transport Through Fractured Vaults .. A-26

A.2 GROUNDWATER FLOW AND MASS TRANSPORT MODEL

AND SIMULATIONS ................... A-34

A.2.1 Conceptual Saturated Flow and Transport Model .... A-34

A.2.2 Saturated Flow and Transport Simulations ......... A-42

A.3 ANALYSIS OF ATMOSPHERIC EFFLUENTS ........... A-46

A.3.1 Analysis of Maximum Radon-222 Dose Potential ..... A-47

A.3.2 Analysis of Maximum H-3 and C-14 Dose Potential ... A-49

Rev. 0 
A.4 DOSE ANALY'SIS FOR OFF-SITE INDIVIDUALS AND

INADVERTENT INTRUDERS $\ldots \ldots \ldots \ldots \ldots \ldots \ldots \ldots$ A.53

A.4.1 Introduction $\ldots \ldots \ldots \ldots \ldots \ldots \ldots \ldots \ldots \ldots$ A-53

A.4.2 Radionuclides of Importance for Dose Analyses .... A A-54

A.4.3 Assumed Exposure Scenarios and Exposure Pathways . A-56

A.4.4 Dose Conversion Factors for Internal and External

Exposure ..................... A-59

A.4.5 Models and Parameter Values for Exposure Pathways . A-66

A.4.6 Summary ......................... A-87

APPENDIX A REFERENCES $\ldots \ldots \ldots \ldots \ldots \ldots \ldots \ldots \ldots \ldots \ldots \ldots \ldots \ldots$

APPENDIX B COMPUTER CODES/CALCULATIONAL METHODS

B.1 CODE SELECTION CRITERIA AND CONSIDERATIONS ....... B-1

B.2 GEOCHEMICAL COMPUTER CODES $\ldots \ldots \ldots \ldots \ldots \ldots \ldots \ldots$ B-2

B.3 VAULT DEGRADATION COMPUTER CODE ............ B-5

B.4 SATURATED/UNSATURATED FLOW AND TRANSPORT CODE B-11

APPENDIX B REFERENCES $\ldots \ldots \ldots \ldots \ldots \ldots \ldots \ldots \ldots \ldots \ldots$ B-21

APPENDIX C DATA TABULATION

C.1 RADIONUCLIDE INVENTORY $\ldots \ldots \ldots \ldots \ldots \ldots \ldots \ldots \ldots$, C-1

C.2 PORFLOW INPUT FILES $\ldots \ldots \ldots \ldots \ldots \ldots \ldots \ldots \ldots \ldots \ldots, \mathbf{C}-6$

C.3 Z-AREA STREAM FLOW DATA $\ldots \ldots \ldots \ldots \ldots \ldots \ldots \ldots \ldots, \mathrm{C}-24$

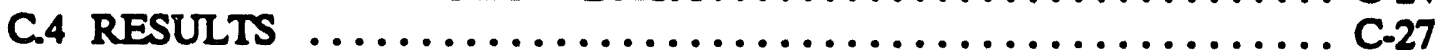

C.4.1 Fluxes to Water Table ................... C-27

C.4.2 Concentrations in Soil Around Vaults .......... C-50

C.4.3 Groundwater Concentrations .................. C-61

APPENDIX D GEOCHEMICAL INTERACTIONS

D.1 INTRODUCTION $\ldots \ldots \ldots \ldots \ldots \ldots \ldots \ldots \ldots \ldots \ldots \ldots \ldots \ldots \ldots$, D-1

D.1.2 Background $\ldots \ldots \ldots \ldots \ldots \ldots \ldots \ldots \ldots \ldots \ldots$ D-2

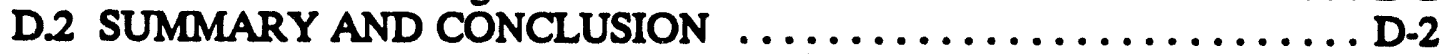

D.3 PORE-FLUID COMPOSITION WITHIN SALTSTONE $\ldots \ldots \ldots \ldots \ldots$ D-3

D.3.1 Hydration Calculation $\ldots \ldots \ldots \ldots \ldots \ldots \ldots$ D-4

D.3.2 Concentration of Technetium-99 and Nitrate in Saltstone

Pore Fluids .................... D-7

D.4 FLUID COMPOSITIONS IN SEDIMENTS OUTSIDE THE VAULT D-11

D.4.1 Modeling Steps .................... D-11

D.4.2 Interactions With the Sediment $\ldots \ldots \ldots \ldots \ldots \ldots$ D-12

APPENDIX D REFERENCES $\ldots \ldots \ldots \ldots \ldots \ldots \ldots \ldots \ldots \ldots \ldots$ D-15

Rev. 0

vi 
APPENDIX E HYDROGEOLOGY OF THE SRS

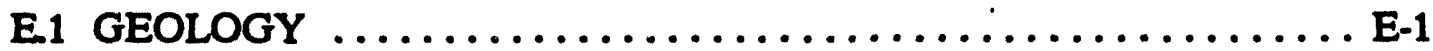

E.1.1 Late Cretaceous Lumbee Group $\ldots \ldots \ldots \ldots \ldots \ldots$ E-1

E.1.2 Paleocene-Eocene Black Mingo Group .......... E-3

E.1.3 Middle Eocene Orangeburg Group ............ E-4

E.1.4 Late Eocene Barnwell Group .............. E-5

E.1.5 "Upland Unit" ....................... E-6

E.1.6 Quaternary Deposits ..................... E-6

E.2 GROUNDWATER HYMROLOGY $\ldots \ldots \ldots \ldots \ldots \ldots \ldots \ldots \ldots$ E-6

E.2.1 Hydrology of Coastal Plain Sediments - Zone 1 ...... E-7

E.2.2 Hydrology of Coastal Plain Sediments - Zone 2 ...... E-9

E.23 Hydrology of Coastal Plain Sediments - Zone 3 ...... E-9

E.2.4 Hydrology of Coastal Plain Sediments - Zone 4 ...... E-12

E.2.5 Hydrology of Coastal Plain Sediments - Zone $5 \ldots \ldots$ E-12

E26 Hydrology of Coastal Plain Sediments - Zone $6 \ldots \ldots$ E-13

E.2.7 Hydrology of Coastal Plain Sediments - Zone $7 \ldots \ldots$ E-16

E28 Hydrology of Coastal Plain Sediments - Zone 8 ...... E-19

E.2.9 Hydrologic Characteristics of the Unsaturated Zone .. E-21

APPENDIX E REFERENCES $\ldots . \ldots \ldots \ldots \ldots \ldots \ldots \ldots \ldots \ldots \ldots$ E-26

APPENDIX F SOFTWARE PLANS

APPENDIX G PERFORMANCE ASSESSMENT PEER REVIEW PANEL RECOMMENDATIONS

G.1 INTRODUCTION .......................... G-1

G.2 RECOMMENDATIONS OF PERFORMANCE ASSESSMENT

PEER REVIEW PANEL $\ldots \ldots \ldots \ldots \ldots \ldots \ldots \ldots$ G-1

APPENDIX H SENSITTVITY/UNCERTAINTY ANALYSIS

Rev. 0

vii 


\section{FIGURES}

1.1-1. Location map of the Savannah Rive Site $\ldots \ldots \ldots \ldots \ldots \ldots \ldots \ldots \ldots \ldots \ldots$

1.2-1. High-level liquid waste management at the SRS $\ldots \ldots \ldots \ldots \ldots \ldots \ldots \ldots \ldots$

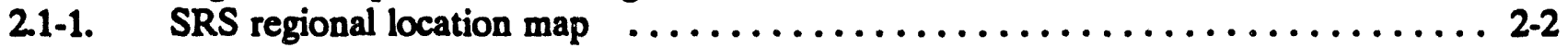

2.1-2. Facility location map of the SRS, showing surface drainage $\ldots \ldots \ldots \ldots \ldots \ldots$

21-3. Population distribution within an $80-\mathrm{km}$ radius of the central SRS $\ldots \ldots \ldots \ldots 2-5$

2.1-4. Location of the Bowman and Charleston-Summerville seismic zones, and the

Dunbarton Basin on the SRS ........................... 2-8

2.1-5. Hydrologic and stratigraphic units underlying the SRS. . . . . . . . . . . 2-11

2.1-6. The total average effective dose equivalent from various sources in the Central

Savannah River Area. ............................ 2-18

2.2-1. Topographic map in the vicinity of Z-Area $\ldots \ldots \ldots \ldots \ldots \ldots \ldots \ldots \ldots \ldots \ldots$

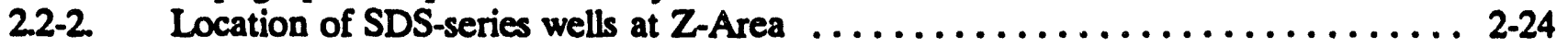

2.2-3. Lithologic cross-section, $A-A^{\prime}$, in the vicinity of $Z$-Area. Well SDS-12 is in
Z-Area; SDS-7 is just east of the facility boundary $\ldots \ldots \ldots \ldots \ldots \ldots \ldots \ldots$. $\ldots \ldots \ldots$.

2.2-4. Lithologic cross-section, B-B', in the vicinity of Z-Area. Well SDS-7 is just

east of the facility boundary $\ldots \ldots \ldots \ldots \ldots \ldots \ldots \ldots \ldots \ldots \ldots \ldots \ldots . \ldots \ldots 26$

2.2-5. Lithology and water level data for well SDS-7. . . . . . . . . . . . . . 2-28

2.3-1. Projected distribution of radionuclide activity in salt solution feed to Z-Area. . . . 2-43

2.3-2. Saltstone production process $\ldots \ldots \ldots \ldots \ldots \ldots \ldots \ldots \ldots \ldots \ldots \ldots \ldots \ldots . \ldots \ldots$

24-1. Chromium toxicity results for slag- and cement-based saltstone $\ldots \ldots \ldots \ldots \ldots$ 2-53

2.4-2. Comparison of technetium vs. nitrate leaching for slag- and cement-based

saltstone lysimeters . . . . . . . . . . . . . . . . . . . . . . . 2-54

2.5-1. Projected vault layout in the Z-Area Saltstone Disposal Facility . . . . . . . . 2-59

27-1. Vault closure concept $(2 \mathrm{~cm} /$ year infiltration $) \ldots \ldots \ldots \ldots \ldots \ldots \ldots \ldots \ldots 2$

27-2 Vault closure concept $(40 \mathrm{~cm} /$ year infiltration) $\ldots \ldots \ldots \ldots \ldots \ldots \ldots \ldots \ldots .73$

3.0-1. Overall conceptual model for the Radiological Performance Assessment of the

Saltstone Disposal Facility ........................... 3-2

3.1-1. Representation of contaminant release mechanisms. .............. $3-4$

3.1-2 Schematic of modeled scenarios $\ldots \ldots \ldots \ldots \ldots \ldots \ldots \ldots \ldots \ldots \ldots \ldots \ldots$

3.1-3. Carbonation controlled leaching. $\ldots \ldots \ldots \ldots \ldots \ldots \ldots \ldots \ldots \ldots \ldots \ldots \ldots \ldots \ldots$

3.1-4. Concrete controlled leaching. $\ldots \ldots \ldots \ldots \ldots \ldots \ldots \ldots \ldots \ldots \ldots \ldots \ldots \ldots \ldots$

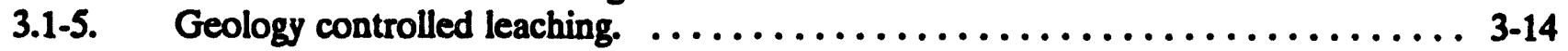

3.1-6. Hydrogen evolution corrosion $\ldots \ldots \ldots \ldots \ldots \ldots \ldots \ldots \ldots \ldots \ldots \ldots \ldots \ldots \ldots$. $\ldots \ldots$

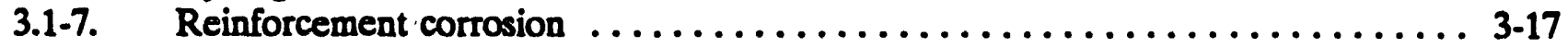

3.2-1. Potential pathways to human exposure for a buried LLW source. . . . . . . . . 3-24

3.3-1. Domains of the near-field conceptual model. . . . . . . . . . . . . . . . 3-57

3.4-1. Integration of computational methods for the Radiological Performance

3.4-2. Integration of computational methods for the Radiological Performance Assessment of degraded Saltstone Facility vaults. . . . . . . . . . . . . . . . . 3-70

3.4-3. Interrelationships of near-field performance assessment computations. . . . . . 3-71

3.4-4. Three-steps to implement degraded vault model. $\ldots \ldots \ldots \ldots \ldots \ldots \ldots \ldots \ldots$

$$
\text { Rev. } 0
$$

ix 
3.4-5. Model domain for PORFLOW-3D simulations of groundwater in Z-Area vicinity.. 3-78

3.4-6. Actual potentiometric surface for Zone $7 / 8$ and simulated surface for Zone $6 / 7 / 8$. $\quad 3-80$

3.4-7. Actual potentiometric surface for Zone 6 and simulated surface for Zone $6 / 7 / 8$. . . 3-81

3.4-8. Locations of stream-gauging stations in creeles near Z-Area $\ldots \ldots \ldots \ldots \ldots \ldots$ 3-82

3.4.9. Ilustration of SDF source area in PORFLOW-3D grid. $\ldots \ldots \ldots \ldots \ldots \ldots \ldots .3 .84$

4.2-1. Nitrate release rate vs. perched water and time $\ldots \ldots \ldots \ldots \ldots \ldots \ldots \ldots .4,36$

4.2-2 Nitrate release rate vs. crack width and time $\ldots \ldots \ldots \ldots \ldots \ldots \ldots \ldots \ldots \ldots, 437$

4.2-3. Nitrate release rate vs. crack spacing and time $\ldots \ldots \ldots \ldots \ldots \ldots \ldots \ldots \ldots 4$ 438

4.2-4. Technetium-99 release rate vs. distribution coefficient and time .......... 4-39

4.2-5. Cumulative probability distribution function for nitrate concentration in groundwater $100 \mathrm{~m}$ from the SDF, arising from uncertainties in fluxes to the

water table and in saturated hydraulic conductivities $\ldots \ldots \ldots \ldots \ldots \ldots \ldots \ldots, 4-44$

A.1-1. Idealized cross-section for the SRP Vadose Zone. $\ldots \ldots \ldots \ldots \ldots \ldots \ldots \ldots \ldots$ A-2

A.1-2. Domain of the upper moisture barrier simulation $\ldots \ldots \ldots \ldots \ldots \ldots \ldots \ldots \ldots$ A-4

A.1-3. Moisture characteristic curves generated for backfill $\ldots \ldots \ldots \ldots \ldots \ldots \ldots \ldots$ A-8

A.1-4. Moisture characteristic curves generated for gravel ................. A-9

A.1-5. Moisture characteristic data for Z-Area soils mixed with VOLCLAY SG-40

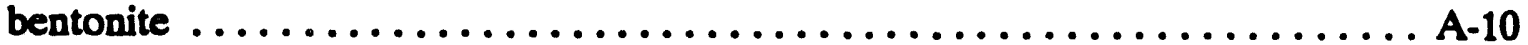

A.1-6. Domain for moisture barrier simulation, showing steady-state pressure head

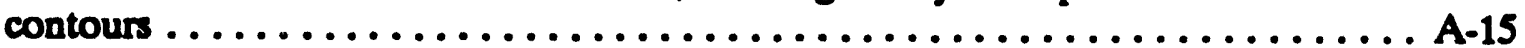

A.1-7. Upper moisture barrier steady-state saturations $\ldots \ldots \ldots \ldots \ldots \ldots \ldots \ldots \ldots \ldots$ A-17

A.1-8. Vertical fluxes in domain of upper moisture barrier simulations $\ldots \ldots \ldots \ldots \ldots$ A-18

A.1-9. Vault simulation domain and time history nodes $\ldots \ldots \ldots \ldots \ldots \ldots \ldots \ldots$ A-20

A.1-10. Steady-state pressure head contour for vault simulation at 2 or $40 \mathrm{~cm} / \mathrm{year}$

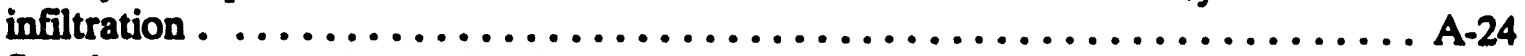

A.1-11. Steady-state saturation profile for vault simulation with 2 or $\mathbf{4 0} \mathrm{cm} / \mathrm{year}$

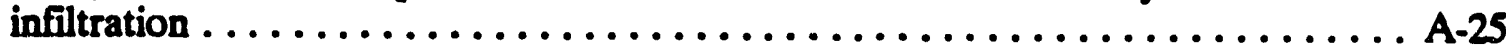

A.1-12. Comparison of more realistic system and modeled representation of flow rate

through backfill (clay in this case) and fractured vault ................ A-28

A.1-13. Schematic of conceptual model of release from fractured vault ............ 32

A.2-1. Model domain for PORFLOW-3D simulation of groundwater in Z-Area vicinity . A-36

C.2-1. PORFLOW-3D input file for near-field flow and transport simulations. .......... C-7

C.2-2 PORFLOW-3D input file for estimating travel time beneath fractured saltstone .. C-12

C.2-3. PORFLOW-3D input file for saturated groundwater flow simulations

(40 cm/year infiltration through Z-Area without SDF) .............. C-14

C.2-4. PORFLOW-3D input file for saturated groundwater flow simulations

$(0.175 \mathrm{~cm} / \mathrm{year}$ infiltration through SDF, $40 \mathrm{~cm} / \mathrm{year}$ elsewhere........... C-17

C.2-5. Example PORFLOW-3D input file for mass transport simulation in groundwater

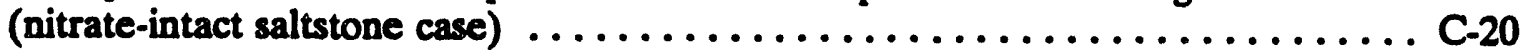

C.2-6. Example PORFLOW-3D input file for mass transport simulation in groundwater (nitrate-fractured saltstone case) $\ldots \ldots \ldots \ldots \ldots \ldots \ldots \ldots \ldots \ldots \ldots \ldots$ C-22

C.3-1. Location of stream flow measurements on November $12-14,1991$ at SRS . . . . . C-26

Rev. 0 
C.4-1. Fractional flux of H-3 from the SDF to the water table estimated from near-field simulations for intact saltstone and vaults $\ldots \ldots \ldots \ldots \ldots \ldots \ldots$ C-28

C.4-2 Fractional llux of C-14 from the SDF to the water table estimated from near-field simulations for intact saltstone and vaults ................ C-29

C.43. Fractional flux of Se-79 from the SDF to the water table estimated from near-field simulations for intact saltstone and vaults $\ldots \ldots \ldots \ldots \ldots \ldots \ldots \ldots$ C-30

C.4-4. Fractional flux of Sr-90 from the SDF to the water table estimated from near-field simulations for intact saltstone and vaults ............... C-31

C.4-5. Fractional flus of Tc-99 from the SDF to the water table estimated from near-field simulations for intact saltstone and vaults $\ldots \ldots \ldots \ldots \ldots \ldots \ldots$ C-32

C.4-6. Fractional flux of Sn-126 from the SDF to the water table estimated from near-field simulations for intact saltstone and vaults $\ldots \ldots \ldots \ldots \ldots \ldots \ldots$ C-33

C.47. Fractional flux of I-129 from the SDF to the water table estimated from near-field simulations for intact saltstone and vaults $\ldots \ldots \ldots \ldots \ldots \ldots \ldots$ C-34

C.4-8. Fractional flux of Cs-137 from the SDF to the water table estimated from near-field simulations for intact saltstone and vaults ............... C-35

C.4-9. Fractional flux of Pu-238 from the SDF to the water table estimated from near-field simulations for intact saltstone and vaults $\ldots \ldots \ldots \ldots \ldots \ldots \ldots$. C-36

C.4-10. Fractional flux of Am-241 from the SDF to the water table estimated from near-field simulations for intact saltstone and vaults ................ C-37

C.4-11. Fractional flux of nitrate from the SDF to the water table estimated from near-field simulations for intact saltstone and vaults $\ldots \ldots \ldots \ldots \ldots \ldots \ldots \ldots$ C-38

C.4-12 Time history pore water concentrations for H-3 in soil above the vault (Node 1), in soil to the side of the vault near the base of the saltstone (Node 2), and in saltstone at the centroid of the monolith (Node 3) .................. C-51

C.4-13. Time history pore water concentrations for C-14 in soil above the vault (Node 1), in soil to the side of the vault near the base of the saltstone (Node 2), and in saltstone at the centroid of the monolith (Node 3) ................. C-52

C.4-14. Time history pore water concentrations for Se-79 in soil above the vault (Node 1), in soil to the side of the vault near the base of the saltstone (Node 2), and in saltstone at the centroid of the monolith (Node 3) ................. C-53

C.4-15. Time history pore water concentrations for Sr-90 in soil above the vault (Node 1), in soil to the side of the vault near the base of the saltstone (Node 2), and in saltstone at the centroid of the monolith (Node 3) $\ldots \ldots \ldots \ldots \ldots \ldots \ldots \ldots$ C-54

C.4-16. Time history pore water concentrations for Tc-99 in soil above the vault (Node 1), in soil to the side of the vault near the base of the saltstone (Node 2), and in saltstone at the centroid of the monolith (Node 3) .................. C-55

C.4-17. Time history pore water concentrations for Sn-126 in soil above the vault (Node 1), in soil to the side of the vault near the base of the saltstone (Node 2), and in saltstone at the centroid of the monolith (Node 3) $\ldots \ldots \ldots \ldots \ldots \ldots \ldots \ldots$ C-56

C.4-18. Time history pore water concentrations for I-129 in soil above the vault (Node 1), in soil to the side of the vault near the base of the saltstone (Node 2), and in saltstone at the centroid of the monolith (Node 3) $\ldots \ldots \ldots \ldots \ldots \ldots \ldots$ 
C.4-19. Time history pore water concentrations for Cs-137 in soil above the vault (Node 1), in soil to the side of the vault near the base of the saltstone (Node 2), and in saltstone at the centroid of the monolith (Node 3) ................. C-58

C.420. Time history pore water concentrations for Pu-238 in soil above the vault (Node 1), in soil to the side of the vault near the base of the saltstone (Node 2), and in saltstone at the centroid of the monolith (Node 3) .................. C-59

C.4-21. Time history pore water concentrations for Am-241 in soil above the vault (Node 1), in soil to the side of the vault near the base of the saltstone (Node 2), and in saltstone at the centroid of the monolith (Node 3) ................. C-60

C.4-22. Predicted groundwater concentrations of nitrate as a function of time, resulting from releases from fractures and intact saltstone and vaults $\ldots \ldots \ldots \ldots \mathrm{C}-62$

C.4-23. Predicted groundwater concentrations of H-3 as a function of time, resulting from releases from fractures and intact saltstone and vaults $\ldots \ldots \ldots \ldots \ldots \ldots . \mathrm{C}-63$

C.4-24. Predicted groundwater concentrations of C-14 as a function of time, resulting from releases from fractures and intact saltstone and vaults ............. C-64

C.4-25. Predicted groundwater concentrations of Se-79 as a function of time, resulting from releases from fractures and intact saltstone and vaults $\ldots \ldots \ldots \ldots \ldots . \mathrm{C}-65$

C.4-26. Predicted groundwater concentrations of Tc-99 as a function of time, resulting from releases from fractures and intact saltstone and vaults $\ldots \ldots \ldots \ldots \ldots \ldots$ C.66

C.4-27. Predicted groundwater concentrations of Sn-126 as a function of time, resulting from releases from fractures and intact saltstone and vaults ............ C-67

C.4-28. Predicted groundwater concentrations of I-129 as a function of time, resulting from releases from fractures and intact saltstone and vaults $\ldots \ldots \ldots \ldots \ldots \ldots, \mathrm{C}-68$

E.1-1. Hydrologic and stratigraphic units underlying the SRS $\ldots \ldots \ldots \ldots \ldots \ldots \ldots \ldots$, E-2

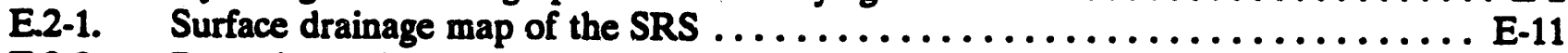

E.2-2. Potentiometric surface of Zone 5 a, in Z-Area vicinity ............... E-14

E.2-3. Regional potentiometric surface of Zone 5 a (Christensen and Gordon 1983) .... E-15

E.2-4. Botentiometric surface of Zone $7 \mathrm{a}$ in $\mathrm{Z}$-Area vicinity $\ldots \ldots \ldots \ldots \ldots \ldots \ldots$ E-17

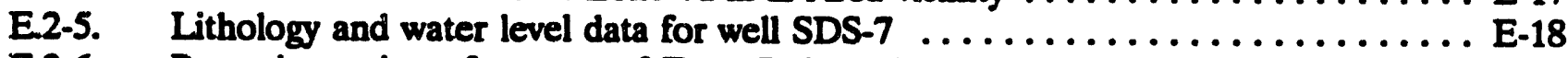

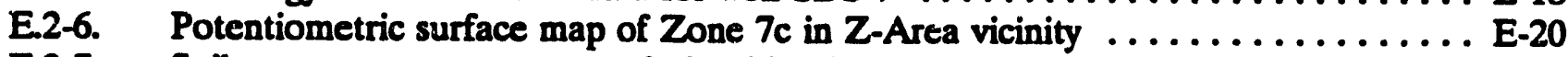

E.2-7. Soil water content-pressure relationships for undisturbed soils in Z-Area

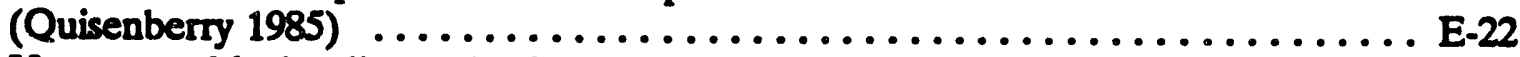

E.2-8. Unsaturated hydraulic conductivity as a function of moisture content at $Z$-Area

(Quisenberry 1985) ................................. E-23

E.2-9. Soil water content - pressure relationships for undisturbed soils at SRS burial grounds (Gruber 1980) ............................. E-24

E.2-10. Unsaturated hydraulic conductivity as a function of moisture content at SRS

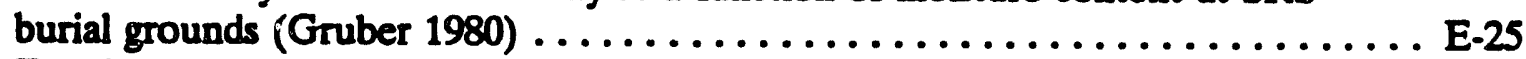

H.1-1. Fractional nitrate flux release as a function of time for reference run $\ldots \ldots \ldots \ldots . \mathrm{H}-1$

H.1-2 Fractional nitrate flux release as a function of time for twelve uncertainty

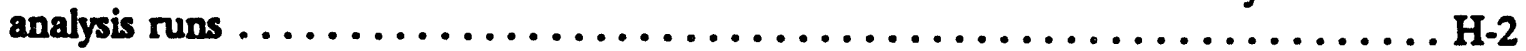

H.1-3. Fractional nitrate flux release as a function of time for nine uncertainty

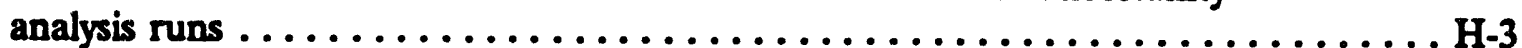

Rev. 0 
H.1-4. Fractional nitrate flux release as a function of time for sixteen uncertainty

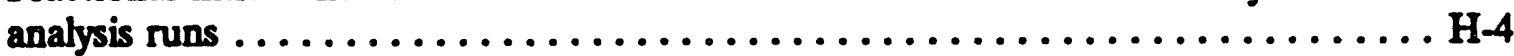

H.1-5. Fractional nitrate flux release as a function of time for eleven uncertainty

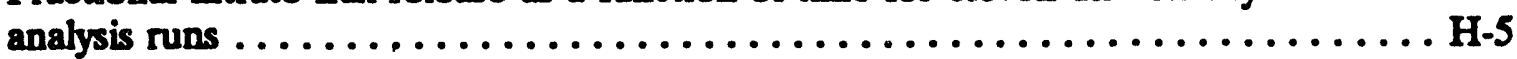

H.1-6. Fractional nitrate flux release as a function of time for eighteen uncertainty

H.1-7. Fractional nitrate flux release as a function of time for nineteen uncertainty

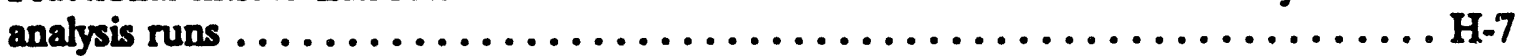

H.1-8. Fractional nitrate flux release as a function of time for fifteen uncertainty analysis runs H-8

Rev. 0

xiii 
WSRC-RP-92-1360

A.4-7. Elemental plant-to-soil concentration ratios in vegetables $\ldots \ldots \ldots \ldots \ldots \ldots$ A-70

A.48. Annual effective dose equivalents from vegetable pathway per unit concentration

of radionuclides in exhumed waste for agriculture scenario $\ldots \ldots \ldots \ldots \ldots \ldots$ A-72

A4-9. Annual effective dose equivalents from soil ingestion pathway per unit

concentration of radionuclides in exhumed waste for agriculture scenario . . . . A A-73

A4-10. Annual effective dose equivalents from external exposure in vegetable garden

per unit concentration of radionuclides in exhumed waste for agriculture

scenario ....................................... A-75

A4-11. Annual effective dose equivalents from external exposure in home per unit concentration of radionuclides in soil at homesite for agriculture scenario . . . . . . A-77

A4-12. Annual effective dose equivalents from inhalation exposure in vegetable garden

per unit concentration of radionuclides in exhumed waste for agriculture scenario .................................... A-80

A.4-13. Annual effective dose equivalents from inhalation exposure in home per unit concentration of radionuclides in soil at homesite for agriculture scenario . . . . . A-82

A.4-14. Annual effective dose equivalents per unit concentration of radionuclides from all exposure pathways for agriculture scenario $\ldots \ldots \ldots \ldots \ldots \ldots \ldots \ldots \ldots \ldots$ A -83

A.4-15. Annual effective dose equivalents per unit concentration of radionuclides in disposal units for resident scenario $\ldots \ldots \ldots \ldots \ldots \ldots \ldots \ldots \ldots \ldots \ldots$ A -86

A.416. Annual effective dose equivalents per unit concentration of radionuclides

in exhumed waste for post-drilling scenario $\ldots \ldots \ldots \ldots \ldots \ldots \ldots \ldots \ldots$ A -88

A.417. Summary of radionuclide-independent parameter values used in dose analyses

for off-site individuals and inadvertent intruders $\ldots \ldots \ldots \ldots \ldots \ldots \ldots \ldots$ A-90

B.4.1. Evaluation of identified alternative subsurface flow and transport codes $\ldots \ldots \ldots$ B-14

C.1.1. Approximate radionuclide content of the waste streams and the

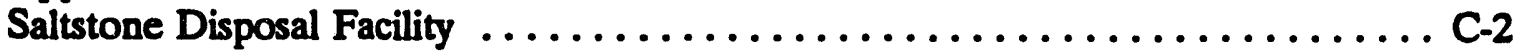

C.3-1. Stream gauging results for SRS creeks in the vicinity of Z-Area (field measurements made on November $12-14,1991$ by Peter M. Kearl) ......... C-25

C.4-1. Fractional flux of H-3 from fractures in the degraded scenario for the SDF . . . . C-39

C.4-2. Fractional flux of C-14 from fractures in the degraded scenario for the SDF . . . . C-40

C.4-3. Fractional flux of Se-79 from fractures in the degraded scenario for the SDF . . . C-41

C.4-4. Fractional flux of Cs-137 from fractures in the degraded scenario for the SDF . . . C-42

C.4-5. Fractional flux of Sr-90 from fractures in the degraded scenario for the SDF . . . C-43

C.4-6. Fractional flux of Tc-99 from fractures in the degraded scenario for the SDF . . . . C-44

C.47. Fractional flux of Sn-126 from fractures in the degraded scenario for the SDF ... C-45

C.4-8. Fractional flux of I-129 from fractures in the degraded scenario for the SDF . . . C C-46

C.4-9. Fractional flux of Pu-238 from fractures in the degraded scenario for the SDF . . C C-47

C.4-10. Fractional flux of Am-241 from fractures in the degraded scenario for the SDF . . C-48

C.4-11. Fractional flux of Nitrate from fractures in the degraded scenario for the SDF . . . C-49

D.3-1. Composition of starting material for saltstone formation in weight percent ...... D-5

D.3-2. Summary of saltstone hydration calculations for a mixture of $47 \%$ salt feed and

$53 \%$ cement mix. Composed of $47.17 \%$ each of slag and fly ash and $5.66 \%$ of

Portland cement. Normalized to $100 \mathrm{~g}$ of cement mix .............. D -6

Rev. 0

xvii 
D.3-3. Calculated saltstone pore fluid composition using MINTEQ, the results of the hydration calculations and equilibrium with calcite, $\mathrm{C}_{3} \mathrm{AH}_{6}, \mathrm{C}-\mathrm{S}-\mathrm{H}$ gel, and $\mathrm{C}_{3} \mathrm{FH}_{6}$.

${ }^{9} \mathrm{Tc}$ is calculated by assuming equilibrium with $\mathrm{Tc}_{2} \mathrm{~S}_{7,}$ as described in the text ... D-9

D.41. Composition of interstitual fluid after reaction with unsaturated zone materials, and type and amount of precipitated solids .................. D-13

D.4-2 Percentage distribution of components in reacted interstitial fluid .......... D-14

E.2-1. Summary of hydraulic conductivities reported for hydrologic units of the Coastal Plain Sediments ................................. E

E.2-2 Hydrologic data for the upper cretaceous formations and the paleocene black mingo group . . ................................... E-10

H.1-1. Sampled parameter values for uncertainty analysis of near-field model; results for the $\mathbf{1 0 0}$ runs in terms of calculated peak fractional flux of nitrate to the water table and time of peak $\ldots \ldots \ldots \ldots \ldots \ldots \ldots \ldots \ldots \ldots \ldots \ldots \ldots$

H.2-1. Variable input for the 100 uncertainty runs for the groundwater transport model . H-13

H.2-2 Predicted peak nitrate concentrations in groundwater at $100 \mathrm{~m}$ from the SDF, node at which they occur, and time of peak for the 100 uncertainty analysis runs listed in Table H.2-1

Rev. 0

xviii 
WSRC-RP-92-1360

\section{TABLES}

2.1-1. Water quality of the Savannah River above SRS (Cummins et al. 1990) ...... 2-15

2.1-2.

2.2.1.

Comparison of natural radiation doses near SRS with U.S. averages ......... 2-19

Summary of hydraulic conductivities reported for upper hydraulic units of the

coastal plain sediments (horizontal unless otherwise stated) $\ldots \ldots \ldots \ldots \ldots .2-29$

2.2-2. Concentration of dissolved elements in groundwater in Zones 5, 6, and 7

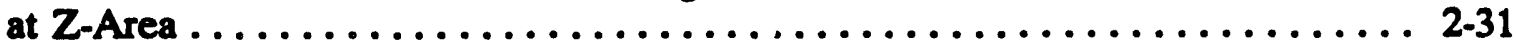

22-3. Water quality of Upper Runs Creek at $\operatorname{Road} A \ldots \ldots \ldots \ldots \ldots \ldots \ldots \ldots$

22-4. Groundwater monitoring results for the Z-Area Saltstone Facility $\ldots \ldots \ldots \ldots$ 2-34

22-5. Maximum constituent results exceeding applicable standards for wells at the

Z-Area Saltstone Facility $\ldots \ldots \ldots \ldots \ldots \ldots \ldots \ldots \ldots \ldots \ldots \ldots \ldots, 2-36$

2.3-1.

2.3-2.

Weight percent of saltstone components (Heckrotte 1988) ............ 2-38

Approximate chemical composition of salt solution feed (Heckrotte 1988) $\ldots \ldots .2-41$

2.3-3. Composition of saltstone cementitious materials (Malek et al. 1985) ........ 2-44

2.4-1. Disposal alternatives considered for decontaminated salt $\ldots \ldots \ldots \ldots \ldots \ldots$ 2-49

2.4-2. Approximate chemical composition of saltstone grout (Heckrotte 1988) . . . . . 2-57

2.6-1. Projected inventory and concentration of principal chemical components ...... 2-65

2.6-2. Projected inventory and concentration of key radionuclides $\ldots \ldots \ldots \ldots \ldots \ldots 2-66$

26-3. Comparison of key radionuclides in Vault 1 to SDF projections $\ldots \ldots \ldots \ldots \ldots$ 2-69

2.6-4. Naval Fuels Material Facility drummed waste disposal in cell A of Vault $4 \ldots \ldots .2-70$

2.7.1 Values for bydraulic properties of vault closure design $\ldots \ldots \ldots \ldots \ldots \ldots \ldots$ 2-75

3.1-1. Concentration limits for trace-metals in slag saltstone, Langton (1989b) . . . . . 3-20

3.3-1. Summary of hydraulic properties assumed in the near-field model $\ldots \ldots \ldots \ldots \ldots 3-60$

3.3-2. Hydraulic conductivities for saturated zone simulations $\ldots \ldots \ldots \ldots \ldots \ldots \ldots, 3-64$

3.3-3. Aquifer matrix-specific mass transport parameters $\ldots \ldots \ldots \ldots \ldots \ldots \ldots$ 3-65

3.4-1. Implementation of NQA-1 by ORNL for the Saltstone Disposal Facility RPA . . 3 3-87

4.1-1. Flow field results from near-field analysis $\ldots \ldots \ldots \ldots \ldots \ldots \ldots \ldots \ldots \ldots$ 4-3

4.1-2 Maximum predicted near-field concentrations of radionuclides $\ldots \ldots \ldots \ldots \ldots$ 4-4

4.1-3. Maximum predicted contaminant flux to water table and corresponding times

for Z-Area vaults - intact vaults and saltstone $\ldots \ldots \ldots \ldots \ldots \ldots \ldots \ldots \ldots, 4.5$

4.1-4. Maximum predicted contaminant flux to water table and corresponding times

for Z-Area vaults - degraded vaults and saltstone $\ldots \ldots \ldots \ldots \ldots \ldots \ldots \ldots 46$

4.1-5. Peak predicted groundwater concentration at compliance point for Z-Area

vaults - intact vaults and saltstone $\ldots \ldots \ldots \ldots \ldots \ldots \ldots \ldots \ldots \ldots \ldots \ldots, 4,8$

4.1-6. Peak predicted groundivater concentration at compliance point for Z-Area

vaults - degraded vaults and saltstone $\ldots \ldots \ldots \ldots \ldots \ldots \ldots \ldots \ldots \ldots \ldots$ 4.9

4.1-7. Annual effective dose equivalents from drinking water pathway per unit

concentration of radionuclides in groundwater $\ldots \ldots \ldots \ldots \ldots \ldots \ldots \ldots \ldots$ 4-11

4.1-8. Results of dose for off-site releases of radionuclides from drinking water

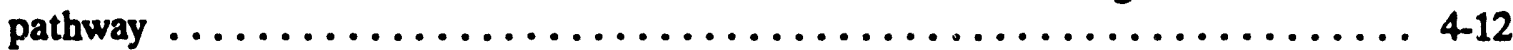

4.1-9. Annual effective dose equivalent per unit concentration of radionuclides

from all exposure pathways for agriculture scenario $\ldots \ldots \ldots \ldots \ldots \ldots \ldots .4 .14$

Rev. 0 
4.1-10. Upper bound estimates of dose to inadvertent intruders for agriculture scenario involving direct intrusion into disposal units $\ldots \ldots \ldots \ldots \ldots \ldots \ldots$ 4-17

4.1-11. Best estimates of dose to inadvertent intruders for agriculture scenario involving direct intrusion into disposal units ................... 4-20

4.1-12. Annual effective dose equivalents per unit concentration of radionuclides in disposal units for resident scenarios $\ldots \ldots \ldots \ldots \ldots \ldots \ldots \ldots \ldots \ldots .4 .23$

4.1-13. Upper bound estimates of dose to inadvertent intruders for resident scenario involving home on top of intact concrete roof above disposal unit $\ldots \ldots \ldots \ldots$ 4-24

4.1-14. Upper bound estimates of dose to inadvertent intruders for resident scenario involving home on top of intact saltstone monolith $\ldots \ldots \ldots \ldots \ldots \ldots \ldots .425$

4.1-15. Best estimates of dose to inadvertent intruders for resident scenario involving home on top of intact saltstone monolith $\ldots \ldots \ldots \ldots \ldots \ldots \ldots \ldots \ldots \ldots$ 4-27

4.1-16. Annual effective dose equivalents per unit concentration of radionuclides in exhumed waste for post-drilling scenario .................... 4-28

4.1-17. Worst-case estimates of dose to inadvertent intruders for post-drilling scenario . . 4-30 4.2-1. Parameters studied and perturbations for sensitivity study of near-field calculations for intact saltstone and vaults $\ldots \ldots \ldots \ldots \ldots \ldots \ldots \ldots \ldots, 4,32$

4.2-2 PORFLOW-3D parameters for sensitivity/uncertainty analysis $\ldots \ldots \ldots \ldots \ldots .4434$

4.2-3. Values of saturated hydraulic conductivity assumed in uncertainty analysis or groundwater transport model $\ldots \ldots \ldots \ldots \ldots \ldots \ldots \ldots \ldots \ldots \ldots \ldots \ldots, 4,42$

4.3-1. Results of inadvertent intruder dose analysis for the four exposure scenarios assumed $\ldots \ldots \ldots \ldots \ldots \ldots \ldots \ldots \ldots \ldots \ldots \ldots \ldots \ldots \ldots \ldots \ldots, 4.54$

5.1-1. Summary of RPA results compared with performance objectives $\ldots \ldots \ldots \ldots \ldots$ 5-2

A.1-1. Longitudinal and transverse dispersivities and effective diffusion coefficients used in the PORFLOW-3D near-field model ............... A-12

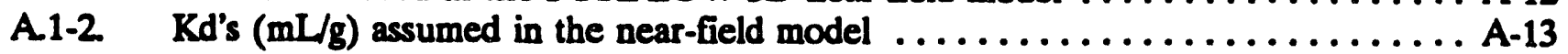

A.1-3. Initial pore solution concentrations of radionuclides and nitrate used in the near-field simulations $\ldots \ldots \ldots \ldots \ldots \ldots \ldots \ldots \ldots \ldots \ldots \ldots \ldots \ldots$ A-22

A.1-4. Input values assumed for flow calculations $\ldots \ldots \ldots \ldots \ldots \ldots \ldots \ldots \ldots \ldots \ldots$ A-30

A.1-5. Values of variables used in determination of release rate from vault ......... A-35

A.2-1. Measured and assumed hydraulic conductivities for saturated hydraulic units ..... A-40

A.2-2 Total and effective porosities - Z-Area $\ldots \ldots \ldots \ldots \ldots \ldots \ldots \ldots \ldots \ldots \ldots$ A-41

A.2-3. Results of preliminary sensitivity analysis for Z-Area groundwater

flow simulations $\ldots \ldots \ldots \ldots \ldots \ldots \ldots \ldots \ldots \ldots \ldots \ldots \ldots \ldots \ldots \ldots . \ldots \ldots . \ldots \ldots$

A.4-1. Radionuclides considered in dose analyses for off-site individuals

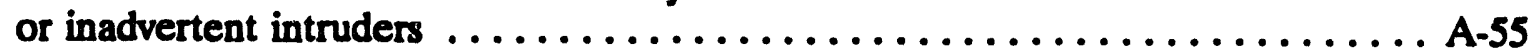

A.4-2. Internal dose conversion factors for ingestion of radionuclides $\ldots \ldots \ldots \ldots \ldots \ldots$ A-60

A4-3. Internal dose conversion factors for inhalation of radionuclides $\ldots \ldots \ldots \ldots \ldots$ A-61

A.4-4. External dose-rate conversion for radionuclides uniformly distributed in

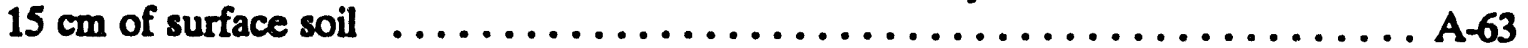

A4-5. External dose-rate conversion factors for radionuclides uniformly distributed in infinite thickness of soil-equivalent material .................... A-65

A.4-6. Annual effective dose equivalents from drinking water pathway per unit concentration of radionuclides in water

Rev. 0

xvi 


\section{ACRONYMS AND ABBREVIATIONS}

\begin{tabular}{|c|c|}
\hline ALARA & as low as reasonably achievable \\
\hline ANSI & American National Standards Institute \\
\hline ASL & above sea level \\
\hline ASME & American Society of Mechanical Engineers \\
\hline ASTM & American Society for Testing and Materials \\
\hline $\mathbf{C i}$ & curie \\
\hline cpu & central processor unit \\
\hline CSRA & Central Savannah River Area \\
\hline DOE & Department of Energy \\
\hline DWPF & Defense Waste Processing Facility \\
\hline EDE & effective dose equivalent \\
\hline $\mathbf{E P}$ & extraction procedure \\
\hline EPA & Environmental Protection Agency \\
\hline ETF & Effluent Treatment Facility \\
\hline HLW & high-level waste \\
\hline INEL & Idaho National Engineering Laboratory \\
\hline ITP & In-Tank Precipitation \\
\hline LLW & low-level waste \\
\hline MMI & Modified Mercalli Intensity \\
\hline NB & Nominal Blend \\
\hline
\end{tabular}


NCRP

NQA

NRC

ORNL

PC

QA

RCRA

RPA

SAR

SCDHEC

SDF

SPF

SRS

SSH́T

TPB

TCLP

WHC

WSRC
National Council on Radiation Protection and Measurements

Nuclear Quality Assurance

Nuclear Regulatory Commission

Oak Ridge National Laboratory

personal computer

Quality Assurance

Resource Conservation and Recovery Act

Radiological Performance Assessment

Safety Analysis Report

South Carolina Department of Health and Environmental Control

Saltstone Disposal Facility

Saltstone Production Facility

Savannah River Site

Salt Solution Hold Tank

tetraphenylborate

Toxicity Characteristic Leach Procedure

Westinghouse Hanford Company

Westinghouse Savannah River Company

Rev. 0 
WSRC-RP-92-1360

\section{EXECUTIVE SUMOMARY}

This radiological performance assessment (RPA) for the Savannah River Site (SRS) Saltstone Disposal Facility (SDF) was prepared in accordance with the requirements of Chapter III of the U. S. Department of Energy Order 5820.2A. The Order specifies that an RPA should provide reasonable assurance that a low-level waste (LLW) disposal facility will comply with the performance objectives of the Order. The performance objectives require that: 1) exposures of the general public to radioactivity in the waste or released from the waste will not result in an effective dose equivalent of 25 mrem per year; 2) releases to the atmosphere will meet the requirements of 40 CFR $61 ; 3)$ inadvertent intruders will not be committed to an excess of an effective dose equivalent of 100 mrem per year from chronic exposure, or 500 mrem from a single acute exposure; and 4) groundwater resources will be protected in accordance with Federal, State, and local requirements.

The SDF, located in a $650,000 \mathrm{~m}^{2}$ area of the SRS designated as Z-Area, is a near-surface disposal facility that will receive low-level radioactive waste generated at the SRS which has been incorporated into a cementitious form called saltstone. Saltstone grout is produced in Z-Area by mixing an aqueous low-level waste stream containing copious amounts of sodium salts with a dry blend of slag, fly ash and cement. Up to fifteen concrete vaults may be constructed and filled with saltstone grout. The saltstone will harden and cure into a monolithic solid waste form with low water conductance properties and high retention properties for some of the waste constituents of concern. The saltstone monoliths are resistant to degradation, and thus are expected to stabilize the low-level radioactive waste for thousands of years.

The RPA process requires a thorough understanding of the waste to be disposed of and the environment in which it will be placed. The composition of saltstone is projected based on known processes from which the waste originates. Properties important to the performance of the waste form have been studied in the laboratory and in an ongoing lysimeter rrogram since 1979. The subsurface environment at Z-Area has likewise been studied extensively. Important characteristics of Z-Area that led to its selection as the site for the SDF include a considerable depth to the water table under the site (7 to $18 \mathrm{~m}$ ) and its proximity to the waste generation site. An underlying aquitard and nearby streams that almost entirely surround Z-Area virtually isolate groundwater under the site, further supporting this choice of location for the SDF.

Rev. 0

xxi 
To evaluate the long-term performance of the SDF, site-specific conceptual models were developed to consider: 1) exposure pathways and scenarios of potential importance; 2) potential releases from the facility to the environment; 3) effects of degradation of engincered features; 4) transport in the environment; and 5) doses potentially received as a result of exposure. Based on results of the performance evaluation, the calculated doses from estimated radionuclide concentrations in groundwater are at least two orders of magnitude below the 4 mrem per year limit for groundwater resource protection, even if the facility degrades. Based on these results and their associated uncertainties, this RPA provides reasonable assurance that the groundwater protection limit for radionuclides, and other dose limits for off-site individuals, will be met. The concentration of nitrate estimated in this RPA complies with the drinking water standard for nitrate of $45 \mathrm{mg} / \mathrm{L}$, which is applied to groundwater for the SDF. The peak calculated concentration is $5 \mathrm{mg} / \mathrm{L}$ for an intact facility and $38 \mathrm{mg} / \mathrm{L}$ for a degraded facility. Because the peak for the degraded facility approaches the drinking water standard, further work should be conducted to reduce the uncertainty associated with this nitrate value to provide reasonable assurance of compliance with groundwater protection standards. In tive exposure scenarios considered for inadvertent intruders, estimated doses are less than or equal to the $\mathbf{1 0 0}$ mrem per year limit. Thus, this RPA provides reasonable assurance that the performance objectives are also met for intruders because the calculated exposures are based on conservative assumptions.

Rev. 0 
WSRC-RP-92-1360

\section{INTRODUCTION}

The Savannah River Site (SRS) was acquired by the U.S. Government in 1950. Since that time, the U. S. Government has contracted for the design, development, construction, and operation of various facilities at the SRS to support national defense and space exploration. Because of these activities at the site, several million gallons of wastewater containing spent process chemicals and radioactive species have been and will continue to be generated (U.S.DOE 1982, 1991).

The policies and guidelines of the Department of Energy (DOE) and other regulatory agencies require that radioactive waste be managed, treated, stored, and disposed in a manner that protects public health and safety, the environment, and ground water resources. These practices must be done in accordance with standards specified in federal, state, and local regulations. The level of radioactivity in any effluents released to the environment should be maintained "as low as reasonably achievable", known as the "ALARA" principle within the DOE complex.

DOE Order 5820.2A, issued in 1988 (U.S.DOE 1988a), established policies, guidelines, and minimum requirements for the management of radioactive waste, mixed waste, and contaminated facilities at the DOE sites. This Order addresses the storage, treatment, and disposal of high-level waste (HIL), mixed waste, low-level waste (LLW), transuranic waste, and naturally occurring and accelerator-produced radioactive materials that are generated by the DOE operations. Chapter III of the Order requires the DOE field sites to prepare and maintain a site-specific radiological performance assessment (RPA) for any LLW disposal facility located at DOE field sites. An RPA must provide reasonable assurance that the facility design and method of disposal will comply with the performance objectives of the Order (Dodge et al. 1991).

The Saltstone Production and Disposal Facilities (located at Z-Area, Fig. 1.1-1) are the first of several new facilities at SRS that will incorporate radioactive waste generated at the SRS into a cementitious LLW form suitable for near-surface disposal. The saltstone facilities are only part of an integrated radioactive waste managemerit system that is being put in place at the SRS. As principal contractor and operator at SRS, the Westinghouse Savannah River Company (WSRC) will complete the design, construct and operate several facilities to manage and dispose of radioactive waste generated at the SRS. Assuming adequate funding is maintained at the SRS, all facilities that are a part of this integrated waste management system are projected to be in operation by the year 2000. 


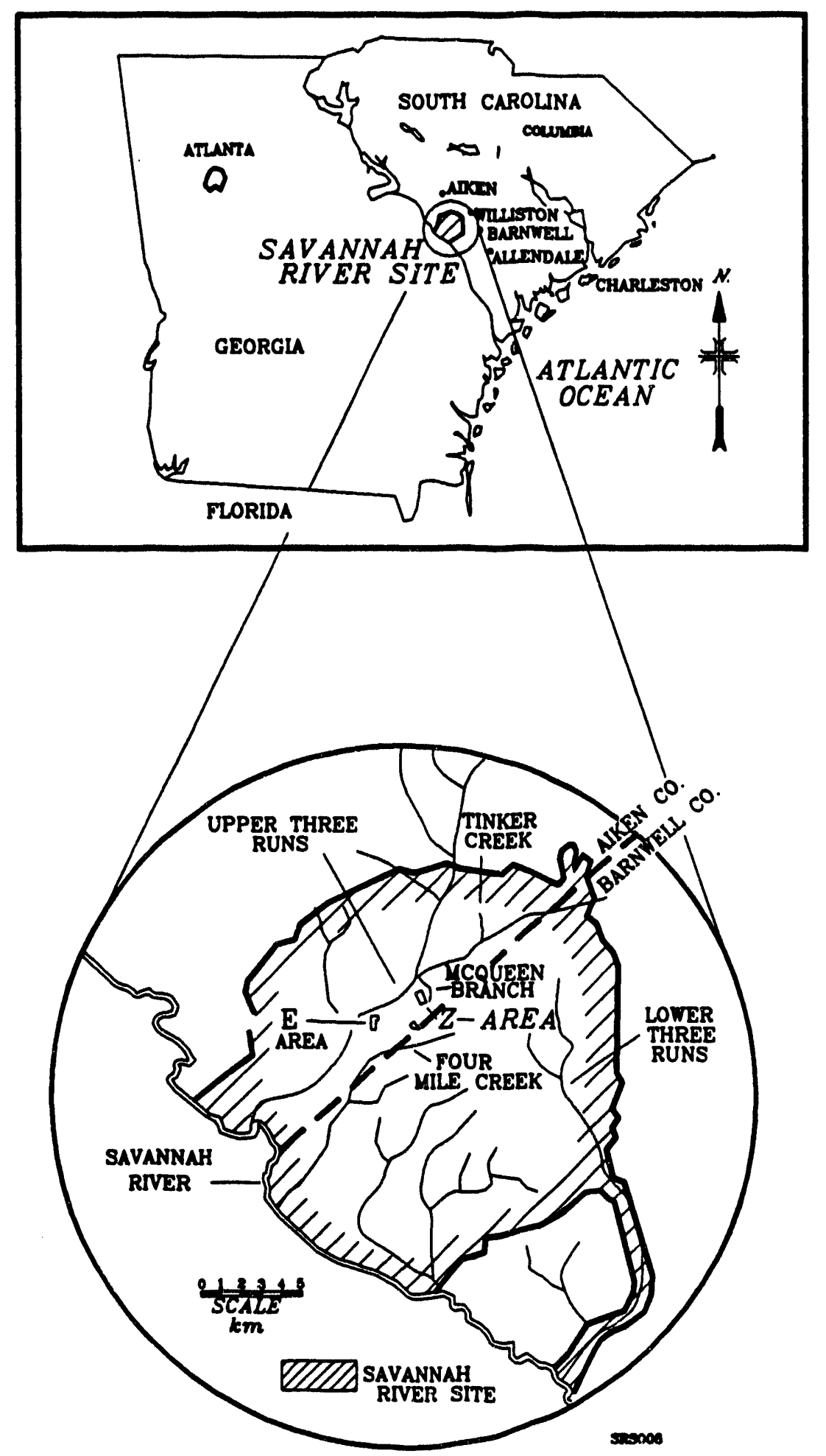

F1g. 1.1-1. Location map of the Savannah River Site.

Rey. 0 
Before the SRS will comply completely with DOE Order 5820.2A, a separate RPA must be completed for at least three operating or planned disposal facilities at the SRS: 1) the Saltstone Disposal Facility (SDF), 2) the E-Area Vaults solid waste disposal facility, and 3) the Hazardous Waste/Mixed Waste Disposal Facility. To fulfill the RPA requirement of DOE Order 5820.2A for the SDF, the long-term radiological impacts on the environment and on the public due to saltstone disposal have been assessed. Results of this assessment are documented in this report.

\subsection{PURPOSE AND SCOPE}

Z-Area is the location of a new mixed wastewater treatment facility and a LLW disposal facility located at SRS. Saltstone production and LLW disposal operations began in Z-Area in 1990 . The Z-Area facilities are classified as low hazard nuclear facilities as defined by DOE orders (WSRC 1992a). The Z-Area Saltstone Production Facility (SPF) incorporates mixed wastewater into a cement matrix to produce LLW grout. Mixed waste is defined in DOE order $5820.2 \mathrm{~A}$ as a waste that contains hazardous and radioactive contaminants. This grout is pumped to concrete vaults that are within the SDF boundary where it solidifies into a nonhazardous monolithic LLW solid waste called saltstone (SCDHEC 1986a, 1986b; U.S.DOE 1986a, 1986b; SCDHEC 1988a, 1988b, 1989a, 1989b). Nonhazardous waste is defined as that waste which passes the Toxicity Characteristic Leach Procedure (10 CFR 268).

Extensive monitoring systems and procedures are in place to establish both the impact to the environment and the risks to operating personnel and off-site populations during normal operations and subsequent closure operations at the disposal site. Air, groundwater, and surface water monitoring procedures are in place to provide baseline monitoring data and to confirm that disposal and closure operations do not adversely affect air or water quality. This RPA concentrates on establishing, with reasonable assurance, that LLW disposal in Z-Area will meet the performance objectives of DOE Order 5820.2A after the facility is closed (U.S.DOE 1986a, 1986b). The objectives of the Order are described in Sect. 1.3.

Radiological and other hazards prior to closure have been analyzed in the Safety Analysis Report (SAR) for the operational period of the SPF and the SDF (WSRC 1992a). In particular, the SAR for Z-Area addresses the issues and hazards related to safety and radiological doses to on-site and off-site populations during active disposal operations. The location of Z-Area is well within the confines of the secured boundary of the SRS, thus precluding inadvertent access to the Z-Area site by unauthorized personnel during active treatment and disposal operations. Furthermore, the distance to the present SRS site boundary obviates the need for extensive analysis of performance prior to closure and/or loss of institutional control. In the event of a spill during the operational period, response procedures are in place to minimize environmental insult and off-site radiological doses (U.S.DOE 1990; Fowler 1992; WSRC 1992a).

Rev. 0 


\section{SOURCE OF WASTEWATER TO BE TREATED AND DISPOSED IN ZAREA}

The wastewater processed into saltstone in Z-Area comes from two sources, the SRS high-level waste tanks in F and H-Areas and the Effluent Treatment Facility (ETF) located in H-Area. A schematic of the high-level liquid waste processes which affects the SDF is shown in Fig. 1.2-1. High-level liquid radioactive waste has been generated in $F$ and H-Areas during the processing of irradiated fuel and target elements. The waste is neutralized with sodium hydroxide and transferred to the high-level waste tanks. Through a process of settling, decantation, and evaporation, the waste is separated into a solid sludge phase containing about $95 \%$ of the radioactivity and about $5 \%$ of the volume. The bulk of the volume is composed of crystallized soluble salts and supernate salt solution.

To prepare the salt waste for treatment and disposal in Z-Area, it is pretreated in the H-Area waste tank farm to remove most of the residual cesium and strontium. Pretreatment is accomplished by dissolving the salt in a waste tank, transferring it to another waste tank, adjusting the sodium concentration to about $5 \mathrm{M}$ and adding sodium tetraphenylborate (TPB) and sodium titanate. The TPB precipitates cesium and potassium while the solid sodium titanate sorbs strontium and plutonium. The insoluble solids are removed by filtration. The concentrated precipitate slurry will be transferred to the Defense Waste Processing Facility (DWPF) to be combined with the sludge from the waste tanks, and made into borosilicate glass. The decontaminated salt solution is passed through an air stripper to remove benzene (formed by the radiolytic decomposition of TPB) and is transferred to waste tank number $50 \mathrm{H}$ in $\mathrm{H}$-Area to await transfer to Z-Area.

Low-level radioactive wastewater streams generated in F and H-Area (Separations Canyons) were disposed of by sending them to unlined earthen seepage basins until 1988. Since 1988, these streams have been treated in the ETF which is located in H-Area. Through a combination of ion-exchange, filtration, and reverse osmosis, the radioactivity and soluble salts in the wastewater are removed. Purified water is discharged to an NPDES outfall. The salts and radioactivity are neutralized and concentrated by evaporation. The concentrate is then transferred to Tank $50 \mathrm{H}$, and subsequently transferred to Z-Area for treatment and disposal.

The salt decontamination process (called In-Tank Precipitation, or ITP) is expected to begin operations during 1993. A large-scale demonstration of ITP was conducted in 1983 and about $500,000 \mathrm{gal}$ of decontaminated salt solution were stored in Tank $50 \mathrm{H}$. Although the ITP process has not yet begun operations, the decontaminated salt solution produced in the large-scale demonstration and concentrate from ETF have provided enough waste in Tank $50 \mathrm{H}$ to begin producing saltstone. Operations with this radioactive waste began in July 1990 within Z-Area. 


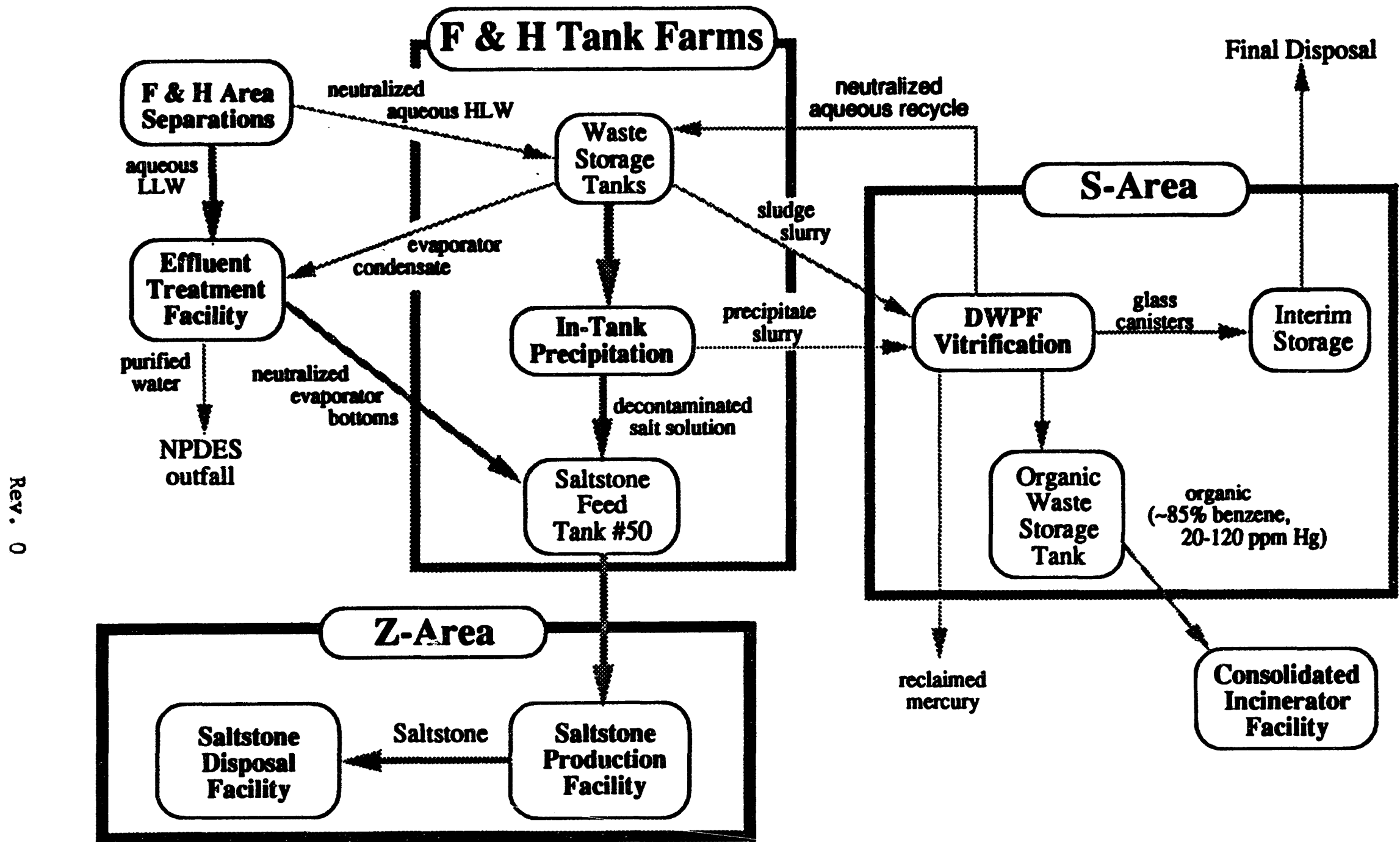

Fig. 1.2-1 High-Level Liquid Waste Management at the SRS 


\section{REGULATORY LMMIS}

DOE approved startup and radioactive operations in Z-Area in 1990, based on interim (conservative) wastewater feed specifications that were proposed during the Startup Authorization Review (U.S.DOE 1990). The feed specifications are based on extensive laboratory testing and earlier modeling studies that served as the basis for the design and operations in Z-Area (INTERA 1986; U.S.DOE 1986a, 1986b; INTERA 1988).

The State of South Carolina is concerned with the protection of water resources within the state. The state, through the South Carolina Department of Health and Environmental Control (SCDHEC), regulates wastewater treatment and disposal facilities to assure that waste-treatment operations and disposal methods will not degrade water quality. Saltstone is classified as a non-hazardous industrial waste as defined by state regulations and the SPF is permitted by the state as a wastewater treatment facility (BNAI 1985a, 1985b; SCDHEC 1988a). Because there is no direct release of liquid streams to the environment, the SPF is specifically excluded from Resource Conservation and Recovery Act (RCRA) permitting under the exemption clause for a totally enclosed facility [40 CFR 260.10, 40 CFR 264.1.(g).(5), and 40 CFR 270.1.(c).(2).(iv)]. Because saltstone is a non-hazardous waste, the SDF is permitted as an industrial solid waste disposal landfill site (SCDHEC 1986b, 1989a). The SCDHEC permits require periodic reports to the state that describe wastewater composition (chemical and radiochemical), physical and chemical test results on the saltstone produced, and groundwater monitoring results.

Because saltstone is classified as nonhazardous waste, the SDF is designed as a "controlled release" industrial landfill disposal facility. The principal long-term risk to the environment and to the general public is through possible degradation of surface water quality or groundwater quality due to release of chemical and/or radioactive pollutants from the disposal site into surface streams or into the underlying groundwater (INTERA 1986, 1988).

Although the Nuclear Regulatory Commission (NRC) has no regulatory authority over the DOE sites, the DOE uses the NRC regulations as a basis for their own regulatory orders and guidance letters. In response to the ALARA principle specified in DOE Order 5820.2A and to minimize the long-term environmental impact of saltstone disposal, WSRC has established a goal to keep the overall average concentration of long-lived radionuclides in all the saltstone placed in Z-Area vaults at or below NRC limits for Class A LLW waste disposal. This goal does not preclude the disposal of occasional batches of saitstone that could contain some radionuclides at a concentration above the Class $A$ limits as defined by NRC, providing all performance objectives are achieved. The SDF design and operating permits do not allow the disposal of saltstone that contains any radionuclides that exceed Class $C$ limits or the disposal of any hazardous waste (U.S.NRC 1982; SCDHEC 1986b, 1989a).

Rev. 0 
Based on projected average compositions of mixed wastewater that will be treated for disposal in Z-Area, the bulk average concentration of radionuclides in saltstone will be well below the Class A disposal limits defined by the NRC. The State of South Carolina does not directly regulate radionuclide disposal at the SRS, but the operating permits for Z-Area require periodic reporting of the concentration of radionuclides in waste processed at the site to the state. Records must also be maintained that reflect the total inventory of radionuclides in the disposal vaults (U.S.DOE 1988b; SCDHEC 1989a).

\subsubsection{Regulatory Radiological Limits}

Permits issued by SCDHEC restrict waste disposal in the SDF (SCDHEC 1986b, 1989a) to be within Class C limits, as defined by the NRC. Furthermore, SCDHEC must be informed if the radionuclide content of the waste exceeds NRC Class A limits.

\section{Operational Radiological Limits}

Operational limits on radionuclide concentrations in saltstone are derived from operational shielding considerations, and are specified in the SAR for Z-Area (WSRC 1992a).

\subsubsection{Chemical Composition Limits}

Limits on chemically hazardous contaminants have been established for wastewater sent to Z-Area to assure that saltstone, as presently formulated, will meet regulatory requirements defined by the Environmental Protection Agency (EPA) and adopted by SCDHEC. In earlier modeling studies the transport of nitrate was used as a basis to model transport of waste components from the saltstone disposal vaults to the underlying groundwater. Nitrate was selected as a basis for prediction because of its high concentration in the waste, its high solubility in water, and its minimal chemical interaction with soil (INTERA 1986, 1988). Limits for toxic metals (Ag, As, Ba, Cd, Cr, $\mathrm{Pb}, \mathrm{Hg}, \mathrm{Se}$ ) were tested over a range of concentrations in saltstone simulants to establish limits in wastewater feed to Z-Area. EP Toxicity testing (10 CFR 216) was used to establish these limits (Langton and Wilhite 1988; Langton 1989a, 1989b; Langton and Wilhite 1990). Regulatory changes have now replaced EP toxicity testing with the Toxicity Characteristic Leach Procedure (TCLP) to establish if waste is classified as a hazardous waste (10 CFR 268). 


\subsection{PERFORMANCE OBJECTIVES}

The specific performance objectives for LLW waste disposal in Z-Area are contained in DOE Order 5820.2A (U.S.DOE 1988a):

1. Protect public bealth and safety in accordance with standards specified in applicable EH Orders and other DOE Orders.

2. Assure that external exposure to the waste and concentrations of radioactive material which may be released to surface water, groundwater, soil, plants, and animals results in an effective dose equivalent (EDE) that does not exceed 25 mrem per year to a member of the general public. Releases to the atmosphere shall meet the requirements of $40 \mathrm{CFR}$ 61. Reasonable effort should be made to maintain releases of radioactivity in effluents to the general environment ALARA.

3. Assure that the committed EDE received by individuals who inadvertently may intrude into the facility after the loss of active institutional control (100 years) will not exceed 100 mrem per year for continuous exposure or $\mathbf{5 0 0}$ mrem for a single acute exposure.

4. Protect ground water resources, consistent with Federal, State, and local requirements.

Compliance with the performance objective for protection of groundwater resources usually has been interpreted as meaning that concentrations of chemical and radioactive contaminants at any points of compliance should not exceed standards for public drinking water supplies established by the EPA. Such a requirement is included in the SCDHEC regulations and permits for the Z-Area disposal facility.

In this analysis, the point of compliance for groundwater protection requirements is assumed to be that location more than $100 \mathrm{~m}$ from any disposed waste at which the predicted concentrations of contaminants in groundwater are the highest. That is, requirements for protection of groundwater are assumed not to apply inside a 100-m buffer zone around the disposal units. The assumed point of compliance is consistent with the SCDHEC regulations and permits.

For chemical contaminants, such as nitrate, the performance objectives for protection of groundwater at the point of compliance are assumed to be the same as current EPA standards for public drinking water supplies. For radionuclides, however, a performance objective somewhat different from, but functionally equivalent to, EPA standards for drinking water is used to define protection of groundwater. Specifically,

Rov. 0 
the performance objective is assumed to be the following:

For protection of groundwater resources at the point of compliance at least $100 \mathrm{~m}$ from any disposed waste, concentrations of all radionuclides arising from waste disposal will not result in an effective dose equivalent greater than $4 \mathrm{mrem}$ per year, assuming consumption of $2 \mathrm{~L}$ per day of water from the affected source.

The rationale for this performance objective is described below.

Current EPA standards for radionuclides in public drinking water supplies, promulgated in 1975, include: 1) a limit on concentration of $5 \mathrm{pCi} / \mathrm{L}$ for $\mathrm{Ra}-226$ plus Ra-228, 2) a limit on cuncentration of $15 \mathrm{pCi} / \mathrm{L}$ for gross alpha-particle activity, including Ra-226 but excluding radon and uranium, and 3) a limit on dose equivalent to whole body or any organ of 4 mrem per year from man-made, beta/gamma-emitting radionuclides. In implementing the dose limit for beta/gamma-emitting radionuclides, the EPA usually assumes a consumption rate of drinking water of $2 \mathrm{~L}$ per day.

In 1991, the EPA published proposed revisions of the drinking water standards for radionuclides. These standards include: 1) separate limits on concentration of $20 \mathrm{pCi} / \mathrm{L}$ for $\mathrm{Ra}-226$ and $\mathrm{Ra}-228,2$ ) a limit on concentration of $300 \mathrm{pCi} / \mathrm{L}$ for $\mathrm{Rn}-222,3$ ) a limit on concentration of $20 \mu \mathrm{g} / \mathrm{L}$ for uranium, which is based on prevention of chemical toxicity in the kidney rather than limitation of cancer risk from radiation exposure and which corresponds to an activity concentration of $14 \mathrm{pCi} / \mathrm{L}$ for naturally occurring uranium with its normal isotopic abundances, 4) a limit on concentration of $15 \mathrm{pCi} / \mathrm{L}$ for gross alpha-particle activity, excluding Ra-226, uranium, and Rn-222, and 5) a limit on effective dose equivalent of 4 mrem per year for beta/gamma-emitting radionuclides. Final revised standards have not yet been promulgated.

In regard to standards for beta/gamma-emitting radionuclides, the EPA clearly intends to replace the present dose limit for whole body or any organ by a limit on effective dose equivalent, with the numerical value for the limit staying the same. Thus, for these radionuclides, the assumed groundwater protection requirement for the Z-Area disposal facility is the same as the proposed revision of the EPA drinking water standards. Replacement of dose limits for whole body or any organ by a limit on effective dose equivalent is in agreement with current radiation protection policies of the DOE, NRC, and EPA.

It would be possible to express the groundwater protection requirements for alphaemitting radionuclides in terms of concentration limits, as in current EPA standards and their proposed revisions. However, the assumed groundwater protection requirements for the Z-Area disposal facility include all alpha-emitting radionuclides in the limit on effective dose equivalent. For these radionuclides, the EPA has used concentration limits, rather than dose limits, because of the desire for a standard that is expressed in terms of quantities that could be measured directly by operators of public drinking water

Rev. 0 
systems. This approach has not been used for man-made, beta/gamma-emitting radionuclides because the EPA has presumed that only naturally occurring, alpha-emitting radionuclides would be of concern for public drinking water supplies.

In a prospective analysis, such as the Z-Area performance assessment, there clearly is no intent to demonstrate compliance with a groundwater protection requirement by actual measurement. Therefore, there is no need to express the performance objective for alpha-emitting radionuclides in terms of concentration limits. Indeed, using a single dose limit for all radionuclides provides a consistent and transparent regulatory approach.

It also should be emphasized that the assumed performance objective for groundwater protection is more restrictive than the EPA's proposed revisions of the drinking water standards for radionuclides. That is, in the EPA's proposed standards, the dose limit of 4 mrem per year applies only to beta/gamma-emitting radionuclides and the concentration limits for alpha-emitting radionuclides are in addition to this dose limit. However, the dose limit of 4 mrem per year in the assumed performance objective applies to all radionuclides. To illustrate this point, the current EPA standard for radium of $5 \mathrm{pCi} / \mathrm{L}$ corresponds to an effective dose equivalent of about 5 mrem per year.

In summary, this analysis has assumed a limit on effective dose equivalent of 4 mrem per year from all radionuclides arising from waste disposal as the performance objective for groundwater protection near the Z-Area disposal facility. Use of the effective dose equivalent complies with current radiation protection policies of the DOE, NRC, and EPA and replaces the outdated dose limits for whole body or any organ. The inclusion of alpha-emitting radionuclides in the dose limit provides a performance objective which is more restrictive than the EPA's proposed revisions of drinking water standards and provides a common basis for determining concentration limits in groundwater for all radionuclides. 


\section{DISPOSAL FACIIITY DESCRIPTION}

In this chapter of the SDF RPA, characteristics which may either govern the impact of the SDF or be impacted by the SDF are described. In Sect. 2.1, regional characteristics of the SRS and vicinity are described that focus on geography, demography, metcorology, seismicity, hydrogeology, quality of surface waters and groundwaters, soils, ecology, and the existing radiological environment. Sect. 2.2 , is organized similarly to Sect. 2.1, but this section concentrates on characteristics specific to the vicinity near Z-Area.

In Sect. 2.3, the sources of wastewater sent to Z-Area for treatment and disposal, the projected composition of the wastewater, and the physical facilities and processes that are used to produce and dispose of Saltstone are described. The Saltstone product and properties are described in Sect. 2.4. The disposal vaults and the projected site layout that is used as a basis for this assessment of long-term performance at the SDF are described in Sect. 2.5. The minimum projected Saltstone waste volume, the maximum projected Saltstone waste volume, and the projected concentrations and total quantity of contaminants (chemical and radiochemical) that are pertinent to assessing long-term performance are described in Sect. 2.6. In Sect. 2.7, the site closure concept used to complete this assessment is described.

\section{REGIONAL CHARACTERISTICS}

The, SDF is located within the SRS in an area designated as Z-Area. Before describing the physical facility, the geography, demography, meteorology, seismicity, hydrogeology, surface water hydrology, water quality, soils, and ecology of the SRS relevant to assessing the facility's performance are described.

\subsection{Geography of the Region}

The SRS occupies about $780 \mathrm{~km}^{2}$ in Aiken, Barnwell, and Allendale counties on the Upper Atlantic Coastal Plain of southwestern South Carolina (Fig. 2.1-1). The center of the SRS is approximately $40 \mathrm{~km}$ southeast of Augusta, GA; $32 \mathrm{~km}$ south of Aiken, SC; $160 \mathrm{~km}$ from the Atlantic Coast; and is bounded on the southwest by the Savannah River, for about $28 \mathrm{~km}$. The Fall Line, which separates the Atlantic Coastal Plain physiographic province from the Piedmont physiographic province, is approximately $50 \mathrm{~km}$ northwest of the central SRS. 


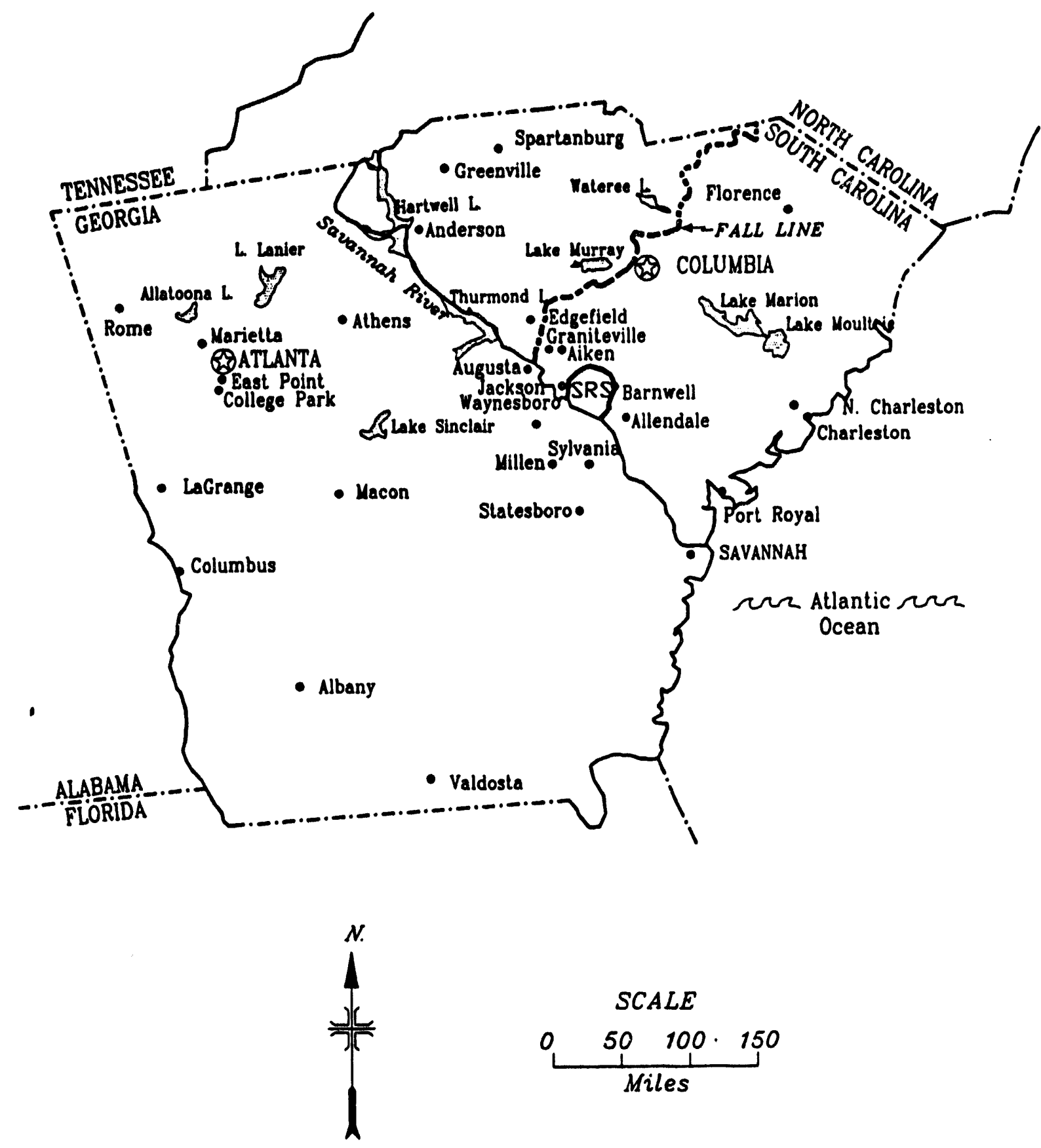

SRSOBI

Fig. 2.1-1. SRS regional location map.

Rev. 0 
In addition to the Savannah River, other prominent geographical features within $80 \mathrm{~km}$ of the SRS are Thurmond Lake, Par Pond and L-Lake. Thurmond Lake is the largest nearby public recreational area. This reservoir is on the Savannah River and is about $64 \mathrm{~km}$ upstream of the center of the SRS. Par Pond is a $11 \mathrm{~km}^{2}$ reactor cooling water impoundment that lies in the eastern sector of the SRS. L-Lake is a $4 \mathrm{~km}^{2}$ reactor cooling water impoundment that lies in the southern sector of the SRS.

The elevation of the SRS ranges from $24 \mathrm{~m}$ above sea level at the Savannah River to about $122 \mathrm{~m}$ above sea level in the upper northwest portion of the site. The Pleistocene Coastal terraces and the Aiken Plateau form two distinct physiographic subregions at the SRS (WSRC 1992b). The Pleistocene Coastal terraces are below $82 \mathrm{~m}$ in elevation, with the lowest terrace constituting the present flood plain of the Savannah River and the higher terraces characterized by gently rolling topography. The relatively flat Aiken Plateau occurs above $82 \mathrm{~m}$.

The Aiken Plateau is dissected by numerous streams. Because of the large number of tributaries to small streams on the SRS site, no location on the site is far from a flowing stream, most of which drain to the Savannah River. The Savannah River bounds the SRS for $28 \mathrm{~km}$ on the southwest.

The dominant vegetation on the SRS is forest, with types ranging from scrub oak communities on the driest areas to bald cypress and black gum in the swamps. Pine forests cover more area than any other forest type. Land utilization presently is about $56 \%$ in pine forests, $35 \%$ in hardwoods, $7 \%$ in SRS facilities and open fields, and $2 \%$ in water (WSRC 1992b).

Except for three roadways and a railway that are near the edge of the SRS, public access to, the SRS is restricted to guided tours, controlled deer hunts, and authorized environmental studies. Figure 2.1-2 shows the major areas at the SRS and their location within the site boundary. The major production areas located at the site include: Raw Materials (M Area), Separations (F and H Areas), Waste Management Operations (E, F, and H Areas), and Defense Waste Processing (S and Z Areas) (WSRC 1992b). Administrative and support services, the Savannah River Technology Center and the Savannah River Ecology Laboratory are located in A Area.

\section{Demography}

The population within $80 \mathrm{~km}$ of the SRS consists of a permanent (resident) and transient population, the latter of which includes industrial, recreational, and casual components. The distribution of the permanent populations within a $80 \mathrm{~km}$ radius of the SRS, based on 1980 U. S. Census data, is illustrated in Fig. 2.1-3. The data were assembled by geographical division formed by subdividing the study area into 16 radial segments centered on the north overlain by concentric circles with radii of $16,32,48,64$, and $80 \mathrm{~km}$. The area within the $16 \mathrm{~km}$ radii are DOE-owned properties within the SRS. There are no permanent population groups within this area. 

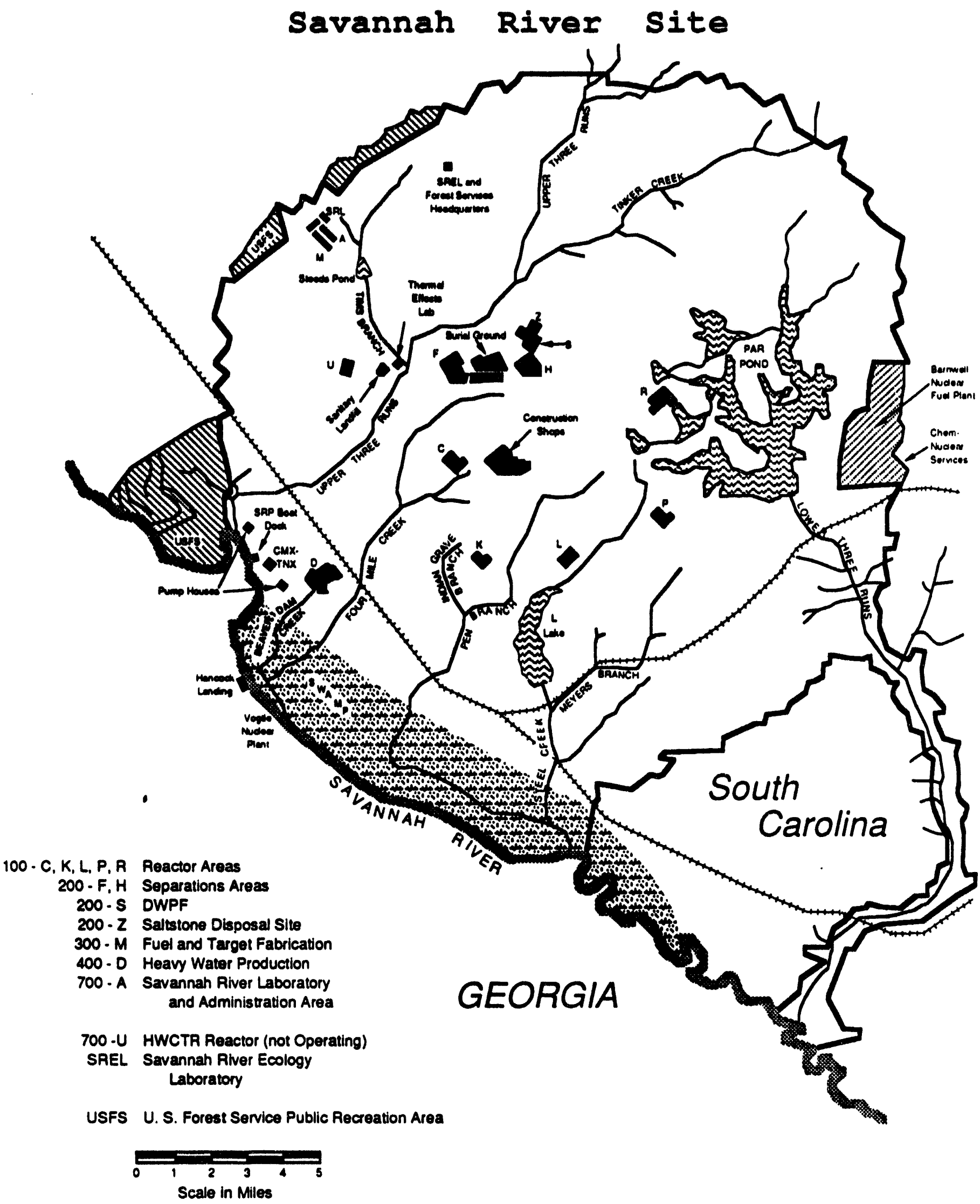

Fig. 2.1-2. Facility location map of the SRS, showing surface drainage. 


\section{SOUTH CAROLINA}

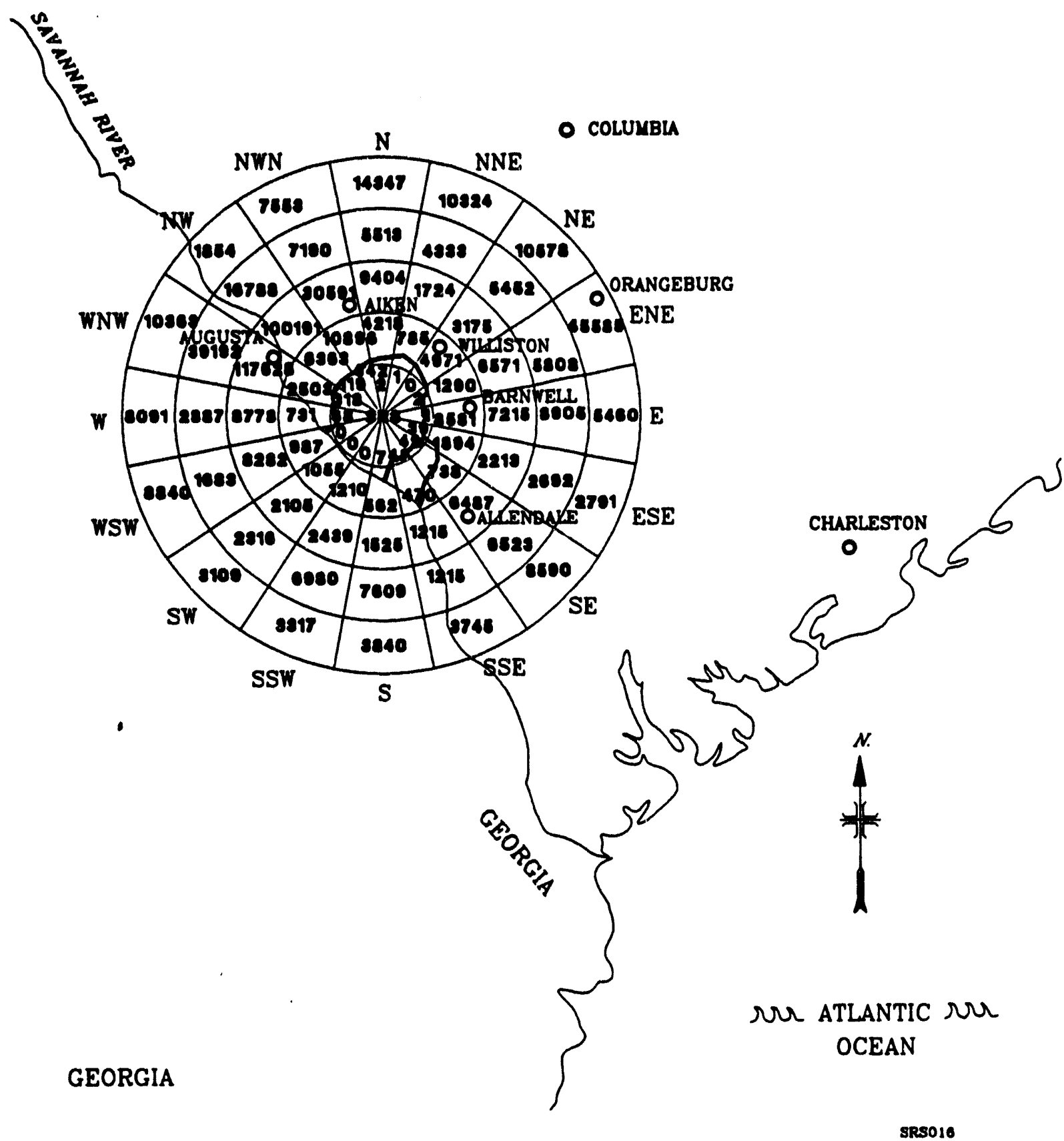

F1g. 2.1-3. Population distribution within an $80-\mathrm{km}$ radius of the central SRS. 
The major residential population centers $80 \mathrm{~km}$ from the approximate SRS plant center point are Augusta, Georgia, about $37 \mathrm{~km}$ to the northwest; Aiken, South Carolina, about $27 \mathrm{~km}$ to the north; and Orangeburg, South Carolina, about $79 \mathrm{~km}$ to the east northeast (Fig. 21-1). In 1980, the estimated population within the $80 \mathrm{~km}$ radius around the SRS was approximately 553,000 (Cook et al. 1987). More than $50 \%$ of the population is in the Augusta, Georgia - South Carolina Standard Metropolitan Statistical Area (SMSA) which includes Richmond and Columbia Counties in Georgia, Aiken County in South Carolina, and the Fort Gordon Military Reservation. Between 1980 and 2030, the residential population within the $80 \mathrm{~km}$ radius of the $S R S$ is projected to increase from 553,000 to 845,000 , or $153 \%$ (Cook et al. 1987 ).

The growth characteristics of the cities and towns around the SRS are similar to those of the rest of the state. There is a distinct pattern of population increase in the areas just outside cities. Cities of Aiken and North Augusta, South Carolina are expected to become major urban centers with populations over 25,000. No other major urban centers are expected to develop in this area.

The transient population consists almost entirely of the SRS work force. The Fort Gordon Military Reservation, Alvin W. Vogtle Nuclear Power Plant, and Chem-Nuclear Systems employ approximately 4500,3400 , and 300 , respectively.

\section{Meteorology}

The regional climate of the SRS is classified as humid subtropical, characterized by short, mild winters and long, warm and humid summers. Summer usually lasts from May through September, at which time daytime temperatures are frequently above $90^{\circ} \mathrm{F}$. Winter conditions alternate between warm, moist subtropical air from the Gulf of Mexico and cool, dry polar air. Less than one-third of all winter days have a minimum temperature below freezing. Annual average precipitation, computed from daily meteorological data collected at a SRS meteorological tower from 1964 to 1987, is $124 \mathrm{~cm} \mathrm{yr}^{-1}$.

Hourly averaged wind data from the H-Area (Fig. 2.1-2) meteorological tower in 1982 through 1986 indicate an average wind speed for all stability classes of $3.25 \mathrm{~m} / \mathrm{s}$ (WSRC 1992b). Sixty percent of the hours for which data were collected are characterized by wind speeds less than $6 \mathrm{~m} / \mathrm{s}$, and less than $0.1 \%$ of the hours are characterized by wind speeds exceeding $12 \mathrm{~m} / \mathrm{s}$. Observed wind directions are fairly well distributed among the 16 wind direction sectors in the data. Stability class $D$, indicative of relatively neutral diffusion conditions, occurs more frequently than any other class (28\% of the hours). 


\subsection{Seismicity}

The susceptibility of the SRS, and particularly Z-Area, to seismic motion is of interest to establish if Z-Area is suitable for waste disposal. Below is a discussion of seismic zones that are known to exist in the vicinity of the SRS, and the expected intensity associated with seismic activity in these zones at the SRS.

\subsubsection{Location of Nearby Seismic Zones}

The SRS is located in the interior of the North American plate. The nearest zones of concentrated seismic activity in the region, in the last 200 years, are centered in the Charleston-Summerville area of South Carolina and near Bowman, SC, which is $60 \mathrm{~km}$ northwest of Summerville, SC (Fig. 2.1-4). Recent seismic activity in the Charleston area, probably including the earthquake of 1886 , has originated largely or entirely in the basement beneath the Coastal Plain sediments. The seismicity in the Charleston area is believed to occur at the intersection of the Ashley River fault and the Woodstock fault, at minimum depths of $4 \mathrm{~km}$ and $8 \mathrm{~km}$, respectively. Seismicity associated with the Bowman seismic zone occurs along a border fault of a buried Triassic basin, exterding to a depth of about $6 \mathrm{~km}$ (WSRC 1992b).

Underlying the Coastal Pl_in sediments of the central and southern portions of the SRS is a Triassic-Jurassic rift basin within the crystalline basement. This basin, called the Dunbarton Triassic basin, is located in the Aiken Plateau, about $50 \mathrm{~km}$ southeast of the Fall Line (Fig. 2.1-4). Associated with this basin on the SRS are at least two faults; the northern border fault and a parallel northwest-trending fault the Pen Branch fault, which may coincide with the border fault. Several reverse faults have been identified beneath Z-Area, which are believed to be contained in the crystalline basement, although seismic activity associated with them has not been documented.

Faulting has also been recognized in sediments as young as Oligocene in the Atlantic Coastal Plain sediments of South Carolina. Faulting has been postulated to occur in these sediments based on structure-contour mapping of the Eocene-Oligocene unconformity, which lies between 30 and $61 \mathrm{~m}$ below the surface, in the vicinity of Charleston and about $100 \mathrm{~km}$ from the SRS. A shallow fault, associated with a 16-km wide graben of Oligocene and Miocene rocks which crosses beneath the Savannah River from Georgia into South Carolina, is postulated about $56 \mathrm{~km}$ southeast of the SRS. It is not currently possible to relate these shallow faults to modern earthquakes that occur at depths greater than about $2 \mathrm{~km}$. 


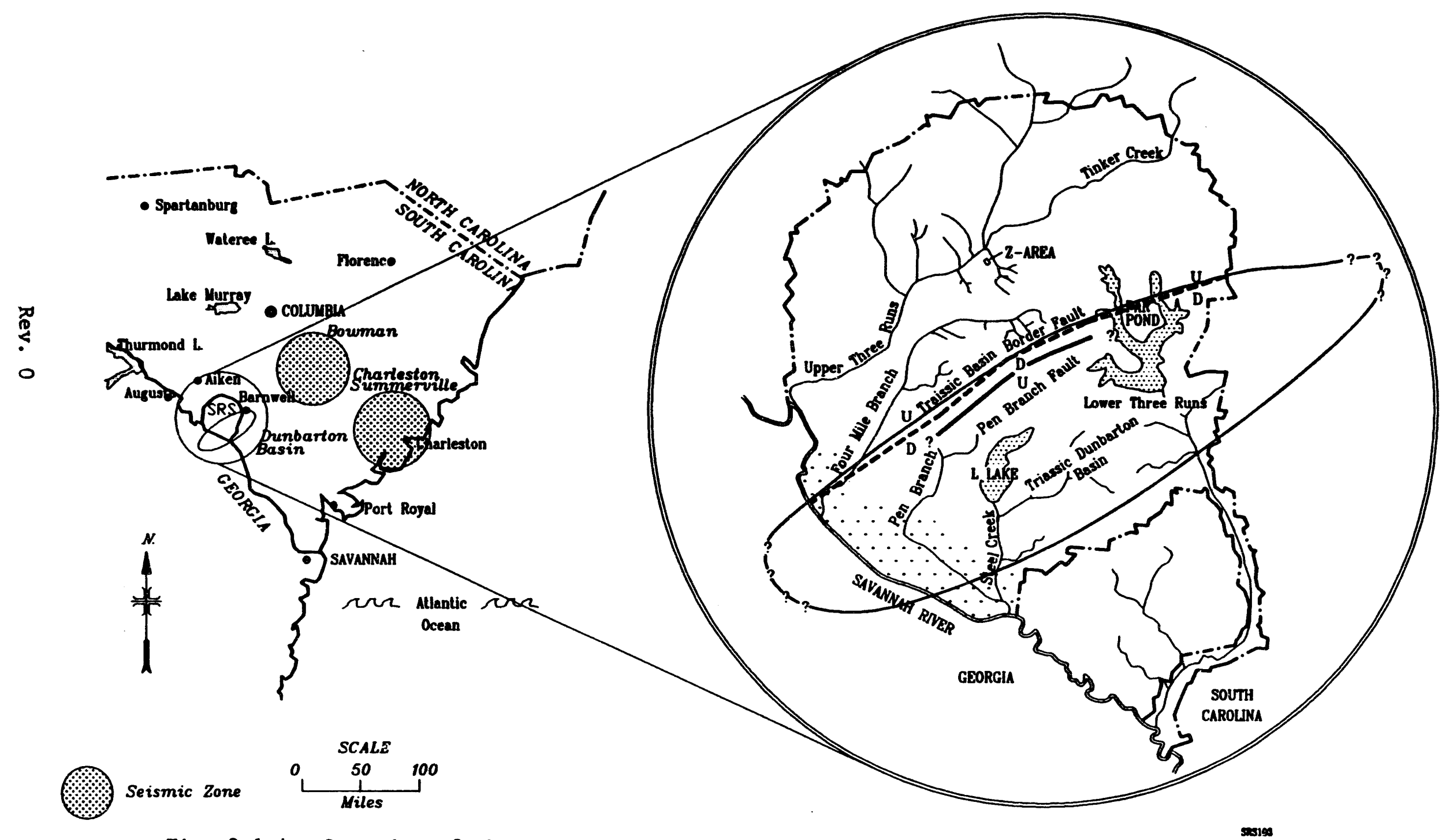

Fig. 2.1-4. Location of the Bowman and Charleston-Summerville seismic zones, and the Dunbarton Basin on the SRS. 


\subsection{Intensities of Historical Earthquakes}

The largest known earthquake to affect the site region was the Charleston earthquake of 1886 . This Modified Mercalli Intensity (MMI) X earthquake struck Charleston SC, on August 31, 1886. The greatest intensity felt at the SRS has been estimated at MMI VI-VII (felt by all; everyone runs outdoors; damage negligible in buildings of good structure, but considerable in poorly built structures) as a result of this earthquake (WSRC 1992b). Minor tremors from aftershocks of the 1886 Charleston event were also felt in the area where the SRS is now located. Intensities of these tremors were estimated to be equal to or less than MMI IV.

Seismic activity, producing earthquakes of estimated MMI up to V to VII, has been present in the Bowman area (about $95 \mathrm{~km}$ northeast of SRS) over the last 200 year (WSRC 1992b). These earthquakes produced motion at the SRS corresponding to a MMI of less than VI. An earthquake (MMI VII) that struck Union County, SC (about $160 \mathrm{~km}$ north-northeast of the SRS) in 1913 was felt at Aiken (6 km north -northwest of SRS) with a MMI of II-III (vibration indoors like a passing truck).

Two earthquakes of MMI III or less have occurred with epicentral locations within the boundaries of the SRS (Stephenson et al., 1985; Stephenson 1988). A MMI III earthquake with a local magnitude of 2.5 occurred in June 1985 at the SRS, as did a MMI I-II earthquake in August 1988. Neither of the earthquakes triggered the seismic alarms at the SRS facilities, which are triggered when ground accelerations equal or exceed $.002 \mathrm{~g}$. The epicenters of these earthquakes appear to be located within about six miles of the intersection of a northwest-trending fault and the northeast-trending border fault at the northern edge of the Dunbarton Triassic basin, and are relatively shallow (1 to $3 \mathrm{~km}$ below the earth's surface).

\subsubsection{Projected Recurrence of Earthquates}

According to Bollinger et al. (1989), the recurrence interval for a Charleston size shock (MMI X) for the Charleston area and for the Coastal Plain is on the order of 1000 years, at the $95 \%$ confidence level. A recurrence of the 1886 Charleston earthquake would result in an intensity of MMI VII at the SRS (URS/Blume 1982). Recurrence of earthquakes associated with other known seismic zones in the region are not expected to be of greater intensity, nor cause greater shaking at the SRS (WSRC 1992b).

A MMI of VII at the SRS is estimated by URS/Blume (1982) to correspond to an expected peak ground acceleration of $0.10 \mathrm{~g}$. The annual probability of exceeding a peak ground acceleration of $0.20 \mathrm{~g}$ is $2 \times 10^{-4}$. Liquefaction is known to occur at peak ground accelerations less than $0.20 \mathrm{~g}$. Historical occurrences of soil liquefaction, however, suggest that potential for occurrence is greater for fine sands and silty sands, rather than clayey sand and silts, and for saturated soils at depths of $6 \mathrm{~m}$ or less. At Z-Area, the water table occurs at no less than $7.5 \mathrm{~m}$, and the presence of clay lenses throughout the upper aquifer suggest liquefaction is unlikely. Evaluation of field test data on liquefaction potential at the SRS was done by URS/Blume, with the conclusion that liquefaction potential was low at this site. 


\subsection{Hydrogeology}

The surface of the Upper Atlantic Coastal Plain on which SRS is located slopes gently seaward. This province is underlain by a seaward dipping wedge of unconsolidated and semi-consolidated sediments that extends from the Fall Line to the seaward edge of the continental shelf. Sediments begin at the Fall Line, where the crystalline Piedmont province gives way to the Coastal Plain. These sediments increase to a thickness of more than $1.2 \mathrm{~km}$ near the coast of South Carolina. The SRS is underlain by about 180 to $370 \mathrm{~m}$ of Coastal Plain sediments. The Coastal Plain sediments vary in age from Late Cretaceous to Recent (WSRC 1992b).

The Coastal Plain sediments are divided into several groups based principally on age and lithology (WSRC 1992b). The stratigraphic units are illustrated in Fig. 2.1-5. Names previously used to describe the units are shown.

The Coastal Plain sediments are underlain by Triassic sediments in the central and southern portions of the SRS, which are subsequently underlain by a basement consisting of Late Precambrian and Paleozoic metamorphic and igneous rocks. The reader is referred to Appendix $E$ for an in-depth treatment of the stratigraphy of the SRS.

Following is an overview of the groundwater hydrology associated with the hydrologic units identified in Fig. 2.1-5. Appendix E documents the hydrology of the bedrock formations and the Coastal Plain sediments. In this section, the hydrology of the upper Coastal Plain sediments, specifically Zones 5, 6, 7, and 8 (Fig. 2.1-5) will be summarized. These upper zones are the zones potentially affected by contaminant release from the SDF. An upward pressure gradient exists at the base of Zone 5, in the region of interest, suggesting that downward flow from Zone 5 does not occur.

\subsection{Hydrogeology of Coatal Plains Sediments - Zone 5}

Zone 5 consists of the clastic sediments of the Congaree Formation (Zone 5a) and the glauconite-bearing sands and clays of the lowermost Santee Limestone Formation (Zone 5b). Zone $5 a$ is an aquifer that consists predominaintly of fine-to-coarse quartz sand. Clay laminae occur throughout the formation, but they are too thin and discontinuous to be effective seals except locally. Zone 5b, identified as the "green clay" layer, or Caw Caw member of the Santee Formation, is characterized by rapid facies changes. The permeability of this layer varies greatly from place to place.

Potentiometric surface maps, provided in Appendix E, indicate that Zone 5a at the SRS naturally discharges into the swamps and marshes along Upper Three Runs Creek and the Savannah River. Upper Three Runs Creek dissects the clay layer of Zone 5b, causing unconfined conditions in the Zone Sa aquifer in the stream valleys. Four Mile Creek does not incise Zone 5b (Parizek and Root 1986), and thus does not affect the head in this zone. Elsewhere on the SRS, Zone Sa behaves as a confined to semiconfined aquifer (WSRC 1992b). Near the marshy flood plain of Upper Three Runs 


\section{HYDROLOGIC UNITS}

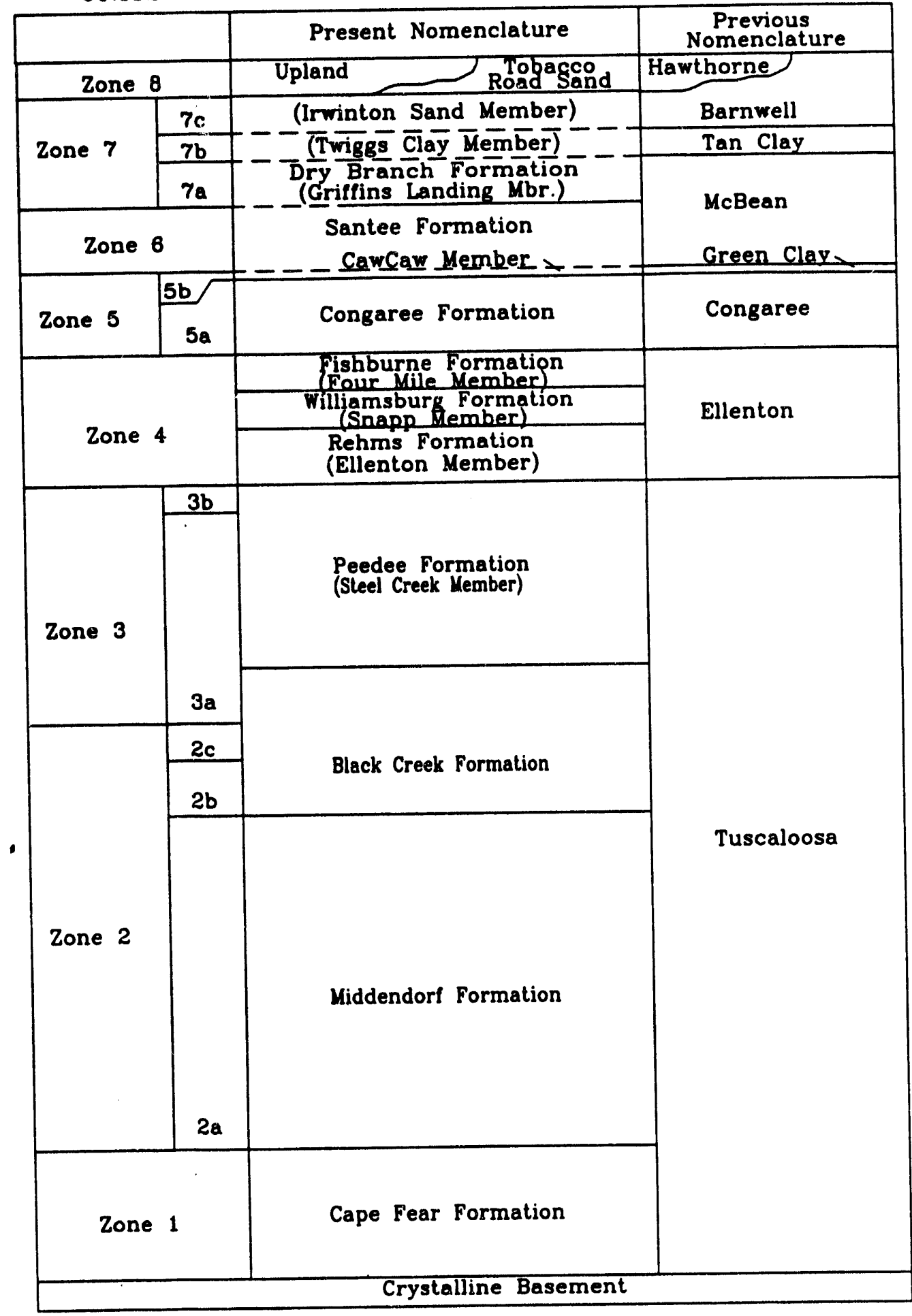

SR9005

Fig, 2,1-5. Hydrologic and stratigraphic units underlying the SRS. 
Creek, the measured hydraulic gradients in Zone 5 are much steeper than they are elsewhere at the SRS; however, measurements have not been made near the Savannah River.

\subsection{Hydrogeology of Coastal Plain Sediments - Zone 6}

Zone 6 consists of clastic and carbonate sediments of the Santee Formation that lie above the "green clay" layer of Zone 5b. Porosity and permeability of Zone 6 strata vary greatly, depending on the dominant lithology and amount of clay present at any particular location. Nowhere on the SRS, however, do the clays in this zone form effective aquitards.

Zone 6 is incised by many of the streams on the SRS, including Upper Three Runs, McQueen and Crouch Branches. Thus, flow in this zone is affected to a large degree by the surface water on the site.

\subsubsection{Hydrogeology of Coastal Plain Sediments - Zone 7}

Zone 7 is comprised of three subzones: 7a, 7b, and 7c, which correspond to two members of the Dry Branch Formation and the lower Tobacco Road Sand Formation. Zones 7a (Griffins Landing and Irwinton Sand Members) and 7c (Tobacco Road Sand Formation) are aquifers whereas Zone $7 \mathrm{~b}$ (Twiggs Clay Member) is locally an aquitard. Zone $7 \mathrm{a}$ acts as an aquifer when the amount of clay and carbonate is low. Zone $7 \mathrm{~b}$ is called the "tan clay" on the SRS. Zone 7c consists of moderately to poorly sorted quartz sand with interlaminated clays abundant in places, and supports a perched water table in areas where the piezometric surface in Zone 7a is below the tan clay (Intera 1986). Zone 7 varies from about $15 \mathrm{~m}$ thick at the northwestern SRS boundary to $24 \mathrm{~m}$ at the southeastern boundary. The "tan clay" varies from 0.6 to $3 \mathrm{~m}$ in thickness where present.

\subsubsection{Hydrogeology of Cosstal Plain Sediments - Zone 8}

Zone 8 consists of the upper gravels, sands, and clays of the Tobacco Road Sand and "Upland" unit. Both the Tobacco Road and "Upland" unit contain appreciable clay layers, but these are discontinuous and do not form an effective regional aquitard. The thickness of the Tobacco Road Sand is extremely variable, but can be at least $15 \mathrm{~m}$ thick in places. The "Upland" unit may be up to $21 \mathrm{~m}$ thick in some areas of the SRS.

Zone 8 is commonly water bearing. The water-table often occurs in this zone, at an altitude ranging from 63 to $77 \mathrm{~m}$ above sea level, leaving the "Upland" unit and overlying Quaternary deposits unsaturated. Near the creeks, where Zone $7 \mathrm{a}$ is a free water table, the groundwater in Zone 8 must be considered perched. 


\subsection{Surface Water Hydrology}

The Savannah River cuts a broad valley approximately $76 \mathrm{~m}$ deep through the Aiken Plateau, on which most of the SRS sits. The Savannah River Swamp lies in the floodplain along the Savannah River for a distance of about $16 \mathrm{~km}$ on the SRS, and averages about $2.4 \mathrm{~km}$ wide. Upper Three Runs Creek, Fourmile Branch, Tinker Creek, Pen Branch, Steel Creek, and Lower Three Runs Creek (Fig. 2.1-2) are the major tributaries of the Savannah River that occur on the SRS. Three breaches of the natural levee occur at the confluences of the Savannah River with Beaver Dam Creek, Fourmile Branch, and Steel Creek, allowing discharge of these streams to the river. During swamp flooding, water from Beaver Dam Creek and Fourmile Branch flows through the swamp that parallels the river and combines with the Pen Branch flow. Pen Branch joins Steel Creek about $0.8 \mathrm{~km}$ above its mouth.

Surface water is held in artificial impoundments and natural wetlands on the Aiken Plateau. Par Pond, the largest impoundment on the SRS, is located in the eastern part of the SRS, covering about $11 \mathrm{~km}^{2}$. A second impoundment, L Lake, lies in the southern portion of SRS and covers approximately $4 \mathrm{~km}^{2}$. The waters drain from Par Pond and L Lake to the south, via Lower Three Runs Creek and Steel Creek, respectively, into the Savannah River. Lowland and upland marshes, and natural and manmade basins on the SRS retain water intermittently.

Near the SRS, the flow of the Savannah River has been stabilized by the construction of upstream reservoirs. The yearly average flow is approximately $290 \mathrm{~m}^{3} \mathrm{~s}^{-1}$. From the SRS, river water usually reaches the coast in five to six days, but may take as few as three days. At low flow, which usually occurs in autumn months, the Savannah River is about $100 \mathrm{~m}$ wide and 3 to $5 \mathrm{~m}$ deep, with an average velocity of approximately $3 \mathrm{~m} \mathrm{~s}^{-1}$ corresponding to a flow of $1200 \mathrm{~m}^{3} \mathrm{~s}^{-1}$.

\subsubsection{Water Quality and Usage}

\subsubsection{Groundwater}

The sand beds of Zones 2 and 3 are an important source of water for wells neighboring the SRS. Industrial wells in these sands are yielding, or are projected to yield, more than $5.0 \times 10^{-2} \mathrm{~m}^{3} \mathrm{~s}^{-1}$ (Cook et al. 1987). Most municipal and industrial water supplies in Aiken County, SC are developed in these zones. In Barnwell and Allendale counties, some municipal users are supplied from the shallower Zones 5 and 6 . Private domestic supplies in all of these counties are primarily obtained above Zones 2 and 3.

Municipal and industrial groundwater use in the vicinity of the SRS indicated total pumpage from Zones 2 and 3 on the order of $1 \mathrm{~m}^{3} \mathrm{~s}^{-1}, 0.2 \mathrm{~m}^{3} \mathrm{~s}^{-1}$ from Zone 5; and up to $0.04 \mathrm{~m}^{3} \mathrm{~s}^{-1}$ from Zone 6 . The SRS uses up to $0.4 \mathrm{~m}^{3} \mathrm{~s}^{-1}$ on site, from Zones 2 and 3 (Cook et al. 1987).

Rev. 0 
Water quality parameters for groundwater at the SRS are likely to be quite variable. Parameters specific to Z-Area are presented in Sect. 2.2 below.

\subsection{Surface Water}

Water from the Savannah River is used for drinking water at two locations below the SRS. About $160 \mathrm{~km}$ downstream of SRS, The Beaufort-Jasper Water Treatment Plant at Hardeeville, SC, withdraws about $0.3 \mathrm{~m}^{3} \mathrm{~s}^{-1}$ for a consumer population of approximately 51,000. The Cherokee Hill Water Plant at Port Wentworth, GA, about $160 \mathrm{~km}$ downstream of the SRS, presently withdraws about $2 \mathrm{~m}^{3} \mathrm{~s}^{-1}$ for an effective consumer population of about 20,000 . The Savannah River is also used for commercial and sport fishing and for recreational boating. Surface water quality is presently monitored by the Environmental Monitoring Section and the Savanuah River Technology Center at the SRS (Cummins et al. 1990). Surface water is characterized with respect to radiological and non-radiological aspects, both on-site and downstream of the SRS. Some water quality characteristics of the Savannah River upstream of the SRS, classified as a Class B water by the SCDHEC, are listed in Table 21-1. The temperature, dissolved oxygen, and $\mathrm{pH}$ values reflected in this table are within the standards required for Class B waters (Cummins et al. 1990). Other water quality parameters listed in this table are within the ranges observed in previous years (Cummins et al. 1990), indicating that the quality of the Savannah River is not being degraded at the point of measurement.

\subsection{Soils}

Most of the soils at the SRS are sandy over a loamy or clayey subsoil. The distribution of soil types is very much influenced by the creeks on the site, with colluvial deposits on hilltops and hillsides giving way to alluvium in valley bottoms (Dennehy et al. 1989). Road cuts and excavations on interstream areas near the SRS commonly expose a deeply developed soil profile. Two horizons are apparent; the A horizon may be up to $3 \mathrm{~m}$ thick, and typically consist of structureless fine- to medium-grained quartz sand, and the lower B horizon, which may be from 0.6 to $3 \mathrm{~m}$ in thickness, contains iron and aluminum compounds leached from the overlying material.

Weathering effects are evident. In some areas, intense chemical weathering has produced tensional soil fractures as a result of volume reduction. These fractures are dominant features in shallow exposures such as drainage ditches.or roadside embankments. Average soil erosion rates for the area surrounding the SRS, much of which is cropland, range from 1.5 to $2.0 \mathrm{~kg} \mathrm{~m}^{-2} \mathrm{yr}^{-1}$. (U.S. Department of Agriculture 1985) Employing the Universal Soil Loss Equation to predict erosion at the SRS under different vegetative conditions, Horton and Wilhite (1978) estimate that the presence of natural successional forests would reduce erosion by a factor of 400 to 500 over cropland erosion. 
Table 21-1. Water quality of the Savannah River above SRS (Cummins et al 1990)

\begin{tabular}{|c|c|c|c|c|c|}
\hline Parameter & Units & $\begin{array}{c}\text { No. of } \\
\text { Analyses }\end{array}$ & $\begin{array}{l}\text { Arithmetic } \\
\text { Mean }\end{array}$ & $\operatorname{Max}$ & Min \\
\hline Temperature & $\operatorname{deg} C$ & 12 & 18 & 27 & 10 \\
\hline pH & pH & 12 & & 7.4 & 6.2 \\
\hline Dissolved oxygen & $\mathbf{m g} / \mathbf{L}$ & 12 & 8.0 & 9.6 & 6.4 \\
\hline Alkalinity & $\mathbf{m g} / \mathbf{L}$ & 12 & 21 & 24 & 17 \\
\hline Conductivity & umhos $/ \mathrm{cm}$ & 12 & 84 & 104 & 61 \\
\hline Turbidity & NTU & 12 & 6.9 & 18 & 23 \\
\hline Suspended solids & $\mathbf{m g} / \mathbf{L}$ & 12 & 13 & 22 & 6.0 \\
\hline Volatile solids & $\mathbf{m g} / \mathbf{L}$ & 12 & 2.3 & 40 & 1.0 \\
\hline Total dissolved solids & $\mathbf{m g} / \mathbf{L}$ & 12 & 62 & 76 & 46 \\
\hline Total solids & $\mathrm{mg} / \mathrm{L}$ & 12 & 74 & 86 & 58 \\
\hline Fixed residue & $\mathbf{m g} / \mathbf{L}$ & 12 & 10 & 19 & 5.0 \\
\hline Chemical oxygen demand & $\mathbf{m g} / \mathbf{L}$ & 12 & 9.7 & 17 & 7.0 \\
\hline Chloride & $\mathbf{m g} / \mathbf{L}$ & 12 & 7.8 & 11 & 4.6 \\
\hline Nitrogén (as $\mathrm{NO}_{2} / \mathrm{NO}_{3}$ ) & $\mathrm{mg} / \mathrm{L}$ & 12 & 0.99 & 0.99 & 0.15 \\
\hline Sulfate & $\mathbf{m g} / \mathbf{L}$ & 12 & 7.8 & 11 & 6.0 \\
\hline Phosphorus (as $\mathrm{PO}_{4}$ ) & $\mathrm{mg} / \mathrm{L}$ & 12 & 0.09 & 0.16 & 0.05 \\
\hline Nitrogen (as $\mathrm{NH}_{3}$ ) & $\mathbf{m g} / \mathbf{L}$ & 12 & .13 & 0.34 & $<0.02$ \\
\hline Cadmium & $\mathrm{mg} / \mathrm{L}$ & 4 & $<0.01$ & $<0.01$ & $<0.01$ \\
\hline Mercury & $\mu g / L$ & 4 & $<0.20$ & 0.20 & $<0.20$ \\
\hline Chromium & $\mathrm{mg} / \mathrm{L}$ & 4 & $<.02$ & $<.02$ & $<0.02$ \\
\hline
\end{tabular}

Rev. 0 


\subsection{Ecology}

\subsubsection{Aquatic Ecology}

Flora in the Savannah River basin and in creeks on the SRS site is diverse and seasonally variable. Several species of diatoms, green algae, yellow-green algae, and bluegreen algae are present. In seasonally tlooded areas, bald cypress and tupelo gum thrive. In less severely flooded areas, oak, maple, ash, sweet gum, ironwood, and other species, less tolerant of flooding, are found. In the river swamp formed by the Savannah River in the vicinity of the SRS, herbaceous growth is sparse. A number of macrophytes, such as cattail and milfoil, are found in areas receiving sufficient sunlight.

The fish communities in the Savannah River and in creeks on the SRS are very diverse. Redbreast sunfish, spotted sucker, channel catfish, and flat bullhead are the dominant species. Sunfish, crappies, darters, minnows, American shad, and striped bass are also abundant.

Macroinvertebrate communities are largely comprised of true flies, mayflies, caddisflies, stoneflies, and beetles. Leaf litter input is high, but is rapidly broken down by macroinvertebrate shredders. The Asiatic clam is found in the Savannah River and its larger tributary streams.

\subsubsection{Terrestrial Ecology}

Prior to its acquisition by the U. S. Government in 1951, approximately one-third of the SRS was cropland, about half was forested, and the remainder was floodplain and swamp. Since that time, the U. S. Forest Service has reclaimed many previously disturbed areas through natural plant succession or by planting pine trees. As was noted in Sect. 2.1.1, 91\% is now pine or hardwood forests, with the remaining $9 \%$ divided between SRS facilities and water bodies.

A variety of vascular plants exist on the site. Scrub oak communities cover the drier sandy areas, which includes predominantly longleaf pine, turkey oak, bluejack oak, blackjack oak, dwarf post oak, three awn grass, and buckleberry (U.S.DOE 1987). On the more fertile, dry uplands, white oak, post oak, southern red oak, mockernut hickory, pignut hickory, and loblolly pine predominate, with an understory of sparkleberry, holly, greenbriar, and poison ivy. Pine trees cover more area than any other tree genus.

The heterogeneity of the vegetation on the SRS supports a diverse wildlife population. Several species of reptiles and amphibians are present due to the variety of aquatic and terrestrial habitats. These include snakes, frogs, toads, salamanders, turtles, lizards, and alligators. More than 213 species of birds have been identified on the SRS. Burrowing animals at the SRS include: Peromyscus polionotus, known commonly as the Old Field Mouse; Blarine brevicauda, known as the Short Tail Shrew; Scalopus aquiticus, 
known as the Eastern Mole; Poponomyrmex badius, known as the Harvester Ant; Dorymyrmex pyramicus, known as the Pyramid Ant; and earthworms (Briese and Smith 1974; Davenport 1964; Golley and Gentry 1964; Smith 1971; Van Pelt 1966).

\subsection{Existing Radiological Environment}

All human beings are exposed to sources of ionizing radiation which include naturally occurring and man-made sources. The average individual dose contribution estimates from various sources were obtained from recent reports of the National Council on Radiation Protection and Measurements (NCRP) and the EPA. On average, a person living in the Central Savannah River Area (CSRA) receives an annual radiation dose of 379 mrem (Cummins et al. 1990). The average dose contributions from the various radiation sources to an individual in the CSRA are given in Fig. 2.1-6.

The major source of radiation exposure to the average number of the public in the CSRA is attributed to naturally-occurring radiation. This naturally-occurring radiation is often referred to as natural background radiation. Natural sources of radiation include cosmic radiation from outer space, cosmogenic radionuclides formed by interaction of cosmic radiation with elements in the earth's atmosphere, terrestrial radiation from natural radioactive materials in the ground, radiation from radionuclides occurring naturally in the body, and inhaled and ingested radionuclides of natural origin. The amount of exposure an individual receives depends on their location. Table 2.1-2 compares national averages for exposure to natural background radiation to average exposures in the vicinity of the SRS.

The average annual dose to people in the U.S. from cosmic radiation is about 27 mrem, which is lower than estimated for the vicinity of the SRS because a large fraction of the U.S. population lives near sea level, where cosmic radiation is lower. A report published by the EPA gives a specific outdoor cosmic radiation dose for Augusta, GA of about $41 \mathrm{mrem}$ (Oakly 1972). When shielding and the time spent indoors are considered, the annual average cosmic radiation dose for the CSRA population is about $33 \mathrm{mrem}$, about $22 \%$ higher than the national average. The average annual dose from terrestrial gamma radiation is about $28 \mathrm{mrem}$ in the U.S. This annual dose varies geographically across the U.S. Values from the SRS vicinity include $43 \mathrm{mrem}$ for Augusta, GA, 23 mrem for Charleston, SC, and $68 \mathrm{mrem}$ for Columbia, SC (Oakly 1972).

The major contributors to the annual dose equivalent for internal radionuclides are the short-lived decay products of radon (mostly $2 \mathcal{R n}_{\mathrm{R}}$ ), which contribute an average dose of about 200 mrem per year. This dose estimate is based on an average radon concentration of about $1 \mathrm{pCi} / \mathrm{L}$ (NCRP 1987). The results of long term measurements in living areas of about 30,000 homes in the U.S. suggest that the mean radon concentration levels are about $3.6 \mathrm{pCi} / \mathrm{L}$ for the U.S. population and about $1 \mathrm{pCi} / \mathrm{L}$ for South Carolina (Alter and Oswald 1988). The average dose from other internal radionuclides is about 39 mrem per year, which is predominantly attributed to the 


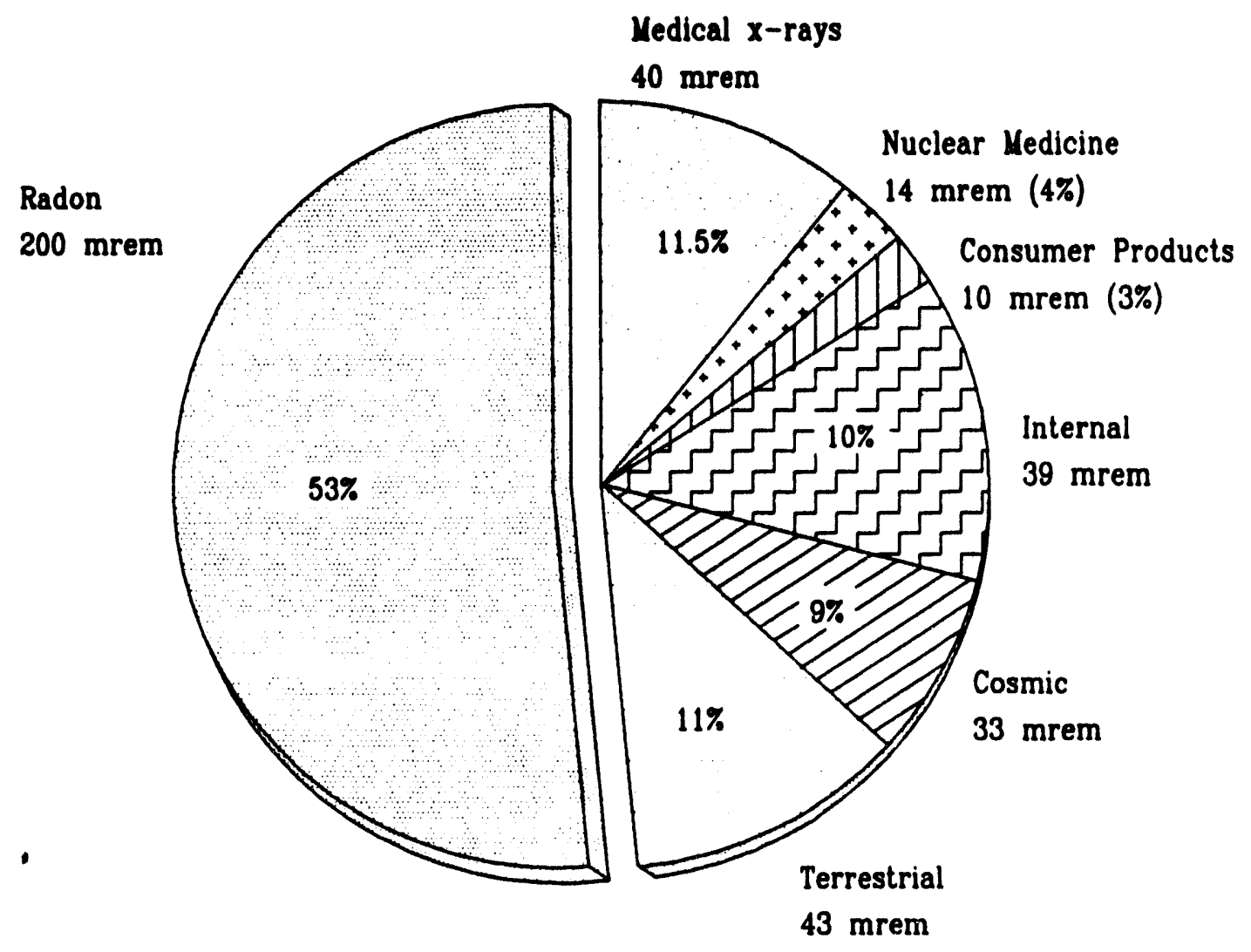

F18. 2,1-6. The total average effective dose equivalent from various sources in the Central Savannah River Area. 
Table 21-2 Comparison of natural radiation doses near SRS with U.S. averages

\begin{tabular}{lcc}
\hline Natural Radioactivity & \multicolumn{2}{c}{ Annual Average Dose (mrem) } \\
\cline { 2 - 3 } & S0-mile radius of SRS & U.S. Average \\
\hline Cosmic radiation & 33 & 27 \\
Terrestrial radiation & 43 & 28 \\
Internal radiation" & 239 & 240 \\
Total & 315 & 295 \\
\hline
\end{tabular}

- Approximately $\mathbf{2 0 0}$ mrem of the dose from internal radiation is attributed to radon exposure. An EPA study, which was scheduled to be published in 1991, will update the information on the U.S. distribution of doses from radon. Preliminary information suggests that the U.S. average dose from radon may be higher than 200 mrem. 
naturally occurring radioactive isotope of potassium, ${ }^{10} \mathrm{~K}$. The concentration of ${ }^{40} \mathrm{~K}$ in human tissues is similar in all parts of the world (NCRP 1987).

A wide range of consumer products also contain sources of ionizing radiation. The U.S. average annual dose to an individual is about $10 \mathrm{mrem}$ (NCRP 1987).

Radiation is an important tool of diagnostic medicine and cancer treatment. The average annual EDE to all individuals from all medical examinations is $54 \mathrm{mrem}$ (about 40 mrem for diagnostic $x$-rays and 14 mrem for nuclear medicine procedures). The actual doses to individuals who receive such medical exams is much higher than these values, because not everyone receives such exams each year (NCRP 1989).

There are a few additional sources of radiation that contribute minor doses to individuals in the U.S. About 1,320,000 people performed radiation work in 1980 and received an average dose of 110 mrem per year (Cummins et al. 1990). This exposed population represents only about one half of $1 \%$ of the U.S. population. The dose to the general public from nuclear fuel cycle facilities, such as uranium mines, mills, fuel processing plants, nuclear power plants, and transportation routes, has been estimated at leas than 1 mrem per year.

Small doses to individuals occur as a result of radioactive fallout from atmospheric atomic bomb tests, which have now been suspended; emissions of radioactive materials from other nuclear facilities, such as DOE facilities; emissions from certain mineral extraction facilities; and transportation of radioactive materials. The combination of these sources contributes less than 1 mrem per year to the average dose to an individual (Cummins et al. 1990).

Environmental monitoring is performed at the SRS to demonstrate that releases of radionuclides from the site do not exceed the radiation protection guidelines for the general public. Thousands of samples are collected and analyzed each year. Materials monitored include: air, groundwater, drinking water, milk, food stuffs, SRS streams and basins, vegetation, rainwater, Savannah River water, soil and sediments, fish, and wildlife. These samples are collected in defined ways from on-site, at the site perimeter, and at locations up to $160 \mathrm{~km}$ from SRS. The samples are analyzed for specific radionuclides. Measurements of environmental gamma radiation are also made at numerous on-site and off-site locations (Cummins et al 1990).

The non-radiological environment is also monitored at SRS. The materials sampled in the non-radiological program include: air, groundwater, Savannah River sediment, SRS streams and outfalls, and fish. In addition to labc atory analyses, water and air quality measurements are routinely made in the field. Non-radiological compounds monitored include nitrate, some heavy metals, and some chlorinated organics. 
An environmental monitoring program has been maintained continuously in the SRS region since 1951. Public reports have been published since 1959 dealing with various aspects of the environmental program at SRS. In 1985, the on-site and off-site environmental monitoring reports were merged into a single publication. Recent monitoring results specific to Z-Area, that provide information on the existing radiological environment at the SDF site, are provided in Sect. 2.2.5.

\section{Z-AREA SITE DESCRIPTION}

Z-Area was chosen for the SDF site based on considerations of depth to the water table, distance to surface water and the public, available surface area, surface topography, and its proximity to the wastewater generation site. A study was conducted comparing the site characteristics of Z-Area to those of 17 sites considered for the location of a new low-level radioactive waste disposal facility at SRS (Cook 1984a). This study concluded that Z-Area was one of the top-rated sites at SRS for waste disposal. Following is a discussion of site characteristics specific to Z-Area, that were not covered explicitly in the above discussion on regional characteristics.

\section{Z-Area Location, Description and Land Use}

The Z-Area at the SRS, where the SDF is located, consists of approximately $650,000 \mathrm{~m}^{2}$, and is situated about $2 \mathrm{~km}$ northeast of the SRS DWPF at S-Area

(Fig. 2.1-2). The latitude and longitude coordinates for the boundaries of Z-Area are approximately: at the northwest corner, latitude $33^{\circ} 18^{\prime} 35^{\prime \prime}$ longitude $81^{\circ} 38^{\prime} 38^{\prime \prime}$; at the northeast corner, latitude $33^{\circ} 18^{\prime} 12^{\prime \prime}$ longitude $81^{\circ} 37^{\prime} 55^{\prime \prime}$; at the southwest corner, latitude $33^{\circ} 18^{\prime} 20^{\prime \prime}$ longitude $81^{\circ} 38^{\prime} 52^{\prime \prime}$; and at the southeast corner, latitude $33^{\circ} 17^{\prime} 55^{\prime \prime}$ longitude $81^{\circ} 38^{\prime} 6^{\prime \prime}$.

The Aiken Plateau is dissected by numerous streams near Z-Area that greatly influence the local groundwater system (Dennehy et al. 1989). A topographic map showing elevations and the local streams in the vicinity of Z-Area is provided in Fig. 2.2-1. The Z-Area lies on a local topographic high, at approximately $91 \mathrm{~m}$ above sea level. Z-Area is bounded by McQueens Branch in the northeast and Upper Three Runs Creek in the northwest. The local relief is about $50 \mathrm{~m}$. McQueens Branch is a tributary of Upper Three Runs Creek. Upper Three Runs Creek drains into the Savannah River, some $15 \mathrm{~km}$ southwest of Z-Area. Upper Three Runs Creek lies about $1.2 \mathrm{~km}$ from the northwest corner of Z-Area. The northeast corner of Z-Area is located only about $150 \mathrm{~m}$ from McQueens Branch. McQueens Branch and Crouch Branch are incised into the topographic high, southeast and southwest of Z-Area, such that their headwaters come within about $1 \mathrm{~km}$ of each other at approximately $1.4 \mathrm{~km}$ south of Z-Area (Dennehy et al. 1989). The elevations of both tributaries range from about $46 \mathrm{~m}$ to $76 \mathrm{~m}$. Presently, open fields characterize Z-Area. 

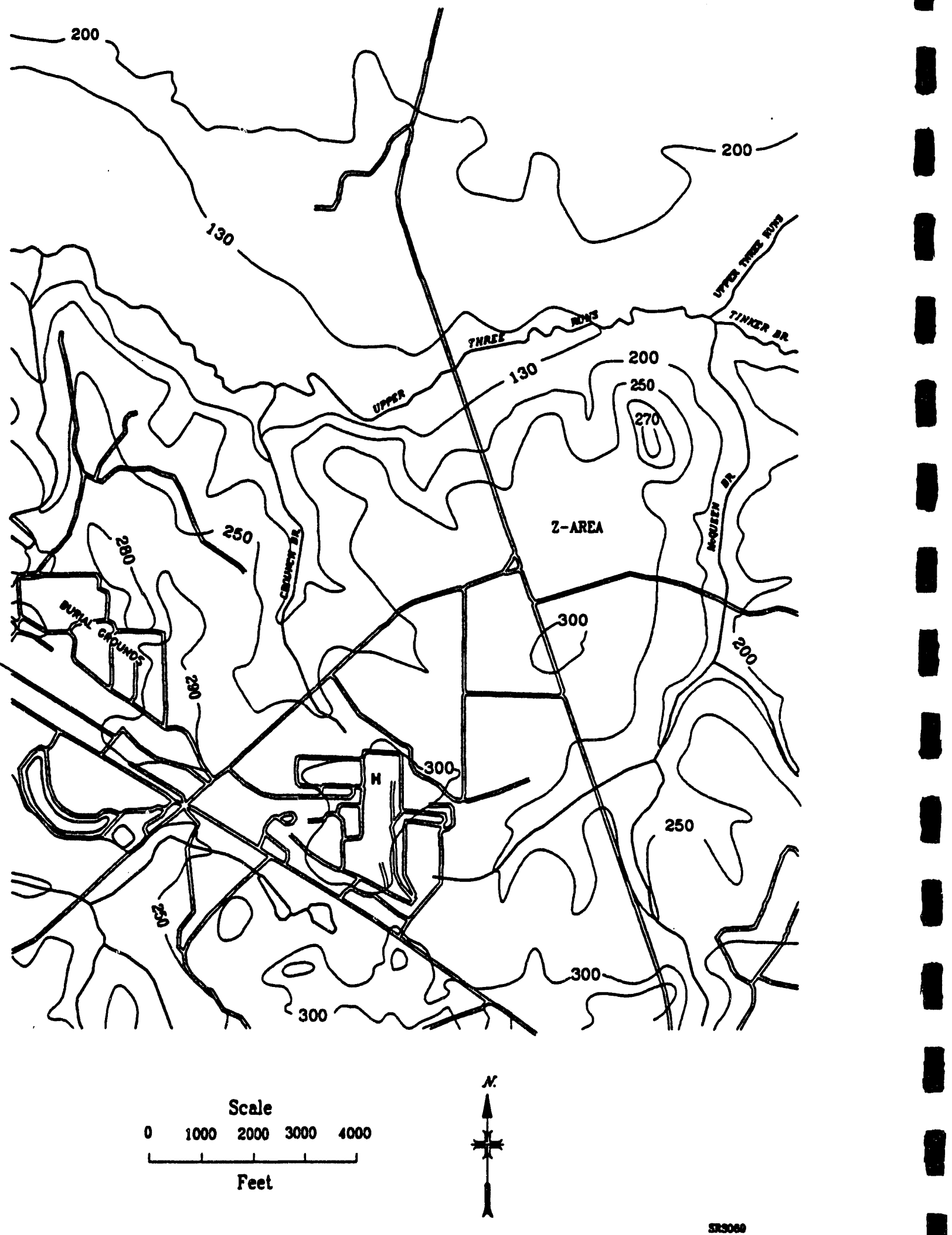

Fig. 2.2-1. Topographic map in the vicinity of Z-Area. 


\section{Hydrogeology of Z-Area}

The Coastal Plain sediments in Z-Area rest directly on a layer of clay which is a residual product of weathering of the crystalline basement rock (Intera 1986). The Triassic sediments are not present under Z-Area. The hydrogeology of the upper Coastal Plain sediments (Zones 5 through 8, Fig. 21-5) in the vicinity of Z-Area is discussed in this section, as these upper sediments are those most likely affected by the SDF. Zone 4, which is 15 to $24 \mathrm{~m}$ thick in the vicinity of Z-Area (Dennehy et al. 1989), is believed to be a local aquitard based on water level data that indicate the pressure head in this zone exceeds that in the overlying aquifer (Zone 5a) (WSRC 1992b), which would suggest that downward flow through Zone 4 does not occur. As was noted in the regional hydrogeology section above (Sect. 2.1.5), information on the hydrogeology of lower units is presented in Appendix $\mathrm{E}$. Much of the hydrogeologic information specific to Z-Area comes from well boring logs and water level data from a series of wells placed in the late 1970s and early 1980s; the SDS series wells. A location map of these wells is provided in Fig. 2.2-2. Two lithologic cross-sections developed from this information are shown in Fig. 2.2-3 and 2.2-4.

The lowermost hydrologic zone potentially affected by the SDF is Zone 5a (Fig. 2.1-5), in the Congaree Formation. Zone 5a, in the vicinity of Z-Area, is an aquifer about 15 to $21 \mathrm{~m}$ thick (Dennehy et al. 1989). Locally, the horizontal gradient in Zone Sa is about $3.8 \times 10^{-3}$ to $7.6 \times 10^{-3}$ toward Upper Three Runs Creek. Upper Three Runs Creek cuts down into this zone; however, Crouch Branch and McQueens Branch do not. Local water level data for this surface are not available in sufficient quantity to generate definitive potentiometric surfaces for this unit. However, regional potentiometric surface maps, and the limited Z-Area data, both indicate flow in this unit is towards Upper Three Runs Creek, to the north and northwest of Z-Area.

The overlying "green clay" layer, or Zone $5 \mathrm{~b}$, near Z-Area averages about $3 \mathrm{~m}$ in thickness, and appears to be continuous through the disposal site (Dennehy et al. 1989). The permeability of this layer at Z-Area has not been measured.

Zone 6 is the aquifer overlying Zone 5b. The thickness of this zone in the Z-Area vicinity is about $9 \mathrm{~m}$ (Dennehy et al. 1989). Zone 6 is incised by local streams in the vicinity of Z-Area. McQueens Branch and Crouch Branch cut down into the aquifer to varying degrees. North and northwest of Z-Area, Upper Three Runs Creek cuts into this hydrologic unit. A potentiometric surface map of Zone 7a (Appendix E), to which Zone 6 is hydraulically connected, indicates flow is predominantly northward beneath Z-Area, with lateral components towards either Upper Three Runs Creek or McQueens Branch. There is a vertical head difference between the overlying sandy layer of Zone 7 and Zone 6 of about $0.6 \mathrm{~m}$, indicating a downward component of groundwater flow beneath Z-Area in this zone (Intera 1986). 


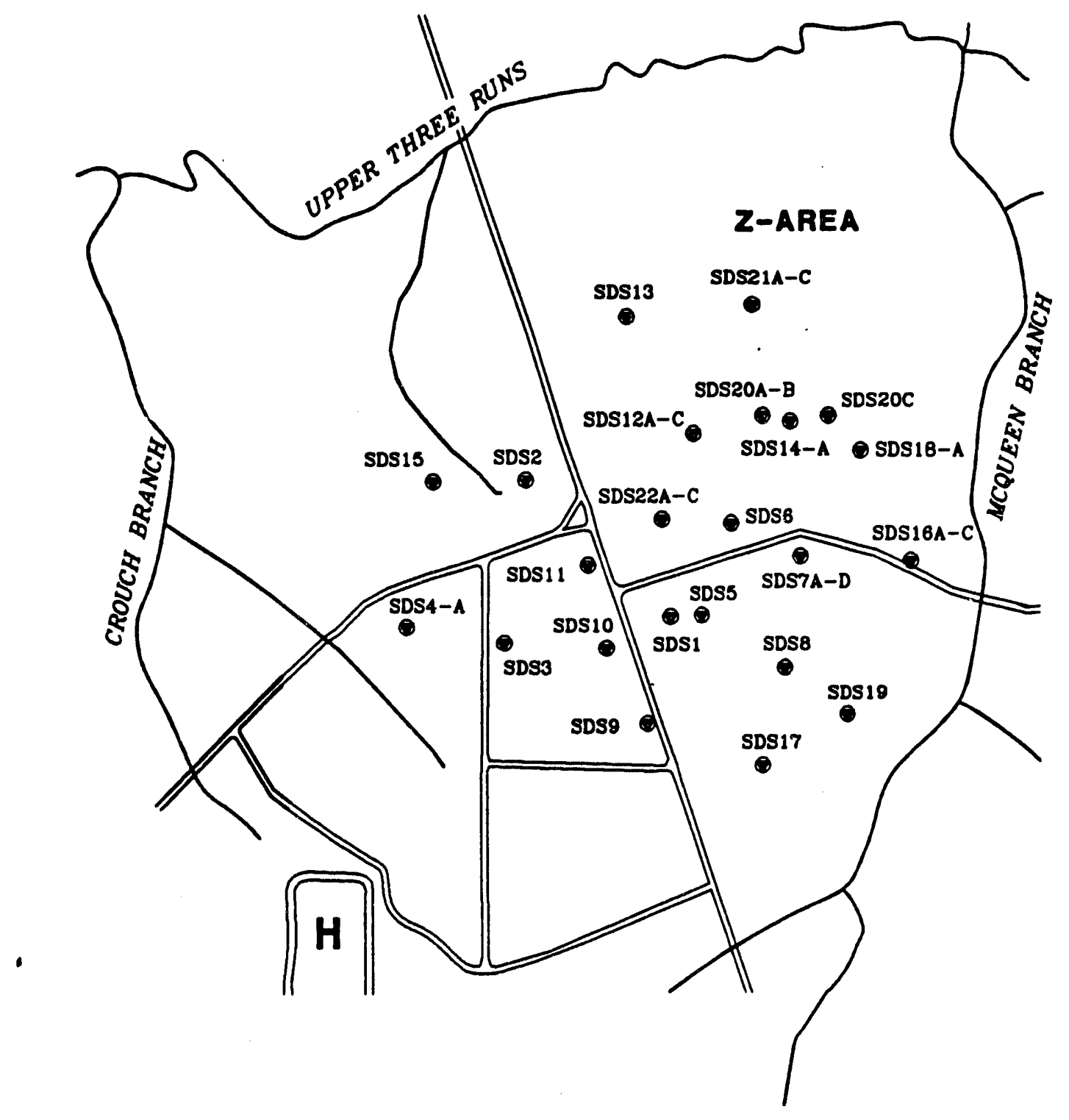

- Monitor well locations

Plant North

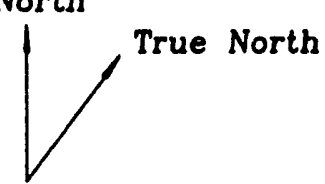

FEET

$0=\frac{5001000}{200 \quad 400} 2000$

METERS

Fig. 2.2-2. Location of SDS-series wells at Z-Area. 

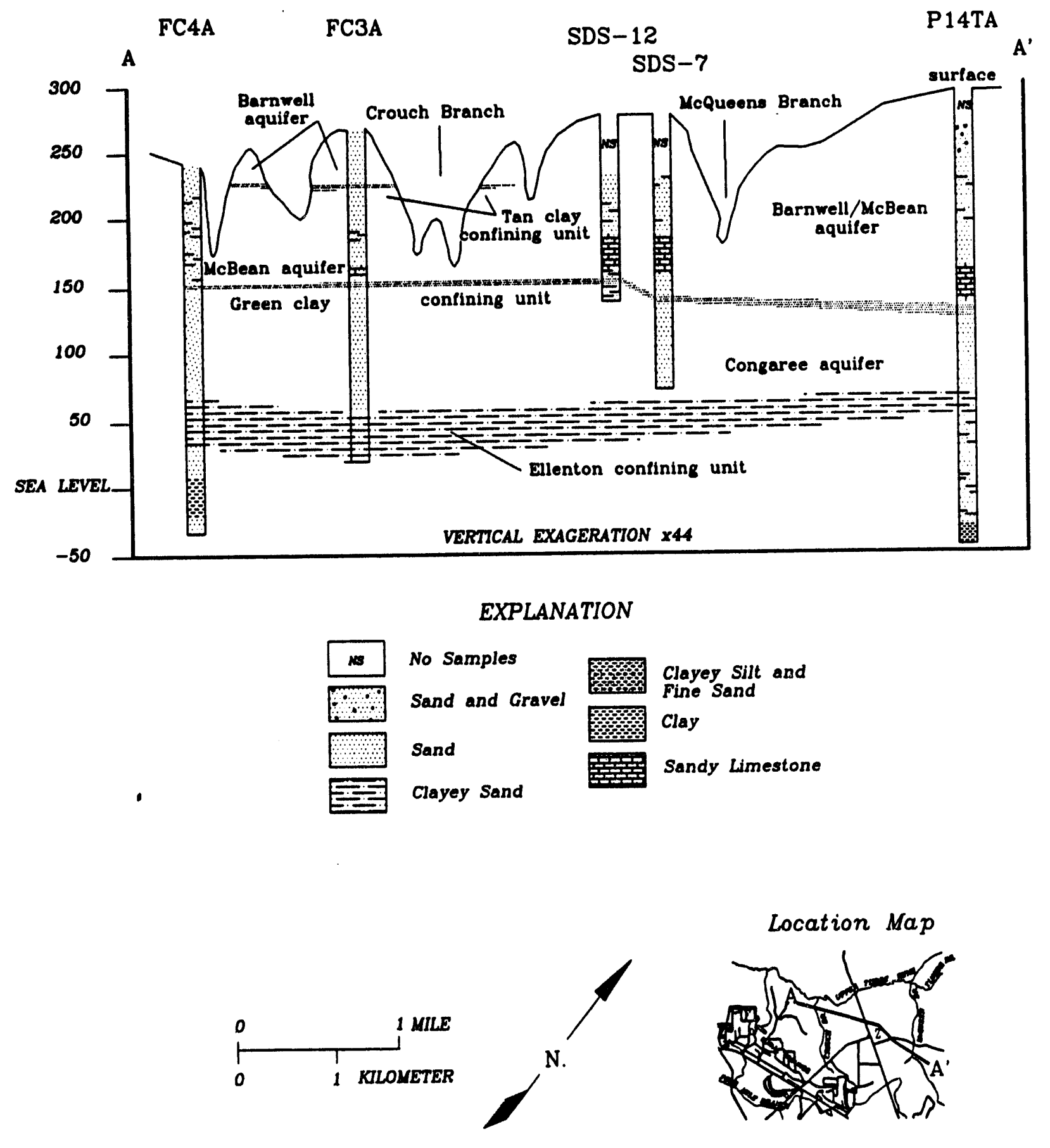

Fig. 2.2-3. Lithologic cross-section, A-A', in the vicinity of Z-Area. Well SDS-12 ${ }_{\text {spsoos }}$ is in Z-Area; SDS-7 is just east of the facility boundary.

Rev. 0 


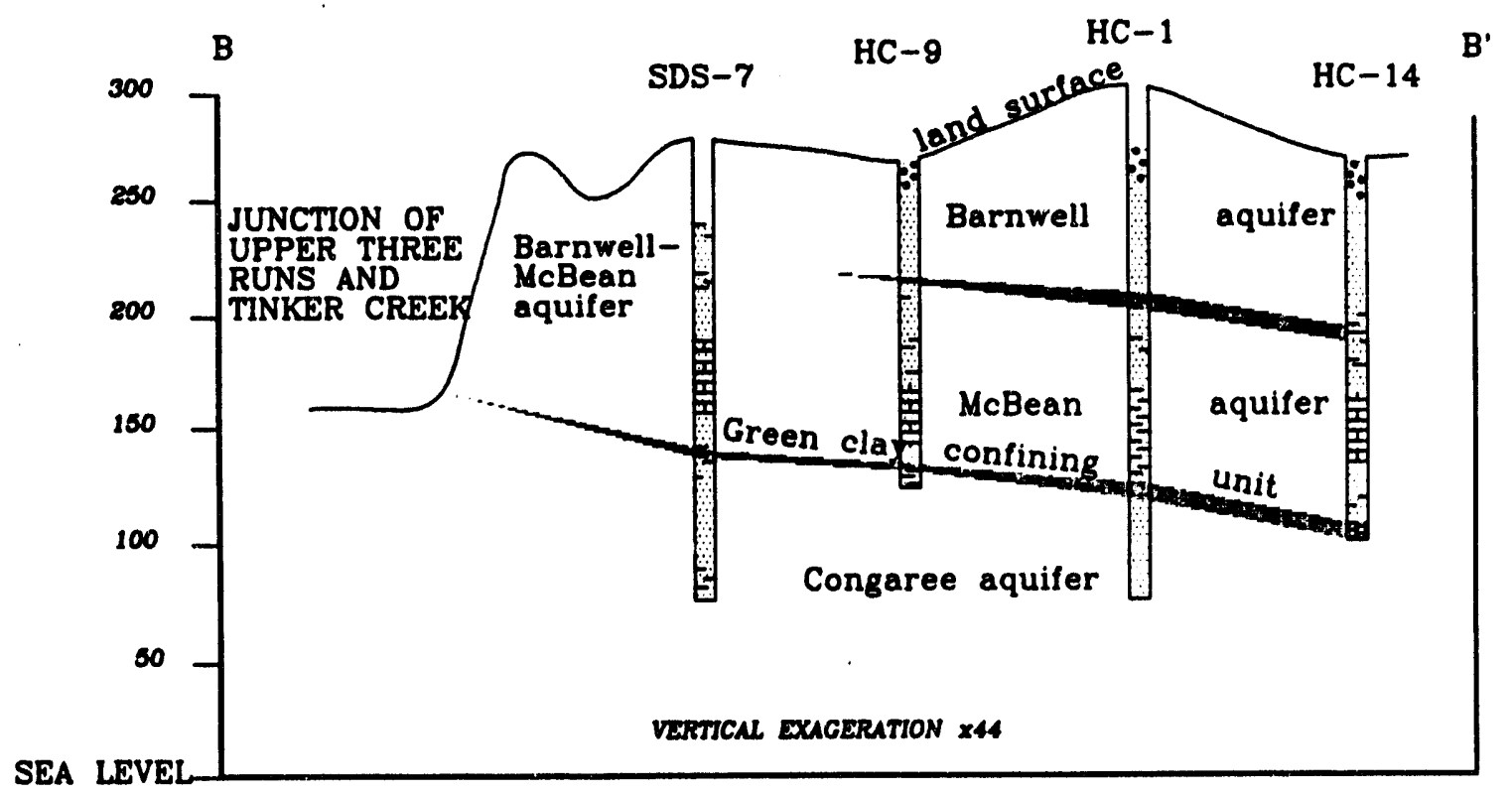

EXPLANATION

\begin{tabular}{|c|c|c|c|}
\hline$\infty$ & No Samples & 8 & Silt and \\
\hline $\mathrm{n}$ & Sand and Gravel & xax & $\begin{array}{l}\text { Pine Sand } \\
\text { Clay }\end{array}$ \\
\hline & Sand & & 'sendy limegton \\
\hline & Clayey Sand & & \\
\hline
\end{tabular}
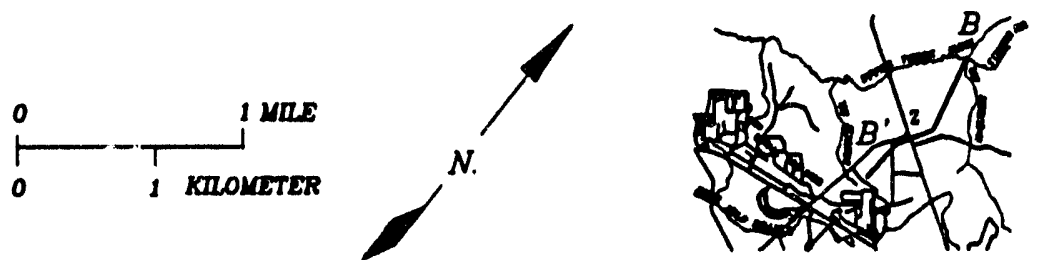

Fig. 2.2-4. Lithologic cross-section, B-B', in the vicinity of Z-Area. Well SDS-7 is just east of the facility boundary.

Rev. 0 
As discussed in Appendix E, the heterogeneity of the Zone 6 and Zone 7 sediments have a measurable effect on the hydraulic head. The variability of these sediments is illustrated in Fig. 2.2-5 which includes the lithology from well cluster SDS-7 in Z-Area, as described by Cook et al. (1984b), and water level data from Table 6-5 in the INTERA (1986) report. The 0.6-m head differential between wells SDS-7c and SDS-7d, both developed in Zone $6 / 7 \mathrm{a}$, indicated the locally confining influence of the discontinuous clay lenses found throughout Zone 6 and 7. This suggests that even in areas where the tan clay is absent, the presence of other nondescript clay lenses may achieve the same confining ability. The "tan clay" is absent in the northeastern half of Z-Area (Dennehy et al. 1989).

Zone $7 \mathrm{a}$ is the hydrologic unit immediately overlying Zone 6. This aquifer is dissected by the creeks near Z-Area, and potentiometric surface data (Appendix E) indicate flow predominantly in the northern direction, although east or west components of flow exist due to the presence of the affecting creeks. The horizontal gradient ranges from 0.007 at the center of Z-Area to 0.030 at the western hill slope. The piezometric surface of Zone 7a is a free water table near the creeks (INTERA 1986).

Zone $7 \mathrm{~b}$ at Z-Area is important because it supports perched water in Zone $7 \mathrm{c}$ in some areas. Evidence of perched water supported by Zone $7 \mathrm{~b}$ is provided in water level data presented by INTERA (1986). Head differential across Zone $7 \mathrm{~b}$ varies from 3 to $12 \mathrm{~m}$ at Z-Area.

In the northeastern section of Z-Area, Zone $7 \mathrm{a}$ is hydraulically connected to Zone 7c, because the "tan clay" layer (Zone $7 b$ ) is absent in this area. Perched water can be found within Zone 7c due to the presence of discontinuous clay lenses. Zone 7c forms the lower portion of what has previously been designated the Barnwell aquifer. Like Zone 7a, Zone 7c is drained by the creeks in the vicinity of Z-Area.

Except in the vicinity of the creeks, the water table occurs in Zone 8 near Z-Area. The depth to the water table in a normal precipitation year, in the Z-Area vicinity, ranges from 8 to $18 \mathrm{~m}$ (Dennehy et al. 1989). Under Z-Area only, the minimum depth to the water table from the ground surface in any given year is estimated to be $13 \mathrm{~m}$, on the basis of water table fluctuations from several years data (Cook 1983). This minimum depth corresponds to a year in which the highest recorded precipitation, of $188 \mathrm{~cm}$, occurred near the SRS, and thus, corresponds to the historic high water table. The direction of flow is affected by the creeks, and is generally in a northern direction at Z-Area (Dennehy et al. 1989). The horizontal gradient ranges from 0.002 in the southern part of Z-Area to 0.05 at the northeastern hill slope.

Measured hydraulic conductivities of the hydrologic zones described above are listed in Table 2.2-1. As was noted earlier in this section, measured values for Zone 5b, the "green clay" layer are absent.

Rev. 0 


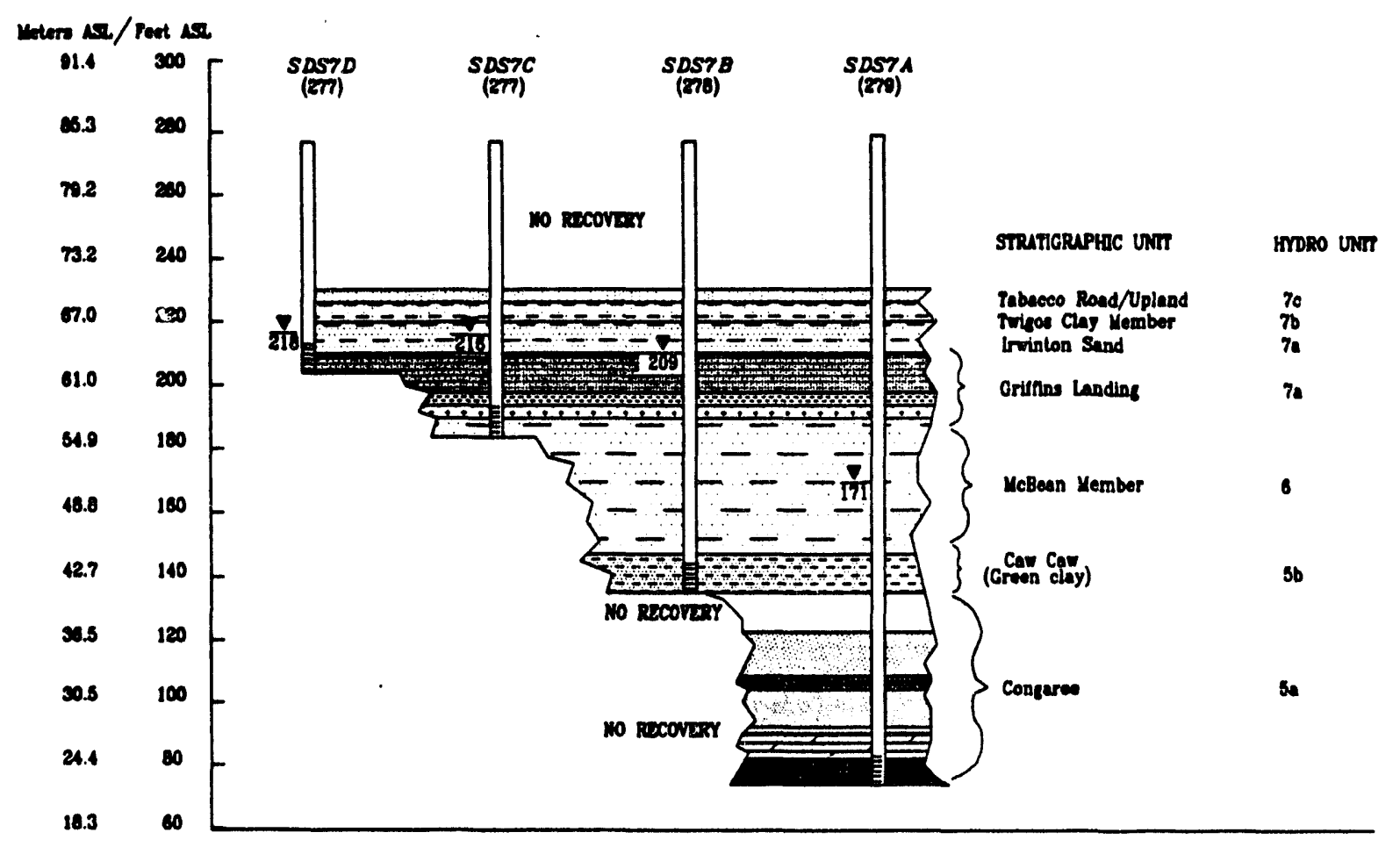

\section{EXPLANATION}

Savo-orasge, tine to couren, traces of graval.

E-7 CuYrT SWD-dart brown ten, fine to medium, trace of clay. sund-tan orange and brown, fine to medium, small clay leases. sund-tan brown and orange, fine to canse.

SWD-tan purple, flote to medium, zmall clay lensea.

8:7 SWD-yellow lan and brom. fine to coares, trace of olay.

7 currex 3WND-tan whife brown orange and yellow, tine to coarse.

SWD-groen to gray, fibe to medtum. trace of mion.

SWD-creen, fine to medium.

cuY-dart mosy, trece of mad.

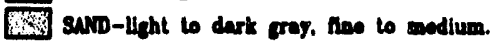

Fif curey sund-dark gros, tise to medlum. SND-light gras hen, fine to modium.

sos-4 Nell number

(001) Deration

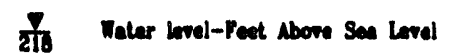

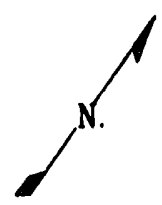

Not to reale
Location Nap

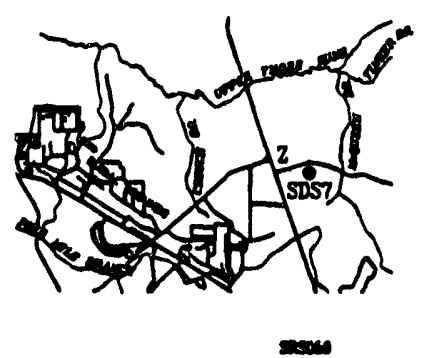

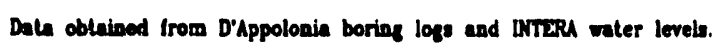

Fig. 2.2-5. Lithology and water level data for well SDS-7. 
Table 22-1 Summary of bydraulic conductivities reported for upper hydrologic units of the coastal plain sediments (horizontal unless otherwise stated)

\begin{tabular}{|c|c|c|c|c|}
\hline $\begin{array}{l}\text { Hydrologic } \\
\text { Units }\end{array}$ & $\begin{array}{l}\text { Sub- } \\
\text { Units }\end{array}$ & $\begin{array}{l}\text { Field-determined } \\
\text { Hydraulic } \\
\text { Conductivity } \\
\left(\mathrm{m} \mathrm{s}^{-1}\right)\end{array}$ & $\begin{array}{c}\text { Hydraulic } \\
\text { Conductivity } \\
\text { determined } \\
\text { from Soil Cores } \\
\left(\mathrm{m} \mathrm{s}^{-1}\right)\end{array}$ & $\begin{array}{l}\text { Hydraulic } \\
\text { Conductivity } \\
\text { determined from } \\
\text { Sieve Analysis } \\
\left(\mathrm{m} \mathrm{s}^{-1}\right)\end{array}$ \\
\hline Zone 8 & & - & $10^{-5}$ & - \\
\hline \multirow{3}{*}{ Zone 7} & $7 c$ & $2 \times 10^{-7}-10^{-4 b, c}$ & $10^{-6 a d}$ & - \\
\hline & $\mathbf{7 b}$ & $\begin{array}{c}2 \times 10^{-9}-8 \times 10^{-9} c \\
\text { (vertical) }\end{array}$ & $10^{+\alpha}$ & $\ldots$ \\
\hline & $7 \mathrm{a}$ & $10^{-5}-10^{-4 \text { base }}$ & - & - \\
\hline Zone 6 & & $6 \times 10^{-7}-2 \times 10^{-5 b, c}$ & & $-\infty$ \\
\hline \multirow{2}{*}{ Zone 5} & $5 \mathbf{b}$ & $\infty$ & $\cdots$ & $\infty$ \\
\hline & $5 \mathbf{a}$ & $10^{-7}-5 \times 10^{-46,90}$ & - & $3 \times 10^{-5}-2 \times 10^{-3}$ \\
\hline
\end{tabular}

- Source: Dennehy et al. 1989; Z-Area vicinity

- Source: Christensen and Gordon 1983; regional data

- Source: Parizek and Root, 1986; SRS data, near Z-Area

- Source: Cook 1986; Z-Area vicinity

- Source: INTERA 1986; Z-Area vicinity

f Source: WSRC 1992b; regional data 
Hydraulic characteristics of unsaturated soil near Z-Area are reported in Appendix E Soil water content - soil water pressure relationships for soil in two areas are provided, as are relationships between hydraulic conductivity and water content. The disparity between the relationships at the two areas are indicative of the heterogeneous nature of soils in the vicinity of Z-Area.

\section{Surface Water in the Vicinity of Z-Area}

The watershed of Upper Three Runs Creek drains about $500 \mathrm{~km}^{2}$ of the Upper Coastal Plain northeast of the Savannah River. Significant tributaries to this creek are Tinker Creek, which is a headwaters branch that comes in north of Z-Area, and Tims Branch, which connects up south of Z-Area (Fig. 2.1-2). There are no lakes or flow control structures on Upper Three Runs Creek or its tributaries. The stream channel has a low gradient and is meandering. Its floodplain ranges in width from 0.4 to $1.6 \mathrm{~km}$ and is heavily forested 'vith hardwoods.

Upper Three Runs Creek is gauged at three points within SRS: 1) near the northern SRS boundary, 2) just upstream of the Tinker Creek confluence, and 3) about $5 \mathrm{~km}$ above the confluence with the Savannah River. The average discharge at the two northern-most gauges normalized to drainage area is $0.013 \mathrm{~m}^{3} \mathrm{~s}^{-1} \mathrm{~km}^{-2}$, ranging from $0.006 \mathrm{~m}^{3} \mathrm{~s}^{-1} \mathrm{~km}^{-2}$ to $0.06 \mathrm{~m}^{3} \mathrm{~s}^{-1} \mathrm{~km}^{-2}$ (Dennehy et al. 1989). Maximum flows are attributed to excess precipitation runoff.

Two smaller tributaries of Upper Three Runs Creek, McQueens Branch and Crouch Branch, are located north and south, respectively, of the Z-Area. Both tributaries receive runoff from Z-Area. McQueens Branch has a drainage area of about $11 \mathrm{~km}^{2}$ and Crouch Branch has a drainage area of about $2.8 \mathrm{~km}^{2}$. One set of data from gauging stations on each of these tributaries reflects less than a full year's gauging results (Dehnehy et al. 1989). At that time, the southeastern United States was in a drought condition. These data thus represent a low-flow condition, in which all streamflow is from groundwater discharge. Discharge rates as a function of gauge height could not be developed due to the low flow. Seepage investigations on one particular day indicated that McQueens Branch gained groundwater at an average rate of $0.012 \mathrm{~m}^{3} \mathrm{~s}^{-1} \mathrm{~km}^{-1}$ of stream length. The average number for Crouch Branch on that day was $0.010 \mathrm{~m}^{3} \mathrm{~s}^{-1} \mathrm{~km}^{-1}$ of stream length, and for Upper Three Runs Creek in the vicinity of Z-Area, was $0.16 \mathrm{~m}^{3} \mathrm{~s}^{-1} \mathrm{~km}^{-1}$.

\section{Water Quality and Usage in the Z-Area Vicinity}

Currently, groundwater in Zones 5 through 8 are not pumped from Z-Area. Groundwater quality at Z-Area was recently assessed by the U. S. Geological Survey.

Results of chemical analyses of water samples from five wells at Z-Area are presented in Table 2.2-2 (Dennehy et al. 1989). In general, water from the lower Zones 5 and 6 tends to be higher in $\mathrm{pH}$, higher in dissolved calcium and bicarbonate concentrations, and higher in dissolved silica concentrations than water from Zone 7.

Rev. 0 
Table 22-2 Concentration of discolved elements in groundwater in Zones 5, 6, and 7 at Z-Area

\begin{tabular}{|c|c|c|c|c|c|}
\hline Parameter & $\begin{array}{c}\text { Zone } 5 \\
(\text { SDS 12A) }\end{array}$ & $\begin{array}{c}\text { Zone } 5 \\
\text { (SDS 20A) }\end{array}$ & $\begin{array}{c}\text { Zone } 6 \\
\text { (SDS 20B) }\end{array}$ & $\begin{array}{c}\text { Zone } 7 \\
\text { (SDS 12C) }\end{array}$ & $\begin{array}{c}\text { Zone } 7 \\
\text { (SDS 20C) }\end{array}$ \\
\hline $\mathrm{Ca} \quad(\mathrm{mg} /)$ & 38.0 & 31.0 & 19.0 & 4.8 & 1.6 \\
\hline$M g \quad(m g /)$ & 1.6 & 0.57 & 0.52 & 1.2 & 0.42 \\
\hline $\mathrm{Na} \quad(\mathrm{mg} /)$ & 2.7 & 1.8 & 1.9 & 1.1 & 1.5 \\
\hline$K \quad(m g /)$ & 1.3 & 1.7 & 0.7 & 0.4 & 0.42 \\
\hline Cl (mgl) & 1.7 & 2.2 & 1.8 & 0.85 & 2.1 \\
\hline $\mathrm{SO}_{4} \quad(\mathrm{mg} /)$ & 12.0 & 10.0 & 5.5 & 0.2 & 0.2 \\
\hline $\mathrm{HCO}_{3}$ (mg/l) & 123.0 & 85.0 & 62.0 & 18.0 & 6.0 \\
\hline $\mathrm{pH}$ & 8.09 & 7.81 & 8.40 & 6.85 & 6.04 \\
\hline $\mathrm{T} \quad\left({ }^{\circ} \mathrm{C}\right)$ & 21.2 & 22.7 & 20.7 & 21.5 & 20.9 \\
\hline $\mathrm{Cd} \quad(\mu \mathrm{g} /)$ & $<1.0$ & $<1.0$ & $<1.0$ & $<1.0$ & $<1.0$ \\
\hline $\begin{array}{l}\text { Dissolved } \\
\mathrm{O}_{2} \quad(\mathrm{mg} /) \\
\end{array}$ & 0.6 & $<0.1$ & 8.4 & 6.8 & 8.8 \\
\hline $\begin{array}{l}\mathrm{NO}_{2} / \mathrm{NO}_{3} \\
(\mathrm{mg} / \mathrm{as} \mathrm{N}) \\
\end{array}$ & $<0.10$ & $<0.10$ & 1.2 & 0.89 & 0.65 \\
\hline $\begin{array}{l}\mathrm{PO}_{4} \\
(\mathrm{mg} / \mathrm{as} \mathrm{P})\end{array}$ & $<0.01$ & 0.08 & 0.06 & $<0.01$ & $<0.01$ \\
\hline $\mathrm{SiO}_{2} \quad(\mathrm{mg} /)$ & 40.0 & 24.0 & 24.0 & 5.7 & 6.4 \\
\hline
\end{tabular}

Rev. 0 
Dissolved oxygen, nitrite, and nitrate concentrations in water from Zone 5 were significantly lower than in water from Zones 6 and 7. The different chemistry of the zones has partially been attributed to the dissolution reactions that occur as water from the upper Zone 7 moves downward through the lower calcite-bearing portion of Zone 6, and through the silica-bearing illite/smectite minerals in the "green clay". (Dennehy et al. 1989) These reactions also tend to increase pH. Differences in nitrate/nitrite concentrations may be due to the activity of nitrate/nitrite-reducing bacteria. (Dennehy et al. 1989)

Water from the creels local to Z-Area are not currently used for human consumption. Some water quality characteristics of Upper Three Runs Creek downstream of Z-Area, classified as a Class B water by the SCDHEC, are listed in Table 2.2-3. The temperature, dissolved oxygen, and $\mathrm{pH}$ values reflected in this table are within the standards required for Class B waters (Cummins et al. 1990). . Other water quality parameters listed in this table are within the ranges observed in previous years (Cummins et al., 1990), indicating that the quality of Upper Three Runs Creek is not being degraded at the point of measurement.

\section{Existing Radiation Euvironment at Z-Area}

The environmental monitoring program at the SRS includes the assessment of radionuclides in the groundwater and in stream sediments. Additional monitoring is performed for the air pathway and river water. The background level of interest at the Z-Area site location for this RPA is predominantly the long term concentrations related to the groundwater pathway.

Three ZBG wells were installed to obtain background data for the Z-Area SDF and to monitor the Z-Area SDF after startup. Wells ZBG \#1 and ZBG \#2 monitor the water table aquifer, and well ZBG \#1A monitors a perched water-bearing zone between $276 \mathrm{ft}$ and $281 \mathrm{ft}$ msl. Well ZBG \#1A was dry every time it was sampled in 1990 . Well ZBG \#1 is upgradient of the SDF, and well ZBG \#2 is downgradient of an existing vault, but within the facility.

During $1990,{ }^{25} \mathrm{Ra}$ and ${ }^{223} \mathrm{Ra}$ activities in the upgradient well (well ZBG \#1) and ${ }^{25} \mathrm{Ra}$ activity in down-gradient well (well ZBG \#2) exceeded drinking water standards (Cummins et al. 1991). Dichloromethane and tetrachloroethylene values also exceeded drinking water s:-ndards (Tables 2.2-4 and 2.2-5). Nitrate was well below drinking water standards. No chemical or radiological constituents were reported above drinking water standards in the ZBG wells during 1991. Radium-226 and ${ }^{28} \mathrm{Ra}$ were below drinking water standards in 1989 and 1988 (Arnett et al. 1992). 
Table 22-3. Water quality of Upper Rums Creek at Road A

\begin{tabular}{|lccccc|}
\hline Parameter & Units & $\begin{array}{c}\text { No. of } \\
\text { Analyses }\end{array}$ & Mean & Max & Min \\
\hline Temperature & $\mathrm{deg} \mathrm{C}$ & 12 & 18 & 32 & 8.7 \\
$\mathrm{pH}$ & $\mathrm{pH}$ & 12 & & 7.7 & 6.4 \\
Dissolved oxygen & $\mathrm{mg} / \mathrm{L}$ & 12 & 8.9 & 11 & 7.3 \\
Alkalinity & $\mathrm{mg} / \mathrm{L}$ & 12 & 4.3 & 6.0 & 1.0 \\
Conductivity & umhos/cm & 12 & 28 & 40 & 23 \\
Turbidity & $\mathrm{NTU}$ & 12 & 2.5 & 4.2 & 1.6 \\
Suspended soils & $\mathrm{mg} / \mathrm{L}$ & 12 & 8.1 & 15 & 2.0 \\
Volatile solids & $\mathrm{mg} / \mathrm{L}$ & 12 & 3.7 & 7.0 & 1.0 \\
Total dissolved solids & $\mathrm{mg} / \mathrm{L}$ & 12 & 27 & 32 & 20 \\
Total solids & $\mathrm{mg} / \mathrm{L}$ & 12 & 35 & 41 & 26 \\
Fixed residue & $\mathrm{mg} / \mathrm{L}$ & 12 & 4.6 & 8.0 & 1.0 \\
Chemical oxygen demand & $\mathrm{mg} / \mathrm{L}$ & 12 & 8.7 & 18 & 3.0 \\
Chloride & $\mathrm{mg} / \mathrm{L}$ & 12 & 1.8 & 2.6 & 0.31 \\
Nitrogen (as $\mathrm{NO}_{2} / \mathrm{NO}_{3}$ ) & $\mathrm{mg} / \mathrm{L}$ & 12 & 0.11 & 0.14 & 0.08 \\
Sulfate & $\mathrm{mg} / \mathrm{L}$ & 12 & 3.2 & 4.0 & 2.0 \\
Phosphorus (as $\mathrm{PO}_{4}$ ) & $\mathrm{mg} / \mathrm{L}$ & 12 & 0.03 & 0.12 & $<0.02$ \\
Nitrogen (as $\mathrm{NH}_{3}$ ) & $\mathrm{mg} / \mathrm{L}$ & 12 & 0.05 & 0.14 & $<0.02$ \\
Cadmium & $\mathrm{mg} / \mathrm{L}$ & 4 & $<0.01$ & $<0.01$ & $<0.01$ \\
Mercury & $\mu \mathrm{g} / \mathrm{L}$ & 4 & $<0.20$ & $<0.20$ & $<0.20$ \\
Chromium & $\mathrm{mg} / \mathrm{L}$ & 41 & $<0.02$ & 0.02 & $<0.02$ \\
\hline
\end{tabular}

Rev. 0 
Table 22-4. Groundwater monitoring results for the Z-Area Saltstone Fraility

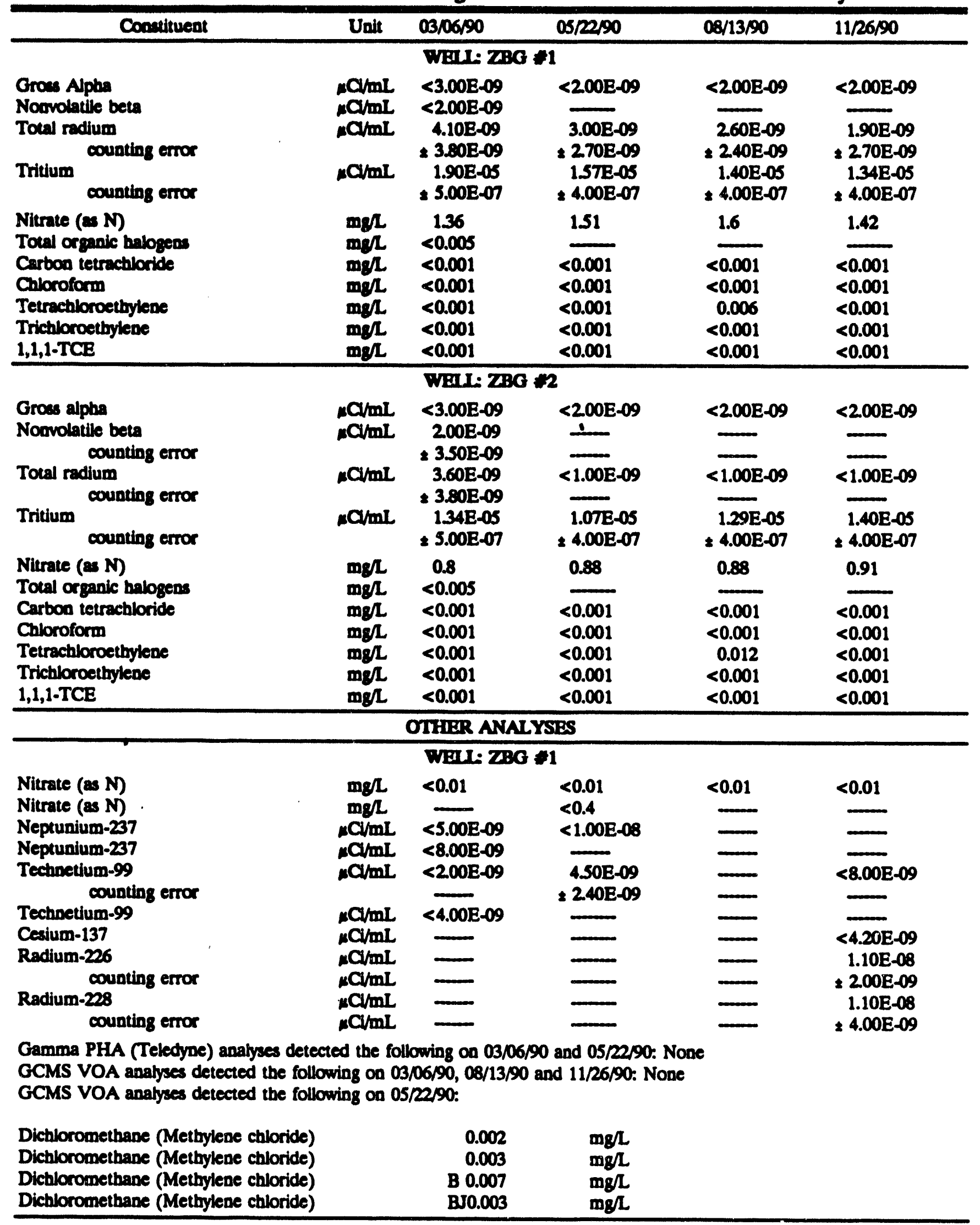


Table 22-4. (cont)

\begin{tabular}{|c|c|c|c|c|c|}
\hline Constituent & Unit & $03 / 06 / 90$ & $05 / 2090$ & $08 / 13 / 90$ & $11 / 26 / 90$ \\
\hline \multicolumn{6}{|c|}{ OIHIRR ANAL YSES (CONT.) } \\
\hline \multicolumn{6}{|c|}{ WEI : ZBG :2 } \\
\hline $\begin{array}{l}\text { Niturate (as N) } \\
\text { Neptunium-237 } \\
\text { Technetium-99 } \\
\text { Coaium-137 } \\
\text { Cesium-137 } \\
\text { Radium-226 } \\
\text { counting error } \\
\text { Radium-226 } \\
\text { counting error } \\
\text { Radium-228 } \\
\text { Radium-228 }\end{array}$ & 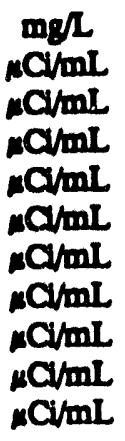 & $\begin{array}{l}<0.01 \\
<7.00 \mathrm{E}-09 \\
<5.00 \mathrm{E}-09 \\
\square \\
\square \\
\square\end{array}$ & $\begin{array}{l}<0.01 \\
<9.00 \mathrm{E}-09 \\
<1.00 \mathrm{E}-08 \\
\square \\
\square \\
\square\end{array}$ & 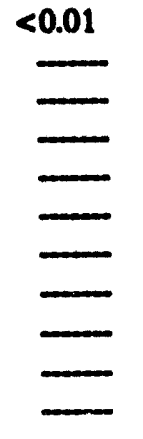 & $\begin{array}{l}<0.01 \\
<8.00 \mathrm{E}-09 \\
<4.00 \mathrm{E}-09 \\
<4.40 \mathrm{E}-09 \\
9.30 \mathrm{E}-09 \\
21.30 \mathrm{E}-09 \\
9.70 \mathrm{E}-09 \\
+1.60 \mathrm{E}-09 \\
<6.60 \mathrm{E}-08 \\
<7.90 \mathrm{E}-08\end{array}$ \\
\hline
\end{tabular}

Rev. 0 
Table 22-5. Maximum constituent results exceeding applicable standards for wells at the Z-Area Saltstone Facility

\begin{tabular}{lccc}
\hline Constituent & Unit & Standard & $\begin{array}{c}\text { Maximum } \\
\text { Result }\end{array}$ \\
\hline $\begin{array}{c}\text { Dichloromethane } \\
\text { (methylene chloride) }\end{array}$ & $\mathrm{mg} / \mathrm{L}$ & 0.005 & 0.007 \\
Radium-226 & $\mu \mathrm{Ci} / \mathrm{mL}$ & $4.0 \times 10^{-9}$ & $1.1 \times 10^{-8}$ \\
Radium-228 & $\mu \mathrm{Ci} / \mathrm{mL}$ & $8.0 \times 10^{-9}$ & $1.1 \times 10^{-8}$ \\
Tetrachloroethylene & $\mathrm{mg} / \mathrm{L}$ & 0.005 & 0.012 \\
\hline
\end{tabular}

Rev. 0 


\section{DESCRIPTION OF Z-AREA OPERATIONS, FACILTTIES, AND FEED STREAMS}

The Saltstone Production Facility (SPF) and the SDF are part of an integrated waste treatment and disposal system being installed at the SRS. The SPF and SDF are regulated by the State of South Carolina, DOE Orders and other Federal regulations that are applicable to disposal of solid waste.

Saltstone is a solid waste form that is the product of chemical reactions between a salt solution and a blend of cementitious materials (slag, flyash, and a lime source). An acceptable saltstone product can be produced over a range of these four components. The demonstrated range of acceptability for each component with respect to physical properties and resistance to contaminant leaching is shown in Table 2.3-1. As presently formulated, saltstone is comprised of about 47 wt\% salt solution, 25 wt\% of Grade 120 slag (ASTM C989-82), 25 wt\% of Class F fly ash (ASTM C618-85) and 3 wt\% of type II cement (ASTM C150-85A). Calcium hydroxide can be used as a substitute for the cement to function as a lime source in the blend.

\subsection{Description of the Salt Solution Feed to Z-Area (Design Basis)}

As presently permitted, contaminated wastewater from two sources will be sent to Z-Area for treatment and disposal. The wastewater sent to Z-Area contains principally soluble solids and very low levels of radioactive contaminants. Filtrate (decontaminated salt solution) from an ITP Process that treats soluble HLW at the SRS is a major source of wastewater sent to Z-Area. A second wastewater stream also containing principally soluble solids and very low levels of radioactive contaminants is generated in the $\mathrm{F} / \mathrm{H}$ ETF. This wastewater is also sent to Z-Area for treatment and disposal. Processes that generate,wastewater sent to Z-Area are briefly described below. .

\subsubsection{HWW In-Tank Precipitation (ITP) Processing (Design Basis)}

As presently planned, soluble HIW wastewater (salt solution) will be treated in an ITP Process at the SRS to reduce the level of Cs-137, Sr-90 and plutonium isotopes in the waste before transferring it to Z-Area for treatment and disposal. The Z-Area treatment process converts the mixed wastewater from the ITP process to saltstone, a non-hazardous solid LLW.

In the ITP process, aged HLW salt cake is dissolved using either spent washes from other in-tank operations or fresh process water. The salt concentration in the HLW wastewater (salt solution) is adjusted to the optimum concentration for treatment by diluting with either process water or spent washes from previous precipitate slurry batches. The resulting solution is then chemically treated with a solution of sodium TBP to convert soluble potassium and cesium salts to insoluble TPB salts. A slurry of insoluble sodium titanate is sometimes added during this operation to adsorb trace amounts of radioactive strontium and plutonium that may also be present in the salt solution. 
Table 23-1. Weight percent of saltstone components (Heckrotte 1988)

\begin{tabular}{lcc}
\hline $\begin{array}{l}\text { Saltstone } \\
\text { Component }\end{array}$ & $\begin{array}{c}\text { Nominal Blend } \\
(\mathrm{Wt} \%)\end{array}$ & $\begin{array}{c}\text { Range } \\
(\mathrm{Wt} \%)\end{array}$ \\
\hline Lime Source & 3 & 0 to 10 \\
Fly Ash & 25 & 10 to 40 \\
Slag & 25 & 10 to 40 \\
Salt Solution & 47 & 40 to 55 \\
\hline
\end{tabular}

- Either Portland Class II cement or $\mathrm{Ca}(\mathrm{OH})_{2}$. 
The resultant HLW wastewater slurry is filtered to yield clarified filtrate (decontaminated salt solution) and a concentrated $\mathrm{HLW}$ wastewater slurry of precipitated solids. This process removes more than $99 \%$ of the radioactive Cs-137 that was in the original salt solution. Thus most of the HLW wastewater containing high levels of soluble waste chemicals is converted to mixed wastewater containing low levels of residual radioactive contaminants.

The clarified filtrate from ITP will be passed through a gas-stripping column to reduce the level of volatile organics that may be present. After the stripping operation is completed, the decontaminated salt solution will be sent to Tank $50 \mathrm{H}$, where it may be combined with another wastewater stream from ETF (Sect. 2.3.1.2). The wastewater is stored in Tank $50 \mathrm{H}$ untii rurther treatment and disposal can be completed in Z-Area (U.S.DOE 1986a, 1986b; WSRC 1991).

\subsubsection{F/H Area Effluent Treatment Facility (ETF)}

Condensate from evaporators in the Separations Facilities and the HLW Tank Farm is a primary source of wastewater sent to the ETF for treatment. Miscellaneous wastewater streams containing low levels of radioactive contamination from other sources on the site are also treated in the ETF. For example, contaminated runoff from rainfall in operations areas and contaminated steam condensate are treated, when necessary. Liquid effluents from the ETF are:

- treated water that is released from the ETF to a surface stream under the site-wide NPDES permit (outfall H-0016);

- evaporator bottoms (aqueous mixed wastewater) from the ETF evaporator that are sent to Tank $50 \mathrm{H}$.

The ETF is a multimode wastewater treatment facility that uses a combination of chemical treatment, filtration, reverse osmosis, ion exchange, and distillation to remove contaminants from wastewater. These operations reduce the level of contaminants sufficiently to allow discharge of treated water to a surface stream on the site. Contaminants in wastewater that are removed during ETF rocessing are concentrated by distillation using a wastewater evaporator located in the ETF. Condensate from this distillation is combined with other wastewater receipts at the ETF for additional treatment in the ETF. Wastewater concentrate (bottoms) from the ETF evaporator are sent to Tank $50 \mathrm{H}$ where it may be combined with decontaminated salt solution from the ITP Process (see Sect. 2.3.1.1). The wastewater, containing principally soluble solids, is stored in Tank $50 \mathrm{H}$ until it can be sent to Z-Area for further treatment and disposal as non-hazardous Saltstone. (U.S.DOE, 1986a, 1986b; WSRC 1991). 


\subsubsection{General Characteristics of Salt Solution}

Although the chemical and radiochemical composition of wastewater streams sent to tank 50H are expected to vary as waste is processed through ITP and ETF, tests have shown that a broad range of concentrations of contaminants can be tolerated by the treatment process used to produce saltstone (Wilhite 1985, Langton and Wilhite 1988, and Langton 1989a). Salt solution sent to Z-Area for disposal is expected to contain $15-32 \mathrm{wt} \%$ soluble salts, with an expected average of about $28 \mathrm{wt} \%$. Specific gravity of the solution is expecied to range from 1.10 to 1.28 . The average specific gravity of the salt solution is expected to be about 1.25 .

For purposes of permit applications and for establishing long term performance of the SDF, a projected "nominal blend" composition for the wastewater is used to project the composition of Saltstone that will be sent to the SDF for disposal. This average composition is also used to calculate the projected composition of Saltstone and the total inventory of various waste components and radionuclides of concern for long-term performance (U.S.DOE 1986b, Heckrotte 1988).

\subsubsection{Chemical Composition of Salt Solution}

Individual wastewater streams and the blend of decontaminated salt solution from the ITP and the ETF processes are classified as MW because they will be corrosive (high $\mathrm{pH}$ ) and will contain low levels of toxic metals and radionuclides. (Langton 1989b). The projected long-term average chemical composition of these two streams and their volumetric nominal blend are shown in Table 2.3-2. For purposes of this RPA, the volumetric nominal blend (designated Nominal Blend (NB) in the various tables in the report) is used as a basis to project the chemical composition of Saltstone (see Sect. 2.4) and the inventory of specific components in the saltstone that will be produced (see Sect. 2.6). The chemical compositions shown in this table are based on the projected soluble waste compositions of HLW currently stored at the SRS and the projected composition of the evaporator bottoms to be produced by ETF (Fowler 1982a, b, c; Heckrotte 1988).

\subsubsection{Radiochemical Composition of Salt Solution}

The 1978 reactor production forecast at the SRS was used to establish a conservative design basis for both the Vitrification Facility (S-Area) and the Saltstone Production and Disposal Facilities (Z-Area) to assure that adequate shielding would be provided to protect workers in these facilities. Based on this forecast, the projected production mix for the years 1988-1990 was used to generate a waste containing the highest concentration of radionuclides that are potential hazards to workers due to the emission of high-energy gamma rays. The SHIELD reactor code was used to generate a fission product distribution for the waste, based on the forecasted production mix and burnup, and projected losses to waste for $\mathrm{U}$ and $\mathrm{Pu}$ ( DuPont 1980).

Rev. 0 
Table 23-2 Approximate chemical composition of salt solution feed (Heckrotte 1988)

\begin{tabular}{|c|c|c|c|c|c|c|}
\hline $\begin{array}{l}\text { Solution } \\
\text { Component }\end{array}$ & $\underset{(W+\%)}{\operatorname{mTP}^{\infty}}$ & $\begin{array}{l}\text { ETF' }^{\mathbf{E}} \\
(\mathrm{Wt \%})\end{array}$ & $\begin{array}{c}\mathrm{NB}^{6} \\
(\mathrm{Wt} \%)\end{array}$ & $\begin{array}{c}\operatorname{ITP} \\
\text { (moles/L) } \\
\end{array}$ & $\begin{array}{c}\text { ETF } \\
(\mathrm{moles} / \mathrm{L})\end{array}$ & $\begin{array}{c}\mathrm{NB} \\
(\text { moles } / \mathrm{L}) \\
\end{array}$ \\
\hline H2O & 71.80 & 69.90 & 71.60 & & & \\
\hline NaNO3 & 13.30 & 21.90 & 14.30 & $1.94 \mathrm{E}+00$ & $3.19 \mathrm{E}+00$ & $2.08 \mathrm{E}+00$ \\
\hline $\mathrm{NaOH}$ & 4.20 & 4.40 & 4.20 & $1.30 \mathrm{E}+00$ & $1.36 \mathrm{E}+00$ & $1.30 \mathrm{E}+00$ \\
\hline NaNO2 & 4.10 & 0.02 & 3.60 & $7.36 \mathrm{E}-01$ & $3.59 \mathrm{E}-03$ & $6.46 E-01$ \\
\hline $\mathrm{NaAl}(\mathrm{OH}) 4$ & 2.90 & 0.06 & 260 & $3.04 E-01$ & $6.29 E-03$ & $2.73 E-01$ \\
\hline $\mathrm{Na} 2 \mathrm{CO} 3$ & 1.40 & 1.40 & 1.40 & $1.64 E-01$ & $1.64 \mathrm{E}-01$ & $1.64 \mathrm{E}-01$ \\
\hline $\mathrm{Na} 2 \mathrm{SO} 4$ & 1.60 & 0.22 & 1.40 & $1.39 \mathrm{E}-01$ & $1.92 \mathrm{E}-02$ & $1.22 \mathrm{E}-01$ \\
\hline $\mathrm{Na} 2 \mathrm{C}_{2} \mathrm{O} 4$ & 0.16 & 0.05 & 0.15 & $1.48 \mathrm{E}-02$ & 4.62E-03 & $1.39 \mathrm{E}-02$ \\
\hline $\mathrm{Na} 3 \mathrm{PO} 4$ & 0.11 & 0.02 & 0.10 & $8.31 \mathrm{E}-03$ & $1.51 \mathrm{E}-03$ & $7.55 \mathrm{E}-03$ \\
\hline $\mathrm{NaCl}$ & 0.11 & 0.08 & 0.10 & $2.33 E-02$ & $1.69 \mathrm{E}-02$ & $2.12 \mathrm{E}-02$ \\
\hline NH4NO3 & $d$ & 0.60 & 0.07 & $9.43 E-07$ & $9.28 \mathrm{E}-02$ & $1.08 \mathrm{E}-02$ \\
\hline $\mathrm{NaB}(\mathrm{C} 6 \mathrm{H} 5) 4$ & 0.07 & & 0.06 & $2.53 \mathrm{E}-03$ & $0.00+00$ & $2.17 \mathrm{E}-03$ \\
\hline $\mathrm{Na} 2 \mathrm{SiO} 3$ & 0.04 & 0.20 & 0.06 & $4.06 \mathrm{E}-03$ & $2.03 \mathrm{E}-02$ & $6.09 \mathrm{E} ;-03$ \\
\hline $\mathrm{NaF}$ & 0.05 & 0.012 & 0.05 & $1.47 \mathrm{E}-02$ & $5.01 \mathrm{E}-03$ & $1.47 \mathrm{E}-02$ \\
\hline $\mathrm{Na} 2 \mathrm{CrO} 4$ & 0.04 & $d$ & 0.04 & $3.06 \mathrm{E}-03$ & $6.88 \mathrm{E}-05$ & $3.06 \mathrm{E}-03$ \\
\hline $\mathrm{CaSO} 4$ & $d$ & 0.30 & 0.03 & $2.09 \mathrm{E}-05$ & $2.73 E-02$ & $3.09 \mathrm{E}-03$ \\
\hline $\mathrm{Na} 2 \mathrm{MoO} 4$ & 0.01 & & 0.01 & $4.21 \mathrm{E}-04$ & $0.00+00$ & $3.61 \mathrm{E}-04$ \\
\hline KNO3 & $d$ & 0.02 & $d$ & $9.55 \mathrm{E}-07$ & $2.45 \mathrm{E}-03$ & $2.45 \mathrm{E}-04$ \\
\hline $\mathbf{P b}$ & $d$ & $d$ & $d$ & $1.20 \mathrm{E}-13$ & $6.57 \mathrm{E}-05$ & $5.98 \mathrm{E}-06$ \\
\hline Se & $d$ & & $d$ & $1.25 \mathrm{E}-05$ & $0.00+00$ & $1.10 \mathrm{E}-05$ \\
\hline $\mathrm{NaHgO}(\mathrm{OH})$ & $d$ & $d$ & $d$ & 2.03E-07 & 2.41E-05 & $2.89 \mathrm{E}-06$ \\
\hline $\mathrm{Ba}$ & $d$ & $d$ & $d$ & $1.71 \mathrm{E}-09$ & $2.70 \mathrm{E}-05$ & $2.70 \mathrm{E}-05$ \\
\hline $\mathrm{Cd}$ & $d$ & d & $d$ & $5.51 E-07$ & 7.71E-06 & $1.10 \mathrm{E}-06$ \\
\hline $\mathrm{NaAg}(\mathrm{OH}) 2$ & $d$ & & $d$ & 9.76E-09 & $0.00 \mathrm{E}+00$ & $9.01 \mathrm{E}-09$ \\
\hline As & 0.00 & & 0.00 & $4.96 \mathrm{E}-09$ & $0.00 \mathrm{E}+00$ & $4.96 \mathrm{E}-09$ \\
\hline Total Organies & 0.10 & & 0.09 & $0.00 \mathrm{E}+00$ & $0.00 \mathrm{E}+00$ & \\
\hline
\end{tabular}

ITP - In-Tank Precipitation Process

- ETF - F\&H Area Effluent Treatment Facility

c NB - Nominal Blend of ITP and ETF feed solutions at 8:1 mixing.

- Expected to be present, but at a concentration that is less than 0.01 wt\%. 
For purposes of shielding design for S-Area and Z-Area facilities, sludge to be processed was assumed to be aged 5 years and soluble waste (salt and salt solution) was assumed to be aged 15 years. The longer aging of soluble waste was used to allow decay of short-lived gamma emitters that are present in freshly generated salt solution, thus eliminating the need for extensive shielding in the SPF and SDF (Dupont 1980; U.S.DOE 1982). Many of the radionuclides projected to be present in unaged salt solution have half-lives of less than 1 year and thus do not contribute significantly to the expected average total activity in the salt solution of about $0.3 \mathrm{mCi} / \mathrm{L}$ at the time of processing. These short-lived species have no impact on the long-term radiological performance of the SDF.

Distributions of fission products between sludge and soluble waste were subsequently revised to reflect available experimental data and/or the expected chemical characteristics of the fission product species. After additional experimental data were obtained on I-129 and Tc-99, the distributions for these two isotopes were further refined and the total quantity of these two isotopes in the waste inventory was estimated (Fowler and Cook 1984a,b).

The initial projections for key long-lived radioactive contaminants in salt solution have subsequently been adjusted to reflect results from analyses of waste samples, as additional experimental data has become available. These adjustments are reflected in the projected nominal radionuclide content in wastewater sent to Z-Area and Saltstone. Projected average concentrations for selected radionuclides in wastewater streams to be sent to Z-Area for treatment and disposal are listed in Table C.1-1. At the time of saltstone production, about $90 \%$ of the total activity in the salt solution is expected to be due to the presence of Tc-99, Ru/Rh-106, Cs/Ba-137, H-3 and Sm-151, as shown in Fig. 2.3-1.

\section{Description of Dry Materials}

The chemical composition of the dry materials used in the production of saltstone are shown in Table 2.3-3. The Santee Type II cement composition (Malek et al. 1985) agrees well with typical Type II Portland cement (ASTM 1985). The NEWCEM slag is a glassy material that contains less than $5 \%$ crystalline phases. Compositional differences between the unreacted cement and slag are readily apparent; however, the hydration products of the slag are similar to the hydration products of portland cement (Malek et al. 1985). Differences between the listed fly-ash compositions are minimal with the exception of the percentages for $\mathrm{CaO}$ and $\mathrm{SiO}_{2}$.

\subsection{Saltstone Production and Disposal}

Mixed wastewater from other wastewater treatment facilities at the SRS is sent to a large storage tank (Tank 50-H, 5.7 million L) located in the H-Area Waste Tank Farm. As presently permitted by the State of South Carolina, sources of wastewater sent to this tank are evaporator bottoms from the F/H ETF and the decontaminated filtrate from the ITP. 


\section{$(9.94 \%)$}

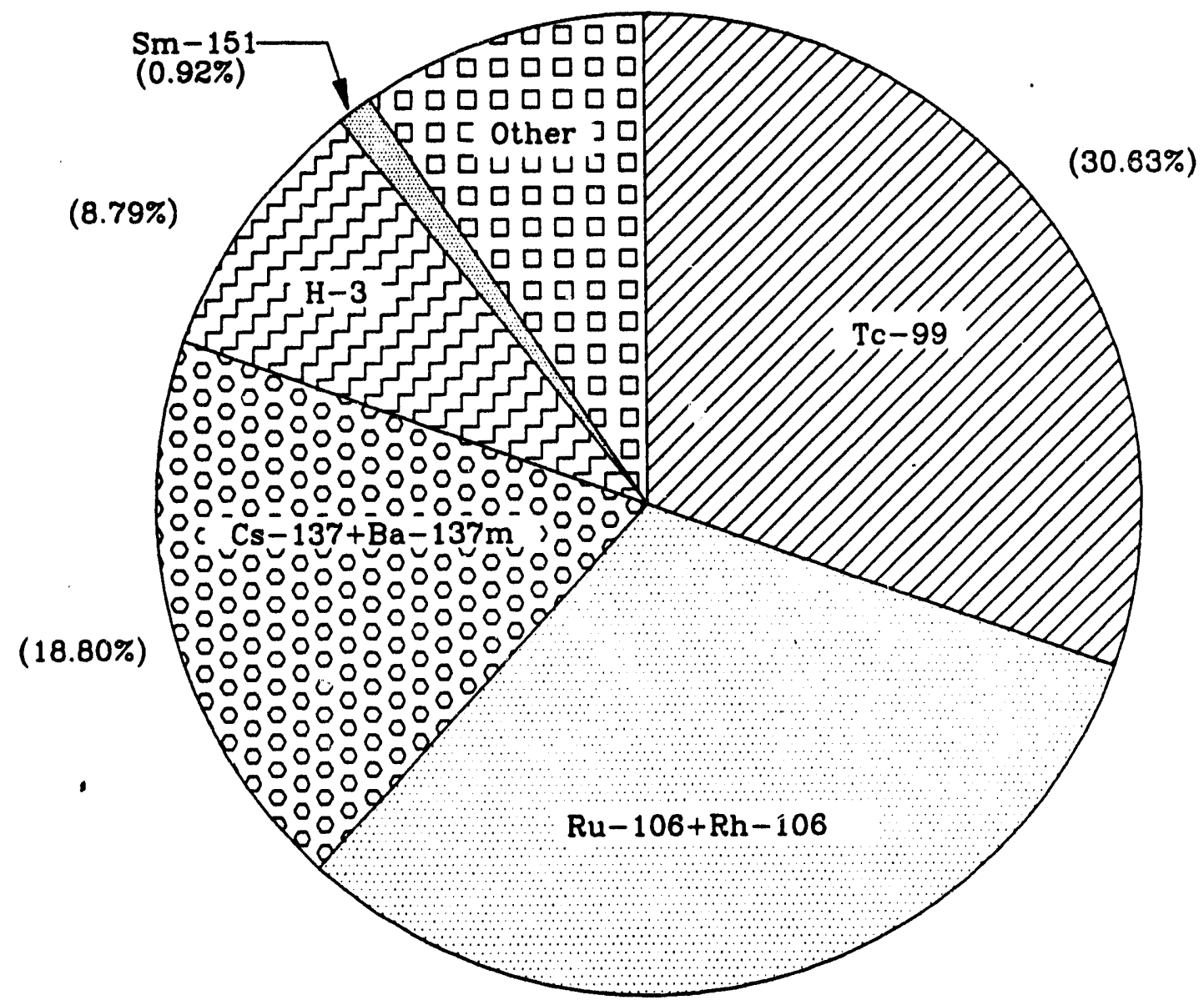

(30.92\%)

Fig. 2.3-1. Projected distribution of radionuclide activity in salts solution feed to Z-Area. 
Table 23-3. Composition of saltstone cementitious materials (Malek et al 1985)

\begin{tabular}{|c|c|c|c|c|c|}
\hline Component & $\begin{array}{l}\text { Cement } \\
\text { Type II } \\
\text { Santee } \\
(W t \%) \\
\end{array}$ & $\begin{array}{c}\text { Slag Grade } \\
120 \\
\text { NEWCEM" } \\
\text { (Wt\%) }\end{array}$ & $\begin{array}{c}\text { Fly Ash } \\
\text { Class F } \\
\text { Low CaO } \\
(\mathrm{W} \%)\end{array}$ & $\begin{array}{c}\text { Fly Ash } \\
\text { Class F } \\
\text { Low CaO } \\
(\mathrm{Wt} \%)\end{array}$ & $\begin{array}{l}\text { Fly Ash } \\
\text { Class F } \\
\text { D-Area } \\
\text { (Wt\%) } \\
\end{array}$ \\
\hline $\mathrm{SiO}_{2}$ & 21.10 & 34.70 & 52.17 & 50.95 & 45.70 \\
\hline $\mathrm{Al}_{2} \mathrm{O}_{3}$ & 4.66 & 10.70 & 27.60 & 26.00 & 29.40 \\
\hline $\mathrm{TiO}_{2}$ & 0.23 & 0.51 & 1.98 & 1.28 & \\
\hline $\mathrm{Fe}_{2} \mathrm{O}_{3}$ & 4.23 & 0.41 & 4.36 & 7.75 & 5.60 \\
\hline $\mathrm{MgO}$ & 1.21 & 11.90 & 0.61 & 1.89 & 0.80 \\
\hline $\mathrm{CaO}$ & 64.55 & 39.37 & 0.96 & 5.60 & 1.10 \\
\hline $\mathrm{MnO}$ & 0.016 & 0.539 & 0.014 & 0.060 & \\
\hline $\mathrm{BaO}$ & 0.02 & 0.05 & 0.10 & 0.17 & \\
\hline $\mathrm{Na}_{2} \mathrm{O}$ & 0.11 & 0.25 & 0.26 & 0.51 & 0.52 \\
\hline $\mathrm{K}_{2} \mathrm{O}$ & 0.34 & 0.55 & 1.53 & 3.33 & 1.91 \\
\hline $\mathrm{P}_{2} \mathrm{O}_{5}$ & 0.31 & $<0.05$ & 0.12 & 0.24 & \\
\hline $\mathrm{SO}_{3}$ & 2.25 & & 0.33 & 0.46 & 1.85 \\
\hline - SrO & & & 0.04 & & \\
\hline LOI $\left(900^{\circ} \mathrm{C}\right)$ & 1.35 & $1.34^{b}$ & 9.92 & 1.83 & 12.06 \\
\hline Totals & 100.40 & 100.36 & 100.00 & 100.10 & 98.94 \\
\hline
\end{tabular}

- Also referred to as Atlantic

- The loss-on-ignition (LOI) values for slag is negative indicating the existence of sulfur as $\mathrm{S}$ rather than $\mathrm{SO}_{3}$ (i.e., samples gained weight on heating). 
Wastewater is transferred by pipeline in up to 45,000 -gal batches from the storage tank in H-Area to a process feed tank in the SPF in Z-Area. The wastewater is then mixed with a dry blend of flyash, slag, and cement to generate a non-hazardous LLW saltstone grout. The grout is pumped through 3-in. pipelines from the SPF to vaults located in the SDF where the saltstone grout solidifies into a monolithic, non-hazardous solid LLW form called saltstone (See Sect. 2.4 and 2.5).

Although wastewater sent to Z-Area is a MW (i. e., hazardous and radioactive) due to high pH, chromium, and the presence of radionuclides, the SPF is totally enclosed and no liquid effluents are released directly to the environment. The SPF is permitted as a totally-enclosed wastewater treatment plant by the State of South Carolina. The SDF is permitted as a Solid Industrial Waste Landfill.

\subsubsection{SPF Equipment}

Major equipment components of the SPF include: 1) bulk storage silos for dry materials; 2) dry blending and transfer equipment; 3) the Salt Solution Hold Tank (SSHT) that receives wastewater to be processed; 4) the Flush Water Receipt Tank (FWRT) that receives equipment flushes and liquids collected in sumps located in Z-Area; 5) a mixer that blends wastewater (and flush water, when necessary) with dry feeds to produce a nonhazardous saltstone grout; 6 ) a Saltstone Hold tank that provides a reservoir of grout to prevent cavitation of the grout pumps; 7) grout pumps; 8) pipelines that are used to transfer wastewater solutions, flush water and saltstone grout within the production facility and grout to the disposal vaults; and 9) a pneumatic "pigging" system that is used to clean grout transfer lines from the SPF to the disposal vaults.

Tanks and processing equipment with potentially hazardous materials in them are isolated from the immediate environment by seconilary containment. The SSHT and the FWRT are carbon steel tanks surrounded by concrete dikes. The dikes are sized to assure that the entire contents of the tanks will be contained in the event of a catastrophic failure of a tank. All other processing equipment is located in a process building constructed of reinforced concrete that contains a sump designed to collect any spills (U.S.DOE 1986a, 1986b).

\subsubsection{SPF Process}

The saltstone production process is very simple. Dry feed materials are blended automatically in the desired ratio and transferred pneumatically to the Premix Feed Bin. The dry blend (Premix) is then fed at a preset rate to a mixer. Wastewater is also fed to the mixer where it is mixed with the premix to produce saltstone grout. The grout is then pumped to the disposal vaults. Except for special design considerations and operating procedures because of the presence of low levels of radioactivity, the process is identical to a concrete batch plant. Shielding, containment, off-gas treatment, 
operational procedures, and administrative controls are in place to assure that employee exposure to radiological and chemical hazards are minimized in the SPF. A schematic of the process is shown in Fig. 23-2 (U.S.DOE 1986a, 1986b).

\section{SALTSTONE WASTE FORM}

As described in Sect. 23, saltstone is produced from a mixture of salt solution and a dry blend of cementitious materials (slag, fly ash, and cement), and an acceptable waste form can be produced over a range of these individual components (See Table 2.3-1). Solid saltstone is a complex mixture of insoluble solids, soluble solids, and water. As the saltstone grout is prepared and cured, several chemical reactions occur between the components of the dry blend and contaminants in the salt solution. Several wastewater contaminants are converted to insoluble species or incorporated into the cement matrix, effectively retarding their release from the saltstone waste form. Development of this waste form, and its physic?l and chemical properties that are pertinent to this assessment, are described in this section.

\subsection{History of Saltstone Development}

Since the beginning of production at the Savannah River Site, storage of high-level waste in underground tanks has been considered to be an interim measure because storage tanks have a finite useful life. The tanks require continual surveillance to ensure that the contents of the tanks remain isolated from their surroundings.

The goal of waste management operations at the SRS is to isolate and dispose of the stored waste in a manner that does not rely on continued vigilance of man to provide protection to current and future generations and their environment. Several alternatives have been considered. Vitrification has been selected as the preferred alternative for immobilizing aqueous wastes containing high levels of radioactive contaminants, HIW (U.S.DOE 1982).

To reduce the volume of $H L W$ to be vitrified, a process to decontaminate soluble salts that are a part of the HLW waste currently stored at the SRS was proposed and the decontaminated salt solution would be treated by some other method to allow disposal that is environmentally acceptable. The evolution of the saltstone waste form and the landfill design are summarized below. Rationale for the selection of the disposal site is also described. 


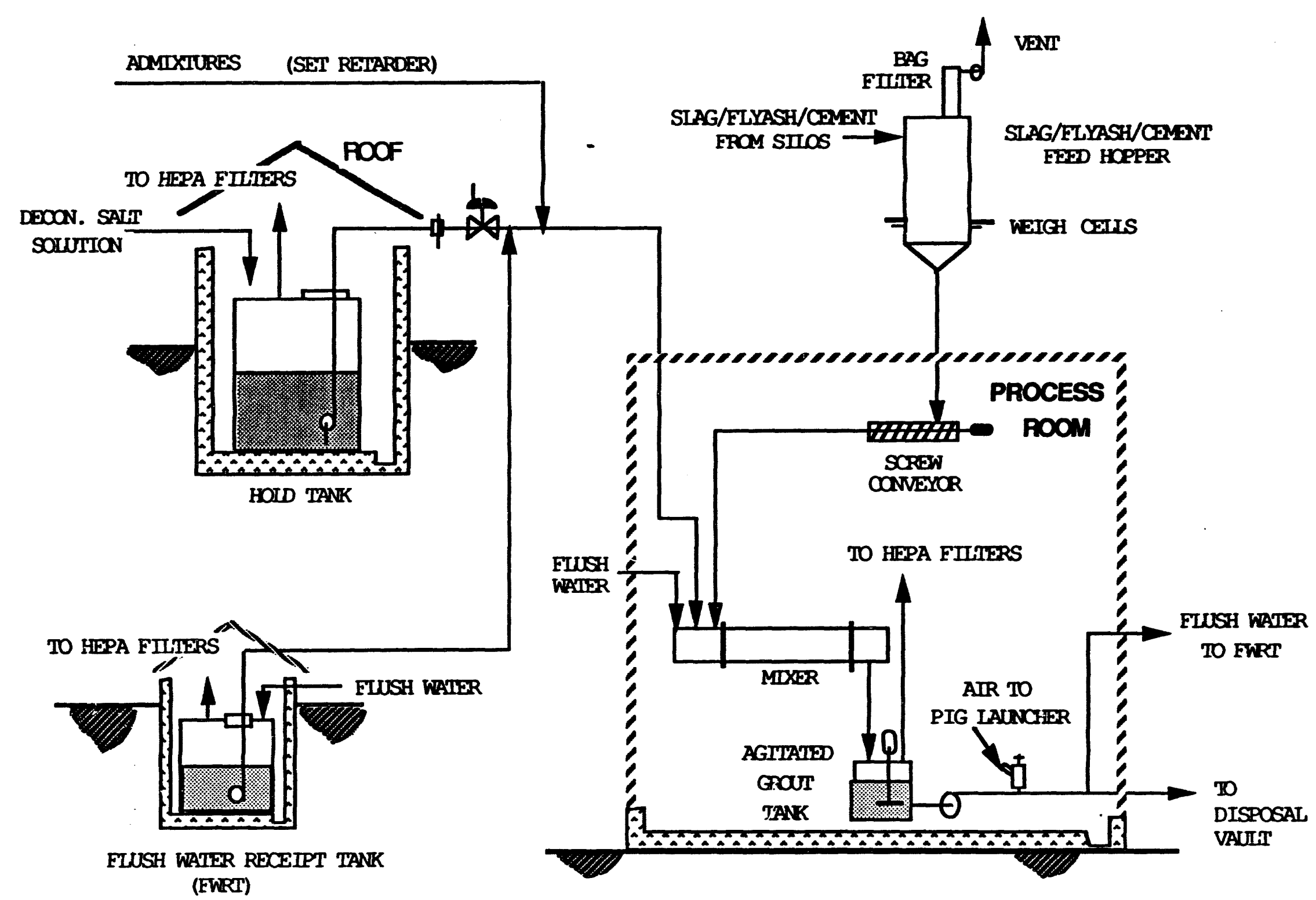

Fig. 2.3-2 Saltstone Production Process 


\subsubsection{Salt Disposal Alternatives Considered}

Alternatives for the final disposal of decontaminated salt or decontaminated salt solution have been studied, as listed in Table 2.4-1. The conversion to a stable, cementitious waste form suitable for shallow land disposal in a landfill on the SRS was selected as the preferred alternative for final disposal of the decontaminated salt waste. A cementitious waste form was selected because such a waste form is: 1) resistant to leaching and thus, acceptable for shallow land disposal; 2) tolerant to variations in waste composition, waste loading, and radiation levels; 3) produced from low-cost inorganic materials that are readily available; and 4) suited to high volume production and emplacement using known concrete production technology. The bases for this decision were discussed extensively in the Environmental Impact Statement for DWPF facilities at the SRS (U.S.DOE 1982). After this decision was reached, extensive development to optimize the production process and the solid waste product, and to select an appropriate landfill design and location was undertaken. Continuing changes in environmental regulatory requirements over the past 25 years have required continuing changes in the treatment and disposal technology of the decontaminated salt solution.

The treatment process has evolved from a portable concrete batch plant that would receive decontaminated salt solution hauled by truck to the totally enclosed wastewater treatment facility, now located in Z-Area, that receives decontaminated salt solution by a doubly-contained pipeline. The final waste form has evolved from a mixture of salt solution and cement to its present formulation containing a blend of slag, fly ash, and cement mixed with salt solution that assures the waste form is non-hazardous, as defined by EPA protocol.

The disposal technology has evolved from a series of simple trenches that would be filled with waste and covered with native soil to above-grade concrete vaults that provide an engineered secondary containment barrier for the waste. During the closure of the disposal site, the vaults will be covered with soil. Final closure will also incorporated features that are designed to minimize water infiltration through the waste for hundreds or thousands of years, and perhaps even longer.

\subsection{Evolution of the Saltstone Waste Form}

\section{Salt Solution Feed}

In 1979, when initial technical data was being developed for treatment and disposal of HLW glass, a treatment and disposal conrept was proposed that would efficiently handle and dispose of decontaminated salt solution, a byproduct waste stream from the HIW treatment process in the DWPF. The salt decontamination process was based on an ion-exchange process that would be installed in a separate canyon facility as a part of the DWPF (U.S.DOE 1982). 
Table 241. Disposal alternatives considered for decontaminated salt

- Convert to cementitious solid for on-site disposal in a landfill

- Evaporate solution and return salt solids to HIW storage tanks

- Transport and dump salt solution into the ocean

- Deep-well injection of salt solution

- Use salt solution as fertilizer at SRS (high nitrate content)

- Sell for use as fertilizer off-site (high nitrate content)

- Denitration to recover nitric acid for reuse in SRS processess

- Solidify in drums and ship to a commercial landfill

Rev. 0 

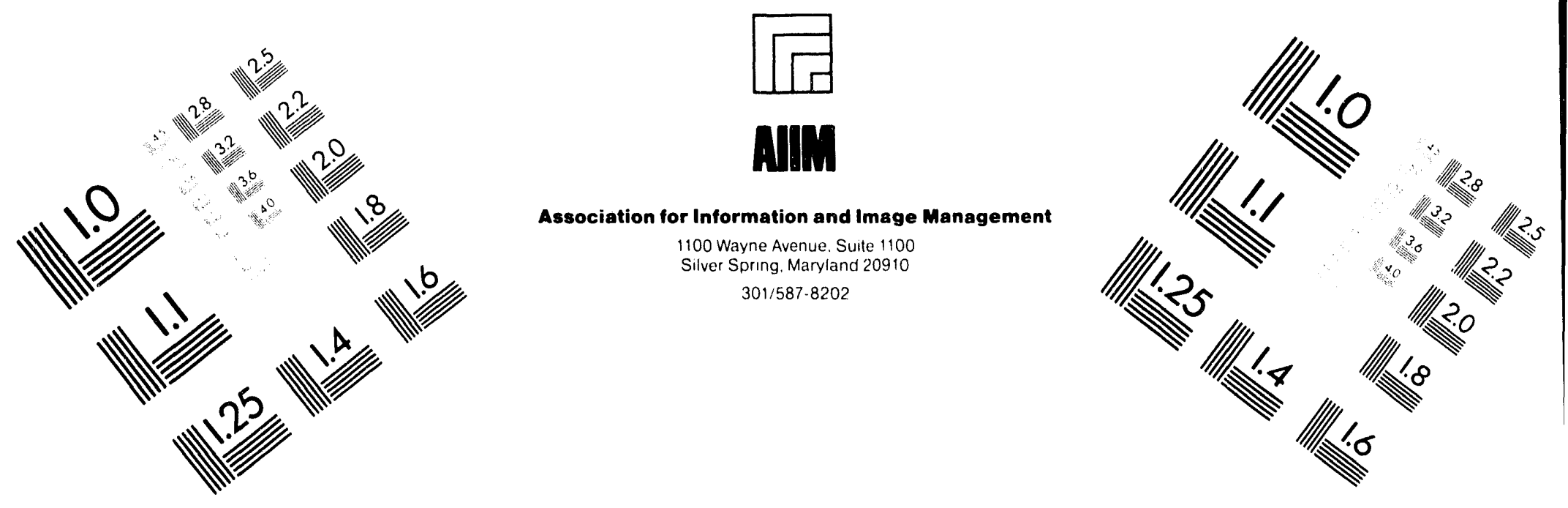

\section{Centimeter}

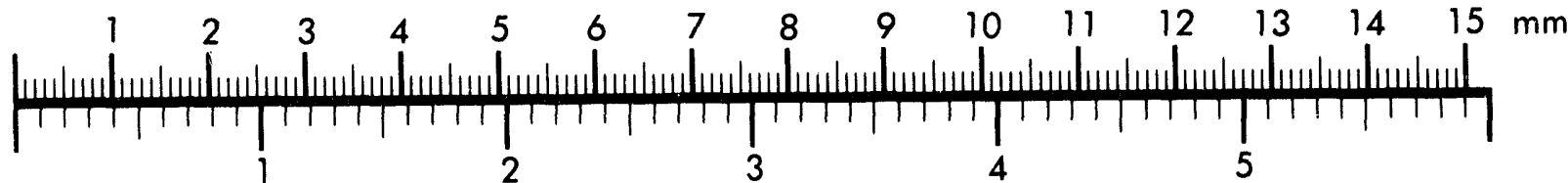

Inches
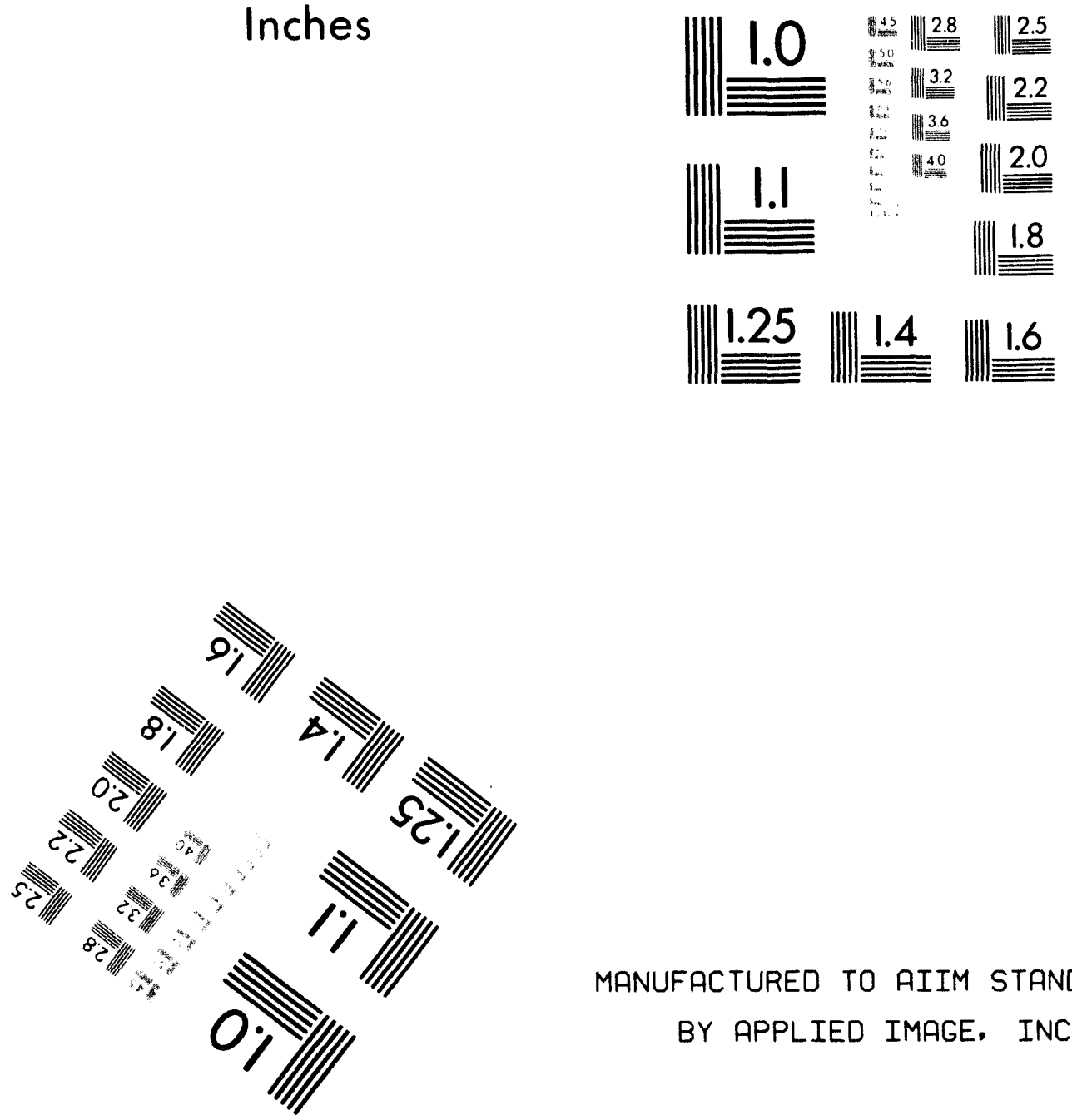

MANUFACTURED TO AIIM STANDARDS

BY APPLIED IMAGE. INC.

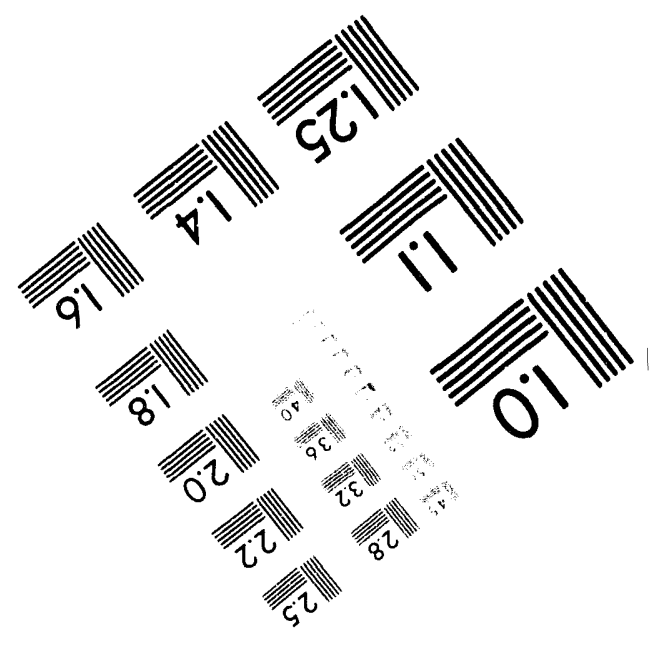



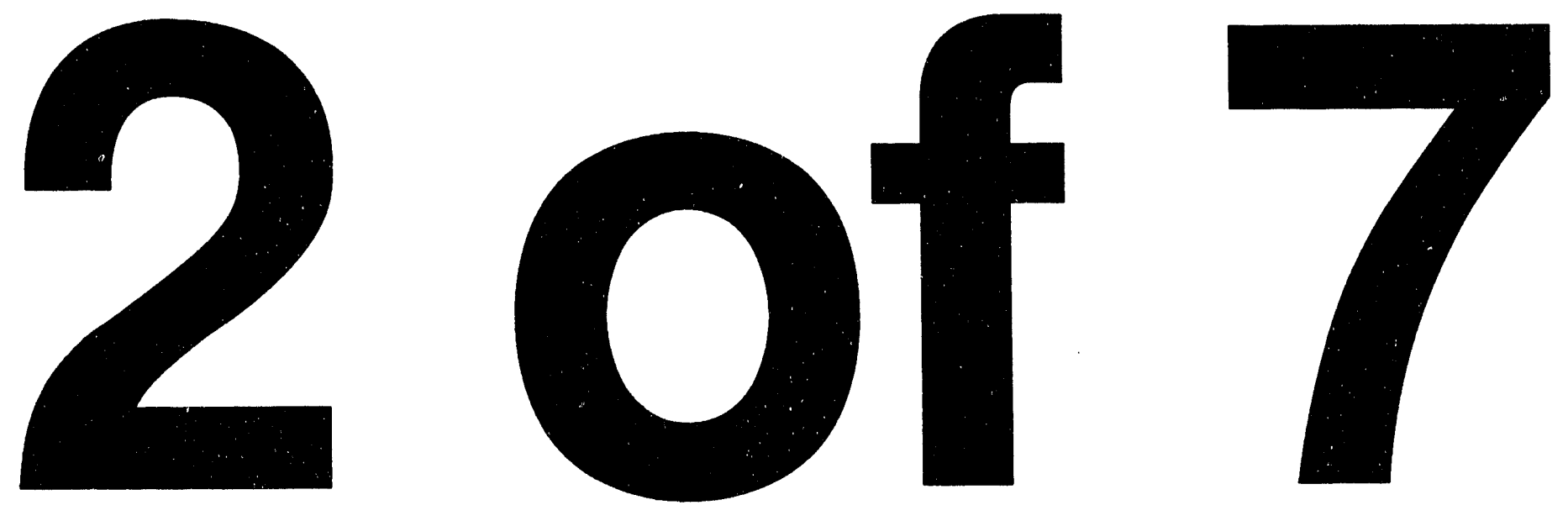
During the 1981-83 time period, an "in-tank" salt decontamination process based on coprecipitation of cesium and potassium tetraphenylborate was developed to decontaminate the salt solution. This process, to be done using existing HLW waste storage tanks as process vessels, would eliminate the need for a separate canyon facility for an ion-exchange process in the DWPF and thus, offered significant cost-savings relative to the ion-exchange process. Because existing facilities would be used, the DWPF process to vitrify HIW was shifted to coprocess sludge slurry and precipitate slurry from the beginning, rather than starting with sludge in Stage I and shifting to a coupled process after the ion exchange process came on line.

The In-Tank Precipitation Process (ITP) was adopted at the SRS in late 1982 as the process to be used to reduce the level of radioactivity in the salt solution. Filtrate from this process was deemed suitable for treatment and disposal as LLW in an on-site solid waste disposal site, providing acceptable resistance to leaching of the product waste form could be demonstrated.

Initial flow sheets for the ITP process projected that the filtrate would contain $\mathbf{3 0}$ to $35 \mathrm{wt} \%$ salts. Subsequent refinement of the process has demonstrated that the process will produce a decontaminated salt solution containing 25 to 30 wt\% soluble salts, thus, increasing the volume of salt solution that must be treated for disposal as a cement-based solid. The projected volume of salt solution waste to be treated for disposal was increased further in 1987, when a salt waste stream from the F/H ETF was shown to be within limits established for treatment and disposal in Z-Area. Thus, the projected nominal composition of salt solution sent to Z-Area for disposal is projected to be a nominal 8-to-1 blend of filtrate from the ITP process and salt solution waste from the ETF.

\section{Saltcrete (1979-81)}

Because of 1) the high volume of salt solution that would be treated, 2) the desired high rate of treatment and disposal, and 3) the high cost related to drumming and subsequent handling of drummed waste, the treatment and disposal process initially proposed would simply pour large volumes of a cement-based grout directly into trenches at a landfill site to form concrete monoliths that would be $6.1 \mathrm{~m}$ wide, $6.1 \mathrm{~m}$ deep, and $15.3 \mathrm{~m}$ long ( $20 \mathrm{ft}$ wide by $20 \mathrm{ft}$ deep by $50 \mathrm{ft}$ long). The salt solution to be used would contain a nominal $32 \mathrm{wt} \%$ soluble solids, based on the reference ion exchange process to be used in the DWPF (Benjamin and Roggenkamp 1982).

This waste form was named "saltcrete" to reflect its makeup from salt solution and cement. The nominal composition of saltcrete was $51.1 \mathrm{wt} \%$ Portland Type I cement, 48.5 wt\% salt solution (32 wt\% salt), and 0.4 wt\% of Pozzolith 122-R. The Pozzolith was a part of this formulation to reduce the viscosity and retard the rate of set (Albenesius 1982). 
In initial development work, thermal calculations projected that saltcrete produced by simply mixing salt solution with cement to produce slabs that would be $3 \mathrm{~m}$ thick (or thicker) would generate significant heat during curing due to the high heat of hydration of cement. The internal temperature of the slabs would exceed the boiling point of the salt solution, leading to embrittlement of the waste form, and a design limit of $90^{\circ} \mathrm{C}$ was imposed. Either the addition of cooling coils to the disposal trenches would be needed to remove the excessive heat during curing or thinner slabs must be poured. Thinner slabs would necessitate the simultaneous use of several trenches to achieve the desired production rate. This product also exhibited relatively high permeability and the use of clay-lined trenches were proposed to minimize leaching from the waste (Dukes 1981; Albenesius 1982).

\section{Soilcrete (1981-82)}

In 1982, alternative formulations of wet and dry components were tested that included replacing a portion of the cement with native soil (sand and clay mixtures). The salt solution was also diluted slightly to $32 \mathrm{wt} \%$ salts to prevent the crystallization of solid salts in transfer lines that could occur in colder weather with the higher salt content. The nominal composition of "soilcrete" was $24.5 \mathrm{wt} \%$ Portland cement, $42.2 \mathrm{wt} \%$ soil, 33.1 wt\% salt solution ( 32 wt\% salt), and 0.2 wt\% of Pozzolith 122-R. The cement in this formulation was a commercially available cement consisting of $80 \mathrm{wt} \%$ Portland Type I cement and $20 \mathrm{wt} \%$ fly ash. The soil was specified to contain 75 to $90 \mathrm{wt} \%$ sand and 10 to 25 wt\% clay, consistent with the native soils at the SRS (Hooker and Dukes 1982).

The soil added to the mixture served as a heat sink and diluent to eliminate the need for additional cooling during curing through the use of cooling coils or by pouring thinner slabs in several trenches to allow curing without exceeding the thermal limit of $90^{\circ} \mathrm{C}$. This product waste form also had significantly lower permeability. Thus, the soilcrete formulation eliminated both a process weakness and a product weakness of the original saltcrete formulation.

Subsequent testing to produce larger quantities of this new formulation containing soil over a range of compositions showed that the formulation was too viscous to enable self-leveling, highly sensitive to variations in the soil and salt solution composition, and subject to "flash setting" if process conditions were not carefully controlled. These undesirable properties required additional development to yield and acceptable process to produce a solid waste product for disposal. 


\section{Saltstone with Fly Ash (1982-83)}

To lower the viscosity of the grout and to increase the tolerance of the production process to variations in salt solution feeds, compositions that replaced the soil component and a portion of the cement with Class $\mathrm{C}$ fly ash were developed beginning in 1983. This change significantly improved the ability to process the grout while retaining the lower permeability in the solidified waste form that was observed with "soilcrete". Nominal composition of this solid was 12.0 wt\% API Class H cement, 48.0 wt\% Class $C$ fly ash, and $40 \mathrm{wt} \%$ salt solution ( $32.5 \mathrm{wt} \%$ salt). This formulation was the first that was identified as "saltstone" (Wolf 1984).

\section{Saltstone with Fly Ash and Slag (1983-87)}

From 1983 to 1987 , alternative formulations were tested to optimize the long-term performance of saltstone and to broaden the envelope of acceptable compositions that would provide the flexibility needed to process a broad range of salt solution compositions. Results from this work led to replacement of some of the cement and fly ash with slag. The addition of slag to the saltstone formulation provides a chemical reductant [iron (II)] and a precipitating agent [sulfide] that chemically binds several contaminants as insoluble species, thus, reducing the propensity of these contaminants to leach from the solid waste form. Type II Portland cement and Class F fly ash, more readily available dry materials, were also shown to be suitable for saltstone formulations (Licastro et al. 1985; Langton 1987a,b,c,d,e).

Of particular note, leaching of chromium and technetium was effectively reduced to a level that enabled all projected salt solution compositions to be processed into a non-hazardous solid waste, as defined by EPA protocol. Results for chromium leaching using the Extraction Procedure Toxicity Test (also known as EP Toxicity Test) are shown in Fig. 2.4-1. Lysimeter results, comparing the leaching of Tc-99 relative to nitrate with and without slag in the saltstone formulation are shown in Fig. 2.4-2.

In the course of this development work, a broad range of compositions were shown to yield saltstone that qualifies as non-hazardous waste, as defined by the EPA (and adopted by SCDHEC). Ranges of demonstrated acceptability for non-hazardous saltstone were:

Type II Portland cement or lime Class F fly ash

Grade 120 slag

salt solution (29 wt\% salt)
0 to $10 \mathrm{wt} \%$

10 to $40 \mathrm{wt} \%$

10 to $40 \mathrm{wt} \%$

40 to 55 wt\%

The recommended nominal composition for saltstone, using a nominal salt solution blend, is 3 wt\% Type II Portland cement or lime, 25 wt\% Class F fly ash, 25 wt\% Grade 120 slag, and $47 \mathrm{wt} \%$ salt solution ( $29 \mathrm{wt} \%$ salt). 


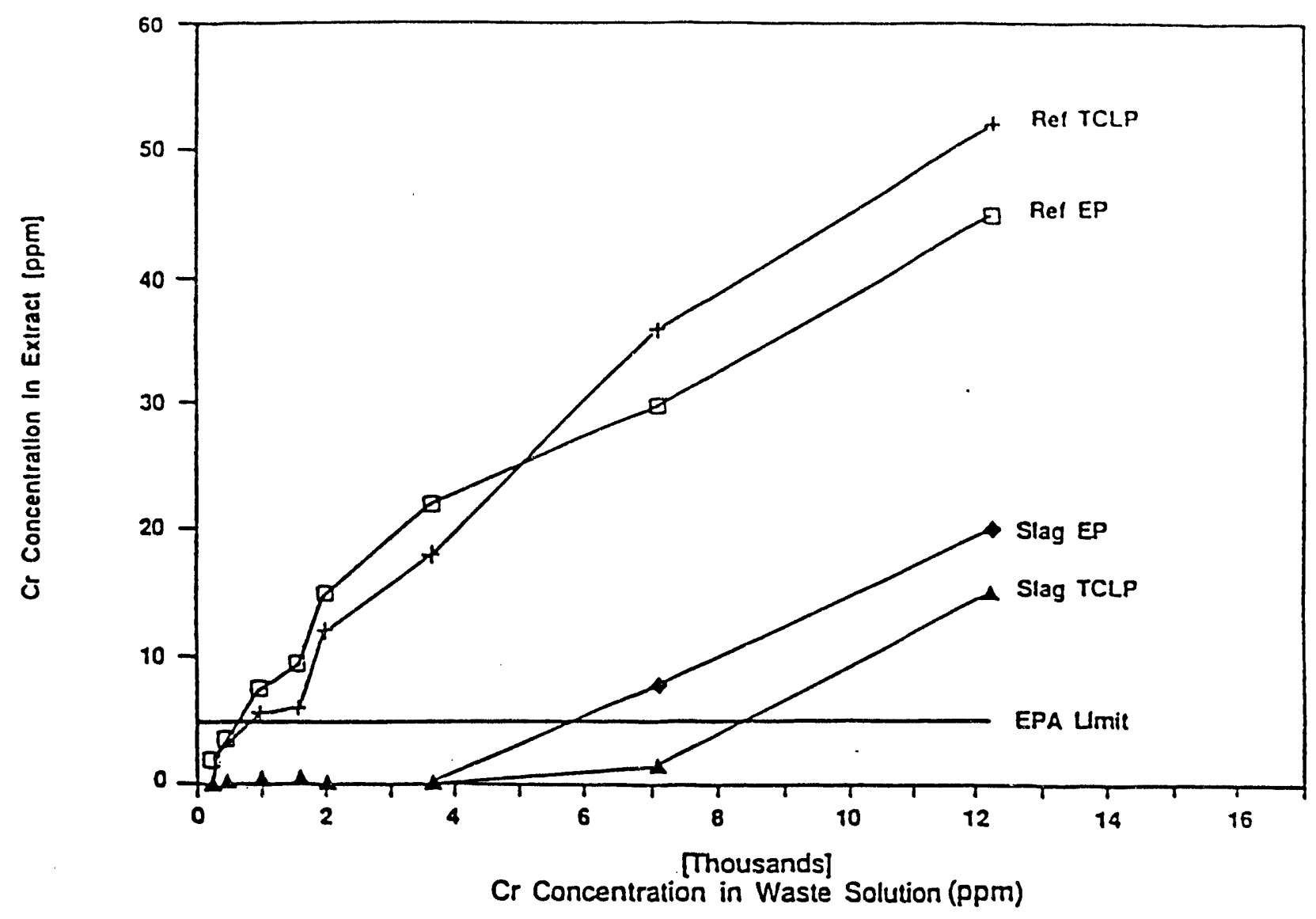

Fig. 2.4-1 Chromium Toxicity Results for Slag- and Cement-Based Saltstone.

Rey. 0 


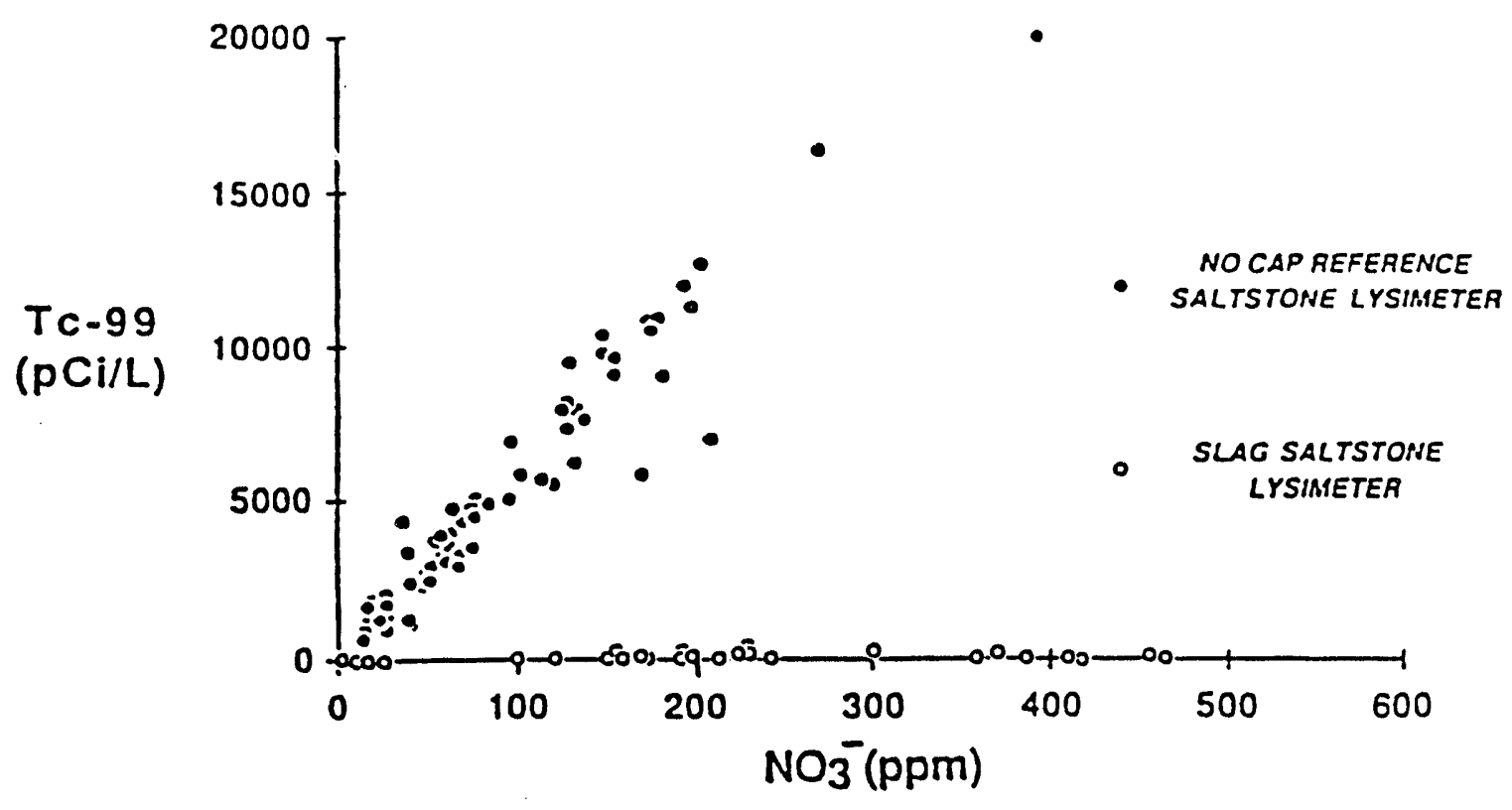

Fig. 2.4-2 Comparison of Technetium vs. Nitrate Leaching for Slag- and Cement-Based Saltstone Lysimeters. 


\subsubsection{Evolution of the Landfill Design}

Slit Trenches (1979)

In the initial concept of the disposal site proposed in 1979, slit trenches would be opened, filled with saltcrete grout, and backfilled with native soil. Trenches would be sized to enable filling with saltcrete and a portable trench cover would remain in place until the waste had solidified. After the waste had solidified, trenches would be backfilled with native soil, consistent with commercial landfill operations and regulations of that era (Benjamin and Roggenkamp 1979).

\section{Slit Trenches Lined and Capped with Clay (1982)}

With the evolution of disposal and groundwater protection regulations through the implementation of the Resource Conservation and Recover Act (RCRA), modeling, laboratory leaching tests, and lysimeter tests showed a need for improved waste disposal methods to minimize the rate of release of contaminants from the waste to the general environment and into the underlying groundwater. Contaminants of principal concern were nitrate (due to the projected high inventory), technetium-99 (due to its long halflife), and chromate (due to a hazardous waste classification, if chromate leach rates were too high). The slag formulation for saltstone eliminated concerns with chromium and technetium leaching (see Sect. 2.4.1.2), but modeling results indicated nitrate releases might be too high to meet the groundwater standards that were to be imposed by the state of South Carolina.

\section{Concrete Vaults (1984)}

Continuing modeling studies (Wilhite 1986) showed that disposal in concrete vaults was likely to effectively reduce the rate of nitrate release from the saltstone waste form, thus, eliminating a key environmental concern with the disposal of saltstone. Vaults would be constructed above grade and backfilling would be delayed until most or all of the vaults were filled with waste. Final site closure would be done in a manner that would comply with landfill regulatory requirements imposed by the state of South Carolina. A general closure concept was described in the permit application to the state, but detailed engineering was deferred until a future date prior to beginning final closure operations.

\subsection{Physical Characteristics of Saltstone}

For this performance assessment a composition containing $47 \mathrm{wt} \%$ salt solution, $25 \mathrm{wt} \%$ slag, $25 \mathrm{wt} \%$ fly ash, and $3 \mathrm{wt} \%$ cement is used to represent the average projected composition of the saltstone that will be sent to the SDF for disposal. When first prepared, the saltstone grout has the consistency and flow characteristics of 
buttermilk or latex paint and is readily pumped from the SPF to a cell in a disposal vault. The saltstone grout self-levels in the vault and gels in 30 to $60 \mathrm{~min}$. The saltstone hardens in 12 to $18 \mathrm{~h}$ with no evidence of bleed water on the upper surface. After setting, the saltstone is self-supporting with a 28-day compressive strength in excess of $1.4 \times 10^{6} \mathrm{~Pa}$. The specific gravity of both the saltstone grout and the solidified saltstone ranges from 1.6 to 1.8 . A bulk density of $1.7 \times 10^{3} \mathrm{~kg} / \mathrm{m}^{3}$ was used in this assessment to establish the projected inventory and concentration of species in the waste.

The effective diffusivity of saltstone, defined as the product of the molecular diffusivity and tortuosity of the matrix, was estimated from the results of nitrate leach tests on $250 \mathrm{cc}$ blocks of saltstone (Langton 1986). An average value of the apparent diffusion coefficient, which for nitrate is equivalent to the effective diffusion coefficient, was determined to be $5 \times 10^{-9} \mathrm{~cm}^{2} / \mathrm{s}$.

\subsection{Chemical Composition}

After the saltstone solidifies, it can best be described as a porous solid that contains a solution of salts in the pores of the solid. The composition on mixing (i.e., the Saltstone grout composition) is first described in Sect. 2.4.2.1. As a first approximation, the grout composition also describes the solid saltstone. However, pertinent reactions during curing can strongly influence long-term performance of the final waste form, and can alter the composition of the pore solution. Chemical interactions during mixing and curing will change the salt solution composition in the pores, when compared to the solution initially used to prepare the saltstone.

\subsubsection{Chemical Composition of Saltstone Grout}

- The projected composition for saltstone grout is described in terms of the components used to make the grout. The composition shown in Table 2.4-2 is the projected saltstone grout composition from ETF wastewater, ITP wastewater, and the NB composition of wastewater. For each of these compositions, the same NB of dry materials is used. These compositions assume a grout mixture containing $47 \mathrm{wt} \%$ of a salt solution and 53 wt\% dry blend comprised of 47.17 wt\% slag, 47.17 wt\% fly ash and 5.66 wt\% cement. This ratio yields a mixture containing 25 wt\% slag, 25 wt \% fly ash, $3 \mathrm{wt} \%$ cement, and $47 \mathrm{wt} \%$ salt solution. These compositions provide a reasonable representation of the range of saltstone grout produced from the two projected waste stream compositions, and it also provides a nominal blend for the purpose of estimating the composition of the saltstone waste form.

\subsection{Chemical Composition of Solid Saltstone}

As noted above, chemical reactions between components in the salt solution and the dry blend will change the composition of the saltstone when compared to the starting materials. Chromium (VI) species, technetium (VII) species, and salt solution contaminants that form sparingly soluble sulfides ( $\mathrm{Hg}, \mathrm{Co}, \mathrm{Ni}, \mathrm{Zn}, \mathrm{Tc}, \mathrm{Ru}, \mathrm{Rh}, \mathrm{Sb}, \mathrm{Sn}$ ) 
Table 24-2 Approximate chemical composition of saltstone grout (Heckrotte 1988)

\begin{tabular}{|c|c|c|c|}
\hline Component & $\begin{array}{c}\operatorname{IrP}_{(1)} \\
(\mathrm{W} \%)\end{array}$ & $\begin{array}{c}\text { ETF } \\
(\mathbf{W} / \%)\end{array}$ & $\begin{array}{c}\text { Blend } \\
(\mathrm{W} \%)\end{array}$ \\
\hline $\mathrm{H}_{2} \mathrm{O}$ & 33.70 & 32.90 & 33.60 \\
\hline $\mathrm{NaNO}_{3}$ & 6.30 & 10.30 & 6.70 \\
\hline $\mathrm{NaNO}_{2}$ & 1.90 & 0.01 & 1.70 \\
\hline $\mathrm{NaOH}$ & 200 & 2.10 & 2.00 \\
\hline $\mathrm{Na}_{2} \mathrm{CO}_{3}$ & 0.70 & 0.70 & 0.70 \\
\hline $\mathrm{NaA}(\mathrm{OH})_{4}$ & 1.40 & 0.03 & 1.20 \\
\hline $\mathrm{Na}_{2} \mathrm{SO}_{4}$ & 0.80 & 0.10 & 0.70 \\
\hline $\mathrm{NaF}$ & 0.02 & 0.01 & 0.02 \\
\hline $\mathrm{NaCl}$ & 0.10 & 0.03 & 0.05 \\
\hline $\mathrm{Na}_{2} \mathrm{SiO}_{3}$ & 0.02 & 0.09 & 0.03 \\
\hline $\mathrm{Na}_{2} \mathrm{CrO}_{4}$ & 0.02 & $\bullet$ & 0.02 \\
\hline $\mathrm{NaHgO}(\mathrm{OH})$ & - & - & • \\
\hline $\mathrm{NaAg}(\mathrm{OH})_{2}$ & $\cdot$ & - & $\bullet$ \\
\hline $\mathrm{Na}_{2} \mathrm{MoO}_{4}$ & $\bullet$ & & - \\
\hline $\mathrm{KNO}_{3}$ & • & 0.01 & - \\
\hline $\mathrm{CaSO}_{4}$ & • & 0.14 & 0.02 \\
\hline $\mathrm{Na}_{2} \mathrm{C}_{2} \mathrm{O}_{4}$ & 0.08 & 0.02 & 0.07 \\
\hline $\mathrm{Na}_{3} \mathrm{PO}_{4}$ & 0.05 & 0.01 & 0.05 \\
\hline $\mathrm{NH}_{4} \mathrm{NO}_{3}$ & - & 0.30 & 0.03 \\
\hline $\mathrm{NaB}\left(\mathrm{C}_{6} \mathrm{H}_{5}\right)_{4}$ & 0.03 & & 0.02 \\
\hline Other Salts & $\bullet$ & 0.33 & 0.04 \\
\hline Total Organics & 0.05 & & 0.04 \\
\hline Subrotal (salt solution) & 47.18 & 47.08 & 46.99 \\
\hline Dry Blend & 52.82 & 52.92 & 53.01 \\
\hline TOTAL & 100 & 100 & 100 \\
\hline
\end{tabular}

- Expected to be present, but at a concentration less than $0.01 \mathrm{wt} \%$.

Rev. 0 
will react with components of the slag to form insoluble species that are not readily leached from the saltstone waste form. Water and soluble aluminum (III), calcium (II), barium (II), and strontium (II) species are incorporated into the cement matrix as the dry materials hydrate and the saltstone sets. Pertinent chemical reactions that can directly impact the long-term radiological performance are discussed in detail in Appendix D.

Based on chemical equilibrium calculations, Tc (VII) will react with components of the slag to form $\mathrm{Tc}_{2} \mathrm{~S}_{7}$, while chromate in the solution will be reduced to a lower oxidation state and precipitate as Chromium (III) hydroxide. Strontium and barium are incorporated as aluminosilicates within the calcium aluminosilicate structure of the cement paste. These less soluble forms effectively fix these contaminants, thus reducing their potential impact on long-term performance through groundwater pathways.

\section{DESCRIPTION OF THE SALTSTONE DISPOSAL LANDFILL SITE}

The SDF is permitted as a landfill for the disposal of solid industrial waste by the state of South Carolina. As presently planned, the facility will contain several large concrete vaults divided into cells. Each of the cells will be filled with solid saltstone. The saltstone itself provides primary containment of the waste, and the walls, floor, and roof of the vaults provide secondary containment.

Approximately 3 to $4.5 \mathrm{~m}$ of overburden have been removed to prepare and level the site for vault construction. All vaults will be built at or slightly below the grade level that exists after the overburden and leveling operations are complete. The bottom of the'saltstone monoliths will be at least $8 \mathrm{~m}$ above the historic high water table (Sect. 2.2.2) beneath the Z-Area site, thus avoiding disposal of waste in a zone of water table fluctuation. Runon and runoff controls are installed to minimize site erosion during the operational period.

\subsection{Site Layout and Capacity}

In the proposed disposal site layout, up to fifteen concrete vaults will be constructed for saltstone disposal (Fig. 2.5-1). Fourteen of these vaults will each have dimensions of approximately $60 \mathrm{~m}$ wide by $180 \mathrm{~m}$ long by $7.6 \mathrm{~m}$ high. The other vault (Vault 1) is approximately $30 \mathrm{~m}$ wide by $180 \mathrm{~m}$ long by $7.6 \mathrm{~m}$ high. Based on current vault designs, each of the fourteen larger vaults will be divided into twelve cells that are approximately $30 \mathrm{~m}$ wide by $30 \mathrm{~m}$ long by $7.6 \mathrm{~m}$ high. Vault 1 is divided into 6 cells with the same cell dimensions as the larger vaults. In terms of capacity, the disposal site is best described in terms of the number of vault cells used to receive waste. The proposed layout will thus contain 174 vault cells distributed over the 15 vaults that can receive saltstone grout. Each cell is sized to handle the volume of saltstone that would be produced from the treatment of approximately 4.2 million L ( 1.1 million gal) of wastewater. 

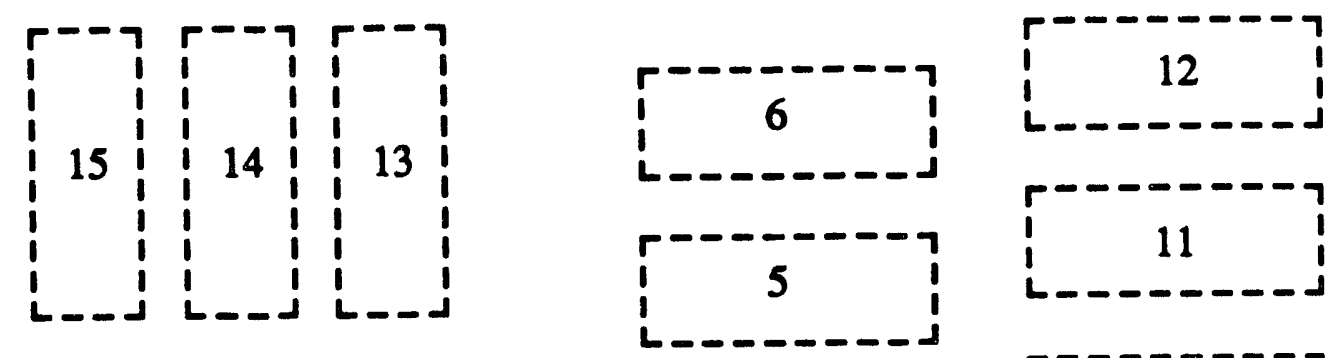

\section{Existing Vault 4}

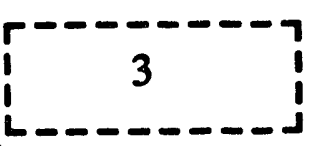

Saltstone Production Facility

$\Gamma^{\text {North }}$

-

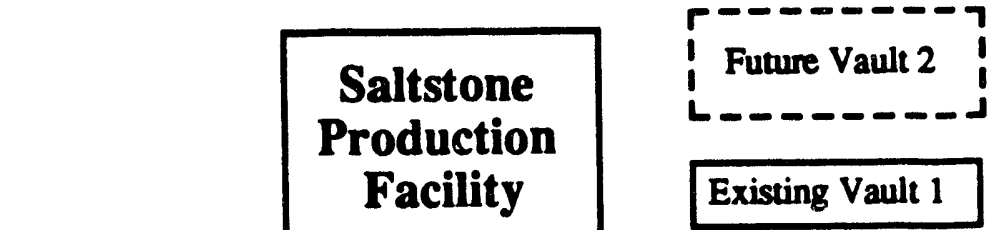

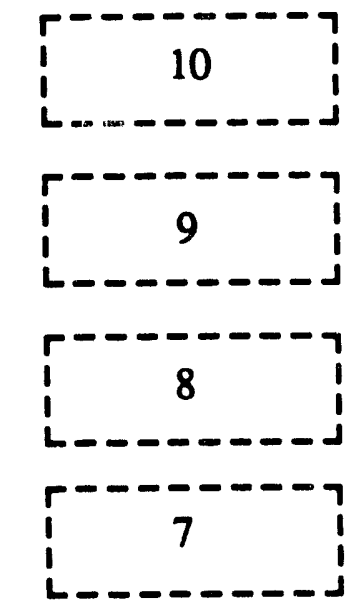

Fig. 2.5-1 Projected Vault Layout in the Z-Area Saltstone Disposal Facility 
Functionally, the vaults serve as a form to support the saltstone grout until it sets into a solid, monolithic waste form. The vaults also provide a secondary containment barrier for the contaminants in the waste and isolate the waste from direct contact with the environment.

More than half of the proposed Z-Area disposal capacity will be needed to dispose of mixed wastewater generated from existing HLW wastewater inventory now stored on the site in the F/H Tank Farm Facilities. Even with the changing production mission at the SRS, the minimum saltstone inventory in the SDF will fill 100-120 of the vault cells. Based on the projected average composition of wastewater that will be generated from HLW wastewater and the ETF, the average concentration of radionuclides in saltstone will be well below the Class A disposal limits defined by the NRC. South Carolina does not directly regulate radionuclide disposal at the SRS, but the operating permits for Z-Area require periodic reporting of the concentration of radionuclides in waste treated in Z-Area. Disposal of waste that exceeds NRC Class A criteria must also be reported to SCDHEC, and records must be maintained that reflect the total inventory of radionuclides in the disposal vaults.

Z-Area must operate for about 12 years at full production capacity to dispose of the mixed wastewater from existing HLW wastewater inventory and the LLW wastewater generated by the ETF during this same operating period. The projected volume of saltstone that would be produced from the existing soluble HLW inventory will fill about 8 to 9 large vaults plus the space in the smaller Vault 1 (about 110 cells). The existing HLW wastewater inventory represents 30 to 35 years of SRS production. Assuming the future HLW waste generation rate is comparable to the historical rate, the remaining 62 cells would provide disposal capacity for at least 15 years additional production at the SRS.

- Alternatively, this additional disposal capacity could be used to dispose of wastewater streams generated from other operations and activities at SRS. For example, decontamination and decommissioning of other facilities will likely produce wastewater streams that can be sent to Z-area for final treatment and disposal. However, neither the technology to complete these operations nor the compositions of waste streams have been defined; therefore, the possible impact of these waste streams cannot be a part of this performance assessment at this time. However, the composition of these steams are not expected to contain hazardous or radioactive contaminants that exceed the levels projected for the NB. Results presented in the RPA are thus, conservative, even with the changing DOE mission. Regardless of the source of waste, active disposal operations in Z-Area are projected to continue for about 30 years before the permitted disposal capacity is reached.

Except for erosion control purposes, backfilling around the vaults will not be done prior to filling the vaults with saltstone. Final back-filling to cover vaults will be deferred until several or all of the vaults have been built and filled. This approach of delaying backfilling until near the end of the operational period allows the vaults to be visually monitored for several years before closure operations begin. This approach also would 
enable the use of improved closure technology that may be developed during the operational period at the SDF. The closure concept for the SDF that was used as a basis for this performance assessment is described in Sect. 2.5.4.

\section{Vault Description}

Construction details for the two existing vaults are described in the permit application for the SDF. These two vaults are constructed of reinforced concrete containing slag. Slag has now been incorporated into the saltstone composition, and the functionality of the slag to mitigate release of certain contaminants is now provided by the saltstone itself, rather than relying on the slag in the vault concrete. Part or all of the slag may be removed in the concrete mix used to construct future vaults. Removal of the slag may reduce costs, while simultaneously improving the integrity of the vault structure (less likely to crack due to shrinkage during curing). Other changes are incorporated into the new design to eliminate operational difficulties observed with the initial vault design. These changes are described in Sect. 2.5.22.

\section{Existing Vaults 1 and 4}

Two vaults, designated as Vault 1 and Vault 4 on the site layout plan, have been built at the SDF (see Fig. 25-1). Vault 1 consists of six cells while Vault 4 consists of twelve cells. An expansion joint is provided at the center of the vault, thus Vault 1 really consists of two sets of 3 cells adjacent to each other, while Vault 4 consists of 2 sets of 6 cells adjacent to each other. The floor and walls of these two vaults are constructed of reinforced concrete containing slag.

Water stops are provided at all connecting joints between the walls and the floor, and a waterproof coating based on asphalt and polyurethane has been installed on the interior surfaces of the walls to seal the walls and mitigate migration of contaminants through the walls during the operational period. The coating will still be functional after closure, but no credit is taken for its effectiveness in this RPA. Permanent roofs were not installed on these vaults during initial construction. Instead, a movable metal cover is provided that spans two adjacent cells to provide weather protection during disposal operations.

The interior dimensions of the concrete walls of the cells on Vaults 1 and 4 are $30.0 \mathrm{~m}$ long and $7.6 \mathrm{~m}$ high. The concrete walls of the vault are $0.46 \mathrm{~m}$ thick, while the concrete floor of the vault is $0.76 \mathrm{~m}$ thick.

Operationally, two cells of these vaults will be filled to a height of about $7.3 \mathrm{~m}$ with saltstore, and then a layer of uncontaminated grout approximately $0.30 \mathrm{~m}$ thick will be poured to encapsulate the waste. After the layer of uncontaminated grout has set, the metal cover will be moved to cover the next two cells and disposal operations will continue in that vault. After all cells of a vault are filled, a permanent roof of concrete 
will be installed on the filled vault. The permanent roof has a specified minimum thickness of $0.30 \mathrm{~m}$ and a minimum slope of $2 \mathrm{~cm} / \mathrm{m}$.

\section{Future Vaults}

A modified vault design has been completed for other vaults to be built in the SDF. The same general dimensions and layout of the existing Vault 4 will be retained, but several changes have been made in the design and specifications to improve the long-term integrity and eliminate operational difficulties related to the initial design.

The new vaults will also be subdivided into twelve cells. The interior dimensions of the concrete walls will be the same as existing Vaults 1 and 4 and the walls will also be $0.46 \mathrm{~m}$ thick. Load requirements have been reevaluated, and the thickness of the base mat (floor) has been reduced to $0.61 \mathrm{~m}$ in the new design. To minimize the potential for cracking during curing of the concrete vault structure, additional expansion joints with water stops have been added in the vault walls, and concrete mixes with less shrinkage during curing will be used to construct the vaults. Because slag is now a part of the saltstone formulation, incorporating slag into the concrete used to construct vaults is redundant. Eliminating slag from these mixes is being considered to reduce the overall cost of materials used to construct the vaults while simultaneously improving the resistance to cracking due to shrinkage during curing.

The new vault design will be built with a permanent concrete roof constructed of precast reinforced concrete panels. The permanent roof will be installed before the vaults are filled with saltstone, thus eliminating the potential of spreading contamination during the dismantling and moving of the metal roof that is used on Vaults 1 and 4. To support the roof panels before filling the vaults with saltstone, two rows of support columns will be placed $10.3 \mathrm{~m}$ from the side and center wall at $6.1 \mathrm{~m}$ spacing. The panels will be constructed to provide a roof that is as watertight as possible; the roof will have a minimum slope of $2 \mathrm{~cm} / \mathrm{m}$.

\section{PROJECTED SDF WASTE INVENTORY}

To maximize the usefulness of the models use $d$ to assess the performance of the SDF, fractional releases are computed. This approach enables a relatively simple calculation to determine the effect of a change in the concentration of a contaminant on the performance. Accordingly, the total inventory of contaminants is needed to establish concentrations of species of concern in the waste form and the impact of subsequent releases to the surrounding environment.

Based on the present projected vault and site layout of the SDF, the capacity of the SDF will enable up to 730 million L (192 million gal) of wastewater to be treated for subsequent disposal as saltstone. Approximately 25 years at the design basis production rate for the SPF (based on a one-shift operation) would be needed to reach this disposal 
capacity. The present $\mathrm{HLW}$ inventory alone and related waste treatment processes (ITP, sludge washing, vitrification, ETF) are projected to generate about 460 million L (121 million gal) of wastewater for disposal as saltstone, if the projected process Howsheets and waste generation forecasts for these processes are reasonably accurate. Using the disposal capacity of waste and the projected nominal composition of the wastewater to be treated, the projected waste inventory and concentrations can be calculated for the SDF. The results of these calculations are discussed below. The current inventory in the existing two vaults is also given in Sect. 2.6.4.

\subsection{Disposal Capacity in the SDF}

Based on the cell dimensions for the vaults and the projected mode of operation, the volume of saltstone in each cell can be calculated:

$$
30 \mathrm{~m} \times 30 \mathrm{~m} \times 7.3 \mathrm{~m}=6.57 \times 10^{3} \mathrm{~m}^{3} / \text { cell }
$$

The disposal capacity of the SDF, based on the projected site layout that contains 174 cells, will be:

$$
6.57 \times 10^{3} \mathrm{~m}^{3} / \text { cell } \times 174 \text { cells }=1.14 \times 10^{6} \mathrm{~m}^{3}
$$

Based on a density of $1.7 \times 10^{3} \mathrm{~kg} / \mathrm{m}^{3}$ for saltstone and the total volume of the waste, a total of about 2 million metric tons of saltstone can be disposed in the SDF.

\subsection{Projected Minimum Saltstone Volume in the SDF}

An estimated 110 cells will be required to handle the projected waste volume from existing HLW waste already stored at the SRS. Thus the minimum volume of saltstone in the SDF is projected to be:

$$
6.57 \times 10^{3} \mathrm{~m}^{3} / \text { cell } \times 110 \text { cells }=7.23 \times 10^{5} \mathrm{~m}^{3}
$$

This volume corresponds to $\mathbf{1 . 2}$ million metric tons of saltstone.

\section{Projected Inventory of Components}

As noted in Sect. 2.5.1, each cell is sized to contain the saltstone produced from about 4.2 million $\mathrm{L}$ (1.1 million gal) of wastewater. Using this.value as a basis, the projected total inventory of any component in the SDF may be estimated using this relationship:

Cn $\times 4.2 \times 10^{6}$ L/cell $\times$ no. of cells $=$ total quantity 
where $\mathrm{Cn}$ is the projected or actual concentration per liter of salt solution in the desired units (moles, grams, tons, $\mathrm{Ci}$, etc.). To obtain the concentration of any species in saltstone, the total quantity is simply divided by the corresponding volume of saltstone containing the total inventory $\left(1.15 \times 10^{6} \mathrm{~m}^{3}\right)$ calculated in Sect. 2.6.1.

\subsection{Chemical Components}

To project the total inventory of chemical components, the concentrations of species in the "nominal blend" salt solution shown in Table 2.3-2 were used. Results from these calculations are shown in Table 2.6-1.

\section{Radioactive Components}

To project the total inventory of key radioactive components of particular concern for long-term performance, the concentrations of these species in the "nominal blend" salt solution shown in Table C.1-1 were used. This table contains the radionuclide inventory for all species estimated to be in concentrations greater than $10^{-15} \mathrm{Ci} / \mathrm{L}$. Results from these calculations are shown in Table 2.6-2, for all radionuclides in concentrations in excess of $10^{-12} \mathrm{Ci} / \mathrm{L}$ in the "nominal blend" salt solution. Dose analysis shows that only radionuclides with concentrations considerably higher than $10^{-12} \mathrm{Ci} / \mathrm{L}$ contribute significantly to the doses.

\subsection{Existing Inventory in the SDF}

The Saltstone Production Facility and Vaults 1 and 4 of the SDF were already constructed and non-radioactive testing was underway at the time DOE Order $5820.2 \mathrm{~A}$ was issued. Waste processing capabilities initially were demonstrated in Z-Area using solutions that simulated the expected composition of wastewater to be sent to Z-Area for treatment and disposal. Non-radioactive saltstone produced from these operations were sent to Cells A and B of Vault 1 for disposal. Radioactive operations were approved in June of 1990 following a startup authorization review by DOE-HQ, with the understanding that a program must be in place to enable Z-Area operations to fully comply with the new DOE Order in a reasonable time period by issuing a Z-Area SAR that conformed with the specified SAR format and a Z-Area RPA.

\subsubsection{Current SDF Saltstone Waste Inventory}

By early 1991, about 2.3 million $L$ of radioactive wastewater had been sent to Z-Area for treatment and disposal in Cell A of Vault 1. (Fowler 1991) Disposal of this waste completely filled Cell A of Vault 1. Disposal was shifted to Cell B of Vault 1. By late 1992, over 4 million L of wastewater had been treated for disposal in Vault 1. The wastewater that has been processed consisted of about 1 million $\mathrm{L}$ of decontaminated salt solution from the In-Tank Precipitation Process demonstration completed in 1984 and about 3 million L of evaporator bottoms from the F/H ETF facility. As shown in 
Table 26-1. Projected inventory and concentration of principal chemical components

\begin{tabular}{llccc}
\hline Solution Component & \multicolumn{1}{c}{$\begin{array}{c}\mathrm{NB}^{a} \\
(\mathrm{~mol} / \mathrm{L})\end{array}$} & $\begin{array}{c}\text { Inventory } \\
(\mathrm{mol})\end{array}$ & $\begin{array}{c}\text { Inventory } \\
(\mathrm{Kg})\end{array}$ & $\begin{array}{c}\text { SDF conc. } \\
\left(\mathrm{kg} / \mathrm{m}^{3}\right)\end{array}$ \\
\hline $\mathrm{NaNO}_{3}$ & 2.08 & $1.5 \times 10^{9}$ & $1.3 \times 10^{8}$ & 112 \\
$\mathrm{NaOH}$ & 1.30 & $9.5 \times 10^{9}$ & $3.8 \times 10^{7}$ & 33 \\
$\mathrm{NaNO}_{2}$ & $6.46 \times 10^{-1}$ & $4.7 \times 10^{8}$ & $3.2 \times 10^{7}$ & 28 \\
$\mathrm{NaAl}(\mathrm{OH})_{4}$ & $2.73 \times 10^{-1}$ & $2.0 \times 10^{8}$ & $2.3 \times 10^{7}$ & 20 \\
$\mathrm{Na}_{2} \mathrm{CO}_{3}$ & $1.64 \times 10^{-1}$ & $1.2 \times 10^{8}$ & $1.3 \times 10^{7}$ & 11 \\
$\mathrm{Na}_{2} \mathrm{SO}_{4}$ & $1.22 \times 10^{-1}$ & $8.9 \times 10^{7}$ & $1.3 \times 10^{7}$ & 11 \\
$\mathrm{Na}_{2} \mathrm{CrO}_{4}{ }^{c}$ & $3.06 \times 10^{-3}$ & $2.2 \times 10^{6}$ & $3.6 \times 10^{5}$ & 0.3 \\
\hline
\end{tabular}

- NB = Nominal Blend as shown in Table 2.3-2.

b Assumes projected inventory of $1.15 \times 10^{6} \mathrm{~m}^{3}$ saltstone in the SDF.

- $\mathrm{Cr}(\mathrm{VI})$ is reduced to $\mathrm{Cr}(\mathrm{III})$ in saltstone; $\mathrm{Cr}(\mathrm{III})$ precipitates as $\mathrm{Cr}(\mathrm{OH})_{3}$. 
Table 26-2 Projected inventory and concentration of key radionuclides

\begin{tabular}{|c|c|c|c|}
\hline Constituent & $\begin{array}{c}\mathrm{NB}^{a} \\
(\mathrm{C} i / \mathrm{L})\end{array}$ & $\begin{array}{c}\text { Inventory } \\
\text { (Ci) }\end{array}$ & $\begin{array}{l}\text { SDF conc. }{ }^{c} \\
\left(\mathrm{Ci} / \mathrm{m}^{3}\right)\end{array}$ \\
\hline Tc-99 & $8.9 \times 10^{-5}$ & $6.5 \times 10^{4}$ & $5.6 \times 10^{-2}$ \\
\hline Ru-106 + d & $4.5 \times 10^{-5}$ & $3.3 \times 10^{4}$ & $2.9 \times 10^{-2}$ \\
\hline Cs-137 + d & $27 \times 10^{-5}$ & $2.0 \times 10^{4}$ & $1.7 \times 10^{-2}$ \\
\hline H-3 & $2.6 \times 10^{-5}$ & $1.9 \times 10^{4}$ & $1.7 \times 10^{-2}$ \\
\hline$S b-125$ & $8.9 \times 10^{-6}$ & $6.5 \times 10^{3}$ & $5.6 \times 10^{-3}$ \\
\hline Pm-147 & $5.4 \times 10^{-6}$ & $3.9 \times 10^{3}$ & $3.4 \times 10^{-3}$ \\
\hline Sm-151 & $2.7 \times 10^{-6}$ & $2.0 \times 10^{3}$ & $1.7 \times 10^{-3}$ \\
\hline Sr-90 + d & $9.3 \times 10^{-7}$ & $6.8 \times 10^{2}$ & $5.9 \times 10^{-4}$ \\
\hline Eu-154 & $8.9 \times 10^{-7}$ & $6.5 \times 10^{2}$ & $5.6 \times 10^{-4}$ \\
\hline Se-79 & $4.4 \times 10^{-7}$ & $3.2 \times 10^{2}$ & $2.8 \times 10^{-4}$ \\
\hline Eu-155 & $4.4 \times 10^{-7}$ & $3.2 \times 10^{2}$ & $2.8 \times 10^{-4}$ \\
\hline Co-60 & $2.8 \times 10^{-7}$ & $2.0 \times 10^{2}$ & $1.8 \times 10^{-4}$ \\
\hline Te-125m & $2.7 \times 10^{-7}$ & $2.0 \times 10^{2}$ & $1.7 \times 10^{-4}$ \\
\hline$S n-126+d$ & $1.8 \times 10^{-7}$ & $1.3 \times 10^{2}$ & $1.1 \times 10^{-4}$ \\
\hline Am-241 & $1.8 \times 10^{-7}$ & $1.3 \times 10^{2}$ & $1.1 \times 10^{-4}$ \\
\hline Cs-134 & $8.9 \times 10^{-8}$ & $6.5 \times 10^{1}$ & $5.6 \times 10^{-5}$ \\
\hline Pu-238 & $6.7 \times 10^{-8}$ & $4.9 \times 10^{1}$ & $4.3 \times 10^{-5}$ \\
\hline Pu-241 & $4.4 \times 10^{-8}$ & $3.2 \times 10^{1}$ & $2.8 \times 10^{-5}$ \\
\hline Sn-121m & $3.6 \times 10^{-8}$ & $2.6 \times 10^{1}$ & $2.3 \times 10^{.5}$ \\
\hline I-129 & $2.7 \times 10^{-8}$ & $2.0 \times 10^{1}$ & $1.7 \times 10^{-5}$ \\
\hline $\mathrm{Ni}-63$ & $2.7 \times 10^{-8}$ & $2.0 \times 10^{1}$ & $1.7 \times 10^{-5}$ \\
\hline Sb-126 & $1.8 \times 10^{-8}$ & $1.3 \times 10^{1}$ & $1.1 \times 10^{.5}$ \\
\hline C-14 & $8.9 \times 10^{-9}$ & 6.5 & $5.6 \times 10^{-6}$ \\
\hline Eu-152 & $8.0 \times 10^{-9}$ & 5.8 & $5.1 \times 10^{-6}$ \\
\hline $\mathrm{Ce}-144+d$ & $4.4 \times 10^{-9}$ & 3.2 & $2.8 \times 10^{-6}$ \\
\hline Pu-239 & $1.7 \times 10^{-9}$ & 1.2 & $1.1 \times 10^{-6}$ \\
\hline
\end{tabular}

Rev. 0 
Table 26-2 (continued)

\begin{tabular}{|c|c|c|c|}
\hline Constituent & $\begin{array}{l}\mathrm{NB} \\
(\mathrm{Ci} / \mathrm{L})\end{array}$ & $\begin{array}{l}\text { Inventory } \\
\text { (Ci) }\end{array}$ & $\begin{array}{l}\text { SDF conc. } \\
\left(\mathrm{Ci} / \mathrm{m}^{3}\right)\end{array}$ \\
\hline $\mathrm{Cm}-244$ & $8.9 \times 10^{-10}$ & $6.5 \times 10^{-1}$ & $5.6 \times 10^{-7}$ \\
\hline Ag-110m & $8.0 \times 10^{-10}$ & $5.8 \times 10^{-1}$ & $5.1 \times 10^{-7}$ \\
\hline $\mathrm{Pu}-240$ & $4.4 \times 10^{-10}$ & $3.2 \times 10^{-1}$ & $28 \times 10^{-7}$ \\
\hline Zr-93 & $3.6 \times 10^{-10}$ & $2.6 \times 10^{-1}$ & $2.3 \times 10^{-7}$ \\
\hline U.234 & $3.6 \times 10^{-10}$ & $2.6 \times 10^{-1}$ & $2.3 \times 10^{-7}$ \\
\hline Ni-59 & $2.7 \times 10^{-10}$ & $2.0 \times 10^{-1}$ & $1.7 \times 10^{-7}$ \\
\hline $\mathrm{Th}-231$ & $1.8 \times 10^{-10}$ & $1.3 \times 10^{-1}$ & $1.1 \times 10^{-7}$ \\
\hline Am-242m & $8.9 \times 10^{-11}$ & $6.5 \times 10^{-2}$ & $5.6 \times 10^{-8}$ \\
\hline Am-242 & $8.9 \times 10^{-11}$ & $6.5 \times 10^{-2}$ & $5.6 \times 10^{-8}$ \\
\hline Cm-242 & $8.9 \times 10^{-11}$ & $6.5 \times 10^{-2}$ & $5.6 \times 10^{-8}$ \\
\hline$N p-237+d$ & $8.0 \times 10^{-11}$ & $5.8 \times 10^{-2}$ & $5.1 \times 10^{-8}$ \\
\hline U-232 & $6.2 \times 10^{-11}$ & $4.5 \times 10^{-2}$ & $3.9 \times 10^{-8}$ \\
\hline Am-243 & $5.3 \times 10^{-11}$ & $3.9 \times 10^{-2}$ & $3.4 \times 10^{-8}$ \\
\hline Cs-135 & $5.3 \times 10^{-11}$ & $3.9 \times 10^{-2}$ & $3.4 \times 10^{-8}$ \\
\hline Cm-243 & $3.6 \times 10^{-11}$ & $2.6 \times 10^{-2}$ & $2.3 \times 10^{-8}$ \\
\hline Pd-107 & $2.7 \times 10^{-11}$ & $2.0 \times 10^{-2}$ & $1.7 \times 10^{-8}$ \\
\hline $\mathrm{Pa}-234$ & $5.3 \times 10^{-12}$ & $3.9 \times 10^{-3}$ & $3.4 \times 10^{-9}$ \\
\hline U-233 & $3.6 \times 10^{-12}$ & $2.6 \times 10^{-3}$ & $2.3 \times 10^{-9}$ \\
\hline U-238 & $2.7 \times 10^{-12}$ & $2.0 \times 10^{-3}$ & $1.7 \times 10^{-9}$ \\
\hline Th-234 & $2.7 \times 10^{-12}$ & $2.0 \times 10^{-3}$ & $1.7 \times 10^{-9}$ \\
\hline Th-228 & $1.8 \times 10^{-12}$ & $1.3 \times 10^{-3}$ & $1.1 \times 10^{-9}$ \\
\hline Other alpha & $1.8 \times 10^{-7}$ & $1.3 \times 10^{2}$ & $1.1 \times 10^{-4}$ \\
\hline Other beta/gamma & $8.9 \times 10^{-6}$ & $6.5 \times 10^{3}$ & $5.6 \times 10^{-3}$ \\
\hline
\end{tabular}

- NB = Nominal Blend data for wastewater feed to saltstone, from Table C.1-1.

b Based on projected total volume of wastewater disposed of in SDF of $7.3 \times 10^{8} \mathrm{~L}$.

- Based on projected inventory of $1.15 \times 10^{6} \mathrm{~m}^{3}$ saltstone wasteform in the SDF. 
Table 2.6-3, the concentration of radionuclides critical to long-term performance are significantly lower in this waste than the projected nominal blend that was used as a basis for this RPA. Note that the concentrations of radionuclides shown in this table do not include the non-radioactive saltstone previously sent to Cells $A$ and $B$ of Vault 1 during non-radioactive operations, so the overall average radionuclide concentrations for the total saltstone inventory in Cells A and B of Vault 1 is actually about half of the concentrations shown for the radioactive saltstone produced to date.

\subsection{Naval Fuels Material Facility Drummed Waste Disposal}

Operations at the Naval Fuels Material Facility located on the SRS generated 10,032 drums containing solidified chemical waste and low levels of uranium. The solid waste in the drums was formed by combining aqueous chemical waste with a blend of cement and fly ash. The drums were then stored on a concrete pad at the SRS until final disposal could be completed. Total waste volume contained in the drums is about 2,035 cubic meters that contains a total of about $30 \mathrm{~kg}$ of uranium.

To meet the requirements of an order from SCDHEC that required final disposal of these drums, tests were completed on this waste that showed the chemical composition was compatible with permit requirements for disposal in the SDF. A permit modification was then obtained from SCDHEC to enable disposal of the drums in a vault in the SDF. Prior to disposal, void space within the drums were filled with non-radioactive grout. The drums were then placed in Cell A of Vault 4 and encased in clean grout to achieve final disposal. As noted in Table 2.6-4, the only radionuclide contaminant in this waste is alpha emitters from the uranium contaminant. Total alpha concentration is significantly below the concentrations projected for the overall SDF inventory (Fowler 1991).

\section{SDF CLOSURE CONCEPT}

One of the key performance objectives of any closure of a waste disposal site is to limit moisture flux through the waste, thus minimizing contamination of surface runoff and underlying groundwater. Because the SDF is designed as a controlled release facility, proper closure to meet the objective of limiting moisture through the waste will be an integral part of long-term acceptability of the disposal site. Because backfilling around the vaults and final closure of the SDF will be delayed for several years, a detailed closure design has not been fully developed for the SDF. Thus an integral part of the SDF RPA required that a closure concept be described and subsequently tested in models that simulate the performance characteristics of the proposed closure concept. 
Table 26-3. Comparison of key radionuclides in Vault 1 to SDF projections

\begin{tabular}{lcc}
\hline Nuclide & $\begin{array}{c}\text { Cells A \& B } \\
\text { Ci/m }\end{array}$ & $\begin{array}{c}\text { SDF Projections } \\
\text { Ci/m }\end{array}$ \\
\hline H-3 & $5.6 \times 10^{-3}$ & $1.7 \times 10^{-2}$ \\
C-14 & $1.4 \times 10^{-4}$ & $5.6 \times 10^{-6}$ \\
Se-79 & $2.7 \times 10^{-5}$ & $2.8 \times 10^{-4}$ \\
Sr-90 + d & $<2.0 \times 10^{-6}$ & $5.9 \times 10^{-4}$ \\
Tc-99 & $1.1 \times 10^{-2}$ & $5.6 \times 10^{-2}$ \\
Sn-126 + d & $8.7 \times 10^{-5}$ & $1.1 \times 10^{-4}$ \\
I-129 & $3.0 \times 10^{-6}$ & $1.7 \times 10^{-5}$ \\
C $-137+$ d & $7.0 \times 10^{-4}$ & $1.7 \times 10^{-2}$ \\
Np-237 + d & $9.0 \times 10^{-9}$ & $5.1 \times 10^{-3}$ \\
Total alpha & $6.1 \times 10^{-5}$ & $7.0 \times 10^{-4}$ \\
\hline
\end{tabular}

Notes:

1. Concentrations based on salt solution analyses at the time of production (1990-92).

2. Concentrations shown for cell A \& B reflect only the volume of radioactive saltstone produced.

3. Cell A contains about $3840 \mathrm{~m}^{3}$ non-radioactive saltstone (simulant) from SPF process demonstrations that were placed in the cell prior to radioactive operations in Z-Area.

4. Cell B contains about $2740 \mathrm{~m}^{3}$ non-radioactive saltstone (simulant) from SPF process demonstrations that were placed in the cell prior to radioactive operations in Z-Area. 
Table 26-4. Naval Fuels Material Facility drummed waste disposal in cell A of Vault 4

\begin{tabular}{lcc}
\hline Nuclide & $\begin{array}{c}\text { Cell A } \\
\mathrm{Ci}^{3}\end{array}$ & $\begin{array}{c}\text { SDF Projections } \\
\mathrm{Ci} / \mathrm{m}^{3}\end{array}$ \\
\hline $\mathrm{H}-3$ & - & $1.7 \times 10^{-2}$ \\
$\mathrm{C}-14$ & - & $5.6 \times 10^{-6}$ \\
Se-79 & - & $2.8 \times 10^{-4}$ \\
Sr-90 + d & - & $5.9 \times 10^{-4}$ \\
Tc-99 & - & $5.6 \times 10^{-2}$ \\
Sn-126 + d & - & $1.1 \times 10^{-4}$ \\
I-129 & - & $1.7 \times 10^{-5}$ \\
Cs-137 + d & - & $1.7 \times 10^{-2}$ \\
Np-237 + d & - & $5.1 \times 10^{-3}$ \\
Total alpha & $2.5 \times 10^{-5}$ & $7.0 \times 10^{-4}$ \\
\hline
\end{tabular}

Notes:

1. To meet an order from SCDHEC, 10,032 drums containing about $2035 \mathrm{~m}^{3}$ of solidified chenuisal waste containing low levels of uranium were sent to the SDF for disposal.

2. Concentration in the waste is based on the waste volume, and does not include the volume occupied by clean grout that was placed around the drums in the cell.

Rev. 0 


\subsection{Physical Description of the SDF Closure Concept}

Closure concepts developed for this assessment are illustrated in Fig. 2.7-1 and Fig. 27-2. Figure 2.7-1 represents the closure concept with an intact upper moisture barrier (see Sect. 3.1.3.1 for a discussion of cover degradation), while Fig. 2.7-2 represents the degraded cover system, in which the properties of the upper moisture barrier have reverted to that of the backfill (see Sect. 3.1.3.5). Closure operations will begin near the end of the active disposal period in the SDF vaults, i.e., after most or all of the vaults have been constructed and filled. Backfill of native soil will be placed around the vaults. The vaults will be covered with a clay/gravel drainage system comprised of $0.5 \mathrm{~m}$ of clay with an overlying $0.15 \mathrm{~m}$ layer of gravel. The clay/gravel drainage system is intended to prevent the buildup of perched water above the vaults. Above the clay/gravel drainage sysem, a geotextile fabric, to maintain layer separation from overlying backfill, and a minimum of $0.3 \mathrm{~m}$ of backfill will be placed. Above this layer of backfill, a laterally extensive moisture barrier will be installed. This upper moisture barrier will consist of $0.76 \mathrm{~m}$ of clay and an overlying layer of $0.3 \mathrm{~m}$ of gravel. A geotextile fabric will also be placed on this upper gravel layer, and a second backfill layer, approximately $0.76 \mathrm{~m}$ thick, will be placed over the moisture barrier. Finally, $0.15 \mathrm{~m}$ layer of topsoil of topsoil will be placed on the top layer of backfill to complete disposal operations at the SDF. This sequence of layers will provide a minimum of $2.92 \mathrm{~m}$ of cover for each vault.

Final closure of the SDF will be accomplished by constructing a drainage system and re-vegetating the site. The drainage system will consist of a system of rip-rap lined ditches that intercept the gravel layer of the moisture barrier. These ditches will divert surface runoff and water intercepted by the moisture barrier away from the disposal site. The drainage ditches will be constructed between rows of vaults and around the perimeter of the SDF.

The topsoil will be revegetated with bamboo. A study conducted by the USDA Soil Conservation Service (Cook and Salvo 1992) has shown that two species of bamboo (Phyllostachys bissetii and Phyllostachys rubromarginata) will quickly establish a dense ground cover which will prevent the growth of pine trees, the most deeply rooted naturally occurring plant type at SRS. Bamboo is the shallow-rooted climax species which cvapotranspirates year-around in the SRS climate, thus, removing a large amount of moisture from the soil and decreasing the infiltration into the underlying disposal system. 


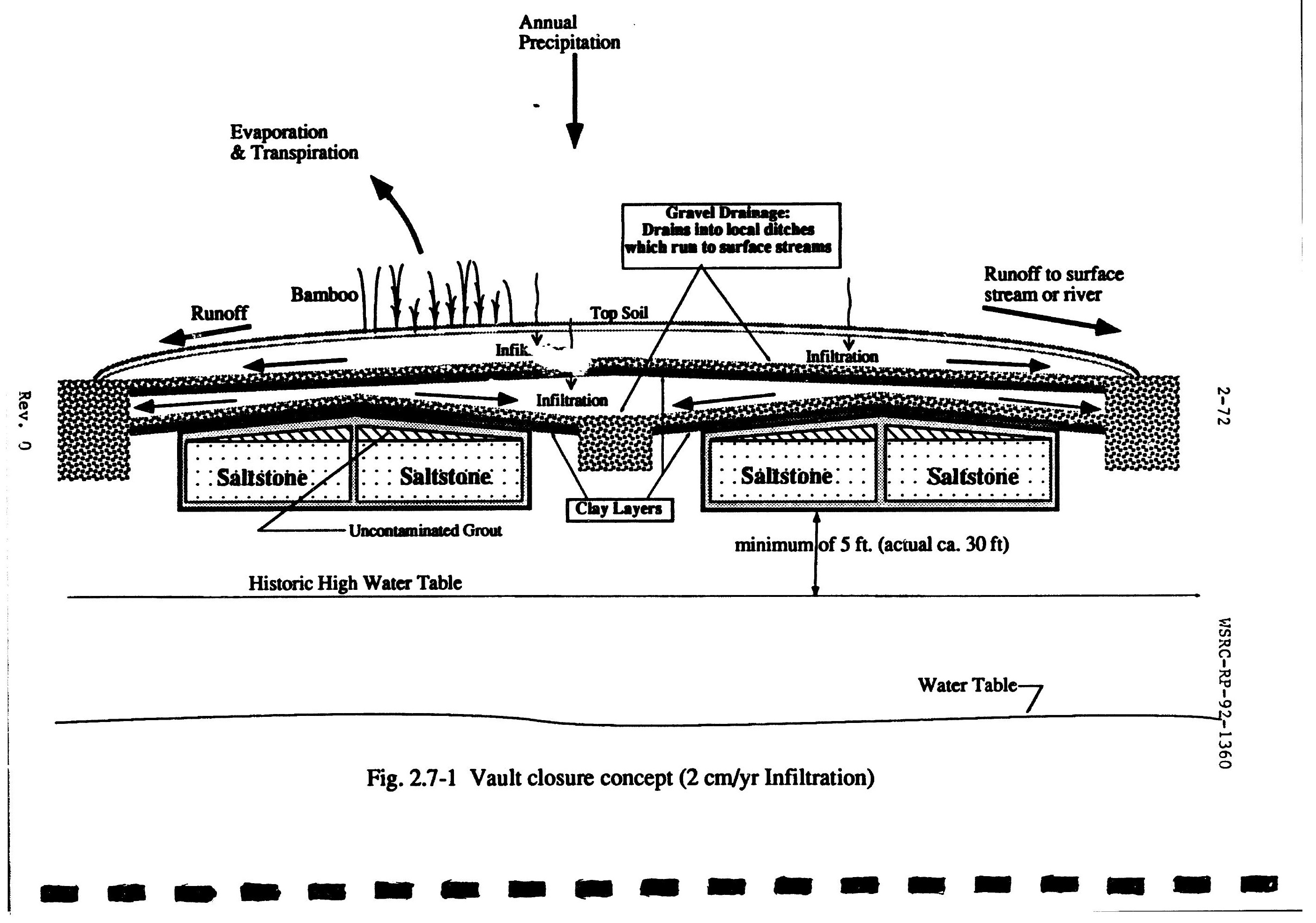




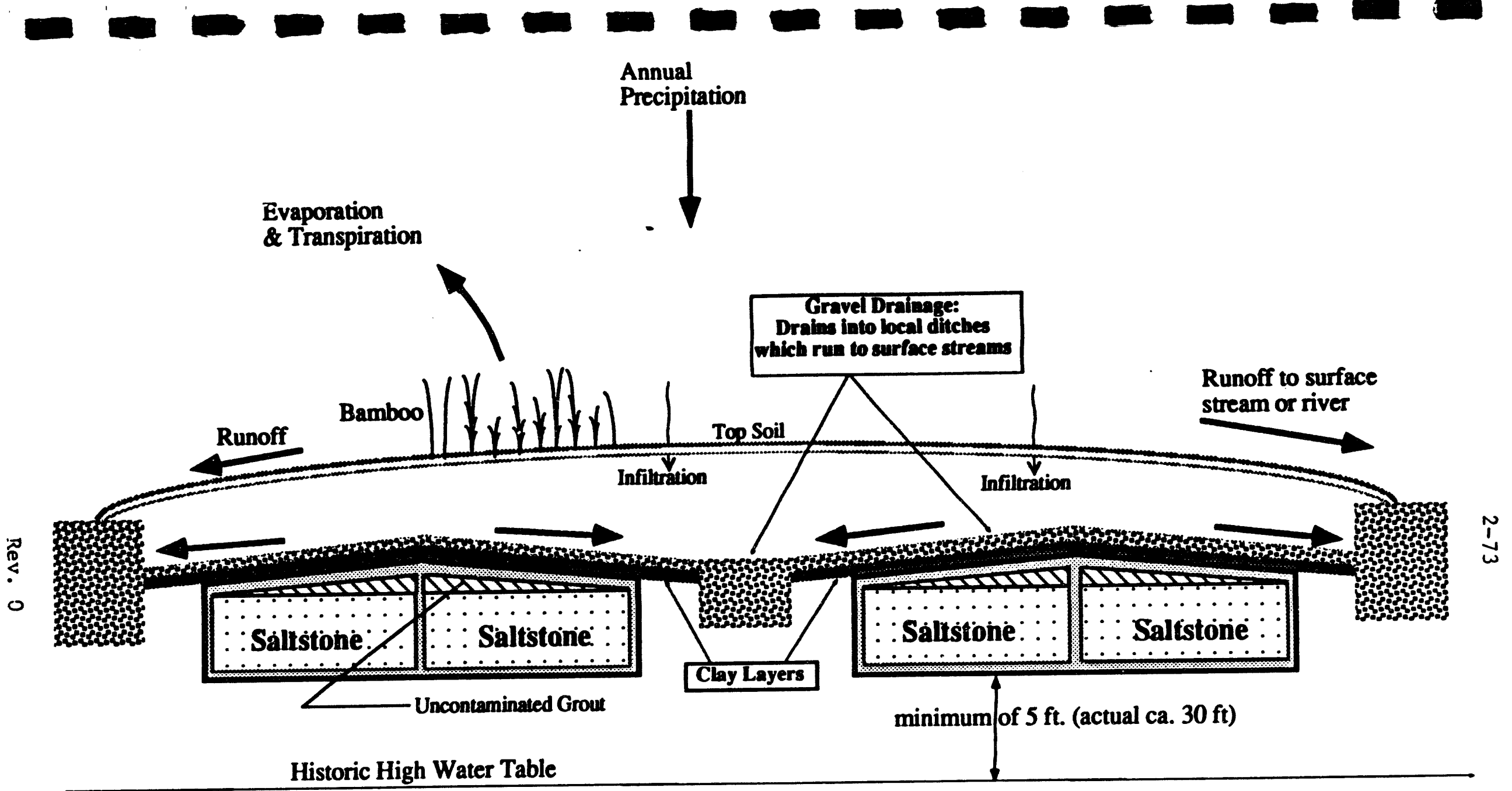

Fig. 2.7-2 Vault closure concept (40 cm/yr Infiltration) 


\section{Functional Description of the SDF Closure Concept}

Performance requirements for the closure concept are expressed in terms of hydraulic properties for the various soil layers (Thompson 1991). These properties are listed in Table 2.7-1. The topsoil and upper backfill layer serve to store and distribute infiltrating water. In contrast, the gravel and clay layers constitute "moisture barriers" to infiltrating water. These barriers intercept incoming pore water and redirect a significant portion in the horizontal direction to drainage ditches installed at the SDF. Computer simulations of flow through this system show that the upper gravel drainage layer and lower clay/gravel drainage system will carry away a major portion of the water that would normally infiltrate at the SDF (40 cm/year). The vertical moisture flux through the upper moisture barrier will be limited to less than $2 \mathrm{~cm} / y e a r$, based on the hydraulic properties of the closure system.

\section{SUMMMARY OF DISPOSAL FACILITY DESCRIPTION}

The information provided in this chapter of the RPA for the SDF provides the basis for the assessment of performance described in the following chapters. Several of the more significant aspects of the SDF location and design are summarized here.

In Sect. 2.1 and 2.2, characteristics of the SDF local and regional environment were described. The SDF is located at Z-Area, which is on a topographic high within the SRS. The water table occurs at a depth ranging from 7.6 to $18 \mathrm{~m}$ in the Z-Area vicinity. Z-Area is located in a region of the SRS that is almost completely surrounded by streams to which groundwater discharges. Furthermore, strong evidence exists that groundwater under Z-Area is confined vertically by the Ellenton Formation. Therefore, groundwater contamination which may result from the SDF is restricted to the region under Z-Area and towards the streams.

In Sect. 2.3 through 2.7, the SDF facility waste inventory and wasteform were described. The design basis radionuclide inventory, used in the assessment, is based on known sources of radionuclides (i.e., known processes creating the waste for disposal), and thus the identity and projected concentrations of radionuclides can be estimated fairly accurately. The confidence level in the inventory is therefore greater than with LLW which is accumulated from poorly characterized and highly variable sources. With regard to the design of the SDF, the most significant feature of this facility, with regard to performance assessment, is the wasteform, which was designed to minimize leaching of radionuclides and structurally provides considerable resistance to physical degradation mechanisms such as seismic events, and to human or other biotic intrusion. 
Table 27-1. Values for hydraulic properties

\section{of vault closure design}

\begin{tabular}{lc}
\hline Layer description & $\begin{array}{c}\text { Hydraulic } \\
\text { Conductivity }(\mathrm{cm} / \mathrm{s})\end{array}$ \\
\hline Clay & $1 \times 10^{-7}$ \\
Gravel & $1 \times 10^{\circ}$ \\
Backfill & \\
Top soil & $1 \times 10^{-3}$ \\
\hline
\end{tabular}

Rev. 0 


\section{ANALYSIS OF PERFORMANCE}

The methods used to analyze the long-term performance of the SDF are described in this chapter. Source term development is discussed first, in Sect. 3.1. This section includes a description of the inventories of radionuclides assumed, potential mechanisms of contaminant release from the facility, and of potential mechanisms responsible for loss of integrity of the engineered barriers of the SDF. A discussion of how non-radioactive constituents of saltstore are addressed in this RPA is also provided.

Following the source term discussion, potential receptors are identified in Sect. 3.2 by recognizing the time periods of concern in this RPA, the potentially significant pathways from the SDF to the environment, and exposure scenarios that should be evaluated for both off-site members of the public and inadvertent intruders. In this section, the SDF radionuclide inventory is screened to eliminate radionuclides that, under unrealistically conservative conditions, are insignificant with respect to potential human exposures.

The conceptual models developed and the computational approach used to assess the performance of the SDF are also described in this chapter. The conceptual models are derived from technical information presented in Chapter 2. These models embody a number of simplifying assumptions to facilitate the computational analysis required to assess long-term performance of the SDF.

An overall conceptual model was used to prepare the RPA for the SDF and is illustrated schematically in Fig. 3.0-1. This overall conceptual model indicates the linkage of 1) a source term submodel (Sect. 3.1), which considers mechanisms of release of saltstone constituents from the saltstone matrix, 2) a near-field submodel (Sect. 3.3.1), which addresses movement of released constituents within the saltstone matrix and through the vaults and unsaturated zone around the facility, 3) an environmental transport submodel, which addresses potential transport pathways including groundwater and air (Sect. 3.2.2 and 3.3.2), and 4) a dose submodel (Sect. 3.3.3) which relies on the exposure/intruder scenarios developed in Sect. 3.2.3 and 3.2.4. The computational methods used to implement the conceptual models are described in Sect. 3.4.

\subsection{SOURCE TERM}

In this section of the RPA, the inventory of radionuclides assumed for subsequent analyses is discussed, followed by a qualitative description of the means by which saltstone constituents may be released to the environment. The source term relies to a great extent on the engineered features of the SDF (Sect. 2.4), but also on aspects of the Z-Area environment (Sect. 2.2). Results of source term analysis are used in the near-

Rev. 0 


\section{Conceptual Model}

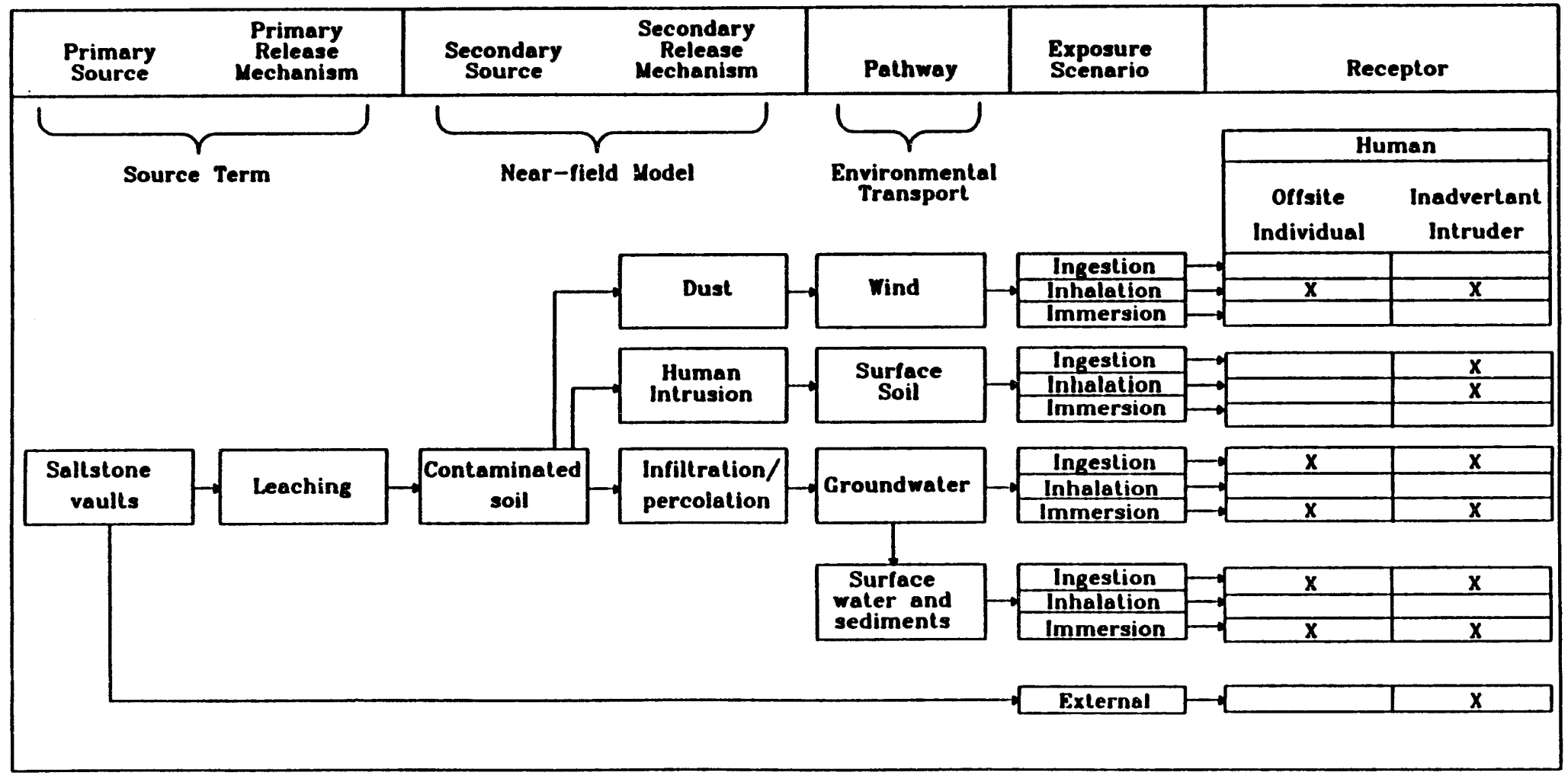

SRSOB2

Fig. 3.0-1. Overall conceptual model for the Radiological Performance Assessment of the Saltstone 
field analysis to determine the availability of radionuclides for environmental transport from the facility and to determine the near-field quantity of radionuclides available to an isadvertent intruder.

The release of radionuclides from the saltstone matrix, and ultimately from the vaults to the geosphere, is governed by several processes. The conceptualization of how releases potentially occur is conceptualized in Sect. 3.1 .2 below.

The performance of the SDF is a function of the engineered features of this facility. Therefore, the effect of degradation and failure of engineered barriers to radionuclide release is also addressed in this RPA. Mechanisms of cover, vault, and saltstone degradation conceptualized for this facility, and the assumptions made to compute the effects of degradation are described in Sect. 3.1.3.

Although the focus of an RPA is on the potential impact of the radioactive constituents of a disposal facility, other requirements imposed by the State of South Carolina on the SDF as an industrial solid waste disposal landfill site (Sect. 1.2) are of concern to the SRS. These latter requirements address both radioactive and nonradioactive saltstone constituents. In discussing the performance of the SDF, the nonradioactive constituents of saltstone should be considered. Therefore, a discussion of these constituents and their impact are discussed at the end of this section (Sect. 3.1.4).

\subsubsection{Chemical and Radionuclide Inventories}

As noted in Sect. 2.3, a nominal blend (NB) of waste streams was used as a basis for the chemical and radiochemical composition of the salt solution sent to Z-Area for treatment and disposal. Base on this NB composition and the projected capacity of the SDF in terms of total inventories of solid saltstone waste, major chemical components (Table 26-1), and key radionuclides (Table 2.6-2) have been projected to provide source terms for this RPA. Specific calculations used to project these total inventories are described in Sect. 2.6.

\subsubsection{Release Mechanisms}

At a conceptual level, the mechanisms that lead to release of contaminants from the saltstone consist of dissolution, diffusion, dispersion, and advection (Fig. 3.1-1). Contaminants bound in the solid matrix of the monoliths are released into the pore fluid through the process of dissolution. Contaminants dissolved in the pore fluid move through the saltstone by molecular diffusion, mechanical dispersion, and advection (i.e., transport by bulk motion of the fluid). The rates of contaminant release by these mechanisms are principally controlled by these factors:

- chemical and physical properties of the contaminants,

- moisture flux to the saltstone through the vault from the overlying soil, and

- physical properties (e.g., void structure and hydraulic conductivity, etc.) and state (e.g., integrity) of the waste form and vault.

Rev. 0 


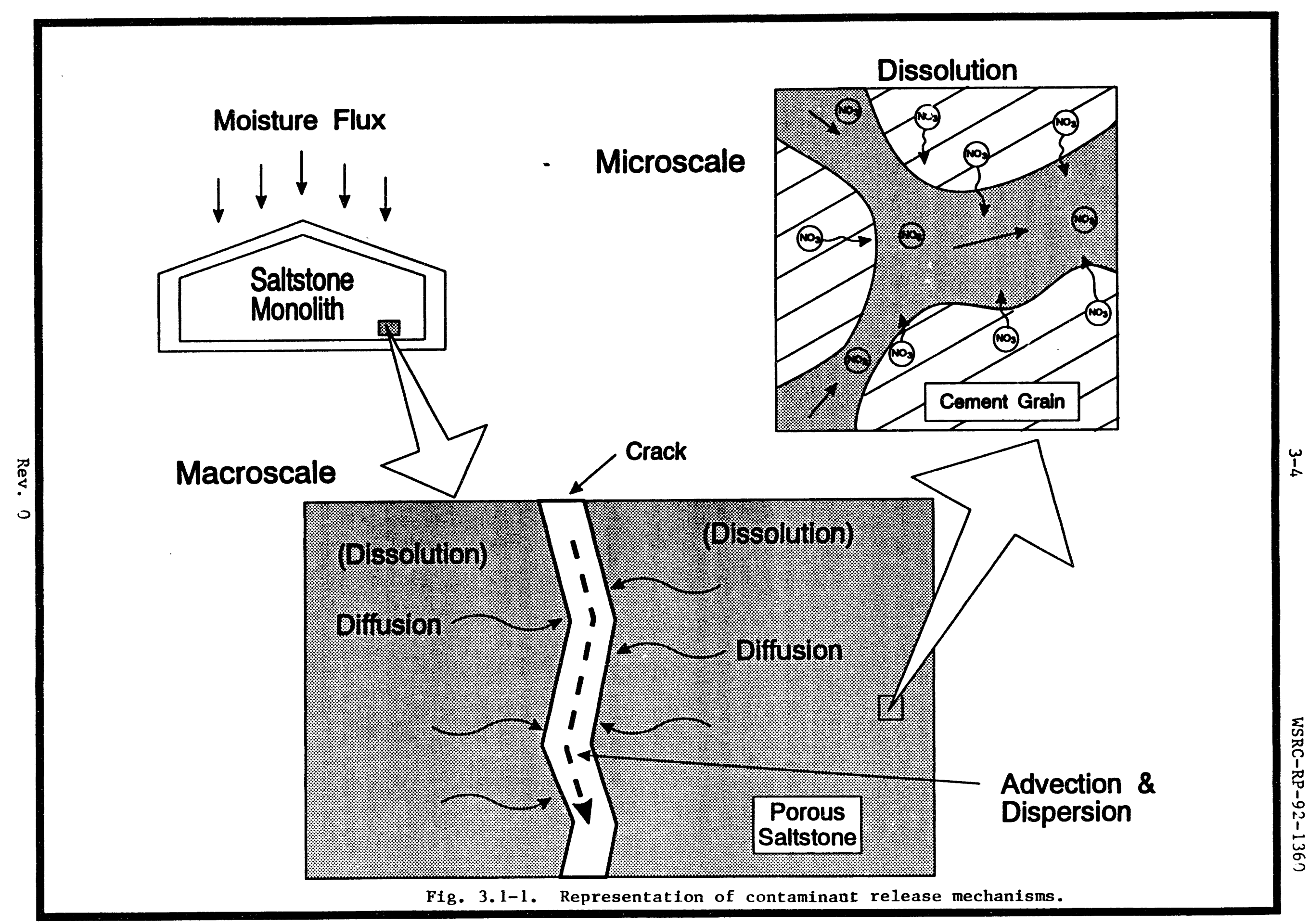


The rate at which contaminants are released from the saltstone matrix, and thus are available for release, depends primarily on their solubility, sorption, diffusive properties, and on their rate of radioactive decay. The presence of the blast furnace slag in the saltstone will produce chemically reducing conditions in the pore-fluid which, in turn, will result in low solubilities for certain components. At present, there are limited data for diffusion coefficients for vault-specific concrete (Atkinson and Nickerson 1988). In contrast, diffusion of both chemical and radioactive contaminants has been extensively characterized for the saltstone waste form (Kumar et al. 1985, Langton et al. 1988, and Oblath 1989). Apparent diffusion coefficients have been measured for several radionuclides and nitrate in saltstone in laboratory experiments. These coefficients are influenced not only by the effective diffusivity of the contaminants, described below, but also by their solubility and sorptive behavior. As expected, highly insoluble or sorptive compounds are characterized by relatively low apparent diffusion coefficients, when compared to non-sorbing and very soluble species such as nitrate.

Moisture flux to the saltstone is controlled by characteristics of the overlying materials, including the roof of the vault. The annual average precipitation at the SRS is $124 \mathrm{~cm} / y e a r$ (Sect. 2.1.4) of which about $40 \mathrm{~cm} /$ year infiltrates through the soil to the underlying aquifers (Appendix A.1.1). The moisture barriers (i.e., clay-gravel layer, Sect. 2.4.3.2) placed above the vault is designed to intercept infiltrating water and to divert the downward flow around the vaults. However, some infiltrating water will reach the vault and the saltstone monolith. Immediately after closure of the disposal system, the moisture flux through the vault is expected to be low because:

- moisture flux through the upper moisture barrier and clay/gravel drain system will be very small,

- the vault and waste form possess low hydraulic conductivity, and

- the vault and waste form are intact, i.e., minimal cracking.

These favorable characteristics, however, may eventually result in the formation of a perched water layer, or a saturated zone, on the vault roof. Details of the conceptual model of moisture penetration through the clay-gravel layers, and the resulting flux of water to the saltstone, are provided in Sect. 3.3.1, the Near-Field Model.

An intact or degraded vauli and saltstone monolith will have certain hydraulic properties associated with it that uill affect the release of radionuclides from the SDF. In particular, the hydraulic conductivity of the vault and saltstone will affect the rate at which pore water within the monolith can advect contaminants to the soil surrounding each vault. The degree of tortuosity, which reflects the convoluted path the pore water follows in a porous medium, is also a physical property of the saltstone and vaults which affects the effective diffusive flux of radionuclides in the following manner. The effective 
diffusive flux, $F_{0}$ is expressed as:

$$
F_{e}=D_{e} \nabla C
$$

where $\nabla C$ is the contaminant concentration gradient in all directions in pore solutions, and $D_{e}$ is the effective diffusion coefficient. The effective diffusion coefficient is related to tortuosity, $\tau$, by:

$$
D_{c}=D_{m} \times \tau
$$

where $D_{\mathbf{a}}$ is the molecular diffusion coefficient in water.

The degree to which the vaults and monoliths retain their original undegraded state will impact both the moisture flux to the saltstone and physical properties of the saltstone. If either the vaults or the monoliths degrade, the release is likely to increase based on increased advection of contaminants. If preferential flow paths develop, such as occurs with fractured media, the rate at which contaminants migrate from intact portions of the saltstone to the fractures is likely to be dominated by diffusion. Therefore, the importance of diffusive transport is likely to increase under conditions in which the saltstone has degraded.

This RPA addresses all of the mechanisms of release described above to estimate the source term for the SDF. A rigorous geochemical analysis of initial pore solution concentrations of Tc-99, I-129 and nitrate is documented in Appendix D. However, in the interest of time and budget, conservative assumptions were made for constituents of the saltstone that were determined to be relatively unimportant with respect to acceptable performance of the facility. Before near-field modeling was done, the inventory was screened to eliminate radiological constituents that would not result in individual exposures approaching the limits specified in Sect. 1.4 of this report using an extremely conservative approach to estimate this exposure. The screening procedures and results are described in Sect. 3.2.3.4, for the groundwater pathway, and in Sect. 3.2.4.4 for inadvertent intruders.

In addition to chemical considerations, both diffusive and advective transport are addressed in source term development for this RPA. The computer code, PORFLOW. 3D (Runchal and Sagar 1992), was used to simulate these processes. A description of the conceptual model of flow and transport in the saltstone and vaults, as well as in the surrounding soil, is provided in Sect. 3.3.1.1.

\subsubsection{Engineered Barriers Degradation and Failure}

As was noted in the previous section describing release mechanisms, the source term for the SDF is a function of the integrity of the engineered features to some extent. In this section, mechanisms of possible failure are discussed. Failure scenarios that were conceptualized for this RPA are described.

Rev. 0 
Engineered barriers used in the saltstone disposal system consist of three main components: 1) the cover (i.e., moisture barrier, backfill and top soil), 2) the concrete vault, and 3) the saltstone waste form. These barriers are expected to degrade with time by both internal and external processes. The rate and sequence of degradation will determine the long-term isolation performance of the disposal system.

\subsubsection{Cover Degradation}

Degradation of the upper moisture barrier (cover) is expected to occur by a number of processes. Potential processes are erosion; penetration by plants and animals; external events such as settling or slumping, or a seismic event; and human intrusion. These processes will reduce the effectiveness of the cover to limit the vertical moisture flux. Over the isolation period, the net flux through the cover is expected to approach the background levels for the site, i.e., $\mathbf{4 0} \mathrm{cm} / \mathrm{year}$.

As presently conceived in the closure concept (Sect. 2.4.3), shallow-rooted bamboo will be planted on the disposal site and a system of drainage ditches will be constructed to handle surface runoff and diverted infiltration. As specified in DOE Order 5820.2A, institutional control is assumed for 100 years. During this time, periodic site inspection would reveal any degradation of the overlying cover and drainage system and corrective actions would be taken. Cover degradation during this first 100 years is likely to be minimal. Sheet erosion will occur, but the bamboo vegetative cover would minimize the effects of this disturbance. Groundwater monitoring at the compliance point and in surface streams near the site would likely continue during this period. Return of the SRS land to unrestricted use after 100 years may result in a usage conversion to agricultural practices, consistent with past and current land use in the SRS vicinity. Row crop farming, which is consistent with historical practices in the vicinity, would increase the erosive effects of precipitation. Soil erosion rates for cropland in the vicinity of the SRS are on the order of $1.7 \mathrm{~kg} \mathrm{~m}^{-2} \mathrm{yr}^{-1}$ (Sect. 2.1.7). This suggests that the cover may be eroded down to the gravel layer in about 800 years after the bamboo vegetative layer is cleared. Erosion of gravel is difficult to predict, however. Moisture flux through the upper moisture barrier (cover) was modeled assuming an intact cover with an infiltration rate of $2 \mathrm{~cm} /$ year for the entire time period or no such cover with an infiltration rate of $40 \mathrm{~cm} / y e a r$ for the entire time period. These scenarios were used for both the intact and degraded vault cases (Fig. 3.1-2). The lower clay/gravel layer directly on top of the vault and extending between vaults was assumed to remain intact.

\subsubsection{Vault Degradation}

The concrete vault will most likely degrade through a combination of physical, chemical, and mechanical processes (Walton et al. 1990). Physical and mechanical degradation processes that produce cracking are of primary concern, because of the concomitant increase in permeability. Shrinkage cracks occur as a result of the temperature cycling during curing of concrete structures, and thus are present before the cover over the facility is constructed. This allows for filling of the outer portion of the cracks, in the vault walls or roof, with epoxy. Cracking might occur after the vaults have 

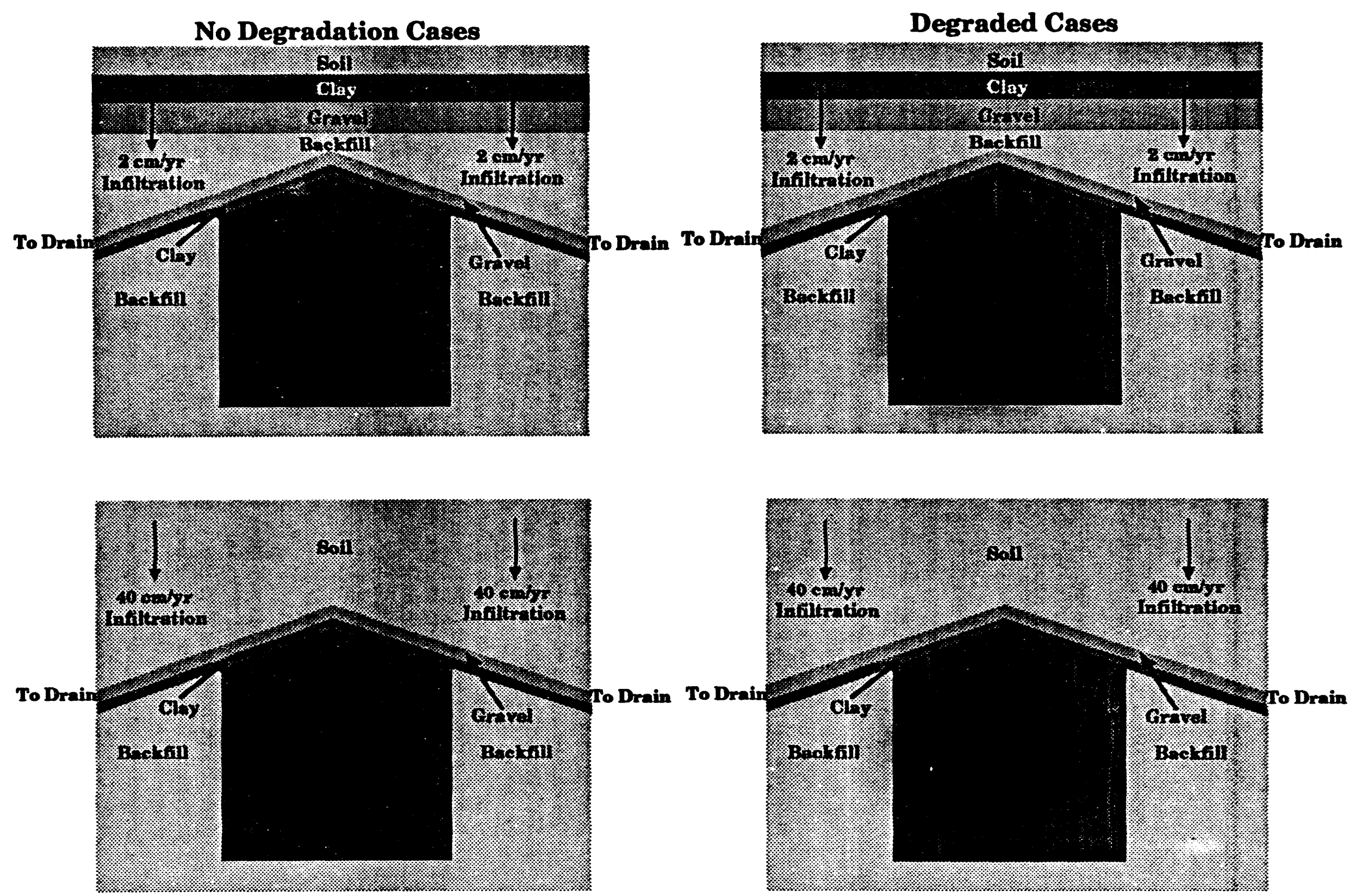

Fig. 3.1-2, Schematic of modeled scenarios. 
been covered as a result of degradation of the epoxy used to fill shrinkage cracks, foundation settling, or rebar expansion.

Seismic events conceivably could result in cracking of the vault's saltstone monoliths at Z-Area. However, crumbling is not expected to occur as a result of seismic-induced ground motion. While liquefaction is considered to be of low, but finite, probability at the SRS based on a review of previous studies at the SRS (Sect. 2.4.3), loss of underlying structural support of the monolithic structures is expected to have an effect similar to settling. That is, the saltstone monoliths and vaults may crack due to the loss of support from underlying soils.

The principal chemical processes that could cause disruption of the concrete vaults are: sulfate attack, carbonation, calcium hydroxide leaching, and rebar corrosion. The effects of these processes on vault degradation have been analyzed using the methodology described in Walton, et al. (1990). The methodology quantifies the extent of concrete degradation in terms of the penetration depth. This depth is the amount of wall thickness that has degraded. The analysis of chemical degradation effects are summarized here.

\section{Sulfate attack}

Concrete degradation by sulfate and/or magnesium attack occurs when sulfate or magnesium ions in the pore-fluid migrate into the concrete and react with the cement paste. Sulfate reacts with tri-calcium aluminate in the cement paste to form calcium aluminum sulfates. Magnesium reacts with hydroxide ions to form magnesium hydroxide. The products of these reactions have considerably greater volume than the compounds they replace. The expansive reactions can result in disruption of the concrete.

The major sources of sulfate and magnesium at the site are from groundwater and the saltstone. Concentrations of sulfate and magnesium in groundwater at Z-Area (Sect. 2.2.4) are very low (i.e., a few parts per million).

The methodology developed by Atkinson and Hearne (1984) (and summarized in Walton et al. 1990) was used to assess the impact of sulfate and magnesium attack associated with the ingress of the soil-moisture. The results showed that concrete degradation by sulfate attack on the outer walls of the vault will be insignificant, even over 10,000 years.

Measured concentrations of sulfate in the saltstone pore-fluid are about $25,000 \mathrm{mg} / \mathrm{L}$ (Malek et al. 1987). Such levels are high enough to cause sulfate attack from inside the vault. Sulfate leached from the waste form will first contact the inner walls of the vault. Subsequently, expansion at the contact between saltstone and vault may lead to cracking and degradation of the vault walls. The task of predicting concrete degradation for this case is very complex, and has not been attempted here. 


\section{Carbonation}

Carbonation occurs when calcium in concrete reacts with carbon dioxide $\left(\mathrm{CO}_{2}\right)$ in air to form calcium carbonate. At the saltstone disposal site, carbon dioxide will be present in soil-air and dissolved in soil-water. Carbon dioxide will slowly migrate into the concrete, potentially leading to a carbonated zone. Concrete degradation, in this case, is aseociated with concrete expansion due to corrosion of the reinforcement bars (i.e., rebar). Typically, the $\mathrm{pH}$ of concrete is very high which is favorable to very low rebar corronion. However, the carbonation reaction can reduce the pore-fluid $\mathrm{pH}$ which, in turn, makes the rebar susceptible to corrosion.

Carbonation may also result in potentially beneficial effects. For example, carbonate carried by the pore-fluid into cracks and pores of the vault structure may precipitate and reduce the effective porosity of the vaults. At the bottom of the vault, water which has percolated through the vault roof and saltstone will be saturated with portlandite $\left[\mathrm{Ca}(\mathrm{OH})_{2}\right]$. The $\mathrm{Ca}(\mathrm{OH})_{2}$ can react with soil-air containing $\mathrm{CO}_{2}$, forming a calcium carbonate mass that then seals cracks and reduces effective pore sizes at any exposed surfaces of the vault structure.

The extent of carbonation was estimated using a shrinking core model (Walton et al. 1990). Carbonation was modeled as a uniform coating which forms on the surface of the concrete. The results of the calculations are summarized in Fig. 3.1-3. Carbonation was predicted to penetrate approximately $15 \mathrm{~cm}$ into the concrete over a period of 10,000 years. Thus, it is concluded that carbonation is not likely to be a significant factor in reinforcement corrosion.

\section{Calcium bydroxide leaching}

'Ingress of water into the vaults and flow of water around the vaults will provide a pathway for leaching of soluble components of the concrete. In particular, leaching of calcium hydroxide from the concrete can lead to loss of strength and increases in concrete permeability (Walton et al. 1990). Leaching is typically important in humid sites, such as the SRS, because high infiltration rates promote leaching of soils.

The rate of leaching can be estimated using simple screening models or more complex numerical models. For this application, conservative screening calculations were performed. Two different simplifying assumptions were used in the calculations (Atkinson and Hearne 1984), namely: 1) concrete controlled leaching, and 2) geology controlled leaching. Concrete controlled leaching assumes that the leaching rate is limited by diffusion through the concrete into the surrounding soil. Once the calcium reaches the soil it is rapidly removed leading to a zero concentration boundary condition. If water is flowing around the vault, then a low concentration of calcium can conservatively be assumed in the soil moisture. 


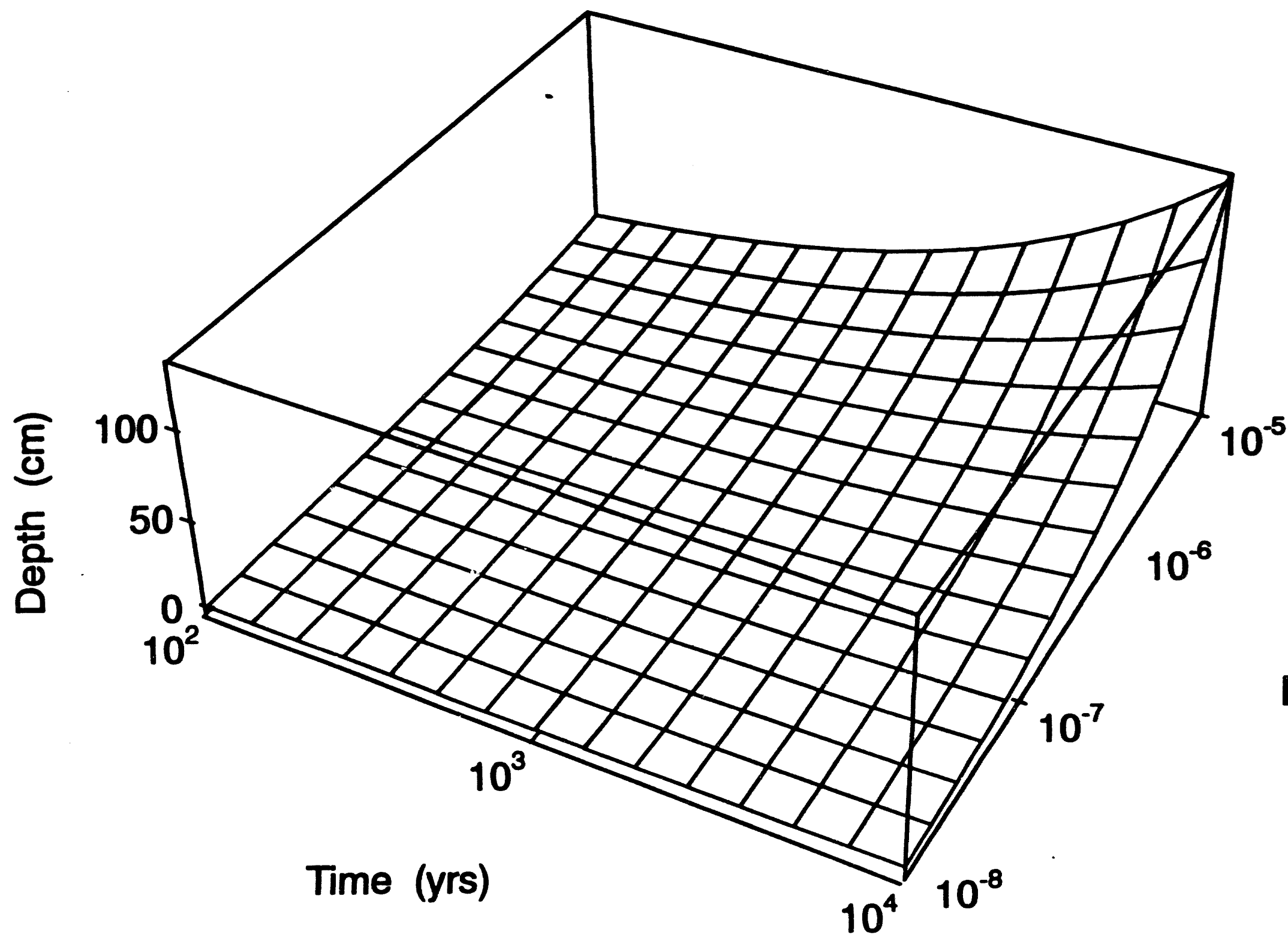

$D_{\theta}\left(\mathrm{cm}^{2} / \mathrm{s}\right)$

Fig. 3.1-3. Carbonation controlled leaching. 
The results for concrete controlled leaching are summarized in Fig. 3.1-4. The results are reported as the depth of concrete which has been depleted of soluble calcium hydroxide (i.e. leach penetration). A major area of uncertainty in the calculations is the selection of an appropriate diffusion coefficient value for the depleted concrete layer. For this reason, the calculations were performed using a broad range of diffusion coefficient values; the upper bound value of $10^{-5} \mathrm{~cm}^{2} / \mathrm{s}$ corresponds to diffusion of ions in water (the worst case). From these calculations, leaching of calcium hydroxide is only likely to affect the integrity of the vaults after time periods in excess of 5,000 years.

For the case of geology controlled leaching, diffusion of calcium into surrounding soils is assumed to limit the process. For this condition, the degradation effects are insignificant. Results for this case are shown in Fig. 3.1-5. This particular type of process, however, is only valid in diffusion dominated systems where water flow is low. Portions of the vault exterior where water flow around the vault is low (e.g., beneath the vault) are expected to leach at the lower geology controlled rate.

\section{Rebar corrosion}

Corrosion of the reinforcing bars (rebar) is another possible mechanism of vault degradation. Corrosion occurs when iron in the rebar reacts with oxygen to form iron oxides. Corrosion of the rebar has two major effects on concrete structures: 1) corrosion lowers the strength of the rebar and 2) corrosion disrupts the integrity of the surrounding concrete.

Rebar is used in concrete structures to increase tensile strength. As the rebar corrodes, the tensile strength of the structure declines. For the monolithic saltstone vaults, the structural role of the vault is essentially finished when the vault is filled. Thus, loss of tensile strength from rebar corrosion is not important to long-term isolation performance.

Iron oxides have a molar volume which is over twice that of steel. As rebar corrosion occurs, the volume occupied by the rebar will expand. The expansion leads to stress development around the reinforcement and eventually to disruption of the integrity of the concrete. This process is easily visible in old concrete structures where fractures and spalling of the concrete occur adjacent to corroded reinforcement.

Reinforcement corrosion is typically modeled in two stages: 1) initiation, and 2) active corrosion (Walton et al 1990). Initially the steel is protected from corrosion by a "passivating layer" of iron oxides on the metal surface. The stability of the passive layer is supported by the high $\mathrm{pH}$ of the concrete. Before significant corrosion can begin, the passive layer must be disrupted. This occurs when the $\mathrm{pH}$ of the concrete is lowered by carbonation or when aggressive anions (such as chloride) penetrate into the concrete to the depth of the steel. 


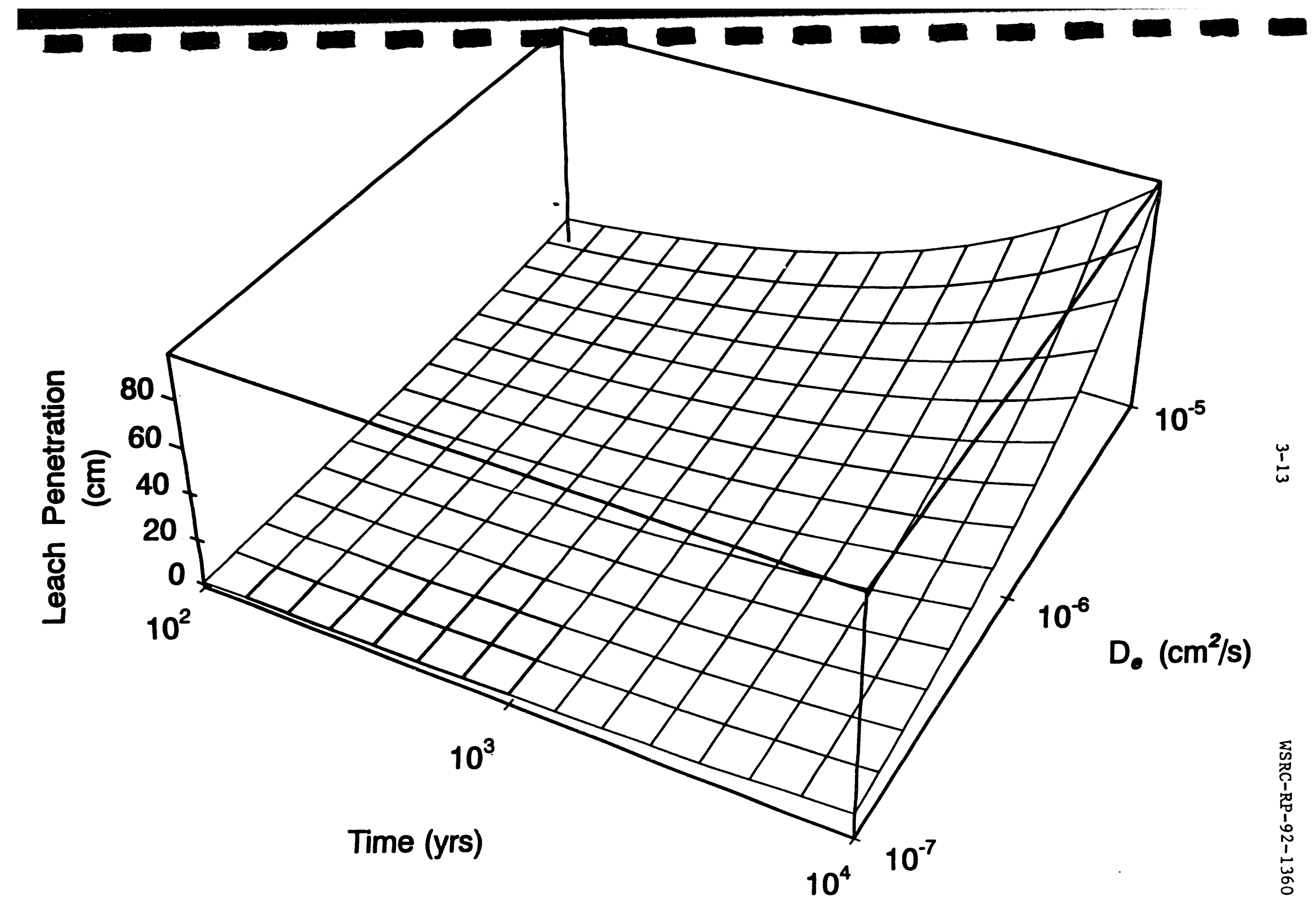

Fig. 3.1-4. Concrete controlled leaching. 


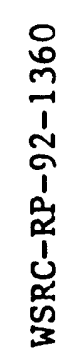

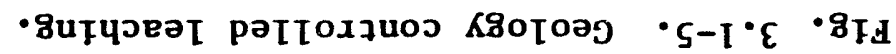

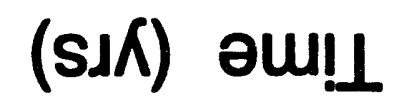

$\begin{array}{llllll}0000 \mathrm{~L} & 0008 & 0009 & 000 t & 0002 & 000 \mathrm{~L}\end{array}$

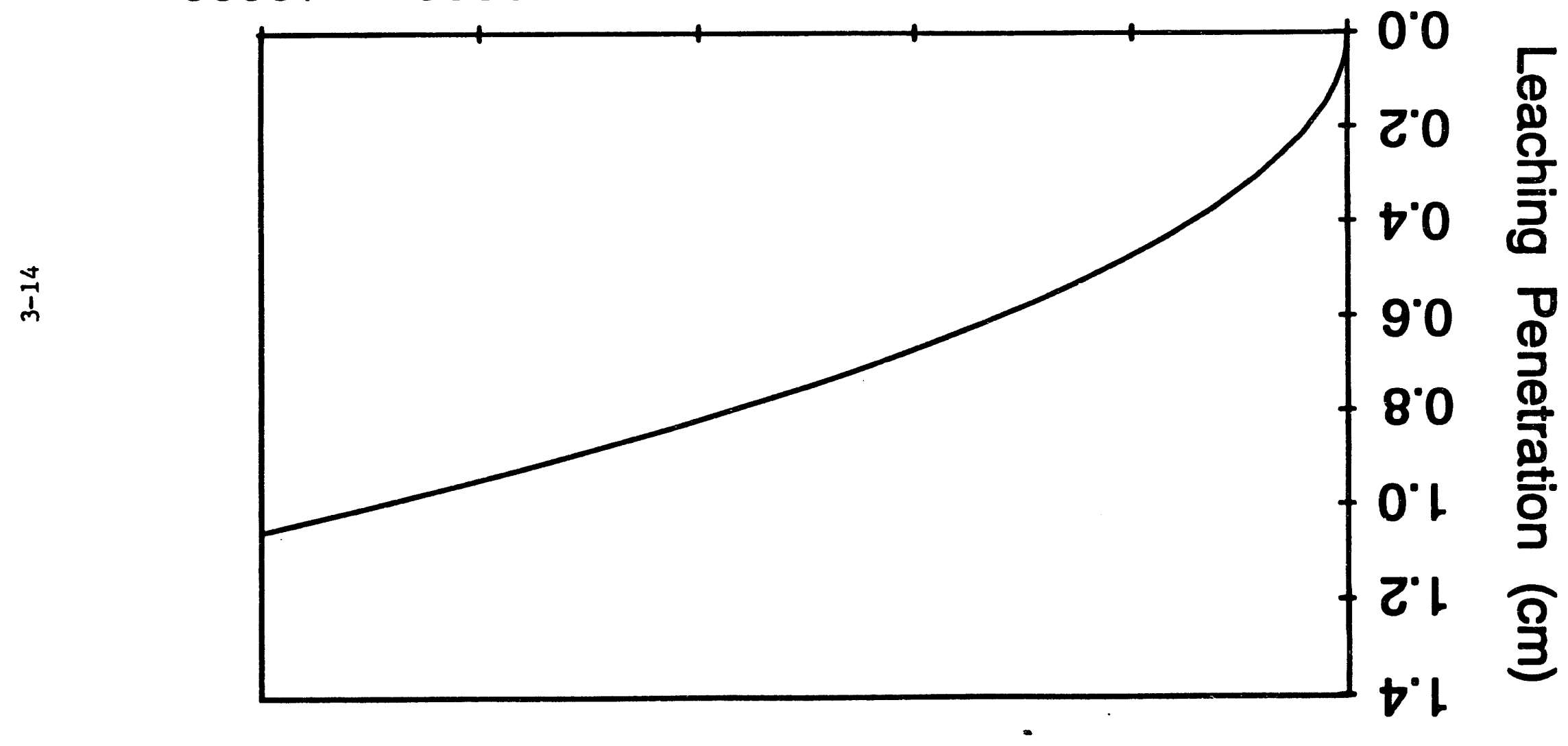


As discussed previously, carbonation of the structure is too slow to be a factor in concrete corrosion of the saltstone vaults. Accordingly, carbonation is even less of a factor in rebar corrosion. Concentrations of chloride ions in the soil moisture at the SRS are also too low to initiate active corrosion. Migration of chloride in the waste out to the rebar would control the time of the initiation stage noted above. To establish if rebar corrosion would significantly affect the rate of vault degradation, active corrosion was assumed to begin immediately after closure and no credit for the initiation lag time was taken in the corrosion calculations.

Once active corrosion begins, the corrosion rate may be limited by availability of oxygen. However, at very low oxygen concentrations, water can be used as a source of oxygen for corrosion (hydrogen evolution reactions). Because the thickness of concrete over the rebar limits the availability of oxygen for rebar corrosion, hydrogen evolution was considered as an additional process for rebar corrosion (Fig. 3.1-6). By combining the oxygen diffusion and hydrogen evolution reactions an estimate of the total rebar corrosion were made (Fig. 3.1-7).

Processes such as leaching are expected to reduce the effective thickness of the concrete cover over the rebar, leading to enhanced corrosion rates. However, rebar corrosion is not likely to degrade the waste isolation performance of the vault for at least $\mathbf{5 0 0}$ years after closure, and degradation by this mechanism will not be significant for at least 2000 years.

\subsubsection{Saltstone Degradation}

The bulk of the saltstone is expected to last for an indefinite period in excess of 10,000 years. It may crack, thus increasing permeability, but it should not otherwise degrade significantly.

\subsubsection{Effects of Degradation}

The relationship between degree of degradation of the saltstone monoliths and vaults, and resulting changes in transport properties is difficult to ascertain. The greatest impact on the rate of water infiltration will be from cracking of the vault and saltstone. The relationship between equally spaced, open, parallel cracks and permeability can be estimated and serves as an upper bound for vault permeability. Actually, some cracks may become filled with porous material and/or self heal. Both of these processes will lower the effective permeability of the vault and saltstone. However, information concerning these processes is limited. If they occur, their effect would improve long-term performance by limiting influx of water through the fractures that form. 


\section{Hydrogen Evolution Corrosion}

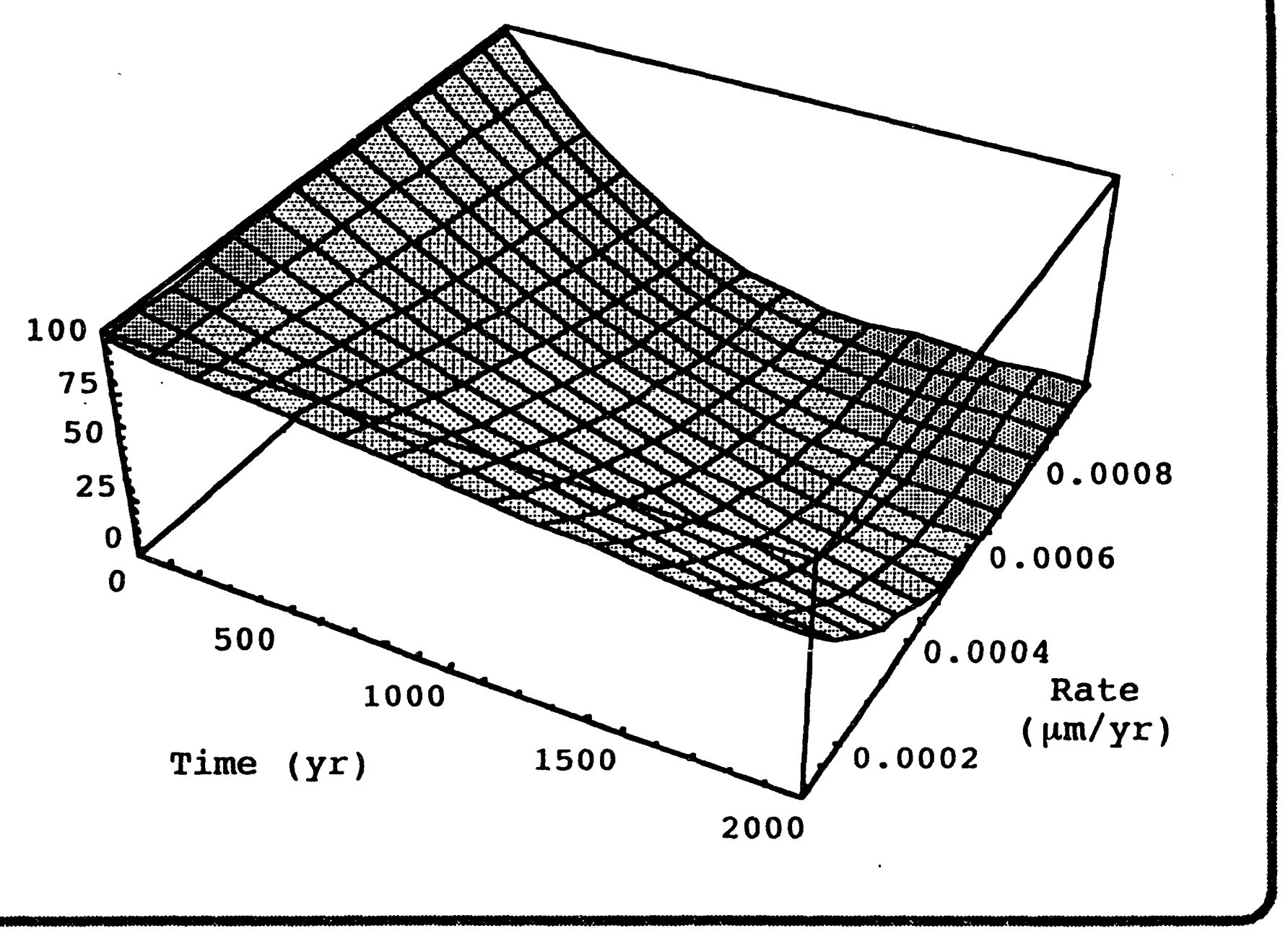

Fig. 3.1-6. llydrogen evolution corrosion. 


\section{Combined Corrosion at 1,000 Years}

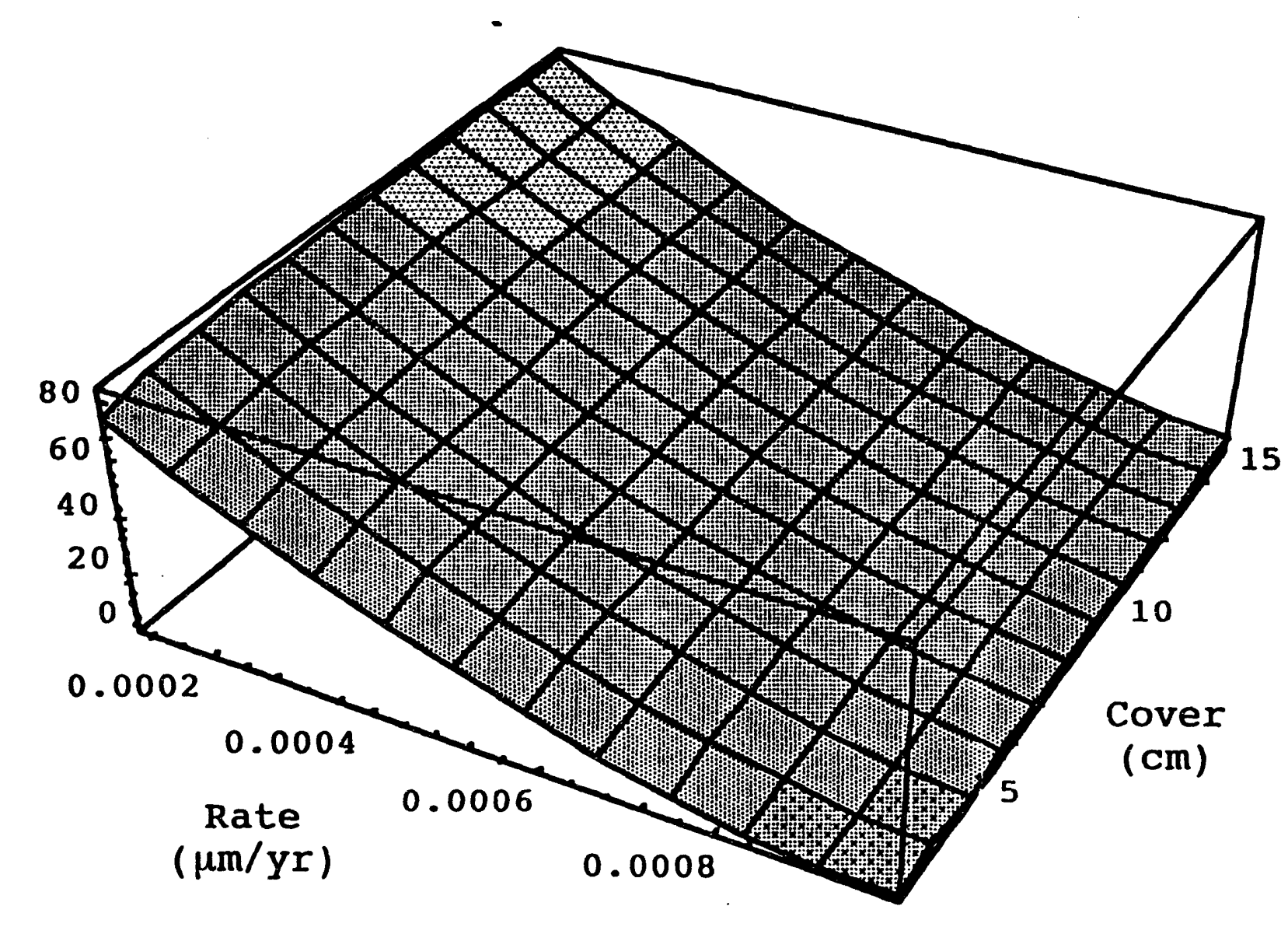

Fig. 3.1-7. Reinforcement corrosion. 
A set of parametric simulations were performed to assess the effective permeability as a function of crack width and fraction for the degraded vault and saltstone

(Sect. 4.21.2). The crack fraction is the total portion of the vault and saltstone which consists of open crack space. At a constant crack fraction there can be many closelyspaced small cracks or fewer widely-spaced large cracks. Maximum flow rates occur at intermediate crack sizes. Note that if the cracks become filled with porous material, the permeability will be much lower than open cracks.

\subsubsection{Summary of Degradation Scenarios}

The discussions above address mechanisms of degradation that may alter the integrity of the cover system, and the permeability of the saltstone monoliths and vaults, but the timing and extent of degradation are not readily predictable due to enormous uncertainties in conditions over thousands of years. In this RPA, cracking of the vaults was chosen to represent the increased permeability of the waste and vaults. Cracking is a complex function of all the processes described above and requires detailed modeling of thermal-mechanical stresses, which is beyond the scope of this analysis. For simplicity, vault cracking was idealized as follows:

- cracks that fully penetrate the vault and saltstone develop at closure,

- the cracks are vertical,

- the crack spacing is $3 \mathrm{~m}$, and

- average crack aperture is $.005 \mathrm{~cm}$.

These assumptions were made based on observations of saltstone vault \#1. However, they are believed to be conservative largely because: 1) the presence of fully-penetrating cracks has not been established, and 2) the new design incorporates measures to minimize cracking.

The importance of the cover system to the performance of the SDF was also investigated. For this RPA, cover degradation was addressed by considering two scenarios: 1) an intact upper moisture barrier cover over the entire time period of computation; and 2) a completely degraded upper moisture barrier cover over this same time period. These two scenarios were assumed for both the intact vault computations, and the degraded vault computations. The degraded cover was assumed to be of the same permeability as the surrounding soil, and thus the entire $40 \mathrm{~cm} / y e a r$ of infiltration was assumed to pass through this zone. The actual case will likely be bounded by these two cases. Initially, (soon after loss of institutional control), the cover will be non-degraded. Erosion is conservatively estimated to remove surface soil at a rate of about $1 \mathrm{~mm}$ per year (Sect. 2.8) for predominately crop land. Thus, after about 800 years, the gravel layer would be exposed, assuming the bamboo is removed and the land is used for growing crops. With the upper gravel layer exposed, the underlying clay could possibly become unsaturated, in which case the hydraulic conductivity would increase due to cracking. Under these conditions, the moisture flux would probably be greater than $2 \mathrm{~cm} / \mathrm{year}$, but less than $40 \mathrm{~cm} / \mathrm{year}$.

Rev. 0 
In summary, four facility degradation scenarios were addressed in this analysis and are listed below.

1) The intact scenario, where all systems (i.e., cover, vaults, and saltstone) were as.jumed nondegraded.

2) The degraded cover scenario, where all systems except the upper moisture barrier were assumed to remain intact.

3) The degraded vault/saltstone scenario, where all systems except the vaults and saltstone were assumed to remain intact.

4) The degraded vault/saltstone and cover scenario, where all systems except the clay and gravel drain in contact with the vaults were assumed to be degraded.

These scenarios were shown schematically in Fig. 3.1-2.

\subsubsection{Non-Radioactive Constituents}

The non-radioactive constituents of the feed have been described in a previous section (Sect. 2.3.1.2). As stated previously, excluding water, the most abundant chemical components in the feed solution are $\mathrm{NaNO}_{3}, \mathrm{NaNO}_{2}$ and $\mathrm{NaOH}$. Lesser amounts of $\mathrm{Na}_{2} \mathrm{CO}_{3}, \mathrm{NaAl}(\mathrm{OH})_{4}, \mathrm{Na}_{2} \mathrm{SO}_{4}$, and trace-level compounds (silver, mercury, chromium) are also expected to be in the solution.

In considering the elements and compounds that comprise the chemical component of the saltstone feed solution, sodium stands out as the most ubiquitous. However, its presence would not adversely affect the quality of the water other than adding to its overall salinity (TDS). Sulfate is another compound of minimal concern because it merely adds to the TDS of the water. The most significant inorganic constituents, in terms of impact on water quality, in the list are nitrate and nitrite. Nitrate levels above $45 \mathrm{mg} / \mathrm{L}$ (or $10 \mathrm{mg} / \mathrm{L}$ as $\mathrm{N}$ ) are unacceptable, according to U.S.EPA DWS (40 CFR 141), which the State of South Carolina presently plans to use to evaluate groundwater protection compliance at disposal sites. A separate standard for nitrite does not exist, and the nitrate and nitrite concentrations (as nitrogen) were assumed to be additive, with respect to evaluation of compliance.

Leaching studies have been conducted that immerse a saltstone block in water to determine the rate at which various contaminants are released. These tests have been used as a means of measuring the ability of the saltstone to bind these contaminants. Leach tests have been conducted by Brookhaven National Laboratory on $107 \mathrm{~L}$ blocks of cured saltstone prepared from decontaminated salt solution from Tank 50H. The ANS 16.1 leach procedure was used on the block to determine the leachability of contaminants. Nitrate, nitrite and sulfate leach rates for these large blocks agreed well with leaching tests on smaller samples. Chromium concentrations were low and only observed in a few of the leachates collected from the reference block. No chromium was found in the leachate from mixes containing slag (Oblath 1986a). 
A range of slag saltstone mixes and waste solution proportions have been tested by the EPA leach test for toxic metals (EP-Toxicity Test). The solutions were doped with $100 \mathrm{ppm} \mathrm{Ag}, \mathrm{As}, \mathrm{Ba}, \mathrm{Cd}, \mathrm{Hg}, \mathrm{Pb}, \mathrm{Se}$, and $2000 \mathrm{ppm} \mathrm{Cr}$. With the exceptions of $\mathrm{Ba}$ and $\mathrm{Cr}$, tested concentrations are at least 1000 times higher than those anticipated in the actual feed solution. All slag mixes passed the EP-Toxicity Test allowing the classification of slag-substituted saltstone as non-hazardous waste (Langton 1989a). The upper limits of concentration allowed according to the EP-Toxicity Test for the feed solution are listed in Table 3.1-1.

Table 3.1-1 Concentration limits for trace-metals in slag saltstone Langton (19896)

\begin{tabular}{|l|c|}
\hline Trace Metal & $\begin{array}{l}\text { Concentration limit (mg/L) for slag } \\
\text { saltstone based on EP-Toxicity Tests }\end{array}$ \\
\hline $\mathrm{Cr}$ & 2000 \\
\hline $\mathrm{As}, \mathrm{Ag}, \mathrm{Ba}, \mathrm{Pb}$ & 1000 \\
\hline $\mathrm{Cd}, \mathrm{Se}, \mathrm{Hg}$ & 500 \\
\hline
\end{tabular}

From these studies, hazardous metals in saltstone will not be a limiting factor in the performance of the facility if the solution concentrations are maintained at or below specified limits. Nitrate will be a key factor in facility performance, and is addressed in the remainder of this RPA in relation to groundwater protection compliance.

Benzene and phenol are generated through the radiolysis of tetraphenylborate (TPB) in the In-Tank Precipitation Process used to decontaminate the HLW soluble waste presently stored at the SRS. As a part of the ITP process, residual benzene is stripped from the solution to less than $3 \mathrm{ppm}$ prior to transfer to the Z-Area feed tank (Tank $50 \mathrm{H}$ ). Because of the high $\mathrm{pH}$ of the salt solution, phenol is rendered nonvolatile through its conversion to a sodium salt and will be retained in the solution as an ionic salt.

To establish if residual TPB in the wastewater sent to Z-Area would pose an environmental hazard through decomposition during subsequent treatment and curing of the saltstone, a series of isothermal tests to establish the rate of benzene evolution from saltstone were conducted. Results showed that TPB decomposition and benzene release is dependent on the temperature of the saltstone mass and the surface area of the saltstone. Based on a test to match the temperature profile of a large saltstone mass that was placed in a lysimeter, the total release of benzene from the saltstone will be less than $0.5 \%$ of the theoretical maximum of benzene that could be released if all the TPB were to decompose to benzene and sodium borate. Release rates on the order of 2 to $5 \mathrm{mg}$ benzene per day were observed from $1-\mathrm{kg}$ samples and a $2-\mathrm{kg}$ samples over a 
14-day test period at $80^{\circ} \mathrm{C}$. Similar tests at $25^{\circ} \mathrm{C}$ released less than $0.005 \%$ of the theoretical maximum benzene, indicating that TPB decomposition is negligible at lower temperatures after curing is complete. (Oblath 1986b; Bruns 1985, 1986) The decomposition of TPB as a possible source of benzene contamination in groundwater is therefore too low to be of concern.

\subsection{PATHWAYS AND SCENARIOS}

In this section of the RPA, the time periods of concern, and patbways to human exposure to saltstone constituents potentially released in the manner described in Sect. 3.1 above, are addressed. The information provided in this section is subsequently used in the development of models to evaluate doses potentially received as a result of releases of radionuclides from the SDF.

\section{Time Periods of Concern}

For the purpose of assessing the performance of the Z-Area Saltstone Facility, three time periods of concern are addressed. The time periods include the operational period, the institutional control period, and the post-institutional control period.

\subsection{Operational Period}

The operational period is defined as the period during which waste is actively treated for disposal by producing saltstone. The facility is fenced and patrolled, preventing unauthorized access, during this period. Because careful monitoring of the operating facility is done during this time period, there will be opportunity to correct any failures sush as leaking slurry lines or cracks in the vaults.

The operational period for the Z-Area Saltstone Facility is expected to be at least 30 years. Doses to maximally exposed off-site individuals during this time period are addressed in the SAR for the Z-Area Saltstone Facility (WSRC 1992a). These doses considered inhalation exposure. Contamination of other media (i.e., soil and water) is considered to be mitigated before off-site exposures can take place. A summary of these calculated doses is provided here.

A conservative worst case unmitigated accident scenario was analyzed which bounded the consequences of any credible event that could occur in Z-Area due to the presence of the hazardous salt solutions containing radioactive contaminants (hazardous because it was not yet considered to be in the non-hazardous saltstone form). This bounding accident scenario assumes: 1) the Salt Solution Hold Tank (SSHT) in Z-Area is filled to capacity $(45,000$ gal $) ; 2)$ concentrations of radionuclides and toxic chemicals exceed all actual process concentrations expected and are much higher than the nominal concentrations expected to be processed during the operation period; 3) concentrations of radionuclides expected to be highly variable in the wastewater (Sr-90, Tc-99, I-129, short-lived gamma emitters, total alpha) are simultaneously adjusted to their maximum

Rev. 0 
expected values to encompass all credible compositions from the Tank Farms; 4) the entire volume of salt solution in the SSHT is released from both primary and secondary containment and evaporates completely in $2 \mathrm{~h} ; 5)$ no credit is taken for operator intervention to minimize or contain the spill; 6) no credit is taken for secondary containment provided by the concrete dike surrounding the SSHT; and 7) no credit is taken for infiltration of any salt solution into the ground outside the dike (WSRC 1992a).

EDE calculated from this bounding accident scenario are: 1) a maximum individual EDE at $100 \mathrm{~m}$ from the edge of the Z-Area facility of 1.97 rem; and 2) a maximum indivi-dual EDE at the SRS site boundary of $3.9 \times 10^{-3} \mathrm{rem}$. Radiological hazards during normal operations are based on projected maximum stack releases from the Saltstone Production and Disposal Facilities in Z-Area. The estimated doses during the projected operational period of 30 years resulting from these releases are: 1) a maximum individual EDE at $100 \mathrm{~m}$ from the edge of the facility of $1.4 \times 10^{-5} \mathrm{rem}$; and 2) a maximum individual EDE at the SRS site boundary of $3.6 \times 10^{-9} \mathrm{rem}$ (WSRC 1992a). Z-Area operations and the SDF are considered to be low hazard, as defined by DOE Order 5480.1A.

\section{Institutional Control Period}

The institutional control period is the 100-year time interval specified in the DOE Order 5820.2A (U.S.DOE 1988a) following closure of a disposal site. Periodic maintenance and monitoring of groundwater and surface waters are conducted during this period. The disposal site is assumed to be stabilized and no longer operational during this period, but will remain part of the SRS and therefore, fenced and patrolled to eliminate the possibility of inadvertent intruders. Realistically, this period is expected to continue for at least 100 years after closure of the SDF, and possibly longer.

\section{Post-Institutional Control Period}

The final time period of concern is when the facility is no longer maintained by the SRS, and could be accessed by the public. The total duration of this period for the purpose of performance assessment depends on the time of predicted maximum impact with respect to potentially exposed individuals. Projretions of conditions and activities during this period are uncertain and difficult to assess. However, because of the presence of long-lived radionuclides in the saltstone, the maximum off-site impact will occur many thousands of years after closure. The DOE Order 5820.2A, as currently written, does not provide a time limit for evaluating the performance objectives (Sect. 1.4). Therefore, it is interpreted in this RPA that this final time period extends at least until estimated doses are predicted to reach a peak. 


\section{Transport Pathways}

The purpose of this section is to identify potential pathways of transport of radionuclides potentially released from the SDF to human receptor locations (Sect. 3.2.2.1), and to justify eliminating some of these pathways from further consideration (Sect. 3.222). The results of this section are used to develop exposure scenarios for offsite members of the public, which are discuseed in Sect. 3.23.

\section{Pathway Identification}

Radionuclides released from the SDF to the geosphere have the potential of reaching locations where human exposure may sccur through numerous pathways. Most conceivable pathways for a buried LLW source are indicated in Fig. 3.2-1. The pathways identified in this figure are for facilities undisturbed from the standpoint of human intrusion. Pathways pertinent to intruder exposures are addressed separately in Sect. 3.2.4. In the list below, each pathway is briefly defined.

(1) Leaching - migration of radionuclides from the wasteform by a combination of dissolution, diffusion, and advection.

(2) Gascous Diffusion - upward migration of gaseous radionuclides from the wasteform by diffusion through the caps and cover soils to the atmosphere.

(3) Irrigation - contamination of cover soil by radionuclides which have reached groundwater which is subsequently used for irrigation.

(4) Deposition - contamination of surface water by radionuclides which have - reached the atmosphere; represents deposition of particulate associated radionuclides or gaseous species partitioning at the air-water interface.

(5) Volatilization - partitioning of volatile radionuclides species present in surface water into air above the water body.

(6) Discharge - discharge of radionuclides present in groundwater into surface water.

(7) Recharge - movement of radionuclides into the groundwater from contaminated surface water.

(8) Irrigation - contamination of cover soil by radionuclides which have reached surface water which is being subsequently used for irrigation.

(9) Washload - contamination of surface water by soil containing radionuclides as a result of erosion by rain or irrigation water. 


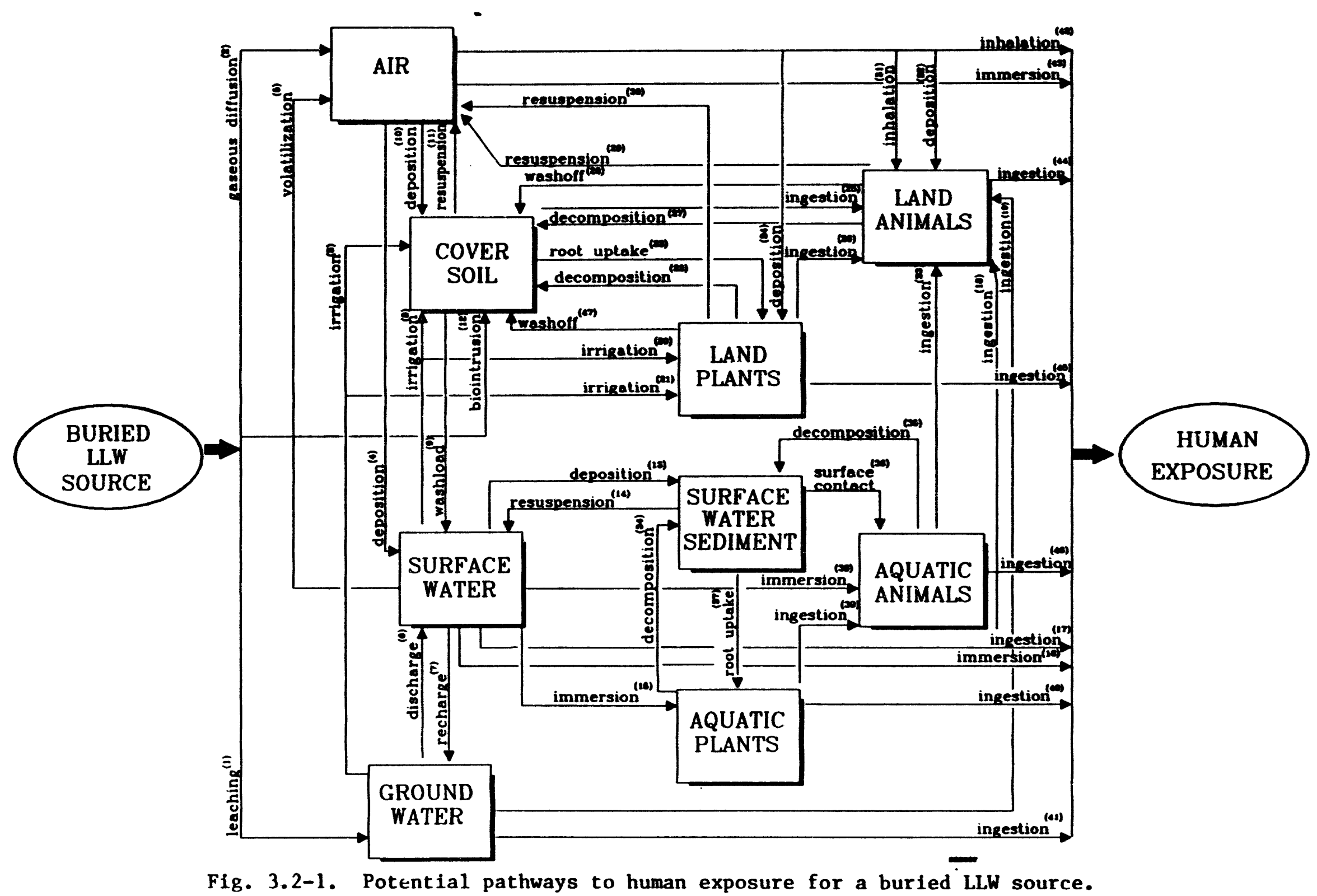

Fig. 3.2-1. Potential pathways to human exposure for a buried LLW source. 
(10) Deposition - contamination of cover soil by radionuclides which have reached the atmosphere and have become associated with airborne particulate matter.

(11) Resuspension - Resuspension of soil-associated radionuclides as a result of wind erosion.

(12) Biointrusion - contamination of cover soil by soil-associated radionuclides that are brought to the surface from the vicinity of the wasteform by burrowing animals, such as rodents or ants, or by intruding plant roots.

(13) Deposition - deposition of radionuclides in surface water that have partitioned onto suspended sediment.

(14) Resuspension - resuspension of particulate-borne radionuclides in the sediment of surface water as a result of hydrodynamic forces at the sediment-water interface.

(15) Immersion - contamination of aquatic plants by radionuclides in surface water attributable to the immersion of the plants in the contaminated water.

(16) Immersion - human exposure to radionuclides as a result of immersion in contaminated surface water.

(17) Ingestion - human exposure to radionuclides as a result of ingestion and inhalation of radionuclides present in surface water.

(18) Ingestion - contamination of terrestrial animals from their ingestion of radionuclides in surface water.

(19) Ingestion - contamination of terrestrial animals from their ingestion of radionuclides in groundwater.

(20) Irrigation - contamination of terrestrial plants as a result of irrigation with surface water containing radionuclides.

(21) Irrigation - contamination of terrestrial plants as a result of irrigation with groundwater.

(22) Decomposition - contamination of cover soil as a result of decomposition of terrestrial plants in the soil.

(23) Root uptake - contamination of terrestrial plants by uptake through roots of soil water containing radionuclides. 
(24) Deposition - deposition of airborne radionuclides onto terrestrial plant surfaces.

(25) Ingestion - ingestion of radionuclides by grazing animals as a result of contaminated soil ingestion.

(26) Ingestion - ingestion of radionuclide-containing vegetation by terrestrial animals.

(27) Decomposition - contamination of cover soil as a result of decomposition of terrestrial animals in the soil.

(28) Washoff - contamination of surface soil as a result of washoff of externally contaminated terrestrial animals.

(29) Resuspension - resuspension of surficial radionuclides on terrestrial animals to the atmosphere.

(30) Resuspension - resuspension of surficial radionuclides on terrestrial plants to the atmosphere.

(31) Inhalation - contamination of terrestrial animals as a result of inhalation of radionuclides in the atmosphere.

(32) Deposition - surface contamination of terrestrial animals via deposition of particulate-borne radionuclides in the atmosphere.

(33) Ingestion - contamination of terrestrial animals as a result of their ingestion of aquatic animals.

(34) Decomposition - contamination of surface water sediment as a result of decomposition of aquatic plants in the sediment.

(35) Decomposition - contamination of surface water sediment as a result of decomposition of aquatic animals in the sediment.

(36) Surface contact - surface contamination of aquatic animals as a result of contact with contaminated sediment.

(37) Root uptake - contamination of aquatic flora via radionuclide uptake through roots.

(38) Immersion - contamination of aquatic animals as a result of immersion in surface water containing radionuclides. 
(39) Ingestion - contamination of aquatic animals as a result of their ingestion of aquatic plants containing radionuclides.

(40) Ingestion - human exposure to radionuclides as a result of ingestion of contaminated aquatic flora.

(41) Ingestion - human exposure to radionuclides as a result of ingestion of contaminated groundwater.

(42) Inhalation - human exposure to radionuclides as a result of inhalation of airborne radionuclides.

(43) Immersion - human exposure to radionuclides as a result of immersion in contaminated air.

(44) Ingestion - human exposure to radionuclides as a result of ingestion of contaminated terrestrial animals.

(45) Ingestion - human exposure to radionuclides as a result of ingestion of contaminated terrestrial plants.

(46) Ingestion - human exposure to radionuclides as a result of ingestion of contaminated aquatic animals containing radionuclides.

(47) Washoff - contamination of surface soil below vegetation due to rain-induced surface washoff.

\section{Pathway Screening}

The list in Sect. 3.2.2.1 above is generic in nature, and the significance of each pathway must be evaluated on a site-specific basis to ultimately develop an exposure model. Many pathways may be removed from consideration for particular sites because of a negligible contribution to human exposure.

For the SDF, leaching of saltstone and transport to the saturated zone (pathway (1)) is the predominant means that radionuclides may be subsequently transported in the environment. Thus, this pathway must be addressed in developing an exposure model, and is addressed in this RPA in the near-field model (Sect. 3.3.1). Other pathways which may contribute to human exposure are those tied to groundwater concentrations of contaminants. Irrigation with contaminated groundwater may lead to contamination of agricultural crops and animals (pathways (3), (21), (23), (25) and (26)). Discharge of contaminated groundwater to surface water (pathway (6)) may result in contamination of the aquatic ecosystem including the water body itself, sediment, and aquatic plants and animals (pathways (13), (14), (15), (34), (35), (36), (37), (38), and (39)). Ingestion of contaminated surface water, aquatic animals or groundwater by terrestrial animals 
(pathways (18), (33), and (19)) may lead to human exposure, and can be tied to groundwater contamination. Human exposure may occur as a result of direct human ingestion of contaminated surface water or groundwater (pathways (17) and (41)), as a result of consumption of contaminated food supplies (pathways (44), (45), and (46)), and as a result of immersion in contaminated surface water during recreational activities such as swimming (pathway (16)). Consumption of contaminated aquatic plants (pathway (40)) was not considered in the SDF RPA because there is no indication that aquatic plants present in potentially-contaminated surface water in the vicinity of the SRS are consumed by humans.

Of the 47 pathways listed above, only 26 are accounted for in the above discussion. This leaves 21 pathways that are not considered significant for developing exposure scenarios discussed in the next section. The justification for neglecting these pathways is given below. Pathways that may result in human exposure directly or indirectly as a result of atmospheric dispersion and deposition (pathways (2), (4), (5), (10), (11), (24), (28), (29), (30), (31), (32), (42), (43), and (47)) are not included in exposure scenarios for the following reason. The only potentially volatile radioactive components of the saltstone monolith are $\mathbf{R n - 2 2 2 , ~} \mathrm{H}-3$, and C-14. Atmospheric release of these compounds at the time of the saltstone grout production, which occurs during the operational period, is addressed in the SDF SAR (WSRC 1992a), the results of which are summarized in Sect 3.2.1.1 above. Calculations providing an upper bound on doses received from volatilization of these radionuclides from the SDF after disposal (pathway (2)) are described in Sect. A.3. Results of these very conservative calculations indicate the following. For Rn-222, the concentrations of U-238 and U-234 in saltstone are significantly less than natural levels in soil. A conservative analysis indicates a flux rate from the bare saltstone, which is approximately 25 times below the flux limit of $20 \mathrm{pCi} \mathrm{m}^{-2} \mathrm{~s}^{-1}$ specified in 40 CFR 61 for radium-containing waste at DOE facilities. For H-3 and C-14, an upper limit on potential annual inhalation doses to an inadvertent intruder of $10^{-2} \mathrm{rem}$ is estimated, which is an order of magnitude below the annual dose limit for intruders. This upper bound does not exceed the limit for off-site individual doses, which can be expected to be much lower than intruder doses due to dilution in the atmosphere. Therefore, volatile components are not considered further in this RPA Pathways leading to exposure to resuspended contaminated soil (pathways (11), (42), and (43)) are addressed in the intruder exposure analysis (Sect. A.4). Other atmospheric pathways are indirect in nature; e.g., the contaminants must first be suspended or volatilized from one medium, then redeposited in another. These indirect pathways are not believed to be more significant than the direct pathways $(2,11,42$, and 43$)$, and thus are not addressed in this RPA.

Pathway (7) considers contamination of groundwater due to recharge by surface water. This pathway is not considered significant in the SDF RPA because some dilution of radionuclides in surface water can be expected for all streams, and thus concentrations in groundwater as a result of this patbway will always be lower than the concentrations which led to contamination of the surface water. Pathways (8) and (20), representing contamination of cover soil and terrestrial plants as a result of irrigation with 
contaminated surface water, respectively, are not considered important because of the relatively dilute concentration of radionuclides expected in surface water with respect to groundwater. Irrigation by groundwater is expected be a more important pathway for radionuclides potentially reaching crops. Contamination of surface water from erosion of contaminated soil (pathway (9)) was not considered significant, because buildup of radionuclides in surface soil would only result from radionuclides with high sorption potential. These radionuclides would not partition readily into the surface water if introduced as a result of erosive events. Pathways (22) and (27), representing the pathways of radionuclides to surface soil via decomposition of terrestrial plants and animals, were not considered significant relative to the exposure resulting from direct consumption of these potentially contaminated products.

Finally, contamination of cover soil over the SDF as a result of biointrusion of burrowing animals or plant roots (pathway (12)) must be addressed. Biointrusion is a potentially significant pathway of contamination of cover soil over a LLW facility, as is concluded in a study by McKenzie et al. (1983). For the humid southeast, where ground cover and soil moisture limit resuspension of soil, biointrusion is likely to result in contamination of soils over the facility, but probably not significant contamination offsite. Therefore, the relative significance of biointrusion to the inadvertent intruder is the issue of concern in addressing this pathway for this RPA.

Most of the burrowing animals identified as likely residents at the SRS (Sect. 2.1.10) do not burrow below $0.5 \mathrm{~m}$ (McKenzie et al. 1986). Only one burrower, the Florida Harvester Ant, is expected to burrow below $2 \mathrm{~m}$, and then, only $5 \%$ of its burrows are expected to be that deep, resulting in very little potentially contaminated soil being moved. As the cover soil erodes, however, the significance of burrowers' activities may increase. Furthermore, if Z-Area reverts to a hardwood/pine forest sometime after loss of institutional control, it is possible that deeper roots may contact contaminated soil above, or adjacent to, the vaults and translocate radionuclides to other plant organs. Radionuclides may subsequently be released back to the soil as roots and leaves wither and degrade. It is, therefore, likely that biointrusion may cause some mixing of the components of saltstone within the soil column. Intrusion into the saltstone wasteform is believed to be unlikely, because of the extremely high pH/high salt environment in addition to the mechanical barriers provided by the vault and wasteform.

The significance of biointrusion is evaluated here by considering the effect of the mixed soil column on an inadvertent intruder. An inadvertent intruder, who is assumed to dig next to or above the vaults, mixes the contaminated soil near the vaults with soil near the surface (Sect. 3.2.4). While it is not known how effective biointruders might be in causing mixing in the soil, the McKenzie et al. (1983) study of a reference humid site estimated that soil concentrations resulting from biointrusion are significantly lower than those resulting from intruder excavation activities, except for more biologically available compounds, where concentrations are of the same order of magnitude. The effect of burrowing animals or intrusive roots, then, is not expected to enhance the

Rev. 0 
inadvertent intruder's contact with contaminated soil by more than a factor of two for any radionuclide. Doses that are calculated in this RPA are uncertain to the extent that a factor of two is inconsequential, and thus, the biointrusion pathway was neglected.

In summary, the following pathways, of the original 47 identified in Fig. 3.2-1, are considered to be of possible consequence to exposures of off-site members of the public, and are considered further in this RPA. Pathways related to contaminated groundwater are believed to be of potential consequence, including: 1) leaching of the wasteform resulting in contamination of groundwater local to the SDF; 2) contamination of agricultural crops and animals as a result of irrigation with contaminated groundwater; 3) contamination of surface water and aquatic animals as a result of discharge of contaminated groundwater to local streams; and 4) immersion in contaminated surface water resulting from discharge of contaminated groundwater to streams. In the following section, the relative importance of these pathways is further addressed.

\subsection{Exposures of Off-Site Members of the Public and Protection of Groundwater}

As described in Sect. 1.4, disposal of low-level radioactive waste in the Z-Area SDF must meet certain performance objectives for protection of off-site members of the public and sources of groundwater. In this section, the different exposure scenarios and pathways for off-site members of the public which have been considered in the performance assessment for the SDF are described. Requirements for groundwater protection assumed in this analysis also are described, and an analysis is presented which demonstrates the relative importance of the requirements for protection of off-site members of the public and sources of groundwater in determining the acceptability of waste disposal at the SDF. The overwhelming importance of groundwater protection requirements is established, and a simple screening analysis of radionuclides in the SDF inventory with respect to the groundwater pathway is provided.

\subsection{Off-Site Members of the Public}

This section discusses the requirements for protection of off-site members of the public and the exposure pathways assumed in the dose analysis for such individuals.

The performance objectives for LLW disposal specify that the EDE to off-site members of the public from all exposure pathways and at any time after disposal should not exceed 25 mrem per year (U.S.DOE 1988a). The nearest location from the disposal site for off-site members of the public depends on the time period after disposal. During the period of active institutional control for the first 100 years after facility closure, offsite members of the public are assumed to be located no closer to the disposal site than the present boundary of the SRS. However, after active institutional control ceases, offsite members of the public could be located as close as $100 \mathrm{~m}$ from any of the vaults at the SDF. 
As discussed in Sect. 3.1. and 3.2.2, the primary mechanism for mobilization and release of radionuclides from the SDF is expected to be infiltration of precipitation, and the primary pathway for subsequent exposures of off-site members of the public is expected to be transport of radionuclides in groundwater and surface water. Because of such factors as (1) the design of the disposal facility and the closure concept that is intended to inhibit infiltration of precipitation, (2) the considerable distance from the disposal site to the boundary of the SRS, and (3) the expected discharge of contaminated groundwater to surface streams near the disposal site and the considerable dilution in radionuclide concentrations provided by such discharge, it is reasonable to conclude that the dose analysis for off-site members of the public can focus on exposure pathways resulting from use of contaminated groundwater at distances from the disposal vaults as close as $100 \mathrm{~m}$ for the time period after active institutional control ceases.

Thus, in the dose analysis for the groundwater pathway, an off-site member of the public is assumed to use water from a well for domestic purposes, and the well is assumed to be located at least $100 \mathrm{~m}$ from the disposal vaults where the maximum concentrations of radionuclides in groundwater are predicted to occur after institutional control ceases. The following exposure pathways involving use of contaminated well water are assumed to occur:

- direct ingestion of contaminated water;

- ingestion of milk and meat from dairy and beef cattle that drink contaminated water;

- ingestion of vegetables grown in garden soil irrigated with contaminated water;

- direct ingestion of contaminated soil in conjunction with intakes of vegetables from the garden;

- external exposure to contaminated soil while working in the garden; and

- inhalation of radionuclides suspended into air from contaminated soil while working in the garden.

Rainfall normally is abundant at the SRS (see Sect. 2.1.3). Therefore, irrigation of a vegetable garden is assumed to occur only occasionally during the summer and only in small amounts relative to the annual rainfall (Murphy 1990). Irrigation of pasture grass ingested by dairy and beef cattle is neglected because agricultural land is not extensively irrigated near the SRS (U.S. Department of Commerce 1977; Baes and Sharp 1983).

Additional exposure pathways for off-site members of the public could involve release of radionuclides into the air and airborne transport to off-site locations. Radionuclides could be attached to particulates suspended into air from the ground surface, and volatile radionuclides (e.g., H-3, C-14, and isotopes of radon) could be released from the waste or contaminated soil. Exposures of off-site members of the public resulting from the air pathway are considered in this analysis.

Rev. 0 


\section{Protection of Groundwater}

This section discusses the requirements for protection of groundwater that are applied to the performance assessment for the SDF.

The performance objectives for LLW disposal specify that contamination of groundwater is to be limited in accordance with federal, state, and local standards. The State of South Carolina requires that concentrations of chemicals in groundwater be limited in accordance with federal DWS at any time after disposal. Presently, no federal, state, or local standards exist that limit radionuclides released to groundwater from the SDF. However, the SRS has established the objective of protecting groundwater for Site operations. The standard adopted for groundwater protection is that concentrations of radionuclides in groundwater arising from waste disposal must not result in an EDE exceeding 4 mrem per year, assuming $2 \mathrm{~L}$ of water per day are consumed. This standard is applied to protect groundwater as a resource, irrespective of the potential for use. In this performance assessment, the standard is applied at the predicted location of the maximum concentrations of radionuclides in groundwater at least $100 \mathrm{~m}$ from any disposal vault and at any time after disposal. The rationale for the assumed performance objective for protection of groundwater is discussed in detail in Sect. 1.4.

\section{Comparison of Performance Objectives for Protection of Off-Site Members of the Public and Groundwater}

As described in Sect. 3.2.3.1 and 3.2.3.2, concentrations of radionuclides in groundwater at distances more than $100 \mathrm{~m}$ from the location of disposal vaults are limited by two performance objectives: 1) a maximum EDE of 25 mrem per year from all exposure pathways involving use of contaminated water and 2) a maximum EDE of 4 mrem per year from consumption of drinking water only. This result assumes that use of contaminated groundwater is the only significant exposure mode for off-site members of the public. The question then arises as to which of these dose limits would be the more restrictive, i.e., which dose limit would result in lower limits on acceptable concentrations of radionuclides in groundwater and, thus, in waste in the SDF.

In order to address the relative importance of the two dose limits that apply to use of contaminated groundwater given above, the doses from the pathways involving ingestion of milk and meat from dairy and beef cattle that drink contaminated water, ingestion of vegetables grown in garden soil irrigated with contaminated water, direct ingestion of contaminated soil from the vegetable garden in conjunction with vegetable intakes, external exposure to contaminated soil while working in the garden, and inhalation of radionuclides suspended into air while working in the garden (see

Sect. 3.2.3.1) must be investigated in relation to the dose from direct ingestion of contaminated water. The relative importance of the pathway involving ingestion of contaminated vegetables is considered first. 
For direct consumption of radionuclides in drinking water, the dose to an exposed individual is given by

$$
\mathrm{H}_{w} \quad=\mathrm{C}_{\boldsymbol{w}} \mathrm{U}_{\boldsymbol{w}} \mathrm{DCF}_{\mathrm{ins}}
$$

where

$H_{w} \quad=$ EDE from drinking water (rem/year),

C. = radionuclide concentration in groundwater $(\mu \mathrm{Ci} / \mathrm{L})$,

$U_{\text {. }} \quad$ = consumption of drinking water (Lyear), and

$D F_{\text {ing }}=E D E$ per unit activity of radionuclide ingested, i.e., the ingestion dose conversion factor (rem/ $/ \mathrm{Ci})$.

In determining compliance with the groundwater protection requirement, a consumption rate of drinking water of $730 \mathrm{~L}$ /year (i.e., $2 \mathrm{~L} /$ day) is assumed. Therefore, the dose from direct consumption of contaminated groundwater is given by

$$
\mathrm{H}_{w}(\text { rem/year })=(730 \mathrm{~L} / \mathrm{y}) \mathrm{C}_{w}(\mu \mathrm{Ci} / \mathrm{L}) \mathrm{DCF}_{\mathrm{ing}}(\mathrm{rem} / \mu \mathrm{Ci}) \text {. }
$$

In order to estimate the dose per unit concentration of radionuclides in groundwater resulting from consumption of vegetables irrigated with contaminated water, a simple model developed by Baes and Sharp (1983) for estimating radionuclide concentrations in surface soil is used. In this model, the top layer of soil is treated as a well-mixed compartment, and radionuclides deposited in surface soil by irrigation are assumed to be removed from the soil compartment by a first-order leaching process resulting from infiltration of water, as well as by radioactive decay. The removal rate constant from leaching is given by

$$
\lambda_{1}=\left(\mathrm{V}_{w} / \theta\right) /\left[\mathrm{d}\left(1+\rho \mathrm{K}_{d} / \theta\right)\right],
$$

where

$\lambda_{1}=$ fraction of activity in soil compartment removed by leaching per year,

$V_{w}=$ infiltration rate of water in soil (m/year),

$\theta=$ volumetric water content of soil (dimensionless),

d = depth of soil compartment (m),

$\rho=$ bulk density of soil, and

$\mathbf{K}_{\mathbf{d}}=$ equilibrium solid/solution distribution coefficient for radionuclide.

The density of soil and the distribution coefficient must be expressed in compatible units; e.g., if $\mathrm{K}_{\mathrm{d}}$ is given in units of $\mathrm{mL} / \mathrm{g}$ (or $\mathrm{L} / \mathrm{kg}$ ), then $\rho$ must be expressed in $\mathrm{g} / \mathrm{cm}^{3}$. Since radioactive decay also removes activity from soil, the total removal rate constant for a radionuclide in the surface soil compartment is given by

$$
\lambda=\lambda_{1}+\lambda_{n}
$$


where $\lambda_{r}$ is the radiological decay constant $\left(y^{-1}\right)$.

In the linear-compartment model described above, the equilibrium activity of a radionuclide in the surface soil compartment is simply the ratio of the input rate of activity to the total removal rate constant. The input rate of activity by irrigation assumed in this analysis is estimated as follows. At the SRS, growing vegetables normally requires irrigation only occasionally during the summer months. On the basis of experience with crop management at the ste (Murphy 1990), an amount of irrigation equal to $0.2 \mathrm{~m}$ /year is assumed to be applied to a vegetable garden. This amount corresponds to application of $2.5 \mathrm{~cm}$ once a week during the two hottest summer months. The assumed amount of irrigation probably is more than would occur in most years, since one reported experiment required watering only on one or two occasions each summer (Murphy 1990). Over a unit area of $1 \mathrm{~m}^{2}$, the assumed irrigation rate corresponds to $0.2 \mathrm{~m}^{3}$, or 200 L/year. The assumed unit area is arbitrary and is used only to obtain radionuclide concentrations in soil in the desired units of $\mu \mathrm{Ci} / \mathrm{m}^{3}$. Therefore, the average concentration of radionuclides input to surface soil per year from use of contaminated irrigation water, which is denoted by $I_{2}$ is given by

$$
\text { I. }\left(\mu \mathrm{Ci} / \mathrm{m}^{3} \text { per year }\right)=\left[\left(200 \mathrm{~L} / \mathrm{y} \text { per } \mathrm{m}^{2}\right) / \mathrm{d}(\mathrm{m})\right] \mathrm{C}_{w}(\mu \mathrm{Ci} / \mathrm{L}) \text {, }
$$

where

$$
\begin{aligned}
& d=\text { depth of soil layer, and } \\
& C_{w}=\text { concentration of radionuclide in groundwater. }
\end{aligned}
$$

From the equations derived above, the equilibrium concentration of radionuclides in soil from use of contaminated groundwater for irrigation then is given by

$$
\mathrm{C}_{\mathrm{s}}\left(\mu \mathrm{Ci} / \mathrm{m}^{3}\right)=\mathrm{I}_{\mathrm{i}} / \lambda=\left[\left(200 \mathrm{~L} / \mathrm{y} \text { per } \mathrm{m}^{2}\right) / \mathrm{d}(\mathrm{m})\right] \mathrm{C}_{\mathrm{w}}(\mu \mathrm{Ci} / \mathrm{L}) / \lambda\left(\mathrm{y}^{-1}\right) \text {. }
$$

Given this concentration of a radionuclide in soil, the dose from ingestion of contaminated vegetables is given by

$$
H_{v}=B_{v}\left(C_{d} / \rho\right) U_{v} D C F_{i n g}
$$

where

$\mathrm{H}_{\mathbf{v}} \quad$ = EDE from vegetable intakes (rem/year),

B $\quad$ = plant-to-soil concentration ratio for radionuclide (dimensionless),

p = bulk density of soil,

$\mathrm{U}_{\mathrm{v}} \quad$ = consumption rate of vegetables (kg/year), and

$\mathrm{DCF}_{\mathrm{ing}}=$ ingestion dose conversion factor $(\mathrm{rem} / \mu \mathrm{Ci})$.

If $\mathrm{C}_{\mathrm{s}}$ is expressed in units of $\mu \mathrm{Ci} / \mathrm{m}^{3}$ and $\mathrm{U}_{\mathrm{y}}$ in units of $\mathrm{kg} / \mathrm{year}$, then the density of soil in this equation must be expressed in $\mathrm{kg} / \mathrm{m}^{3}$. 
Given the equation for the dose from consumption of contaminated vegetables derived using the model of Baes and Sharp (1983) for retention of radionuclides in surface soil and the equation for the dose from direct consumption of drinking water, a direct comparison of the relative importance of the two exposure pathways can be obtained. Using the equations for $\mathrm{H}_{6} \mathrm{H}_{v a}$ and $\mathrm{C}_{8}$ derived above, the ratio of the doses from the drinking water and vegetable pathways is given by

$$
\mathrm{H}_{\mathrm{L}} / \mathrm{H}_{\mathrm{v}}=\left[\left(3.65 \mathrm{~m}^{2}\right) \mathrm{d}(\mathrm{m}) \rho\left(\mathrm{kg} / \mathrm{m}^{3}\right) \lambda\left(\mathrm{y}^{-1}\right)\right] /\left[\mathrm{B}_{v} \mathrm{U}_{v}(\mathrm{~kg} / \mathrm{y})\right] .
$$

This ratio does not depend on the radionuclide concentration in groundwater or the ingestion dose conversion factor.

In this analysis, the following radionuclide-independent parameter values are assumed: 1) a depth of the soil compartment (d) of $0.3 \mathrm{~m}$, which is a typical depth of the root zone for vegetation, 2) a water infiltration rate through soil of $0.4 \mathrm{~m} / \mathrm{year}$, which is the average infiltration rate of precipitation (see Appendix A.1.1) and is appropriate when irrigation is considerably less than the total precipitation, 3) a volumetric water content of soil $(\theta)$ of 0.3 (Baes and Sharp 1983), 4) a bulk density of soil $(\rho)$ of $1,400 \mathrm{~kg} / \mathrm{m}^{3}$, or $1.4 \mathrm{~g} / \mathrm{cm}^{3}$ (Baes and Sharp 1983), and 5) a consumption of contaminated vegetables of $90 \mathrm{~kg}$ fresh weight per year, which is half of the estimated total consumption of vegetables by an average adult (Rupp 1980; Hamby 1992). It should be noted that if the removal rate constant, $\lambda$, is dominated by the contribution from leaching, $\lambda_{1}$, then the ratio of the doses from the drinking water and vegetable pathways does not depend on the assumed depth of the soil compartment, $d$.

The equation for $\mathrm{H}_{2} / \mathrm{H}_{2}$ given above is evaluated for the radionuclides Tc-99, Sn-126, Pu-239, and Cs-137. Tc-99 represents radionuclides with a high plant-to-soil concentration ratio $\left(B_{v}\right)$ but a low distribution coefficient $\left(K_{\mathrm{f}}\right)$; Sn-126 has intermediate values of $B_{v}$ and $K_{d} ;$ Pu-239 has a low value of $B_{v}$ but a high $K_{d}$; and $C_{s-137}$ has an intermediate value of $B_{v}$ and a high $K_{d}$, but the half-life is sufficiently short that the equilibrium concentration in soil is determined by the half-life rather than the leaching constant, $\lambda_{1}$. In implementing the model, it is important to recognize that $B_{v}$ and $K_{d}$ are correlated; i.e., radionuclides with high plant-to-soil concentration ratios have low distribution coefficients resulting in relatively low equilibrium concentrations in soil, and vice versa (Baes et al. 1984; Sheppard 1985). Thus, evaluating the model for these four radionuclides should give results that are representative of any other important radionuclides in the SDF.

The radionuclide-specific parameter values for the example calculations are listed as follows:

$$
\begin{array}{lll}
\text { Tc-99- } & \mathbf{B}_{\mathrm{v}}=2.4, & \mathrm{~K}_{\mathrm{d}}=1.5 \mathrm{~mL} / \mathrm{g} ; \\
\text { Sn-126- } & \mathrm{B}_{\mathrm{v}}=0.0075, & \mathbf{K}_{\mathrm{d}}=250 \mathrm{~mL} / \mathrm{g} ; \\
\text { Pu-239- } & \mathrm{B}_{\mathrm{v}}=0.00011, & \mathbf{K}_{\mathrm{d}}=4,500 \mathrm{~mL} / \mathrm{g} ; \\
\text { Cs-137- } & \mathrm{B}_{\mathrm{v}}=0.02, & \mathbf{K}_{d}=1,000 \mathrm{~mL} / \mathrm{g} .
\end{array}
$$

Rev. 0 
The values of $\mathrm{B}_{v}$ and $\mathrm{K}_{\mathbf{\gamma}}$ for each radionuclide were obtained from the compilation of Baes et al (1984). The values of $B$, reported on a dry-weight basis were converted to a fresh-weight basis by multiplying by a factor of 0.25 (U.S.NRC 1977). The values of

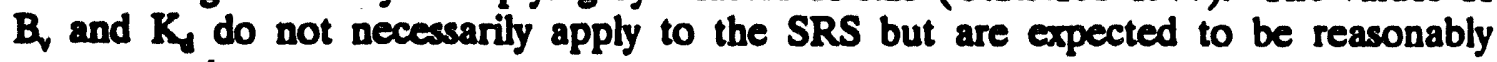
representative.

For the model and assumed parameters described above, we obtain the following comparisons of the dose from direct consumption of drinking water and the dose from consumption of vegetables irrigated with contaminated water. The dose from the drinking water pathway exceeds the dose from the vegetable pathway by about a factor of four for Tc-99, a factor of nine for Sn-126, a factor of 30 for Pu-239, and a factor of 20 for $\mathrm{Cs}_{3}$-137. If removal by radioactive decay were not taken into account for Cs-137, the dose from the vegetable pathway would be about the same as the dose from the drinking water pathway. Isotopes of $\mathrm{Cs}$ represent an extreme case where the plant-tosoil concentration ratio relative to the distribution coefficient is higher than for almost all other elements (Sheppard 1985), and a similar result would not be expected for any long-lived radionuclides.

The analysis presented above illustrates that the dose from direct ingestion of drinking water is expected to be considerably greater than the dose from ingestion of vegetables contaminated with irrigation water from the same source. This conclusion is expected to apply to all important radionuclides in the SDF.

The next pathways considered in this comparison are consumption of milk and meat from dairy and beef cattle that drink contaminated water. A previous analysis of these pathways (ORNL 1990) supplemented by data on transfer coefficients for the milk and meat pathways for isotopes of Sn obtained from the compilation by Baes et al. (1984) gives the following results. The dose from the drinking water pathway exceeds the dose from the milk and meat pathways by about a factor of five for Tc-99, 15\% for Sn-126, a factor of three for Cs-137, and five orders of magnitude for Pu-239. For Sn-126, the near equality between the doses from the drinking water and the milk and meat pathways results from the unusually high transfer coefficient for the meat pathway (Baes et al. 1984). A similar result would not be expected for other important radionuclides in the SDF.

The analysis presented above illustrates that, for most important radionuclides in the SDF, the dose from direct ingestion of drinking water is expected to be considerably greater than the dose from ingestion of milk and meat obtained from dairy and beef cattle that drink contaminated water from the same source. Only for Sn-126 are the doses from these pathways similar in magnitude.

Rev. 0 
The next pathway considered in this comparison is direct ingestion of contaminated soil in conjunction with vegetable intakes. For a given concentration of a radionuclide in garden soil, a direct comparison of the doses from the vegetable and soil ingestion pathways can be obtained from the results given in Tables A.4-8 and A.49, respectively, of Appendix A.4. The dose from the drinking water pathway relative to the dose from the soil ingestion pathway then is the product of two factors: 1) the ratio of the doses from the vegetable and soil ingestion pathways obtained from the tables listed above and 2) the ratio of the doses from the drinking water and vegetable pathways obtained previously in this section. Using this procedure, the dose from the drinking water pathway exceeds the dose from the soil ingestion pathway by about a factor of 600 for Tc-99, a factor of 200 for $\mathrm{Sn}-126$, a factor of 500 for Cs-137, and a factor of 8 for Pu-239.

The analysis presented above illustrates that the dose from direct ingestion of drinking water is expected to be considerably greater than the dose from direct ingestion of contaminated soil from a vegetable garden that is contaminated with irrigation water from the same source. This conclusion should a ply to all important radionuclides in the SDF.

The next pathway considered in this comparison is external exposure to contaminated soil while working in the vegetable garden. For a given concentration of a radionuclide in garden soil, a direct comparison of the doses from the vegetable and external exposure pathways can be obtained from the results given in Tables A.4-8 and A.4-10, respectively, of Appendix A.4. The dose from the drinking water pathway relative to the dose from the external exposure pathway then is the product of two factors: 1) the ratio of the doses from the vegetable and external exposure pathways obtained from the tables listed above and 2) the ratio of the doses from the drinking water and vegetable pathways obtained previously in this section. Using this procedure, the dose from the drinking water pathway exceeds the dose from external exposure by about $30 \%$ for $\mathrm{Sn}-126$ and a factor of 25 for Cs-137. The dose from the external exposure pathway is essentially zero for Tc-99 and Pu-239.

The analysis presented above illustrates that the dose from direct ingestion of drinking water is expected to be greater than the dose from external exposure to contaminated soil while working in a vegetable garden that is contaminated with irrigation water from the same source. This conclusion is expected to apply to all important photon-emitting radionuclides in the SDF.

The final pathway considered in this comparison is inhalation exposure to radionuclides suspended into air from contaminated soil while working in the vegetable garden. For a given concentration of a radionuclide in garden soil, a direct comparison of the doses from the vegetable and inhalation pathways can be obtained from the results given in Tables A.4-8 and A.4-12, respectively, of Appendix A.4. The dose from the drinking water pathway relative to the dose from the inhalation pathway then is the product of two factors: 1) the ratio of the doses from the vegetable and inhalation

Rev. 0 
pathways obtained from the tables listed above and 2) the ratio of the doses from the drinking water and vegetable pathways obtained previously in this section. Using this procedure, the dose from the drinking water pathway exceeds the dose from inhalation exposure by about 5 orders of magnitude for Tc-99 and Sn-126, 6 orders of magnitude for C3-137, and a factor of 300 for Pu-239.

The analysis presented above illustrates that the dose from direct ingestion of drinking water is expected to be much greater than the dose from inhalation exposure while working in a vegetable garden that is contaminated with irrigation water from the same source. This conclusion should apply to all radionuclides in the SDF.

The comparisons of the doses from the drinking water pathway and the vegetable, soil ingestion, external exposure, and inhalation pathways for the same concentration of particular radionuclides in water may be summarized as follows: for Tc-99, the dose from the drinking water pathway exceeds the dose from all other pathways by about a factor of two; for Sn-126, the dose from all other pathways exceeds the dose from the drinking water pathway, but only by about $70 \%$; for $\mathrm{Cs}-137$, the dose from the drinking water pathway exceeds the dose from all other pathways by about a factor of two; and, for Pu-239, the dose from the drinking water pathway exceeds the dose from all other pathways by about a factor of seven. These results should be representative of those that would be obtained for any other radionuclides in the SDF.

Given the estimated doses for the drinking water pathway in comparison with the estimated doses for the other exposure pathways involving use of contaminated groundwater from the same source and given the higher dose limit for all exposure pathways in comparison with the dose limit for the drinking water pathway only, the follpwing important conclusion is obtained.

In the performance assessment for the SDF, a determination of allowable releases of radionuclides to off-site locations by the groundwater pathway can be based entirely on the limit on EDE of 4 mrem per year from direct consumption of $2 \mathrm{~L} /$ day of drinking water. If the dose limit from consumption of drinking water is met, then the limit on EDE of 25 mrem per year from all exposure pathways will also be met without further analysis.

This result means that the dose limit for off-site members of the public from all exposure pathways is irrelevant in judging compliance of the disposal facility with the applicable performance objectives, provided doses from airborne releases of radionuclides are insignificant. If this is the case, only the performance objective for protection of groundwater needs to be considered in this analysis.

Rev. 0 


\subsubsection{Screening of Radionuclides for Groundwater Pathway}

As demonstrated in the previous section, limitation of concentrations of radionuclides in groundwater at any location beyond the boundary of the disposal facility is the only concern for the dose analysis for off-site individuals. Although a large number of radionuclides are present in waste placed in the SDF (Table C.1-1), only a few radionuclides are potentially important in estimating doses from direct ingestion of contaminated groundwater beyond the disposal site boundary. This section presents the results of a simple screening analysis for selecting the radionuclides to be considered for the groundwater pathway. A more detailed analysis of releases from the disposal facility and transport in groundwater would be required for the radionuclides selected by the screening procedure.

The screening analysis is based, first, on the concentrations of radionuclides in groundwater that would give an annual EDE of 4 mrem from consumption of 2 L/day (i.e., 730 L/year) of contaminated water. For each radionuclide, this is the limiting concentration that must be met in order to ensure that the dose limit defining protection of groundwater would not be exceeded. Thus, for radionuclide $i$, the limiting concentration in groundwater in units of $\mu \mathrm{Ci} / \mathrm{L}$, which is denoted by $\mathrm{C}_{\mathrm{m} \text {, limip }}$ is given by

$$
C_{\text {in, tiait }}=(0.004 \mathrm{rem} / \mathrm{y}) /\left[(730 \mathrm{~L} / \mathrm{y}) \mathrm{DCF}_{\mathrm{j}}\right] \text {, }
$$

where $\mathrm{DCF}_{\mathrm{i}}$ is the ingestion dose conversion factor for the radionuclide in units of $\mathrm{rem} / \mathrm{MCl}$. Values of ingestion dose conversion factors for selected radionuclides are given in Table A.4-2 of Appendix A.4.

The screening analysis then assumes that active institutional control will be maintained over the disposal site for 100 years after facility closure (U.S.DOE 1988a) and, furthermore, that the performance of the facility will be monitored to detect and/or prevent significant releases of radionuclides to the environment throughout the period of active institutional control. This assumption eliminates from concern any radionuclide with a half-life less than about 5 years, because the inventory in the waste at 100 years after facility closure will be reduced to innocuous levels by radioactive decay.

Given the assumption described above regarding prevention of releases during the period of active institutional control, the screening procedure can be based on the concentrations of radionuclides in saltstone at 100 years after disposal, which for radionuclide $i$ is denoted by $C_{h, v}(100 \mathrm{y})$. These concentrations are obtained for this analysis from Table $2.6-2$ by applying the appropriate correction for radioactive decay over 100 years, but are expressed in units of $\mu \mathrm{Ci} / \mathrm{L}$ for this analysis. The actual activity concentration at closure may differ from the values in Table 2.6-2 because the projected composition was obtained from a conservative hypothetical production mix used for facility design and does not consider decay of existing waste prior to disposal. 
The final step in the screening procedure is to convert the assumed radionuclide concentrations in saltstone at 100 years after disposal to concentrations in water. These concentrations, which clearly are maximum (bounding) values as they represent the pore solution concentration in the wasteform, are denoted by $\mathrm{C}_{\mathrm{tw} \text { max }}$ for radionuclide $i$. Given the concentrations in the disposal facility at 100 years after disposal, $C_{h, v}(100 y)$, the maximum concentrations in groundwater obtained from the screening model are given by

$$
C_{i m \max }=C_{h v}(100 y) /\left(\theta+K_{d p_{L}}\right)
$$

where

$\theta$ - porosity of saltstone,

$\mathbf{K}_{\mathbf{\gamma}}=$ equilibrium solid/solution distribution coefficient, and

$p_{1}=$ bulk density of saltstone.

In this analysis, $\theta$ is assumed to be 0.5 and $\rho_{1}$ is assumed to be $1.4 \mathrm{~kg} / \mathrm{L}$. Thus, if $\mathrm{K}_{\mathrm{d}}$ is expressed in units of $\mathrm{L} / \mathrm{kg}$ and $\mathrm{C}_{\mathrm{h}, \mathrm{v}}$ in units of $\mu \mathrm{Ci} / \mathrm{h}, \mathrm{C}_{\mathrm{h}, \mathrm{max}}$ will be expressed in the desired units of $\mu \mathrm{Ci} / \mathrm{L}$. In the screening analysis, the values of $\mathrm{K}_{\mathrm{f}}$ for each element were obtained from the list provided in Table A.1-2 in Appendix A.1.2, for saltstone.

Given the limiting concentration of a radionuclide in water for meeting the groundwater protection requirement, $\mathrm{C}_{\mathrm{kw} \text {,imin }}$ and the estimate from the screening model for the maximum concentration of a radionuclide in groundwater given the concentration in saltstone at 100 years after disposal, $\mathrm{C}_{\mathrm{im} \text { mans }}$ a radionuclide would be selected for further analysis by the screening procedure only if the following inequality is satisfied:

$$
\text { . } C_{i m, \max }>C_{i m, l i a i r}
$$

The screening procedure should be sufficiently conservative that any radionuclides eliminated from further consideration by the procedure could not possibly contribute more than a small fraction of the dose limit of 4 mrem per year from contamination of groundwater.

Application of the screening procedure described above yields the following radionuclides that should be considered in the dose analysis for off-site individuals via the groundwater pathway:

$$
\text { H-3, C-14, Se-79, Sr-90, Tc-99, Sn-126, I-129, Cs-137, Pu-238, and Am-241. }
$$

Thus, the screening procedure has selected only ten radionuclides that are possibly of concern for the groundwater pathway. These radionuclide: are subjected to further analysis in Appendix A.4. However, in a more realistic analysis, it is likely that only a few of these radionuclides would contribute significantly to the total dose from consumption of contaminated drinking water.

Rev. 0 


\section{Exposure Scenarios for Inadvertent Intruders}

As described in Sect. 1.4, disposal of low-level radioactive waste in the Z-Area SDF must meet certain performance objectives for protection of inadvertent intruders onto the disposal site at any time after loss of active institutional control. In particular, active institutional control is assumed to cease at 100 years after facility closure; and, at any time thereafter, the EDE to an intruder should not exceed 100 mrem per year for scenarios involving continuous exposure or 500 mrem for scenarios involving a single acute exposure (U.S.DOE 1988a). These dose limits apply to the sum of dose equivalents from all exposure pathways that are assumed to occur in a given exposure scenario for an inadvertent intruder.

In this section, the different exposure scenarios for an inadvertent intruder which have been considered in the performance assessment for the SDF are described. An important assumption in all scenarios is that an intruder has no prior knowledge of the existence of a waste disposal facility at the site. Therefore, after active institutional control ceases, certain exposure scenarios are assumed to be precluded only by the physical state of the disposal facility, i.e., the integrity of the engineered barriers used in facility construction. Passive institutional controls, such as permanent marker systems at the disposal site and public records of prior land use, also could prevent inadvertent intrusion after active institutional control ceases, but the use of passive institutional controls is not assumed in this analysis.

\subsubsection{Chronic Exposure Scenarios for Inadvertent Intruders}

Three distinct 3cenarios resulting in chronic exposure of inadvertent intruders are considered in the dose analysis for the SDF. Two of these scenarios, which usually are referred to as the agriculture (or homesteader) and post-drilling scenarios, have often been applied in other intruder dose analyses for LLW disposal (U.S. NRC 1981; Oztunali and Roles 1986; Kennedy and Peloquin 1988; ORNL 1990). The third scenario considered in this analysis is referred to as the resident scenario. As noted previously, all chronic exposure scenarios for inadvertent intruders are subject to a limit on EDE of 100 mrem per year.

In previous intruder dose analyses, such as those referred to above, the agriculture scenario usually was found to be more important than the post-drilling scenario; i.e., the agriculture scenario usually results in higher doses per unit concentration of radionuclides in the disposal facility than the post-drilling scenario. Thus, the agriculture scenario usually results in lower concentrations of radionuclides that would be acceptable for disposal. However, as discussed later in this section, the agriculture scenario possibly could be less important than the post-drilling scenario for the SDF if the saltstone waste form were to maintain its physical integrity for a very long time after disposal. During this time, direct excavation into a disposal facility presumably would be precluded, but a significant fraction of the radionuclide inventory in the waste could migrate into soil next to the facility and exposures of intruders could result from drilling into the contaminated soil. This possibility is investigated in the present analysis.

Rev. 0 
The following sections describe the assumptions for the agriculture, resident, and post-drilling scenarios.

\section{Agriculture scenario}

The agriculture scenario assumes that an intruder comes onto the site after active institutional control ceases and establishes a permanent homestead, including on-site sources of water and foodstuffs. This scenario normally assumes that waste is accessed when an intruder constructs a home directly on top of a disposal facility and the foundation of the home extends into the facility itself. An important assumption in this scenario is that all radioactive waste in the disposal facility at the time the foundation is dug essentially is physically indistinguishable from native soil. Thus, for the SDF, direct intrusion into the saltstone waste form presumably would not occur until a substantial thickness of the top layer of saltstone has lost its integrity as an intact monolith and assumed a physical form similar to native soil.

In the agriculture scenario, some of the waste exhumed from the disposal facility is assumed to be mixed with native soil in the intruder's vegetable garden. The following exposure pathways involving exhumed waste or waste remaining in the exposed disposal facility on which the intruder's home is located then are assumed to occur:

- ingestion of vegetables grown in contaminated garden soil;

- direct ingestion of contaminated soil, primarily in conjunction with intakes of vegetables from the garden;

- external exposure to contaminated soil while working in the garden or residing in the home on top of the disposal facility;

- inhalation of radionuclides attached to soil particles that are suspended into air from contaminated soil while working in the garden or residing in the home; and

- inhalation of volatile radionuclides released into air from contaminated soil while working in the garden or residing in the home.

For the last exposure pathway listed above, the only radionuclides of concern would be H-3, C-14, and isotopes of radon.

The agriculture scenario also assumes that the intruder's entire supply of water for domestic use is obtained from a well on the disposal site. The well is assumed to be placed at the location where the maximum concentrations of radionuclides in groundwater are predicted to occur. The following exposure pathways involving use of contaminated well water then are assumed to occur:

- direct ingestion of contaminated water;

- ingestion of milk and meat from dairy and beef cattle that drink contaminated water; and

- ingestion of vegetables grown in garden soil irrigated with contaminated water. 
These pathways are the same as those assumed in Sect. 3.23 for off-site members of the public who use contaminated groundwater or surface water for domestic purposes. Again, since rainfall normally is abundant at the SRS (Sect. 2.1.3), irrigation of a vegetable garden is assumed to occur only occasionally during the summer and only in small amounts relative to the annual rainfall (Murphy 1990), and irrigation of pasture grass ingested by dairy and beef cattle is neglected because extensive irrigation of agricultural land is not practiced near the SRS (U.S. Department of Commerce 1977; Baes and Sharp 1983). In the performance assessment for the agriculture scenario, the potential importance of the exposure pathways resulting from use of contaminated well water at the disposal site compared with the exposure pathways resulting from direct intrusion into the disposal facility is described below.

The SRS has established the objective that concentrations of radionuclides in groundwater at the disposal site be limited such that the EDE from direct consumption of all radionuclides in groundwater arising from waste disposal is no more than 4 mrem per year for a consumption rate of drinking water of $2 \mathrm{~L} /$ day. Thus, as shown by the analysis in Sect. 3.2.3.3, the maximum dose equivalent in any year that could result from use of contaminated groundwater on the disposal site, taking into account all of the exposure pathways listed above, is only a small fraction of the maximum dose equivalent to an intruder from all exposure pathways of 100 mrem per year. Therefore, for purposes of demonstrating compliance with the dose limit for inadvertent intruders, only the exposure pathways involving direct intrusion into the disposal facility need to be considered, and the exposure pathways involving use of contaminated well water can be neglected.

In this analysis, direct intrusion into the disposal facility is assumed to be precluded for the period of time after loss of active institutional control when the roof of the concrete vaults, the top layer of uncontaminated grout, and saltstone waste forms maintain their structural and physical integrity. That is, the intact concrete roof constructed as described in Sect. 2.5, the intact layer of uncontaminated grout between the roof and the saltstone, and intact saltstone monoliths are assumed to preclude direct access to waste in the disposal facility by the types of equipment that normally would be used in digging a foundation for a home at the SRS. A simple model used to estimate the time required for excavation into a significant surface layer of saltstone first to become credible is described as follows.

The model for degradation and failure of the concrete roof developed for purposes of this performance assessment is described in Sect. 3.1.2. As a result of the model for rebar corrosion and conversion of intact concrete to rubble, the roofs are assumed to preclude direct intrusion into the disposal facility for a time period of at least 1,000 years after disposal and perhaps for as long as 10,000 years. Thus, only long-lived radionuclides in the waste are of concern for an agriculture scenario involving direct intrusion

Rev. 0 
into the disposal facility. In addition, saltstone monoliths presumably will maintain their physical integrity and, thus, not be penetrable by excavation procedures normally used at the SRS for a considerable period of time after degradation of the concrete roofs.

In order to estimate the rate at which an intact saltstone monolith and an intact layer of uncontaminated grout on top of the saltstone will weather to soil-equivalent material, and thus the time at which a substantial amount of the weathered material could be exhumed by normal excavation procedures, saltstone and grout are assumed to resemble carbonate rock (e.g., limestone) in their weathering properties. Available data summarized by Ketelle and Huff (1984) indicate that the weathering rate of carbonate rock in regions near the SRS is in the range 35 to $100 \mathrm{~mm}$ per 1,000 years. For purposes of this analysis, a weathering rate for grout and saltstone of $100 \mathrm{~mm}(0.1 \mathrm{~m})$ per 1,000 years is assumed. This value applies to the expected infiltration rate of water in native soil of about $40 \mathrm{~cm} / y e a r$. A weathering rate at the upper end of the range of reported values for carbonate rock is chosen, because saltstone and grout should have a somewhat higher porosity than average carbonate rock and, thus, should be correspondingly more susceptible to weathering by infiltrating water.

On the basis of the assumed weathering rate described above, the time required for a substantial amount of grout and saltstone (e.g., a layer about $1 \mathrm{~m}$ thick) to weather to soil-equivalent material would be about 10,000 years at the normal infiltration rate of water. When the concrete roof is intact, the infiltration rate is expected to be about 5\% of the rate in native soil and the weathering rate should be reduced by the same amount. Therefore, the weathering rate while the concrete roof is intact essentially can be ignored and, depending on the lifetime of the roof, the time required after disposal for about $1 \mathrm{~m}$ of the top layer of grout and saltstone to weather to soil-equivalent material should be between 10,000 and 20,000 years. Since the half-lives of such important radionuclides as Tc-99 and Sn-126 are 100,000 years or greater and the release rate of long-lived radionuclides from the disposal facility is expected to be much less than the assumed weathering rate of grout and saltstone (see Sect. 3.3.1), it is reasonable to conclude that an agriculture scenario involving direct excavation into saltstone is credible at some time in the future, but probably only after at least 10,000 years.

Because of the likelihood that the saltstone and grout monoliths will maintain their physical integrity for a considerable period of time after degradation of the concrete roofs, and thus prevent direct intrusion into the disposal facility by normal excavation procedures, an alternative agriculture scenario that has not been considered previously is taken into account in the intruder dose analysis for the SDF. During the period when the saltstone and grout monolith is intact, radionuclides presumably will be released to the soil surrounding the facility (Sect 3.3.1). Thus, even though direct intrusion into the disposal facility may be precluded by an intact waste form, it is reasonable to assume that an inadvertent intruder would excavate contaminated soil next to the disposal facility while digging a foundation for a home at the disposal site. 
The exposure pathways resulting from excavation of contaminated soil next to an intact vault or saltstone monolith would be similar to the pathways resulting from direct intrusion into the disposal facility listed previousty. The principal difference would be in calculating the dose from external exposure while residing in the home on top of the disposal facility. In the usual agriculture scenario, the radionuclides are essentially uniformly distributed over a semi-infinite source region. In the alternative agriculture scenario, however, the distribution of radionuclides between the saltstone and the contaminated soil outside the disposal facility must be taken into account because this distribution generally will not be uniform. In addition, for inhalation exposure while residing in the home, only radionuclides in the contaminated soil at the edge of the excavation are subject to suspension into air, but radionuclides remaining in the saltstone would not become airborne.

Because of the design of the SDF, the applicability of the alternative agriculture scenario described above is rather limited. In defining an agriculture scenario based on excavation at a waste disposal site, the excavation normally is assumed to extend no more than $3 \mathrm{~m}$ below the ground surface (U.S. NRC 1981; Oztunali and Roles 1986), because deeper excavations usually do not occur in digging a foundation for a home. Therefore, since the current concept for closure of the disposal facility calls for a minimum cover thickness of $2.6 \mathrm{~m}$ above the vaults and the thickness of the concrete roof on top of the vaults is $0.5 \mathrm{~m}$ (Sect. 2.5 ), the alternative agriculture scenario reasonably can be applied only to radionuclides that have migrated into soils above the vaults. That is, most radionuclides that have migrated into soil beside or below the vaults would be too far below the ground surface to be accessible according to the agriculture scenario.

Therefore, in this analysis, an evaluation of the alternative agriculture scenario takes into account radionuclides that migrate into soil above the disposal facility, presumably primarily, by diffusion. The scenario involving excavation of contaminated soil above the vaults is assumed to occur at any time after active institutional control ceases, because there are no engineered barriers to preclude such excavation.

The alternative agriculture scenario used in this analysis assumes implicitly that erosion of the cover material above the vaults is not rapid. If erosion were rapid, excavation along the sides of the disposal facility would be credible within a relatively short time. Average erosion rates for cropland in the area around the SRS are about $1 \mathrm{~mm}$ per year (Sect. 2.1.7). Thus, if we assume that this erosion rate applies to the cover material above the vaults and assume an average density of soil of $1.4 \mathrm{~g} / \mathrm{cm}^{3}$ (Baes and Sharp 1983), about 3,000 years would be required under present climatological conditions for the entire cover material above the concrete vaults to be eroded away. However, the use of bamboo as a ground cover at the disposal site (Sect. 1.2.3) should reduce the erosion rate considerably compared with the average value given above. Erosion also would be substantially reduced if the top of the gravel layer located about $1 \mathrm{~m}$ above the vaults (Sect. 2.3.3.2) were uncovered. Therefore, it indeed seems reasonable to assume that the alternative agriculture scenario involving excavation into contaminated soil outside the disposal facility applies mostly to soil above the vaults but that little contaminated soil along the side of the vaults would be excavated.

Rev. 0 


\section{Rexident scenario}

As in the agriculture scenario described above, the resident scenario assumes that an intruder excavates a foundation for a home on top of a disposal facility. During excavation, however, the intruder is assumed to encounter an intact concrete roof or saltstone monolith that cannot easily be penetrated by the types of excavation equipment normally used at the SRS. That is, the presence of intact engineered barriers is assumed to preclude direct intrusion into saltstone during excavation. But instead of abandoning the site, the intruder constructs a home directly on top of the intact barrier and, thus, establishes a permanent residence at that location.

From the definition of the resident scenario, the only exposure pathway of concern is external exposure to photon-emitting radionuclides during the time the intruder resides in the home on the disposal site. The presence of intact barriers precludes any inhalation or ingestion exposures. Inhalation or ingestion exposures resulting from excavation of radionuclides that have migrated from the disposal facility into soil are taken into account in the agriculture scenario described previously.

The resident scenario is assumed to occur at any time after active institutional control over the disposal facility ceases. However, even though the concentrations of radionuclides in the disposal facility will decrease monotonically with time, due to the radioactive decay and migration from the disposal facility, the dose in the resident scenario is not necessarily the highest at 100 years after facility closure. At this time, the concrete roof and layer of uncontaminated grout above the saltstone are assumed to be intact (Sect. 3.1.2) and a negligible amount of radioactivity in the saltstone has migrated into the overlying grout and concrete roof. Therefore, at the earliest time the resident scenario could occur, the concrete roof and layer of uncontaminated grout provide $0.75 \mathrm{~m}$ of shielding that substantially reduces the external dose compared with the dose from unshielded saltstone. At some later time, i.e., between 1,000 and 10,000 years after disposal, the concrete roof is assumed to have lost its integrity (Sect. 3.1.2.2), and the $30-\mathrm{cm}$ layer of uncontaminated grout is assumed to weather to soil-equivalent material within another few thousand years, as described previously. Therefore, for long-lived radionuclides that are retained in saltstone for long periods of time, the external dose in the resident scenario would be considerably higher long after active institutional control ceases, when excavation to the depth of intact and unshielded saltstone is assumed, than at $\mathbf{1 0 0}$ years after disposal, when excavation only to the depth of the top of the concrete roof is assumed.

Thus, the maximum dose to an inadvertent intruder according to the resident scenario and the time at which the maximum dose occurs depend on 1) the half-lives and concentrations of the importa:- pisoton-emitting radionuclides in the waste, 2) the time period over which the engineered barriers above the saltstone lose their integrity and can easily be excavated, and 3) the rate at which the important radionuclides migrate from the saltstone. However, the maximum dose for this scenario can be estimated by considering two bounding cases: 1) intrusion at 100 years after disposal in the presence 
of an intact concrete roof, but with no reduction in radionuclide inventories at disposal except by radioactive decay, and 2 ) intrusion at a time beyond a few thousand years after disposal when exposure to unshielded but intact saltstone is credible, but again with no reduction in radionuclide inventories except by radioactive decay. The first bounding case takes into account radionuclides of both shorter and longer half-lives and the shielding provided by the concrete roof and layer of uncontaminated grout, whereas the second bounding case applies to time periods when only long-lived radionuclides are present but the saltstone is unshielded. In both cases, self-shielding provided by the saltstone is taken into account in estimating external dose.

In this analysis, the two bounding cases for the resident scenario described above are evaluated. A more rigorous analysis involving, for example, consideration of the migration of radionuclides from the saltstone over time would be required only if the bounding estimates of EDE approach the performance objective of 100 mrem per year for a chronic exposure scenario.

\section{Comparison of agriculture and resident scenarios}

From the definition of the resident scenario, this scenario can be regarded as a variation of the agriculture scenario in which only one of the exposure pathways is potentially important - namely, external exposure while residing in the home located on top of the disposal facility. Therefore, since this exposure pathway is essentially the same in the two scenarios and the agriculture scenario includes other exposure pathways that are not relevant for the resident scenario, the agriculture scenario probably will be more important than the resident scenario. That is, the dose per unit concentration of radionuclides in disposed waste probably will be higher in the agriculture scenario than in the resident scenario. Thus, the agriculture scenario is expected to be more restrictive in regard to determining acceptable disposals.

However, the tentative conclusion about the relative importance of the agriculture and resident scenarios could be incorrect if the removal rate of radionuclides from the top layer of saltstone by infiltrating water were comparable to or greater than the weathering rate of saltstone. If such an occurrence were possible, then the external dose that would result at the time the overlying layer of uncontaminated grout has weathered to soil-equivalent material, but not any of the saltstone itself, could be greater than the total dose from all exposure pathways that would result at a later time when a significant layer of saltstone also has weathered to soil. Therefore, the resident scenario, as well as the agriculture scenario, is considered in the intruder dose analysis. 


\section{Post-Drilling scenario}

The post-drilling scenario assumes that an intruder who resides permanently on the disposal site drills through contaminated material in constructing a well for a domestic water supply. Following construction of the well, the contaminated material brought to the surface during drilling operations, which is assumed to be indistinguishable from native soil, is assumed to be mixed with native soil in the intruder's vegetable garden. The exposure pathways involving ingestion of contaminated vegetables, ingestion of contaminated soil, and external and inhalation exposures while working in the garden then are the same as the pathways described previously for the agriculture scenario. In the post-drilling scenario, however, external and inhalation exposures while residing in the home on the disposal site, which are important in the agriculture scenario, are not relevant, because all drilling waste is assumed to be mixed with native soil in the garden and the intruder's home is assumed not to be located directly on top of exposed waste.

As in the agriculture scenario, the post-drilling scenario assumes that the intruder's entire supply of water is obtained from the on-site well, and the exposure pathways from use of contaminated well water are the same as those described previously for the agriculture scenario. Again, however, because of the stringent requirement of the SRS on allowable contamination of groundwater at the disposal site in comparison with the maximum allowable dose to an intruder from all exposure pathways, demonstrations of compliance with the dose limit for inadvertent intruders for the post-drilling scenario can be based only on the exposure pathways involving direct intrusion into solid waste; i.e., the exposure pathways involving use of contaminated well water can be neglected.

In this analysis, two alternatives for the post-drilling scenario are considered which are analogous to the two agriculture scenarios discussed previously. In the usual treátment of the post-drilling scenario (Oztunali and Roles 1986; Kennedy and Peloquin 1988; ORNL 1990), an intruder is assumed to drill directly through a disposal facility and waste in the facility is brought to the surface. However, as in the agriculture scenario, drilling through saltstone is assumed to be precluded during the time when concrete vaults and saltstone monoliths maintain their integrity. Thus, the post-drilling scenario involving drilling through a disposal facility is assumed not to be credible until the same time as the agriculture scenario involving direct excavation into a disposal facility. The basis for this assumption is that the types of drill bits normally used in constructing wells in the soft sand and clay soils at the SRS (Sect. 2.1.7) could not easily penetrate an intact concrete vault or saltstone monolith. Therefore, in attempting to drill directly through a disposal facility, it is reasonable to assume that an intruder would encounter considerable resistance and, instead of taking extraordinary measures to obtain a drill bit designed to penetrate through hard rock, would move the drilling operation to a different location away from a disposal facility. 
As in the agriculture scenario, it would be reasonable to assume an alternative postdrilling scenario in which an intruder drills a well through contaminated soil immediately adjacent to a vault, because no unusual resistance to drilling would be encountered. Such a scenario is considered in this analysis, and the scenario is assumed to occur at any time after active institutional control ceases. The dose analysis for the alternative postdrilling scenario is based on the predicted maximum concentrations of radionuclides in soil along the sides of vaults. The alternative scenario would apply until such time as the concrete vaults and saltstone monoliths lose their integrity and drilling through a disposal facility becomes credible. When drilling through a disposal facility is credible, the concentrations of radionuclides in the disposal facility will always be greater than the concentrations in contaminated soil next to the facility, and the alternative scenario need not be considered.

\section{Comparison of agriculture and post-drilling scenarios}

Previous analyses of the agriculture and post-drilling scenarios (Oztunali and Roles 1986; Kennedy and Peloquin 1988; ORNL 1990) have shown that the dose to an intruder per unit concentration of radionuclides in excavated material will always be considerably greater for the agriculture scenario than for the post-drilling scenario, provided a reasonably consistent set of assumptions for the exposure pathways in the two scenarios is used. The principal reasons for the greater doses in the agriculture scenario are: 1) the greater volume of waste exhumed during construction of a foundation for a home compared with the volume of waste exhumed during drilling of a well, which results in greater concentrations of radionuclides in contaminated soil in the intruder's vegetable garden and 2) the doses from external and inhalation exposure while residing in a home on the disposal site, which are not relevant for the post-drilling scenario.

However, if the post-drilling scenario could occur before an analogous agriculture scenario (e.g., if the use of drill bits that could easily penetrate intact concrete vaults and saltstone monoliths were assumed), then previous analyses have shown that the dose from the post-drilling scenario could exceed the dose from the agriculture scenario (ORNL 1990). Whether or not this is the case depends on the concentrations of the particular radionuclides in the waste and the assumed difference in time between the first credible occurrences of the post-drilling and agriculture scenarios.

In this analysis, two types of agriculture and post-drilling scenarios are considered involving: 1) excavation or drilling directly into a disposal facility and 2) excavation or drilling into contaminated soil immediately adjacent to a disposal facility. For the first type of scenario, it is assumed, as described previously, that the agriculture and postdrilling scenarios would occur at the same time after disposal, i.e., when the concrete vaults and saltstone monoliths have lost their integrity. In this case, the dose from the agriculture scenario will always be considerably greater than the dose from the postdrilling scenario and, since the two scenarios are subject to the same dose limit, the postdrilling scenario involving drilling directly through a disposal facility can be neglected. That is, for direct intrusion into the SDF, demonstrations of compliance with the dose

Rev. 0 
limit for chronic exposure of inadvertent intruders can be based only on an analysis of the agriculture scenario.

For the alternative scenarios involving excavation or drilling into contaminated soil next to a disposal facility, the post-drilling and agriculture scenarios also occur at the same time, i.e., at any time after active institutional control ceases. In this case, however, the agriculture scenario is not necessarily more restrictive (i.e., does not necessarily result in higher doses) because the agriculture scenario is assumed, as described previously, to involve excavation of contaminated soil mostly above the disposal units but the postdrilling scenario involves excavation of contaminated soil beside a vault. Thus, if the concentrations of radionuclides alongside a disposal facility are substantially greater than the concentrations above a facility, then this type of post-drilling scenario could be more restrictive than the analogous agriculture scenario.

\section{Acute Exposure Scenarios for Intruders}

Three distinct scenarios resulting in acute exposure of inadvertent intruders have commonly been applied to $\mathrm{LLW}$ disposal facilities. These scenarios usually are referred to as the construction, discovery, and drilling scenarios (U.S. NRC 1981; Oztunali and Roles 1986; Kcanedy and Peloquin 1988; ORNL 1990). As noted previously, all acute exposure scenarios for inadvertent intruders are subject to a limit on EDE of 500 mrem. The following sections describe the three acute exposure scenarios considered in this analysis.

\section{Construction scenario}

The two chronic agriculture scenarios described in Sect. 3.2.4.1 are based on the assumption that an intruder builds a home on the disposal site, with the foundation extending either into a disposal facility or into contaminated soil mostly above a disposal facility. The construction scenario considers exposures during the short period of time for digging a foundation and building a home.

During construction, the relevant exposure pathways are assumed to be inhalation of radionuclides suspended into air from an uncovered disposal facility or contaminated soil and external exposure to radionuclides in the disposal facility or contaminated soil. Ingestion exposure is assumed to be unimportant during normal work activities. The potential importance of the construction scenario arises primarily from the assumption that construction activities result in airborne concentrations of radionuclides that are substantially higher than those resulting from normal activities while inhabiting the site, as in the agriculture scenarios. The construction scenario also assumes external exposure to unshielded waste or soil, whereas in the agriculture scenario shielding during indoor residence on the disposal site usually is taken into account. 
From its definition, the construction scenario would occur at the same time as the agriculture scenario. Therefore, the dose analysis for the two scenarios would be based on the same concentrations of radionuclides. Previous calculations (Kennedy and Peloquin 1988) provide a direct comparison of doses from the two scenarios. For a few radionuclides, the dose per unit concentration is slightly greater for the construction scenario but, for most radionuclides, the dose per unit concentration is much greater for the agriculture scenario. This result assumes a reasonable exposure time for the construction scenario and the use of a reasonably consistent set of assumptions for the exposure pathways in the two scenarios. Therefore, since the dose limit for the acute construction scenario is a factor of five higher than the dose limit for the chronic agriculture scenario, the construction scenario generally can be neglected in demonstrating compliance of the SDF with the performance objectives for protection of inadvertent intruders.

\section{Discovery scenario}

As in the resident scenario described in Sect. 3.2.4.1, the discovery scenario assumes that an intruder attempts to dig into a disposal facility while excavating a foundation for a home on the disposal site, but encounters an intact concrete roof or saltstone monolith which cannot easily be penetrated by the types of excavating equipment that normally would be used at the SRS. However, in distinction from the resident scenario, the intruder soon decides to abandon digging at that location and moves elsewhere. Since intact concrete roofs and saltstone monoliths are assumed not to be breached during excavation, the only exposure pathway for this scenario is external exposure to photonemitting radionuclides in the disposal facility during the time the intruder digs at the site and the roofs or monoliths are uncovered. The presence of intact barriers precludes any inhalation or ingestion exposures.

From its definition, the discovery scenaric would occur at the same time as the resident scenario, as described in Sect. 3.2.4.1. Furthermore, the relevant exposure pathway - namely, external exposure to photon-emitting radionuclides in saltstone - is essentially the same in the discovery and resident scenarios. Other than the exposure time, the only difference is the shielding factor during indoor residence, which is relevant only for the resident scenario. Therefore, since the exposure time for the discovery scenario presumably would be no more than $100 \mathrm{~h}$ (ORNL 1990), which is considerably less than the assumed exposure time of $4,380 \mathrm{~h} / y e a r$ for the resident scenario, and the dose limit for the discovery scenario is a factor of five greater than the limit for the resident scenario, it is clear that the discovery scenario generally can be neglected in demonstrating compliance of the SDF with the performance objectives for protection of inadvertent intruders. 


\section{Drilling scenario}

The two chronic post-drilling scenarios described in Sect. 3.2.4.1 are based on the assumption that an intruder drills a well either directly through a disposal vault or through contaminated soil adjacent to a disposal vault. The drilling scenario considers exposures during the short period of time for drilling and construction of the well.

During well drilling and construction, the most important exposure pathway is assumed to be external exposure to uncovered drilling wastes confined to a pile near the well. Although some radionuclides in the drilling waste could be suspended into the air and inhaled during well drilling and construction, inhalation exposures are expected to be relatively unimportant due to such factors as the initial water content of the drilling wastes, the small volume of the waste produced, and the absence of direct mechanical disturbance of the waste pile. Ingestion exposure is also assumed to be unimporiant during normal drilling activities. The potential importance of the drilling scenario arises primarily from the assumption that an intruder could be located near an unshielded waste pile for a substantial period of time.

From its definition, the drilling scenario would occur at the same time as the postdrilling scenario. Therefore, the dose analyses for the two scenarios would be based on the same concentrations of radionuclides. Previous calculations (Kennedy and Peloquin 1988) provide a direct comparison of doses from the two scenarios. For all radionuclides, the dose per unit concentration for the drilling scenario is at least an order of magnitude less than the dose per unit concentration for the post-drilling scenario, provided a reasonable exposure time for the drilling scenario and a reasonably consistent set of assumptions for the exposure pathways in the two scenarios are used. Therefore, the drilling scenario generally can be neglected in demonstrating compliance of the SDF with the performance objectives for protection of inadvertent intruders.

\section{Summary of acute exposure scenarios}

In this section, three scenarios for acute exposure of inadvertent intruders were discussed, i.e., the construction, discovery, and drilling scenarios. However, an evaluation of these scenarios has shown that all three scenarios can be neglected for purposes of demonstrating compliance of the SDF with the performance objectives for protection of intruders because the chronic agriculture, discovery, and post-drilling scenarios will always be more restrictive.

\subsection{Summary of Exposure Scenarios for Inadvertent Intruders}

Several chronic and acute exposure scenarios for inadvertent intruders have been considered for use in the performance assessment for the SDF. However, on the basis of previous analyses and considerations of how these scenarios would apply to the SDF, it is evident that only the following four chronic scenarios need to be included in the 
performance assessment:

- an agriculture scenario involving direct intrusion into a disposal facility at any time after the concrete vaults and saltstone monoliths have lost their structural and physical integrity;

- an agriculture scenario involving excavation of contaminated soil mostly above a disposal facility at any time after loss of active institutional control at 100 years after facility closure;

- a resident scenario involving permanent residence in a bome on an intact concrete roof or saltstone monolith at any time after loss of active institutional control at 100 years after facility closure; and

- a post-drilling scenario involving excavation of contaminated soil along the side of a disposal facility at any time after loss of active institutional control at 100 years after facility closure.

Estimates of dose for all four of these scenarios are considered in this analysis. All acute exposure scenarios would be less restrictive in regard to demonstrating compliance with the performance objectives for protection of inadvertent intruders and thus, are not considered further in this analysis.

A comparison of the relative importance of the chronic exposure scenarios for inadvertent intruders considered in this analysis requires a detailed analysis of each scenario based on the expected long-term performance of the disposal facility. Therefore, all four scenarios are evaluated in this analysis.

\subsubsection{Screening of Radionuclides for Intruder Dose Analyses}

As indicated in Table C.1-1, a large number of radionuclides are present in waste placed in the SDF. However, only a few radionuclides are potentially important in estimating doses to inadvertent intruders according to the different scenarios considered in this analysis. This section presents the results of a simple screening analysis for selecting the radionuclides that are potentially of concern for protection of inadvertent intruders.

The commitment that active institutional control will be maintained over the disposal site for 100 years after facility closure is an important factor in eliminating many radionuclides from consideration for the intruder dose analysis. In particular, any radionuclide with a half-life less than 5 years can be neglected, because the inventory at 100 years after disposal will be reduced to innocuous levels by radioactive decay. Then, previous dose analyses that are relevant for the agriculture, resident, and post-drilling scenarios can be used for further screening of radionuclides in each case. In particular, the dose analysis for Solid Waste Storage Area 6 at Oak Ridge National Laboratory (ORNL 1990) can be used in screening of radionuclides for these scenarios, because the assumptions used in the dose analysis for the SDF (see Appendix A.4) are quite similar to those used in the Oak Ridge analysis.

Rev. 0 


\section{Screening for agriculture scenario}

The previous dose analysis for the agriculture scenario at ORNL (1990) showed that the annual EDE per unit concentration of any radionuclide in the waste at the time this scenario occurs would be less than $10 \mathrm{mrem}$ per $\mu \mathrm{Ci} / \mathrm{m}^{3}$. Therefore, for any radionuclide, the limit on annual EDE of 100 mrem possibly could be exceeded only if the concentration at the time this scenario occurs is greater than $10 \mu \mathrm{Ci} / \mathrm{m}^{3}$. The screening analysis for selecting radionuclides for the agriculture scenario then assumes that this scenario occurs at 100 years after disposal, which is the earliest possible time, and that a safety factor of ten should be applied in reducing the minimum concentration of concern estimated above. Application of this safety factor ensures that the total dose from all radionuclides that would be neglected in the dose analysis for this scenario would be less than $10 \%$ of the dose from all radionuclides that are included in the analysis, because the annual dose per unit concentration for most radionuclides is considerably less than the maximum value of $10 \mathrm{mrem}$ per $\mu \mathrm{Ci} / \mathrm{m}^{3}$ assumed for purposes of screening.

From the assumptions described above, a radionuclide would be of potential concern for the agriculture scenario only if the concentration at 100 years after disposal, taking into account only the concentration at disposal given in Table 2.6-2 and the reduction in concentration by radioactive decay, is greater than $1 \mu \mathrm{Ci} / \mathrm{m}^{3}$. Application of this screening procedure yields the following radionuclides that are considered in the intruder dose analysis for the agriculture scenario:

H-3, C-14, Ni-63, Se-79, Sr-90, Tc-99, Sn-121m, Sn-126, I-129, Cs-137, Sm-151, Pu-238, Pu-239, and Am-241.

Thys, the screening procedure has selected only fourteen radionuclides that are possibly of concern for the agriculture scenario. These radionuclides are subjected to more detailed analysis in Appendix A.4. However, because the annual dose per unit concentration for most of these radionuclides is well below the value of 10 mrem per $\mu \mathrm{Ci} / \mathrm{m}^{3}$ used for purposes of screening, only a few of these radionuclides should contribute significantly to the dose for this scenario.

\section{Screening for resident scenario}

The selection of radionuclides of potential concern for the resident scenario can be based on the results of the screening procedure for the agriculture scenario given above, because both scenarios have an exposure pathway in common - namely, external exposure while residing in a home located on top of a disposal facility. Since this is the only pathway of concern for the resident scenario, the only radionuclides of potential importance for this scenario are the photon-emitting radionuclides selected by the screening procedure for the agriculture scenario. Therefore, the screening procedure yields the following radionuclides that are considered in the intruder dose analysis for the 
resident scenario:

Sn-126, I-129, Cs-137, and Am-241.

Thus, the screening procedure has selected only four radionuclides that are possibly of concern for the resident scenario. These radionuclides are subjectec to more detailed analysis in Appendix A.4.

\section{Screening for post-drilling scenario}

The previous dose analysis for the post-drilling scenario at ORNL (1990) showed that the annual EDE per unit concentration of any radionuclide in the waste at the time this scenario occurs would be less that $1 \mathrm{mrem}$ per $\mu \mathrm{Ci} / \mathrm{m}^{3}$. Therefore, for any radionuclide, the limit on annual EDE of $100 \mathrm{mrem}$ possibly could be exceeded only if the concentration at the time this scenario occurs is greater than $100 \mu \mathrm{Ci} / \mathrm{m}^{3}$. As in the screening analysis for the agriculture scenario described previously, the screening analysis for selecting radionuclides for the post-drilling scenario then assumes that this scenario occurs at 100 years after disposal, which is the earliest possible time, and that a safety factory of ten should be applied in reducing the minimum concentration of concern estimated above.

From the assumptions described above, a radionuclide would be of potential concern for the post-drilling scenario only if the concentration at 100 years after disposal, taking into account only the concentration at disposal given in Table 2.6-2 and the reduction in concentration by radioactive decay, is greater than $10 \mu \mathrm{Ci} / \mathrm{m}^{3}$. Application of this screening procedure yields the following radionuclides that are considered in the intruder dose analysis for the post-drilling scenario:

H-3,' Se-79, Sr-90, Tc-99, Sn-126, I-129, Cs-137, Sm-151, Pu-238, and Am-241.

Thus, the screening procedure has selected only ten radionuclides that are possibly of concern for the post-drilling scenario. These radionuclides are subjected to more detailed analysis in Appendix A.4. However, as in the case of the agriculture scenario, only a few of these radionuclides should contribute significantly to the dose for this scenario.

\subsection{MODELS AND ASSUMPTIONS}

To evaluate the performance of the SDF over an indefinite period of time, conceptual models representing the facility, its environment, and potential receptors of contamination were developed. These conceptual models were intended to embody the most significant aspects of the problem, balancing simplicity of approach with reasonable assumptions. This section describes the models adopted and assumptions made to complete the computations necessary to estimate doses. 


\subsection{Near-Field Model}

The following discussion addresses the means by which radionuclides and nitrate released from the SDF would be transported in the near-field environment. The nearfield environment is defined in this RPA as the portion of the subsurface environment extending from the ground surface to the water table. Conceptual models of flow and mass transport through both intact (Sect. 3.3.1.1) and fractured (Sect. 3.3.1.2) vaults are considered.

For the near-field models, a relatively complex numerical approach to simulating flow was adopted because the analysis required to predict the flow field around and through the facility. The flow of water through a variably-saturated system consisting of numerous materials with widely-varying hydraulic properties is not readily simulated analytically. The problem is highly non-linear, and flow in one material is affected by that in an adjacent material. Because the unsaturated zone is characterized by varying degrees of saturation, and this condition is further affected by the presence of the SDF, transit time is not readily estimated based on estimates of hydraulic conductivity or moisture characteristic curves that are available. Therefore, prediction of the flow regime under the conceptual facility based on assumed properties of materials present was necessary.

The flow regime in the subsurface purposes of analysis. These three re The first region is composed of the sec

arated conceptually into three regions for combined on the left side of Fig. 3.3-1. tran iration grity Below this region, but above gre vaults, is the region that includes the upper engineered moisture barrier, described in Sect. 2.4. The last region extends to the water table, and consists of the backfill sediment, the lower clay/gravel drain, the concrete vault, the saltstone waste form, and underlying native soil.

The conceptual model for water movement in the near field is as follows. Water infiltrates at the surface and either undergoes evapotranspiration through the surface and out of the domain, or penetrates the first region. This water is then available for subsurface runoff or infiltration through the second region. With the upper moisture barrier in place, the majority of this infiltrating water is diverted around the facility; however, some water penetrates this upper barrier. The lower clay/gravel drain system intercepts most of this penetrating water. A very small amount of water penetrates this lower barrier, most of which then flows around the vault and down to the water table. Some water penetrates the concrete roof and flows through the saltstone. The amount of water that penetrates the concrete and saltstone is dependent on the many factors, including the integrity of the vault and saltstone, as noted in Sect. 3.1.3. 


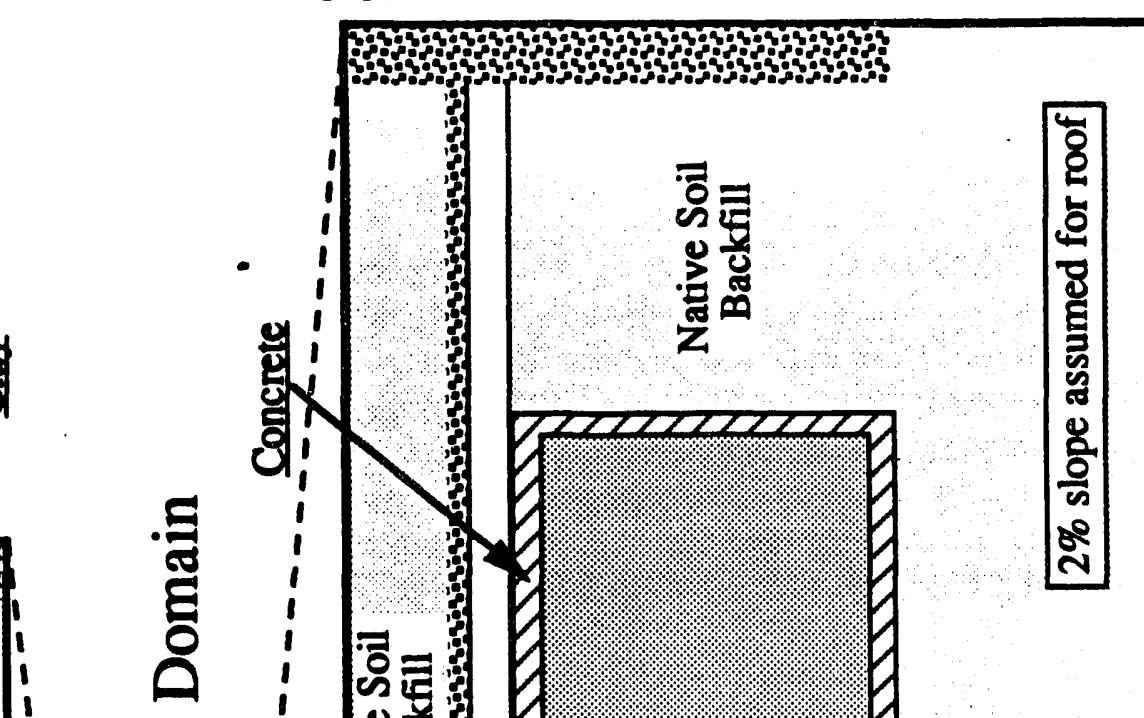

I

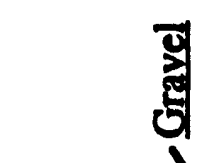

章

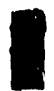

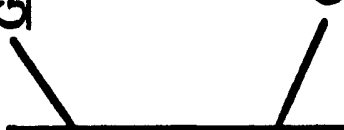

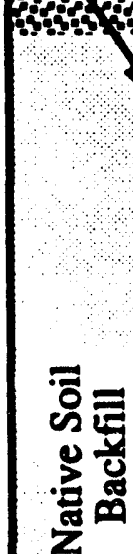
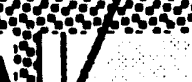

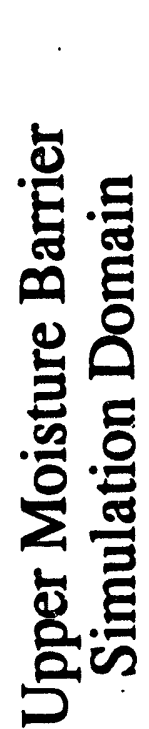

I

I

宮宅

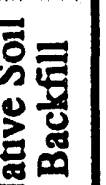

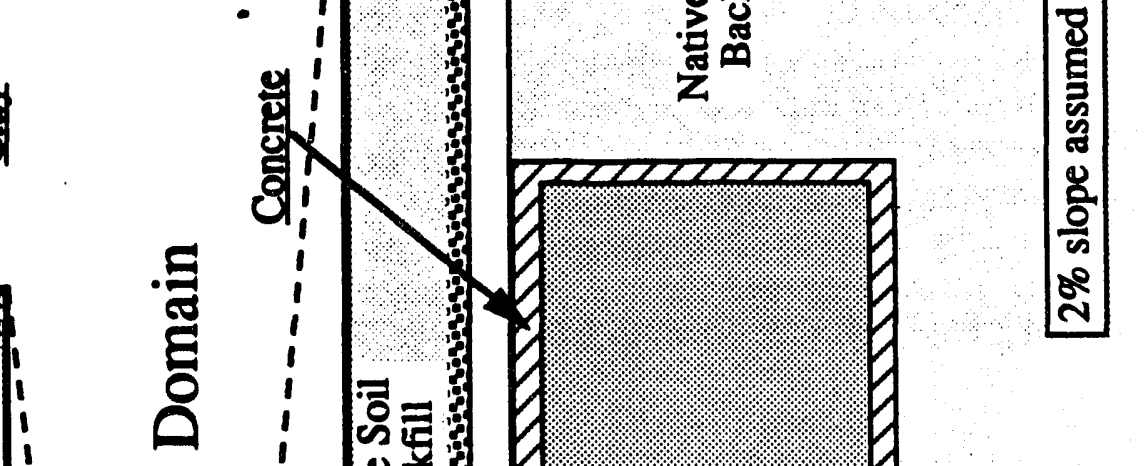

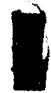

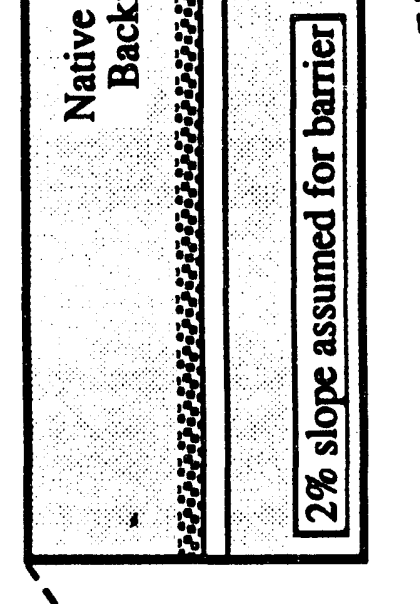

1

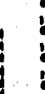

ถู่

i: 当

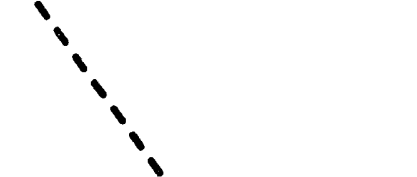

i i

i i

i i

i i

च

S룰

1 瓷

1 Z

$\mathrm{z}^{\mathrm{n}} \mathrm{d}$ 
An assumption inherent in dividing the flow regime into these three regions is that contaminants escaping the vault do not diffuse upwards through the cover system. This assumption is imposed because flow from the upper region is determined before mass transport simulations are conducted. Mass transport simulations are only carried for the vault/saltstone domain. The basis for this assumption is that advection will dominate transport of contaminants once they are outside of the vault, and that contaminants that have diffused upward through the concrete roof of the vaults will be swept horizontally along the vault and down to the water table.

The conceptual model for mass transport involves several processes. These processes are diffusion, advection, dispersion, sorption, and radioactive decay. All of these processes, which were discussed in Sect. 3.1.2 as mechanisms also pertinent to release from the saltstone matrix, occur within each of the three material types considered in the near-field conceptual model (i.e., saltstone, concrete vault, and backfill soil).

This RPA addresses both an intact vault scenario and a degraded vault scenario (Sect. 3.1), based on the belief that some degree of degradation of the engineered barriers of the SDF will occur. The remainder of this discussion of the near-field conceptual model will distinguish aspects that are pertinent to the intact vault scenario (Sect. 3.3.1.1) and those pertinent to the degraded vault scenario (Sect. 3.3.1.2).

\subsubsection{Intact vault model}

Two scenarios were addressed with vaults and monoliths assumed to be intact (Sect. 3.1.3.5): 1) an intact vault with an intact upper moisture barrier (Sect. 2.4); and 2) an intact vault with a completely degraded upper moisture barrier, in which the perpeability of the upper region is that of the backfill soil. In both cases, the lower clay/gravel drain system is assumed to be intact. In either scenario, the influx of water determined through the two upper regions (Fig. 3.3-1) is assumed constant. For a nondegraded cover system, no consideration is given to the time required for the flux through the cover to achieve steady-state in the subsequent flow and transport simulations; a steady-state flux through the cover is assumed at time zero. For the degraded cover scenario, the steady-state flux through the upper region is assumed to be equivalent to the average annual infiltration rate, or $40 \mathrm{~cm} / \mathrm{year}$ determined in Appendix A.1.1. However, transient simulations are carried out for the lower region (Fig. 3.3-1) to evaluate the effect that placement of the vaults and cover system have on flow and transport in an exvironment accustomed to receiving an infiltration rate of $40 \mathrm{~cm} / \mathrm{year}$.

In order to assess the distribution, and subsequent mass transport through the lower region (Fig. 3.3-1) of the model for the intact vault scenario, several assumptions were required regarding the material properties of the saltstone, concrete vaults, surrounding soils and the properties of the potential contaminants. Consideration was given to the type and quality of data available, as well as to computational requirements. 
Numerical simulation requires, for practical reasons, averaging of spatial properties. Thus, the conceptual model used to provide a framework for the numerical simulation of the near-field movement of water and contaminants from the SDF relies heavily on such averaging. The subsurface is treated as if it consists of five material types: 1) the backfill or native soil; 2) clay; 3) gravel; 4) concrete; and 5) the saltstone waste form. Each of these materials are treated as if they are homogeneous and isotropic.

Hydraulic properties for each material type are assumed to be adequately described by the following hydraulic parameters: saturated hydraulic conductivity, effective porosity, and moisture characteristic curve. The moisture characteristic curve describes the nonlinear relationship between the matrix potential or pressure head, the moisture content, and the hydraulic conductivity. Details and references for the data and expressions used to quantify the aydraulic properties for each material type in the nearfield model are provided in Appendix A.1.2. A summary of hydraulic properties assumed is provided in Table 3.3-1.

In addition to hydraulic properties, assumptions to allow quantification of mass transport are necessary in the near-field model. Specifically, contaminant-specific sorption coefficients, diffusion coefficients, and radioactive decay constants are required. Dispersivities, which determine the spreading of a simulated contaminant plume, are also needed. Tables of these values for contaminants of significance, and references to their source are provided in Appendix A.1.2.1. Solubility considerations are not explicitly addressed in the near-field model, except through the use of media-specific sorption coefficients which do not distinguish surface sorption from precipitation or other processes causing immobilization.

\subsubsection{Degraded Vault and Saltstone}

Twó scenarios were addressed for vaults and monoliths assumed to be degraded (i.e., cracks present, Sect. 3.1.3.5): 1) a degraded vault with an intact upper moisture barrier (Sect. 2.4); and 2) a degraded vault with a completely degraded upper moisture barrier, in which the permeability of the degraded cover is that of the backfill soil and the clay layer on top of the vault roof. The only parameter required from Table 3.3-1 for the degraded case is the hydraulic conductivity of the clay on the $\mathrm{rc}$ of of the vault.

A simplified conceptual model is used to represent the degraded condition of the saltstone and surrounding concrete vault. Two factors contributed to this decision: 1) numerical difficulties associated with modeling fractures in a groundwater computer code and 2) large uncertainty associated with inputs such as the timing, frequency, and size of fractures in the saltstone. Sensitivity analyses are then used to consider a range of possible input values and provide an indication of the impact that changes in the inputs have on the results. Such analyses also provide a set of results that form an envelope around the possible results. Results of sensitivity analyses are discussed in this section and Sect. 4.2.1. 
Table 3-1 Summary of hydraulic properties assumed in the near-field model

\begin{tabular}{|l|c|c|c|c|c|}
\hline Material & $\begin{array}{c}\mathbf{K}_{\mathbf{r}}^{-1} \\
\left(\mathrm{~cm} \mathrm{~s}^{-1}\right)\end{array}$ & $\begin{array}{c}\text { Effective } \\
\text { porosity, } \\
\boldsymbol{\theta}_{\mathrm{s}}\end{array}$ & $\begin{array}{c}\text { Residual } \\
\text { moisture } \\
\text { content, } \theta_{\mathrm{r}}\end{array}$ & $\begin{array}{c}\alpha \\
\left(\mathrm{cm}^{-1}\right)^{a}\end{array}$ & $\mathrm{n}^{a}$ \\
\hline Backfill & $1.0 \times 10^{-5}$ & 0.44 & $\mathrm{na}^{b}$ & $\mathrm{na}^{b}$ & $\mathrm{na}^{b}$ \\
\hline Clay & $7.6 \times 10^{-9}$ & 0.39 & 0.115 & $8.2 \times 10^{-4}$ & 1.33 \\
\hline Gravel & 0.5 & 0.38 & 0.010 & $8.2 \times 10^{-2}$ & 3.70 \\
\hline Concrete & $1.0 \times 10^{-10}$ & 0.08 & 0.064 & $7.5 \times 10^{-7}$ & 1.57 \\
\hline Saltstone & $1.0 \times 10^{-11}$ & 0.46 & 0.368 & $7.4 \times 10^{-6}$ & 4.41 \\
\hline
\end{tabular}

- Fitting parameter for van Genuchten and Mualem expressions for moisture characteristic curves.

- A Stone's correlation curve was used to describe the moisture characteristic curve for the backfill.

- Saltstone, concrete, gravel, and backfill properties not required for fractured saltstone case. 
The conceptual model of a degraded vault and saltstone waste form assumes, as discussed in Sect. 3.1.3.5, that: 1) all monoliths and vaults in the facility are fractured, 2) fractures occur every $3 \mathrm{~m}, 3$ ) all fractures open simultaneously, 4) the fractures are assumed to open at closure of the facility, when remediation of cracks will no longer be routine, 5) transport is assumed to be diffusive (constant diffusion coefficient) out of the intact saltstone matrix and into the fracture where transport is assumed to be dominated by advection (i.e., the fracture case results are independent of the hydraulic conductivity of the saltstone), 6) the clay is assumed to sit immediately on top of the saltstone, and 7) the base of the saltstone is assumed to be adjacent to the backfill soil beneath the vault. Since the majority of the degradation occurs to the vault as opposed to the saltstone, for the vault is conservatively neglected as a barrier to transport. Thus, this case addresses flow and transport through the fractured saltstone. The fractures are assumed to be $0.005 \mathrm{~cm}$ in aperture; filling or plugging by soils or precipitates is not considered. Diffusion is assumed to be the only mechanism of transport of radionuclides and nitrate from the saltstone matrix to the fractures, and advection is assumed to be the only means of transporting these potential contaminants from the fractures to the soil beneath the vaults.

This simplified model is considered to be a bounding case on release from fractured vaults because fracturing of the vaults is expected to increase the effective permeability of the vaults, and thus increase radionuclide and nitrate release. The release rate would increase as the number of fractures increases. However, release rates for soluble species would likely decrease with time, as the resident pore water is flushed from the fracture, and diffusion from the saltstone ratrix would then control the concentration in the fracture. Therefore, assuming simultaneous opening of all fractures is believed to represent an upper bound on release rates. Remediation of fractures that occur before closure involves filling with epoxy upon discovery. Degradation of the epoxy is likely to be a gradpal process rather than immediate. Furthermore, shrinkage cracks in pours may be filled to some extent by subsequent pours. This would also reduce the flow rate through fractures.

Details of the various submodels that were used to adapt a model for flow and transport in fractures, to which semi-analytical solution techniques could be applied, are provided in Appendix A.1.3. Some of the critical assumptions, however, are noted here since they are fundamental to the conceptual approach and the resulting analytical model. One of the primary underlying assumptions is that the fractures remain saturated once they open. Another critical input necessary to evaluate the flow of water through a fracture is the height of water perched on fractured vaults. The intact vault model (Appendix A.1.2.1) was used to predict the depth of the perched water on the vault. Perched water is shown to occur on an intact vault, and the assumption of saturated flow is assumed to be reasonable. These assumptions are discussed in more detail in Appendix A.1.3.

For the fractured saltstone, effective flow rates and subsequent transport were estimated based on the methods described in Appendix .A.1.3. 


\subsection{Groundwater Transport Model}

A brief summary of the conceptual model of the subsurface transport of radionuclides in the saturated zone is provided here, while a more detailed description is given in Appendix A.2. Radionuclides that leach from the SDF will eventually reach the water table unless their half-lives are sufficiently short relative to the transport time in the unsaturated zone. Radionuclides that reach the water table, as determined in the near-field models for both intact and degraded vaults (Sect. 3.3.1), would be transported in the saturated zone beneath the facility to discharge points along nearby streams; specifically, Upper Three Runs Creek, McQueen and Crouch Branches (Fig. 2.1-2). The three hydrologic units (Appendix A.2) of interest, Zones 5a (Congaree Formation), Zone 5b (Green Clay), and Zones 6/7/8 (Santee/Dry Branch/Tobacco Road Formations), are incised to varying degrees by the creeks. Zone 6, 7, and 8 are dissected by all creeks to some degree, while Zones $5 \mathrm{a}$ and $5 \mathrm{~b}$ are incised only by Upper Three Runs Creek.

To model saturated flow, a numerical approach was adopted for the following reasons. First, although analytical models are available to predict maximum downgradient concentrations in a constant flow field, they generally require simplifications and assumptions that were not acceptable for this RPA. First, analytical approaches require that a flow field be specified and remain constant throughout the flow domain for the simulation time period. In this analysis, however, it was necessary to predict the flow field as a result of the presence of the facility, which limited recharge from precipitation. Although the effect of limiting recharge under the facility was found to be minor on the flow field affecting contaminant transport, this could not be predicted a priori. Second, due to the presence of the continuous, semi-confining Green Clay hydrologic unit beneath Z-Area, it was necessary to consider mass transport in three-dimensions, taking into account the interaction between the various hydrologic units. Although one might predict that the Green Clay would limit mass transport to the lower Congaree unit, which is more likely to be developed for a water supply than the upper water table unit, the numerical simulations indicated a large enough gradient across the Green Clay such that potential contamination of the lower unit is significant. Therefore, a numerical approach to simulating saturated flow and mass transport under Z-Area was adopted.

The computer code PORFLOW-3D (Runchal and Sagar 1991) was used to simulate groundwater flow under Z-Area. PORFLOW-3D is a three dimensional code capable of simulating multi-phase fluid flow in variably saturated porous or fractured media. The PORFLOW-3D computer code is described in detail in Appendix B.5. The purpose of this section is to briefly describe the system simulated with this computer code with respect to the physical boundaries of the model domain, the assumptions made regarding the hydrologic characteristics within that domain, and the assumptions macle regarding physical characteristics of the porous media and chemical characteristics of the radionuclides that affect mass transport in groundwater. A more in-depth treatment of the conceptual saturated flow and transport model is provided in Appendix A.2. A description of the method by which the conceptual model described below is represented by PORFLOW-3D simulations is provided in Sect. 3.4.2. 


\subsection{Model Domain}

The hydrologic setting at Z-Area is conceptualized as a three-dimensional domain, due to the divergent nature of the flow in the aquifers of interest. Available well logs indicate that the Green Clay (Zone $5 b$ ) is continuous over the model area, thus, necessitating incorporation of this semi-confining unit in the conceptual model. The model domain in the saturated zone beneath the SDF is defined by the lateral and vertical extent of interest; i.e., that volume which is believed potentially subject to contamination by radionuclides. At Z-Area, the creeks in part (i.e., to the east, west, and north) define the lateral boundaries of flow for the hydrologic units of interest; i.e., Zones $6 / 7 / 8$, 5b, and 5a. Piezometric measurements indicate that groundwater in these zones flow towards, and discharges to, these creeks (Appendix E). The topographic watershed divide, where surface water is not bounding, serves as the southern boundary for these aquifers in the vicinity of Z-Area.

Vertically, the domain is divided into three layers corresponding to the three hydrologic units which potentially would be involved in transport of radionuclides originating in the SDF. The upper unit, Zone 6/7/8, is the water table unit. The Green Clay unit, Zone $5 b$, is semi-confining due to its low conductivity. The lower unit, Zone 5a, was considered the lowest unit of interest, because of the underlying lowpermeability sediments and piezometric data indicating an upward flow direction from the underlying unit (Zone 3a). The existence of these natural conditions precludes the possibility of deeper migration of contaminants. These units are described in detail in Appendix E.

\subsubsection{Model Assumptions}

\section{Hydraulic characteristics}

The model domain, described above, requires a number of assumptions. First, constant head boundaries for the water table aquifers are assumed along Upper Three Runs, McQueen, and Crouch Branches. This assumption is considered to be a good approximation. The extent of surface flow has been verified by recent stream gaging that measured significant groundwater discharge from the water table aquifers into these creeks (Sect. 3.4.2.1). The upper or southern boundary for these water-table aquifers is assumed to be a no-flow boundary and is defined along the watershed, or drainage, divide. The boundary conditions are described further in Appendix A.2.1.

For the lower aquifer and aquitard within the model domain, Zones $5 \mathrm{a}$ and $5 \mathrm{~b}$, respectively, only Upper Three Runs Creek is considered a constant-head boundary, since the other streams do not incise these zones. No-flow boundaries are assumed for the lateral boundaries underneath McQueen and Crouch Branches, as flow is approximately parallel to these streams in Zone 5a. The southern boundary, which for the overlying zones is the drainage divide, is assumed to be a constant flux boundary in Zone $5 \mathrm{a}$. For Zone 5b, the green clay, the southern boundary is considered a no-flow boundary. 
The three zones conceptualized for the groundwater model are considered to be homogeneous and anisotropic for computational purposes. While the assumption of homogeneity is a generally gross simplification of the real aquifers, computational methods require it. It is recognized that homogeneity does not exist in the aquifers of concern, but by assuming that vertical hydraulic conductivities of the units are significantly less than the horizontal conductivities (i.e., anisotropy) allows some accounting for the effect of interbedded clay layers within the aquifers which are believed to hinder vertical movement. Values of hydraulic conductivity for the groundwater flow and transport simulations were selected from studies done over the last ten years at Z-Area, the results of which are documented in Table 2.2-1, and on the basis of the model calibration process, documented in Sect. 3.4.21. The horizontal and vertical hydraulic conductivities for the three hydrologic units assumed for the simulations in this RPA are listed in Table 3.3-2.

Table 3.3-2 Hydraulic conductivities for saturated zone simulations

\begin{tabular}{|c|c|c|}
\hline Hydrologic Unit & $\begin{array}{c}\text { Horizontal Hydraulic } \\
\text { Conductivity }\left(\mathrm{m} \mathrm{s}^{-1}\right)\end{array}$ & $\left.\begin{array}{c}\text { Vertical Hydraulic } \\
\text { Conductivity (m s}\end{array}\right)$ \\
\hline $6 / 7 / 8$ & $6 \times 10^{-6}$ & $4 \times 10^{-6}$ \\
\hline $5 b$ & $4 \times 10^{-8}$ & $3 \times 10^{-9}$ \\
\hline $5 \mathrm{a}$ & $6 \times 10^{-5}$ & $6 \times 10^{-6}$ \\
\hline
\end{tabular}

The annual average recharge of the water table aquifers is assumed to be $40 \mathrm{~cm} \mathrm{yr}^{-1}$ based on the analysis in Sect. A.1.1, in the absence of the facility. With the facility present, recharge is diverted with gravel drains, and thus, is reduced directly under the facility. The recharge under the facility was estimated for all scenarios to be approximately $0.2 \mathrm{~cm} \mathrm{yr}^{-1}$ from the near-field analysis.

\section{Mass transport parameters}

Mass transport in the saturated zone occurs by advective, diffusive, and dispersive processes, but is hindered by sorptive processes. In the saturated zone, advective transport is sufficient to render diffusive transport relatively insignificant. Mechanical dispersion, which causes spreading of the plume both longitudinally along, and transverse to, a contaminant plume is not expected to be important for the SDF because the area of the source (i.e., area of the SDF) is large. Spreading of the plume from such a large source will not significantly reduce concentrations at a point $100 \mathrm{~m}$ from the facility, the compliance point for groundwater protection assumed in this RPA. Other characteristics of the porous media that affect mass transport simulations include density and porosity of the media. Values of the aquifer matrix-specific parameters assumed in the mass transport simulations are listed in Table 3.3-3. 
Table 3.3-3 Aquifer matrix-specific mass transport parameters

\begin{tabular}{|l|c|}
\hline Matrix Property & Assumed property value \\
\hline Effective diffusion coef. & $5 \times 10^{-10} \mathrm{~m}^{2} \mathrm{~s}^{-1} \mathrm{a}$ \\
\hline Longitudinal dispersivity & $3 \mathrm{~m}^{6}$ \\
\hline Transverse dispersivity & $0.3 \mathrm{~m}^{b}$ \\
\hline Matrix density & $2650 \mathrm{~kg} \mathrm{~m}^{3 c}$ \\
\hline Total porosity & $0.40^{d}$ \\
\hline Effective porosity & $0.30^{\circ}$ \\
\hline
\end{tabular}

- Chosen from a range given for coarse-grained and clayey geologic deposits (Freeze and Cherry 1979).

- Estimated in lieu of site specific data from Freeze and Cherry (1979).

- Estimated from dry bulk density of $1600 \mathrm{~kg} / \mathrm{m}^{3}$ (Dennehy et al. 1989) and in agreement with average value for mineral soils (Freeze and Cherry 1979).

d From data for Z-Area soils (Table A.2-2).

- An approximation from de Marsily (1986), corresponding to a total porosity of 0.40 . 
Characteristics of contaminants that are needed to simulate mass transport are sorption coefficients, or $\mathrm{Kd}$ 's, and half-lives of radioactive decay.

The value of Kd varies with the contaminant and the media to a large degree. The values used for the saturated zone are consistent with those used in the near-field model (Sect 3.3.1), and were site-specific when possible. Table A.1-2 of Appendix A.1.2 lists the Kd's used for backfill in the near-field model, which are the same as those in the saturated zone modeling. Half-lives of radioactive decay are listed in Table C.1-1.

\subsubsection{Models for Dose Estimation}

As described in Sect. 3.2.3 and 3.2.4, two basic exposure situations are considered in the performance assessment for the Z-Area SDF. The first is exposure of members of the general public following transport of radionuclides beyond the boundary of the disposal site, and the second is exposure of inadvertent intruders onto the disposal site following loss of active institutional control at $\mathbf{1 0 0}$ years after facility closure. In each case, models for calculating radiation dose from estimated concentrations of radionuclides in the environment are required.

\subsubsection{Models for Estimating Dose to Off-Site Individuals}

The different transport pathways for exposure of off-site members of the public following release of radionuclides from the SDF are discussed in Sect. 3.2.3. The two principal pathways of concern are transport in groundwater following mobilization of radionuclides by infiltrating precipitation and transport in air following releases of volatile radionuclides to the atmosphere. However, an analysis presented in Appendix A.3 shows that doses to off-site members of the public following releases to the atmosphere are negligible. Thus, only the groundwater pathway needs to be analyzed in estimating doses beyond the boundary of the disposal site.

For transport of radionuclides via the groundwater pathway, an analysis presented in Sect. 3.2.3.3 then shows that the only exposure pathway of concern for off-site members of the public is direct consumption of contaminated drinking water obtained from a well beyond the boundary of the disposal site. The drinking water pathway is subject to a limit on EDE of $4 \mathrm{mrem}$ per year, assuming consumption of $2 \mathrm{~L} /$ day of water from the contaminated source. The analysis in Sect. 3.2.3.3 shows that, at the SRS, the dose limit for the drinking water pathway is more restrictive than the limit on EDE of 25 mrem per year from all exposure pathways. Therefore, doses from other exposure pathways involving use of contaminated groundwater need not be considered in the dose analysis for off-site members of the public. 
The model for estimating dose from the drinking water pathway is presented in Appendix A.4.5.1. The model uses, as input, the maximum concentrations of radionuclides in groundwater at any location beyond the boundary of the disposal site, and at any time after disposal, as obtained from the models for mobilization and transport of radionuclides described in Sect. 3.4. The model for the drinking water pathway is summarized in Table A.4-6 of Appendix A.4. For each radionuclide, the factor in this table gives the EDE in rem/year from the drinking water pathway for a unit concentration in groundwater of $1 \mu \mathrm{Ci} / \mathrm{L}$. Thus, the annual dose from any radionuclide is simply obtained by multiplying the estimated maximum concentration in groundwater by the factor given in this table.

\subsubsection{Models for Estimating Dose to Inadvertent Intruders}

The different exposure scenarios and exposure pathways for inadvertent intruders assumed for the SDF are discussed in Sect. 3.2.4. The principal exposure scenarios of concern involve direct intrusion into the disposal facility or into contaminated soil adjacent to disposal units. Doses to inadvertent intruders resulting from use of contaminated groundwater obtained from a well on the disposal site are negligible compared with the doses from direct intrusion into solid waste, because the maximum permissible doses from the groundwater pathway are only a small fraction of the dose limits for inadvertent intruders from all exposure pathways. The analysis in Appen$\operatorname{dix}$ A.3 also shows that doses to inadvertent intruders following release of volatile radionuclides to the atmosphere can be neglected.

The discussion of possible exposure scenarios for inadvertent intruders in Sect. 3.2.4 shows that only four scenarios need be considered in the analysis for the SDF. All of these scenarios involve chronic exposure and, thus, are subject to a limit on EDE from all exposure pathways of $\mathbf{1 0 0}$ mrem per year. These scenarios include 1) an agriculture scenario involving direct intrusion into disposal units at any time after the concrete vaults and top layer of the saltstone monoliths have lost their structural and physical integrity, 2) an agriculture scenario involving excavation of contaminated soil above disposal units at any time after loss of active institutional control, 3) a resident scenario involving permanent residence in a home located immediately above an intact concrete vault or saltstone monolith at any time after loss of active institutional control, and 4) a postdrilling scenario involving excavation of contaminated soil along the side of disposal units at any time after loss of active institutional control. The discussion in Sect. 3.2.4 shows that other scenarios involving chronic or acute exposure either are not credible for the SDF, would result in lower doses than the scenarios considered in the analysis, or are subject to a higher dose limit in the case of acute exposure scenarios (i.e., 500 mrem) and, thus, would be less restrictive than the chronic exposure scenarios considered in the analysis. 
The models for estimating dose for the four chronic exposure scenarios for inadvertent intruders considered in this analysis are presented in Appendix A.4.5.2. The model for each scenario uses as input the maximum concentrations of radionuclides in the disposal facility or in contaminated soil adjacent to disposal units at any time after the scenario is first assumed to be credible. The concentrations of radionuclides in disposal units and adjacent soil over time are estimated using the models for mobilization and transport of radionuclides described in Sect. 3.4. The models for the two agriculture scenarios, the resident scenario and the post-drilling scenario, are summarized in Tables A.4-14, A.4-15, and A.4-16, respectively, of Appendix A.4. For each radionuclide and exposure scenario, the factor in the appropriate table gives the EDE in rem/year for a unit concentration in the disposal facility or in soil of $1 \mu \mathrm{Ci} / \mathrm{m}^{3}$. Thus, for any scenario, the annual dose from any radionuclide is simply obtained by multiplying the estimated maximum concentration in either the disposal facility or contaminated soil by the factor given in the table for that scenario.

\subsection{PERFORMANCE ANALYSIS METHODOLOGY}

This section describes the computational methods used to implement conceptual models for release and transport of saltstone constituents. As discussed in Sect. 3.1, several separate scenarios were analyzed. One analysis addressed the performance of a fully intact facility; the others considered performance of a facility of which various engineered features have degraded.

Analyses of potential pathways of transport of saltstone constituents through the environment (Sect. 3.2.2) to receptors (Sect. 3.2.3 and 3.2.4) indicate that soil and groundwater concentrations will dominate the performance of the facility. Thus, the computational analyses focussed on determining concentrations in these media for both an intact and degraded facility, and on doses received as a result of such concentrations. These analyses were aided by the use of several computer codes, which are described in detail in Appendix B. Integration of the results of various computations was accomplished in the manner outlined in Fig. 3.4-1, for the intact facility, and Fig. 3.4-2, for the degraded facility. The manner in which each of the computer codes and analytical techniques were adapted to address the conceptual model is described in detail in the following sections.

\subsubsection{Near-Field Model Analysis}

Computational software (i.e., WingZ, MathCAD, Mathematica) and sophisticated computer codes (i.e., MINTEQ, PORFLOW-3E) were used in the near-ineld analysis of the SDF. The software and computer codes were applied to analyze or predict: 1) waste inventories at vault closure; 2) degradation of the concrete; 3 ) geochemical conditions in the saltstone pore-fluid; 4) water flow patterns and travel-times through the vadose zone; and 5) contaminant migration patterns and fluxes to the aquifer. The interrelationships of these computational categories are illustrated in Fig. 3.4-3 below.

Rev. 0 


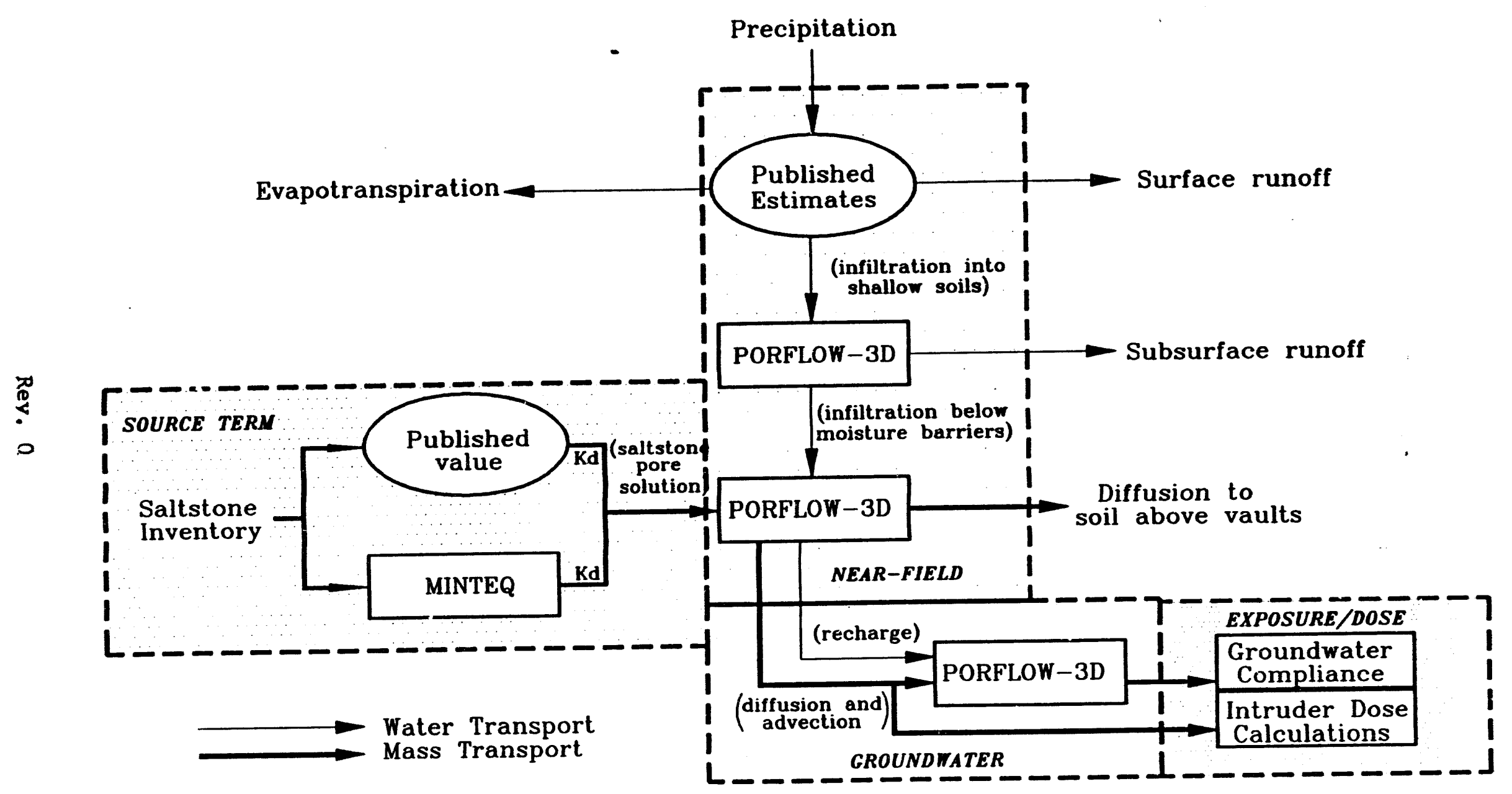

Fig. 3.4-1. Integration of computational methods for the Radiological Performance Assesssnent of intact Saltstone Disposal Facility vaults. 

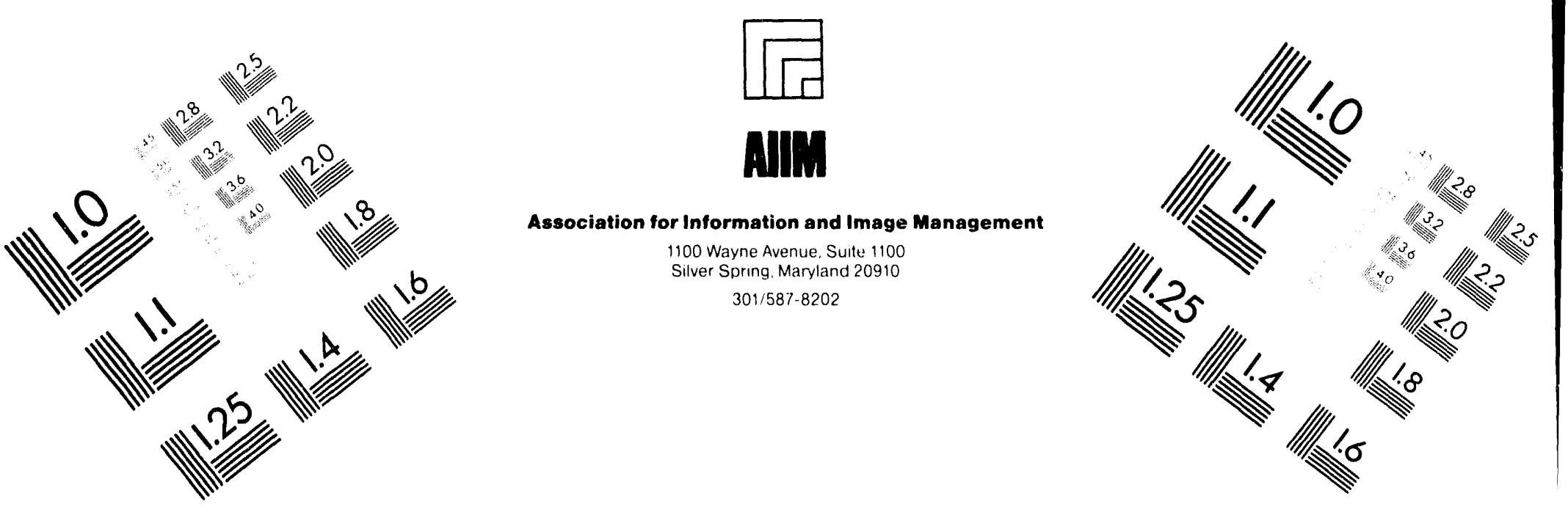

\section{Centimeter}

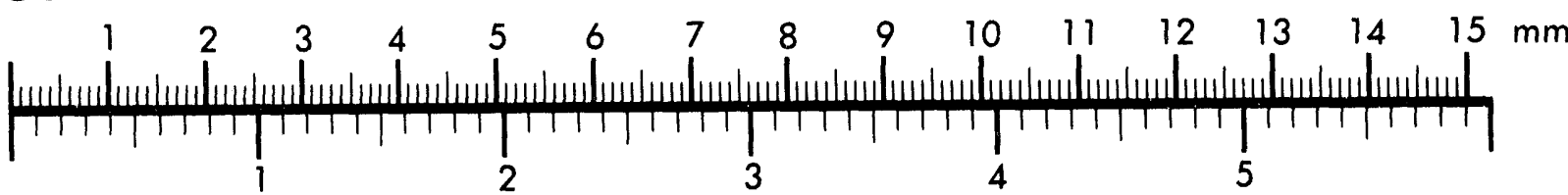

Inches
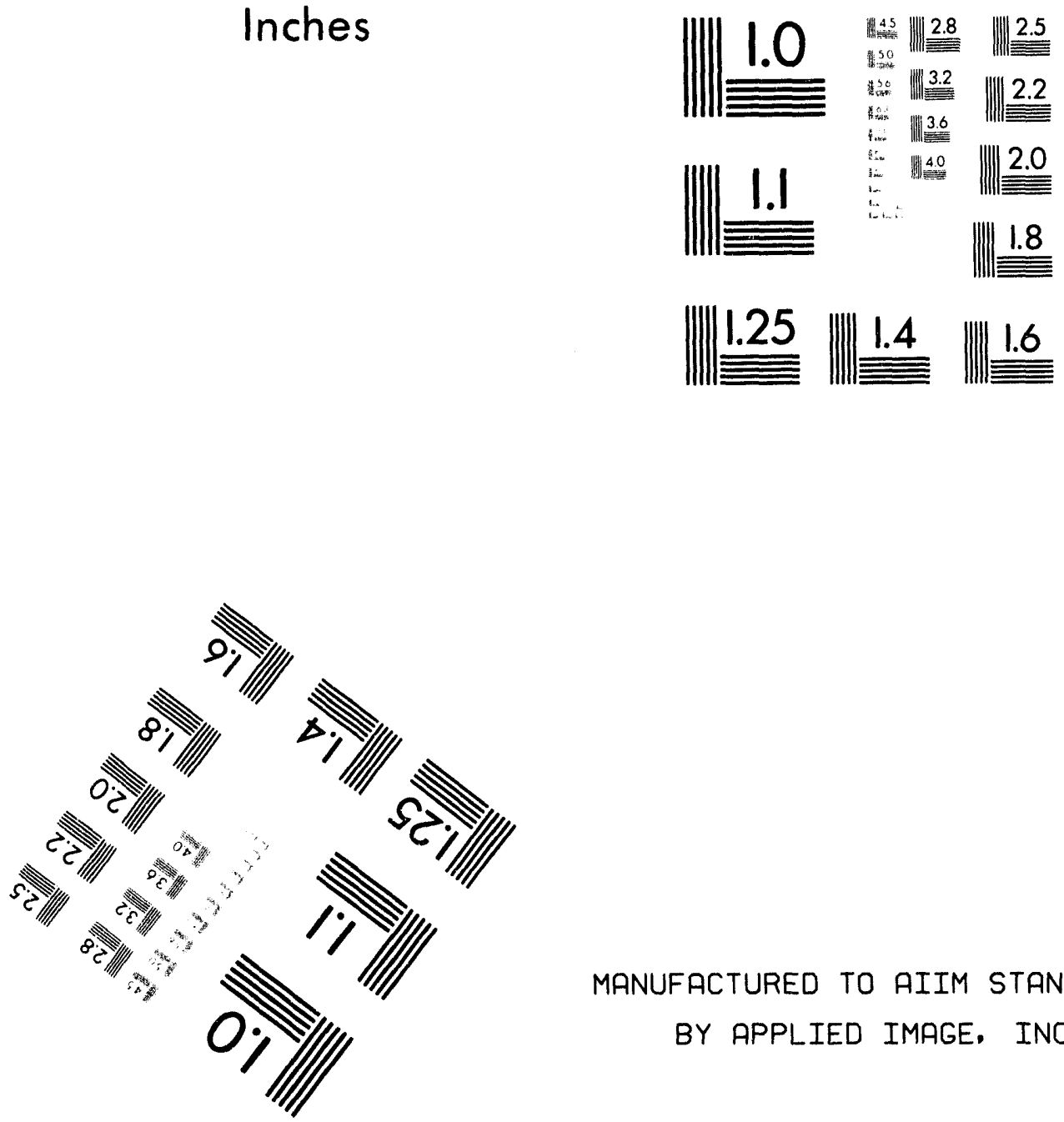

MANUFACTURED TO AIIM STANDARDS

BY APPLIED IMAGE, INC.

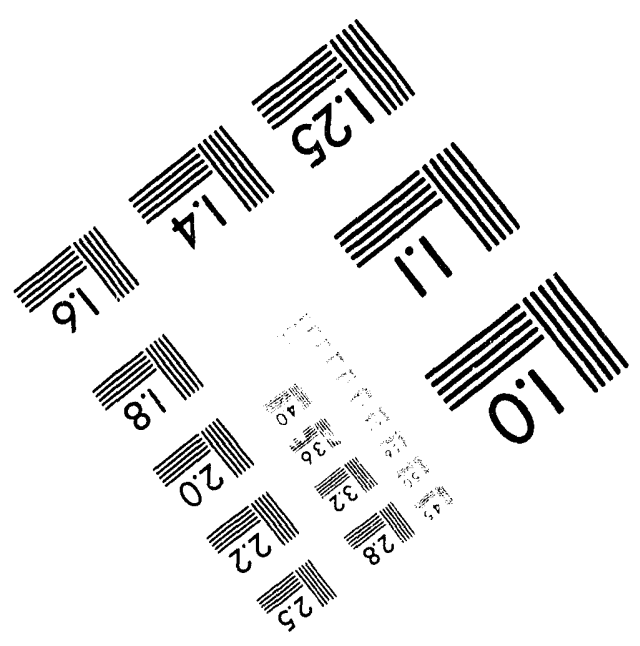



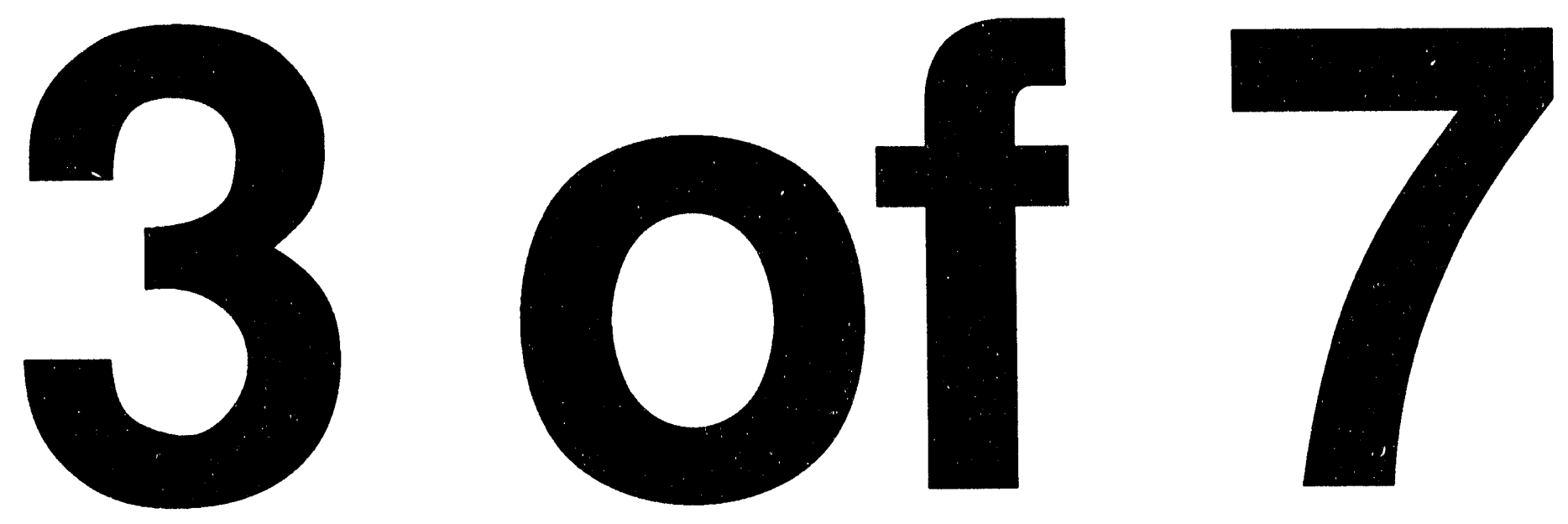
Precipitation

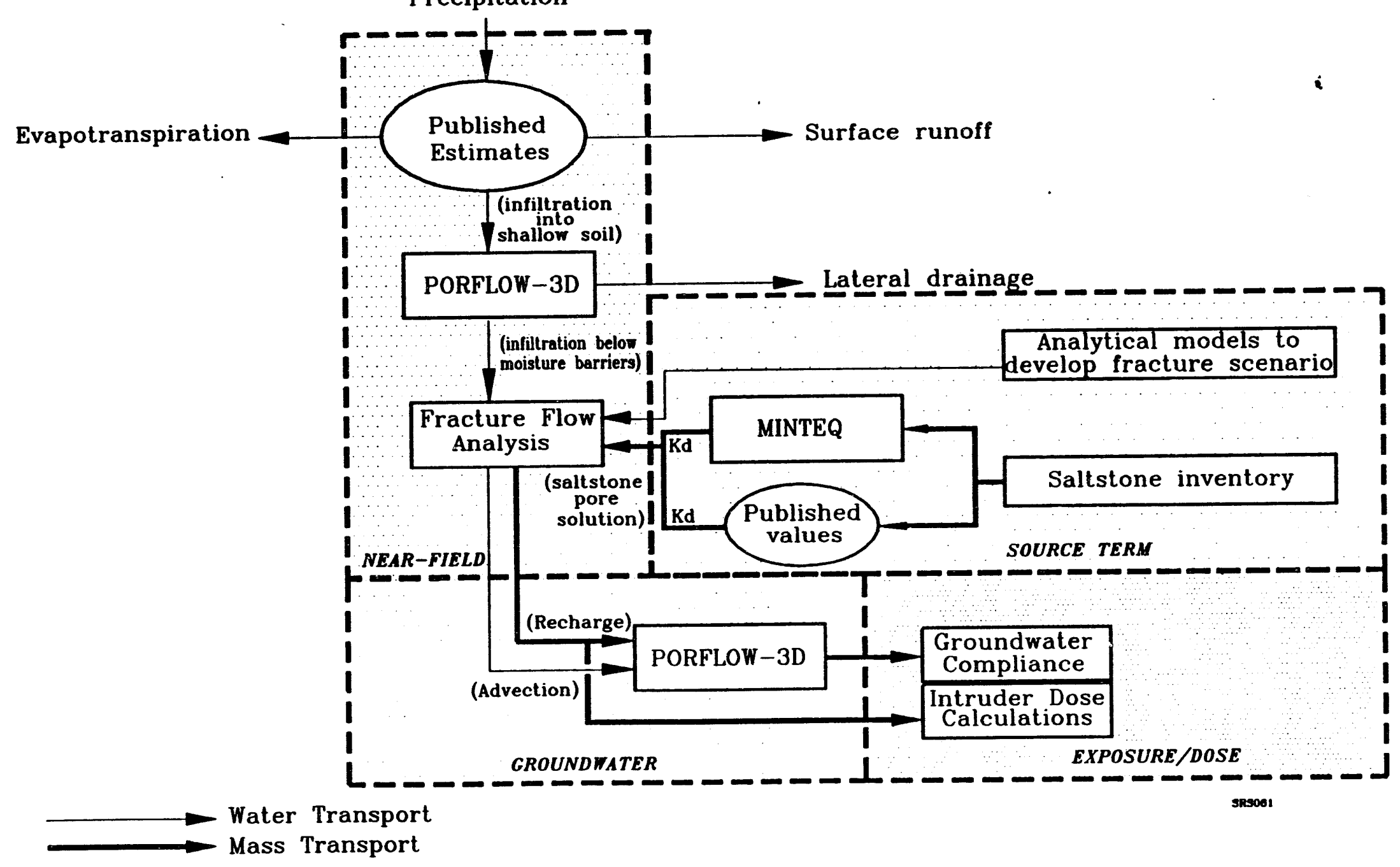

Fig. 3.4-2. Integration of computational methods for the Radiological Performance Assessment of degraded Saltstone Disposal Facility vaults. 


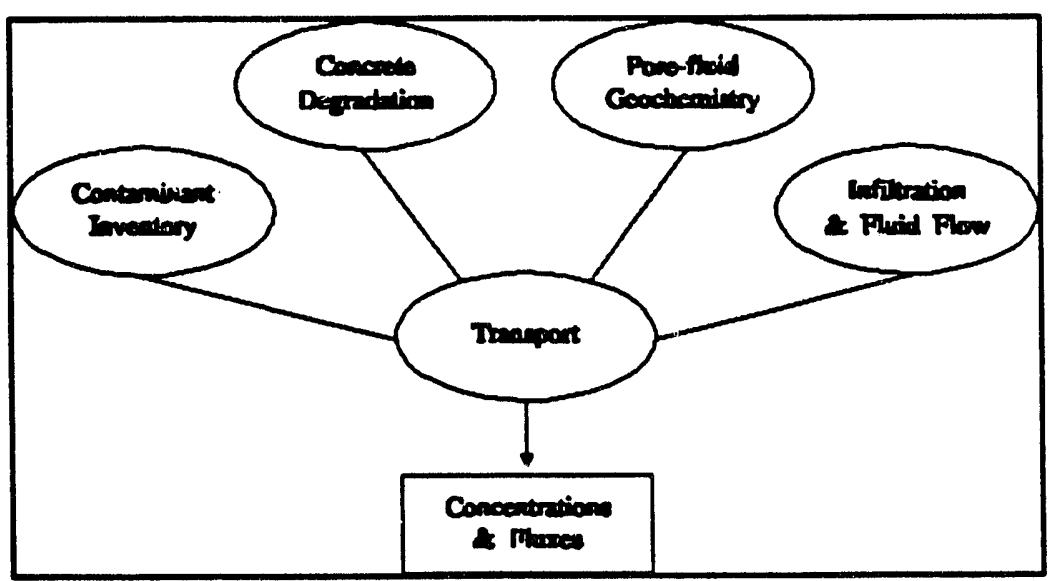

Fig. 3.4-3. Interrelationships of near-field performance assessment computations. 
A complex sequence ul computations and computer simulations were performed to answer the following technical questions:

- What are the contaminant concentrations in the saltstone at vault closure?

- Which of the numerous radioactive and chemical constituents in the saltstone are likely to control the long-term performance of the disposal system?

- What are the pore-fluid concentrations of the key contaminants in the saltstone and what geochemical conditions may control the release rates?

- What is the average infiltration rate into the vadose zone?

- What are the likely water flow paths and average travel-times through the cover materials and vaults?

- As the cover and vaults degrade, what quantities (i.e. concentrations and fluxes) of contaminants will reach the underlying aquifer?

This section describes the computational methods and simulation approaches that were used in the near-field analysis. Methods and approaches have been divided into several sections. Intact and degraded vault scenarios were used in the performance assessment. The first discussion addresses methods and approaches pertinent to both scenarios, followed by a discussion of the intact vault scenario approach and finally a degraded vault approach.

\section{Contaminant inventory computations}

Initial inventories of radioactive and chemical constituents in the saltstone were estimated by WSRC, as described in Sect. 3.1.1. These data were entered into a spread sheet data base and then converted to consistent units. For radioactive constituents, activities were decayed to account for the 30 years operational period of the saltstone facility.

\section{Concrete degradation computations}

The general methodology of Walton et al. (1990) was used to investigate degradation of the structural and hydraulic properties of the vault (Sect. 3.1.3). The methodology, which consists of empirical relationships and diffusion submodels, provides a basis for predicting the degradation penetration depth. To specialize the methodology for the saltstone vaults, mathematical relationships were modified to account for the specific composition of the concrete (e.g., water-to-cement ratio, carbonate content, thickness, etc.) and the pore-water chemistry ( $\mathrm{pH}$, carbonate, sulfate and magnesium concentrations, etc.) of the vadose zone.

The degradation methodology was implemented using the commercial computational software Mathematica (Wolfram 1991). The computations with this methodology provided:

- Identification of the dominant degradation processes, and

- penetration depth (i.e., wall degradation thickness). 
A parametric analysis of concrete degradation was carried out to identify the combinations that might lead to significant degradation.

\section{Infiltration and fluid flow computations}

Net moisture flux at the soil surface and through the vadose zone are two primary factors controlling contaminant release and transport rates in the vadose zone. Estimates of the average annual infiltration rate at the site were obtained from previous investigations (Appendix A.1.1). The estimated infiltration rate was then used as a boundary condition for two-dimensional simulations of water flow through the clay and gravel cover and the subsurface region containing the vaults and saltstone.

Two-dimensional simulations of water flow through the vadose zone were performed using the PORFLOW-3D code. These computations were used, in turn, to:

- estimate the net moisture flux through the cover (i.e., gravel-clay layers),

- define the primary flow paths (i.e., streamlines) from the soil surface, through the cover materials, backfill and vault, and to the water table, and

- estimate the water travel-times (i.e., residence times) along the flow paths.

Fluid flow simulations were performed for two distinct subregions of a portion of the SDF. These subregions consisted of: 1) upper moisture barrier (soil, gravel and clay) and 2) a cross-section of a vault and surrounding materials (clay, gravel, vault, saltstone, backfill, and native soil).

\subsubsection{Intact Vault Analysis}

Implementation of the conceptual near-field model of intact vaults was accomplished in the manner summarized below. Details of the simulation techniques are provided in Appendix A.1.2.

\section{Contaminant transport computations}

Mass transport simulations were performed to predict the distribution of the key contaminants as a function of such factors as their initial concentrations, solubilities, pore-water velocities and dispersivities. For consistency with the fluid flow computations, the PORFLOW-3D code was used to perform two-dimensional simulations of contaminant transport. Results were then post-processed using commercial graphing software (e.g., SURFER, GRAFTOOL, and TECPLOT) to produce visualizations of the results of transport computations. 


\section{Pore fluid geochemistry computations}

In order to model mass transport in heterogeneous media, one must estimate the contaminant concentrations in the pore fluid of the saltstone and how they relate to total concentrations in the porous media (contaminant on or in the solid phase plus contaminant in aqueous phase).

The problem of relating total inventory to pore fluid concentrations in saltstone is complicated by several factors including: 1) precipitation/dissolution reactions involving contaminants; 2) complex formation in solution; and 3) sorption. All of these processes are poorly understood and difficult to quantify. The presence of slag in the saltstone mix has been observed to lower the release rate of several components.

The chemical complexities of saltstone were simplified to be consistent with models which consider only reversible linear sorption (i.e., Kd's). Within this context two general approaches are possible:

1) Use theoretical geochemical codes (such as MINTEQ) to estimate Kd's of each contaminant. Assume the contaminants are released from the solid by linear reversible sorption.

2) Obtain Kd's from pertinent literature for each contaminant, using conservative values within the given range.

Both of these approaches were used to compute initial pore solutions in the manner described in Sect. A.1.2.2. The results of the first approach are documented in Appendix D for Tc-99. The remainder of the contaminants of interest used only the second approach (Appendix A.1.2.2) to address contaminant/cement reactions.

The primary output of the intact vault computations were 1) fluid concentration distributions in the vadose zone, 2) mass flux histories at the water table, and 3) mass concentrations in soil adjacent to the vault. In addition, the transport computations were performed in a manner allowing parametric sensitivity analysis to gain insight regarding the impacts of:

- upper moisture barrier effectiveness on performance,

- the saltstone distribution coefficients on performance, and

- hydrologic parameters on performance.

The mass flux histories at the water table were used as input into the mass transport simulations for groundwater (Sect. 3.4.2); fluid concentration distributions in the vadose zone were used in calculation of intruder doses, as described in Appendix A.4. 


\subsubsection{Degraded Vault Analysis}

Computational techniques applied to analysis of flow and transport through a single fracture are summarized in this section. Supporting details are provided in Appendix A1.3. The manner in which these results were incorporated in the overall assessment of the performance of a degraded vault is discussed in Sect. 3.4.2, where the methodology for determining groundwater concentrations of radionuclides and nitrate is described.

The degraded vault scenario assumes a series of equally spaced parallel cracks through the vault and saltstone (Sect. 3.3.1.2). A three-step process is used to implement the conceptual model for the degraded vault cases (see Fig. 3.4-4). Results of each step contribute to the computations in the following step. The presence or absence of perched water on a fractured vault is a prerequisite to determining the potential for flow to occur through the cracks. Effective permeability of cracked vaults and saltstone is needed to quantify how rapidly the perched water above the vault can be conducted through the fractured media. Finally, the estimated permeability and infiltration rate are then used to estimate the release rate from the crack, based on diffusion to the crack from the unfractured portions of the saltstone and advection to the base of the vaults. Computational analyses of these steps are described in Appendix A.1.3.

Conditions for this conceptual model, where flow is rapid through cracks but transport in the matrix is by diffusion, are difficult to solve numerically, but they are amenable to semi-analytical solutions. A semi-analytical solution was used to model the flow of water through cracks running completely through the vault and their influence on the release of contaminants. This approach assumes that transport in the intact matrix is by diffusion only and transport in the fractures is by advection. The simulation is two-dimensional and gives release rates from, and the concentration in, the fractures over time. The primary limitation of the solution is that a constant rate of flow through the fracture must be assumed. In reality, the flow rate will likely increase with time as the cover fails, as reflected by the degradation scenario (Sect. 3.1.3.5).

Release rates from fractures are translated into mass fluxes at the water table in the following manner. First, a simulation of the unsaturated zone beneath a fracture is carried out with PORFLOW-3D to approximate transit time beneath the fractured vault and saltstone. The input file for this simulation is provided in Appendix C.2. A particle tracking feature of PORFLOW-3D allows approximation of the transit time for water, indicating it is on the order of 1200 years. This information is used to predict arrival time of saltstone constituents released from fractures at the water table, taking account of retardation that occurs as a result of sorption processes. Transit time for non-sorbing species is assumed to be that for water. Transit time in years, $t_{c}$, for sorbing species is estimated from

$$
t_{c}=t_{w}\left[1+\frac{\left(1-\theta_{f}\right) p K_{d}}{\phi}\right]
$$

Rev. 0 


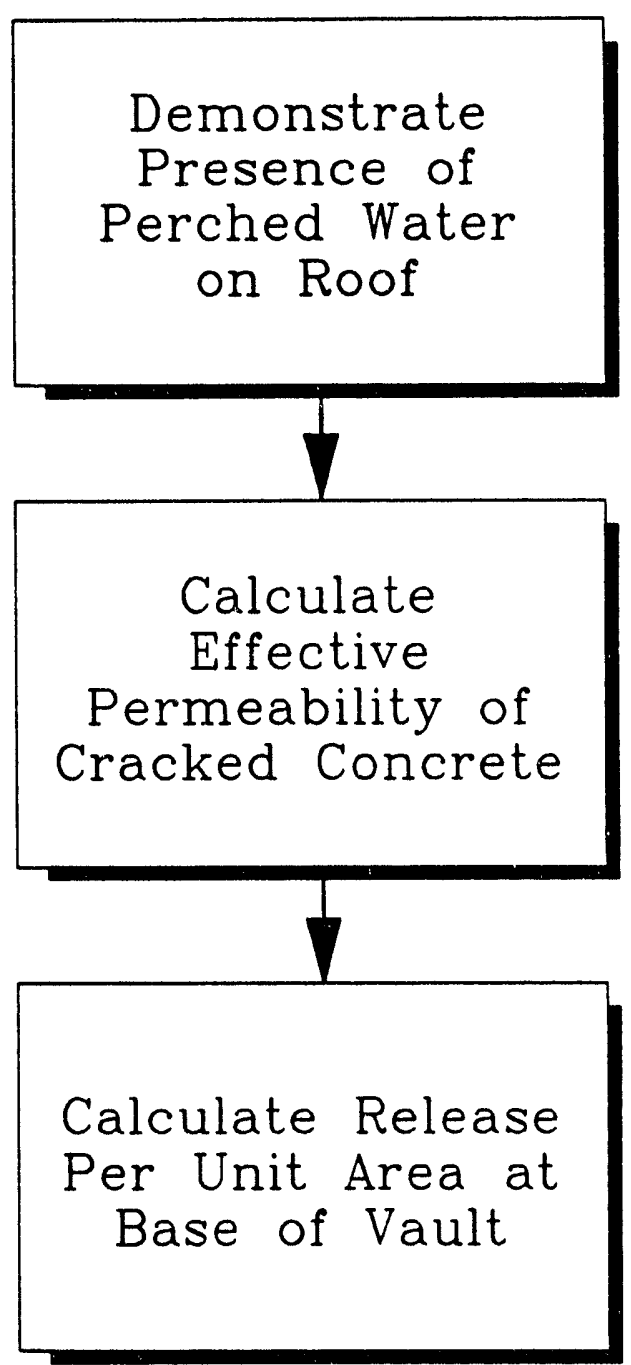

Fig. 3.4-4. Three-steps to implement degraded vault model. 
where

$t_{w}=$ transit time for water (1200 years),

$\theta_{t}=$ total porosity $(0.40)$,

$p_{s}=$ matrix density of soil underlying saltstone vault $(2.65 \mathrm{~g} / \mathrm{cc})$,

$\mathbf{K}_{\mathbf{d}}=$ radionuclide distribution coefficient, in $\mathrm{cc} / \mathrm{g}$, and

$\phi=$ fraction of diffusional porosity filled with fluid (assumed to be 1.0).

Although the fractional moisture content term, $\phi$, varies with depth under the saltstone vaults, it is assumed to be 1.0 , for ease of computation. This in effect shortens the arrival time of sorbing species, and thus, is conservative because less radioactive decay is assumed before radionuclides reach the water table. Radioactive decay is accounted for by assuming the flux out of the fracture $\left(F_{f}\right)$ decays over the time period $t_{c}$. The flux to the water table, $F_{w}$ is calculated from

$$
F_{w}=F_{f} e^{-\lambda_{R} s_{c}}
$$

where $\lambda_{R}$ is the radioactive decay constant $\left(\mathrm{yr}^{-1}\right)$.

\subsection{Groundwater Flow and Mass Transport}

The code PORFLOW-3D (Appendix B.5), developed by Analytical and Computational Research Inc., was used to simulate groundwater flow and contaminant transport in Z-Area. In this section, the means by which the conceptual model for groundwater (described in Sect. 3.3.2) was translated into a computer-simulated model are described.

\subsubsection{1 Ǵroundwater Flow Simulations}

The problem domain consisted of an area defined by the surface water drainages, a drainage divide, and three hydrostratigraphic units as described in Sect. 3.3.2. The model area was discretized into a three-dimensional model consisting of a 49 by 48 by 13 grid as illustrated in Fig. 3.4-5. The three horizontal zones corresponding to the hydrostratigraphic units of interest, specifically Zone 6/7/8 (water table aquifer), Zone $5 \mathrm{~b}$ (the green clay aquitard), and Zone $5 \mathrm{a}$ (the underlying Congaree Formation), were defined in the model input by specifying different hydrologic characteristics for each zone.

The northern model boundary, defined by Upper Three Runs, was designated as a constant head boundary for all of the hydrostratigraphic units. The tributary streams of Crouch and McQueen Branches form the western and eastern boundaries for the water table aquifer (Zones 6/7/8). Nodes corresponding to the surface elevation of the streams were designated as constant head values. The western and eastern boundaries for the remaining hydrostratigraphic units (Zones $5 \mathrm{a}$ and 5 b) were defined as no-flow 


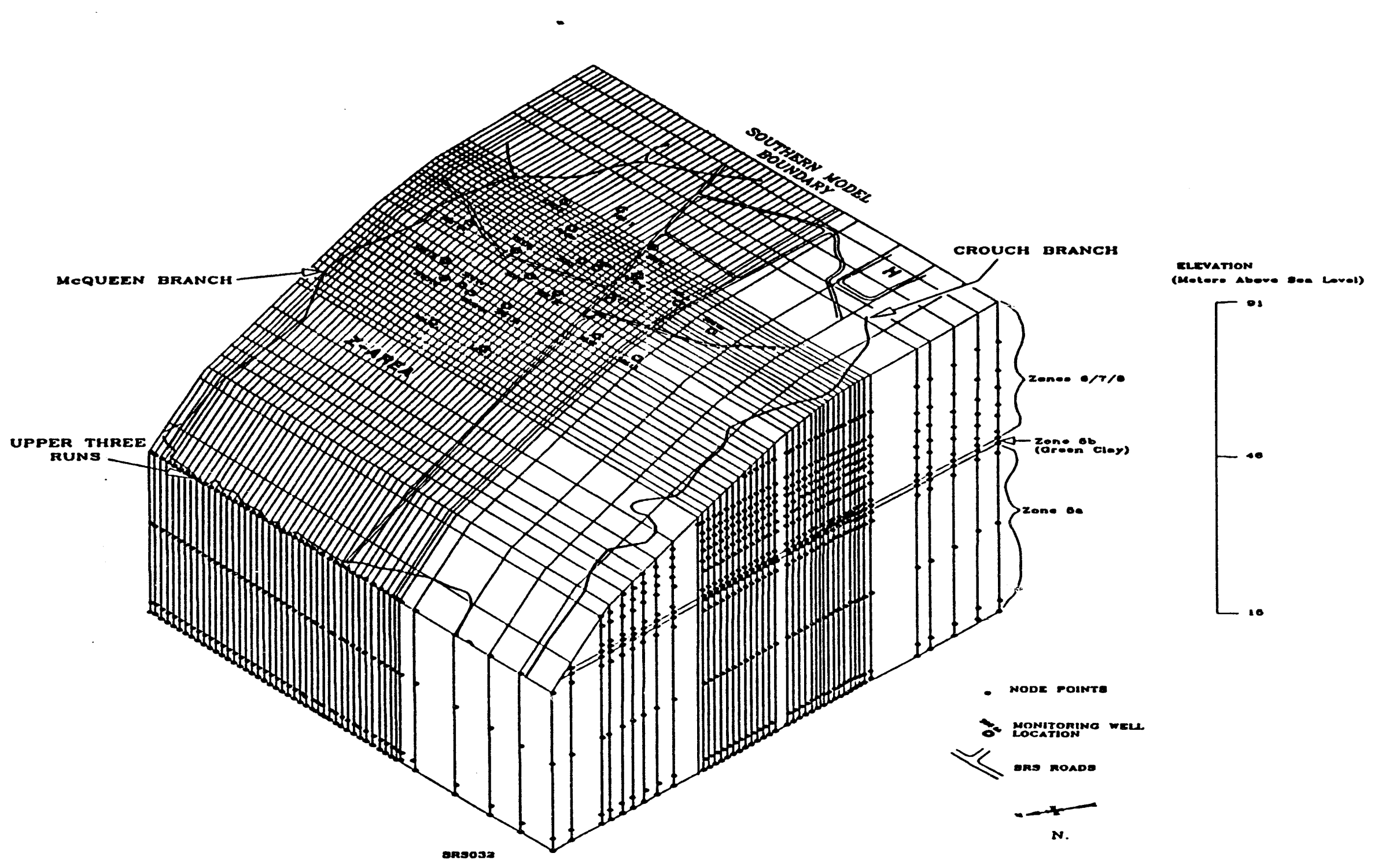

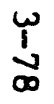

$\Sigma$
0
07
1
0
0
1
0
1
1
$\omega$
0
0

Fig. 3.4-5. Mode1 domain for PORFLOW-3D simulations of groundwater in Z-Area vicinity. 
boundaries. The southern boundary was located along the watershed divide. For Zones $6 / 7 / 8$ and $5 b$, the watershed divide was defined as a no-flow boundary consistent with Toth's (1962) approach for defining regional flow. For Zone 5a (the Congaree Formation), the northern boundary was defined as a constant-flux boundary, reflecting the regional flow characteristics of this aquifer. The base of the Congaree was considered to be impermeable based on the extensive thickness of low permeability sediments which are described in Sect. 2.1.4.

Hydraulic parameters used in the model are discussed in Sect. 3.3.2 and A.2. Recharge to the system was estimated to be $40 \mathrm{~cm} / y e a r$ based on the analysis in Appendix A.1.1.

\section{Model calibration}

Using the saturated flow option of PORFLOW-3D, steady-state groundwater flow conditions were simulated to generate a potentiometric map for the water table aguifer based on the head values calculated by the model (Fig. 3.4-6). In order to calibrate the groundwater flow model, the model-based potentiometric map was compared with potentiometric maps generated from actual water level data from Z-Area. Hydraulic parameters were adjusted within the range of observed values (Table 2.1-1) to achieve the closest comparison between the two types of maps. This calibration process is complicated by the heterogeneous nature of Zones $6 / 7 / 8$ (the Barnwell-McBean hydrostratigraphic unit). As illustrated in Fig. 3.4-6 and 3.4-7, there are differences in the potentiometric surfaces based on the depth of the monitor wells in the water table aquifer. Water levels in wells completed in Zone $7 / 8$ (previously referred to as the Barnwell unit) exhibit values as much as $3 \mathrm{~m}$ higher than in the underlying Zone 6, or McBean unit. This difference is a reflection of the heterogenous nature of this unit and the significant vertical gradient present in the area. However, the conceptual model considered Zones $6 / 7 / 8$ as one homogeneous unit in lieu of sufficient data to assume otherwise. Consequently, depending on which wells are used for calibration purposes,the difference between model and actual data can vary. Since contaminant migration simulations are the goal of the modeling, flow directions and hydraulic gradients are important parameters that were used for calibration. The impact of hydraulic factors in obtaining a calibrated model are discussed in Sect 4.2.2, where a sensitivity analysis of PORFLOW-3D is described.

\section{Model validation}

True validation of the calibrated PORFLOW-3D model requires that the model be capable of accurately predicting flow and transport responses when changes in flow conditions occur. Data are not available to carry out such an exercise. However, local stream flow data were obtained at selected locations along the surface creeks (Fig. 3.4-8) using conventional stream gauging techniques. This stream flow data was used to evaluate the predictive capability of the groundwater flow model with respect to

Rev. 0 


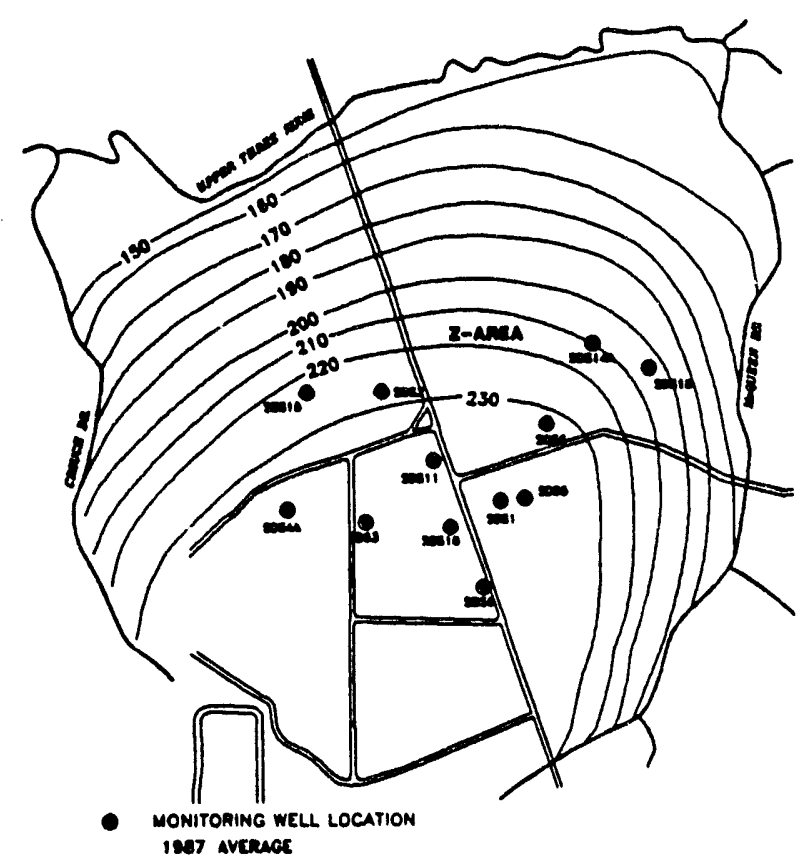

Potentiometric map for the Barnwell Formation based on actual head data.

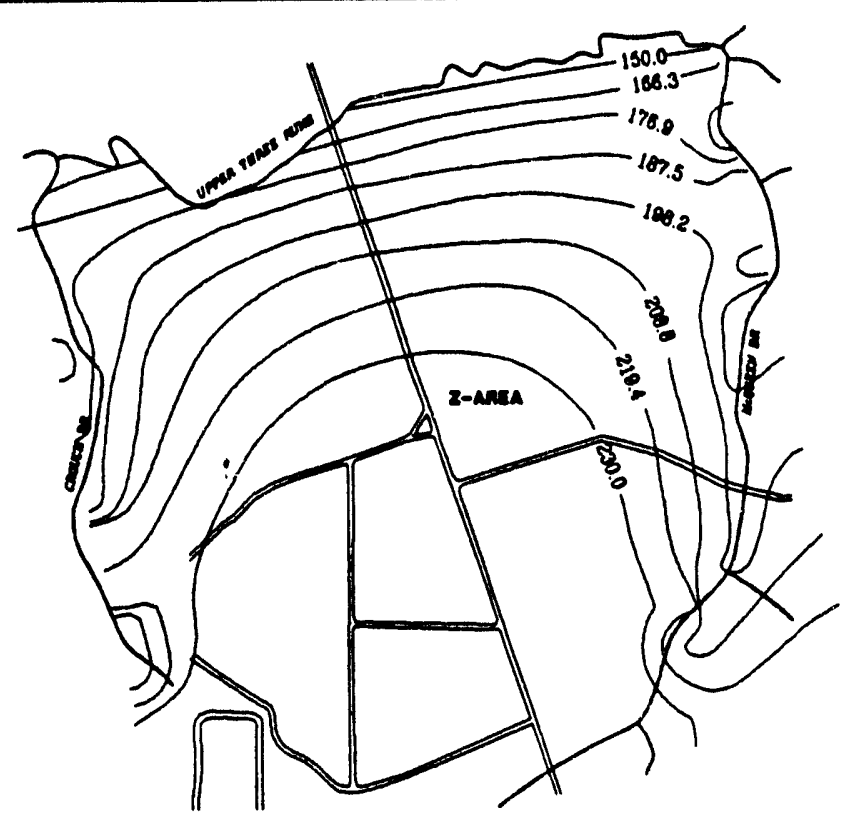

Potentiometric map for the water table aquifer based on model output data.

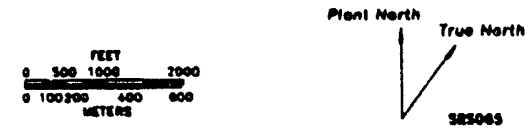

Fig. 3.4-6. Actual potentiometric surface for Zone $7 / 8$ and simulated surface for Zone $6 / 7 / 8$. 


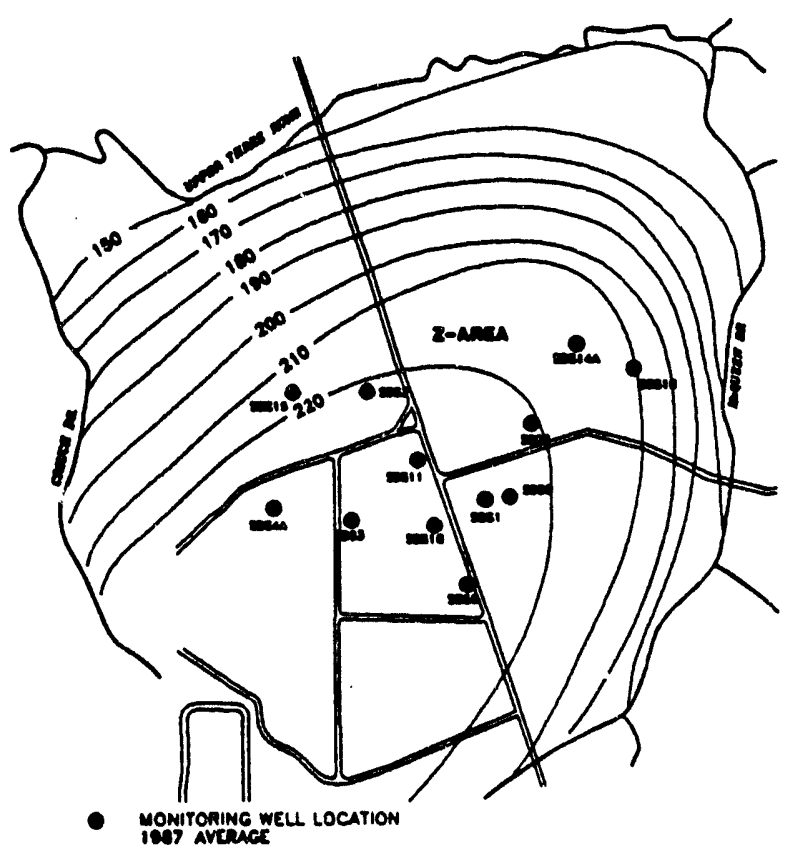

Potentiometric map for the YcBean Pormation based on actual head data.

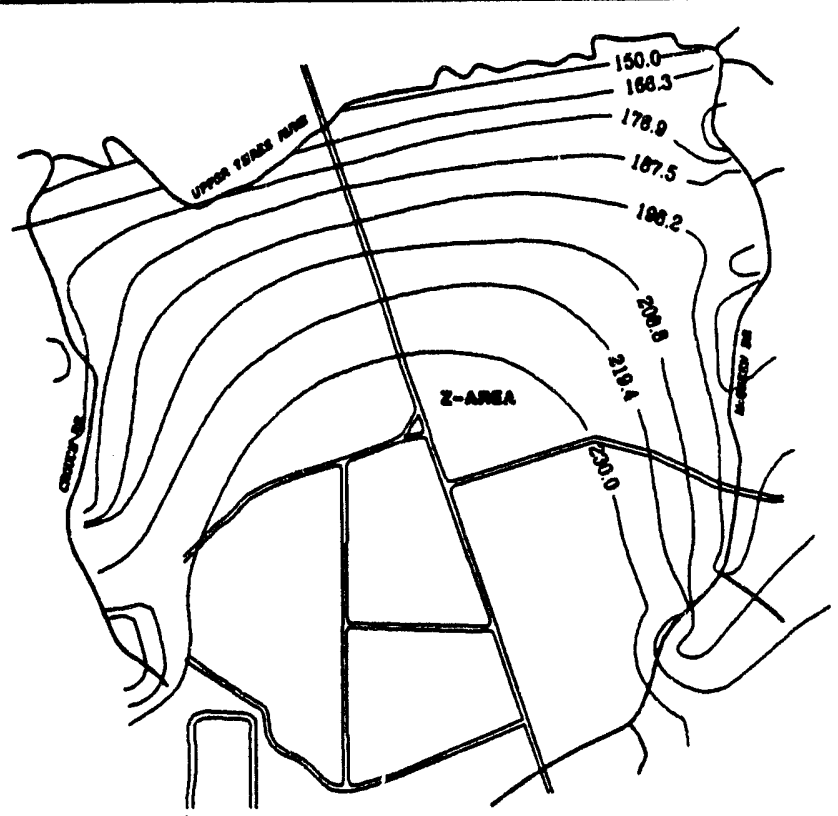

Potentiometrlc map lor the water table aquifer based on model output data.

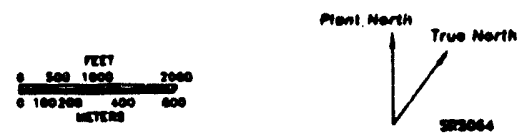

Fig. 3.4-7. Actual potentiometric surface for Zone 6 and simulated surface for Zone $6 / 7 / 8$. 

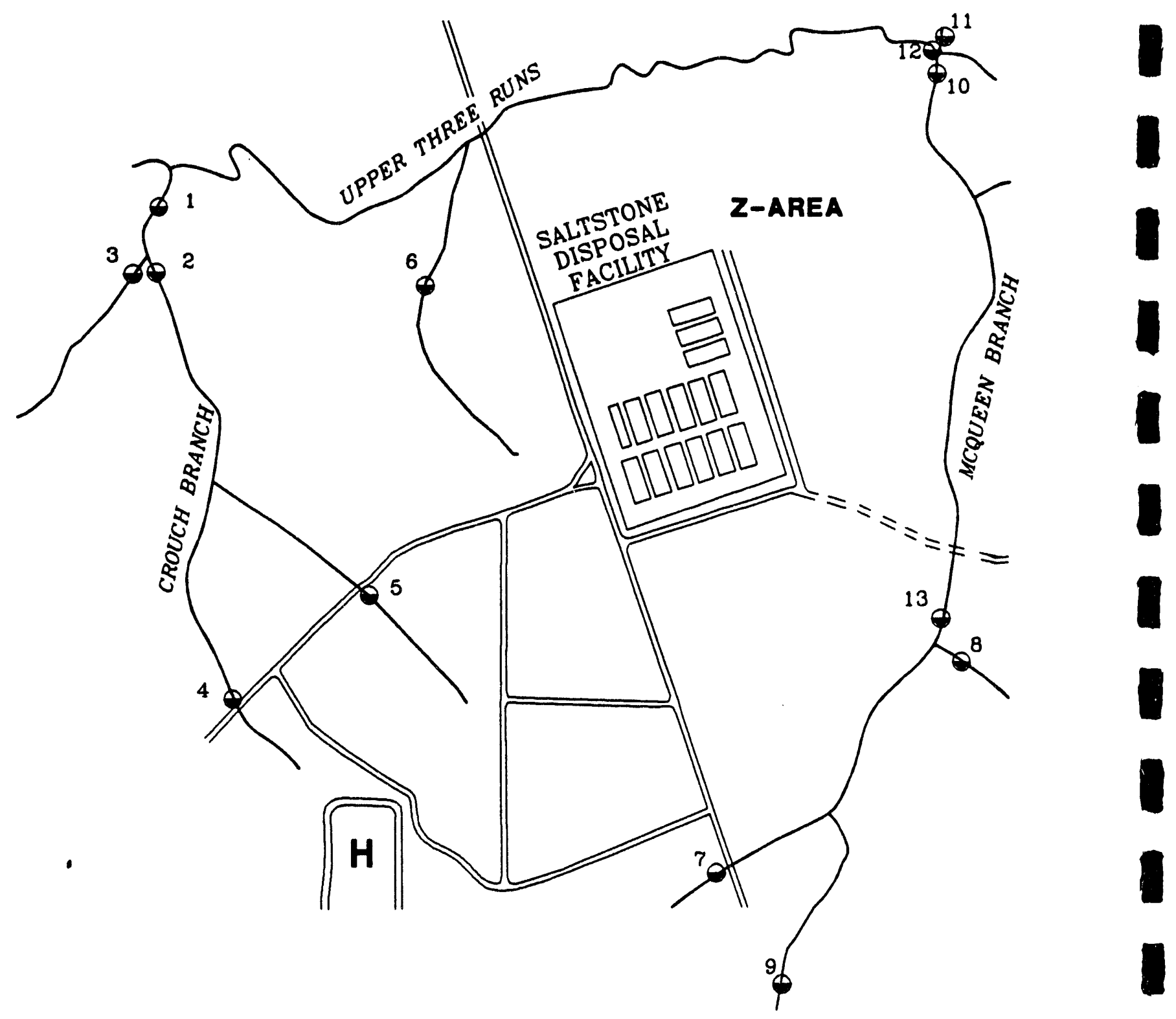

- STREAM GAGING LOCATION

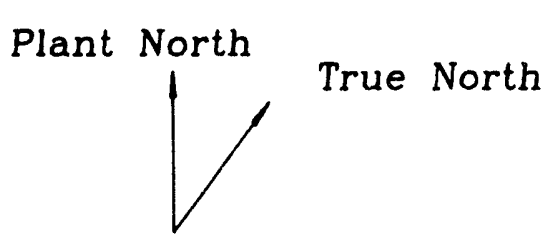

FEET

$$
\overbrace{\substack{0 \\ 0 \\ \text { METERS }}}^{500 \quad 400} 600
$$

SRSOes

Fig. 3.4-8. Locations of stream-gauging stations in creeks near Z-Area. 
discharge to the creeks. The data collected are provided in Table C.2-1. Since the McQueen and Crouch branches are gaining streams (i.e., groundwater is discharging into the streams), an estimate of the groundwater flux can be measured for the site. Assuming that half of the water flowing into the creek is from groundwater discharge from either bank, $8,200 \mathrm{~m}^{3} / \mathrm{d}$ is estimated to discharge from the water table aquifer underlying the Z-Area and its vicinity into the McQueen and Crouch Branches. The groundwater flow model using the reference values calculates a discharge value of $6,300 \mathrm{~m}^{3} / \mathrm{d}$. This water balance analysis shows reasonable agreement between measured and predicted discharge, in light of the large uncertainty in selecting the most representative hydraulic conductivity for this heterogeneous system.

\subsection{Contaminant Transport Simulations}

Contaminant transport simulations used to assess the impact of the saltstone vaults, both intact and degraded, on the underlying groundwater system were dependent on the calibrated flow model and the source input values from the overlying unsaturated zone. Data files for contaminant transport simulations relied on the groundwater flow velocity vectors calculated from the steady-state simulations. During actual contaminant transport, the flow simulation portion of the model was disabled and advective movement of the contaminants were calculated from the steady-state velocity values.

Contaminant fluxes at the water table, obtained as described in Sect. 3.4.1, were injected at nodes that corresponded to the water table elevation beneath the vaults. Areas where contamination was injected into the groundwater system are shown in Fig. 3.4-9.

Conyersions from the water table fluxes evaluated for the two-dimensional near-field domain (Sect. A.1.2.2) to groundwater input flux rates over the area encompassed by the SDF (Fig. 3.4-9) involved adjusting for the source area. The two-dimensional near-field domain corresponds to a half-unit width distance from the midpoint between vaults to one-half the width of the vaults. For contaminant transport simulations, the contaminant fluxes were assumed to represent the average concentration for this area at the water table. Average contaminant concentrations at the water table were calculated by dividing contaminant flux values by $1550 \mathrm{~cm}^{2}$ and by the vertical thickness of the grid block into which the source was being injected. This type of source specification in PORFLOW-3D is in units of mass per unit volume per unit time. Other conversions were made for unit consistency.

As described in the conceptual models for both the intact and degraded vaults (Sect. 3.3.1), two scenarios relating to recharge rate under the facility were evaluated. Scenarios for both the intact and degraded vault case assumed a steady, uniform rate of $40 \mathrm{~cm} / y e a r$ across the entire model domain (degraded cover). The second scenario for both intact and degraded vaults assumed recharge was reduced to $2 \mathrm{~cm} / y e a r$ in the portion of the domain underlying the SDF intact cover. For the latter case, groundwater 
CROSS-SECTION A - A'

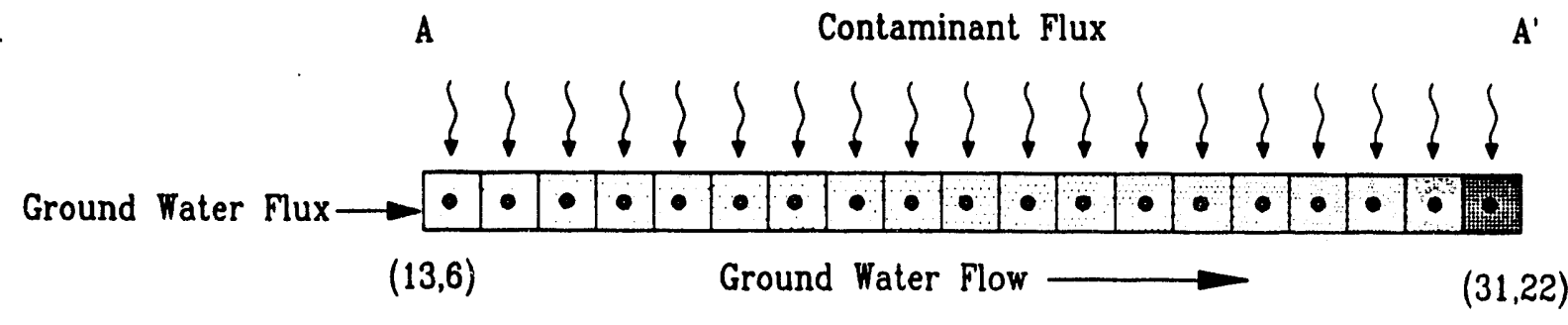

Location Map
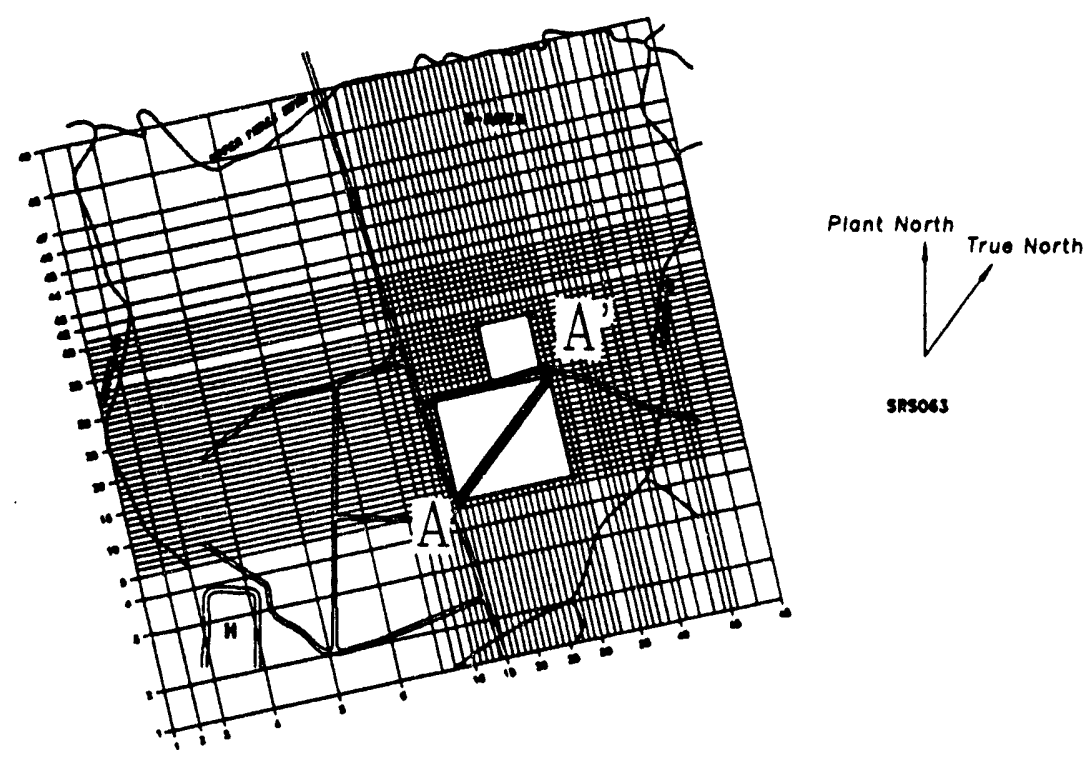

Fig. 3.4-9. Illustration of SDF source area in PORFLOW-3D grid. 
recharge in the area of the vaults was decreased to $2 \mathrm{~cm} /$ year for 40 years prior to the beginning of source injection. The resulting water table was depressed immediately below the vaults.

Concentration contours of radionuclides and nitrate for both the upper and lower aquifer units (Zones $6 / 7 / 8$ and Zone 5a) were selected for output from the PORFLOW3D code (Sect. 4.1.1.3). The points of maximum concentration, at a distance greater than or equal to $100 \mathrm{~m}$ downgradient of the edge of the facility, in both aquifer units were identified from these contours. These maximum concentrations were then used in computations to determine compliance with groundwater protection regulations (Sect. 4.1.2).

A flux balance, computed by PORFLOW-3D, was compared to the specified source term input to the code, to verify that the computations were mass conservative. Copies of the iuput files for the groundwater flow and mass transport simulations are listed in Appendix C.2.

\subsection{Methods for Dose Anałysis}

\subsubsection{Groundwater Protection}

Doses to off-site members of the public resulting from use of contaminated groundwater beyond the $100-\mathrm{m}$ buffer zone around all disposal units were estimated. As described previously (e.g., see Sect. 3.2.3.3), only the dose from the drinking water pathway needs to be considered in regard to protection of groundwater.

Given calculations of the maximum concentrations of radionuclides in groundwater at any location beyond the 100-m buffer zone, which were obtained from the models for the generation of source terms and transport in the near-field region and groundwater described in Sect. 3.3 and 3.4, the estimates of dose from direct ingestion of contaminated drinking water were obtained quite simply. Specifically, the estimates of annual doses were obtained by multiplying the maximum concentrations of radionuclides by the annual doses per unit concentration given in Table A.4-6 of Appendix A.4. Since the maximum concentrations of different radionuclides in groundwater may occur at different times, the time history of the concentrations of the important radionuclides were taken into account in estimating the maximum dose from all radionuclides. The estimates of dose usually were obtained by hand calculation and were checked several times for accuracy. 


\subsection{Intruder Dose Analysis}

Doses to inadvertent intruders into the SDF following loss of active institutional control were estimated. The different exposure scenarios assumed are discussed in Sect. 3.2.4 and the models and parameter values are presented in detail in Appendix A.4. Because of the hypothetical and prospective nature of the intruder scenarios and dose estimates, simple multiplicative-chain models which assume that the concentrations of radionuclides are in equilibrium in all parts of the intruder's exposure environment are used in the intruder dose analysis. The use of such models had the advantage that unnecessarily complex computer codes are avoided; the model and data bases presented in Appendix A.4 describe the calculations in their entirety.

In practice, the models are sufficiently simple that all calculations can be performed by hand, and this approach was used in many cases. However, for ease in repetitive calculations (e.g., in investigating the effects of parameter variations on the estimated doses), the multiplicative-chain models and associated default data bases given in Appendix A.4 were incorporated in an interactive program written for IBM or IBMcompatible personal computer. Quality assurance of the computer program was provided by extensive checks of dose estimates by hand calculation.

\subsubsection{Quality Assurance}

Contributors to this Radiological Performance Assessment conducted pertinent activities of the project under the guidance of the provisions of the American National Standards Institute (ANSI)/American Society of Mechanical Engineers (ASME) Nuclear Quality Assurance (NQA)-1 Program Requirements for Nuclear Facilities (1989), as required by the DOE Order 5820.2a (U.S.DOE 1988a). In doing so, pertinent portions of the U.S. Nuclear Regulatory Commission's QA guidance for LLW disposal facilities were also implemented (U.S.NRC 1989). The manner in which the nineteen basic elements of NQA-1 are implemented by Oak Ridge National Laboratory (ORNL), the RPA coordinator, is indicated in Table 3.4-1. In this table, the ORNL documented QA procedure which implements the specified element of NQA-1 is listed. Some aspects of all nineteen elements were applicable to this RPA. Procedures are documented in the ORNL QA Manual (Oak Ridge National Laboratory Quality Assurance Manual current edition), the ORNL Pollutant Assessments Group Procedures Manual (1992), and the Software QA Plan (Software Quality Assurance Plan for PORFLOW-3D, Appendix F) produced specifically for the PORFLOW-3D computer code used in this assessment. An internal surveillance by the Grand Junction Office QA Coordinator was conducted in the course of the RPA activities, for the purpose of evaluating adherence to the governing QA procedures and plans by ORNL staff. 
Table 3.4-1. Implementation of NQA-1 by ORNL for the Saltastone Disposal Facility RPA

\begin{tabular}{|c|c|c|}
\hline NQA-1 basic element & $\begin{array}{c}\text { Implementing ORNL QA } \\
\text { procedures }^{\alpha}\end{array}$ & $\begin{array}{l}\text { Location of } \\
\text { project-specific } \\
\text { procedure }\end{array}$ \\
\hline 1. Organization & QA-L-1-100 & $a, b, c$ \\
\hline 2. Quality Assurance Program & $\begin{array}{l}\text { QA-L-2-100 } \\
\text { QA-L-2-101 } \\
\text { QA-L-2-103 } \\
\text { QA-L-2-105 } \\
\text { QA-L-2-106 }\end{array}$ & a,b,ache \\
\hline 3. Design Control & $\begin{array}{l}\text { QA-L-3-100 } \\
\text { QA-L-3-101 } \\
\text { QA-L-3-102 } \\
\end{array}$ & $b, c$ \\
\hline $\begin{array}{l}\text { 4. Procurement Document } \\
\text { Control }\end{array}$ & $\begin{array}{l}\text { QA-L-4-100 } \\
\text { QA-L-4-101 }\end{array}$ & $b, c$ \\
\hline $\begin{array}{l}\text { 5. Instructions, Procedures, and } \\
\text { Drawings }\end{array}$ & QA-L-5-100 & $b, c$ \\
\hline 6. Document Control & QA-L-6-100 & c \\
\hline $\begin{array}{l}\text { 7. Control of Purchased Items } \\
\text { and Services } \\
\text {. }\end{array}$ & $\begin{array}{l}\text { QA-L-7-100 } \\
\text { QA-L-7-101 } \\
\text { QA-L-7-102 }\end{array}$ & $b, c$ \\
\hline $\begin{array}{l}\text { 8. Identification and Control of } \\
\text { Items }\end{array}$ & QA-L-8-100 & $b, c$ \\
\hline 9. Control of Processes & QA-L-9-100 & $b, c$ \\
\hline 10. Inspection & QA-L-10-100 & $b, c$ \\
\hline 11. Test Control & QA-L-11-100 & $b, c$ \\
\hline $\begin{array}{l}\text { 12. Control of Measuring and } \\
\text { Test Equipment }\end{array}$ & QA-L-12-100 & $b, c$ \\
\hline $\begin{array}{l}\text { 13. Handling, Storage, and } \\
\text { Shipping }\end{array}$ & QA-L-13-100 & $b, c$ \\
\hline $\begin{array}{l}\text { 14. Inspection, Test, and } \\
\text { Operating Status }\end{array}$ & $\begin{array}{l}\text { QA-L-14-100 } \\
\text { QA-L-14-101 }\end{array}$ & $b, c$ \\
\hline
\end{tabular}

Rev. 0 
Table 3.4-1. (continued)

\begin{tabular}{|l|c|c|}
\hline \multicolumn{1}{|c|}{ NQA-1 basic element } & $\begin{array}{c}\text { Implementing ORNL QA } \\
\text { procedures }\end{array}$ & $\begin{array}{c}\text { Location of } \\
\text { project-specific } \\
\text { procedure }\end{array}$ \\
\hline $\begin{array}{l}\text { 15. Control of Nonconforming } \\
\text { Items }\end{array}$ & QA-L-15-100 & $b, c$ \\
\hline 16. Corrective Action & $\begin{array}{l}\text { QA-L-16-100 } \\
\text { QA-L-16-101 } \\
\text { QA-L-16-102 } \\
\text { QA-L-16-103 }\end{array}$ & $b, c$ \\
\hline 17. Quality Assurance Records & QA-L-17-100 & $b, c$ \\
\hline 18. Audits and Surveillances & QA-L-18-100 & $b, c$ \\
& QA-L-18-101 & \\
\hline 19. Software & QA-L-18-102 & $b, c$ \\
\hline
\end{tabular}

- Source: Oak Ridge National Laboratory Quality Assurance Manual (current edition)

- Source: Software Quality Assurance Plan for PORFLOW-3D (1991), Appendix F

- Source: Pollutant Assessments Group Procedures Manual (1992)

Source: U.S.DOE (1991).

- Source: Quality Assurance Program Requirements for Nuclear Facilities (1989) 
Software QA plans were written by each DOE contractor contributing to this RPA, addressing the provisions of ASME NQA-2a, Part 27, Quality Assurance Requirements of Computer Software for Nuclear Facility Applications. These QA plans were transmitted to Westinghouse Savannah River Company (WSRC) for review and approval. Surveillances were conducted by WSRC at all contractor sites after the RPA project was underway, for the purpose of evaluating adherence to governing QA procedures described in the submitted QA plans and general project integration. Copies of the Software QA Plans submitted are attached (Appendix F). Corrective action is being taken in response to most findings, and responses are being made to observations.

\subsection{SUMMARY OF ANALYSIS OF PERFORMANCE}

The purpose of this chapter of the Radiological Performance Assessment has been to present the conceptual models that were developed for analyzing the performance of the SDF, and to describe the approach taken to obtaining the results that are presented in Chapter 4. The analyses were based on the information provided in the preceding chapter, describing the disposal facility. Some of the significant features of these conceptual models and approaches are summarized below.

Perhaps the most significant aspect of the conceptual model development for evaluating the SDF is the use of degraded scenarios for engineered features of the facility. These scenarios were developed as part of the source term analysis for the facility. Because the SDF contains long-lived radionuclides that are resistant to leaching from the wasteform, the question of long-term integrity of concrete and engineered covers becomes potentially important. The approach used to address this question involved identification of mechanisms of degradation, and development of scenarios represenfing the resulting degradation. Considerable uncertainty in timing and degree of degradation exists, necessitating the development of the scenarios listed in Sect. 3.1.3.5, which are intended to bound degradation problem for some features.

In addition to conceptual model development for the SDF source term, a discussion was provided in this section which established the transport pathways and exposure scenarios of concern to the performance evaluation of this facility. The results of the analyses indicated that for off-site members of the public, the groundwater pathway is the dominant pathway of concern. Demonstration of compliance with the effective dose equivalent limit of 4 mrem per year is believed to be sufficient to demonstrate compliance with other limits for off-site individuals. Intruder scenarios of concern were found to be the four chronic exposure scenarios listed in Sect. 3.2.4.3. Screening of the initial SDF inventory was also carried out in this section, once exposure scenarios of concern were defined. The results of the screening exercise allowed reducing the number of radionuclides of concern from the large number listed in Table C.1.1 to eleven. 
Development of exposure scenarios involved identification of the physical media potentially contaminated by saltstone constituents that are of concern. These media include groundwater, soil adjacent to the vaults containing saltstone, and the saltstone itself. The purpose of the near-field and groundwater model development, then, was to estimate potential concentrations of saltstone constituents in these media. This model development involved developing a simplified representation of an intact and degraded facility, and of the subsurface, while retaining as much detail as warranted by available hydrogeologic data. The selection of parameters describing attributes of the facility and its environment are documented in this Chapter, and in the supporting information provided in Appendix A. In addition to specification of bydraulic parameters for saltstone, concrete, clay, gravel and soil in the SDF, parameters describing the leachability of the wasteform were also quantified.

The methodology of performance analysis for the SDF involved implementing the conceptual models and scenarios in a manner deemed most appropriate for each, taking into consideration the need to provide reasonable assurance of compliance with the performance objectives. Numerical techniques were adopted to quantify flow and transport through the facility, the near-field, and underlying groundwater. Analytical methods were used in screening the inventory and pathways, and in dose estimation. The results of the analyses are provided in the next chapter of this report. 


\section{RESULTS OF ANALYSIS}

In this chapter of the RPA for the Z-Area SDF, the results of the analysis of performance, conducted in accordance with the conceptual models and methodologies described in the previous chapter, are presented. Predicted releases to the environment, resulting concentrations, as well as the results of dose analysis are presented (Sect. 4.1). The results of the sensitivity and uncertainty analyses that were conducted to gain perspective on the meaning of the results are also provided (Sect. 4.2). The interpretation of these results is given in Sect. 4.3.

\subsection{ANALYSIS RESULTS}

In this section, results of the computational analyses conducted to estimate the potential radiological impact of the SDF are provided. Maximum concentrations, and doses based on these maximum values, are provided in tabular form. Time history concentrations are provided in Appendix C.4.

In Sect. 4.1.1, the near-field results are presented. The predicted unsaturated flow field through the facility, predicted concentrations of saltstone constituents in soil surrounding vaults within the facility, and estimated fluxes of these constituents to the water table are described. As has been noted throughout this report, nitrate is included in addition to radiological components for consideration of groundwater protection.

In Sect. 4.1.2, concentrations of radionuclides at the compliance point are presented. The compliance point for groundwater protection standards is assumed to be the point of maximum concentration in groundwater at least $100 \mathrm{~m}$ from the edge of the outermost vaults (Sect. 1.4). These concentrations arise from the contaminant flux to the water table from the near-field calculations, and are used to estimate doses to off-site individuals.

In Sect. 4.1.3 and 4.1.4, the results of the radiological dose analyses for off-site individuals and inadvertent intruders, the two population groups of concern in this RPA, are provided. Although upper bound and best estimate doses are provided, both dose rates are conservatively based on the maximum concentrations predicted in groundwater at the compliance point and in soil around the vaults of the SDF.

\subsubsection{Near-field Results}

The near-field refers to the environment immediately surrounding the disposal vaults within the SDF facility. Conditions in the near-field directly affect the release of potential contaminants from the facility. After closure, the boundary of the near-field extends vertically from the ground surface above the SDF to the water table. Laterally, 
the near-field encompasses enough area to predict the total flux to the water table from the facility, and to identify the point of maximum concentration in the unsaturated region above the water table. Models representing the near-field environment were described in Sect. 3.3.1. These models were implemented through the use of source terms and degradation scenarios described in Sect. 3.1. Results obtained from implementation of the near-field models are summarized here.

The infiltration of rainwater through the facility was first estimated for both an intact and degraded upper moisture barrier (Fig. 27-1 and 2.7-2). For an intact upper moisture barrier, PORFLOW-3D simulations indicated that $2 \mathrm{~cm} /$ year would be an upper limit to the amount of infiltration through the upper cap. In the degraded barrier scenario, the upper clay and gravel layers were assumed to have lost design functionality and, under these conditions, moisture is no longer diverted. Infiltration through the upper cap was assumed to be $\mathbf{4 0} \mathrm{cm} / y e a r$ for the degraded barrier scenario, which is the same as the average annual infiltration in the absence of the facility. Therefore, either 2 or $\mathbf{4 0} \mathrm{cm} / y e a r$ were assumed for infiltration to tte top of the clay/gravel drain system, placed immediately above the vaults (Table 4.1-1).

Water that infiltrates through the upper moisture barrier either recharges the groundwater or is diverted by the clay/gravel drain system which overlies the vaults (Fig. 2.7-1 and 2.7-2). Because this drain system is assumed to remain intact in the present analysis, the amount of water reaching the water table was found to be nearly identical for either intact or degraded cover scenario (i.e., 2 or $40 \mathrm{~cm} / \mathrm{year}$ through the upper cap). Therefore, the same flux of water $(0.175 \mathrm{~cm} / \mathrm{year})$, averaged across the lower boundary of the near-field domain, was assumed to reach the water table under the facility in either infiltration case (Table 4.1-1).

The time-history concentrations of radionuclides in saltstone and soil above and adjacent to the vaults were predicted as part of the near-field analysis for subsequent use in intruder dose analysis. The PORFLOW-3D simulations provided this information for the pore water in soil. The maximum concentrations predicted, and corresponding time of occurrence, are presented in Table 4.1-2. These values are used in Sect. 4.1.4 to estimate total radionuclide contents of the soil in the locations of interest. Time histories of contaminant concentration at the three nodes listed in Table 4.1-2 are provided graphically in Appendix C.4.1.

Predicted fluxes of radionuclides and nitrate to the water table were also obtained from PORFLOW-3D simulations, for the scenarios described in Sect. 3.1.3.5. Maximum contaminant fluxes, in pCifyear (or mg/year for nitrate) to the water table under the facility, are shown in Tables 4.1-3 and 4.1-4. Table 4.1-3 contains maximum flux values for intact vaults and saltstone, and Table 4.1-4 contains values for degraded vaults and saltstone. The $2 \mathrm{~cm} / y e a r$ infiltration cases represent the intact upper moisture barrier, while the $40 \mathrm{~cm} / y e a r$ infiltration cases represent the degraded upper moisture barrier. The maximum flux values for intact vaults and saltstone at either infiltration rate Table 
Table 4.1-1 Flow field results from near-field analysis

\begin{tabular}{|l|l|c|}
\hline \multicolumn{1}{|c|}{$\begin{array}{c}\text { Scenario } \\
\text { (from Sect. 3.1.3.5) }\end{array}$} & \multicolumn{1}{|c|}{ Flow Parameter Predicted } & Quantity Predicted \\
\hline $\begin{array}{l}\text { Intact cover, intact } \\
\text { vault/saltstone }\end{array}$ & $\begin{array}{l}\text { Infiltration flux through upper } \\
\text { moisture barrier } \\
\text { Infiltration flux through clay/gravel } \\
\text { drain and saltstone vaults (average } \\
\text { to water table under facility) }\end{array}$ & $2 \mathrm{~cm} /$ year \\
\hline $\begin{array}{l}\text { Degraded cover, intact } \\
\text { vault/saltstone }\end{array}$ & $\begin{array}{l}\text { Infiltration flux through upper } \\
\text { moisture barrier } \\
\text { Infiltration flux through clay/gravel } \\
\text { drain and saltstone vaults (average } \\
\text { to water table under facility) }\end{array}$ & $0.175 \mathrm{~cm} /$ cear \\
\hline $\begin{array}{l}\text { Intact cover, degraded } \\
\text { vault/saltstone }\end{array}$ & $\begin{array}{l}\text { Infiltration flux through upper } \\
\text { moisture barrier }\end{array}$ & $2 \mathrm{~cm} /$ year \\
\hline $\begin{array}{l}\text { Infiltration flux through clay/gravel } \\
\text { drain and saltstone vaults (average } \\
\text { to water table under facility) }\end{array}$ & $0.175 \mathrm{~cm} /$ /year a \\
\hline $\begin{array}{l}\text { Degraded cover, } \\
\text { degraded } \\
\text { vault/saltstone }\end{array}$ & $\begin{array}{l}\text { Infiltration flux through upper } \\
\text { moisture barrier } \\
\text { Infiltration flux through clay/gravel } \\
\text { drain and saltstone vaults (average } \\
\text { to water table under facility) }\end{array}$ & $0.175 \mathrm{~cm} / \mathrm{year}$ a \\
\hline
\end{tabular}

- Assumes clay/gravel drain system remains intact

Rev. 0 
Table 4.1-2 Maximum predicted near-field concentrations of radionuclides

\begin{tabular}{|c|c|c|c|c|}
\hline \multirow{2}{*}{ Contaminant } & \multicolumn{3}{|c|}{$\begin{array}{l}\text { Maximum Pore WaterConcentration } \\
\left(\mu \mathrm{Ci} / \mathrm{m}^{3}\right)\end{array}$} & \multirow{2}{*}{$\begin{array}{c}\text { Time of Occurrence } \\
\text { (year) }\end{array}$} \\
\hline & Node 1 & Node 2 & Node 3 & \\
\hline H-3 & $5.6 \times 10^{-13}$ & $1.2 \times 10^{-6}$ & $1.6 \times 10^{1}$ & $\begin{array}{l}1.8 \times 10^{2} \\
1.3 \times 10^{2} \\
1.0 \times 10^{2}\end{array}$ \\
\hline C-14 & $2.1 \times 10^{-47}$ & $1.8 \times 10^{-37}$ & $1.0 \times 10^{-3}$ & $\begin{array}{l}9.9 \times 10^{4} \\
9.9 \times 10^{4} \\
1.0 \times 10^{2}\end{array}$ \\
\hline Se-79 & $2.1 \times 10^{-5}$ & $8.0 \times 10^{-3}$ & $3.4 \times 10^{1}$ & $\begin{array}{l}2.8 \times 10^{5} \\
1.4 \times 10^{5} \\
1.0 \times 10^{2}\end{array}$ \\
\hline Sr-90 & $1.6 \times 10^{-39}$ & $2.0 \times 10^{-31}$ & 2.3 & $\begin{array}{l}5.6 \times 10^{2} \\
5.4 \times 10^{2} \\
1.0 \times 10^{2}\end{array}$ \\
\hline Tc-99 & $5.9 \times 10^{-15 b}$ & $1.6 \times 10^{-7}$ & $7.3 \times 10^{1}$ & $\begin{array}{l}2.0 \times 10^{6} \\
1.9 \times 10^{6} \\
1.0 \times 10^{2}\end{array}$ \\
\hline Sn-126 & $6.3 \times 10^{-19}$ & $7.1 \times 10^{-12}$ & $2.0 \times 10^{-1}$ & $\begin{array}{l}1.5 \times 10^{6} \\
1.1 \times 10^{6} \\
1.0 \times 10^{2}\end{array}$ \\
\hline I -129 & $1.7 \times 10^{-5 b}$ & $1.2 \times 10^{-3 b}$ & $5.1 \times 10^{-1}$ & $\begin{array}{l}2.0 \times 10^{6} \\
2.0 \times 10^{6} \\
1.0 \times 10^{2}\end{array}$ \\
\hline Cs-137 & $2.0 \times 10^{.30}$ & $4.5 \times 10^{-22}$ & $3.3 \times 10^{2}$ & $\begin{array}{l}5.9 \times 10^{2} \\
5.6 \times 10^{2} \\
1.0 \times 10^{2}\end{array}$ \\
\hline Pu-238 & $3.0 \times 10^{-72}$ & $4.5 \times 10^{-62}$ & $2.7 \times 10^{-3}$ & $\begin{array}{l}1.7 \times 10^{3} \\
1.6 \times 10^{3} \\
1.0 \times 10^{2}\end{array}$ \\
\hline Am-241 & $1.2 \times 10^{-62}$ & $8.7 \times 10^{-53}$ & $1.6 \times 10^{-2}$ & $\begin{array}{l}8.7 \times 10^{3} \\
7.8 \times 10^{3} \\
1.0 \times 10^{2}\end{array}$ \\
\hline
\end{tabular}

- Node 1 = in soil just above center of concrete vault

Node 2 = in soil adjacent to side of concrete vault, near base

Node 3 = in saltstone, at centroid of monolith

- Peak not reached 
Table 4.1-3. Marimum predicted contaminant flux to water table and corresponding times for Z-Area vaults - intact vaults and saltstone

\begin{tabular}{|lcc|cc|}
\hline & \multicolumn{2}{c|}{$\begin{array}{c}\text { 40 cm/year } \\
\text { infiltration through upper cap }\end{array}$} & \multicolumn{2}{c|}{$\begin{array}{c}2 \text { cm/year } \\
\text { infiltration through upper cap }\end{array}$} \\
\cline { 2 - 5 } Contaminant & $\begin{array}{c}\text { Peak flux } \\
\text { (pCityear) }\end{array}$ & $\begin{array}{c}\text { Time } \\
\text { (years) }\end{array}$ & $\begin{array}{c}\text { Peak flux } \\
\text { (pCi/year) }\end{array}$ & $\begin{array}{c}\text { Time } \\
\text { (years) }\end{array}$ \\
\hline $\mathrm{NO}_{3}$ & $5.5 \times 10^{8}$ & $7.5 \times 10^{3}$ & $4.9 \times 10^{8} \mathrm{c}$ & $7.1 \times 10^{3}$ \\
H-3 & $4.0 \times 10^{8}$ & $8.9 \times 10^{1}$ & $4.0 \times 10^{d}$ & $9.1 \times 10^{-1}$ \\
C-14 & $<10^{-6}$ & $\mathrm{~N} / \mathrm{A}^{d}$ & $<10^{-6}$ & $\mathrm{~N} / \mathrm{A}^{d}$ \\
Se-79 & $1.4 \times 10^{6}$ & $2.1 \times 10^{5}$ & $1.2 \times 10^{6}$ & $2.0 \times 10^{5}$ \\
Sr-90 & $<10^{-6}$ & $\mathrm{~N} / \mathrm{A}^{d}$ & $<10^{-6}$ & $\mathrm{~N} / \mathrm{A}^{d}$ \\
Tc-99 & $6.4 \times 10^{1}$ & $1.6 \times 10^{6}$ & $6.3 \times 10^{1}$ & $1.6 \times 10^{6}$ \\
Sn-126 & $4.8 \times 10^{-3}$ & $8.9 \times 10^{5}$ & $4.6 \times 10^{-3}$ & $8.8 \times 10^{5}$ \\
I-129 & $9.0 \times 10^{5}$ & $>2.0 \times 10^{6}$ & $9.0 \times 10^{5}$ & $>2.0 \times 10^{6}$ \\
Cs-137 & $<10^{-6}$ & $\mathrm{~N} / \mathrm{A}^{d}$ & $<10^{-6}$ & $\mathrm{~N} / \mathrm{A}^{d}$ \\
Pu-238 & $<10^{-6}$ & $\mathrm{~N} / \mathrm{A}^{d}$ & $<10^{-6}$ & $\mathrm{~N} / \mathrm{A}^{d}$ \\
Am-241 & $<10^{-6}$ & $\mathrm{~N} / \mathrm{A}^{d}$ & $<10^{-6}$ & $\mathrm{~N} / \mathrm{A}^{d}$ \\
\hline
\end{tabular}

- Degráded cover scenario (Sect. 3.1.3.5).

- Intact scenario (Sect. 3.1.3.5).

- Units for nitrate concentration are in mg/year.

d $\mathbf{N} / \mathbf{A}=$ (same as footnote $c$ in Table 4.1-4). 
Table 4.1-4. Maximum predicted contaminant flux to water table and corresponding. times for Z-Area vaults - degraded vaults and saltstone

\begin{tabular}{|l|c|c|}
\hline Contaminant & $\begin{array}{c}\text { Peak Flux } \\
\text { (pCi/year) }\end{array}$ & $\begin{array}{c}\text { Time } \\
\text { (year) }\end{array}$ \\
\hline $\mathrm{NO}_{3}$ & $3.4 \times 10^{96}$ & $1.2 \times 10^{3}$ \\
$\mathrm{H}-3$ & $<10^{-6}$ & $\mathrm{~N} / \mathrm{A}^{c}$ \\
$\mathrm{C}-14$ & $7.0 \times 10^{3}$ & $5.8 \times 10^{3}$ \\
$\mathrm{Se}-79$ & $4.3 \times 10^{8}$ & $1.1 \times 10^{4}$ \\
$\mathrm{Sr}-90$ & $<10^{-6}$ & $\mathrm{~N} / \mathrm{A}^{c}$ \\
$\mathrm{Tc}-99$ & $9.9 \times 10^{8}$ & $1.9 \times 10^{3}$ \\
$\mathrm{Sn}-126$ & $7.4 \times 10^{5}$ & $1.9 \times 10^{5}$ \\
$\mathrm{I}-129$ & $6.9 \times 10^{6}$ & $2.3 \times 10^{3}$ \\
$\mathrm{Cs}-137$ & $<10^{-6}$ & $\mathrm{~N} / \mathrm{A}^{\circ}$ \\
$\mathrm{Pu}-238$ & $<10^{-6}$ & $\mathrm{~N} / \mathrm{A}^{c}$ \\
$\mathrm{Am}-241$ & $<10^{-6}$ & $\mathrm{~N} / \mathrm{A}^{c}$ \\
\hline
\end{tabular}

- Intact and degraded cover scenarios (Sect. 3.1.3.5); both cover scenarios give the same groundwater recharge due to presence of clay/gravel drain on top of vaults which is assumed to remain intact.

- Units for nitrate concentration in mg/yzar.

- $\mathbf{N} / \mathbf{A}=$ not applicable; compliance point concentration not calculated because flux less than $10^{-6}$ pCifyear results in an estimated concentration directly under the facility of less than $10^{-12} \mathrm{pCi} / \mathrm{L}$, which is orders of magnitude below relevant drinking water standards.

Rev. 0 
are nearly identical because the saltstone and the clay on top of the vaults control the flux of water through the system with either infiltration rate. Time histories of contaminant fluxes to the water table from intact vaults and saltstone are provided graphically in Appendix C.4.1, in terms of fractional flux. Tables of fractional flux to the water table from fractures are also provided in Appendix C.4.1. These time-history fractional fluxes, representing the fraction of the initial inventory reaching the water table each year, were used to calculate groundwater concentration at the compliance point.

\subsection{Groundwater Concentrations}

Groundwater concentrations at the compliance point for groundwater protection were predicted using the near-field results which supplied recharge rates to the aquifer and contaminant flux to the water table as a function of time. The recharge rate under the facility was predicted to be $0.175 \mathrm{~cm} / \mathrm{year}$ based on near-field simulations, and elsewhere, assumed to be $40 \mathrm{~cm} / y e a r$. Fractional fluxes were specified as the source term to groundwater and converted to activity, or mass, concentrations at the compliance point. The compliance point is assumed to be the point of maximum concentration in groundwater at least $100 \mathrm{~m}$ from the edge of the facility (Sect. 1.4), and was determined by surveying the groundwater simulation results to locate this point.

Tables 4.1-5 and 4.1-6 provide maximum predicted contaminant concentrations at the compliance point for groundwater protection, and the time of occurrence. Results for the intact vaults and saltstone are shown in Table 4.1-5. Results for degraded vaults and saltstone are shown in Table 4.1-6.

In all cases, the maximum predicted concentration occurred in the lower zone, the Congaree formation, indicative of the strong downward gradient in the vicinity of Z-Area. Time histories of maximum groundwater concentrations in the three hydrologic zones simulated, for intact and degraded scenarios, are provided graphically in Appendix C.4.3. In these graphs, the curves marked "fracture" refer to groundwater concentrations resulting from the assumed fractures in the saltstone only. The groundwater concentration limit for each radionuclide, derived from the 4 mrem per year dose limit, is also shown on these graphs. The groundwater concentration resulting from the fractures and the intact saltstone between fractures can be estimated by summing the respective concentrations at each point in time. This will result in a conservative estimate, because loss of contaminated mass in fractures will reduce the contaminant inventory in the intact saltstone, and thus, reduce the intact release rate. Except for nitrate, the peak groundwater concentrations for all potential contaminants occur at very different times, and are of considerably different magnitude. 
Table 4.1-5. Peak predicted groundwater concentration at compliance point for Z-Area vaults - intact vaults and saltstone

\begin{tabular}{|lcc|}
\hline Contaminant & $\begin{array}{c}\text { Peak Conc. } \\
(\mathrm{pC} / \mathrm{L})\end{array}$ & $\begin{array}{c}\text { Time of Peak } \\
\text { GW Conc. } \\
\text { (years) }\end{array}$ \\
\hline $\mathrm{NO}_{3}$ & $5.2^{b}$ & $7.1 \times 10^{3}$ \\
$\mathrm{H}-3$ & $3.5 \times 10^{-5}$ & $1.2 \times 10^{2}$ \\
$\mathrm{C}-14$ & $<10^{-12}$ & $\mathrm{~N} / \mathrm{A}^{c}$ \\
Se-79 & $1.2 \times 10^{-2}$ & $2.1 \times 10^{5}$ \\
Sr-90 & $<10^{-12}$ & $\mathrm{~N} / \mathrm{A}^{c}$ \\
Tc-99 & $6.7 \times 10^{-7}$ & $1.6 \times 10^{6}$ \\
Sn-126 & $4.0 \times 10^{-11}$ & $9.2 \times 10^{5}$ \\
I-129 & $7.2 \times 10^{-3}$ & $22.5 \times 10^{6} d$ \\
Cs-137 & $<10^{-12}$ & $\mathrm{~N} / \mathrm{A}^{c}$ \\
Pu-238 & $<10^{-12}$ & $\mathrm{~N} / \mathrm{A}^{c}$ \\
Am-241 & $<10^{-12}$ & $\mathrm{~N} / \mathrm{A}^{c}$ \\
\hline
\end{tabular}

- Intact and degraded cover scenarios (Sect. 3.1.3.5); both cover scenarios give the

- same groundwater recharge due to presence of clay/gravel drain on top of vaults which is assumed to remain intact.

- Units for nitrate concentration in $\mathrm{mg} / \mathrm{L}$.

- $\mathbf{N} / \mathbf{A}=$ not applicable; compliance point concentration not calculated because estimated groundwater concentration directly under the facility is less than $10^{-12}$ $\mathrm{pCi} / \mathrm{L}$, which is orders of magnitude below relevant drinking water standards.

d Peak concentration for I-129 may occur sometime after given time. 
Table 4.1-6. Peak predicted groundwater concentration at compliance point for Z-Area vaults - degraded vaults and saltstone

\begin{tabular}{|lcc|}
\hline Contaminant & $\begin{array}{c}\text { Peak Conc. } \\
(\mathrm{pCi} / \mathrm{L})\end{array}$ & $\begin{array}{c}\text { Time of Peak } \\
\text { GW Conc. } \\
\text { (years) }\end{array}$ \\
\hline $\mathrm{NO}_{3}$ & $3.6 \times 10^{1 \mathrm{~b}}$ & $1.4 \times 10^{3}$ \\
$\mathrm{H}-3$ & $<10^{-12}$ & $\mathrm{~N} / \mathrm{A}^{c}$ \\
$\mathrm{C}-14$ & $6.0 \times 10^{-6}$ & $7.3 \times 10^{3}$ \\
Se-79 & 4.4 & $1.5 \times 10^{4}$ \\
Sr-90 & $<10^{-12}$ & $\mathrm{~N} / \mathrm{A}^{c}$ \\
Tc-99 & $1.1 \times 10^{1}$ & $2.4 \times 10^{3}$ \\
Sn-126 & $2.2 \times 10^{-3}$ & $2.2 \times 10^{5}$ \\
I-129 & $7.5 \times 10^{-2}$ & $3.2 \times 10^{3} d$ \\
Cs-137 & $<10^{-12}$ & $\mathrm{~N} / \mathrm{A}^{c}$ \\
Pu-238 & $<10^{-12}$ & $\mathrm{~N} / \mathrm{A}^{c}$ \\
Am-241 & $<10^{-12}$ & $\mathrm{~N} / \mathrm{A}^{c}$ \\
\hline
\end{tabular}

- Intact and degraded cover scenarios (Sect. 3.1.3.5).

b Units for nitrate concentration in $\mathrm{mg} / \mathrm{L}$

- $\mathbf{N} / \mathbf{A}=$ not applicable; compliance point concentration not calculated because estimated groundwater concentration directly under the facility is less than $10^{-12} \mathrm{pCi} / \mathrm{L}$, which is orders of magnitude below relevant drinking water standards.

d Peak concentration for I-129 may occur sometime after given time. 
The peak groundwater concentration for nitrate and all radionuclides except $\mathrm{H}-3$ are higher as a result of releases from fractures. Therefore, the peak groundwater concentrations reported in Table 4.1 .6 for the degraded case are essentially those resulting from fractures alone. The intact results for $\mathrm{H}-3$ are higher than the degraded results due to the method employed to account for material diffusing from the end walls of the vaults, which are not simulated (see Sect. A.1.2.2). This method does not account for radioactive decay during transit from the sides of the vaults to the water table. Because the transit time in this portion of the domain is approximately 300 years, decay would be significant, and the flux at the water table is overestimated for H-3 by six to seven orders of magnitude for the intact case. Correcting for decay in transit to the water table, the peak H-3 groundwater concentration becomes higher for the degraded case, consistent with the results for the other radionuclides and nitrate. For most of the radionuclides of concern in this RPA, this method is adequate because the half-lives are much longer than 300 years.

\subsection{Dose Anatysis for Off-Site Releases of Radionuclides}

As described in Sect. 3.2.3.3, the only performance objective of concern for off-site releases of radionuclides is the performance objective for the protection of groundwater. That is, if a limit on effective dose equivalent of 4 mrem per year from direct ingestion of $2 \mathrm{~L}$ day of groundwater obtained from a well located beyond the 100 -m buffer zone around the disposal units is met, then the limit on effective dose equivalent of 25 mrem per year from all exposure pathways for off-site members of the public also will be met without the need for further analysis.

The results of the model for estimating dose from the drinking water pathway, as obtained from Table A.4-6 of Appendix A.4, are summarized in Table 4.1-7. This table gives the annual effective dose equivalent in rem for a unit concentration of each radionuclide in groundwater of $1 \mu \mathrm{Ci} / \mathrm{L}$. The radionuclides listed in this table were selected by the screening analysis described in Sect. 3.2.3.4.

The dose analysis for the drinking water pathway is based on the maximum concentrations of radionuclides in groundwater at any location beyond the $100-\mathrm{m}$ buffer zone and at any time after disposal. These concentrations for the different scenarios involving intact and degraded concrete vaults and saltstone monoliths are presented in Tables 4.1-5 and 4.1-6, respectively.

The results of the dose analysis for the drinking water pathway from off-site releases of radionuclides are given in Table 4.1-8. Again, the estimated annual effective dose equivalent for any radionuclide is the product of the maximum concentration obtained from Table 4.1-5 or 4.1-6 and the annual dose per unit concentration obtained from Table 4.1-7. The estimated dose for the two scenarios is less than the assumed performance objective of 4 mrem per year effective dose equivalent for protection of groundwater resources (see Sect. 1.4). 
Table 4.1-7. Annual effective dose equivalents from drinking water pathway per unit concentration of radionuclides in groundwater

\begin{tabular}{lc}
\hline Radionuclide ${ }^{b}$ & $\begin{array}{c}\text { Annual effective dose equivalent } \\
\text { (rem/y per } \mu \mathrm{Ci} / \mathrm{L} \text { ) }\end{array}$ \\
\hline H-3 & $4.6 \times 10^{-2}$ \\
C-14 & 1.5 \\
Se-79 & 6.1 \\
Sr-90 + d & $1.0 \times 10^{2}$ \\
Tc-99 & $9.5 \times 10^{-1}$ \\
Sn-126 + d & $1.3 \times 10^{1}$ \\
I-129 & $2.0 \times 10^{2}$ \\
Cs-137 & $3.7 \times 10^{1}$ \\
Pu-238 & $2.8 \times 10^{3}$ \\
Am-241 & $3.3 \times 10^{3}$ \\
\hline
\end{tabular}

- Results are obtained from Table A.4-6 of Appendix A.4.

- " $+\mathrm{d}^{\mathrm{n}}$ denotes short-lived decay products that are assumed to be in secular equilibrium with parent radionuclide; see Table A.4-1 of Appendix A.4 for decay products and branching fractions.

Rev. 0 
Table 4.1-8. Results of dose analysis for off-site releases of radionuclides from drinking water pathway

\begin{tabular}{|lccc|}
\hline \multicolumn{1}{|c}{ Radionuclide } & $\begin{array}{c}\text { Concentration } \\
(\mu \mathrm{Ci} / \mathrm{L})^{6}\end{array}$ & $\begin{array}{c}\text { Time } \\
(\text { year })^{c}\end{array}$ & $\begin{array}{c}\text { Effective dose } \\
\text { equivalent } \\
\text { (mrem per year) }\end{array}$ \\
\hline $\begin{array}{l}\text { Intact vaults/saltstone } \\
\text { Se-79 }\end{array}$ & $1.2 \times 10^{-5}$ & $2.1 \times 10^{5}$ & $7 \times 10^{-5}$ \\
I-129 & $7.2 \times 10^{-9}$ & $22.5 \times 10^{6}$ & $1 \times 10^{-3}$ \\
Others & & & $<2 \times 10^{-9}$ \\
Degraded vaults/saltstone & & $1.5 \times 10^{4}$ & $3 \times 10^{-2}$ \\
Se-79 & $4.4 \times 10^{-6}$ & $2.4 \times 10^{3}$ & $1 \times 10^{-2}$ \\
Tc-99 & $1.1 \times 10^{-5}$ & $2.2 \times 10^{5}$ & $3 \times 10^{-5}$ \\
Sn-126 + d & $2.2 \times 10^{-9}$ & $3.2 \times 10^{3}$ & $2 \times 10^{-2}$ \\
I-129 & $7.5 \times 10^{-5}$ & & $<2 \times 10^{-3}$ \\
Others & & & \\
\hline
\end{tabular}

- " $+d^{n}$ denotes short-lived decay products that are assumed to be in secular equilibrium with parent radionuclide; see Table A.4-1 of Appendix A.4 for decay products and branching fractions.

- Maximum concentration in groundwater beyond $100-\mathrm{m}$ buffer zone around disposal units obtained from results given in Table 4.1-5 for intact vaults and saltstone or in Table 4.1-6 for degraded vaults and saltstone.

- Time after disposal at which maximum concentration in groundwater beyond $100-\mathrm{m}$ buffer zone occurs.

- Product of maximum concentration in groundwater and dose per unit concentration given in Table 4.1-7. 


\subsubsection{Dose Analysis for Inadvertent Intruders}

As demonstrated in Sect. 3.2.4, the following exposure scenarios are of concern for inadvertent intruders onto the disposal site following loss of active institutional control at 100 years after facility closure:

- an agriculture scenario involving direct excavation into a disposal unit at any time after significant erosion of the cover material has occurred, the concrete roof has lost its integrity, and the top layer (i.e., about $1 \mathrm{~m}$ ) of the grout and saltstone monolith has weathered to soil-equivalent material;

- an agriculture scenario involving excavation into contaminated soil above a disposal unit at any time after loss of active institutional control;

- a resident scenario involving permanent residence in a home located either on top of an intact concrete roof at any time after loss of active institutional control or on top of an intact saltstone monolith at any time after the concrete roof and top layer of grout have lost their integrity; and

- a post-drilling scenario involving removal by drilling of contaminated soil immediately beside a disposal unit at any time after loss of active institutional control.

The two agriculture scenarios differ only in the time at which they first could occur and the radionuclide concentrations to which an inadvertent intruder would be exposed, but the dose per unit concentration of radionuclides in the excavated material is the same in both cases.

The results of the dose analysis for the different exposure scenarios for inadvertent intruders are presented in the following sections.

\subsubsection{Dose Analysis for Agriculture Scenarios}

The results of the model for estimating dose to inadvertent intruders for either of the two agriculture scenarios, as obtained from Table A.4-14 of Appendix A.4, are summarized in Table 4.1-9. This table gives the annual effective dose equivalent in rem for a unit concentration of each radionuclide in excavated solid waste of $1 \mu \mathrm{Ci} / \mathrm{m}^{3}$. The radionuclides listed in this table were selected by the screening analysis described in Sect. 3.2.4.4.

Scenario for Direct Intrusion into Disposal Units. The agriculture scenario involving direct excavation into a disposal unit is not expected to become credible for a considerable period of time after disposal. Due to the depth of the saltstone below the ground surface after facility closure, the scenario is not credible until significant erosion of the cover material above the disposal units has occurred, because normal excavation procedures would not penetrate more than a few meters below the surface. In addition, the scenario is not credible until the concrete roofs above the disposal units have lost 
Table 4.1-9. Annual effective dose equivalents per unit concentration of radionuclides from all coposure pathways for agriculture scenario"

\begin{tabular}{lc}
\hline Radionuclide & $\begin{array}{c}\text { Annual effective dose equivalent } \\
\text { (rem/y per } \mu \mathrm{Ci} / \mathrm{m}^{3} \text { ) }\end{array}$ \\
\hline H-3 & $3.9 \times 10^{-6}$ \\
C-14 & $8.9 \times 10^{-6}$ \\
Ni-63 & $2.3 \times 10^{-7}$ \\
Se-79 & $7.1 \times 10^{-7}$ \\
Sr-90 + d & $2.7 \times 10^{-4}$ \\
Tc-99 & $1.0 \times 10^{-6}$ \\
Sn-121m & $1.4 \times 10^{-7}$ \\
Sn-126 + d & $3.5 \times 10^{-3}$ \\
I-129 & $5.8 \times 10^{-5}$ \\
Cs-137 + d & $1.0 \times 10^{-3}$ \\
Sm-151 & $2.4 \times 10^{-3}$ \\
Pu-238 & $3.9 \times 10^{-5}$ \\
Pu-239 & $4.5 \times 10^{-5}$ \\
Am-241 & $1.3 \times 10^{-4}$ \\
\hline
\end{tabular}

- Results are obtained from Table A.4-14 of Appendix A.4 and apply to radionuclide concentrations in exposed disposal units or in soil above disposal units.

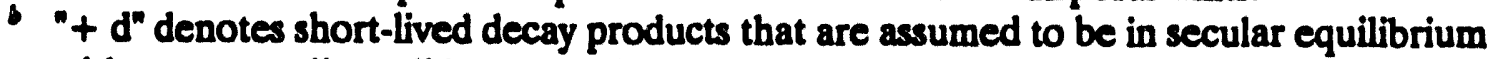
with parent radionuclide; see Table A.4-1 of Appendix A.4 for decay products and branching fractions. 
their physical integrity and a significant thickness of the top layer of grout and saltstone in the disposal units has weathered to soil-equivalent material, because normal excavation procedures used at the SRS would not be expected to penetrate an intact roof or grout/saltstone monolith.

The current closure concept for the SDF described in Sect. 2.7.1 includes a minimum thickness of cover material above the disposal units of about $2.6 \mathrm{~m}$. On the basis of the soil erosion rates for cropland near the SRS given in Sect. 2.1.8, an upper-bound estimate of the erosion rate of the cover material would be about $1.4 \mathrm{~mm}$ per year. If the estimated reduction in the erosion rate due to the presence of natural successional forests given in Sect. 2.1 .8 is taken into account, the erosion rate of the cover material would be as low as $0.003 \mathrm{~mm}$ per year. Therefore, since an excavation normally is assumed to extend no more than $3 \mathrm{~m}$ below the ground surface (U.S. NRC 1981; Oztunali and Roles 1986), at least $1 \mathrm{~m}$ of cover material would need to be removed by erosion for a significant thickness of grout/saltstone (about $1 \mathrm{~m}$ ) to be accessible by excavation. Using the estimated erosion rates given above, the time required for $1 \mathrm{~m}$ of cover material to erode is estimated to be at least 700 years and perhaps as long as 300,000 years.

In regard to degradation of the concrete roof above disposal units, the models described in Sect. 3.1.2 indicate that a roof should maintain its integrity for at least 1,000 years and perhaps as long as 10,000 years. Again, excavation into saltstone is not credible until the roof has lost its integrity as an engineered barrier.

Finally, at least $1 \mathrm{~m}$ of the top layer of grout and saltstone presumably must weather to soil-equivalent material before a significant amount of saltstone can be excavated. As described in Sect. 3.2.4.1, grout and saltstone are assumed to weather at the same rate as carbonate rock in regions near the SRS. For an assumed weathering rate of $0.1 \mathrm{~m}$ per 1,000 years, about 10,000 years will be required for weathering of a layer of overlying grout and saltstone about $1 \mathrm{~m}$ thick to occur.

Given the considerations involving erosion of the cover material, degradation of the concrete roof, and weathering of the grout and saltstone monolith described above, it seems reasonable to conclude that the agriculture scenario involving direct excavation into disposal units will not become credible for at least 10,000 years after disposal. This estimate assumes a relatively high erosion rate of $1 \mathrm{~mm}$ per year for the cover material. If the erosion rate of the cover material is very low, the scenario may not become credible for hundreds of thousands of years after disposal.

Because of the very long time period between waste disposal and the first credible occurrence of the agriculture scenario involving direct excavation into disposal units, the shorter-lived radionuclides listed in Table 4.1-9 do not need to be considered in the dose analysis because their concentrations will be reduced to minuscule levels by radioactive decay before the scenario first could occur. The radionuclides that are eliminated from

Rev. 0 
further consideration thus include H-3, Ni-63, Sr-90, Sn-121m, Cs-137, Sm-151, and Pu-238. Indeed, on the basis of the concentrations in disposed waste in Table 2.6-2 and the doses per unit concentration in Table 4.1-9, each of these radionuclides would result in insignificant doses even if the scenario could occur as soon as 500 years after disposal, which seems extremely unlikely. Am-241, which has an intermediate half-life, also can be neglected in the analysis, because the dose at 500 years after disposal would be less than $10 \%$ of the performance objective of 100 mrem per year and the dose after many thousands of years would be insignificant.

Thus, the only radionuclides that must be considered in the dose analysis for the agriculture scenario involving direct excavation into disposal units are the long-lived isotopes listed in Table 4.1-9. These radionuclides include. C-14, Se-79, Tc-99, Sn-126, I-129, and Pu-239.

In estimating doses to inadvertent intruders for the agriculture scenario involving direct excavation into disposal units, the radionuclide concentrations at disposal, as given in Table 2.6-2, are assumed to decrease with time only by radioactive decay. That is, reductions in concentrations due to mobilization and transport by infiltrating water are assumed to occur very slowly, so that significant transport does not occur before the scenario first becomes credible. This assumption is supported by the estimated release rates of radionuclides from disposal units over time, as given in Sect. 4.1.1, which show that only a very small fraction of the initial inventory of radionuclides will be removed from disposal units by infiltrating water within 10,000 years after disposal.

For the long-lived radionuclides of concern identified above, an upper bound estimate for the dose to an inadvertent intruder for the agriculture scenario involving direct excavation into disposal units is obtained by multiplying the concentrations at disposal in Table 26-2 by the doses per unit concentration in Table 4.1-9. The results are given in Table 4.1-10. The total dose from all radionuclides of $\mathbf{4 5 0}$ mrem per year exceeds the performance objective of $100 \mathrm{mrem}$ per year. The total dose for this scenario is due principally to the contributions from only two radionuclides: Sn-126 and Tc-99.

The dose estimates in Table 4.1-10 do not require more than a crude estimate of the time at which the scenario first could occur. All that is required is the assumption that the scenario could not reasonably occur for at least a thousand years after disposal. If this is the case, then the dose estimates for the more important long-lived radionuclides are essentially the same for any time after disposal.

The dose estimates in Table 4.1-10 are upper bounds because two factors have not been taken into account. First, these estimates assume that an intruder excavates only into a disposal unit but not into the region of essentially uncontaminated soil between disposal units. However, since an intruder is presumed to have no knowledge of the existence of a waste disposal facility at the site, it is reasonable to assume that an 
Table 4.1-10. Upper bound estimates of dose to inadvertent intruders for agriculture scenario involving direct intrusion into disposal units"

\begin{tabular}{|lcc|}
\hline Radionuclide $^{b}$ & $\begin{array}{c}\text { Concentration } \\
\left(\mu \mathrm{Ci} / \mathrm{m}^{3}\right)^{c}\end{array}$ & $\begin{array}{c}\text { Effective dose equivalent } \\
(\text { mrem per year) }\end{array}$ \\
\hline Sn-126+d & $1.1 \times 10^{2}$ & 390 \\
Tc-99 & $5.7 \times 10^{4}$ & 57 \\
I-129 & $1.7 \times 10^{1}$ & 1.0 \\
Se-79 & $2.8 \times 10^{2}$ & 0.2 \\
C-14 & 5.7 & 0.05 \\
ru-239 & 1.1 & 0.05 \\
\multicolumn{1}{c}{ Sum } & & 450 \\
\hline
\end{tabular}

- The dose from all other radionuclides listed in Table 4.1-9 is negligible, because the scenario cannot reasonably occur for at least a few thousand years after disposal.

- " $+d^{n}$ denotes short-lived decay products that are assumed to be in secular equilibrium with parent radionuclide; see Table A.4-1 of Appendix A.4 for decay products and branching fractions.

- Concentration in saltstone at disposal obtained from Table 2.6-2. Reductions in concentrations due to radioactive decay and migration from disposal facility until scenario occurs are assumed to be negligible.

- Product of concentration in saltstone at disposal and dose per unit concentration given in Table 4.1-9. 
intruder excavates into the region occupied by the vaults at random locations. Therefore, the dose estimates for all radionuclides should be reduced by the fraction of the land area encompassed by an envelope around the vaults that is occupied by the vaults themselves. By drawing an envelope around Vaults 1-12 and a separate envelope around Vaults 13-15, as shown in Fig. 2.5-1, and using the known dimensions and spacing of the vaults, this correction factor is determined to be about 0.7 ; i.e., about $70 \%$ of the land area occupied by the vaults contains waste in saltstone.

The second correction applies only to $\mathrm{Sn}-126$. For this radionuclide, the analysis presented in Appendix A.4 (i.e., see Tables A.4-11 and A.4-14) shows that essentially all of the dose results from external exposure while residing in the home located immediately on top of the disposal units. This is not the case for the other radionuclides listed in Table 4.1-10, because they do not emit significant intensities of high-energy photons and other exposure pathways are more important. The dose analysis for the external exposure pathway assumes that the home is located on top of unshielded saltstone and that the unshielded source region is of infinite extent in the horizontal direction. Both of these assumptions are unreasonably pessimistic.

There are two approaches that can be taken to provide a more reasonable estimate of external dose while residing in the home. The first is to correct the dose for the finite size of the excavation, i.e., to assume that only a finite area of saltstone around the home is uncovered during the excavation and that the saltstone outside the excavation remains essentially completely shielded. A previous analysis has shown that taking into account the finite size of the excavation reduces the external dose in the home by about a factor of four (U.S. NRC 1981; Oztunali and Roles 1986). This correction factor would be appropriate at times before most of the cover material above the vaults has eroded away but excavation into the saltstone is credible.

The second approach is to recognize that exposed saltstone probably cannot sustain vegetative ground cover. Thus, in developing a homesite on exposed saltstone, it seems reasonable to presume that the intruder will want to grow grass or some other ground cover at the site and that, for this purpose, the saltstone will be covered with a layer of uncontaminated soil that can sustain plant growth. The minimum thickness of a soil layer that would be required presumably is at least $30 \mathrm{~cm}$ (12 in.) to provide a sufficient root zone. Using the methods for calculating external dose from shielded saltstone described in Appendix A.4, the assumption of a layer of uncontaminated soil of thickness $30 \mathrm{~cm}$ on top of the saltstone reduces the external dose in the home by about a factor of 30 . 
In summary, a more reasonable best estimate of the dose to an inadvertent intruder for the agriculture scenario involving direct excavation into disposal units is obtained from the following factors:

- the upper bound estimates of dose given in Table 4.1-10;

- reduction of the dose from all radionuclides by a factor of 0.7 to take into account the area of the uncontaminated regions between disposal units; and

- further reduction of the dose from Sn-126 by a factor between 4 and 30 to take into account either the finite size of the excavation or the presence of a layer of uncontaminated soil on top of the saltstone that would be needed to sustain vegetative ground cover at a homesite.

Taking these factors into account, the best estimates of dose are given in Table 4.1-11. The results for Sn-126 are given as a range, rather than a single value, because it is not possible to choose between the two correction factors for reducing external dose while residing in the home. The actual dose presumably would not exceed the upper end of this range and probably would be somewhat less than this value, because, for an excavation of finite size, the maximum dose assumes that the saltstone immediately around the home is not shielded by any uncontaminated soil. Thus, the total dose from all radionuclides is estimated to be comparable to or somewhat less than the performance objective of 100 mrem per year.

Scenario for Intrusion into Contaminated Soil above Disposal Units. An alternative agriculture scenario involving excavation of contaminated soil above disposal units was considered in the dose analysis. Soil above the disposal units can become contaminated by upward diffusion of radionuclides from the vaults. This scenario is assumed to be credible at any time after loss of active institutional control at $\mathbf{1 0 0}$ years after disposal.

Estimates of dose for the alternative agriculture scenario are based on the maximum concentrations of radionuclides at any time after disposal that are predicted to occur at a point just above the vault roof at the center of a vault. This procedure results in upper bound estimates of dose, because the average concentrations of radionuclides over a volume of excavated soil above a vault will be considerably less than maximum concentrations at a point just above the center of a vault roof.

The predicted maximum concentrations of radionuclides in pore water just above the center of a vault roof are given in the column labeled "Node $1^{\prime \prime}$ in Table 4.1-2. The resulting concentrations in soil are estimated according to the equation

$$
C_{m}=C_{\max }\left(\theta+p_{g} K_{d}\right) \text {, }
$$

where $\theta$ is the porosity of soil, which is assumed to be 0.3 (Baes and Sharp 1983), $p_{\text {s }}$ is the bulk density of soil, which is assumed to be $1.4 \mathrm{~g} / \mathrm{cm}^{3}$ (Baes and Sharp 1983), and $K_{d}$ is the equilibrium solid/solution distribution coefficient, which depends on the particular 
Table 4.1-11. Beat estimates of dose to inadvertent intruders for agriculture scenario involving direct intrusion into disposal units

\begin{tabular}{|lcc|}
\hline Radionuclide & $\begin{array}{c}\text { Concentration } \\
\left(\mu \mathrm{Ci}^{3}\right)^{6}\end{array}$ & $\begin{array}{c}\text { Effective dose equivalent } \\
(\text { mrem per year })^{c}\end{array}$ \\
\hline Sn-126+d & $1.1 \times 10^{2}$ & $10-70$ \\
Tc-99 & $5.7 \times 10^{4}$ & 40 \\
I-129 & $1.7 \times 10^{1}$ & 0.7 \\
Others & & 0.2 \\
\multicolumn{1}{c}{ Sum } & & $50-110$ \\
\hline
\end{tabular}

- " $+d$ " denotes short-lived decay products that are assumed to be in secular equilibrium with parent radionuclide; see Table A.4-1 of Appendix A.4 for decay products and branching fractions.

- Concentration in saltstone at disposal obtained from Table 2.6-2. Reductions in concentrations due to radioactive decay and migration from disposal facility until scenario occurs are assumed to be negligible.

- Value obtained from effective dose equivalent in Table 4.1-10, corrected as described in Sect. 4.1.4.1. 
radionuclide. The total concentration of radionuclides in excavated soil is the sum of the concentrations in pore water, as given in Table 4.1-2, and the concentrations in the solid phase, as estimated by the equation given above. The assumed values of $K_{d}$ for each radionuclide are given in the column labeled "Clay" in Table A.1-2 of Appendix A.1.

Of the radionuclides listed in Table 4.1-9, the calculations summarized in Table 4.1-2 show that only Se-79 and I-129 are expected to migrate into soil above the vaults in more than minute amounts. However, the total concentrations of these radionuclides in pore water and soil, estimated as described above, are only about $10^{-3} \mu \mathrm{Ci} / \mathrm{m}^{3}$ for Se-79 and $10^{-4} \mu \mathrm{Ci} / \mathrm{m}^{3}$ for I-129. Thus, using the doses per unit concentration from Table 4.1-9, the estimated dose for both of these radionuclides for the agriculture scenario involving excavation into contaminated soil above the vaults is only about $10^{-5}$ mrem per year. This dose is much less than the performance objective of 100 mrem per year.

The very low doses estimated for the agriculture scenario involving excavation into contaminated soil above disposal units are not unexpected when two factors are considered. The first is the generally low release rates of radionuclides from saltstone, as indicated in Sect. 4.1.1. The second is that most of the activity released from saltstone migrates downward, rather than into the soil above the vaults, due to the downward movement of infiltrating water.

\subsubsection{Dose Analysis for Resident Scenarios}

Two resident scenarios have been assumed in the dose analysis for inadvertent intruders. In the first scenario, the intruder is assumed to reside in a home located immediately on top of an intact concrete roof, and this scenario is assumed to be credible at any time after loss of active institutional control at 100 years after disposal. In the second scenario, the home is assumed to be located immediately on top of an intact saltstone monolith, and this scenario is assumed to be credible at any time after the concrete roof and top layer of uncontaminated grout have lost their integrity and can be penetrated during excavation. Thus, the latter scenario probably is not credible for at least a few thousand years after disposal.

In both resident scenarios, the intruder is assumed not to excavate into the saltstone while constructing a home on the disposal site. Thus, the only exposure pathway for these scenarios is external exposure while residing in the home. The only differences between the two scenarios are the time at which they are assumed to become credible, as described above, and the amount of shielding between the source region and the receptor location. For residence on top of an intact concrete roof, $75 \mathrm{~cm}$ of shielding is provided by the roof and the layer of uncontaminated grout. For residence on top of bare saltstone, a worst-case dose estimate is provided by assuming no shielding. This scenario can be regarded as a variation of the agriculture scenario involving direct excavation into disposal units in which only the external exposure pathway while residing in the home is potentially important (see Sect. 3.2.4.1).

Rev. 0 
The results of the model for estimating dose to inadvertent intruders for the two resident scenarios, as obtained from Table A.415 of Appendix A.4, are summarized in Table 4.1-12. This table gives the annual effective dose equivalent in rem for a unit concentration of each radionuclide in saltstone of $1 \mu \mathrm{Ci} / \mathrm{m}^{3}$. The only radionuclides of concern for the resident scenarios are the photon-emitting radionuclides listed in Table 4.1-9. These results are applied as described below.

For the radionuclides of concern, an upper bound estimate of the dose for the resident scenario involving a home on top of an intact concrete roof is obtained by multiplying the concentrations at disposal in Table 2.6-2, but corrected for radioactive decay over the 100 -year institutional control period as appropriate, by the doses per unit concentration in the column in Table 4.1-12 labeled 75-cm shielding". The results are given in Table 4.1-13.

Similarly, an upper bound estimate of the dose for the resident scenario involving a home on top of unshielded saltstone is obtained by multiplying the concentrations at disposal in Table 26-2 by the doses per unit concentration in the column in Table 4.1-12 labeled "No shielding". Since only long-lived radionuclides are of concern for this scenario, no correction for radioactive decay is applied. The results are given in Table 4.1-14. The dose from Am-241 would be negligible if the scenario first occurs beyond 1,000 years after disposal, as expected.

A comparison of the results in Tables 4.1-13 and 4.1-14 shows that the scenario involving residence on top of an intact saltstone monolith, which first becomes credible only at times long after disposal, is more important (i.e., results in higher estimates of dose) than the srenario involving residence on top of an intact concrete roof at 100 years after disposal. Indeed, the dose estimates for the latter scenario are so low in comparison with the performance objective of 100 mrem per year that this scenario need not be considered further.

As for the agriculture scenario involving direct excavation into disposal units described in Sect. 4.1.4.1, the dose estimates for the resident scenario in Table 4.1-14 are upper bounds because they do not take into account (1) the area of the uncontaminated regions between disposal units and (2) either the finite size of the excavation for constructing the home or the presence of a layer of uncontaminated soil on top of the saltstone that probably would be needed to sustain vegetative ground cover. Since $\mathrm{Sn}-126$ is the only important radionuclide for the resident scenario, the corrections for these factors are the same as the corrections to the dose estimate for the agriculture scenario described in Sect. 4.1.4.1; i.e., a reduction by a factor of 0.7 for the uncontaminated areas and further reduction by a factor of 4 or 30 for the finite size of the excavation or the layer of uncontaminated soil. 
Table 4.1-12 Annual effective dose equivalents per unit concentration of radionuclides in disposal units for resident scenarios

\begin{tabular}{|lc|c|}
\hline \multirow{2}{*}{ Radionuclide $^{b}$} & \multicolumn{2}{c|}{$\begin{array}{c}\text { Annual effective dose equivalent } \\
\text { (rem/y per } \mu \mathrm{Ci} / \mathrm{m}^{3} \text { ) }\end{array}$} \\
\cline { 2 - 3 } & No shielding & $75-\mathrm{cm}^{6}$ shielding \\
\hline Sn-126+d & $3.5 \times 10^{-3}$ & $1.0 \times 10^{-6}$ \\
$\mathrm{I}-129$ & $6.3 \times 10^{-6}$ & - \\
Cs-137 + d & - & $2.9 \times 10^{-7}$ \\
Am-241 & $9.5 \times 10^{-6}$ & - \\
\hline
\end{tabular}

- Results are obtained from Table A.4-15 of Appendix A.4 and apply to radionuclide concentrations in disposal units.

- " $+d^{\prime \prime}$ denotes short-lived decay products that are assumed to be in secular equilibrium with parent radionuclide; see Table A.4-1 of Appendix A.4 for decay products and branching fractions.

- Results apply at times long after disposal when engineered barriers are assumed to have lost their physical integrity and construction of a home on top of unshielded saltstone could occur.

Results apply at 100 years after disposal when engineered barriers are assumed to be intact. 
Table 4.1-13. Upper bound estimates of dose to inadvertent intruders for resident scenario involving home on top of intact concrete roof above disposal unit

\begin{tabular}{|lcc|}
\hline Radionuclide & $\begin{array}{c}\text { Concentration } \\
\left(\mu \mathrm{Ci}^{3} \mathrm{~m}^{3}\right)^{6}\end{array}$ & $\begin{array}{c}\text { Effective dose equivalent } \\
(\text { mrem per year) }\end{array}$ \\
\hline Sn-126 +d & $1.1 \times 10^{2}$ & 0.1 \\
Cs-137 + d & $1.7 \times 10^{3}$ & 0.5 \\
Sum & & 0.6 \\
\hline
\end{tabular}

- " $+\mathrm{d}^{n}$ denotes short-lived decay products that are assumed to be in secular equilibrium with parent radionuclide; see Table A.4-1 of Appendix A.4 for decay products and branching fractions.

- Concentration in saltstone at $\mathbf{1 0 0}$ years after disposal obtained from concentrations at disposal in Table 2.6-2, corrected for radioactive decay for Cs-137.

- Product of concentration in saltstone at 100 years after disposal and dose per unit concentration given in third column of Table 4.1-12. 
Table 4.1-14. Upper bound estimates of dose to inadvertent intruders for resident scenario involving bome on top of intact saltstone monolith

\begin{tabular}{|lcc|}
\hline Radionuclide & $\begin{array}{c}\text { Concentration } \\
\left(\mu \mathrm{Ci} / \mathrm{m}^{3}\right)^{b}\end{array}$ & $\begin{array}{c}\text { Effective dose equivalent } \\
(\text { mrem per year) }\end{array}$ \\
\hline Sn-126+d & $1.1 \times 10^{2}$ & 390 \\
$1-129$ & $1.7 \times 10^{1}$ & 0.1 \\
Sum & & 390 \\
\hline
\end{tabular}

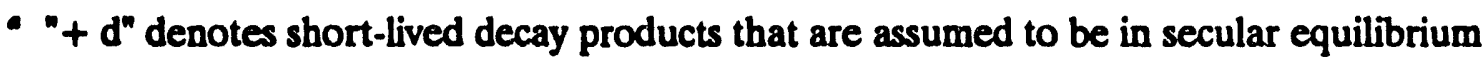
with parent radionuclide; see Table A.4-1 of Appendix A.4 for decay products and branching fractions.

- Concentration in saltstone at disposal obtained from Table 2.6-2. Reductions in concentrations due to radioactive decay in migration from disposal facility until scenario occurs are assumed to be negligible.

- Product of concentration in saltstone at disposal and dose per unit concentration given in second column of Table 4.1-12. 
By applying these correction factors to the dose estimates in Table 4.1-14, the best estimates of dose for the resident scenario given in Table 4.1-15 are obtained. Again, as in Table 4.1-11, the upper end of the range of doses presumably would not be exceeded, and the actual dose probably would be somewhat less than this value. The dose estimate for this scenario is somewhat less than the performance objective of 100 mrem per year.

\subsubsection{Dose Analysis for Post-Drilling Scenario}

The results of the model for estimating dose to inadvertent intruders for the post-drilling scenario, as obtained from Table A.4-16 of Appendix A.4, are summarized in Table 4.1-16. This table gives the annual effective dose equivalent in rem for a unit concentration of each radionuclide in exhumed solid waste of $1 \mu \mathrm{Ci} / \mathrm{m}^{3}$. The radionuclides listed in this table were selected by the screening analysis described in

Sect. 3.2.4.4.

In this analysis, a saltstone monolith is assumed to preclude drilling through the waste by the types of drilling equipment normally used near the SRS. Rather, drilling is assumed to occur immediately adjacent to a vault, and an intruder is exposed to contaminated soil containing radionuclides that have migrated from the vault.

Estimates of dose for the post-drilling scenario are based on the maximum concentrations of radionuclides at any time after disposal that are predicted to occur at any point next to a vault. The maximum concentrations are predicted to occur next to the bottom of a vault. This procedure results in upper bound estimates of dose, because the average concentrations of radionuclides in the volume of drilling waste will be considerably less than the maximum concentrations at any point next to a vault.

The predicted maximum concentrations of radionuclides in pore water next to a vault are given in the column labeled "Node $2^{n}$ in Table 4.1-2. The resulting concentrations in soil are given by the equation in Sect. 4.1.4.2, and the total concentrations in drilling waste are the sum of the concentrations in pore water and those in the solid phase. The assumed values of the distribution coefficient $\left(K_{y}\right)$ for each radionuclide are given in the column labeled "Backfill" in Table A.1-2 of Appendix A.1.

Of the radionuclides listed in Table 4.1-16, the calculations summarized in Table 4.1-2 show that only Se-79 and I-129 are expected to migrate into soil next to the vaults in more than minute amounts. However, the total concentrations of these radionuclides in pore water and soil are only about $0.5 \mu \mathrm{Ci} / \mathrm{m}^{3}$ for Se-79 and $10^{-3} \mu \mathrm{Ci} / \mathrm{m}^{3}$ for I-129. Thus, the estimated dose for the post-drilling scenario from both of these radionuclides is only about $10^{-4}$ mrem per year. This dose is much less than the performance objective of 100 mrem per year. 
Table 4.1-15. Best estimates of dose to inadvertent intruders for resident scenario involving bome on top of intact saltstone monolith

\begin{tabular}{|lcc|}
\hline Radionuclide & $\begin{array}{c}\text { Concentration } \\
\left(\mu \mathrm{Ci} / \mathrm{m}^{3}\right)^{b}\end{array}$ & $\begin{array}{c}\text { Effective dose equivalent } \\
\text { (mrem per year) }\end{array}$ \\
\hline Sn-126+d & $1.1 \times 10^{2}$ & $10-70$ \\
$\mathrm{I}-129$ & $1.7 \times 10^{\mathrm{a}}$ & $<0.1$ \\
\multicolumn{1}{c}{ Sum } & & $10-70$ \\
\hline
\end{tabular}

- " $+\mathrm{d}$ " denotes short-lived decay products that are assumed to be in secular equilibrium with parent radionuclide; see Table A.4-1 of Appendix A.4 for decay products and branching fractions.

- Concentration in saltstone at disposal obtained from Table 2.6-2. Reductions in concentrations due to radioactive decay and migration from disposal facility until scenario occurs are assumed to be negligible.

- Value obtained from effective dose equivalent in Table 4.1-14, corrected as described in Sect. 4.1.4.2. 
Table 4.1-16. Annual effective doce equivalents per unit concentration of radionuclides in exhumed waste for pout-drilling scenario"

\begin{tabular}{lc}
\hline Radionuclide & $\begin{array}{c}\text { Annual effective dose equivalent } \\
\left(\text { rem/y per } \mu \mathrm{Ci} / \mathrm{m}^{3} \text { ) }\right.\end{array}$ \\
\hline H-3 & $3.9 \times 10^{-7}$ \\
Se-79 & $7.1 \times 10^{-5}$ \\
Sr-90 + d & $2.7 \times 10^{-5}$ \\
Tc-99 & $1.0 \times 10^{-7}$ \\
Sn-126+d & $1.9 \times 10^{-6}$ \\
I-129 & $5.2 \times 10^{-6}$ \\
Cs-137 + d & $1.1 \times 10^{-6}$ \\
Sm-151 & $2.3 \times 10^{-9}$ \\
Pu-238 & $2.6 \times 10^{-6}$ \\
Am-241 & $1.1 \times 10^{-5}$ \\
\hline
\end{tabular}

- Results are obtained from Table A.4-16 of Appendix A.4.

- " $+\mathrm{d}$ " denotes short-lived decay products that are assumed to be in secular equilibrium with parent radionuclide; see Table A.4-1 of Appendix A.4 for decay products and branching fractions. 
The very low doses estimated for the post-drilling scenario are not unexpected considering the generally low release rates of radionuclides from saltstone, as indicated in Sect 4.1.1.1. The conclusion that the doses should be very low also is supported by the following analysis. If drilling directly through saltstone were assumed to occur at 100 years after disposal, which is a worst-case scenario that is presumed not to be credible, then, as shown in Table 4.1-17, the concentrations of radionuclides at disposal given in Table 26-2, but corrected for decay over 100 years as appropriate, combined with the doses per unit concentration given in Table 4.1-16 would give an estimated dose from all radionuclides of only about 10 mrem per year. This estimate is $10 \%$ of the performance objective of 100 mrem per year. Thus, a post-drilling scenario is not of concern in an intruder dose analysis for the SDF.

\subsubsection{Summary of Dowe Analysis for Inadvertent Intruders}

A dose analysis for the SDF has shown that only two exposure scenarios are of concern in regard to meeting the performance objective for protection of inadvertent intruders:

- an agriculture scenario involving direct excavation into disposal units; and

- a resident scenario involving residence in a home on top of unshielded saltstone.

The resident scenario essentially is the same as one of the exposure pathways for the agriculture scenario. Furthermore, the dose analyses for these scenarios indicate that only two radionuclides are of concern:

- Sn-126 and Tc-99 for the agriculture scenario; and

- Sn-126 for the resident scenario.

Both of these radionuclides have very long half-lives.

The agriculture and resident scenarios of concern probably are credible only at times far in the future. Because of the depth of the saltstone below the ground surface and the long-term integrity of the engineered barriers (i.e., the concrete roof and the top layer of grout and saltstone), these scenarios probably could not occur for at least several thousand years after disposal. Although the time at which these scenarios reasonably could occur is uncertain, the estimates of dose are not sensitive to this uncertainty provided the release rates of the important long-lived radionuclides from disposal units are low.

The dose estimates for the agriculture and resident scenarios are summarized in Table 4.1-11 and Table 4.1-15, respectively. In either case, the upper end of the range of doses given in these tables presumably would not be exceeded, and the actual dose probably would be somewhat less than the maximum value given. For both scenarios, the best estimate of dose is comparable to or less than the performance objective of 100 mrem per year.

Rev. 0 
Table 4.1-17. Worat-case cetimates of dose to inadvertent intruders for poat-drilling ecenariof

\begin{tabular}{|lcc|}
\hline Radionuclide & $\begin{array}{c}\text { Concentration } \\
\left(\mu \mathrm{C}_{\text {m m }}\right)^{a}\end{array}$ & $\begin{array}{c}\text { Effective dose equivalent } \\
\text { (mrem per year) }\end{array}$ \\
\hline Sr-90+d & $5.2 \times 10^{2}$ & 1.4 \\
Tc-99 & $5.7 \times 10^{4}$ & 5.7 \\
Sn-126+d & $1.1 \times 10^{2}$ & 0.2 \\
I-129 & $1.7 \times 10^{1}$ & 0.1 \\
Cs-137+d & $1.7 \times 10^{3}$ & 1.9 \\
Am-241 & $9.4 \times 10^{1}$ & 1.0 \\
Others & & $<0.1$ \\
\multicolumn{1}{c}{ Sum } & & 10 \\
\hline
\end{tabular}

- Calculations based on assuming that drilling directly through disposal units occurs at 100 years after disposal.

- " $\mathrm{d}^{\prime \prime}$ denotes short-lived decay products that are assumed to be in secular equilibrium with parent radionuclide; see Table A.4-1 of Appendix A.4 for decay products and branching fractions.

- Concentration in saltstone at 100 years after disposal obtained from concentrations at disposal in Table 2.6-2, corrected for radioactive decay as appropriate.

- Product of concentration in saltstone at 100 years after disposal and dose per unit concentration given in Table 4.1-16. 


\section{SENSITIVITY AND UNCERTAINTY ANALYSES}

To interpret the results provided in the previous section (Sect. 4.1), parameters and assumptions to which the results are most sensitive must be identified. The uncertainty associated with these parameters and assumptions must also be considered to determine the degree of confidence in the predicted results. A rigorous quantitative analysis of uncertainty is desirable, but such an analysis is not possible for all aspects of the analyses conducted for this RPA due to: 1) limits of our knowledge with respect to certain physical and functional characteristics or processes; 2) the inability to predict conditions in the future, especially beyond several decades; and 3 ) the inability to quantify uncertainty associated with the definition of a particular scenario. This last type of uncertainty can dominate the overall uncertainty in some cases.

In this section, sensitivity and uncertainty analyses are discussed separately for the following stages of the overall computational approach: 1) analysis of fluxes to the water table from intact and degraded vaults; 2) analysis of groundwater transport; 3) dose analysis for off-site releases; and 4) doses analysis for inadvertent intruders. How these separate analyses are interpreted will be discussed in Sect. 4.3.

\section{Analysis for Intact and Degraded Vaults}

Sensitivity and uncertainty for the intact and degraded vault and saltstone scenarios are discussed separately below. The analysis of sensitivity and uncertainty for the intact scenario, in Sect. 4.2.1.1, also applies to the degraded scenario because intact saltstone occurs between the fractures in a monolith. For the degraded scenario, releases also occur from fractures in the vaults and saltstone. In this RPA, releases from fractures were considered independently of releases from intact saltstone, and therefore the sensitivity and uncertainty analysis of the model for fracture releases (Sect. 4.2.1.2) is presented separately.

\subsection{Fluses to the Water Table from Intact Vaults}

The sensitivity and uncertainty analyses conducted for the intact vault scenario focussed on nitrate release. Early in the RPA effort, the rate of nitrate release was identified as a parameter critical to meeting groundwater protection requirements, even though it is not a radioactive contaminant. Because nitrate is a non-sorbing, non-reactive constituent, the distribution coefficient (Kd) is zero. Therefore, the analysis did not consider the distribution coefficient parameter in the sensitivity and uncertainty analysis.

In order to identify the parameters to which the flux of nitrate to the water table is most sensitive in the PORFLOW-3D simulations of intact vaults, a detailed study of the effect of changes in the physical properties of materials simulated in the unsaturated zone was performed. Parameters that were studies are summarized in Table 4.2-1. The reference run, representing the simulation that was done to produce the results in Sect. 4.1, is an earlier version of the PORFLOW-3D input file for nitrate flux from intact 
Table 42-1. Parameters studied and perturbations for sensitivity study of near-field calculations for intact saltstone and vaults

\begin{tabular}{|c|c|c|}
\hline Case & Parameter Changed & Perturbation \\
\hline 1 & \multicolumn{2}{|c|}{ Reference Run } \\
\hline 2 & Concrete conductivity & Reduced to zero \\
\hline 3 & Concrete diffusivity & Reduced to zero \\
\hline 4 & $\begin{array}{l}\text { Concrete diffusivity } \\
\text { Saltstone diffusivity }\end{array}$ & $\begin{array}{l}\text { Increased by factor of } 10 \\
\text { Increased by factor of } 10\end{array}$ \\
\hline 5 & $\begin{array}{l}\text { Concrete conductivity } \\
\text { Saltstone conductivity }\end{array}$ & $\begin{array}{l}\text { Increased by factor of } 10 \\
\text { Increased by factor of } 10\end{array}$ \\
\hline 6 & \multicolumn{2}{|c|}{ Combines perturbations of runs 4 and 5} \\
\hline 7 & Saltstone conductivity & Increased by factor of 100 \\
\hline 8 & Saltstone conductivity & Decreased by factor of 100 \\
\hline 9 & $\begin{array}{l}\text { Concrete conductivity } \\
\text { Saltstone conductivity } \\
\text { Backefll conductivity }\end{array}$ & $\begin{array}{l}\text { Increased by factor of } 10 \\
\text { Increased by factor of } 10 \\
\text { Increased by factor of } 10\end{array}$ \\
\hline 10 & Concrete porosity & Increased by factor of 2 \\
\hline $11 *$ & $\begin{array}{l}\text { Concrete conductivity } \\
\text { Saltstone conductivity } \\
\text { Soil capillary pressure as function of } \\
\text { saturation }\end{array}$ & $\begin{array}{l}\text { Increased by factor of } 10 \\
\text { Increased by factor of } 10 \\
\text { Reduced all tabular values } \\
\text { by factor of } 10\end{array}$ \\
\hline $11 *$ & Vault infiltration rate & Increased by factor of 20 \\
\hline 12 & $\begin{array}{l}\text { Concrete conductivity } \\
\text { Saltstone conductivity } \\
\text { Soil capillary pressure as function of } \\
\text { saturation }\end{array}$ & $\begin{array}{l}\text { Increased by factor of } 10 \\
\text { Increased by factor of } 10 \\
\text { Increased all tabular values } \\
\text { by factor of } 10\end{array}$ \\
\hline 13 & Vault infiltration rate & Reduced by factor of 20 \\
\hline 14 & Insert sloped roof - vault geometry (1) & $\begin{array}{l}\text { Redefinition of concrete and } \\
\text { soil geometry }\end{array}$ \\
\hline 15 & Insert sloped roof - vault geometry (1) & Reorientation of axes \\
\hline 16 & Insert sloped roof - vault geometry (2) & Reorientation of axes \\
\hline
\end{tabular}

- did not converge to stable solution. 
vaults (provided in Appendix C.2). The reference run does not include a clay/gravel drain over the vaults. While this earlier virsion provides results that are somewhat different than the final version, the differences are mainly due to a shorter travel time to the water table as a resuli of the additional soil moisture in the absence of the clay/gravel drain. For nitrate, the different travel times do not significantly change the magnitude of the peak fractional flux to the water table because nitrate is non-sorbing and non-decaying. The earlier version responds quantitatively in the same manner as the final version, as confirmed by benchmarking tests. Therefore, the sensitivity and uncertainty analyses results presented here are believed to adequately represent the final PORFLOW-3D simulations for the intact vaults.

The parameter values for the reference run, and associated ranges used in the sensitivity and uncertainty analyses, are listed in Table 4.2-2. The infiltration rate, at the top of the vault/saltstone domain, is $2 \mathrm{~cm} /$ year in the reference run. The perturbations on the parameters listed in Table 4.2-2 were made within a range considered reasonable for each parameter. Parameters not listed were those to which the peak nitrate flux is expected to be relatively insensitive. For example, matrix density is only important for non-zero Kd's, and thus was not included. Initial inventory is omitted because the results from the mass transport simulations are provided in terms of fractional flux, where the release is divided by the initial inventory. Based on the sensitivity analysis conducted in the manner described in Table 4.2-1, the four most significant flow parameters are:

1) the saturated hydraulic conductivity of saltstone, 2) the diffusivity of nitrate in the saltstone, 3) the saturated hydraulic conductivity of concrete; and 4) the diffusivity of nitrate in the concrete. The parameter to which the results are most sensitive is the saturated hydraulic conductivity of saltstone. The sensitivity to this parameter decreases below the reference value of $3.15 \times 10^{-4} \mathrm{~cm} / \mathrm{yr}\left(10^{-11} \mathrm{~cm} / \mathrm{s}\right)$, because diffusive transport becomes'more important relative to conductive transport.

An uncertainty analysis was conducted using Latin Hypercube Sampling (LHS) techniques (Iman and Shortencarier 1984) for the four most significant parameters listed above. Parameter values were sampled from the ranges given in Table 4.2-2. The distributions for both diffusivities and the concrete conductivity were assumed to be lognormal. For the saturated hydraulic conductivity of saltstone, a loguniform distribution was assumed because the most probable value of this number is not known since the saturated hydraulic conductivity of slag saltstone has not been measured. Values measured for non-slag saltstone have been reported to range between 0.315 to $3.15 \times 10^{-4} \mathrm{~cm} / \mathrm{yr}\left(10^{-8}\right.$ to $\left.10^{-11} \mathrm{~cm} / \mathrm{s}\right)$.

The sampled parameter values and the resulting peak fractional flux values for nitrate for one hundred runs are listed in Appendix H (Table H.1-1). The time of peak flux is also reported. Plots of the fractional release as a function of time are also provided in Appendix H (Fig. H.1-1 through H.1-8). Results from the analysis show a strong correlation between values of the saltstone conductivity and the peak fluxes, thus confirming the previous indication that sensitivity to this parameter is dominant. A

Rev. 0 
Table 4.2-2 PORFLOW-3D parameters for sensitivity/uncertainty analysis

\begin{tabular}{|c|c|c|c|}
\hline \multirow[b]{2}{*}{ Parameter } & \multirow[b]{2}{*}{$\begin{array}{c}\text { Value in Reference } \\
\text { Run }\end{array}$} & \multicolumn{2}{|c|}{ Ranges Considered } \\
\hline & & Sensitivity Analysis & Uncertainty Analysis \\
\hline Infiltration Rate & 2 confyear & 0.01 to $40 \mathrm{~cm} /$ year & Not analyzed \\
\hline Slope of Root & $0 \%$ & 0 to $2 \%$ & Not analyzed \\
\hline $\begin{array}{l}\text { Bactefill Propertics: } \\
\text { Saturated hydraulic } \\
\text { conductivity } \\
\text { Soll capillary } \\
\text { pressure vs } \\
\text { saturation }\end{array}$ & $\begin{array}{l}158 \mathrm{~cm} / \mathrm{year} \\
\text { Tabulated }\end{array}$ & $\begin{array}{l}158 \text { to } 1580 \text { con/year } \\
\text { Changed pressure by plus } \\
\text { or minus factor of } 10\end{array}$ & $\begin{array}{l}\text { Not analyzed } \\
\text { Not analyzed }\end{array}$ \\
\hline $\begin{array}{l}\text { Concrete Properties: } \\
\text { Saturated bydraulic } \\
\text { conductivity } \\
\text { Effective diffusivity } \\
\text { Total porosity }\end{array}$ & $\begin{array}{l}3.15 \times 10^{-3} \mathrm{~cm} / \text { year } \\
0.315 \mathrm{~cm}^{2} / \text { year } \\
0.08\end{array}$ & $\begin{array}{l}0 \text { to } 3.15 \times 10^{-2} \mathrm{~cm} / \text { year } \\
0 \text { to } 3.15 \mathrm{~cm}^{2} / \text { year } \\
0.08 \text { to } 0.16\end{array}$ & $\begin{array}{l}3.15 \times 10^{-4} \text { to } \\
3.15 \times 10^{-2} \mathrm{~cm} / \text { year } \\
0.05 \text { to } 0.5 \mathrm{~cm}^{2} / \text { year } \\
\text { Not analyzed }\end{array}$ \\
\hline $\begin{array}{l}\text { Saltstone Properties: } \\
\text { Saturated hydraulic } \\
\text { conductivity } \\
\text { Effective diffusivity }\end{array}$ & $\begin{array}{l}3.15 \times 10^{-4} \text { contyear } \\
0.158 \mathrm{~cm}^{2} / \text { year }\end{array}$ & $\begin{array}{l}3.15 \times 10^{6} \text { to } \\
3.15 \times 10^{-2} \mathrm{~cm} / \text { year } \\
0.158 \text { to } 1.58 \mathrm{~cm}^{2} / \text { year }\end{array}$ & $\begin{array}{l}3.15 \times 10^{-4} \text { to } 0.158 \mathrm{~cm} \text { /year } \\
0.1 \text { to } 1.0 \mathrm{~cm}^{2} / \text { year }\end{array}$ \\
\hline
\end{tabular}


strong correlation is also evident between the magnitudes of the peak flux and the time of arrival of the peak at the water table. Thus, more conductive saltstone results in higher contaminant fluxes and earlier arrival times. The peak fractional flux for the reference run was $3.05 \times 10^{-6}$ per year. The maximum peak fractional flux was $1.48 \times$ $10^{-4}$ per year, corresponding to a saturated hydraulic conductivity of saltstone of 0.154 cm/year, a saltstone diffusivity of $0.139 \mathrm{~cm}^{2} / y e a r$, a concrete conductivity of $7.015 \times 10^{-3}$ $\mathrm{cm} /$ year and a concrete diffusivity of $0.24 \mathrm{~cm}^{2} / y e a r$. The smallest peak fractional flux of nitrate from these one hundred runs was $2.39 \times 10^{-6}$ per year, based on a saltstone hydraulic conductivity of 3.15 is $10^{-4}$ cm/year, a saltstone diffusivity of 0.161 , and a concrete diffusivity of $\mathbf{0 . 2 0 4}$. As was noted earlier, diffusive transport in saltstone and concrete becomes considerably more important below this value of conductivity, and flux does not drop significantly using a saturated hydraulic conductivity below $3.15 \times 10^{-4}$ cm/year. The decrease in flux was found to be only $30 \%$ when the conductivity was reduced by two orders of magnitude below $3.15 \times 10^{-4} \mathrm{~cm} / y e a r$.

\section{Sensitivity Analysis for Degraded Conditions}

Sensitivity analyses of the flow and transport simulations were conducted for the degraded vault and saltstone scenarios. Four graphs (Fig. 4.2-1 through 4.2-4) illustrate the sensitivity of mass release rate to two different input parameters. These figures are best interpreted by selecting a value for one of the independent parameters and trace the surface at that value across the range of values for the other independent parameter. The ranges of values considered for the independent parameters were: 1) depth of perched water on top of the vaults, 10 to $100 \mathrm{~cm}$; 2) crack spacing, 100 to $10,000 \mathrm{~cm}$; 3) crack width, or aperture, 0.001 to $10 \mathrm{~cm} ; 4$ ) time, 1 to 10,000 years; and 5) distribution coefficient, .01 to $1,000 \mathrm{~cm}^{3} / \mathrm{g}$.

Figures 4.2-1 and 4.2-2 illustrate the sensitivity of nitrate release to crack spacing and perched water, and the relative insensitivity of nitrate release to time, over the ten thousand year period considered. As shown in Fig. 4.2-3, the predicted nitrate release rate is quite insensitive to crack width over the range of widths considered in the degradation model described in Sect. A.1.3, when $61 \mathrm{~cm}$ of perched water and 300-cm crack spacing are assumed. Figure 4.2-4 indicates technetium release is strongly dependent on the distribution coefficient, or $\mathrm{K}_{d}$. The time dependence of nitrate release under degraded conditions can be explained by the gradual depletion of nitrate and technetium in saltstone in the vicinity of the crack.

As shown in Fig. 4.2-1, nitrate release is roughly linearly related to the amount of perched water on the vault for a given crack spacing at earlier times. The crack spacing of $300 \mathrm{~cm}$ and crack width of $0.005 \mathrm{~cm}$ are consistent with the values assumed in the degraded vault and saltstone calculations in this RPA. Approaching 10,000 years, release becomes less sensitive to depth of perched water. Nitrate release as a function of crack spacing (Fig. 4.2-2) for a given amount of perching also increases with decreasing crack spacing. The sensitivity to crack spacing is due to two factors:

1) decreasing the crack spacing increases the number of fractures; and 2) increasing the

Rev. 0 


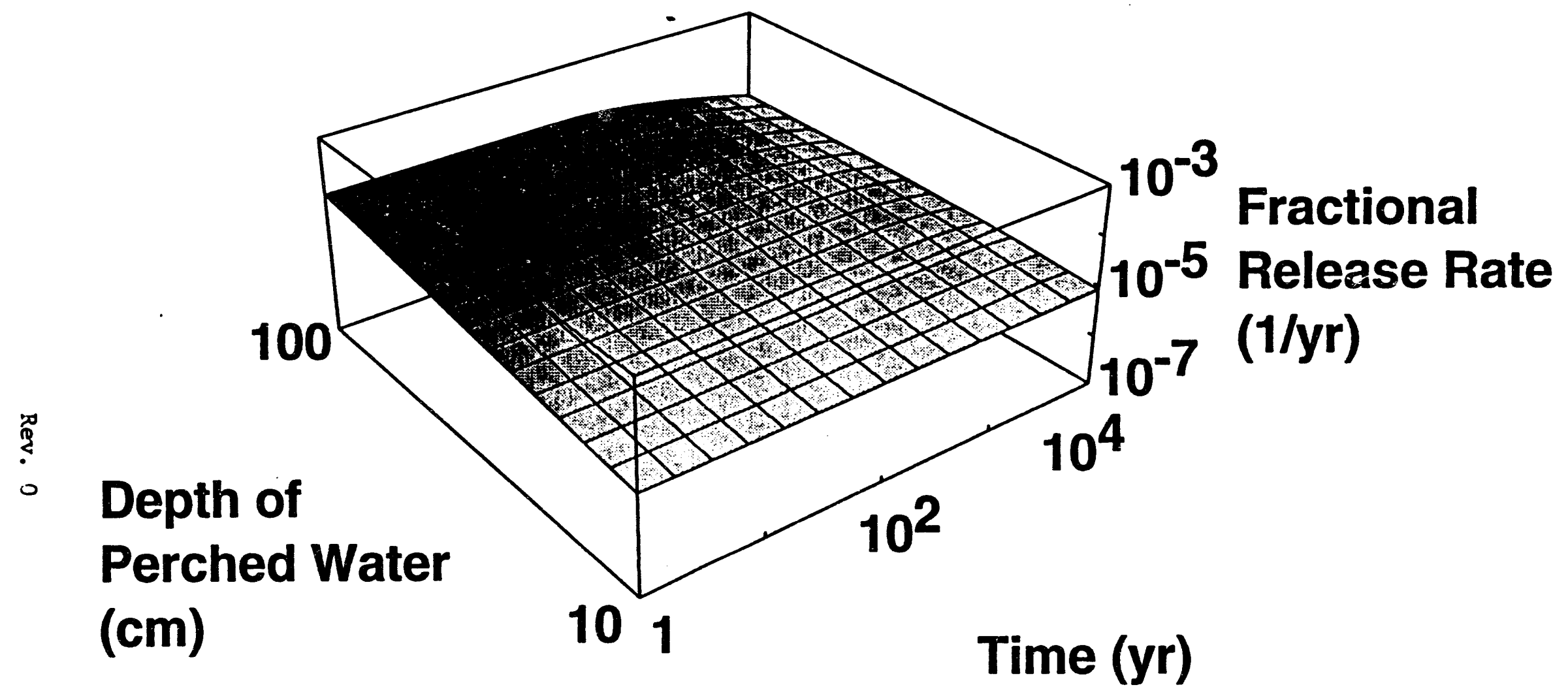

$300 \mathrm{~cm}$ Crack Spacing $0.005 \mathrm{~cm}$ Crack Width

Fig. 4.2-1. Nitrate release rate vs. perched water and time. 


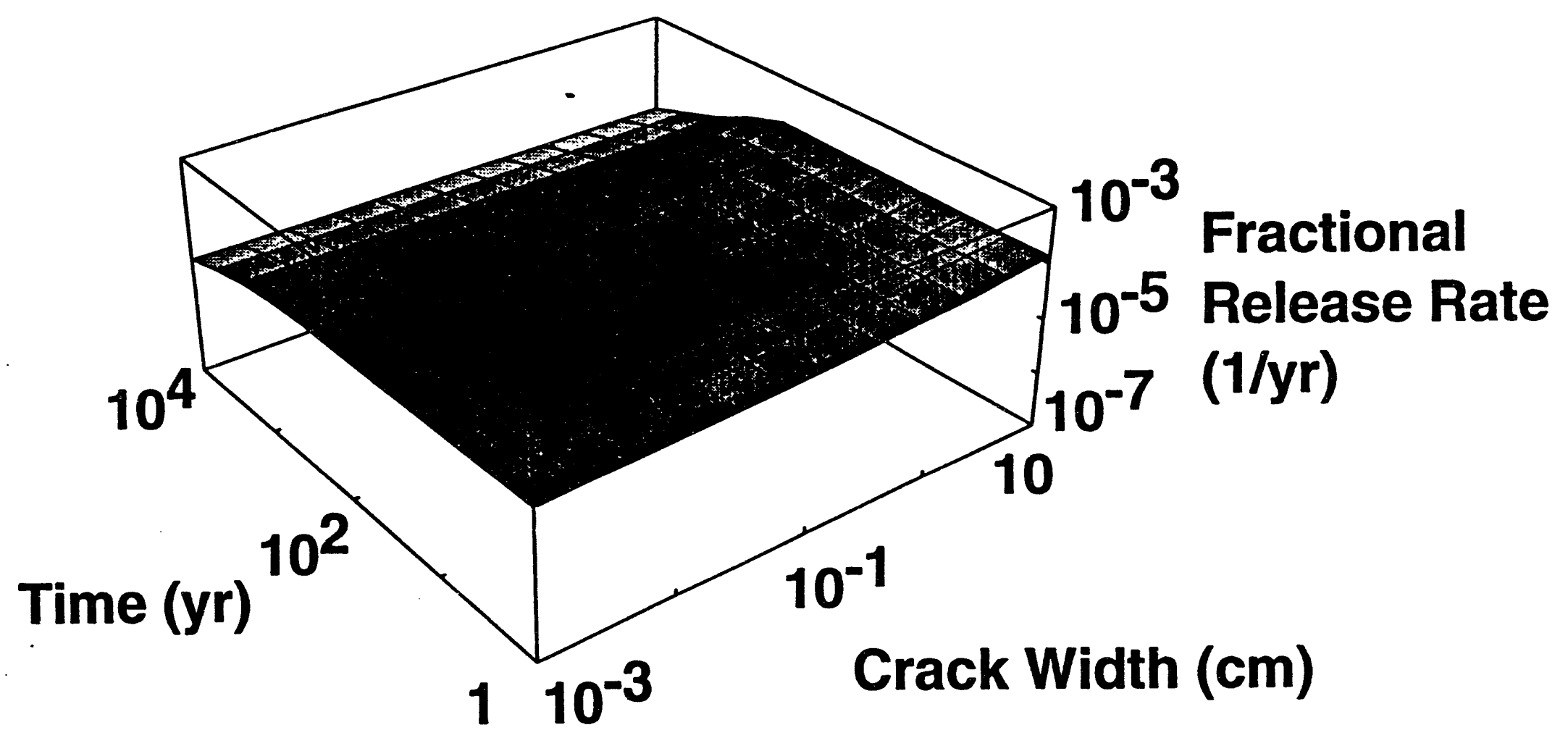

$61 \mathrm{~cm}$ of Perched Water $300 \mathrm{~cm}$ Crack Spacing

Fig. 4.2-2. Nitrate release rate vs. crack width and time. 


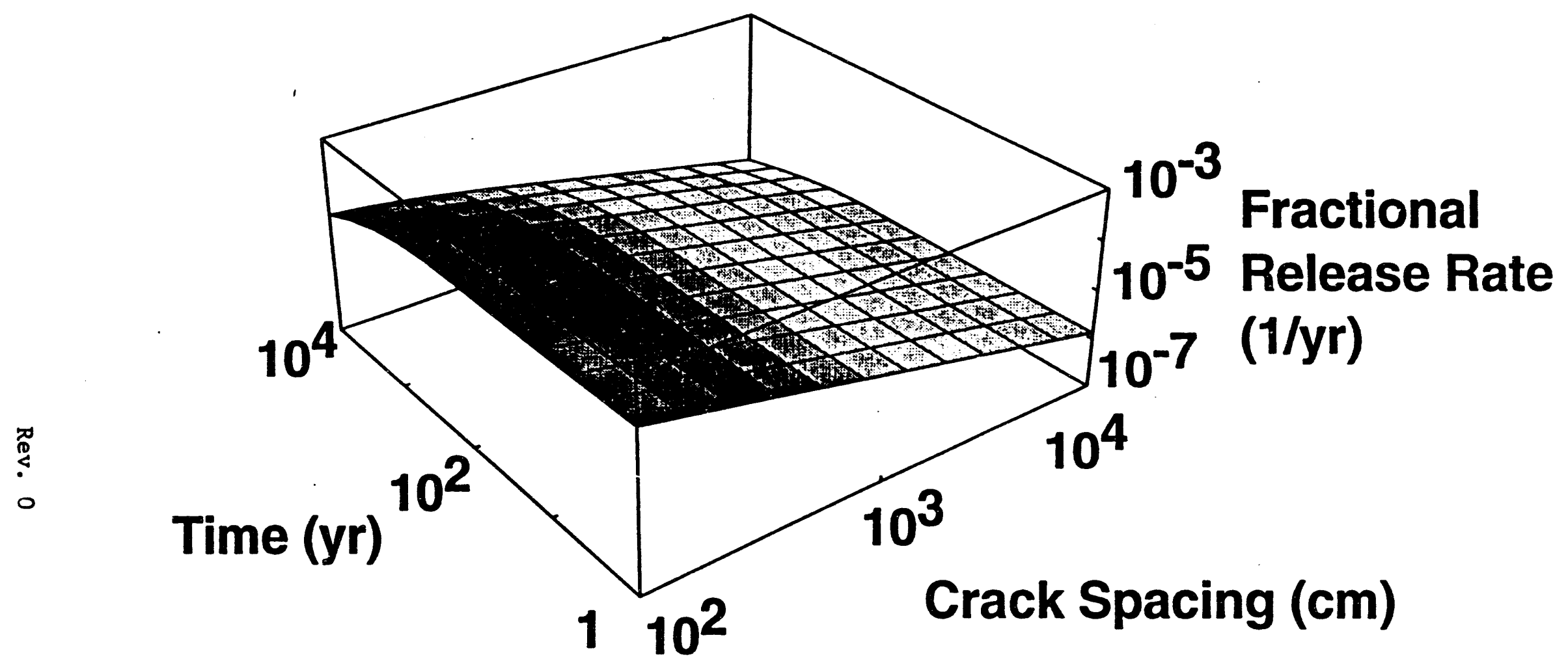

$61 \mathrm{~cm}$ of Perched Water $0.005 \mathrm{~cm}$ Crack Width 
number of fractures reduces the entrance head losses at the crack. As the fractures become very close together, flow, and thus reiease, tends to increase more than linearly. Thus, a rough approximation would be to assume a linear relationship between release and perched water depth and crack spacing.

The simplifications inherent in this semi-analytical approach are believed to add a considerable degree of conservatism to the results (See Sect. 3.3.1.2 and A.1.3), but the uncertainties associated with the model and scenario devised to address fractures are not readily quantified. Testing a range in parameters to which the results are most sensitive (i.e., crack spacing and height of perched water) was considered, but the results obtained by such an analysis would not be easily interpreted because uncertainties in the model and scenario are believed to dominate the uncertainty. For example, the semi-analytical model does not consider the interaction of flow through the fractures with the height of perched water. Flow through fractures is assumed not to affect the height of perched water in the model, but one logical consequence of reducing the spacing between fractures would be to increase the total volumetric flow through the fractures and thus reduce the height of perched water. If the height of perched water is decreased, then the release rate from each fracture would also decrease. Scenario uncertainty is large because the number, the time, the shape, and hydraulic properties of fractures that may occur cannot be accurately predicted. Because of these uncertainties and simplifications in the model, assumptions were used that are believed to lead to predictions of release that are conservative.

\section{Analysis for Groundwater Transport}

In this RPA, the fractional fluxes to the water table were used in a saturated flow and transport model to determine groundwater concentrations as a function of time and distance from the SDF. The sensitivity and uncertainty analysis of the groundwater transport model is discussed in this section. Like the sensitivity and uncertainty analyses of models estimating flux to the water table, the groundwater transport analysis focusses on nitrate transport, because the concentration of this potential contaminant is critical to meeting the groundwater protection requirements for the SDF.

A preliminary sensitivity analysis of the PORFLOW-3D saturated flow and transport model, described in Appendix A.2, indicates that simulation of flow is sensitive to the amount of recharge assumed and the horizontal and vertical saturated hydraulic conductivities of the three hydrologic units assumed in the model. The simulation of transport by groundwater is directly proportional to the flux of nitrate or other contaminant to the water table, but is insensitive to the diffusion coefficient because the transport in groundwater is advection-dominated. Sensitivity of the model to transverse and longitudinal dispersivities within the reasonable ranges for these parameters is low because the plume originating at the facility is so broad.

Rev. 0 
The reference run against which all sensitivity/uncertainty cases were tested in this analysis is documented with the input files in Appendix C.2 for the saturated flow and transport model. The results presented in Sect. 4.1 are based on the reference run. In the reference run, recharge under the SDF is assumed to be $0.175 \mathrm{~cm} / \mathrm{year}$, based on simulation results of the near-field model, and $40 \mathrm{~cm} / y e a r$ over the remainder of the model domain. Increasing recharge to $2 \mathrm{~cm} / y e a r$ under the SDF, corresponding to the absence of the clay/gravel drain, results in only a slight increase in water levels (about $0.3 \%$ increase) and hydraulic gradients under the facility, and virtually no change in the concentration of nitrate at the compliance point for a given flux of nitrate to the water table. This is likely due to the relative unimportance of either 0.175 or $2 \mathrm{~cm} / \mathrm{year}$ recharge to the flow system under the facility. When recharge under the SDF is increased to $\mathbf{4 0} \mathrm{cm} / y e a r$, the simulated elevation of the groundwater table and hydraulic gradient under the facility are observed to increase more dramatically (about an $8 \%$ increase in the water level), but the nitrate concentrations decrease only by about a factor of $\mathbf{4 8 \%}$ for a given nitrate flux to the water table. The results of this simplified analysis of sensitivity of the groundwater transport model to aquifer recharge directly under the facility indicate the model, while sensitive to recharge, is relatively insensitive to recharge within the range considered reasonable for this RPA.

The groundwater transport model used in this RPA is most sensitive to the saturated hydraulic conductivity of the three hydrologic units considered. Therefore, the remainder of the discussion of sensitivity and uncertainties will focus on this parameter. Nine parameters for hydraulic conductivity must be considered, corresponding to the $x$, $y$, and $z$ directional components for this property in each of the three units considered. To conduct an uncertainty analysis, ranges of possible values for these nine components were specified. Although data collected in the field indicates a range in these values over several orders of magnitude, field data do not reflect spatially-averaged values that are assumed in groundwater transport models such as the one used here. Therefore, a more reasonable range was assumed, representing the spatially-averaged saturated hydraulic conductivity. Because the vertical component of hydraulic conductivity is correlated to the horizontal component, and is generally less than or equal to the horizontal component, ratios of $\mathrm{K}_{2}: \mathrm{K}_{2}$ ranging from 0.1 to 1.0 in the aquifers, and ranging from 0.01 to 1.0 in the Green Clay unit, were assumed. The value of $\mathrm{K}_{z}$ was assumed to be equal to $\mathrm{K}_{\mathrm{y}}$ for each unit, based on the model assumption of horizontal isotropy. The reference value and assumed range of the nine components of hydraulic conductivity in the uncertainty analysis are listed in Table 4.2-3. All nine distributions were assumed to be lognormal.

A criterion was imposed on the uncertainty analysis that the water table level should only vary over a range of $3 \mathrm{~m}$ (plus or minus $1.5 \mathrm{~m}$ around the average value). This criterion was imposed because the model is very sensitive to hydraulic conductivity, and some of the possible combinations of hydraulic conductivities lead to unrealistic water levels because the values of the hydraulic conductivities for the three units are correlated. For example, a particularly low vertical conductivity in Zone 5b, the aquitard, may lead to unreasonable water levels in the overlying unit due to impeded drainage 
Table 42-3 Values of saturated hydraulic conductivity assumed in uncertainty analyzis or groundwater transport model

\begin{tabular}{|c|c|c|c|}
\hline Hydrologic Unit & $\begin{array}{l}\text { Component } \\
\text { of Hydraulic } \\
\text { Conductivity }\end{array}$ & $\begin{array}{l}\text { Reference } \\
\text { Value } \\
\text { (cm/year) }\end{array}$ & $\begin{array}{l}\text { Range assumed for } \\
\text { uncertainty analysis } \\
\text { (cm/year) }\end{array}$ \\
\hline $\begin{array}{l}\text { Zone 6/7/8 } \\
\text { (Santee/Dry } \\
\text { Branch/Tobacco } \\
\text { Road) }\end{array}$ & $\begin{array}{l}K_{2} \\
K_{1} \\
K_{2}\end{array}$ & $\begin{array}{l}1.89 \times 10^{4} \\
1.89 \times 10^{4} \\
1.11 \times 10^{4}\end{array}$ & $\begin{array}{l}1.89 \times 10^{3} \text { to } 1.89 \times 10^{5} \\
1.89 \times 10^{3} \text { to } 1.89 \times 10^{5} \\
1.89 \times 10^{2} \text { to } 1.89 \times 10^{4}\end{array}$ \\
\hline $\begin{array}{l}\text { Zone 5b } \\
\text { (Green Clay) }\end{array}$ & $\begin{array}{l}K_{2} \\
K_{1} \\
K_{2}\end{array}$ & $\begin{array}{c}1.11 \times 10^{2} \\
1.11 \times 10^{2} \\
11 \\
\end{array}$ & $\begin{array}{l}\text { 11. to } 1.11 \times 10^{3} \\
\text { 11. to } 1.11 \times 10^{3} \\
1.11 \text { to } 1.11 \times 10^{2}\end{array}$ \\
\hline $\begin{array}{l}\text { Zone 5a } \\
\text { (Congaree) }\end{array}$ & $\begin{array}{l}k_{2} \\
K_{1} \\
K_{2}\end{array}$ & $\begin{array}{l}1.89 \times 10^{5} \\
1.89 \times 10^{5} \\
1.89 \times 10^{4}\end{array}$ & $\begin{array}{l}1.89 \times 10^{4} \text { to } 1.89 \times 10^{6} \\
1.89 \times 10^{4} \text { to } 1.89 \times 10^{6} \\
1.89 \times 10^{3} \text { to } 1.89 \times 10^{5}\end{array}$ \\
\hline
\end{tabular}

Rev. 0 
through the aquitard. Such a combination would be ruled out in the model calibration procedure, described in Appendix A.2. Unfortunately, the correlations between the units are very complex and it is not possible to rigorously factor these correlations into this analysis, necessitating the imposition of the $3.0-\mathrm{m}$ range.

Latin Hypercube Sampling (LHS) techniques (Iman and Shortencarier 1984) and GRESS (Horwedel 1991) were applied to the distributions listed in Table 4.2-3, and the PORFLOW-3D saturated flow and transport model used in this RPA was analyzed with respect to uncertainties in the final nitrate concentration at the compliance point. GRESS (GRadient Enhanced Software System) is an automated method of analyzing the response of computer code results with respect to the changes in model parameters by calculating first derivatives of model equations. One hundred runs were completed that fit the criterion described above, where the water table elevation was allowed to fluctuate by no more than plus or minus $1.5 \mathrm{~m}$. Over 950 PORFLOW-3D runs were necessary to obtain these 100 runs that fit the 3.0-m criterion imposed on pressure variations. The range in hydraulic conductivities corresponding to these 100 runs is significantly narrower than the ranges listed in Table 4.2-3. The sensitivity of nitrate concentrations to hydraulic conductivity is relatively small within this narrower range of values sampled from. The most sensitive of the nine hydraulic conductivity components are the $\mathrm{K}_{z}$ of the Green Clay, and the and the $K_{z}$ and $K_{y}$ of the water table unit, Zone 6/7/8. The results are insensitive to the horizontal hydraulic conductivity of the Green Clay.

To evaluate the effects of the variation in the flux to the water table and the variation in the hydraulic conductivity on the predicted nitrate concentration at the compliance point, results from 100 uncertainty runs (listed in Appendix H, Table H.1-1) were arbitrarily paired with 100 uncertainty runs simulating groundwater transport with varying saturated hydraulic conductivity of the three hydrologic units. The pairings that were tested are listed in Table H.2-1. The results of these paired runs are listed in Appendix H, Table H.2-2. Figure 4.2-5 shows the cumulative distribution function for the nitrate concentration arising from the uncertainties in the flow parameters. This plot also indicates that the probability of obtaining a compliance point concentration of nitrate in groundwater less than $45 \mathrm{mg} / \mathrm{L}$ is about $67 \%$ for the transport model used, based on variations in flux to the water table and variations in saturated hydraulic conductivities of three hydrologic units specified in the model domain. An important observation from these results is that this probability distribution computed from the design matrix composed of 100 unsaturated flow and transport runs and 100 saturated flow and transport runs also accounts for the uncertainty in the saturated hydraulic conductivity of saltstone. Caution should be exercised in interpreting this observation, however, because the probability distribution for the hydraulic conductivity of saltstone is unknown, and was therefore assumed to be loguniform.

Rev. 0 


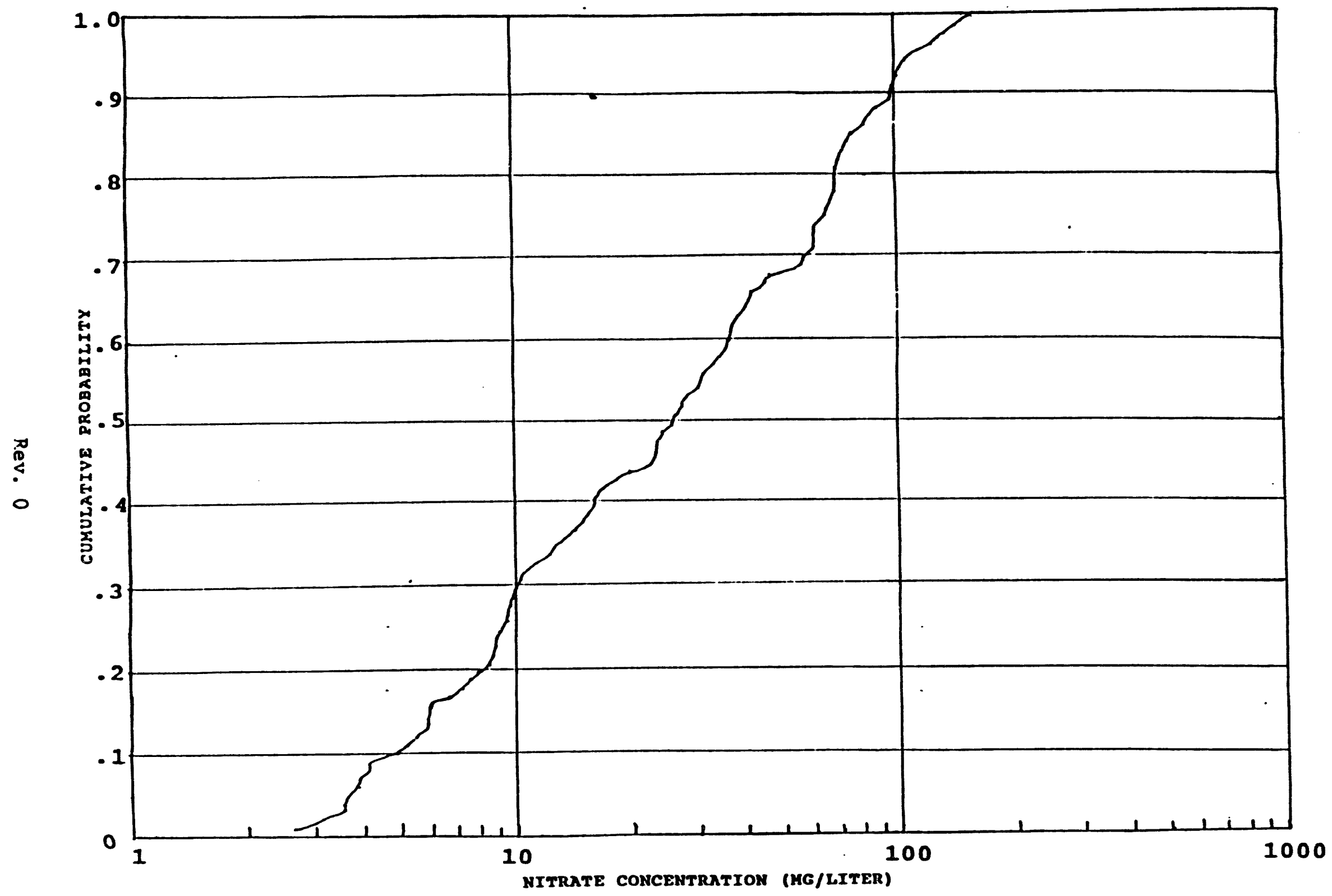

Fig. 4.2-5. Cumulative probability distribution function for nitrate concentration in groundwater $100 \mathrm{~m}$ from the SDF, arising from uncertainties in fluxes to the water table and in saturated hydraulic conductivities. 


\section{Analysis of Dose Model from Off-Site Releases}

As described in Sect. 4.1.3 and elsewhere, the drinking water pathway is the only exposure pathway of concern for releases of radionuclides beyond the $100-\mathrm{m}$ buffer zone around disposal site. In this section, the sensitivity and uncertainty analysis of the model used to estimate dose from the drinking water pathway are discussed.

For a given concentration of a radionuclide in groundwater, the estimated dose from the drinking water pathway involving consumption of the contaminated groundwater is given by Eq. (A.4-1) of Appendix A.4. In this equation, the dose per unit concentration of a radionuclide for the drinking water pathway is directly proportional to two parameters: 1) the consumption rate of drinking water from the affected source and 2) the ingestion dose conversion factor for the radionuclide. Both of these parameters are assumed to be fixed values for a reference adult that are specified by regulatory authorities or international advisory groups. Regulatory authorities or international advisory groups have specified fixed values for both of these parameters when dose calculations are to be performed. In this analysis, the assumed consumption rate of water of $2 \mathrm{~L} / \mathrm{d}$ is the value normally specified by the EPA in demonstrating compliance with drinking water standards for radionuclides; the ingestion dose conversion factors for radionuclides, which are given in Table A.4-2 of Appendix A.4, are values developed by the International Commission on Radiological Protection. Therefore, for purposes of this analysis, the dose from the drinking water pathway per unit concentration of any radionuclide in groundwater is assumed to be a prescribed value with no uncertainty.

In any population of exposed individuals, the intake rate of water and the ingestion dose conversion factors for radionuclides are variables that could be described by a mean value and standard deviation. For the type of dose analysis presented in this report, it is customary to assume, as indicated above, that all exposed individuals are reference adults who experience the same intake rates of water and the same doses per unit activity intakes of radionuclides by ingestion. However, the assumed intake rate of drinking water by a reference adult of $2 \mathrm{~L} /$ day is not likely to be exceeded by most individuals.

Although the dose per unit concentration of a radionuclide in water for a normal population would be subject to some uncertainty, this uncertainty undoubtedly will be much less than the uncertainty associated with estimates of the maximum concentrations of radionuclides in groundwater at any location beyond the $100-\mathrm{m}$ buffer zone. Thus, the assumption of no uncertainty in the model for estimating dose from the drinking water pathway has no effect on the overall uncertainty in the performance of the disposal facility with regard to meeting the performance objective for protection of groundwater resources. 


\section{Analysis of Dose Modek for Inadvertent Intruders}

This section discusses the sensitivity and uncertainty analysis of the models for estimating dose to an inadvertent intruder per unit concentration of radionuclides in disposal units. The discussion of parameter sensitivity and model uncertainty is simplified by two considerations. First, as indicated by the results of the dose analyses for the important exposure scenarios given in Tables 4.1-11 and 4.1-14, only two radionuclides contribute essentially all of the dose to an inadvertent intruder: Tc-99 and Sn-126. Second, for each of these radionuclides, only a single exposure pathway contributes cescentially all of the estimated dose. The models used to estimate dose from these two radionuclides are discussed separately below.

\subsubsection{Dase Models for TC-99}

As indicated in Table 4.1-11, Tc-99 is an important contributor to the total dose to an inadvertent intruder for the agriculture scenario involving direct intrusion into disposal units. As described in Sect. 3.2.4.1 and Sect. A.4.5.2, several exposure pathways were considered in the dose analysis for the agriculture scenario. However, the results for each pathway given in Table A.4-8 through Table A.413 of Appendix A.4 show that the dose from Tc-99 for the agriculture scenario results almost entirely from consumption of vegetables grown in soil that has been contaminated by waste exhumed from disposal units.

The model to estimate dose from the vegetable pathway is given by Eg3. (A.4-2) and (A.4-3) of Appendix A.4. The dose per unit concentration of a radionuclide in waste exhumed from a disposal unit is either directly or inversely proportional to the following parameters: 1) the dilution factor for mixing of exhumed waste into native soil in the vegotable garden, 2) the bulk density of soil, 3) the plant-to-soil concentration ratio for the particular radionuclide, 4) the consumption rate of vegetables from the garden, and 5) the ingestion dose conversion factor for the particular radionuclide.

Of the five parameters for the vegetable pathway described above, the bulk density of soil and the ingestion dose conversion factor are assumed to have no uncertainty. This is a reasonable assumption for the density of soil, because the uncertainty is only a few tens of percent (Baes and Sharp 1983) and, thus, can be neglected. As described previously, the ingestion dose conversion factors for radionuclides are prescribed values for reference adults. The dilution factor for mixing of exhumed waste into soil in the vegetable garden also is treated as a prescribed value with no uncertainty, because this parameter is determined by the definition of the exposure scenario and, thus, cannot be tested experimentally. The assumed dilution factor of 0.2 is intended to be a reasonable maximum value, because values substantially greater than this presumably would result in a soil composition that would not be conducive to growing vegetables. The consumption rate of vegetables from the garden is uncertain by no more than a factor 
of two (Hamby 1992), and this uncertainty also can be neglected. In addition, the assumed consumption rate of $90 \mathrm{~kg} / y e a r$ presumes that half of an intruder's intakes of vegetables comes from the garden containing contaminated soil, and this assumption is intended to provide a reasonable maximum value for this parameter.

Thus, for Tc-99, the dose from the vegetable pathway and the dose for the agriculture scenario are sensitive primarily to the plant-to-soil concentration ratio for Tc. All other parameters in the model used to estimate the dose from Tc-99 for the agriculture scenario either can reasonably be treated as prescribed parameters without urcertainty or are subject to negligible uncertainties.

The assumed plant-to-soil concentration ratio for $\mathrm{Tc}$ is discussed in detail following Eq. (A.43) of Appendix A.4. The assumed value was based on the following information: 1) a recommended generic value of 5 for the concentration ratio for $\mathrm{Tc}$ in relatively soluble chemical form ( $\mathrm{Ng}$ et al. 1982) and 2) data from lysimeter experiments at the SRS (Murphy 1990; Clark and Wilhite 1991). The lysimeter experiments indicated that root uptake of relatively soluble Tc from soils at the SRS would be consistent with the recommended generic value given above, but that root uptake of the relatively insoluble chemical form of Tc that occurs in saltstone would be less than the recommended generic value for soluble $\mathrm{Tc}$ by a factor of about $\mathbf{0 . 0 1 2}$. Thus, the assumed plant-to-soil concentration ratio for Tc is the product of 5 and 0.012 , or 0.06 . The uncertainty in this value depends on the uncertainty in the two factors from which it was derived.

The recommended generic plant-to-soil concentration ratio of 5 for soluble Tc is based on a number of field experiments described by $\mathrm{Ng}$ et al. (1982). Baes et al. (1984) also evaluated these data and showed that the uncertainty, as given by one standard deviation above and below the geometric mean, encompasses a range that is slightly less than a factor of 10; i.e., the range encompassed by the standard deviation is about a factor of 3 above and below the mean. When the factor of 0.25 that converts concentration ratios based on dry weight of vegetation to values based on fresh weight of vegetation is applied (see footnote b in Table A.47 of Appendix A.4), the analysis of Baes et al. (1984) also indicates that the value of 5 for the plant-to-soil concentration is about a factor of two greater than the geometric mean of the distribution. Thus, the adopted value in this RPA more likely overestimates than underestimates the concentration ratio for soluble chemical forms of TC.

The factor of 0.012 for converting the recommended generic plant-to-soil concentration ratio of 5 for soluble Tc to the concentration ratio for the relatively insoluble form of Tc that occurs in saltstone was obtained from the results of two lysimeter experiments at the SRS (Clark and Wilhite 1991). In the first, the concentration of Tc in water relative to the concentration of nitrate was measured repeatedly over a period of about five years using a saltstone wasteform containing $\mathrm{Tc}$ in relatively soluble form. In the 
second, the same measurements were performed over a period of more than a year using the current formulation for saltstone containing relatively insoluble Tc. In the first experiment with soluble Tc, the mean value for the ratio of Tc to nitrate in water was found to be 50 and the standard deviation is about 20; and, in the second experiment with insoluble $\mathrm{Tc}$, the mean value for the ratio of $\mathrm{Tc}$ to nitrate in water was found to be 0.6 and the standard deviation is about 0.5 ( $R$. Hiergesell, private communication). Thus, the standard deviation in the factor of 0.012 , i.e., the ratio of 0.6 to 50 , is estimated to be 0.010 .

Taking into account the uncertainty estimates for the two factors contributing to the adopted plant-to-soil concentration ratio for $\mathrm{Tc}$, and also taking into account that the adopted value of 5 for the generic concentration ratio for soluble $\mathrm{Tc}$ is a factor of two greater than the geometric mean of the distribution of measured values, the following estimate of the uncertainty in the adopted plant-to-soil concentration ratio for Tc-99 is obtained. The upper end of the distribution of values, as given by the standard deviation, would be about two and one-half times greater than the adopted concentration ratio of 0.06, and the lower end of the distribution of values would be about a factor of 8 less than the adopted concentration ratio.

Therefore, since the uncertainty in the estimated dose from Tc-99 for the agriculture scenario is essentially the same as the estimated uncertainty in the plant-to-soil concentration ratio for $\mathrm{Tc}$, the dose estimate of $\mathbf{4 0}$ mrem per year given in Table 4.1-11 could range from about 5 mrem per year to about 100 mrem per year.

\subsection{Dose Models for Sn-126}

As shown in Tables 4.1-11 and 4.1-15, Sn-126 is an important contributor to the total dose for the agriculture and the resident scenario. In each scenario, the dose analysis for Sn-126 presented in Appendix A.4 shows that the only pathway that contributes significantly to the total dose is external exposure while residing in a home located on top of exposed saltstone.

The model used to estimate dose from external exposure to radionuclides in saltstone while residing in a home on top of the salistone is given by eq. (A.4-8) of Appendix A.4. The external dose from a particular radionuclide is directly proportional to three parameters: 1) the fraction of the time that an intruder spends in the home, 2) the shielding factor provided by the walls of the home during indoor residence, and 3) the external dose rate per unit concentration of the radionuclide in saltstone. This model gives the external dose assuming that the home is located on top of an unshielded saltstone monolith of infinite extent. Then, as described in Sect. 4.1.4.1, correction factors are applied to the model to take into account either the finite size of an excavation into the saltstone or the reasonable likelihood that an intruder would cover exposed saltstone with uncontaminated soil in order to maintain vegetative ground cover at the homesite. 
Each of the parameters in the model for estimating external dose either is assigned a value which is not likely to be exceeded by a significant amount or is not subject to significant uncertainty. The indoor residence time could be considerably less than the assumed value of $50 \%$, but the residence time cannot exceed the assumed value by more than a factor of two. The assumed shielding factor during indoor residence of 0.7 cannot result in doses that are underestimated by more than about $20 \%$ for any building material but would result in overestimates of dose for a home constructed with relatively thick walls. Finally, the external dose rate per unit concentration of a radionuclide in saltstone is a standard value based on the known physics of photon transport through soil and has a negligible uncertainty of no more than a few tens of percent.

Thus, the model for estimating external dose during residence in a home located immediately on top of an unshielded saltstone monolith has little uncertainty, because the estimate of external dose is determined primarily by the definition of the exposure scenario and the exposure pathway. Furthermore, from the choice of the model parameters, the model is expected to result in a dose estimate that is a reasonable upper bound.

As discussed in Sect. 4.1.4.1, the correction factors for the finite size of an excavation or the presence of uncontaminated soil on top of the unshielded saltstone are somewhat subjective. For this analysis, reasonably conservative correction factors were chosen so that dose calculations would more likely yield an overestimate of the external dose rather than an underestimate. The uncertainty in these correction factors cannot be estimated quantitatively, because the correction factors depend only upon the assumptions made in their development.

Thus, the uncertainty in the estimated dose from external exposure for Sn-126 cannot be quantified, because the dose depends primarily on the definition of the exposure scenario. However, the model parameters, including the correction factors for the finite size of an excavation and the presence of uncontaminated soil on top of saltstone around a homesite, were selected to provide a reasonable likelihood that the dose would be overestimated rather than underestimated.

For the dose analysis for the resident scenario summarized in Table 4.1-15, the dose is due almost entirely to external exposure to Sn-126. Thus, as described above, the uncertainty in this dose estimate cannot be quantified. However, the dose given in this table, particularly values toward the upper end of the range, is more likely to be an overestimate than an underestimate.

For the dose analysis for the agriculture scenario summarized in Table 4.1-11, both Sn-126 and Tc-99 contribute significantly to the total dose. Taking into account the conclusions regarding the dose estimates for Sn-126 summarized above and the quantitative estimate of the uncertainty in the dose for Tc-99 discussed previously, the dose from all radionuclides could be as high as about $\mathbf{2 0 0}$ mrem per year and could be as low as about 15 mrem per year. Thus, the overall uncertainty in the dose estimate, 
as measured by the standard deviation, ranges over about one order of magnitude. Again, however, the expectation is that the best estimate of dose would not exceed the performance objective for protection of inadvertent intruders of 100 mrem per year, due to some of the assumptions used in the dose assessment models that should be somewhat conservative.

\section{INIERPRETATION OF RESULTS}

The results presented in Sect 4.1 can be interpreted by comparing the calculated doses to dose limits and by comparing the groundwater concentrations to limits allowed by consideration of groundwater protection requirements. However, this alone is not sufficient to address the question of whether there is reasonable assurance that all performance objectives of DOE Order 5820.2A are met. Further interpretation is necessary because limited data exist for performing realistic and definitive uncertainty analyses. Providing reasonable assurance requires consideration of: 1) sensitivities of results to parameters, assumptions and models; 2) uncertainties in models, parameters and scenarios; and 3) conservatisms, or lack thereof, inherent in the calculational approach or scenarios devised. In this section, some of the more significant observations made throughout this report are summarized and results are interpreted in terms of these observations.

Results presented in Sect. 4.1 indicate that the SDF will meet the performance objectives of DOE Order 5820.2a. The results are based on a number of assumptions, simplifications, and scenarios that, in most cases, erred on the side of conservatism. Therefore, most of the results are more likely to overestimate, than underestimate, doses.

\subsection{Off-Site Doses and Groundwater Protection}

For off-site releases, groundwater was demonstrated to be the only pathway of concern, and total doses for all radionuclides are predicted to be less than $3 \times 10^{-2}$ mrem per year for either intact or fractured vaults (see Table 4.1-8). Only ten radionuclides were identified early in the analysis as being of potential concern; the projected concentrations of all other radionuclides are sufficiently low to be eliminated from further concern. The only radionuclides of significance to the maximum predicted dose are I-129, Se-79 and Tc-99. The earliest time that a maximum dose is predicted to occur is around $\mathbf{3 0 0 0}$ years after closure of the SDF. The groundwater protection dose limit of 4 mrem per year is the most restrictive of all applicable limits for off-site doses for this facility. This limit is more than $\mathbf{1 0 0}$ times higher than the maximum predicted dose. The results for nitrate in groundwater are of considerably more concern, because the maximum predicted concentration resulting from fractured vaults $(38 \mathrm{mg} / \mathrm{L}$ at 1400 years) is close to the $45 \mathrm{mg} / \mathrm{L}$ nitrate drinking water standard that is applied to groundwater for this facility. 
Groundwater concentrations at the compliance point for groundwater protection are directly proportional to the flux at the water table. Therefore, sensitivities and uncertainties that affect these fluxes as determined in the near-field simulations also affect the groundwater concentrations in a similar manner. For intact saltstone and vaults, the sensitivity analyses (Sect 4.2 ) indicate that the saturated hydraulic conductivity of saltstone is one of the most important parameters in predicting nitrate flux to the water table. Unfortunately, considerable uncertainty is also associated with this parameter, leading to considerable uncertainty in the maximum groundwater concentrations of released contaminants. However, note that, with the exception of nitrate, predicted releases result in concentrations well below the groundwater protection standard. The uncertainty analysis indicated that peak releases for a non-sorbing species like nitrate might be up to 40 times the predicted value if the saturated hydraulic conductivity of slag saltstone is 50 times higher than the assumed value of $10^{-11} \mathrm{~cm} / \mathrm{s}$. Increasing the saturated hydraulic conductivity of saltstone by a factor of 50 affects results from intact vaults and saltstone, but it would not be expected to alter the results for the fracture analysis. Because the release rates of radionuclides are so low for intact saltstone, the uncertainty in this parameter is not likely to lead to doses exceeding groundwater protection standards for either the intact or degraded vault scenarios. Perhaps as important to groundwater concentrations is the distribution coefficient assumed for the wasteform, since this parameter directly influences the determination of initial pore solutions. However, the values chosen for the distribution coefficient were chosen from the low end of ranges available, and thus are believed to be more likely to overestimate the initial concentrations of radionuclides in the pore solution of the saltstone.

Degradation of the upper moisture barrier, saltstone and vaults were considered in this RPA because the engineered features of the facility are not expected to last forever. .The greatest difficulty, and thus the largest uncertainty, related to degradation is defining a realistic scenario that accurately describes the type and degree of degradation over time. Although many mechanisms potentially contributing to degradation are identified (Sect. 3.2), the impossibility of predicting the timing and magnitude of seismic events, the extent and configuration of fractures, or the very longterm geochemical stability of saltstone renders the uncertainty associated with the degradation scenario high. To further complicate the modeling of degradation, numerical modeling techniques for simulating release from fractured saltstone tend to result in unstable solutions. Semi-analytical techniques were used to address degradation, even though this approach requires simplification and thus more assumptions that further increase the uncertainty of the results.

To consider degradation, scenarios were devised that represented the condition of several engineered features of the $\mathrm{SD}_{i}^{i}$ at various stages of degradation. Calculations were done with and without the upper moisture barrier to test the effect of complete degradation of this engineered feature. Calculations were also done assuming a degraded vault and saltstone monolith. It is not believed that saltstone will crumble in the next 10,000 years based on an analysis of the possible causes of such loss of integrity. Instead,

Rev. 0 
fracturing is believed to be the most likely form of saltstone and vault degradation. Degradation of the upper moisture barrier did not affect the height of perched water. However, degradation of the clay/gravel drain, which was not considered, may result in more perching, and the results are not conservative in this regard. Conservatisms inherent in the fracture analysis are: 1) fractures are spaced every $3 \mathrm{~m}$, and open up simultaneously at closure; 2 ) the fractures are through-running, and do not fill in with soil or precipitates; 3 ) the fractures remain fully saturated, thus maximizing the flow rate; and 4) the amount of perched water on top of the vaults, estimated in the intact vault analysis, is not affected by the fractures. As noted in Sect. 4.2.1.2, the fracture analysis is fairly sensitive to crack spacing and the height of perched water. The results of the degraded vault and saltstone concentrations are, like the intact results, directly proportional to groundwater concentrations at the compliance point. Therefore, uncertainties in the degraded analysis impact groundwater concentrations directly. As was noted in Sect. 4.2.1.2, uncertainties associated with the degraded vaults analysis are not readily quantified. Note, however, that the only non-conservative aspect of the fracture analysis is the lack of consideration of a degraded clay/gravel drain system. Since the estimated annual doses from groundwater concentrations of radionuclides at the compliance point are two order of magnitude below groundwater protection standards, there is reasonable assurance that performance objectives for radiomuclides will be met.

Groundwater transport calculations require the fractional fluxes from the intact anci degraded vaults, utilizing the inventory in Table 2.6-2 to obtain groundwater concentrations at the compliance point. Based on the manner in which fractional flux was estimated, the results are directly proportional to the predicted concentration of saltstone constituents, rather than the total inventory. The initial saltstone concentrations used in this analysis are believed to have little associated uncertainty because the processes from which the wastes originally derive are well known. The average concentration, represented by the nominal blend, may vary somewhat from batch to batch, but the large volume of waste placed in a cell of a vault will tend to damp out the variations. Nitrate concentrations are expected to vary by less than $30 \%$ from batch to batch, and average concentrations in the entire facility are expected to vary by much less than this. Groundwater transport calculations are relatively insensitive to hydrologic parameters within the model design (Sect. 4.2.2). The largest uncertainty is directly related to the conceptual model that was specified initially, since a large amount of spatial averaging is done to identify hydrologic units. The results of the conceptual model implemented in this RPA are believed to be conservative, since the peak groundwater concentrations $100 \mathrm{~m}$ from the facility are not largely different from the concentrations at the water table under the facility. This result is expected because dispersion is minimal in the model due to the homogeneity assumed within the three hydrologic units. A more heterogeneous representation of the hydrologic system would perhaps better describe the hydrology beneath the SDF, but field data do not support modeling the saturated flow system in more detail. Increasing the heterogeneity of the model would add more dispersion to the system, and thus would reduce peak concentrations predicted by the simpler model used in this RPA. 
As discussed in Sect 4.2.3, dose from the drinking water pathway per unit concentration of any radionuclide in groundwater is assumed to be a prescribed value, with no uncertainty. Therefore, uncertainty in the dose calculations does not affect the confidence in the final results for off-site releases to groundwater.

\subsection{Inadvertent Intruders}

Scenarios were developed and dose analyses were completed to provide ultraconservative, upper bound dose estimates for an inadvertent intruder. Acute exposure scenarios for inadvertent intruders were not included, because they would always be less restrictive in regard to demonstrating compliance with performance objectives than chronic exposure scenarios (Sect. 3.2.4.3). When an upper bound dose exceeded the performance objective of $\mathbf{1 0 0}$ mrem per year for chronic exposure, further refinement of assumptions for the dose analysis was completed to provide a best reasonable estimate of dose for a given scenario. The four chronic exposure scenarios subjected to analysis were: 1) an agriculture scenario with direct intrusion into the disposal vaults; 2) an agriculture scenario with intrusion into contaminated soil above the vaults; 3 ) a resident scenario; and 4) a post-drilling scenario (see Sect. 3.2.4). Total estimated doses from this analysis are summarized in Table 4.3-1 for each scenario.

The intruder dose estimates given in Table 4.3-1 indicate that the scenarios of most concern are the agriculture scenario involving direct intrusion into the vaults and saltstone and the resident scenario involving placing a home on top of exposed intact saltstone. The only radionuclides of concern for these two scenarios are Sn-126 and Tc-99. The scenarios require considerable degradation of the disposal units, and thus are not believed credible until after at least a few thousand years. Even then, the estimates believed to be more reasonable indicate the performance objectives are likely to be met.

,

Analysis of sensitivity and uncertainty associated with the inadvertent intruder scenarios, models and parameters (see Sect. 4.2.4) is simplified because only two radionuclides and one exposure pathway contribute essentially all of the estimated dose. For the agriculture scenario involving intrusion into the disposal units, vegetables contaminated with Tc-99 contribute almost all of the estimated dose of 40 mrem per year from Tc-99. The most uncertainty in estimating dose from the vegetable pathway for Tc-99 is believed to be associated with the plant-to-soil concentration ratio, to which the dose is directly proportional. Doses are estimated to range from 5 to 100 mrem per year for Tc-99 in the agriculture scenario, based on the uncertainty analysis.

Tin-126 contributes a significant portion of the dose estimate in the agriculture scenario involving intrusion into saltstone, and essentially all of the estimated dose for the resident scenario involving a home on top of exposed saltstone. The dose from $\mathrm{Sn}-126$ is a result of external exposure. The uncertainty of the estimated dose from this radionuclide arises from the definition of the exposure scenario, and therefore cannot be quantified. However, model parameters were selected to provide a reasonable likelihood that the dose from Sn-126 would be overestimated rather than underestimated.

Rev. 0 
Tabie 43-1. Results of inadvertent intruder dose analysis for the four exposure scenarios assumed

\begin{tabular}{|c|c|c|c|}
\hline Scenario & $\begin{array}{c}\text { Time of } \\
\text { intruder } \\
\text { activity } \\
\text { resulting } \\
\text { in dose } \\
\text { (year) } \\
\end{array}$ & $\begin{array}{l}\text { Best estimate of } \\
\text { dose } \\
\text { (mrem per year) }\end{array}$ & $\begin{array}{l}\text { Upper bound } \\
\text { estimate of dose } \\
\text { (mrem per year) }\end{array}$ \\
\hline $\begin{array}{l}\text { Agriculture scenario involving } \\
\text { direct intrusion into disposal } \\
\text { vaults }\end{array}$ & $>1,000$ & $50-110$ & 450 \\
\hline $\begin{array}{l}\text { Agriculture scenario involving } \\
\text { intrusion into contaminated soil } \\
\text { above disposal units }\end{array}$ & $>100$ & not estimated & $10^{-5}$ \\
\hline Resident scenario & & & \\
\hline $\begin{array}{l}\text { Home on top of intact concrete } \\
\text { roof of disposal unit }\end{array}$ & $>100$ & not estimated & 0.6 \\
\hline $\begin{array}{l}\text { Home on top of intact } \\
\text { saltstone monolith }\end{array}$ & $>1,000$ & $10-70$ & 390 \\
\hline Post-drilling scenario & $>100$ & $10^{-4}$ & not estimated \\
\hline
\end{tabular}


Based on this uncertainty analysis, the dose from all.radionuclides to an inadvertent intruder may range over about an order of magnitude for the saltstone radionuclide concentrations assumed. As discussed in Sect 4.3.1, average saltstone concentrations in a given cell or vault are expected to be very close to the average value used, because the processes generating the wastes are well-characterized. Many conservative assumptions have been made in the exposure scenarios which lead to the expectation that the estimated doses are more likely to overestimate doses. For example, in the agriculture scenario, it is assumed that the excavated saltstone immediately around the home is not shielded by uncontaminated soil which maximizes the dose from Sn-126 for that scenario.

\subsubsection{Conclusions}

Based on the foregoing discussions, the results of the off-site and inadvertent intruder dose analyses do provide reasonable assurance that the performance objectives of DOE Order 5820.2A are met. The results for nitrate for the degraded vault scenario are $84 \%$ of the groundwater resource protection standard. Unresolved uncertainties associated with the saturated hydraulic conductivity of saltstone, and the uncertain longterm integrity of the clay/gravel drain, indicate that further work should be directed toward reducing these uncertainties in order to provide reasonable assurance that the facility will comply with the nitrate standard. 


\section{PERFormanCE EVALUATION}

The purpose of this site-specific Radiological Performance Assessment (RPA) of the Saltstone Disposal Facility at the Savannah River Site is to fulfill the DOE Order 5820.2A requirement that such an assessment be prepared and maintained for any LLW disposal facility located at a DOE field site. The RPA must provide reasonable assurance that the facility design and method of disposal will comply with the performance objectives of the Order, which are concerned with protection of public health and safety, limiting doses to members of the general public and inadvertent intruders, and protecting groundwater resources. In this chapter of the RPA, a summary of how the results of the comprehensive analysis compare with these performance objectives will first be provided, followed by recommendations regarding design changes that are indicated from these results, and recommended data acquisition and research necessary to gain more confidence in the results.

\subsection{COMPARISON TO PERFORMANCE OBJECTIVES}

The performance objectives of DOE Order 5820.2A for LLW disposal are listed in Sect. 1.4. In essence, these objectives put forth dose limits for members of the general public and inadvertent intruders that are not to be exceeded at any point in time through consideration of credible pathways. The performance objectives include protection of groundwater resources consistent with Federal, State and local requirements. The State of South Carolina also requires that drinking water standards must be complied with at $100 \mathrm{~m}$ from the edge of the outermost vaults for all saltstone constituents released from the facility. Thus potential releases of nonradioactive constituents have also been addressed in this RPA.

Table 5.1-1 summarizes a comparison of results of the comprehensive analyses performed in this RPA to the performance objectives. For groundwater resource protection, the performance objective for nitrate is stated in terms of a groundwater concentration. Nitrate is believed to be the only nonradioactive constituent of potential concern for the SDF. Off-site receptors are not listed in Table 5.1-1 because it was demonstrated that compliance with the 4 mrem per year dose limit for ingestion of drinking water will assure that off-site receptors will receive less than the dose limit of 25 mrem per year for all credible exposure scenarios associated with the SDF. Likewise, inadvertent intruder doses resulting from acute exposures are not listed because it was demonstrated in the RPA that the chronic exposure scenarios will always be more restrictive with respect to compliance with performance objectives.

Rev. 0 
Table 5.1-1 Summary of RPA results compared with performance objectives

\begin{tabular}{|c|c|c|c|c|c|}
\hline \multirow[b]{2}{*}{ Recoplor } & \multirow[b]{2}{*}{$\begin{array}{l}\text { Performance } \\
\text { Objective }\end{array}$} & \multicolumn{2}{|c|}{$\begin{array}{l}\text { Intact Saltutoos/Nault } \\
\text { Scearion }\end{array}$} & \multicolumn{2}{|c|}{$\begin{array}{l}\text { Degraded Salutione/Vault } \\
\text { Scenarioa }\end{array}$} \\
\hline & & $\begin{array}{l}\text { Morimum predicted } \\
\text { dowe or concentration }\end{array}$ & $\begin{array}{l}\text { Thue of } \\
\text { cocurreace } \\
\text { (vears) }\end{array}$ & $\begin{array}{l}\text { Movimum } \\
\text { predicted dowe or } \\
\text { concentration }\end{array}$ & $\begin{array}{l}\text { Tlme of } \\
\text { occurrence } \\
\text { (years) }\end{array}$ \\
\hline $\begin{array}{l}\text { Insdvertent } \\
\text { Intruder } \\
\text { (chronic } \\
\text { exposure) }\end{array}$ & 100 mrem per year & 0.6 mrem per year & $>100$ & $\begin{array}{c}50.110 \text { mrem per } \\
\text { year }\end{array}$ & $>1000$ \\
\hline Groundwater & & & & & \\
\hline $\begin{array}{l}\text { Radionuclides } \\
\text { Nitrite }\end{array}$ & 4 mrem per year & $\begin{array}{c}0.001 \text { mrem per year } \\
5 \mathrm{mel}\end{array}$ & $\begin{array}{c}>25 \times 10^{6} \\
7100\end{array}$ & $\begin{array}{c}0.03 \text { mrem per } \\
\text { year } \\
33 \mathrm{mel}\end{array}$ & $\begin{array}{l}15000 \\
1400\end{array}$ \\
\hline
\end{tabular}

The comparison of the results obtained in this RPA shows that the SDF complies with all performance objectives. Uncertainties in these results must be considered, however, before reasonable assurance of compliance is established. A discussion of the uncertainties associated with these results was provided in Sect. 4.3, where it was concluded that there is reasonable assurance that the SDF will comply with the performance objectives for radionuclides. For nitrate, the peak estimated groundwater concentration approaches the drinking water standard for the degraded vault scenarios. The large uncertainties associated with parameters and assumptions inherent in the analyses used to estimate nitrate concentrations suggest that additional work is necessary to reduce these uncertainties to provide reasonable assurance that the nitrate standard will be met for all scenarios tested in this RPA.

\subsection{DESIGN CHANGES REQUIRED TO MEET PERFORMANCE OBIECTIVES}

The RPA process assumed the SDF design described in Sect. 2.5 and the closure concept described in Sect. 2.7 of this report. Because the results indicate compliance with performance objectives, no changes to this design are recommended. However, uncertainties associated with the nitrate results indicate a need for data to gain confidence in the results. 
A few recommendations pertinent to the closure concept are in order. Although degradation of the facility over time was addressed and the performance of a degraded facility was evaluated, degradation of the clay/gravel drain overlying the vaults was not considered. Because of the uncertainty associated with the functional life of this drain, it is preferable from the standpoint of providing reasonable assurance to not have to rely on its continued function as conceptualized. The primary function of this drain system is to reduce potential perching of water on the vaults, and perched water has the most impact analytically on the degraded vault/saltstone scenarios. Therefore, a program of research is recommended to investigate alternatives to this system that would serve a similar purpose. One alternative that has been identified is placing a permeable material on the top of and around the sides of the vaults, for the purpose of enhancing drainage of any perched water. Any changes must be fully investigated in terms of constructibility and possible adverse affects on performance.

Another consideration regarding the closure concept assumed for this RPA is the possibility that the concept may be overdesigned. The results of the RPA indicated that the presence or absence of the upper moisture barrier was not a significant factor in the analysis. This observation in part arises from the fact that the clay/gravel drain directly on top of the vaults was assumed to function indefinitely. There is preliminary evidence from model simulations that indicate normal infiltration into the facility does not necessarily significantly increase releases from the SDF. Furthermore, more dilution water in the near field can lower concentrations of contaminants in water reaching the aquifer beneath the site. Because the hydraulic conductivity of concrete and saltstone is the limiting factor on flow through the wasteform in the intact scenarios, the importance of reducing infiltration through the site is reduced.

One final observation regarding the possibility of overdesign of the SDF is that the waterproof polymer coating applied to the interior walls of the vaults may not be necessary. Credit was not taken for this design feature of the SDF because of the large uncertainty in the effectiveness and the lifetime of this material. However, the analytical results do not indicate a need for this coating since releases from the vaults are predicted to peak thousands of years in the future, even without considering any retardation of release by this coating. The waterproof polymer coating may be superfluous for this facility.

\subsection{DATA AND RESEARCH NEEDS}

A number of data and research needs have been identified in the course of performing the RPA for the SDF. These needs are directed at improving the confidence in the results of the RPA. Because the RPA is to be maintained through time, and thus is a living document, further iterations of the RPA process will benefit greatly if these needs are satisfied.

Rev. 0 
Research and testing to improve the quality of data in the area of hydraulic properties of slag saltstone are needed. The models used in this RPA to simulate releases of contaminants from saltstone are very sensitive to the value of the saturated hydraulic conductivity assumed, and there is a large amount of uncertainty associated with the value that was used. The addition of slag to saltstone resulted in reduced leaching of Tc-99 and chromium, leading to the hypothesis that hydraulic characteristics may be altered in addition to chemical characteristics. The saturated hydraulic conductivity of slag saltstone should be measured experimentally for use in modeling the release from the SDF.

Field measurement over time to determine the degree of saturation of slag saltstone in the field should also be done to further reduce uncertainties related to longterm acceptability of performance. The simulations performed in this RPA assumed that saltstone was near to saturation at steady state. However, if the degree of saturation of the monoliths after curing is even a few percent less than saturation, it may take a considerable amount of time to achieve near-saturation, thus, affecting the time-history profiles of releases. The release rate of saltstone constituents is very sensitive to the degree of saturation, because the unsaturated hydraulic conductivity is orders of magnitude less than the saturated conductivity, even for small reductions in saturation. A modeling investigation is also recommended to establish the sensitivity of model results to initial saturation assumed for saltstone. More sophisticated modeling techniques for the saltstone/concrete/soil system should also be investigated to provide additional insight into the long-term performance of the saltstone wasteform.

A further evaluation of the uncertainties in the degraded vaults scenario is indicated, based on the importance of this analysis to peak groundwater concentrations. Although multiple conservatisms are built into the analysis of this scenario in this RPA, a quantitative evaluation of the effects of these conservatisms is recommended for future iterations of the RPA.

With respect to estimates of dose to inadvertent intruders, confidence in the results would be increased if root uptake of Tc-99 were measure from mix of crushed saltstone and soil. The results of the agriculture scenario involving intrusion into saltstone are the highest values obtained in this RPA for inadvertent intruders, and the analysis supporting the results is quite sensitive to the plant-to-soil concentration ratio for Tc-99. Technetium-99 is believed to be less available from the saltstone-soil mix, but direct experimental evidence is lacking. Furthermore, the time history of root uptake should be measured for such a mix, to evaluate whether the Tc- 99 becomes more or less available over time.

To evaluate the accuracy of the estimated inventory of nitrate and radionuclides in the SDF, multiple measurements of key radionuclides in different batches of LLW streams are recommended. The sensitivity of intruder dose estimates to the inventory of Sn-126 indicates the desirability of such measurements to confirm experimentally whether the estimated inventory is accurate, and the projected variability. 
Finally, detailed engineering plans for closure of the SDF must be completed. These plans will establish the ability to construct the closure as presently conceived, and will also provide a basis for the cost of final closure. As noted in the previous section, the results of this RPA were inconclusive regarding the need for the upper moisture barrier, but suggested the possibility that this barrier may represent an overdesign of the facility. Further evaluation of the impact of closure design on the results should be undertaken. 


\section{PREPARERS}

Below is a list of contributors to this performance assessment effort, and the portions of the assessment for which they are responsible.

COOK, JAMES R., WSRC/SRTC, Geology, Geochemistry

M.S. Geochemistry

B.S. Geology

Experience: Mr. Cook has 13 years of experience at the Savannah Rive Site, 11 of which have been in various aspects of low-level waste research. Research topics have included site selection, site characterization, site closure, and performance assessment. Mr. Cook served on the revision team for Chapter 3 of DOE Order 5820.2A. He is a member of the Performance Assessment Task Team. He serves as the technical lead on the PA advisory team.

Contributions: Advisor to PA team.

DICKE, CRAIG A, INEL, Radionuclide Screening, Concrete Degradation

M.S. Geology

B.S. Geology

Experience: Mr. Dicke has six years experience in modeling geochemical processes related to radioactive waste disposal.

Contributions: Determined nuclides that are of major importance in the performance of the facility, provided pore fluid concentrations for the selected nuclides for unsaturated flow modeling, and modeled degradation of the concrete vault (Sect. 3.1, Appendix B.3 and Appendix C.1). 
FOWLER, JOHN R., WSRC/SRTC, Chemistry, Inorganic Chemistry

$\mathrm{Ph}$.D. Inorganic Chemistry

B.A. Chemistry

Experience: Dr. Fowler has 23 years of professional experience with 15 years experience related to nuclear fuel reprocessing, aqueous high-level nuclear waste characterization, and aqueous waste processing. Specific experience includes collection and analysis of data on aqueous high-level nuclear wastes stored on the Savannah River Site, development of methods and processes for waste treatment, and flowsheet modeling of chemical processes for waste treatment.

Contributions: Provided general technical and administrative oversight of the entire project, projections of chemical and radiochemical compositions of wastewater to be processed, and described processes to be used to treat liquid nuclear waste (Sect. 1, 2.3, 2.4, $2.5,2.6,2.7)$.

\section{HIERGESELI, ROBERT A, WSRC/SRTC, Geology, Hydrology}

M.S. Hydrology

- B.S. Geology

Experience: Mr. Hiergesell has 16 years of experience relating to all aspects of groundwater investigations. Specific experience includes data collection and analysis, aquifer testing, simulation of groundwater flow, and groundwater modeling.

Contributions: Provided assistance with the saturated flow and transport modeling and quality assurance audits. 
HORWEDEL, JIM L, ORNL, Computer Analyst, Sensitivity and Uncertainty Analysis M.A. Math Education

Experience: For the last nine years, Mr. Horwedel has developed the GRESS software system for automation of sensitivity analysis capability into existing computer codes and has applied GRESS to a wide range of waste management and performance assessment analysis codes. Mr. Horwedel has written several drivers for automating the use of statistical sampling methods, such as LHS, for a variety of computers.

Contributions: Applied GRESS to several codes considered for use in the performance assessment of the Z-Area site. Performed all runs, both GRESSed and reference model runs, of PORFLOW for both the saturated and unsaturated models. Developed a driver to carry out these runs based on Latin Hypercube sampling procedures. Developed a post-processor to analyze the output of the multiple PORFLOW runs.

HOOVER, JAMES D., Westinghouse Hanford Company, Geochemistry

Ph.D. Geology/Geochemistry

M.S. Geology/Geochemistry

Experience: Dr. Hoover has over 18 years experience in the geosciences involving research, teaching, and technical direction. Developed validation process for geochemical conceptual models and computer codes. Director of testing programs in the areas of hydrothermal rock-water-waste form-container interactions; radiolysis and radionuclide speciation. Developed and implemented QA/QC criteria for health-based risk concentration limits for waste releases and remedial action.

Contributions: Determined the evolution of pollutant contamination within the interstitial fluids in the vadose zone immediately surrounding the saltstone vaults (Appendix D).

Rev. 0 
KEARI, PETER M., ORNL/GJ, Groundwater Hydrology

M.S. Hydrology/Hydrogeology

B.S. Geology

Experience: Mr. Kearl has extensive experience (13+ years) with designing and installing groundwater monitoring networks to evaluate contaminant transport and for conducting regional aquifer studies. He has dealt with the hydraulics of fractured media as well as cavernous and porous media, and has conducted vadose zone characterizations. He also has several years experience with numerical modeling of groundwater flow.

Contributions: Evaluated the hydrogeologic environment at Z-Area, and developed and implemented a three-dimensional saturated flow and transport model (Sect. 3.3.2, 3.4.2, Appendix A.2).

KOCHER, DAVID C., ORNL, Exposure Scenario Development, Radionuclide Screening, Dose Calculations

Ph.D. Physics

Experience: Dr. Kocher has over 15 years experience in environmental health physics. He also has served on the Performance Assessment Task Team since its inception, and thus, has considerable insight into performance assessment issues.

Contributions: Developed exposure scenarios for intruders and off-site individuals, computed doses from environmental concentrations, and served in an advisory capacity for several other technical issues (Sect. 3.2.3, 3.2.4, 3.3.3, 3.4.3, 4.1.3, 4.1.4, 4.2.3, 4.2.4. Appendix A.4). 
LANGTON, CHRISTINE A, WSRC/SRTC, Saltstone Development

Ph.D. Material Science

M.S. Geochemistry

B.S. Geology

Experience: Dr. Langton has 10 years experience on developing and testing cement wasteforms and inorganic treatment processes for low-level and mixed wastes.

Contributions: Provided background information on saltstone and concrete and technical information for developing degradation scenarios.

LOWE, PAUL E., WSRC/SRTC, Quality Assurance

B.S. Industrial Engineering

Registered Professional Engineer (PE)

Experience: Mr. Lowe has over 20 years of high technology experience in aerospace, commercial nuclear, and DOE facilities. Six of these years have been in Radioactive Waste Program QA. Mr. Lowe has managed major projects and worked for companies such as Hughes Aircraft, Battelle Institute, as well as major nuclear utilities and consulting firms.

Contributions: Interpreted the Quality Assurance requirements of the PA and ensured SRTC and the National Laboratories performed their research in a manner consistent with good QA practice. This was accomplished by reviews and QA surveillances of all the contractors on the project. 
MAGNUSON, SWEN O., INEL, Near-field Simulations

M.S. Hydrology

B.S. Geological Engineering

Experience: Mr. Magnuson has four years experience in conducting numerical simulations of water movement and contaminant transport. These simulations have been for performance assessments being conducted for LLW sites in arid locations.

Contributions: Conducted single-phase unsaturated flow simulations for the cap (moisture barrier) and both flow and transport simulations for the concrete vault and saltstone monolith (Sect. 3.3.1.1, 3.4.1.1, Appendix A.1.2).

MAERKER, RICHARD E, ORNL, Task Leader, Sensitivity and Uncertainty Analysis

Ph.D. Physics

M.S. Physics

Experience: Dr. Maerker has had over twelve years experience in sensitivity and uncertainty analysis in the areas of reactor pressure vessel dosimetry for the NRC and of high and low level waste for both ONWI and the Lawrence Livermore Laboratory, where he was involved in the successful effort of applying GRESS software to the geochemical code EQ3.

Contributions: Orchestrated the task of obtaining credible estimates of the uncertainties in the value of the calculated maximum nitrate compliance concentration arising as a result of uncertainties in the flow parameters in both the saturated and unsaturated zones, as well as obtaining the sensitivities to these parameters form GRESSed versions of PORFLOW-3D (Sect. 4.2.1.1, 4.2.2 and Appendix H) 
MCDOWELLBOYER, LAURA M., ORNL/GJ, Task Group Leader

Ph.D. Civil/Environmental Engineering

M.S. Radiological Health Physics

Experience: Dr. McDowell-Boyer has seven years experience in radiological exposure assessments, has directed the development of a multimedia environmental transport model, and has spent several years studying aspects of subsurface contaminant migration.

Contributions: Integrated results of the various technical tasks, coordinated production of the draft report, analyzed transport pathways, and provided technical support with the saturated flow modeling (Sect. 2.1, 2.2, 3.2.1, 3.2.2, 3.5, 4.1.1, 4.1.2, 4.2.1, 4.3, 5, 6, Appendix B.1, B.4, C, E, F, and G).

PETERSON, SCOTT W., Westinghouse Hanford Company, Geochemistry

M.S. Geology/Geochemistry

Experience: Mr. Peterson has over 12 years experience in geoscience research and computer modeling in the geochemical field.

Contributions: Applied the MINTEQ code to evaluate changes that occur in the vadose zone soils when pore fluid escapes from the saltstone vaults, i.e., dissolution of soil minerals, formation of stable precipitates, and the resultant change in the composition of the water in the vadose zone soils (Appendix D). 
REED, SHAWN R., WSRC/MWE, Senior Engineer

M.S. Geophysics

B.S. Geology

B.S. Mechanical Engineering

Experience: Mr. Reed has a background in ine geological sciences and engineering, and two years experience involving radiological performance assessments. He is the Waste Management sponsor for the E-Area Radiological Performance Assessment.

Contributions: Advisor to PA team.

SEITZ, ROGER R., INEL, Near-Field Degraded Vault Flow and Transport

B.S. Mathematics (pursuing M.S. in Chemical Engineering, over 30 credits completed)

Experience: Mr. Seitz has over 7 years of experience in conducting performance assessments for high- and low-level waste disposal facilities. His experience is primarily in the area of flow and transport modeling in porous media with some additional experience in radiological dose calculations.

Contributions: Conducted calculations for flow and transport through the degraded vault and saltstone (Sest. 3.3.1.2, 3.4.1.2, Appendix A.1.3). 
SMITH, CARY S., INEL, Unsaturated Zone Conceptual Design and Modeling

B.S. Mathematics

Experience: Mr. Smith's primary area of expertise is applied mathematics and mathematical modeling. Mr. Smith has spent two years working with groundwater flow and contaminant transport modeling. He is doing research on numerical algorithms for fluid flow and transport.

Contributions: Contributed to numerical modeling of the fluid flow and contaminant transport for the moisture barrier and concrete vaults.

\section{SMITH, ROBERT, INEL, Geochemistry}

\section{M.S. Geochemistry and Geoscience}

Ph.D. Geochemistry and Geoscience

Experience: Dr. Smith specializes in inorganic aqueous geochemistry, with emphasis on the modeling of water-rock system at ambient and elevated temperatures. His work focuses on characterizing chemical processes important in natural systems by the application of thermodynamic principals, kinetic theories and adsorption phenomenon. In addition, Dr. Smith has extensive experience in both domestic and international high-level nuclear waste repository design. He has numerous publications in the areas of geochemistry, mineralogy, and environmental science.

Contributions: Conducted geochemical modeling of the saltstone monolith and evaluated the distribution coefficients for Tc-99 (Appendix B.2 and Appendix D) 
THORNE, DAVID J., ORNL/GJ, Atmospheric Pathway Screening Calculations, Modeling Support

M.S. Radiological Health Physics

B.S. Geology

Experience: Mr. Thorne has four years experience in radiological transport and dose assessments. His experience includes source term development, contaminant transport modeling, dose and risk assessment, and environmental compliance.

Contributions: Evaluated the atmospheric release and transport of volatile contaminants. In addition, he assisted with PORFLOW-3D modeling of the saturated zone (Appendix A.1.3).

\section{WALTON, JOHN C., INEI, Concrete Degradation}

B.S. Biology

M.S. Environment Science

Ph.D. Chemical Engineering

Experience: Dr. Walton has over 10 years of experience in the areas of performance and risk assessment. His publications are in the areas of contaminant transport, corrosion, and long-term performance of engineered barriers in waste disposal applications.

Contributions: Provided technical assistance with degradation analysis and flow and transport through degraded wasteform.

Rev. 0 
WILHITE, ELMER L., WSRC/SRTC, Advisory Scientist

M.S. Inorganic Chemistry

B.S. Chemistry

Experience: Mr. Wilhite has twenty-two years experience at the Savannah River Site. Most of his experience ( 12 years) has been in low-level waste research. Other experience has included environmental research (3 years), high-level waste research ( 2 years), and analytical development supervision ( 3 years). Mr. Wilhite has contributed to the preparation of DOE Order 5820.2A and is currently chairman of the Peer Review Panel.

Contributions: Advisor to PA teain.

WOLF, KATHLEEN Z., WSRC/DWPF, Manager DWFF Environmental Affairs

B.S. Biology

B.S. Chemical Engineering

Experience: Ms. Wolf has 6-1/2 years of experience relating to all aspects of environmental compliance. Specific experience includes permitting of the Saltstone Facility.

Contributions: Provided guidance on regulatory requirements and permit commitments. 
WORLEY, BRIAN A, ORNL, Task Manager, Sensitivity and Uncertainty Analysis

Ph.D. Nuclear Engineering, Massachusetts Institute of Technology

Experience: Dr. Worley has been involved with reactor physics analysis of advanced reactors since 1977 at ORNL. His has experience in developing methods for sensitivity and uncertainty analysis for reactor systems and waste management systems. He has managed the development of sensitivity and uncertainty analysis work sponsored by ONWI and DOE/LLW since 1985 .

Contributions: Provided management and oversight of the sensitivity and uncertainty analysis for the Z-Area performance assessment.

YU, ANDREW, WSRC/SRTC, Chemical Engineering

Ph.D. Chemical Engineering

Experience: Dr. Yu has 13 years experience in modeling enhanced oil recovery processes prior to joining SRS in 1987. At SRS, he and his coworkers have recommended key design features of disposal vaults based on groundwater protection.

- Contributions: Assisted in setting up the model of the unsaturated zone. 


\section{REFERENCES}

Albenesius, E. L. 1982. Technical Date Summary - Decontaminated Salt Disposal as Saltcrete in a Landfill. DPSTD-82-65. Savannah River Laboratory, E. I. du Pont de Nemours \& Company, Inc..

Alter, H. W., and R. A. Oswald. 1988. Nationwide Distribution of Indoor Radon Measurements, Radiation Protection Practice, Proceedings of the Seventh International Congress of International Radiation Protection Association, Sydney, Pergamon Press.

Arnett, M. W., L. K. Karapatikis, A. R. Mamatey, and J. L. Todd. 1992. Savannah River Site Environmental Report for 1991. WSRC-TR-92-186, Westinghouse Savannah River Company, Savannah River Site, Aiken, SC.

ASTM. 1985. Standard Specification for Portland Cement. ASTM C 150-85a, American Society for Testing and Materials, Philadelphia, Penn.

Atkinson, A and Hearne. 1984. An Assessment of the Long-Term Durability of Concrete in Radioactive Waste Repositories, AERE-R11465, Harwell, U. K.

Atkinson, A. and A. K. Nickerson. 1988. Diffusion and Sorption of Celisum, Strontium and Iodine in Water-Saturated Cement, Nuclear Technology, 81:100-113.

Baes, C. F. III and R. D. Sharp. 1983. A Proposal for Estimation of Soil Leaching and Leaching Constants for Use in Assessment Models, J. Environ. Qual. 12:17.

Baes, C. F. III, R. D. Sharp, A L. Sjoreen, and R. W. Shor. 1984. A Review and Analysis of Parameters for Assessing Transport of Environmentally Released Radionuclides through Agriculture, ORNL-5786, Oak Ridge National Laboratory.

Benjamin, R. W., and P. L. Roggenkamp. 1979. Process for Disposal of SRP Waste Salt. Internal report DPST-79-572. Savannah River Laboratory, E. I. du Pont de Nemours \& Company, Inc.

BNAI. 1985a. South Carolina Landfill Regulation, South Carolina Code of Rules and Regulations, Title 61 - Department of Health and Environmental Conirol, Regulation 70; Environment Reporter, the Bureau of National Affairs, Inc., Washington, D.C. 20037, Sect. 1306:0521- 1306:0523, pp. 1251-1253

(March 22, 1985). 
BNAI. 1985b. South Carolina Industrial Solid Waste Disposal Site Regulation, South Carolina Code of Regulations, Chapter 61 - Department of Health and Environmental Control, Regulation 66; Environment Reporter, by the Bureau of National Affairs, Inc., Washington, D.C. 20037, Sect. 1306:0501 - 1306:0505, pp. 1254-1257 (March 22, 1985).

Bollinger, G. A, F. C. Davison, Jr., M. S. Sibol, and J. B. Birch. 1989. Magnitude Recurrence Relations for The Southeastern United States and its Subdivisions. Joumal of Geophysical Research, 94(B3):2857-2873.

Briese, L. A, and M. H. Smith. 1974. Seasonal Abundance and Movement of Nine Species of Small Mammals. J. Mammal. 55:615-629.

Bruns, B. S. 1985. Benzene Release from Saltstone. International Hydronics Corporation, Rocky Hill, NJ.

Bruns, B. S. 1986. Benzene Release from Saltstone II. International Hydronics Corporation, Rocky Hill, NJ.

Christensen, E. J., and D. E. Gordon. 1983. Technical Summary of Groundwater Quality Protection Program at Savannah River Plant, Volume I, DPST-83-829, Savannah River Laboratory, E. I. du Pont de Nemours \& Co., Inc., Aiken, SC.

Cook, J. R. 1983. 24 Estimation of High Water Table Levels at the Saltstone Disposal Site (Z-Area). DPST-83-607, Savannah River Laboratory, E.I. du Pont de Nemours \& Company, Inc., Aiken, SC.

Cook, J. R. 1984a. Site Selection for Saltstone Disposal, DPST-84-502, E. I. du Pont de Nemours \& Co., Inc., Savannah River Laboratory, Aiken, SC.

Cook, J. R. 1984b. Saltstone Landfill System: A Method for Disposal of Hazardous Industrial Chemicals, DPST-84-521, E. I. du Pont de Nemours \& Co., Inc., Savannah River Laboratory, Aiken, SC.

Cook, J. R. 1986. Hydrogeologic Data from Z-Area, E. I. du Pont de Nemours and Company Savannah River Laboratory, Aiken, South Carolina.

Cook, J. R., M. W. Grant, and O. A. Towler. 1987. Environmental Information Document - New Low-Level Radioactive Waste Sturage/Disposal Facilities at the Savannah River Plant, DPST-85-862, Savannah River Laboratory, E. I. du Pont de Nemours \& Co., Iac., Aiken, SC.

Cook, J. R, and S. K. Salvo. 1992. Final Vegetative Cover for Closed Waste Sites. WSRC-RP-92-1361. Westinghouse Savannah River Company, Savannah River Site, Aiken, SC. 

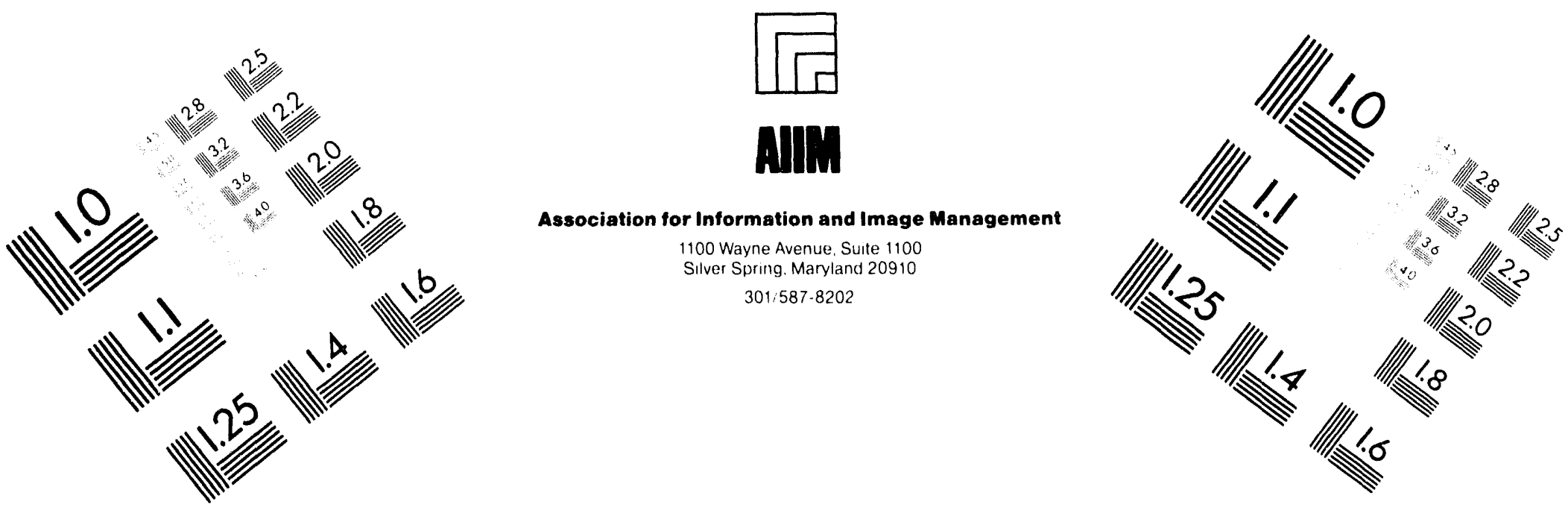

\section{Centimeter}

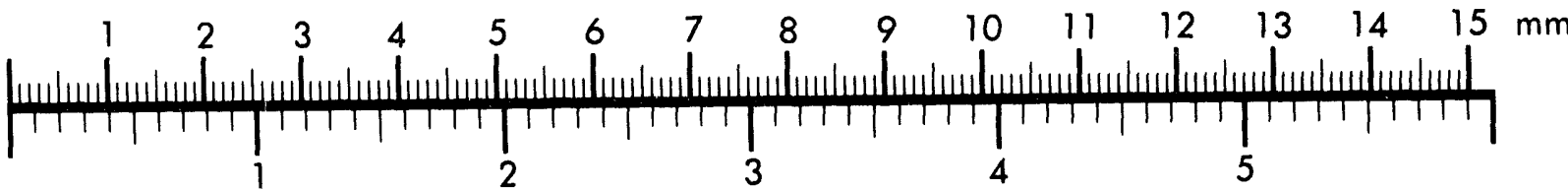

Inches
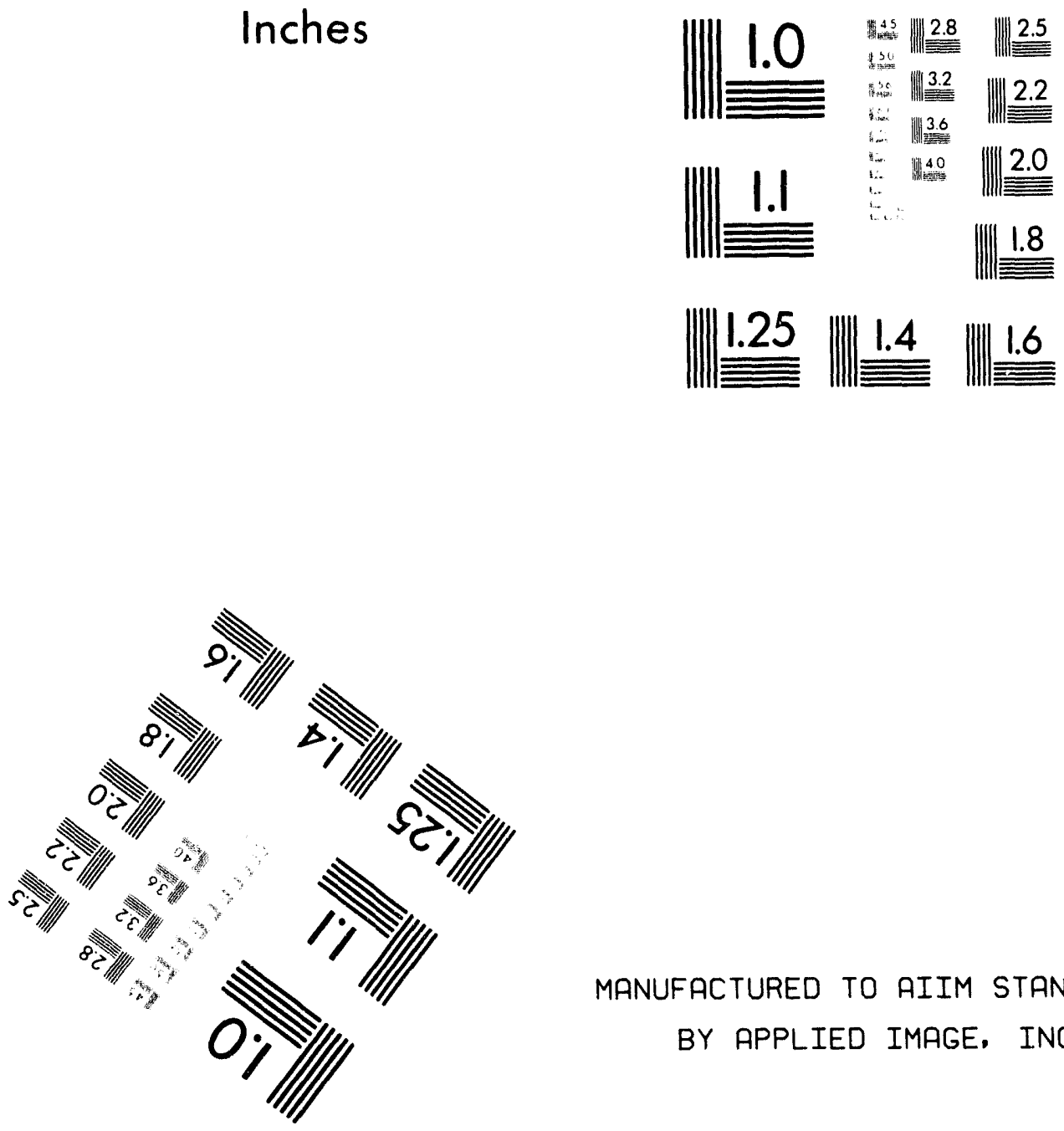

MANUFACTURED TO AIIM STANDARDS

BY APPLIED IMAGE, INC.

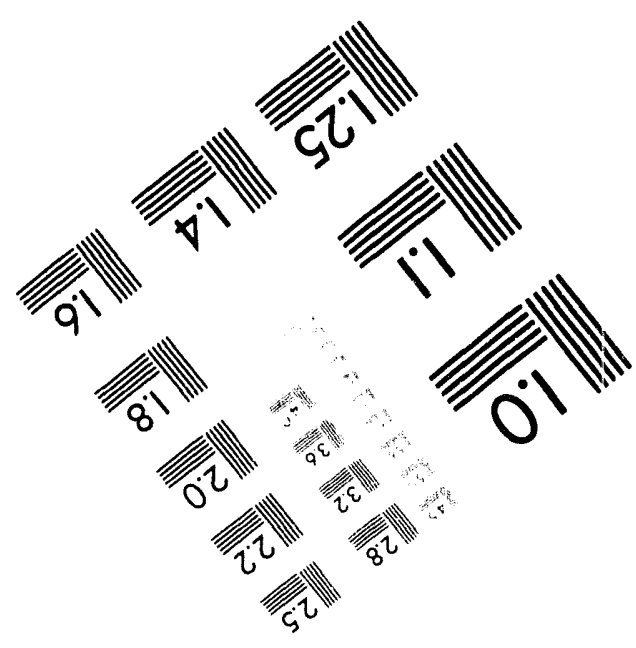



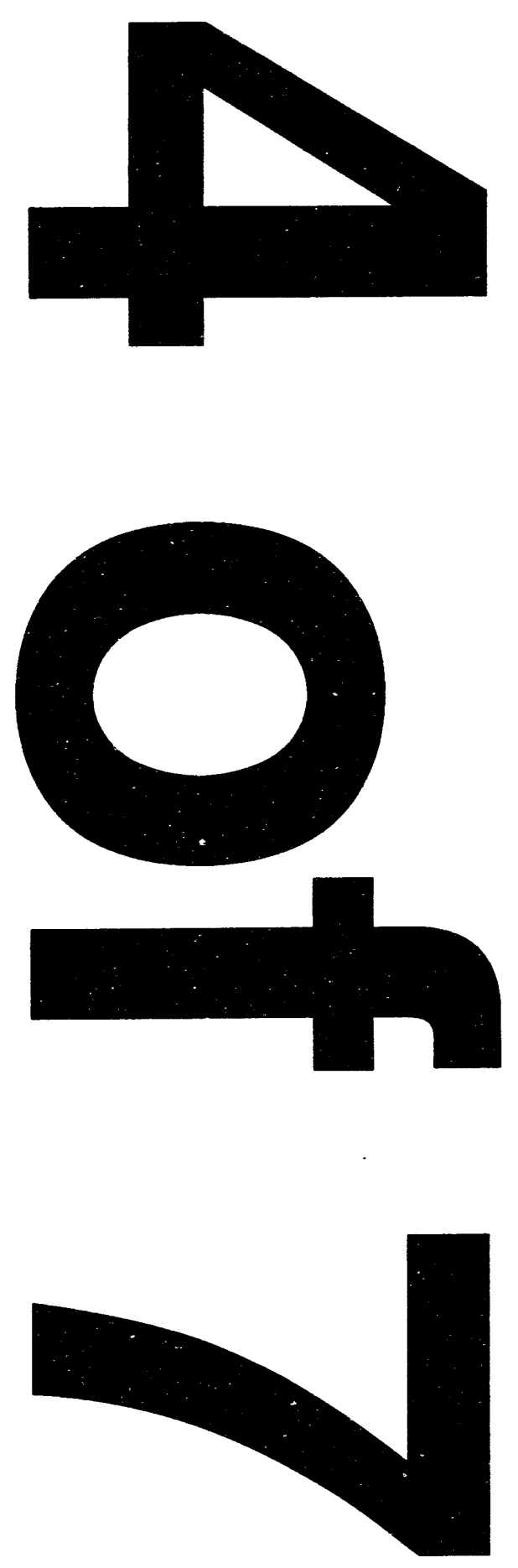
Cummins, C. L, D. K. Martin, and J. L. Todd. 1990. Savannah River Site Environmental Report, WSRC-IM-91-28, Volumes I and II, Westinghouse Savannah River Company, Savannah River Site, Aiken, SC.

Davenport, L. B. 1964. Structure of Two Peromyscus polionotus Populations in OldField Ecosystems at the AED Savannah River Plant. J. Mammal. 45:95-113.

de Marsily, G. 1986. Quantitative Hydrogeology. Academic Press, Inc., New York, NY.

Dennehy, K. F., D. C. Prowell, and P. B. McMahon. 1989. Reconnaissance Hydrological Investigation of the Defense Waste Processing Facility and Vicinity, E. I. du Pont de Nemours and Company Savannah River Laboratory, Aiken, SC.

Dodge, R. L., W. R. Hansen, W. E. Kennedy, Jr., D. W. Layton, D. W. Lee, S. T. Maheras, S. M. Neuder, E. L. Wilhite, R. U. Curl, K. F. Grahn, B. A. Heath, and K. H. Turner. 1991. Performance Assessment Review Guide for DOE Low-Level Radioactive Waste Disposal Facilities. Prepared by Dames and Moore for Department of Energy Office of Environmental Restoration and Waste Management (DOE/LLW-93). Radioactive Waste Technical Support Program, Idaho National Engineering Laboratory EG\&G Idaho, Inc. Idaho Falls, Idaho.

Dukes, M. D. 1981. Heating of Saltcrete Blocks Due to Cement Hydration. Internal report DPST-81-663. Savannah River Laboratory, E. I. du Pont de Nemours \& Company, Inc.

Dupont. 1980. DWPF Basic Data Report. DPSP-80-1033 (rev. 10, rev. 90, rev. 35, rev. 138)

Fowler, J. R. 1982a. Update of Chemical and Radiochemical Composition of Decontaminated Soluble Waste from the Precipitation Process. Internal report DPST-82-759, E. I. du Pont de Nemours \& Co., Inc., Savannah River Laboratory, Aiken, South Carolina.

Fowler, J. R. 1982b. Chemical Composition of F Area Soluble High Level Waste. Internal report DPST-82-390, E. I. du Pont de Nemours \& Co., Inc., Savannah River Laboratory, Aiken, SC.

Fowler, J. R. 1982c. Composition of $H$ Area and SRP Soluble High-Level Waste. Internal report DPST-82-502, E. I. du Pont de Nemours \& Co., Inc., Savannah River Laboratory, Aiken, SC.

Fowler, J. R. 1991. Radionuclide Storage and Disposal in Z-Area. Internal report OPS-DTZ-90-0027, Rev. 1. Westinghouse Savannah River Company, Savannah River Site, Aiken, SC, (December 1990, revised June 1990). 
Fowler, J. R. 1992. Justification for Continued Operation of the SRS Saltstone Facilities (Z-Area) (u), WSRC-RP-92-444, Westinghouse Savannah River Company, Aiken, SC.

Fowler, J. R., and J. R. Cook. 1984a. Technetium-99 in SRP High-Level Waste and Saltstone. Internal report DPST-84-343, E. I. du Pont de Nemours \& Co., Inc., Savannah River Laboratory, Aiken, SC.

Fowler, J. R., and J. R. Cook 1984b. I-129 in SRP High-Level Waste and Saltstone, Internal report DPST-84-343, E. I. du Pont de Nemours \& Co., Inc., Savannah River Laboratory, Aiken, SC.

Freeze, R. A, and J. A. Cherry. 1979. Groundwater. Prentice-Hall, Inc., NJ.

Golley, F. B., and J. B. Gentry. 1964. Bioenergetics of the Southern Harvester Ant, Pogonomyrmex badius. Ecol 45:217-225.

Hamby, D. M. 1992. Site-Specific Parameter Values for the Nuclear Regulatory Commission's Food Pathway Dose Model, Health Phys., 62:136.

Heckrotte, R. W. 1988. Project S-1780 - Savannah River Plant - 200-S Area Defense Waste Processing Facility - Sludge Plant Request to Modify the DWPF Saltstone Industrial Solid Waste Permit, Inter-office Memorandum, DuPont, Savannah River Plant, PP-0001183 (January 29, 1988).

Hooker, R. L, and M. D. Dukes. 1982. Technical Data Summary - Decontaminated Salt Disposal as Saltcrete in a Landfill. DPSTD-82-65, Rev. 1. Savannah River - Laboratory, E. I. du Pont de Nemours \& Company, Inc.

Horton, J. H., and E L. Wilhite. 1978. Estimated Erosion Rate at the SRP Burial Ground. E. I du Pont de Nemours \& Co., Inc., Savannah River Laboratory, Aiken, SC.

Horwedel, J. E 1991. GRESS Version 2.0 User's Manual ORNL/TM-11951. Oak Ridge National Laboratory, Oak Ridge, Tenn.

Iman, R. L, and M. J. Shortencarier. 1984. A Fortran 77 Program and User's Guide for the Generation of Latin Hypercube and Random Samples for Use with Computer Models. NUREG/CR-3624, SAND83-2365. Sandia National Laboratory.

INTERA 1986. Z-Area Site Assessment, INTERA Technologies, Inc., for E. I. du Pont Nemours \& Co., Savannah Research Laboratory, Aiken, SC. 
INTERA. 1988. Prediction of Ground Water Quality at Z-Area, INTERA Technologies, Inc., 6850 Austin Center Blvd., Suite 300, Austin, Texas 78731.

Kennedy, W. E, Jr. and R. A. Peloquin. 1988. Intruder Scenarios for Site-Specific Low-Level Waste Classification. DOE/LLW-71T. Idaho Operations Office, U. S. Department of Energy.

Ketelle, R. H,and D. D. Huff. 1984. Site Characterization of the West Chestnut Ridge Site. ORNL/TM-9229. Oak Ridge National Laboratory, Oak Ridge, Tenn.

Kumar, A. D. M. Roy, P. H. Licastro, and C. A Langton. 1985. Effective Diffusion Coefficients for Several Saltstone Waste Forms, Prepared for E. I. du Pont de Nemours and Company, Inc. by Pennsylvania State University, University Park, Penn.

Langton, C. A 1986. Slag Substituted Concrete for Saltstone Vault Construction. Internal Report DPST-86-830. E. I. du Pont de Nemours \& Company, Inc., Savannah River Laboratory, Aiken, SC.

Langton, C. A 1987a. Reduced Chromium Leaching in Slag-Based Saltstone Formulations. Internal report DPST-86-863. Savannah River Laboratory, E. I. du Pont de Nemours \& Company, Inc.

Langton, C. A 1987b. Slag-Based Saltstone Formulations. Internal report

DPST-87-392. E. I. du Pont de Nemours \& Co., Inc., Savannah River Laboratory, Aiken, SC.

Langton, C. A 1987c. Slag Saltstone Raw Materials Specifications. Internal report DPST-87-760. Savannah River Laboratory, E. I. du Pont de Nemours \& Company, Inc.

Langton, C. A. 1987d. Physical Properties of Slag Saltstone. Internal report DPST-87-673. Savannah River Laboratory, E. I. du Pont de Nemours \& Company, Inc.

Langton, C. A. 1987e. EP Test Results for Slag Saltstone. Internal report DPST-87-869. Savannah River Laboratory, E. I. du Pont de Nemours \& Company, Inc.

Langton, C. A., S. B. Oblath, D. W. Pepper, and E. L. Wilhite. 1988. Waste Salt Disposal at the Savannah River Plant. Chemical Engineering Communications, 66:189-199. 
Langton, C. A. and E. L. Wilhite. 1988. Recommended Salt Solution Feed Specifications for Z-Area (Revised), Internal report DPST-88-372, E. I. du Pont de Nemours \& Co., Inc., Savannah River Laboratory, Aiken, SC (March 15, 1988, Revised May 19, 1988).

Langton, C. A 1989a. EP Taxicity Results for Simulated Saltstone Made in the Z-Area Plant, DPST-89-342, Savannah River Laboratory, E. I. du Pont de Nemours \& Co., Inc., Aiken, SC.

Langton, C. A. 1989b. Guidance on Z-Area Salt Solution Taxic Metal Concentrations Based on EP Taxicity Tests for Saltstone. Savannah River Laboratory Memorandum DPST-89-314.

Langton, C. A, and E. L. Wilhite. 1990. Revised Z-Area Salt Solution Feed Specification for Mercury, WSRC-RP-89-1375, Westinghouse Savannah River Company, Savannah River Site, Aiken, SC.

Licastro, P. H, D. M. Roy, and S. Kaushal. 1985. Thermal Properties of Saltstone. Materials Research Laboratory, Pennsylvania State University, University Park, Penn. (cf. C. A. Langton, Thermal Properties of Saltstone. PSU Progress Report - Internal report DPST-86-460. Savannah River Laboratory, E. I. du Pont de Nemours \& Company, Inc.)

Malek, R. I. A., D. M. Roy, P. H. Licastro and C. A. Langton. 1985. Saltstone Starting Materials Characterization, E. I. DuPont de Nemours and Company, Inc., Savannah River Laboratory, Aiken, SC 29808, 24p.

Malek, R. I. A. P. H. Licastro, and D. M. Roy. 1987. Saltstone Pore Solution Analyses, - Penn. State report to E. I. du Pont.

McKenzie, D. H., L L. Cadwell, L. E. Eberhardt, W. E Kennedy, Jr., R. A. Peloquin, and M. A. Simmons. 1983. Relevance of Biotic Pathways to the Long-Term Regulation of Nuclear Waste Disposal; Topical Report on Reference Eastern Humid Low-Level Sites. NUREG/CR-2675, PNL-4241, Vol. 3, Pacific Northwest Laboratory, Richland, Wash.

McKenzie, D. H., L. L. Cadwell, W. E. Kennedy, Jr., L. A. Prohammer, and M. A. Simmons. 1986. Relevance of Biotic Pathways to the Long-Term Regulation of Nuclear Waste Disposal, Phase II, Final Report. NUREG/CR-2675, PNL-4241, vol. 6, Pacific Northwest Laboratory, Richland, Wash.

Murphy, C. E., Jr. 1990. Lysimeter Study of Vegetative Uptake from Saltstone, WSRCRP-90-421, Westinghouse Savannah River Company. 
NCRP (National Council on Radiation Protection and Measurements). 1987. Ionizing Exposure of the Population of the United States, Washington, D. C., NCRP report No. 93.

NCRP (National Council on Radiation Protection and Measurements). 1989. Exposure of the U. S. Population from Diagnostic Medical Radiation, NCRP report No. 100, Bethesda, MD.

Oak Ridge National Laboratory Quality Assurance Manual. Current Edition. Oak Ridge National Laboratory, Oak Ridge, Tenn.

ORNL. 1990. Performance Assessment for Continuing and Future Operations at SWSA 6, Internal draft report. Oak Ridge National Laboratory, Oak Ridge, Tenn.

Oakly, D. T. 1972. Natural Radiation Exposure in the United States, U. S. Environmental Protection Agency, Washington, D. C., ORP/SID 72-1.

Oblath, S. B. 1986a. Leach Test of 107 Liter Saltstone Blocks at Brookhaven National Laboratory. SRL Memorandum DPST-86-442.

Oblath, S. B. 1986b. Benzene Evolution During the Curing of Saltstone. Internal report DPST-86-645. Savannah River Laboratory, E. I. du Pont de Nemours \& Company, Inc., Aiken, SC.

Oblath, S. B. 1989. Leaching from Solidified Waste Forms under Saturated and Unsaturated Conditions, Environmental Science and Technology, 23(9)1098-1102.

Oztunali, O. I. and G. W. Roles. 1986. Update of Part 61 Impacts Analysis Methodology, NUREG/CR-4370, U. S. Nuclear Regulatory Commission and Envirosphere Company.

Parizek, R. R., and R. W. Root. 1986. Development of a Groundwater Velocity Model for the Radioactive Waste Management Facility, Savannah River Plant, South Carolina, Pennsylvania State University, University Park, Penn.

Pollutant Assessments Group Procedures Manual 1992. ORNL-6645/V2/R1, Oak Ridge National Laboratory, Oak Ridge, Tenn.

Runchal, A. K, and B. Sagar. 1992. PORFLOW: A Model for Fluid Flow, Heat and Mass Transport in Multifluid, Multiphase Fractured or Porous Media, Users Manual, Version 2.4. ACRi/016/Rev. G, Analytic and Computational Research, Inc., Los Angeles, Calif. 
Rupp, E M. 1980. Age Dependent Values of Dietary Intake for Assessing Human Exposures to Environmental Pollutants, Health Phys. 39:151.

SCDHEC. 1986a. SRP/Z-Area Treatment Facility Constriction Permit \#12,683, Aiken County, South Carolina Department of Health and Environmental Control, 2600 Bull St., Columbia, SC 29201.

SCDHEC. 1986b. Industrial Waste Permit IWP-217, Z-Area Saltstone Disposal Facility, Savannah River Plant, Aiken County, South Carolina Department of Health and Environmental Control, 2600 Bull St., Columbia, S.C. 29201 (October 31, 1986). [Note: this permit is reviewed and renewed every three years]

SCDHEC. 1988a. RE: Revision of Industrial Waste Permit, IWP-217, Z-Area Generah Aiken County, South Carolina Department of Health and Environmental Control, 2600 Bull St., Columbia, SC 29201 (July 15, 1988).

SCDHEC. 1988b. Permit to Operate - Z-Area Saltstone Processing Facility, Permit \#12,683, Aiken County, South Carolina Department of Health and Environmental Control, 2600 Bull St., Columbia, SC 29201.

SCDHEC. 1989a. RE: Industrial Waste Permit - 217 (IWP-217), Z-Area Saltstone Disposal Facility, 24 Savannah River Site, South Carolina Department of Health and Environmental Control, 2600 Bull St., Columbia, SC 29201 (October 17, 1989). [Triennial review and renewal, disposal of FMF drums in Z-Area approved].

SCDHEC. 1989b. Modification to Constnuction Permit \#12,683, Z-Area Wastewater Treatment Facility - SRS/DOE, Aiken County, South Carolina Department of - Health and Environmental Control, 2600 Bull St., Columbia, SC 29201.

Sheppard, M. I. 1985. Radionuclide Partitioning Coefficients in Soils and Plants and Their Correlation, Health Phys. 49:106.

Smith, M. H. 1971. Food as a Limiting Factor in the Population Ecology of Peromyscus polionotus (Wagner). Physiol Zool 40:31-39.

Stephenson, D. E., P. Talwani, and J. Rawlins. 1985. Savannah River Plant Earthquake of June 1985. DPST-85-583, E. I. du Pont de Nemours \& Co., Inc., Savannah River Laboratory, Aiken, SC.

Stephenson, D. E. 1988. August 1988 Savannah River Plant Earthquake. DPST-88-841, E. I. du Pont de Nemours \& Company, Inc., Savannah River Laboratory, Aiken, SC. 
Thompson, D. G. 1991. RE: Vault Closure Concept for Saltstone Vaults (u). Internal report OPS-DTZ-91-0002. Westinghouse Savannah River Company, Savannah River Site, Aiken, SC.

Toth, J. 1962. A theory of groundwater motion in small drainage basins in central Alberta, J. Geophys. Res., 67:4375-4387.

URS/Blume, J. A. and Associates, Engineers. 1982. Update of Seismic Criteria for the Savannah River Plant, 1, Geotechnical, DPE-3699, E.I. du Pont de Nemours and Company, Savannah River Laboratory, Aiken, SC.

U. S. Department of Agriculture. 1985. Site Specific Cropland Erosion Inventory. Soil Conservation Service, Columbia, SC.

U. S. Department of Commerce. 1977. 1974 Census of Agriculture, Bureau of the Census, Agriculture Division.

U.S.DOE. 1982. Final Environmental Impact Statement, Defense Waste Processing Facility, Savannah River Plant, Aiken, S.C. DOE/E15/0082, U. S. Department of Energy, Savannah River Plant, Aiken, SC.

U.S.DOE. 1986a. Permit Application for the Proposed Z-Area Saltstone Disposal Facility, Internal report DPSP-85-1142 (Rev. 1), Savannah River Operations Office, U. S. Department of Energy, Aiken, SC.

U.S.DOE. 1986b. Construction Permit Application for the Proposed Z-Area Saltstone Industrial Wastewater Treatment Facility, Savannah River Operations Office, U. S. Department of Energy, Aiken, SC.

U.S.DOE 1987. Waste Management Activities for Groundwater Protection, Savannah River Plant, Aiken, SC. Final Environmental Impact Statement, DOE/EIS-0120, Vol. 1, U. S. Department of Energy, Savannah River Plant, Aiken, SC.

U.S.DOE. 1988a. Radioactive Waste Management, Order 5820.2A, U. S. Department of Energy, Washington, D.C.

U.S.DOE. 1988b. Revision of South Carolina Department of Health and Environmental Control (SCDHEC) Industrial Waste Permit, IWP-217, Z-Area Saltstone Disposal Facility Permit, Savannah River Operations Office, U. S. Department of Energy, Aiken, SC.

U.S.DOE. 1990. Startup Readiness Review, Report of Findings, Saltstone Manufacturing and Disposal Facility, U. S. Department of Energy. 
U.S.DOE. 1991. Analysis of the Environmental Impacts Resulting from Modifications in the Defense Waste Processing Facility. Environmental Division, Savannah River Operations Office, U. S. Department of Energy, Aiken, SC.

U.S.NRC. 1977. Regulatory Guide 1.109. Calculation of Annual Doses to Man from Routine Releases of Reactor Effluents for the Purpose of Evaluating Compliance with 10 CFR Part 50, Appendix I. Nuclear Regulatory Commission.

U.S.NRC. 1981. Draft Environmental Impact Statement on 10 CFR Part 61 "Licensing Requirements for Land Disposal of Radioactive Waste." NUREG-0782, U. S. Nuclear Regulatory Commission, Washington D. C.

U.S.NRC. 1982. Final Environmental Impact Statement on 10 CFR Part 61 "Licensing Requirements for Land Disposal of Radioactive Waste". NUREG-0945 Vol. 1, U. S. Nuclear Regulatory Commission, Washington, D.C.

U.S.NRC. 1989. Quality Assurance Program Requirements for Nüclear Facilities. ASME NQA-1-1989 Edition, The American Society of Mechanical Engineers.

Van Pelt, A. F. 1966. Activity and Density of Old-Field Ants of the Savannah River Plant, South Carolina. J. Elisha Mitchell Sci Soc. 2:343-351.

Walton, J. C., L. E. Plansky, and R. W. Smith. 1990. Models for Estimation of Service Life of Concrete Barriess in Low-Level Radioactive Waste Disposal, NUREG/CR5542, EGG-2597, U.S. Nuclear Regulatory Commission, Washington, D.C.

Wilhite, E. L. 1985. Estimated Composition of Decontaminated Salt Solution Feed to Saltstone. E. I. du Pont de Nemours \& Co., Inc., Savannah River Laboratory, Aiken, SC.

Wilhite, E. L 1986. Evaluation of Potential Disposal Alternatives for Low-Level Salt Solution. Internal report DPST-86-698. E. I. du Pont de Nemours \& Company, Inc., Savannah River Laboratory, Aiken, SC.

Wolf, H. C. 1984. Technical Data Summary: Decontaminated Salt Disposal as Saltstone in an Engineered Landfill, DPSTD-82-65, Rev. 2. E. I. du Pont de Nemours \& Company, Inc., Savannah River Laboratory, Aiken, SC.

Wolfram, S. 1991. Mathematica - A System for Doing Mathematics by Computer. 2nd Edition. Addison-Wesley Publishing Company., Redwood City, Calif. 
WSRC. 1991. As-Built Construction Permit Application for an Industrial Wastewater Treatment Facility for the $F$ and $H$ Area High-Level Radioactive Waste Tank Farms (u). Westinghouse Savannah River Company, Savannah River Site, Aiken, SC and Chase T. Main, Inc., Charlotte, NC.

WSRC. 1992a. Safety Analysis Report - 200-Z Area, Savannah River Site, Saltstone Disposal Facility, WSRC-SA-3, draft in review by Department of Energy. Savannah River Laboratory, Westinghouse Savannah River Company, P. O. Box 616, Aiken, SC 29802.

WSRC. 1992b. Safety Analysis 200 Area Replacement Tritium Facility. WSRC-SA1-1, Savannah River Laboratory, Westinghouse Savannah River Company, Aiken, SC.

10 CFR 216.

10 CFR 268.

40 CFR 61.

40 CFR 141. 


\title{
RADIOLOGICAL PERFORMANCE ASSESSMENT FOR THE Z-AREA SALTSTONE DISPOSAL FACILITY
}

\author{
APPENDICES
}

\author{
Prepared for the \\ WESTINGHOUSE SAVANNAH RIVER COMPANY \\ Aiken, South Carolina
}

by

\author{
MARTIN MARIETTA ENERGY SYSTEMS, INC. \\ EG\&G IDAHO, INC. \\ WESTINGHOUSE HANFORD COMPANY \\ WESTINGHOUSE SAVANNAH RIVER COMPANY
}

December 18, 1992

Rev. 0 
APPENDIX A

DETAIIS OF MODEIS AND ASSUMPTIONS 


\section{A.1 NEAR-FIEID MODEL}

Appendix A.1 provides details of models and assumptions that support the information provided in Sect. 3.3.1 and 3.4.1 of the main body of the RPA draft report.

\section{A.1.1 Infiltration}

The process of infiltration is defined as the entry into soil of water made available at the ground surface, together with the ascociated flow away from the ground surface within the unsaturated zone. This is contrasted with the process of evaporation, or exfiltration, which is detined as the removal of water from the soil across the ground surface, together with the associated flow toward the ground surface within the unsaturated zone.

An idealized cross section of the vadose, or unsaturated soil, zone representing the infiltration area is shown in Fig. A.1-1. Water infiltrates at the surface and either undergoes evapotranspiration through the surface and out of the domain or it infiltrates. The upper region in Fig. A.1-1 consists of the sediments near the surface where evaporation and transpiration have a dynamic role in reversing the downward movement of water due to gravity, and is referred to as the dynamic zone. The remaining region consists of the vadose zone. In the vadose zone, soil pores contain gases and water. Water is typically transported downward by gravity and capillarity.

\section{A1.1.1 Past Infiltration Studies}

Past studies of infiltration at or near the SRS offer estimates of average infiltration rates. Hubbard and Englehardt (1987) used the CREAMS computer code to calculate a water balance for the old SRS burial ground (643-G) for the period 1961-1986. The CREAMS code, developed by the U.S. EPA, considers daily rainfall records, site vegetation, climatic characteristics, and soil properties. Daily rainfall records from $F$ Separations Area were used in the simulation, and soils, vegetation, and climatic characteristics of the burial ground site were ueed for the hydrologic parameters in the model. The average annual infiltration rate was estimated to be $37 \mathrm{~cm}$ or about $1 / 3$ of annual average precipitation. Observed extremes for infiltration were $81 \mathrm{~cm}$ in 1964 and $10 \mathrm{~cm}$ in 1968.

To estimate the net infiltration for time intervals corresponding to pumping of the tank 24 lysimeter, INTERA Technologies (1986) estimated discrete event evaporation using these bases:

- maximum evaporation is limited to $80 \%$ of pan evaporation rates;

- if evaporation exceeds the precipitation by more than $10 \%$ of the pan rate, an infiltration deficit can remove water from the soil;

- the maximum infiltration deficit per month is assumed to be $20 \%$ of the pan rate; and

- the infiltration deficit accumulates until it is overcome by subsequent precipitation exceeding evaporation. 


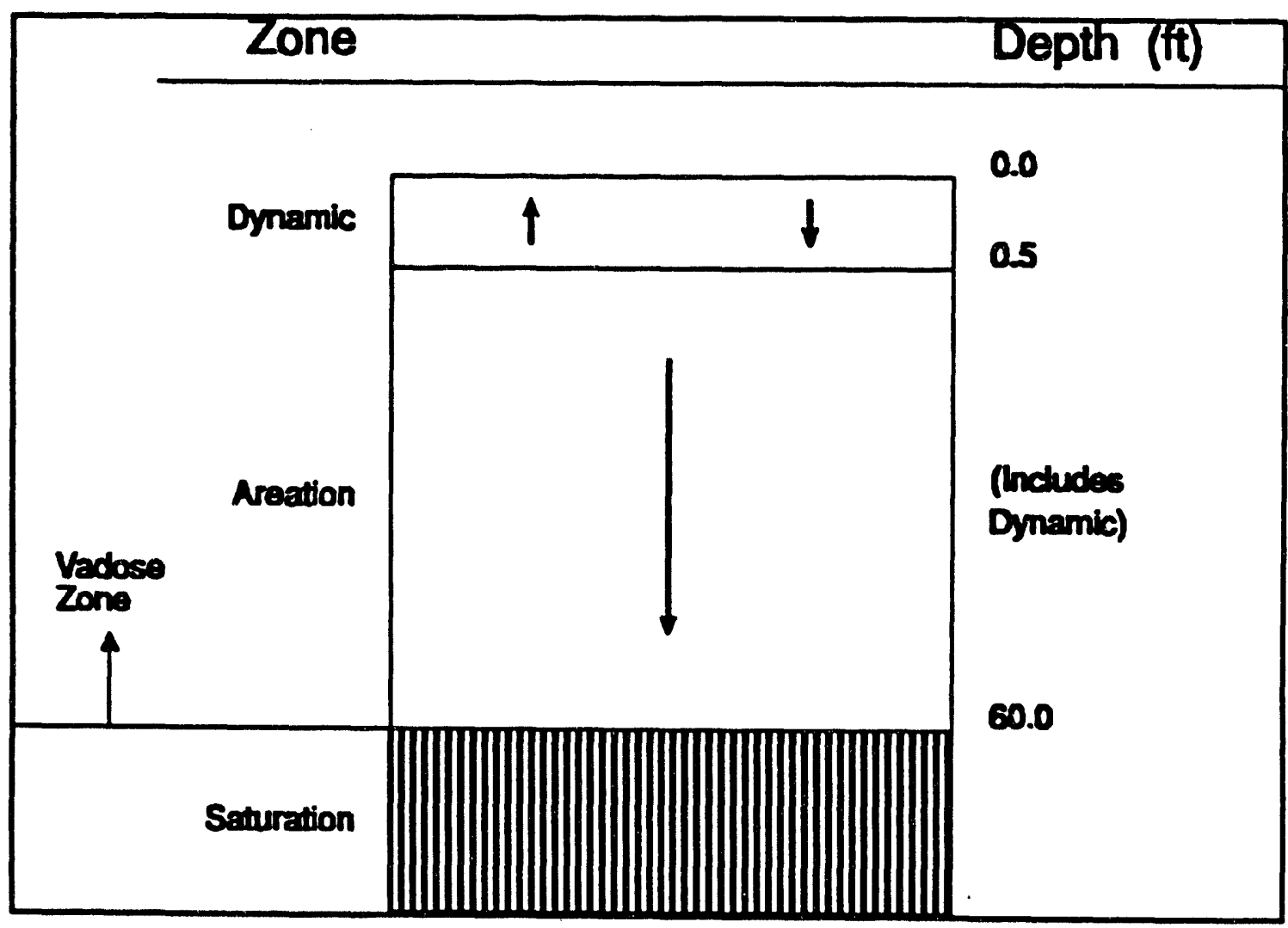

.

Fig. A.1-1. Idealized cross-section of the SRS vadose zone.

Rev. 0 
The algorithm developed from these bases was then used to estimate infiltration rates during discrete periods of precipitation. A yearly infiltration total for the period February 1984 through August 1985 was determined to be approximately $24 \mathrm{~cm}$.

Parizek and Root (1986) used a water balance method, where stream flow measurements were subtracted from annual precipitation to yield an estimated evaporation at $64 \%$ of the total annual precipitation. This estimate gives an average annual infiltration value of $45 \mathrm{~cm}$ for a grassland and intermittently forested portion of the SRS near the low-level waste burial site.

Dennehy and McMahon (1987) conducted a field study of water movement in the unsaturated zone at 4 grass-covered test trenches located at the SRP low-level waste burial site. The study consisted of monitoring actual evapotranspiration, monitoring soil water, and water movement using field techniques and computer simulations. The results of the study relevant to net infiltration were:

- $43 \mathrm{~cm}$ of infiltration neglecting runoff occurred between July 1983 and June 1984;

- precipitation on trenches infiltrated the trench cap and moved vertically into the trench backfill; and

- infiltration mainly occurred during the winter and spring.

\section{A.1.12 Summary of Infiltration into the Vadose Zone}

Past estimates of infiltration at the SRS have ranged from 22 to $45 \mathrm{~cm} / y$ ear. Using the mean of the observed and predicted infiltration studies at the SRS results in an infiltration value of $37 \mathrm{~cm} / y e a r$. This mean infiltration value of $37 \mathrm{~cm} / y e a r$ was rounded to one significant figure for the RPA; i.e., $40 \mathrm{~cm} / \mathrm{year}$ for the infiltration at the SDF.

\section{A1.13 Infiltration Through the Clay Cap}

PORFLOW-3D was used to estimate the average infiltration rate of water through the upper moisture barrier given the infiltration estimated for the vadose zone in Sect. A.1.1.2 Infiltration rate through the clay cap was deteninined by simulating a case with a yearly infiltration into the native soil overlying the vault of $40 \mathrm{~cm} / \mathrm{year}$. The gravel layer above the clay provides a zone of high conductivity to remove water from above the vaults. Clay underlying the gravel serves as an additional barrier because of its low hydraulic conductivity. The domain of the cover simulation is shown in Fig. A.1-2. The code recorded infiltration over time for several locations under the clay cap. The infiltration rate in the zone below the edge of the cap, $2 \mathrm{~cm} / \mathrm{year}$, was used as a conservative estimate of infiltration beneath the cap. Infiltration in the center of the cap may be approximately two orders of magnitude lower than this estimate based on hydraulic conductivity of clay. 


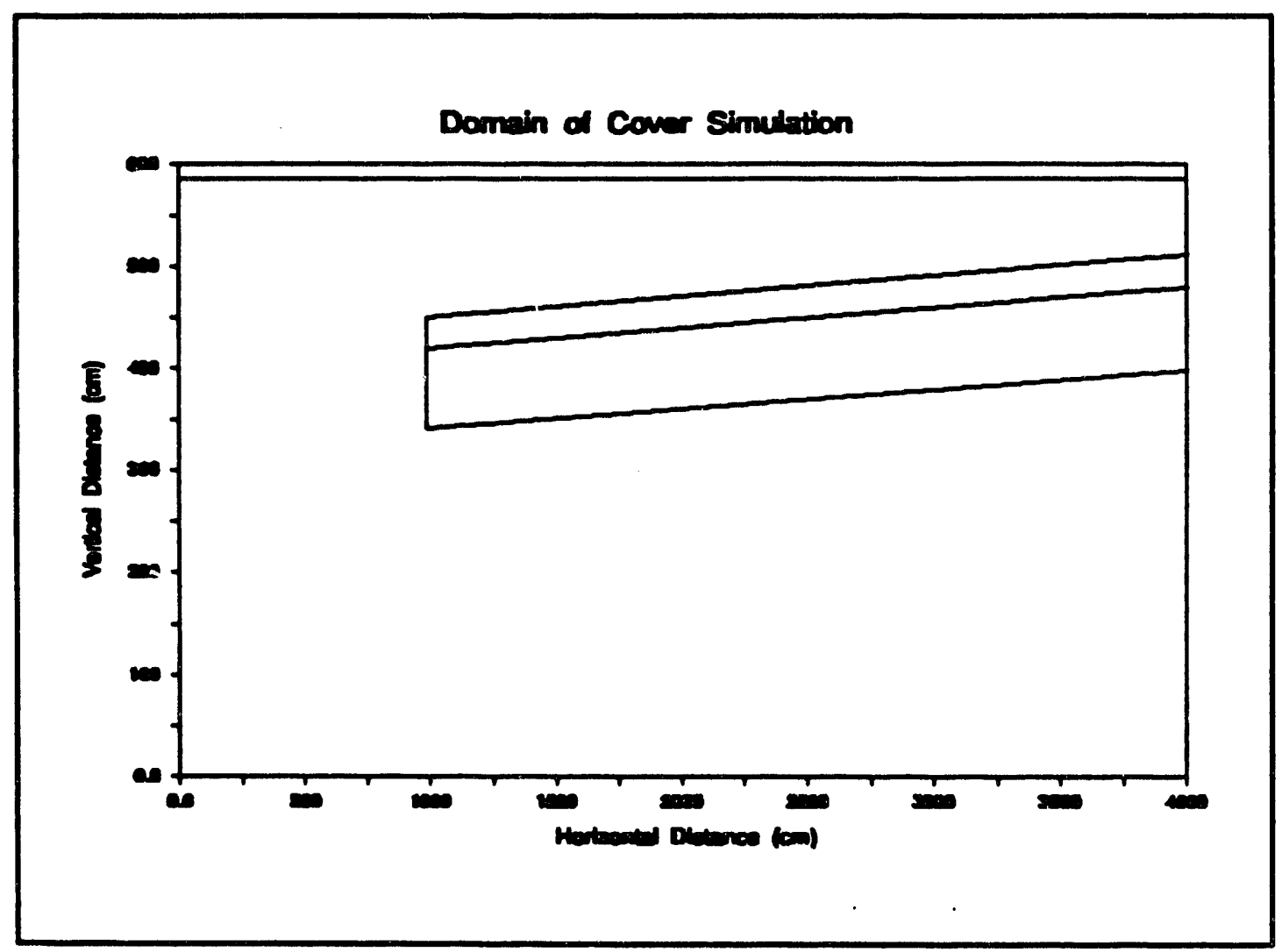

Fig. A.1-2 Domain of the upper moisture barrier simulation.

Rev. 0 


\section{A.1.2 Flow and Mass Transport Through Intact Vaults}

In this section of Appendix A, details supporting the conceptual near-field model of the intact vaults (briefly described in Sect. 3.3.1.1), and the computational analysis (briefly described in Sect. 3.4.1.1) are provided.

\section{A121 Conceptual Model for Near-Field Analysis of the Intact Vaults}

As noted in Sect. 3.3.1, the near-field environment is defined as the portion of the subsurface environment extending from the ground surface to the water table. The flow regime in the subsurface was separated into three regions for purposes of analysis. The first region is the sediments near the surface where evaporation and transpiration have a dynamic role in reversing the downward movement of water due to gravity. Below this region, but above the concrete vaults, is the region that includes the upper moisture barrier, composed of clay and an overlying gravel layer which is expected to divert much of the infiltrating water around the facility. The last region consists of the backfill sediment, soils underlying the SDF, the clay/gravel drainage layer, the concrete vault, and the saltstone waste form; this region extends down to the water table.

Assumptions specific to analysis of flow of water through the first region near the surface are discussed in Appendix A.1.1. The remainder of this section will address assumptions relevant to flow through the moisture barrier and flow and mass transport through the saltstone vaults and surrounding soil.

\section{Flow Through the Upper Moisture Barrier}

Simulating flow through the upper moisture barrier requires assumptions regarding the hydraulic characteristies of the layered clay, gravel, and backfill soil. As noted in Sect. 3.3.1.1, the conceptual model used to provide a framework for the numerical simulation of the near-field movement of water and contaminants from the Z-Area vaults relied on averaging of spatial properties for these three material types. To the extent possible, the characteristics used to represent these materials are site-specific.

Hydraulic properties of each of these porous media are assumed to be adequately described by the following hydraulic parameters: saturated hydraulic conductivity, effective porosity, and moisture characteristic curves. Moisture characteristic curves describe the nonlinear relationship between the matrix potential or pressure head, the moisture content, and the hydraulic conductivity.

Two different analytic expressions are used for describing the moisture characteristic curves. Moisture characteristic curves for backfill and native soil were described using the Stone correlation curve (Stone 1973). The equation for this curve is given as:

Rev. 0 


$$
\downarrow=P_{1}+P_{2}\left(1-S_{v}\right)+P_{3}\left(1-S_{v}\right)^{3}
$$

and

$$
K\left(S_{w}\right)=K_{s} K_{z 0}\left(\frac{S_{w}-S_{w 1}}{1-S_{w 1}}\right)
$$

where

$$
S_{v}=\frac{\theta-\theta_{x}}{\theta_{g}-\theta_{x}}
$$

The fitted Stone parameters for the backfill moisture characteristic curve were:

$$
\begin{aligned}
& P_{1}=0 \\
& P_{2}=120 \\
& P_{3}=600 \\
& K_{s_{0}}=1.0 \\
& S_{S_{i j}}=0.22 \\
& K_{d}=1.0 \times 10^{-5} \mathrm{~cm} / \mathrm{s}
\end{aligned}
$$

The van Genuchten (1978) and Mualem (1976) equations were used to describe this nonlinear relationship for material types other than backfill and native soil. The equations are given as follows:

$$
\theta(\psi)=\theta_{z}+\frac{\left(\theta_{g}-\theta_{x}\right)}{\left[1+(\alpha \psi)^{D}\right]^{-}}
$$

and

$$
K(\psi)=K_{a} \frac{\left[1-(\alpha \psi)^{\alpha-1}\left[1+(\alpha \psi)^{--}\right]\right]}{\left[1+(\alpha \psi)^{n}\right]^{\alpha / 2}}
$$

where

$\theta=$ the volumetric moisture content $\left(\mathrm{cm}^{3} / \mathrm{cm}^{3}\right)$,

$\theta,=$ the residual moisture content $\left(\mathrm{cm}^{3} / \mathrm{cm}^{3}\right)$,

$\theta_{0}=$ the effective porosity $\left(\mathrm{cm}^{3} / \mathrm{cm}^{3}\right)$,

$\downarrow=$ the suction pressure head $(\mathrm{cm})$,

$K_{c}=$ the saturated hydraulic conductivity $(\mathrm{cm} / \mathrm{s})$,

$\alpha$ and $n=$ fitting parameters, and

$m=1 \cdot 1 / \mathrm{n}$.

Rev. 0 
The \& parameter has units of inverse length, and is indicative of the air entry pressure. The $n$ parameter is dimensionless and controis the degree of nonlinearity in the moisture characteristic curve. Table 3.3-1 provides a summary of the hydraulic and van Genuchten parameters used for all the porous macerials of concern in the near-field analysis. The basis for the numbers in this table are described below.

Backfill. Backfill soils were assumed to have the same moisture characteristic curve as the native soil. Gruber's study of soil near Z-Area (Gruber 1980) was determined to be the most complete because it included analyses of hydraulic conductivity. Sample data for the soil from Gruber's study was analyzed with the RETC code (van Genuchten 1988), which used a least squares curve fit to generate the van Genuchien parameters, as well as the saturated hydraulic conductivity. This fitting can be done by using either moisture content versus hydraulic conductivity data, or pressure versus moisture content data. Analysis of the pressure versus moisture content data showed the backfill soil to be highly drainable, contrary to that axpected for a clay-sand soil as is present. Professional judgement suggested that only the $K$ versus $\theta$ data should be used to determine the moisture characteristic curve parameters. The Stone's curve was graphically fitted to the $\theta$ versus $\downarrow$ curve resulting from a fit of the van Genuchten expression to the data. The van Genuchten curve fitted from the $K$ vs $\theta$ data and the Stone's curve, are shown in Fig. A.1-3. The Stone curve does not match known behavior of soils when moisture content is low; however, this was not considered to be a problem in the simulation study because the soils at Z-Area are well described by the portion of the Stone curve, that shows a good match with the van Genuchten curve, due to the moist climate at the SRS.

Gravel. Gravel will be used in constructing the upper moisture barrier. The hydraulic properties of gravel used in this RPA were taken from an analysis by the University of Texas (INTERA 1989). Coarse sand, glacial outwash, and stony soil were studied to determine the best representation of gravel. A hydraulic conductivity of $0.5 \mathrm{~cm} / \mathrm{s}$, and porosity of 0.38 , were suggested. Data from the University of Texas report was analyzed with the RETC code to obtain van Genuchten parameters for the gravel. The results are listed in Table 3.3-1. Figure A.1-4 show data from several soils and the curve recommendation in the University of Texas report, which represents the more drainable end of the spectrum.

Clay. The clay soil used in the upper moisture barrier was assumed to be taken from the SRS and will have a bentonite mix added to it. A contracted study on Z-Area soil mixed with VOLCLAY SG-40 bentonite (Wilhite and Wolf 1986) was the source of information for the clay data. The pressure head versus moisture content data given in the report was used in the RETC code to generate the van Genuchten parameters.

Figure A.1-5 shows the sampled data and the fitted curve. The results from the RETC code are listed in Table 3.3-1. 


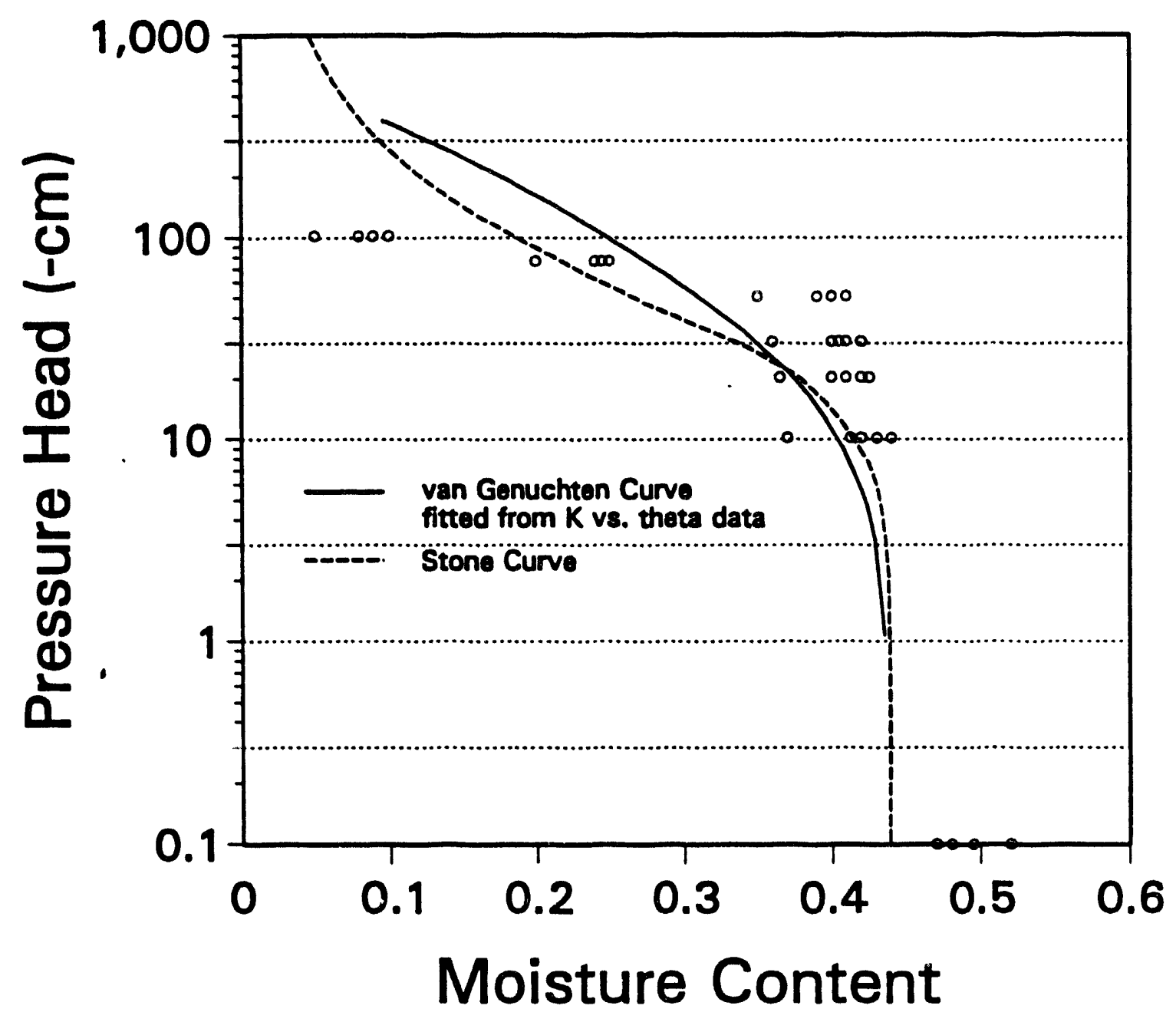

Fig. A.1-3. Molsture characteristic curves generated for backfill. Rev. 0 


\section{Gravel Moisture Characteristic Curve}

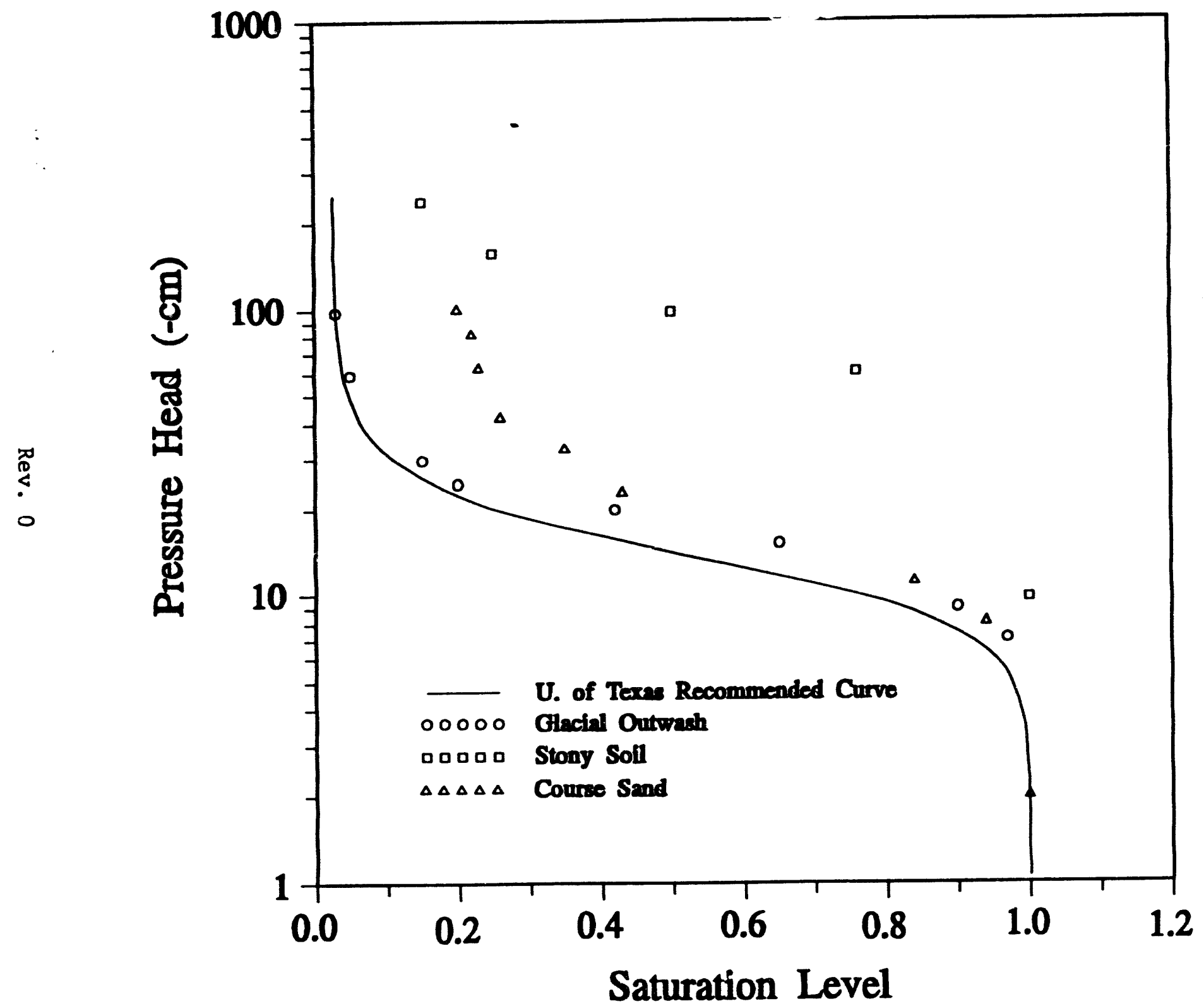

Fig. A.1-4. Moisture characteristic curves generated for grave1. 


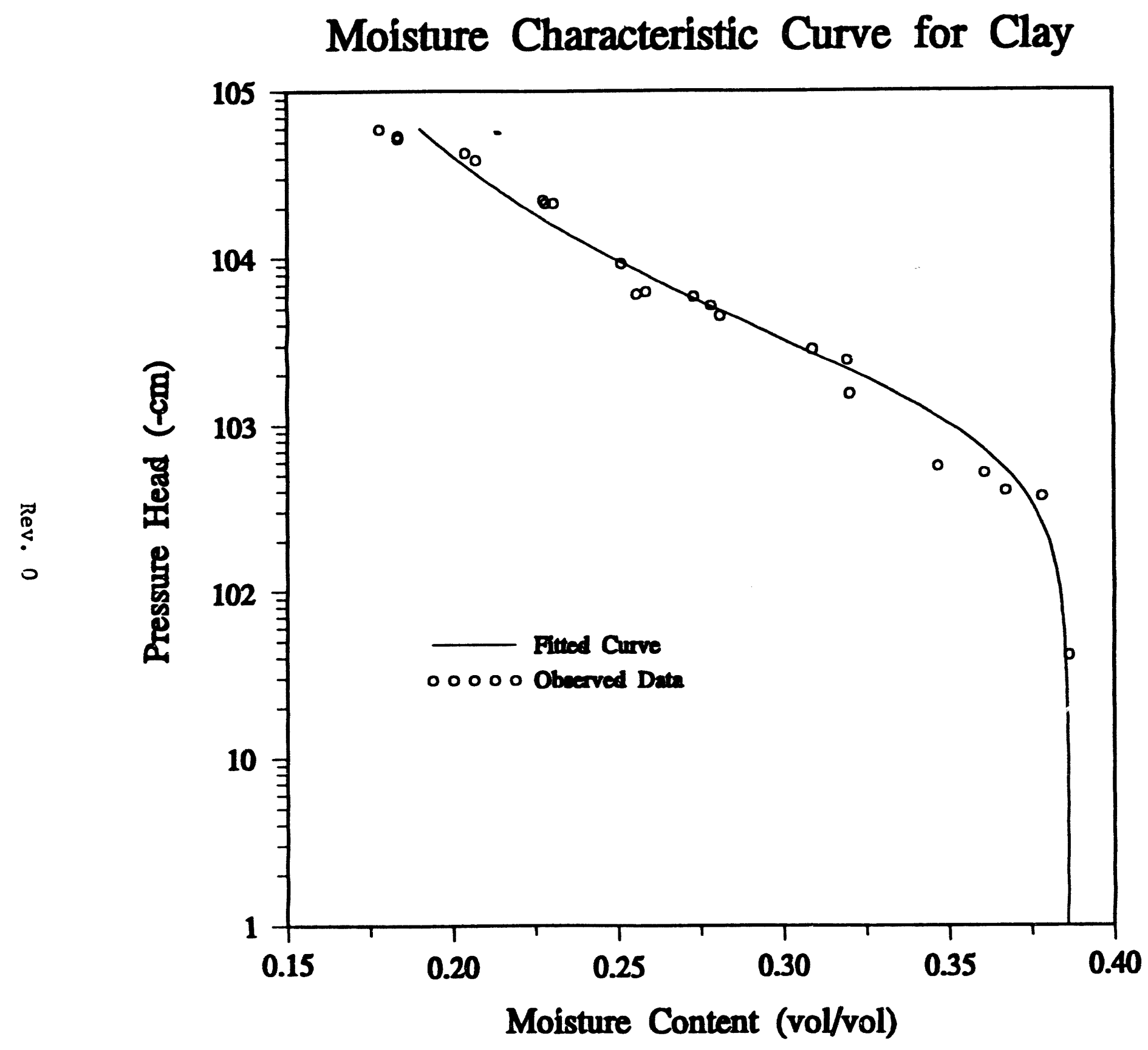

Fig. A.1-5. Moisture characteristic data for Z-Area soils mixed with VOLCLAY SG-40 bentonite. 
Flow and Mass Transport Through Saltstone, Vaults and Surrounding Soil

Like the upper moisture barrier, flow of water through the clay/gravel layer immediately on top of the vaults, the concrete vaults, saltstone monoliths, and soils surrounding the vaults is a function of the hydraulic properties of the different porous materials present. Hydraulic parameters were defined for these materials in the same manner as for the moisture barrier materials, and the assumed values are listed in Table 3.3-1. For the backfill sediments and underlying soils, the same parameter definitions as assumed for the backfill portion of the moisture barrier analysis are assumed. It is reasonable to expect that all backfill soils will originate from the Z-Area vicinity, and will therefore be similar to native soils underlying the facility. For concrete and saltstone, the basis for the hydraulic parameters is provided below.

Concrete. Specific data on the concrete to be used in the vaults was not available. It was assumed that high quality concrete will be used for the construction of the vaults. Studies have been conducted with cement which indicate that saturated hydraulic conductivity can be as low as $10^{-14} \mathrm{~cm} / \mathrm{s}$. However, a reasonable value for high grade cement of $10^{-10} \mathrm{~cm} / \mathrm{s}$ was used (Powers 1960). The van Genuchten moisture characteristic curve parameters used for concrete are listed in Table 3.3-1 (Walton 1991).

Saltstone. The moisture characteristic curve for the saltstone mix was determined using mercury porosimetry analysis (Langton 1985) on saltstone cores. The results were reported as change in volume of mercury in response to changes in injection pressure. These measurements were converted to moisture content versus pressure data. These data were then used as input into the RETC code to determine the van Genuchten parameters. The parameters based on this analysis are reported in Table 3.3-1. A saturated hydraulic conductivity of $10^{-11} \mathrm{~cm} / \mathrm{s}$ was used for saltstone based on laboratory results cited in the SDF permit application (U.S.DOE 1986).

Mass transport in the near-field model is governed by several processes: diffusion, advection, dispersion, sorption, and radioactive decay. In order to address these processes quantitatively, it was necessary to specify dispersivities and diffusion coefficients for the concrete, saltstone, clay/graveh, and backfill, liquidssolid partition coefficients (i.e., Kd's), and half-lives of radioactive decay for all saltstone constituents not screened from further consideration in Sect. 3.23 and 32.4.

Longitudinal and transverse dispersion of a contaminant plume will occur, but the degree to which this may occur at Z-Area is not known. Dispersion is largely a function of the heterogeneity of the porous material encountered. Dispersion may reduce the concentration in a plume, but may also reduce the travel time of the leading edge of a plume at a downstream location. Although saltstone and concrete intuitively seem to be relatively homogeneous, fractures in either material will increase dispersion of a plume passing through these materials. The dispersivities assumed for each material are listed in Table A.1-1. Based on conservatism relative to peak plume concentrations, the dispersivities were assigned values as low as possible that would still maintain an adequate numerical mass balance.

Rov. 0 
Table A.1-1. Longitudinal and tranovere dispercivities and effective diffusion coefficients used in the PORFLOW-3D near-field model

\begin{tabular}{|c|c|c|c|}
\hline $\begin{array}{c}\text { Porous } \\
\text { Material }\end{array}$ & $\begin{array}{c}\text { Longitudinal } \\
\text { Dispersivity } \\
(\mathrm{cm})\end{array}$ & $\begin{array}{c}\text { Transverse } \\
\text { Dispersivity } \\
(\mathrm{cm})\end{array}$ & $\begin{array}{c}\text { Eff Diffusion } \\
\text { Coefficient } \\
\left(\mathrm{cm}^{2} / \text { year) }\right.\end{array}$ \\
\hline Backfill & 10 & 2 & 160 \\
\hline Concrete & 5 & 1 & .32 \\
\hline Saltstone & 10 & 2 & .16 \\
\hline Clay & 5 & 1 & 47 \\
\hline Gravel & 10 & 2 & 45 \\
\hline
\end{tabular}

To calculate the effective diffusive flux of a constituent out of a porous material (described in Sect. 3.1.2) values of the effective diffusion coefficient (molecular diffusion coefficient corrected for tortuosity of the porous medium) are required. Tortuosity cannot be measured directly, but effective diffusion coefficients can be obtained empirically nonsorbing, non-chemically reactive compounds. This has been done for saltstone, using sodium nitrate as the conservative compound (see Sect. 24.2). For a given material, it is expected that the effective diffusivities for various radionuclides and non-radioactive compounds in a given porous medium would be similar because molecular diffusivities in water do not vary significantly. Table A.1-1 lists the effective diffusion coefficients assumed for the various materials. Effective diffusivities for clay and gravel were estimated using an approach by Lerman (1988), in which the effective diffusivity is approximated by the product of the molecular diffusivity and the square of the effective porosity. The matrix density of both clay and gravel was assumed to be $26 \mathrm{~g} / \mathrm{cm}^{3}$.

Sorption or precipitation of radionuclides within the saltstone matrix will result in lower initial pore solution concentrations. During mass transport of radionuclides partitioned into the liquid phase, sorption will serve to retard the movement of the contaminants relative to water. Sorption is often characterized by a $\mathrm{Kd}$, which assume linear, reversible sorption at equilibrium. The $\mathrm{Kd}$ 's used in this assessment are specific to the material to which they are assigned. In saltstone, the $\mathrm{Kd}$ for Tc-99 is assumed to take into account the insolubility of technetium sulfide, as well as sorption on surfaces, as discussed in Appendix D. For other contaminants in saltstone and concrete, conservative values (i.e., on the low end of the range) for concrete, from Allard (1985), were used. For soils, site-specific values were used when available. When site-specific values for soils were not available, conservative values for soil or quartz were used. Table A.1-2 lists the values of $\mathrm{Kd}$ used in the near-field model for intact saltstone, intact vaults, clay, gravel, and backfill/native soils. The source of nonzero $\mathrm{Kd}$ 's is provided in footnotes to Table A.1-2. 
Table A1-2 Kd's (mL/g) assumed in the near-field model

\begin{tabular}{|c|c|c|c|c|c|}
\hline Radionuclide & Backfill ${ }^{/ 6}$ & Clay" & Gravel & Concrete $^{c}$ & Saltstone $^{c}$ \\
\hline $\mathrm{H}-3$ & 0. & 0. & 0. & 0. & $0.2^{d}$ \\
\hline C-14 & $24^{\circ}$ & 0. & 0. & 5000. & 5000. \\
\hline Se-79 & 47. & 20. & 0. & $7 !$ & $7 !$ \\
\hline Sr-90+d & 10.8 & 10. & 0. & 10. & 10. \\
\hline Tc-99 & $0.36^{8}$ & 2.2 & 0. & 700.d & 700.d \\
\hline $\mathrm{Sn}-126+d$ & $100 . "$ & 0. & 0. & 500. & 500. \\
\hline$I-129$ & $0.6^{8}$ & 3. & 0. & 30. & 30. \\
\hline Cs-137+d & 100.8 & 100. & 0. & 2. & 2. \\
\hline Pu-238 & 100.8 & 1000. & 0. & 5000. & 5000. \\
\hline Am-241 & 150. & 1800. & 0. & 5000. & 5000. \\
\hline Nitrate & 0. & & & 0. & 0. \\
\hline
\end{tabular}

- NEA Sorption Data Base 1989.

- Values apply to native soils also.

- Allard (1985).

d MINTEQ calculations.

- McIntyre 1988.

$f$ Based on apparent diffusion coefficient for sulfate.

- Hoeffner 1984.

h Looney et al. 1987. 


\section{A122 Near-Field Flow and Transport Simulations}

As noted in Sect. 3.4.1, computational analysis of the near-field model of intact vaults relied on the PORFLOW-3D (Appendix B.5) computer code to simulate flow and mass transport. This complex code was necessary to address flow through the several adjacent materials in the unsaturated near-field environment, all of which possess different hydraulic properties. Details of the simulations of flow through the moisture barrier and flow and mass transport through the saltstone, vaults and vadose zone are provided in this section. The PORFLOW-3D code was chosen from a list of three dimensional variably saturated flow codes presently available (Appendix B.4).

Simulation of Flow Through the Upper Moisture Barrier .

The simulation of flow through the upper moisture barrier was performed using the PORFLOW-3D code to determine the effectiveness of this barrier. This engineered barrier consists of a layer of highly conductive gravel overtying clay. The surrounding material is composed of backfill soil. A 2\% slope was used in the simulation as a conservative estimate, based on preliminary closure concept information indicating the slope of the clay layer will range between 2 and 5\% (Thompson 1991).

The assumed hydraulic characteristics of each of the material types used in the simulations were discussed previously in this appendix (Sect. A.1.2.1). The simulation domain was $1000 \mathrm{~cm}$ wide and $600 \mathrm{~cm}$ high. Although the upper barrier is assumed to cover the entire facility, it was only necessary to simulate the end $500 \mathrm{~cm}$ of the upper moisture barrier in order to determine its performance. This allows consideration of flow around the end of this barrier in addition to flow through the barrier.

- The two-dimensional domain developed for the upper moisture barrier analyses is illustrated in Fig. A.1-6. This figure also shows simulation results for pressure head. It should be noted that the orientation of gravity was rotated clockwise in the simulation to account for the $2 \%$ slope of the upper moisture barrier.

Boundary conditions for this domain are as follows: The upper boundary is a constant flux boundary, representing the average annual infiltration rate into the soil, estimated in Appendix A.1.1 to be $40 \mathrm{~cm} /$ year. The lateral boundaries are assumed to be no-flow boundaries. These conditions impose an assumption that lateral flow in this region can be neglected. This is reasonable, as long as lateral diversion of water by the clay layer simulated occurs far from these boundaries within the domain. The lateral boundary conditions, thus, assume only vertical flow parallel to the boundaries. The placement of the right no-flow boundary at $500 \mathrm{~cm}$ from the edge of the upper moisture barrier was somewhat arbitrary, based on judgement that the edge effect of this barrier would be not be significant at this distance. From results shown in Fig. A.1-6, the simulated pressure field supports this judgement, the pressure field approaches an equilibrium near the right boundary, and the pressure contours indicate predominantly vertical flow. The lower boundary, is placed far enough away so as not to influence the 


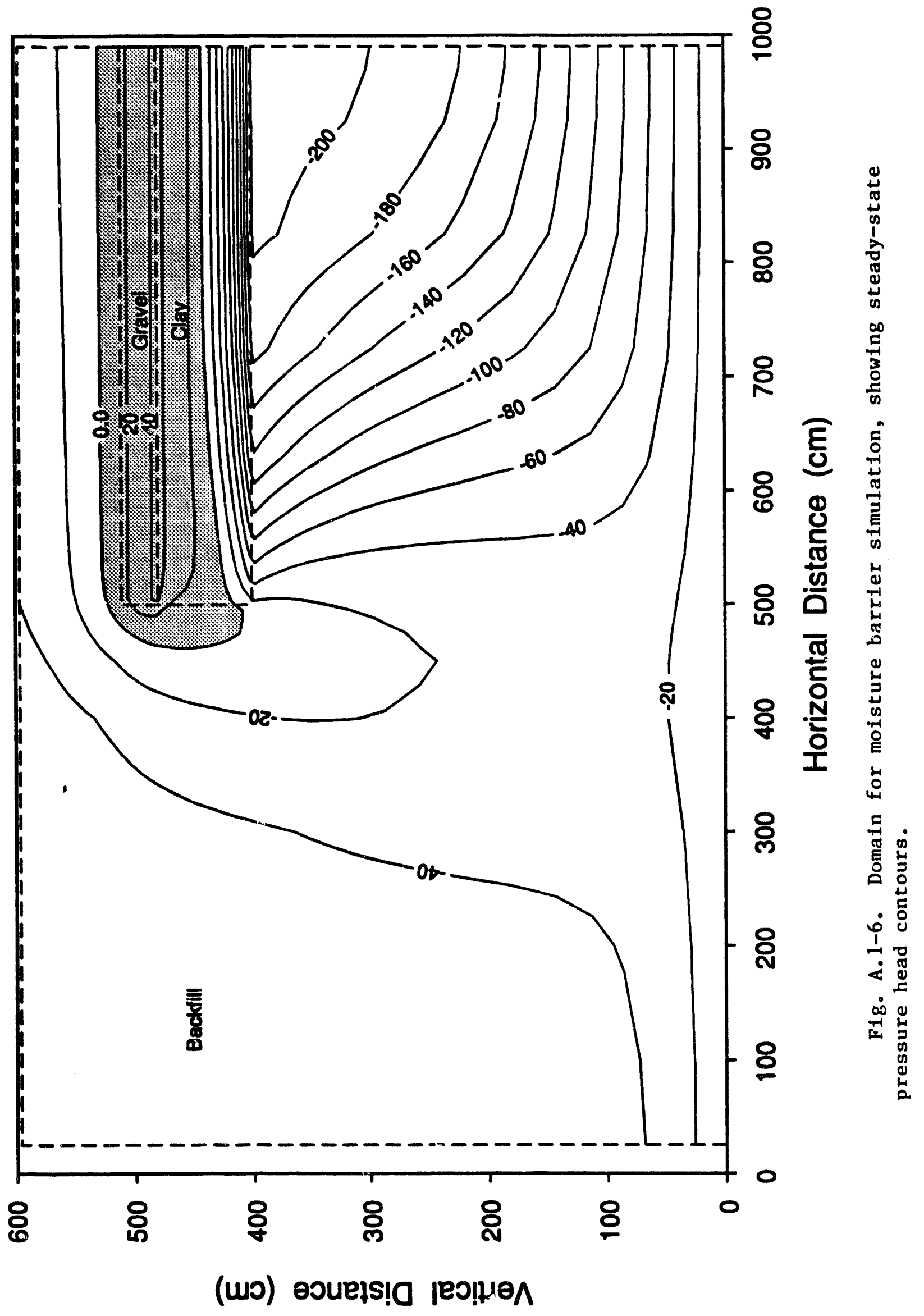

Rev: 0 
flow field near the upper moisture barrier. The lower boundary was assigned a pressure head of zero, in effect simulating the water table. A copy of the input file for the PORFLOW-3D version 24 flow simulations of the moisture barrier is provided in Appendix C2.

The simulation was carried out in several stages. Initially, the entire domain was treated as if it were all backfill to predict a uniform flow field. The clay layer was then included and this simulation was conducted in a transient mode until steady state was achieved. Finally, the gravel layer was added to the simulation domain, and a simulation was conducted in a transient mode until the pressure field (Fig. A.1-6) maintained constant values. The corresponding water saturations at steady-state are shown in Fig. A.1-7.

During these simulations, the predicted pressure field and the total water mass balance were monitored for the simulation domain. The maximum water mass balance error observed in these simulations was less than $3 \%$, which was considered adequate for the purpose of determining the effectiveness of the barrier to diverting water. Reasonable efforts to improve the mass balance failed. A close inspection of the numerical solution showed that the slight increase in water in the system originated within the gravel layer, and persisted through the clay.

The flux across two planes (two-dimensional domains assume a unit width in the third dimension, such that a plane is of unit width) within the simulation domain was monitored to determine how effective the upper moisture barrier was at diverting water. One flux plane extended from the left simulation boundary edge of the clay layer at $500 \mathrm{~cm}$ (Fig. A.1-6), representing flux through the region not covered by clay, but receiving diverted water from the gravel layer overlying the clay. The other flux plane went from the edge of the clay layer to the right simulation boundary at $1000 \mathrm{~cm}$

(Fig. A.1-6), representing the region of the domain "protected" by the clay. A comparison of the two fluxes indicated that $99.5 \%$ of the total water flux across the upper boundary was being diverted through the plane to the left of the assumed-intact clay layer.

To evaluate the flow rate through the upper moisture barrier, the vertical fluzes through a plane beneath the clay layer were plotted. The results are shown in Fig. A.1-8. The results showed that the left boundary (no-flow condition assumed) of the model domain was far enough away from this moisture barrier to support the assumption of negligible lateral flow at this boundary from the gravel drainage layer. The vertical flux adjacent to this boundary is $40 \mathrm{~cm} /$ year parallel to the boundary, as expected. The large amount of water being diverted around the barrier is represented in Fig. A.1-8 by the peak flux occurring in approximately the center of the domain. Inspection of Fig. A.1-8 also shows that an elevated infiltration rate extends past $500 \mathrm{~cm}$, into the region covered by the clay, representing infiltration around the end of the barrier into the protected region. Finally, using only $500 \mathrm{~cm}$ of the barrier was an adequate length to establish a 


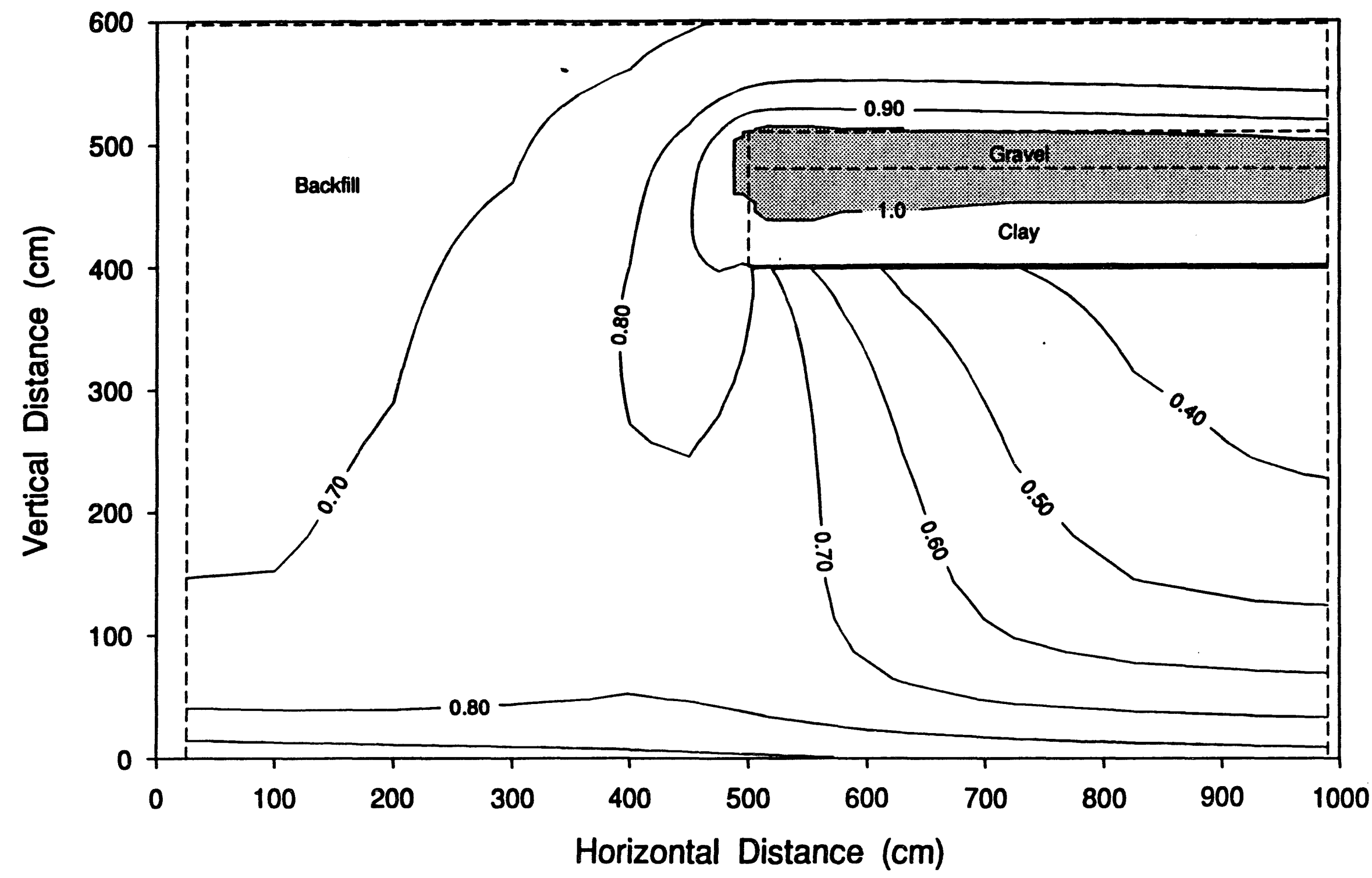

Fig. A.1-7. Upper moisture barrier steady-state saturations. 


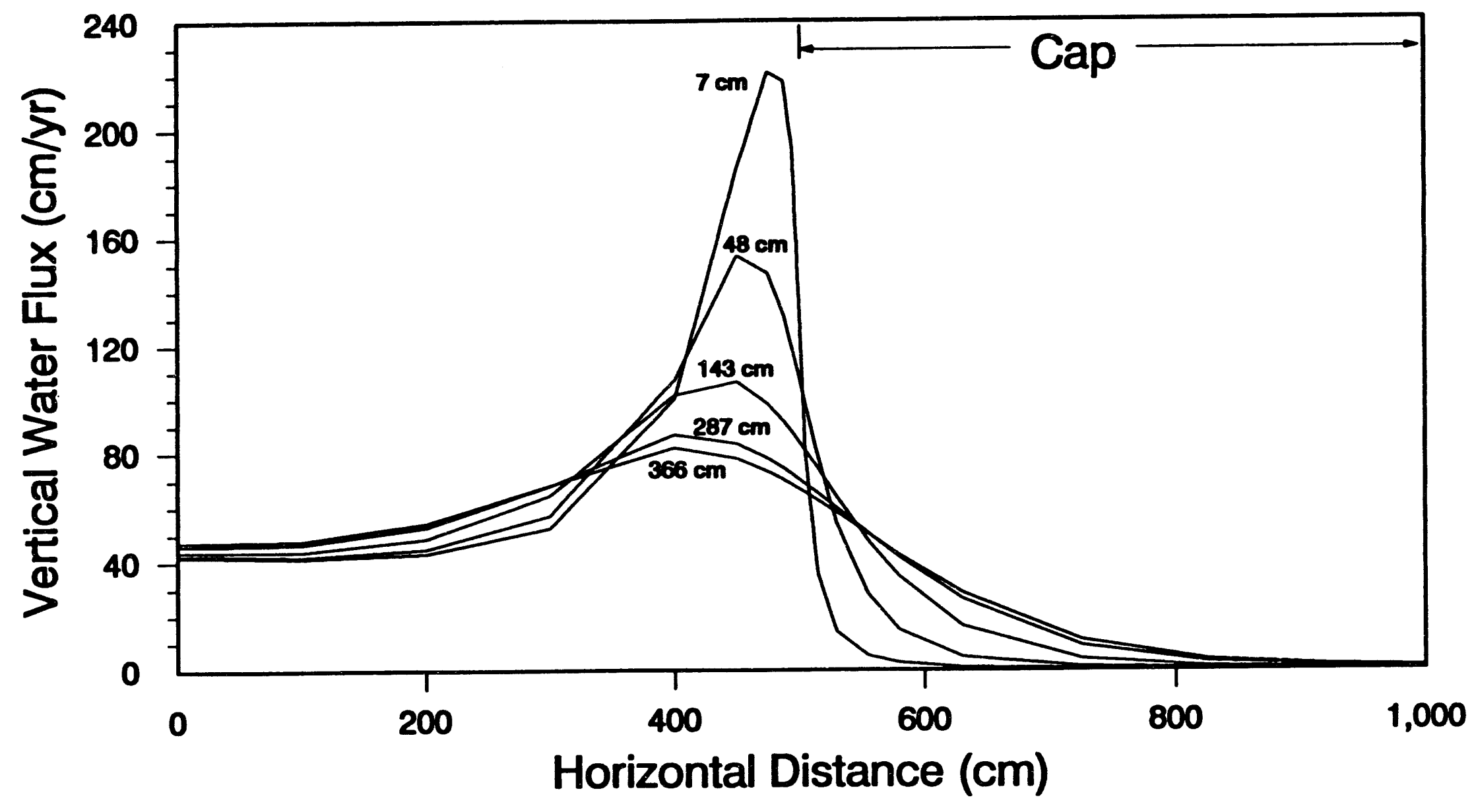

Fig. A.1-8. Vertical fluxes in domain of upper moisture barrier simulations. 
stabilizes about $300 \mathrm{~cm}$ in from the end of the barrier at a value of $0.45 \mathrm{~cm} /$ year. Because an average vertical flux value for the entire cover was desired for the simulation, a flux of $2 \mathrm{~cm} / y e a r$ was assumed, to account for the somewhat higher flux on the edges of the cover and to reflect the uncertainty of achieving a uniform barrier over such a large area that encompasses all to the vaults.

Simulation of Flow and Mass Transport Through the Vadoce Zone, Clay/Gravel Drain Sjotem, Concrete Vaults, and Saltstone

The second part of the near-field analysis consisted of simulating water flow and solute transport in the region below the upper moisture barrier, which includes the vault and saltstone waste form and the clay/gravel drain system immediately overlying the vaults. This simulation was performed using the PORFLOW-3D computer code using double precision. The physical domain in the simulation consisted of a vertical half-plane of the vaults, the overlying clay/gravel drain system, and the surrounding backfill soil (Fig. A.1-9). The simulation domain was rectangular with the vault superimposed on the left side.

Two scenarios were considered for the intact vault simulations (Sect. 3.3.1.1). In the first scenario, the upper moisture barrier was assumed to remain intact, with a $2 \mathrm{~cm} / y e a r$ infiltration rate as discussed earlier. In the second scenario, the moisture barrier was assumed to completely fail upon emplacement such that no reduction in the $40 \mathrm{~cm} / y e a r$ infiltration rate (Appendix A.1.1) was assumed. The upper boundary for water flow in each simulation was treated as a prescribed flux boundary. The assigned value to this flux is dependent on the assumption regarding whether the upper moisture barrier remained intact. Both lateral boundaries were assumed to be no-flux boundaries. The right lateral boundary, away from the vault, was located halfway between adjacent vaults, where the flow field is essentially vertical. The inner boundary is located at the midpoint of a transverse section of a vault, where the flow field is also essentially vertical. The bottom boundary is located at the water table, so that a prescribed pressure head of zero is appropriate.

The boundary conditions for mass transport (i.e, boundary conditions on concentration, rather than fluid pressure) simulations were assigned as follows. No-flux conditions were assigned at the lateral boundaries, based on assumptions of symmetry between vaults and at the midpoint within vaults. The lower boundary condition was a prescribed zero concentration, which corresponds to a condition where contaminants are swept away from the water table surface fast enough to render the concentration relatively low. This assumption serves to maximize the simulated diffusive flux through the domain, which is driven by concentration gradients, and thus is conservative. The upper boundary condition was also specified as a zero concentration boundary, which is reasonable because mass transport is expected to be predominantly downward after contaminants are out of the vaults. 


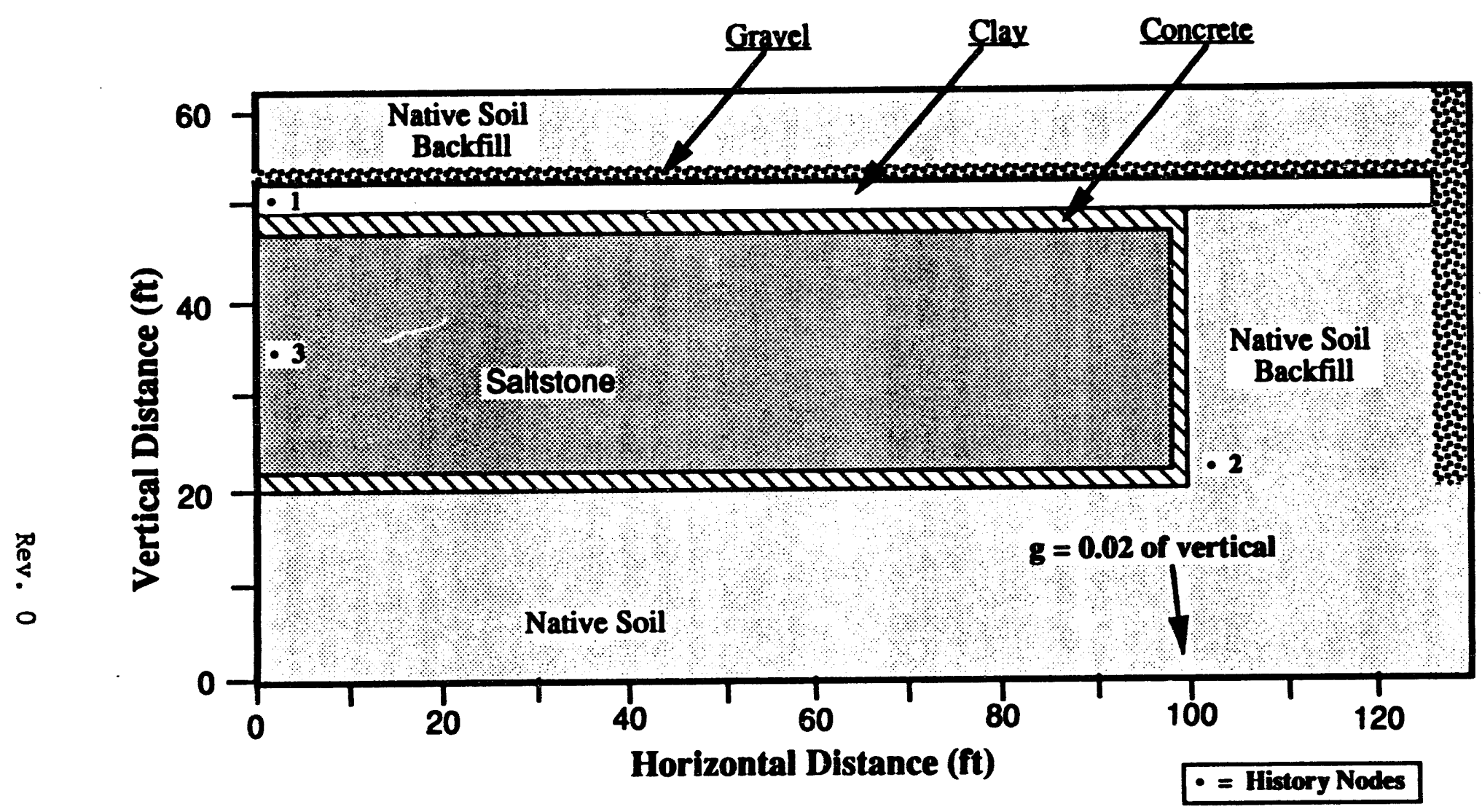

Fig. A.1-9. Vault Simulation Domain and Time History Nodes. 
The assumed hydraulic properties for backfill, concrete and saltstone waste form were previously discussed in the appendix Sect. A.1.2.1. The molecular diffusivities and Kd's used in the simulations are provided in Tables A.1-1 and A.1-2. Dispersivities assumed are also given in Table A1-1. Initial concentrations assigned to the pore fluid within the saltstone waste form are given in Table A.1-3. The initial pore solution concentrations for nitrate and Tc-99 are derived from geochemical analyses, described in Appendix D. Initial pore solution concentrations for other species were estimated in the manner described below. From Sect. 2.6 the volume of feed solution to make one liter of saltstone can be estimated from the fact that approximately 4.6 million L of feed solution fills a $30 \mathrm{~m} \times 30 \mathrm{~m}$ vault cell to $7.3 \mathrm{~m}$. It is estimated that there are $0.58 \mathrm{~L}$ of feed solution per liter of saltstone. This conversion factor was used to estimate the concentration of each nuclide in a one liter block of saltstone after 30 years of decay. Initial pore fluid concentrations for PORFLOW were determined based on the partitioning equation used in PORFLOW shown below. Distribution coefficients used in these estimates can be found in Table A.1-2

$$
C_{\text {pore }}=C_{\text {block }} /\left(\theta+p_{n} K_{d}(1-\theta)\right)
$$

where

$$
\begin{aligned}
& C_{\text {paw }}=\text { pore fluid concentration }(\mathrm{Ci} / \mathrm{L}) \\
& C_{\text {matk }}=\text { concentration of the saltstone block }(\mathrm{Ci} / \mathrm{L}), \\
& \theta \quad \text { porosity of the saltstone }(0.46) \\
& P_{m} \quad=\text { matrix density }(2.07 \mathrm{~g} / \mathrm{cc}), \text { and } \\
& \boldsymbol{K}_{d} \quad=\text { nuclide distribution coefficient }(\mathrm{cc} / \mathrm{g}) .
\end{aligned}
$$

Simulation of flow and transport in the vault region proceeded as foliows:

- A domain consisting entirely of backfill was simulated with the $40 \mathrm{~cm} / y e a r$ upper boundary in order to obtain a uniform initial pressure head and saturation distribution.

- Then, the clay/gravel drain system, vault, and waste form were superimposed on the backfill domain, and the upper boundary flux was defined as either $40 \mathrm{~cm} / \mathrm{year}$ or $2 \mathrm{~cm} / \mathrm{year}$ downward.

- The pressure and velocity within the vault and waste form were assigned zero values.

- A transient flow simulation was run for one year.

- After one year, the transport simulation was started.

- The flow simulation was continued to either 1000 or 450 years for the 2 and $40 \mathrm{~cm}$ /year upper flux boundary, respectively.

- The transport simulation was continued in either case to at least 10,000 years. Additional transport simulations were conducted for longer terms to define peak releases for certain radionuclides. (The I-129 simulation was terminated at $2.5 \times 10^{6}$ years). 
Table A.1-3. Initial pore solution concentrations of radionuclides and nitrate ued in the near-field simulations

(30 years of decas ascumed)

\begin{tabular}{|lc|}
\hline \multicolumn{1}{|c|}{ Radionuclide } & \multicolumn{1}{c|}{ Initial pore concentrations $(\mathrm{PC} / \mathrm{L})$} \\
\hline H-3 & \multicolumn{1}{c|}{$4.4 \times 10^{6}$} \\
\hline C-14 & 1.0 \\
\hline Se-79 & $3.4 \times 10^{4}$ \\
\hline Sr-90 +d & $25 \times 10^{4}$ \\
\hline Tc-99 & $7.2 \times 10^{4}$ \\
\hline Sn-126 +d & $2.0 \times 10^{2}$ \\
\hline I-129 & $5.1 \times 10^{2}$ \\
\hline Cs-137 +d & $3.2 \times 10^{6}$ \\
\hline Pu-238 & 6.0 \\
\hline Am-241 & $2.0 \times 10^{1}$ \\
\hline Nitrate & $1.6 \times 10^{5}(\mathrm{mg} / \mathrm{L})$ \\
\hline
\end{tabular}

Rov. 0 
Once steady-state Dow occurred, the flow simulation was terminated to reduce the computation time. The velocity field from the end of the flow simulation was used for the duration of the transport simulation. The steady-state flow simulation results for both the $40 \mathrm{~cm} /$ year and $2 \mathrm{~cm} /$ year scenarios are shown in Fig. A.1-10. Saturation profiles for both cases are shown in Fig. A.1-11. The flow field results for both infiltration rates were esentially identical due to the efficient removal of water by the clay/gravel drain system overlying the vaults. Therefore, only one recharge rate to the aquifer resulted from considering the two infiltration rates.

The success of the flow simulation was determined by two methods. The first was by monitoring the local convergence of the flow simulation in relation to the specified convergence criterion. The PORFLOW-3D code allows a simulation to proceed even though convergence may not be achieved at a particular time step. This was the case during the first few time stepe of the one-year flow simulation. Because of these nonconvergent time steps, initiating the transport simulation was not started until after one year of the flow simulation.

In the second method, the flow of water in the domain was monitored and compared to the flow leaving it. The volume of water passing through the second Ilux plane indicates a small, but acceptable, water balance error.

The success of the transport simulation was determined through a similar mass balance approach. For each contaminant considered, all the initial mass was contained within the vault. The mass of contaminant leaving the simulation domain via the top and bottom boundaries was integrated over the 10,000 year simulation. For these two boundaries, the amount of contaminant leaving the top boundary by diffusion was always negligible. The sum of the exiting mass and the mass remaining in the domain at the end of the simulation was compared to the initial mass. This mass balance effort focused on nitrate. A mass balance error of $<2 \%$ was computed, which was judged to be acceptable.

The results of the transport simulations were converted to fractional flux to the water table per year for the SDF, by dividing the mass release per unit volume by the original mass inventory per unit volume of radionuclide or nitrate. Another correction to the final flux results was also made, to consider release from the endwalls of the vaults that are not simulated. This was accomplished by adding one-third again the mass exiting the vault sidewall to the flux at the water table. One-third is the ratio of the surface area of the endwalls to the sidewalls. This method conservatively includes the endwall contribution because it does not take account of depletion that would occur at the corners of the vault when mass is lost out both the sidewall and the endwall, nor does it account for radioactive decay that may occur in transit to the water table, which is significant for radionuclides such as H-3. 


\section{Pressure Head (cm)}

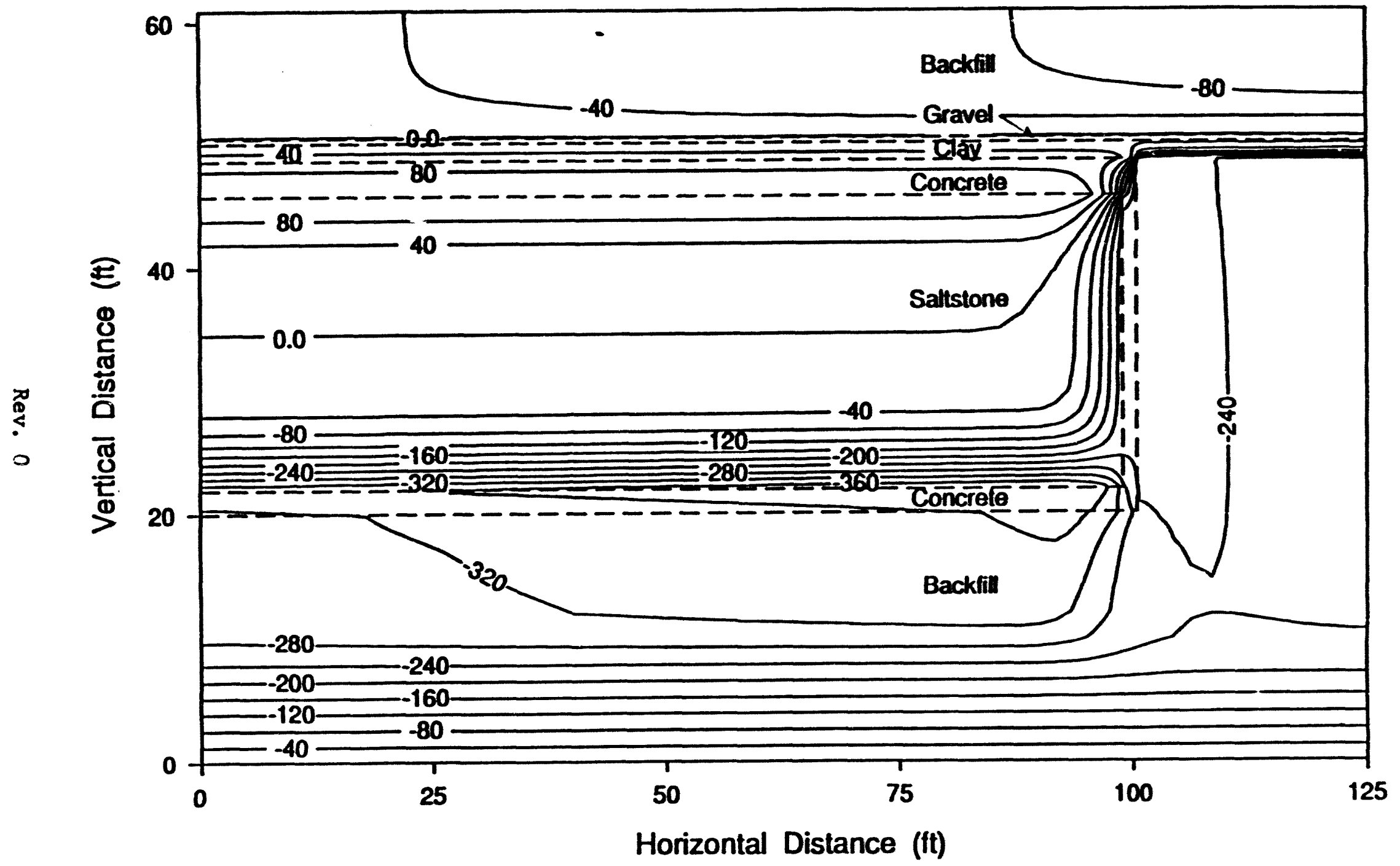

Fig. A.1-10. Steady-state pressure head contour for vault simulation at 2 or $40 \mathrm{~cm} /$ year infiltration. 


\section{Saturation}

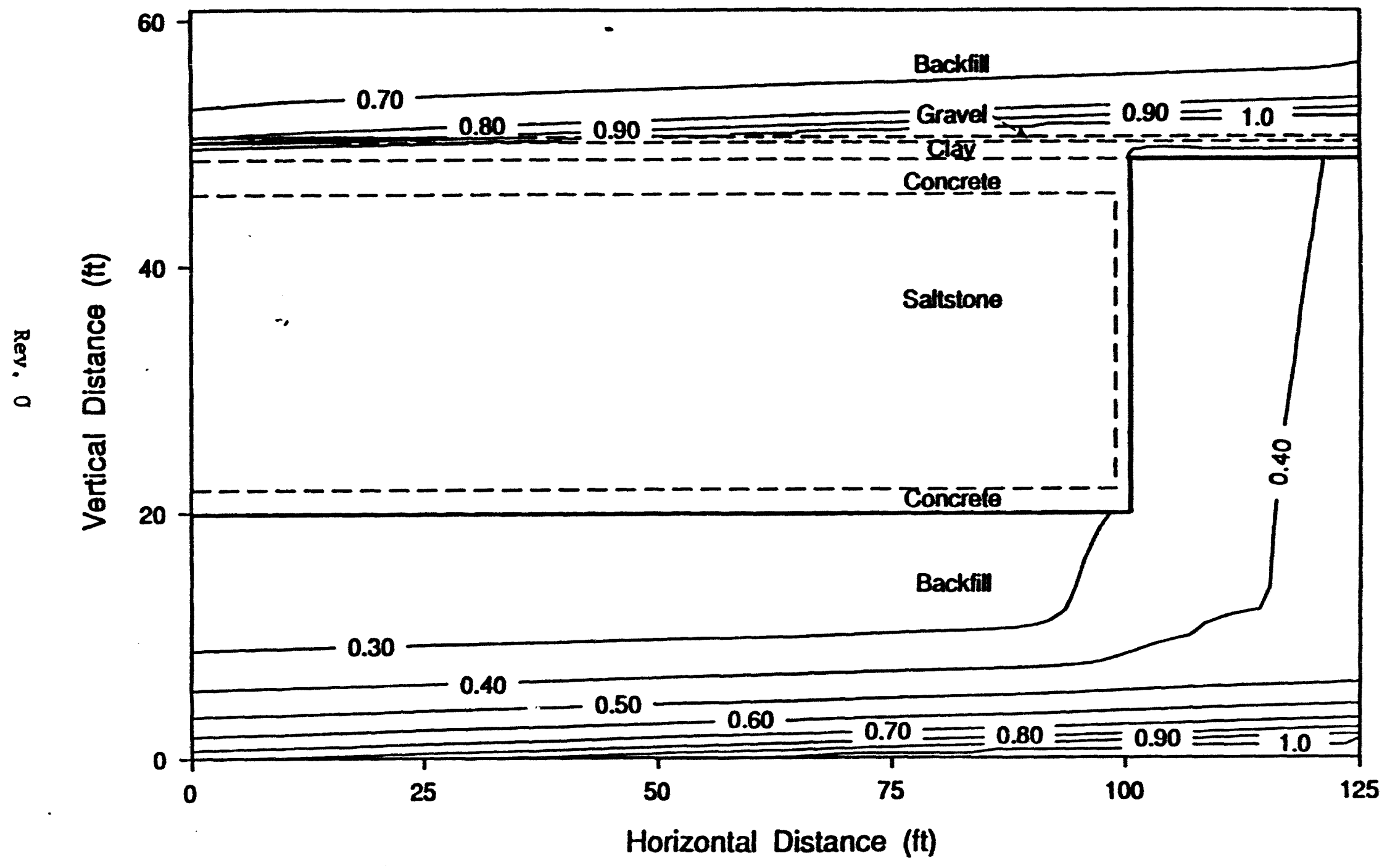

Fig. A.1-11. Steady-state saturation profile for vault simulation with 2 or $40 \mathrm{~cm} /$ year infiltration. 


\section{A1.3 Flow and Mass Transport Through Fractured Vaults}

A suite of semi-analytical and analytical models were used to model flow and transport through the degraded vault and waste form. The degradation scenario is defined in Sect. 3.1.3.5. The conceptual models and assumptions for flow and transport for the degraded scenario were briefly discuseed in Sect. 3.3.1.2 and 3.4.1.2 This section includes a description of the submodels comprising the conceptualization of the degradation scenario, the two solutions used to analyze these submodels, and discussions of the assumptions and limitations inherent in these modek.

As is the case with most analytical models, simplified representations of the system are necessary to fit within the limitations (boundary conditions, etc.) of the mathematical models. These simplified representations are intended to err on the side of conservatism in several areas. This conservatism yields modeb that overpredict llow and transport rater, providing bounding estimates of release out of the dispoeal facility. Given the number of uncertainties simply involved in defining the degraded condition of the vault (degradation rates; size, frequency, and alignment of fractures; etc.), this approach is deemed appropriate. The intent is to provide a bounding eatimate of performance to provide reasonable assurance that fractures in the saltstone will not cause the releases to exceed acceptable levels.

One positive aspect of the analytical or semi-analytical model is the ease of use when compared to a detailed numerical model. This case of use enables numerous runs to be made in less than the time it would take to make a single run with a large numerical model. Sensitivity analyzes can easily be conducted that teat combinations of inputs to identify critical parameters and ranges of critical valuea. The ability to make numerous runs also allows a wide range of conditions and asumptions to be tested that may not be possible when using a numerical code. In this regard, the "tunnel vision" that sometimes occurs when a limited number of runs are made with a numerical model can be minimized. Sensitivity analyzes are discuseed in Sect. $\mathbf{4 . 2}$

Two semi-analytical models used to address fracture flow and transport are discussed in the following sections. The first section discuses the model ured to extimate the effective llow rate through the fractured salustone $\mathrm{s}$ a function of the beight of perched water above the vault, hydraulic conductivity of the clay in the clay/gravel drainage layer above the vault, and fracture characteristica. The second section discuseas the model used to estimate the release rate from the vault given the fracture flow rate eatimated in the previous solution and initial inventory, distribution coefficients, and diffusion coefficients in the intact saltstone matrix.

Flow and transport through fractures in the saltstone is modeled as if the vault does not exist around the saltstone. Degradation calculations have shown that the majority of changes due to chemical attack and rebar corrotion will be to the vault surrounding the saltstone. Thus, for conservatism, it is assumed that the clay in the clay/gravel drainage layer is placed on top of the saltstone and the base of the saltstone is in direct

Rov. 0 
contact with the backfill with no credit for any attenuation that may occur as water passes through the vault. The simulations only address flow and transport through fractures in the saltstone.

The first step in the process outlined in Sect. 3.4.1.2 (Demonstrate presence of perched water on vault roof) was accomplished in the intact vault near-field calculations (Appendix A.1.2). The numerical simulations for the intact vault predicted $61 \mathrm{~cm}$ of perched water on the roof for infiltration rates of 2 and $40 \mathrm{~cm} / y e a r$. This value is a necessary input for the following flow and transport simulations.

\section{A13.1 Determination of Flow Rate Through Fractures in Saltatone}

One approach to determining the permeability of cracked concrete is to use an analogy of parallel plates to provide an estimate. However, for the case of underground vaults, permeability of the soil surrounding the vault can also have an impact on flow rate of the vault. This is due to the relatively large permeability of a fracture relative to the soil. Furthermore, entrance and exit head loses can also affect flow through the fractures when perched water is present above the vault. Thus, effective flow rate through fractured saltstone reflects the physical properties of the soil and characteristics of the cracks in the saltstone, while being independent of the hydraulic conductivity of the intact saltstone matrix. The approach adopted for this assessment accounts for the effects of the material around the vault and entrance and exit head losses. A brief summary of the approach is provided below with further details regarding the approach in Walton and Seitz (1991, pp. 5-4 to 5-6).

For the case of steady-state saturated flow through a crack, a simplified case of an analytical model by Yates (1988) can be applied. Figure A.1-12 is a comparison of the modeled system with the more realistic condition of the degraded vault. The backfill refers to the clay layer above the vault in this figure. The basic assumptions governing the simplified representation are: 1) steady-state saturated flow; 2) constant head at the top of the perched water and at the entrance to the crack; 3) head losees through the crack and at the crack exit are small compared to bead loses at the entrance (if the additional losses are considered, the flow rate would be slightly less); 4) symmetry boundaries apply at the center of the crack and half the distance between cracks; and 5) the cracks in different pours are open and directly aligned.

Inputs required for the modified analytical model are: 1) the distance between the cracks; 2) the crack half-width (one-half of the aperture); and 3) the depth of perched water (distance to constant head boundary). The solution provides a dimensionleas flow rate; that is, the ratio of the flow through the crack to the flow through the backfill. An estimate of the maximum flow rate (i.e, saturated flow rate) can be approximated by multiplying the result from the semianalytic model by the saturated hydraulic conductivity of the clay in the clay/gravel drainage layer (see Sect. A.1.2) above the vault (assuming a unit gradient through the backfill).

Rev. 0 


\section{More Realistic Degradation}

\section{Modeled Conditions}

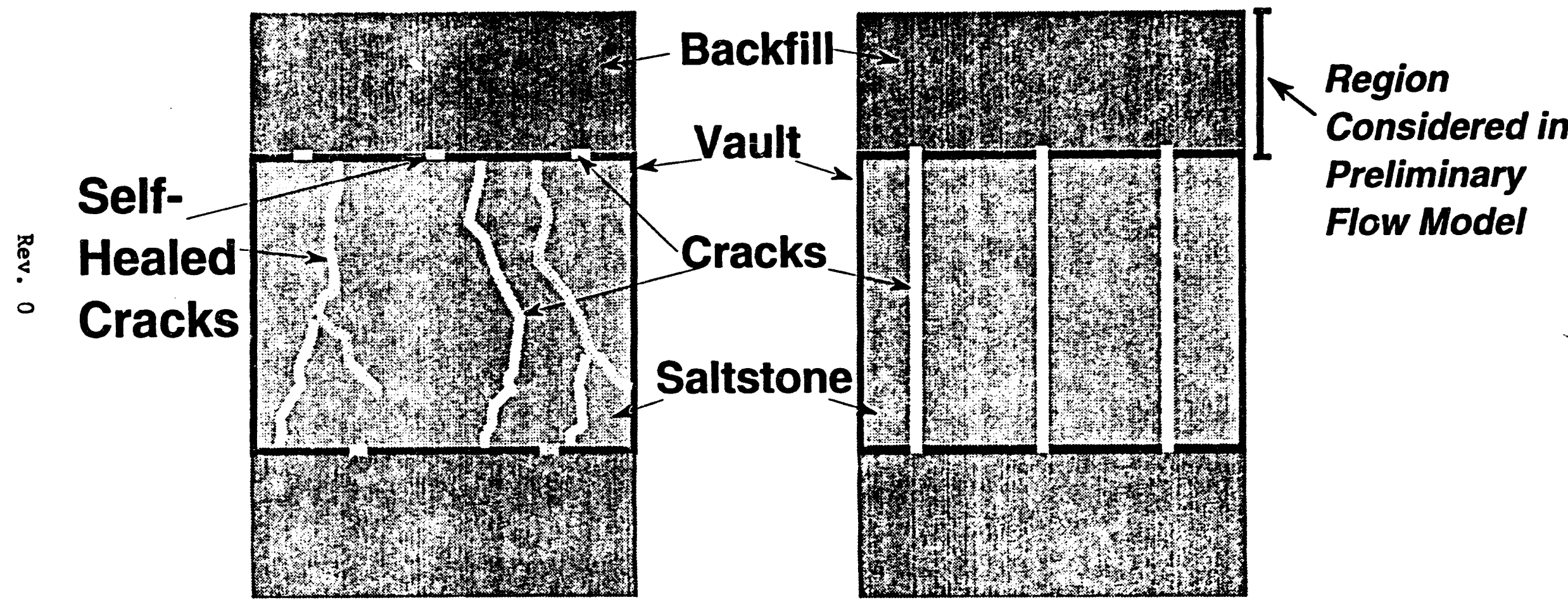

Not to Scale

Fig. A.1-12. Comparison of more realistic system and modeled representation of flow rate through backfill (clav in this case) and fractured vault. 
After normalizing variables and applying the appropriate simplifications (i.e., homogeneous soil, equally-spaced fractures) to Yate's solution, the dimensionless flow rate, $\zeta_{3}$, is calculated using

$$
\zeta_{3}=\frac{-z_{0}}{x_{0}\left[\left(\sum_{n=1}^{\infty} v_{2}\right)-z_{0}\right]}
$$

where

$$
\begin{aligned}
& z_{0}=\frac{z_{0}}{\Psi_{0}} \\
& x_{0}=\frac{X_{0}}{\Psi_{1}} \\
& V_{n}=\frac{\lambda_{1}\left(2 p_{1 j}+2 p_{1 f}^{2} p_{2 j}\right)}{\cosh \left[\tau_{j}\right] \beta j} \\
& \Psi=\text { the half-width of the crack, } \\
& z_{0}=\text { the depth of perched water, and } \\
& x_{0}=\text { balf the distance between the fracture center lines. }
\end{aligned}
$$

The coefficients for $V_{\mathbf{z}}$ are defined as follows:

$$
\begin{aligned}
\lambda_{f} & =\frac{2}{z_{0} \tau_{f}^{2}} \\
p_{1 f} & =\tanh \left[\tau_{f}\left(x_{0}-1\right)\right] \\
p_{2 y} & =\tanh \left[\tau_{f}\right] \\
j & =2 n-1 \\
\tau_{f} & =\frac{\pi j}{2 z_{0}} \\
\beta_{f} & =2 p_{1 f}\left(1+p_{2 f}^{2}\right)+2 p_{2 f}\left(1+p_{1 f}^{2}\right) .
\end{aligned}
$$

Flow through fractured concrete vaults and saltstone was predicted based on the parameter values listed in Table A.1-4. The predicted velocity in each fracture (assuming all flow occurs through the fracture) based on the values in Table A.1-4 was $780 \mathrm{~cm} / \mathrm{year}$ (darcy velocity divided by the ratio of crack width to crack spacing). Contributions from the intact matrix are considered separately in Appendix A.1.2. This value is subsequently used as an input to the transport simulations. Test cases comparing flow results from the analytical solution with results from the PORFLO-2D (Kline et al. 1983) finite difference code have demonstrated excellent agreement (Walton and Seitz 1991). 
Table A.1-4. Input values secumed for flow calculations

\begin{tabular}{lc}
\hline Parameter & Assumed Value \\
Crack width & $0.005 \mathrm{~cm}^{\circ}$ \\
Crack spacing & $300 \mathrm{~cm}^{\circ}$ \\
Depth of perched & \\
Water on roof & $61 \mathrm{~cm}^{\circ}$ \\
Saturated hydraulic & \\
Conductivity of clay & $0.24 \mathrm{~cm} /$ year \\
\hline
\end{tabular}

- Sect. 3.1.3.5

- Appendix A.1.2 
Note that the assumption of saturated flow is conservative for predicting contaminant flux because flow rates through the fracture would be largest when it is saturated. The predicted build-up of perched water on intact vaults, based on PORFLOW-3D simulations, suggests saturated flow is likely to occur. However, neglecting the vault around the saltstone and the assumption of aligned fractures in the different layers of saltstone is likely to result in inflated flow rates. Reduced flow would be expected in the case where fractures are not aligned. Flow rates will also be reduced if cracks in lower pours of saltstone are filled by a subsequent pour. Although flow rates are the greatest source of uncertainty in these degraded vault calculations, it is assumed that neglecting the vault and considering open, aligned fractures in the saltstone represents an upper bound of the flow rate through fractures.

\section{A133 Determination of Release Rate from Vault}

A number of semi-analytical models have been developed for transport through fractured porous media. Of available methods, the solution of Rasmuson and Neretnieks (1981) is perhaps most appropriate for application to release rates from massive concrete waste forms. This solution allows a decaying source term, which is required for leaching, and the soiution is given in terms of dimensionless parameters, which can be used to interpret and generalize the results from the analysis. Note that their published model estimates transport from a decaying source of radionuclides into a fractured porous medium and is the complement of the desired solution for release from a fractured concrete monolith, where contaminants are leached from (rather than into) a fractured porous medium.

The saltstone is envisioned as a large fractured monolith, with blocks of intact concrete separated by fractures. Advection dominates mass transport in the fractures, while diffusion controls mass transport laterally from the porous matrix to the fractures. Figure A.1-13 illustrates this conceptual model in a schematic form. Partitioning of compounds between solid and liquid phases is also considered. The velocity through the saltstone fractures is determined using the methods described in Sect. A.1.3.2. Since the crack is significantly more permeable than the adjacent saltstone matrix, all flow is assumed to occur through the fractures. Thus, this solution is alio independent of the hydraulic conductivity of the intact saltstone matrix. Contributions from the intact saltstone are considered in the intact modeling (Appendix A.12).

This assessment is limited to the case of no dispersion in the fractures in the concrete. This is a conservative case (in terms of concentration) for radionuclide release rates from concrete waste forms. In reality, fractures are likely to be in the form of a tortuous network, with a significant, bit unknown, amount of dispersion resulting. Thus, conservative assumptions are made to account for the uncertainty in accurately representing a fractured vault. 


\section{No Flow/Transport Boundary} $\downarrow$
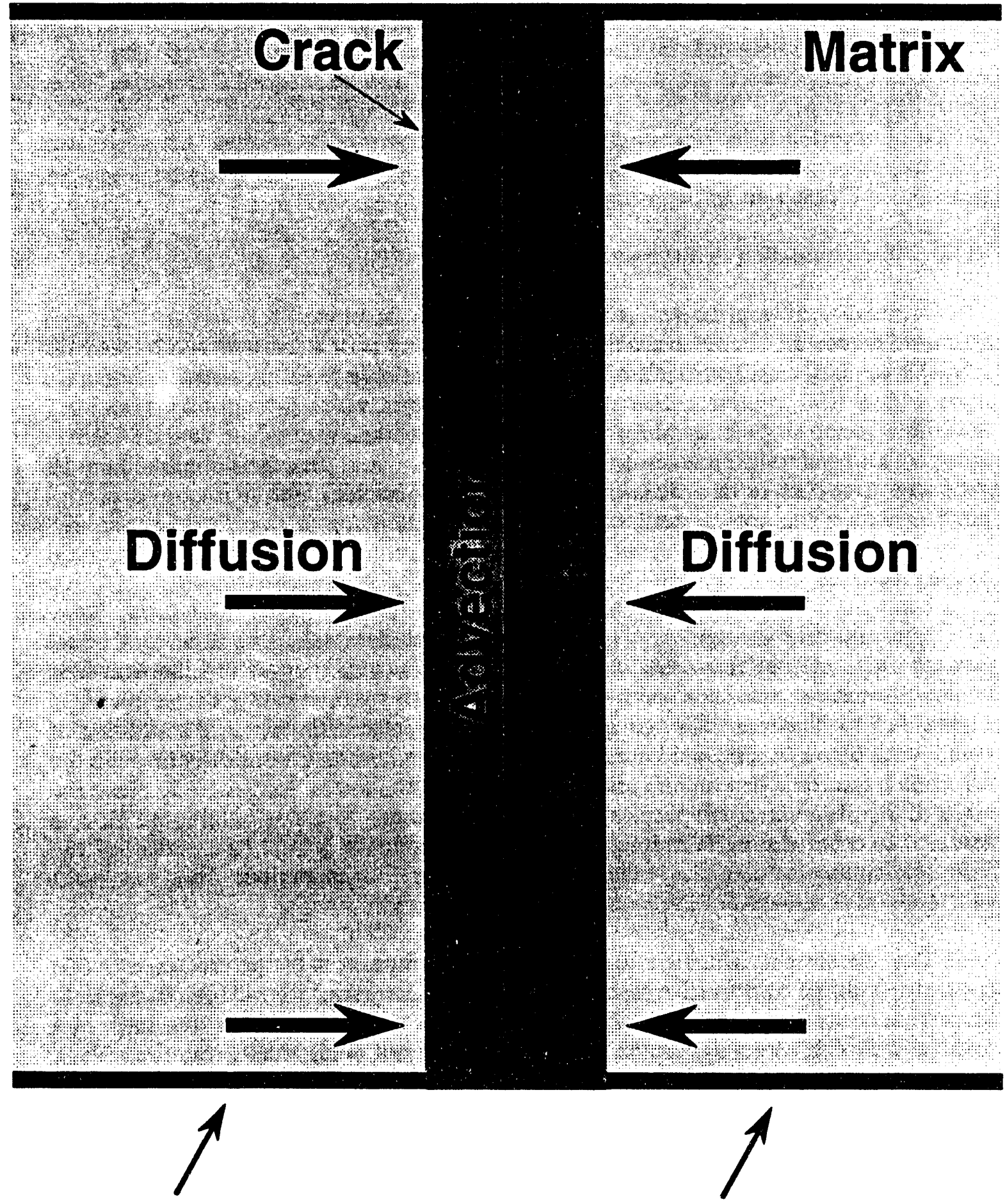

\section{No Flow/Transport Boundary} vault.

Fig. A.1-13. Schematic of conceptual model of release from fractured

$$
\text { Rev. } 0
$$


The analytical solution used for this ascessment is, with slight modification, (i.e., by ignoring dispersion) from Rasmuson and Neretnieks (1981).

$$
\begin{aligned}
& H_{1}(\lambda)=\lambda\left(\frac{(\sinh 2 \lambda+\sin 2 \lambda)}{\cosh 2 \lambda-\cos 2 \lambda}\right)-1 \\
& H_{2}(\lambda)=\lambda\left(\frac{\sinh 2 \lambda+\sin 2 \lambda)}{\cosh 2 \lambda-\cos 2 \lambda}\right)
\end{aligned}
$$

If $\zeta>0$ then,

$$
\begin{aligned}
\frac{\alpha C_{E}}{C_{t_{0}}} & =(1-Y)[\exp (-\beta)] \\
Y & =\frac{1}{2}+\frac{2}{\pi} \int_{0}^{\infty} \exp \left(-8 H_{1}\right) \sin \left(\zeta \lambda^{2}-8 H_{2}\right) \frac{d \lambda}{\lambda}
\end{aligned}
$$

If $\zeta<0$ then,

$$
\frac{a C_{t}}{C_{t_{0}}}=\exp (-\beta)
$$

where the solution depends upon these dimensionless variables that follow:

$$
\begin{array}{ll}
\zeta=\left(2 D_{a} \theta\right) / r_{\bullet}^{2} & =\text { dimensionless contact time, } \\
\alpha C_{d} / C_{b_{0}} & =\text { dimensionless concentration, } \\
\beta=\lambda_{d} t & =\text { dimensionless radioactive decay, and } \\
\delta=(\gamma z) /\left(m U_{j}\right) & =\text { bed length parameter. }
\end{array}
$$

The above variables are derived in turn from these variables

$$
\begin{aligned}
& \theta=t-z / U_{b} \\
& C_{t}=\text { concentration in fractures, } \\
& \alpha=\text { volumetric distribution coefficient (moisture content * retardation factor), } \\
& \lambda_{d}=\text { decay rate }=\ln 2 / t^{1 / 2} \\
& r_{0}=\text { effective radius of spherical blocks }(=0.5 \mathrm{~S} \text { for cubic blocks and } 1.5 \mathrm{~S} \text { for } \\
& \text { slabs), } \\
& S=\text { fracture spacing, } \\
& U_{t}=\text { velocity in fractures, } \\
& D_{0}=\text { apparent diffusion coefficient, } \\
& Z=\text { thickness of vault, }
\end{aligned}
$$




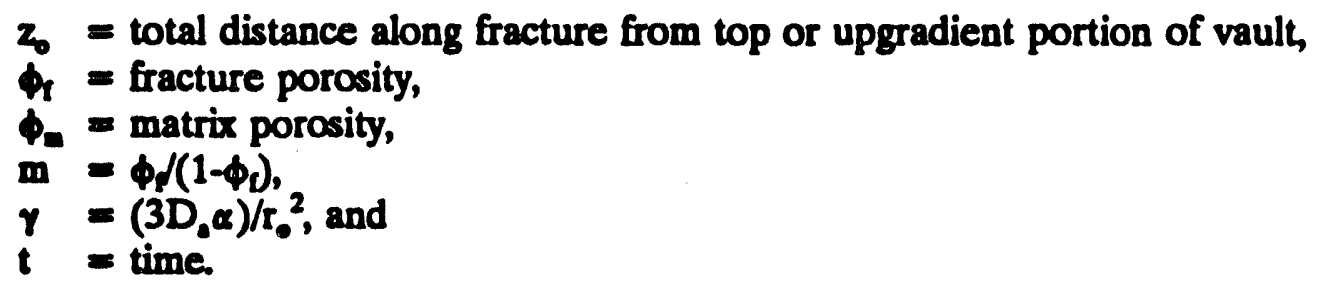

Values for the independent variables are listed in Table A.1-5. The velocity in the fracture, $U_{b}$ was predicted using the approach discussed in Appendix A1.3.2. The crack spacing, $S$, is discussed in Sect. 3.1.3.5. The apparent diffusion coefficient, $D_{a}$, is simply the effective diffusion coefficient from Sect. $24\left(5 \times 10^{-9} \mathrm{~cm}^{2} / \mathrm{s}\right)$ divided by the radionuclide-specific retardation coefficient for saltstone. The porosity values for the fracture and saltstone, $\phi_{l}$ and $\phi_{m}$, assume an open crack and the porosity of saltstone specified in Sect. 24.

The analytical solution was derived for the case of a semi-infinite medium, whereas, the application of concern is for a concrete vault of finite dimensions. If dispersion is ignored, this is not a limitation. Ignoring dispersion is required because of the lack of information concerning dispersion in cracks. Because dispersion in cracks is likely due to variation in aperture, sensitivity analyses addressing changes in crack width can be used to help account for this phenomenon (Sect. 4.2).

The fracture flow solution provides concentrations as a function of time in the fracture. These concentrations, in conjunction with the Darcy velocities predicted, are then used to calculate flux from the fractures of a degraded vault. The total flux of a degraded vault must also consider the flux from the intact portions between fractures. This, was accomplished by adding the releases predicted from the intact modeling (Appendix A.1.2) to the releases predicted from this analysis.

\section{A2 GROUNDWATER FLOW AND MASS TRANSPORT MODEL AND SIMULATIONS}

This section of Appendix A provides details of the conceptual model adopted for simulating flow and mass transport through the saturated hydrologic zones beneath the Z-Area SDF (Sect. A.2.1), and details related to simulation of the model using the PORFLOW-3D computer code (Sect. A.2.2).

\section{A21 Conceptual Saturated Flow and Transport Model}

Based on the piezometric data at Z-Area (Sect. 21.7), it is apparent that the groundwater flow field is highly variable within and among the hydrologic units in the vicinity of Z-Area. A three-dimensional representation of the groundwater flow system was chosen to allow the divergent lateral tlow to be simulated (Fig. A.2-1). 
Table A.1-5. Values of variables ueed in determination of release rate from vault

\begin{tabular}{|c|c|c|}
\hline Parameter & Value Used & Units \\
\hline$U_{1}$ & 780 & $\mathrm{~cm} /$ year \\
\hline$S$ & 300 & $\mathrm{~cm}$ \\
\hline$D_{\mathbf{l}}$ & $D_{d} / R d$ & $\mathrm{~cm}^{2} / \mathrm{s}$ \\
\hline$\phi_{1}$ & 1.0 & \\
\hline$\phi_{\mathbf{R}}$ & 0.46 & \\
\hline
\end{tabular}

- $D_{c}=$ Effective diffusion coefficient (see Sect. 2.4 and A.1.2.1). 


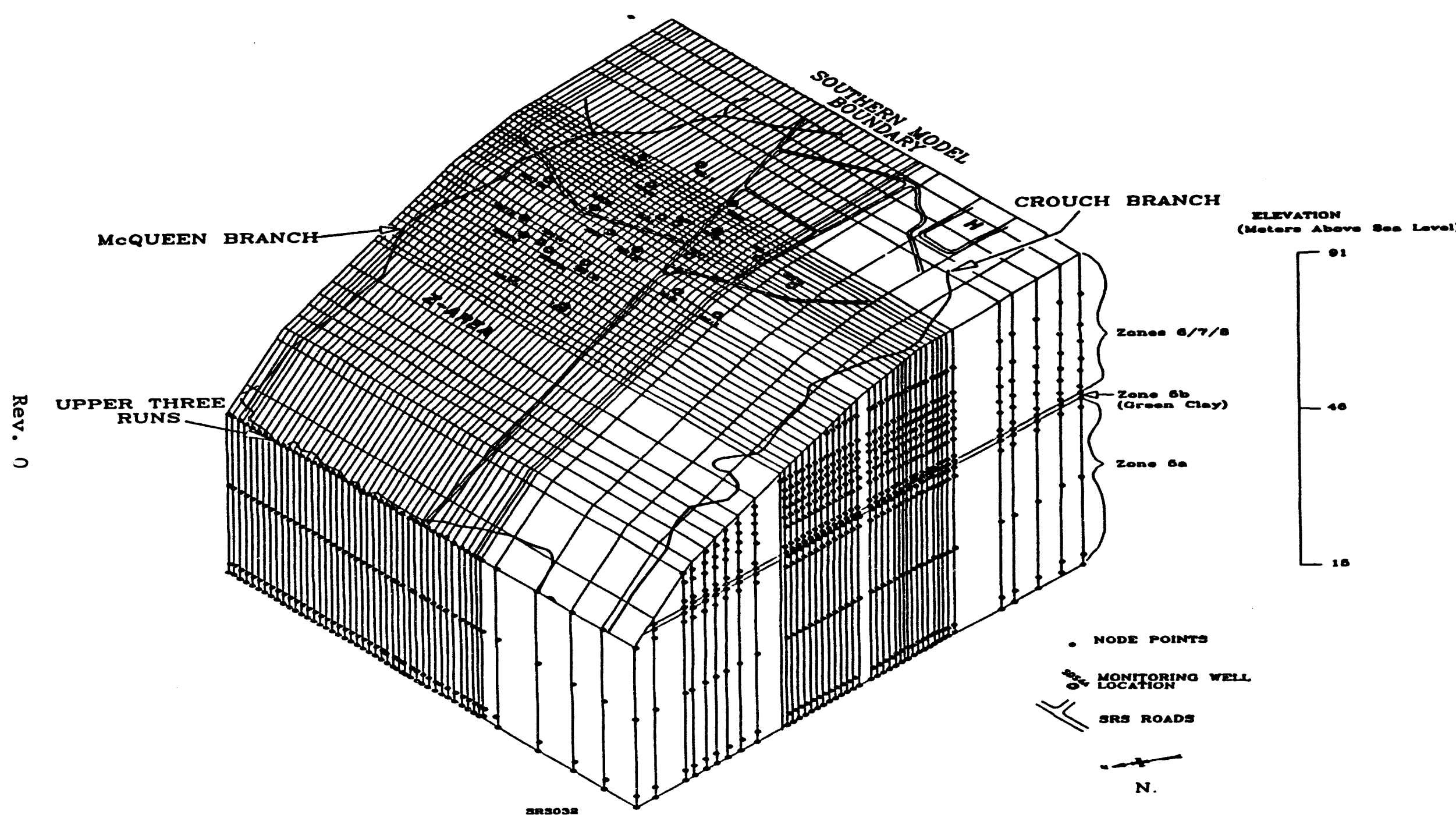

Fig. A.2-1. Model domain for PORFLOW-3D simulations of groundwater in Z-Area vicinity. 
Development of the conceptual model for saturated flow relied on data obtained in the Z-Area wells, as well as available regional data. The Z-Area wells (SDS series wells), shown in Fig. 2.2-2, provided site-specific information on the lithology and hydrologic properties of the subsurface units. Lithologic cross-sections (Sect. 222) developed from the SDS series wells were used to identify hydrologic units. Single well hydraulic test data and pump teat data were used to group units according to similar hydrologic characteristics. Regional hydrogeologic data provided information on potentiometric surfaces, from which hydraulic gradients were estimated. Regional topographic maps were used to eatimati nrmsure beads and gradients in the nearby streams.

In Sect A.21.1, the boundaries selected for the model domain are defined and the basis for these boundaries are justified. Section A.21.2 identifies the three hydrologic units assumed. Characteristics of these units that affect flow are described in Sect. A.21.3. Properties that affect mass transport are described.in Sect. A.2.1.4.

\section{A21.1 Model Boundaries}

Before a model of the saturated zone beneath the SDF was conceptualized, the area of potential concern was defined. This was done by: 1) evaluating hydrologic data available for the SRS, particularly for Z-Area (Sect. 2.1.5, 2.22 and Appendix E), to identify the likely areas of potential contamination and 2) to further limit these boundaries by considering the exposure scenarios of concern, which are outlined in Sect. 3.23 and 3.24 in this report. The vertical extent of the model is described first according to the lower and upper boundaries of the model domain. The areal extent of the model and its boundaries are then described.

\section{Vertical Extent of Model}

The model boundaries for the vertical extent of the Z-Area conceptual groundwater model domain are described in terms of the hydrological units underlying the SDF, which were identified in Sect. 21.7. According to the regional geological and hydrological data, Zone 5 a (the Congaree Formation) is the lowermost hydrostratigraphic unit which could potentially be affected by the planned facility. The lower boundary of the domain (i.e., no flow boundary) is assumed to be the contact between Zone 5a and Zone 4, the Williamsburg Rehms Formatir (Fig. 21-4). There is a considerable thickness of the low-permeability geologic constituents of Zone 4

(Sect. 2.1.4.2) separating the two units. In addition, Christiansen and Gordon (1983) indicated that the lower sand aquifer (Zone 3a) has a higher piezometric head than the overlying Zone 5a, thus forming an effective barrier to downward flow from Zone 5a.

The upper boundary limit in the vertical extent of the model domain is defined by the water table, assumed to be a constant flux boundary defined by the average annual recharge. The historical high water level is considered to be about $7.7 \mathrm{~m}$ below the saltstone vault which is in closest proximity to the water table, as indicated by Thompson 
(1991). The upper boundary of the vertical domain occurs in Zone 7 and 8, in the Dry Branch Formation (Zone 7a) near the creeks and in the Tobacco Road Sand (Zone 7c) or "upland" unit (Zope 8) away from the creeke.

\section{Interal extent of the model}

The upper two bydrologic units included in the model (Zone 7/8 and Zone 6) contain the water table, and are partially drained by the three creels surrounding Z-Area. Groundwater in these upper units diecharges into the creels around Z-Area and through the green clay into the undertying Zone 5a (Fig A2-1). The lowermost unit, Zone 5a, is partially diseceted only by Upper Three Runs Creek.

The model boundaries for the horizontal extent of all bydrologic units are assumed to lie just outside the ereebs on all but the southern model boundary (Fig. A.2-1). This assumption allows simulation of the effect of the creebs on groundwater flow. Upper Three Runs Creek incises all of these units and stream gaging surveys indicate significant groundwater discharge from all units to Upper Three Runs Creek. Flow rates in McQueen and Crouch Branches inciverse from their upper reaches towards Upper Three Runs, suggesting significant groundwater discharge from the water-table units which they incise.

The southern model boundary begins at the upper reach of Crouch Branch and runs toward the upper reach of McQueen Branch (Fig. A2-1). The southern boundary is defined along the drainage divide. Measured potentiometric surfaces for the region (Fig. 21-5, 21-6, 21-7, and 21-9) indicate that flow is away from this divide and toward the creeks.

Before conducting simulation, it is not possible to determine whether contaminated groundwater from Z-Area is expected beyond the lateral boundaries defined above. The presence of the creeks serve to limit the lateral extent of flow, especially those creeles that completely incise a hydrologic unit. The upper water-table unit is completely incised by Upper Three Runs Creek, (Appendix E) and partially by McQueen and Crouch Branches. Zone $5 a$ is partially incised by only Upper Three Runs Creek. The streams are expected to intercept most of a contaminant plume, but simulations were required to support this belief. Results of simulations showed that the streams are efficient sints for the groundwater flow under Z-Area.

To strengthen the basis for ignoring the potential for transport of contaminants in groundwater beyond the lateral boundaries defined, other considerations were used. As noted in Sect. 323.3, groundwater protection requirements are much more restrictive than other performance objectives for off-site individuals; satisfying these requirements will ensure compliance with other objectives for these receptors. In light of this result, Dow of contaminants beyond the defined lateral boundaries can be neglected in this assessment because concentrations outside of these boundaries cannot reasonably exceed 
those inside the boundaries at the compliance point (i.e., at $100 \mathrm{~m}$ from the SDF boundary in the direction of groundwater blow).

\section{A.212 Hydrobogic Units}

Three simplified hydrologic units (Fig. 21-4) are included in the groundwater conceptual model: Zones 6, 7, and 8 make up the upper $20 n e$ containing the water table aquifer, Zone 5b (the Green Clay) is a semi-confining zone between the water table aquifer and the underlying aquifer, and Zone $5 \mathrm{~b}$ (the Congaree Formation). These three units were identified based on similar lithology and hydrologic characteristica. Although data from Z-Area wells indicate that clay lenses are present in the upper unit (comprised of Zones 6, 7, and 8), the data are insufficient to map clay lenses throughout the model domain, or to distinguish the zones within the upper unit bydrologically. The three units are characterized by spatially-averaged hydrologic parameters, which are obtained in pump tests. Anisotropy, which is likely to exist as a result of lithologic beterogeneity, is assumed for each unit by aseigning vertical hydraulic conductivities that are less than horizontal conductivities. Hydrologic characturistics of the zones making up these conceptual units are described in detail in Appendix E.

\section{A.213 Hydrogeologic Propertice}

The hydrogeologic properties chosen to represent the three simplified hydrologic units in the groundwater model are based on previous field, laboratory, and modeling studies at SRS.

The existing horizontal hydraulic conductivity data, listed in Table E2-1 for all hydrologic units at Z-Area, indicate horizontal conductivities ranging over several orders of magnitude for the two aquifer units simulated in this RPA. The range, as well as the value used in simulations, are listed in Table A.2-1. Values used in simulations were chosen from the range of measured values, when available, based on the calibration procedure described in Sect. 3.4.2. The horizontal hydraulic conductivity of Zone Sb, the Green Clay unit, has not been measured. Vertical bydraulic conductivities are not available for Zones $6 / 7 / 8$ and 5 a, but are reported to commonly range from $1 / 10$ to $1 / 2$ of the horizontal values (Freeze and Cherry 1979, Intera 1986). The vertical conductivity for Zone 6/78 is estimated to be much lower than the horizontal conductivity for those zones, due to the extremely heterogenous nature of the zones (Appendix E).

The storage coefficient, representing water expansion and aquifer compaction in response to changes in fluid pressure, is assumed to be 0.0001 for Zones $6 / 7 / 8$ and $5 b$, and .001 for Zone 5a, for computing purposes. The value of this parameter is relatively unimportant for the unconfined conditions being modeled, and does not affect the results of steady state simulations conducted in this analycis. Average annual recharge to the system is assumed to be $40 \mathrm{~cm}$, based on the analysis provided in Sect. A.1.1 of this report. 
Tablo A2-1. Measured and anumed bydraulic coaductivities for enturnted bydrologic units

\begin{tabular}{|c|c|c|c|}
\hline \multirow[b]{2}{*}{$\begin{array}{l}\text { Hydrologic } \\
\text { Unit }\end{array}$} & \multicolumn{2}{|c|}{$\begin{array}{l}\text { Horibontal hydraulic } \\
\left.\text { conductivity }(\mathrm{m} \mathrm{s})^{-1}\right)\end{array}$} & \multirow{2}{*}{$\begin{array}{c}\text { Vertical hydraulic } \\
\text { conductivity }\left(m s^{-1}\right) \\
\begin{array}{c}\text { Value used in } \\
\text { simulations }\end{array}\end{array}$} \\
\hline & $\begin{array}{c}\text { Measured } \\
\text { range }\end{array}$ & $\begin{array}{l}\text { Value used in } \\
\text { simulations }\end{array}$ & \\
\hline Zone $6 / / 8$ & $10^{4} \cdot 10^{4}$ & $6 \times 10^{6}$ & $4 \times 10^{6}$ \\
\hline Zone 5b & not available & $4 \times 10^{8}$ & $2 \times 10^{9}$ \\
\hline Zone 5a & $10^{-7}-2 \times 10^{-3}$ & $6 \times 10^{5}$ & $6 \times 10^{6}$ \\
\hline
\end{tabular}

\section{A21.4 Propertics Affecting Mass Transport}

Mass transport in the saturated zone occurs by advective, diffusive, and dispersive processes, but is hindered by sorptive procesces. In the saturated zone, advective transport is sufficiently high to render diffusive transport relatively insignificant. Mechanical dispersion, which causes spreading of a contaminant plume, is a property of the aquifer matrix and flow characteriatics that has not been measured in aquifers underlying the SRS. Dispersion is not expected to be important for the SDF, however, because the area of the source (i.en area of the SDF), and thus, the potential area of a contaminant plume originating from the facility, is large. Spreading of the plume from such a large source will not significantly reduce concentrations at a point $100 \mathrm{~m}$ from the facility, the compliance point for grounctwater protection assumed in this RPA. Thus, reaspnable dispersivities for longitudinal and transverse dispersion were selected from a reputable groundwater textbook (Freeze and Cherry 1979). The longitudinal and transverse dispersivities selected are $3 \mathrm{~m}$ and $0.3 \mathrm{~m}$ respectively.

Other characteristics of the porous media that affect mass transport simulations include density and porosity of the media. Matrix density of the media is a property used by the simulation code PORFLOW-3D to calculate retardation based on sorption coefficients, or $\mathrm{Kd}$ '. For the three hydrologic units of interest, the matrix density is assumed to be $2650 \mathrm{~kg} / \mathrm{m}^{3}$, based on measurements of dry bulk density made by Dennehy et al. (1989) of Zone 7c, and based on an average value provided by Freeze and Cherry (1979). The total porosity of all zones is assumed to be 0.40 , based on data contained in Table A.2-2 An effective porosity of 0.30 was assumed, based on an average value from de Marsily (1986) corresponding to a total porcaity of 0.40 .

Effective diffusion in the saturated zone is estimated to be of $5 \times 10^{-6} \mathrm{~cm} / \mathrm{s}$, although effective diffusion will vary due to the tortuocity of each hydrologic unit. A more detailed investigation of the value of this parameter is not warranted due to the relative insignificance of diffusive transport in porous media when compared to the magnitude of advective components encountered in saturated zones under the SDF. 
Table A2-2 Total porceitios - Z-Arer

\begin{tabular}{|cll|}
\hline Zone(s) & Boring No. & Total $\theta(\%)$ \\
\hline 7,8 & SDS-3 & 30.8 to $39.5(35.2)^{6}$ \\
\hline 6,7 & SDS-5 & 26.0 to $37.8(32.2)$ \\
\hline 7,8 & SDS-6 & 33.5 to $45.7(41.6)$ \\
\hline 5 & SDS-7A & 34.7 to $38.9(36.8)$ \\
\hline 7,8 & SDS-8 & 51.0 \\
\hline 8 & SDS-9 & 40.3 to 41.5 (40.9) \\
\hline 8 & SDS-10 & 35.0 \\
\hline 7,8 & SDS-11 & 27.0 to $38.6(34.2)$ \\
\hline 7,8 & SDS-13 & 33.6 to $41.8(37.7)$ \\
\hline 7,8 & SDS-14 & 39.5 to $47.4(42.9)$ \\
\hline
\end{tabular}

- Data from D'Appolonia (Cook et al. 1984).

- Numbers in parentheses are arithmetic means of values reported in original document. 
Characteristics of contaminants that are needed to simulate mass transport are sorption coefficients and half-lives of radioactive decay (Table C.1-1). Sorption of a continuous source of contaminants on solid surfaces is often viewed as reversible, schieving equilibrium instantancousty, and applies only to immobile surfaces (i.e., sorption on mobile colloids is not considered). This view of sorption is represented by a Kd, and is the view adopted for this RPA. This representation of sorption serves to retard the computed arrival of a plume of contaminants at a given location, rather than lower the ultimate concentration. However, extending the transit time of a contaminant can allow for radioactive decay or microbial degradation processes to reduce the concentration before the plume reaches a critical receptor location. These decay proceses will be important for radionuclides with balf-lives significantly less than the transit time in groundwater, or for potentially biodegradable compounds such as nitrate.

The value of $\mathrm{Kd}$ varies with the contaminant and the media to a large degree. The values used for the saturated zone are consistent with those used in the near-field model (Sect 3.3.1), and were site-specific when possible. Table A.1-2 lists the Kd's used in both the unsaturated backfill and the saturated zone.

\section{A22 Saturated Flow and Transport Simulations}

In this section, the method for simulating the conceptual saturated flow and transport is described in detail. In Sect. A.221, details of the design of the input file for the PORFLOW-3D compu' ar code simulation are given. In Sect. A.22.2, the initial optimization study that was done, to ascertain that code simulations were producing credible results is discussed.

\section{A221 Simulation Design}

Groundwater flow and mass transport simulations were conducted with PORFLOW3D based on the conceptual model discuseed in Sect. A.2. The model was calibrated by comparing hydraulic head values calculated by PORFLOW-3D with actual bead values from site monitoring wells. An average annual recharge of $40 \mathrm{~cm}$ was assumed for this calibration. The calibration process is discuseed in detail in Sect 3.42

After completing the groundwater flow simulations that generated a predicted steady-state flow field, separate input files were developed for transport simulations. These input filer consist of the concentration boundary conditions and transport parameters described in Sect. A21.4 and the velocity vectors specified from the results of the steady-state flow simulations. The velocity vectors are used in the transport simulations to compute advective and dispersive transport of potential contaminants.

Two separate groundwater flow fields were required, based on the scenarios evaluated in the near-field model. For the intact and degraded vault scenarios assuming a completely degraded cover, the groundwater tlow code, which was calibrated assuming $40 \mathrm{~cm} / \mathrm{year}$ recharge from precipitation, is used as is. For the scenarios assuming an 
intact cover, the calibrated flow code was run to steady state assuming only $2 \mathrm{~cm} / \mathrm{year}$ of recharge over the area covered by the facility (Fig. 3.4-9).

\section{A222 Preliminary Senritivity Study for Groundwater Modeling}

A series of simulations were also conducted to evaluate the sensitivity of the steadystate head distribution for the water table aquifer to initial and boundary conditions, and several independent variables, listed below. These tests are not part of the formal sensitivity analysis reported in Sect. 422 , but were part of a preliminary sensitivity used for: 1) determing the impact of initial conditions on the number of iterations required to achieve a numerically stable, or converged, solution; 2) evaluating whether the model was responding as expected to varied conditions; and 3) indicating of bow sensitive the model is to the independent variables tested, in order that the degree of care necessary in choosing values of the variables could be evaluated. The independent variables studied are as follows:

- Initial bead conditions for Zones 6/7,

- Initial head conditions for Zone 5a,

- Upgradient boundary conditions for Zone 5a,

- Recharge due to precipitation,

- Hydraulic conductivity of the Zones 6/7/8,

- Vertical hydraulic conductivity of Zone $5 \mathrm{~b}$, and

- Horizontal hydraulic conductivity of Zone 5a.

With the exception of the initial head conditions, all of the independent variables listed above affected the head distributions in the water table aquifer. Preliminary sensitivity analysis results are presented in Table A.2-3. The impact of varying these conditions and variables on the resultant flow field to be used in the contaminant transport simulations are discussed below.

\section{Initial Head Condition for the Zones $67 / 8$}

The computed bead distribution for Zones $6 / 7 / 8$ (the water table aquifer) is independent of the initial guess of head distribution for steady-state simulations, as expected (Wang and Anderson 1982). However, if the initial guess for the hydraulic head conditions is close to the steady-state value, fewer iterations are required to converge to a stable solution.

Initial simulations with PORFLOW-3D, using varying initial guesses of the head distribution resulted in an excessive number of iterations to obtain a stable solution. The assignment of constant head conditions along the McQueen and Crouch Branches caused this instability. Initially, the fured beads were assigned from the base of the water table unit to the uppermost active node beneath these streams. All of the nodes in this vertical plane were incorrectly assigned a constant bead value corresponding to the 
Table A.2-3. Results of preliminary sensitivity analysis for Z-Area groundwater fow simulations

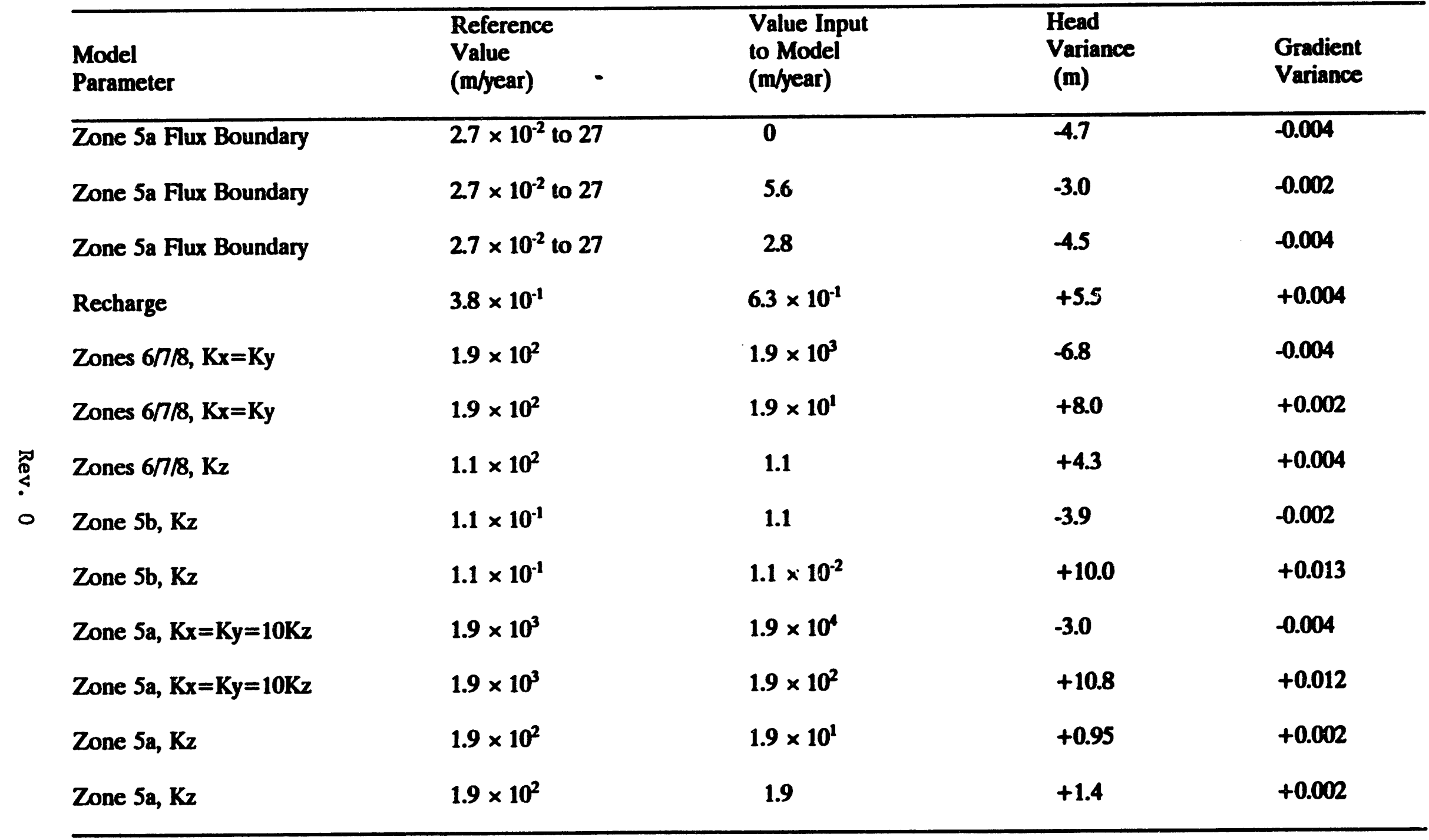


elevation of the stream at that particular location. The fixed-head nodes acted as a sink to the groundwater system, representing water entering the stream. Therefore, the results became dependent on the bead initially assigned in this vertical plane. To eliminate this instability, only the node nearest the stream elevation of a selected location was assigned a fixed value. Groundwater entering below this node would remain in the system.

This change improved the convergence to a stable solution, but the convergence criteria still needed to be changed. Depending on the variance of the initial conditions from the final solution, up to 1200 iterations were required to obtain steady-state conditions were obtained. For the final initial condition simulations, head values approximately $13 \mathrm{~m}$ higher and lower than expected values were fully incorporated into the model. With these setting, model solutions converged with less than a meter of difference between measured and computed pressure heads. Observed differences occurred along the western margin of the model domain where the Crouch Branch fixed nodes isolate a portion of the domain. This result only affects the potentiometric map in the area near Crouch Branch and will not affect the region where contaminant transport occurs. This difference can also be minimized if initial conditions are relatively close to expected head values.

\section{Initial Head Conditions for the Zone 5 a}

If initial head values for the water table aquifer are assumed for the Zone 5a (the Congaree unit), an excessive number of iterations are necessary to obtain steady-state conditions. This is because head values in Zone $5 \mathrm{a}$ vary by approximately $26 \mathrm{~m}$ from water table head values. Using a reasonable estimate for initial head conditions results in a potentiometric map for Zone 5a that matches actual head values for this zone presented in Dennehy et al. (1989).

\section{Boundary Conditions for Zone 5a}

Although Zone 5a (the Congaree Formation) dips to the southeast, the aquifer discharges northward to the Upper Three Runs Creek where the overlying confining units have been removed by erosion. The southern or upgradient boundary of this zone is a constant flux boundary. Using an initial hydraulic conductivity value of $1.9 \times 10^{5}$ cm/year and a gradient based on the potentiometric map of Zone 5a shown in Fig. 2.1-5, a constant flux value of $55 \mathrm{~cm} / \mathrm{year}$ was calculated for the upgradient boundary of this zone. Using this flux value resulted in predicted head values for both the Zone 5 a and the water table aquifers greater than those measured. Using a flux value of $50 \%$ of this value (i.e., $28 \mathrm{~cm} / \mathrm{year}$ ) led to predicted head values only slightly in excess of measured values. If the vertical hydraulic conductivity of Zone $5 \mathrm{~b}$ (the green clay) is reduced, less water is predicted to leak into Zone 5a, and the calculated boundary flux of $55 \mathrm{~cm} / \mathrm{year}$ can be used without over predicting head values. 


\section{Recharge to the Water Table}

Recharge to the water table aquifer resulting from precipitation is assumed to be $40 \mathrm{~cm} / y e a r$. This estimate is based on the results of the analysis presented in Sect. A.1.1. By increasing the recharge rate to $160 \mathrm{~cm} / y e a r$, or $129 \%$ of the average annual precipitation at the SRS, water table elevations increase by 7.6 to $12 \mathrm{~m}$ over a large area of the problem domain.

In another set of simulations, the recharge underlying the proposed cap for the vaults was reduced to $2 \mathrm{~cm} /$ year. Recharge of the remaining problem domain remained at $40 \mathrm{~cm} /$ year. When compared with simulations with a recharge of $40 \mathrm{~cm} /$ year over the entire problem domain, the water levels under the cap decline approximately $1.5 \mathrm{~m}$. Water levels in the remaining areas showed only minor changes between simulations.

\section{Hydraulic Conductivity of Zones 67/8}

Simulations were conducted by varying the horizontal and vertical hydraulic conductivity of the water table aquifer (Zones 6/7/8). The horizontal hydraulic conductivity was varied by plus or minus one order of magnitude. Modeling results indicate that water levels varied by approximately $15 \mathrm{~m}$ in response to these variances. A decrease in the vertical hydraulic conductivity by two orders of magnitude resulted in an increase in the water table elevation of about $4 \mathrm{~m}$.

\section{Vertical Hydraulic Conductivity in Zone $5 \mathrm{~b}$}

Zone 5b, the green clay, is assumed to be an aquitard restricting groundwater flow from the overlying Zones $6 / 7 / 8$ to Zone 5a. The permeability of this unit markedly affeots the water levels in the aquifers. Varying the vertical hydraulic conductivity by an order of magnitude, yields a change in water levels of approximately $14 \mathrm{~m}$.

\section{Horizontal Hydraulic Conductivity in Zone 5 a}

Varying the horizontal hydraulic conductivity by one order of magnitude results in water level changes in Zone $5 \mathrm{a}$ (the Congaree unit) of almost $14 \mathrm{~m}$.

\section{A.3 ANALYSIS OF ATMOSPHERIC EFFLUENIS}

Volatile emissions, such as HTO (tritiated water vapor), $\mathrm{HT},{ }^{14} \mathrm{CO}_{2}$ and $\mathrm{Rn}-222$, are expected to occur from LLW disposal facilities in varying quantities dependent upon the initial disposal activities of each volatile isotope, disposal method, and the surrounding physiochemical environment. 
The purpose of this section is to estimate the potential impact of the presence of these gases containing these radionuclides in terms of off-site individual and inadvertent intruder doses associated with the SDF. The results demonstrate the insignificant impact with respect to allowable doses for both types of receptors.

Tritium will occur as water molecules or hydrogen gas molecules within the SDF, and is thus potentially volatile. Likewise, the presence of C-14 in the facility suggests consideration of volatile compounds comprised of this radionuclide. Radon-222, produced within the saltstone from radioactive daughters of U-234 and U-238, is also a volatile, and non-reactive gas emanating from the monoliths. The initial inventory of $\mathrm{H}-3, \mathrm{C}-14, \mathrm{U}-234$, and $\mathrm{U}-238$ provides a potential source of volatile radionuclides.

The following computational analyses were done to screen the potential importance of volatile radioactive compounds in the SDF. Bounding assumptions were made and the dose estimates are therefore considered overestimates.

\section{A3.1 Analysis of Maximum Radon-222 Dose Potential}

The potential Rn-222 dose from saltstone is a function of the initial inventories of U-238 and U-234, from which Rn-222 will be generated. The initial inventories of U-238 and U-234 in saltstone are estimated to be 0.002 and $0.3 \mathrm{Ci}$ (Table C.1.1), respectively. Assuming approximately $1.2 \times 10^{6} \mathrm{~m}^{3}$ of saltstone in Z-Area, with a density of $1.7 \mathrm{~g}$ (Oblath 1986), U-238 and U-234 concentrations of 0.001 and $0.1 \mathrm{pCi} / \mathrm{g}$, respectively, are expected.

Natural levels of U-238 and U-234 in soil range from a few tenths of a pCi/g to $1 \mathrm{pCi} / \mathrm{g}$ in igneous formations (Kathren 1984). These natural levels of Uranium result in $\mathrm{Rn}-222$ effective cose equivalents on average of $200 \mathrm{mrem}$ per year across the United States, due to this radioactive component of background. Therefore, the concentrations of U-238 and U-234 in the saltstone are expected to result in Rn-222 doses to intruders which are less than that provided by the natural surrounding soil. In other words, the intruder may receive a higher $\mathbf{R n - 2 2 2}$ dose from building a house on the soil between the saltstone vaults, than if the house were constructed directly on top of a saltstone vault. Since the concentrations in saltstone are considered to be less than background levels, the dose from radon and its daughters will not be considered further in this analysis for either the intruder or the off-site individual.

\section{A3.1.1 Rn-222 Flux Equations}

The maximum diffusive flux of $\mathrm{Rn}-222$ from the SDF was determined to ensure compliance with 40 CFR 61, Subpart $O$, which sets a limit of $20 \mathrm{pCi} / \mathrm{m}^{2} \mathrm{~s}$ for radiumcontaining materials at DOE facilities. The flux from bare saltstone was determined from 
the following equation (Rogers et al. 1984)

$$
J_{s}=10^{4} R p E \sqrt{\lambda D_{s}} \tanh \sqrt{\frac{\lambda}{D_{0}}} x_{\Delta}
$$

where

$$
\begin{aligned}
& J_{s}=R n-222 \text { flux }\left(\mathrm{pCi} \mathrm{m}^{-2} \mathrm{~s}^{-1}\right) \text {, } \\
& 10^{4}=\text { conversion factor from } \mathrm{cm}^{2} \text { to } \mathrm{m}^{2} \text {, } \\
& R=\text { maximum Ra-226 activity (pCi/g), } \\
& P=\text { dry bulk density of the porous media }\left(\mathrm{g} \mathrm{cm}^{3}\right) \text {, } \\
& E=R n-222 \text { emanation coefficient, } \\
& \lambda=\mathbf{R n - 2 2 2} \text { decay constant }\left(\mathrm{s}^{-1}\right) \text {, } \\
& D_{d}=\text { molecular diffusion coefficient }\left(\mathrm{cm}^{2} \mathrm{~s}^{-1}\right) \text {, and } \\
& x_{s}=\text { thickness of source }(\mathrm{cm}) \text {. }
\end{aligned}
$$

The following diffusion coefficient was selected for the determination of the Rn-222 flux from the SDF.

$$
D_{\bullet}^{\circ}=1.0 \times 10^{-2} \mathrm{~cm}^{2} \mathrm{~s}^{-1}
$$

(Rogers et al. 1984)

This is an average Rn-222 effective diffusion coefficient value for low moisture content in tailings and is considered to be conservative for saltstone.

It should be noted that several authors have used the term "effective diffusion coefficient, $D_{a}$. . This is defined by

$$
D_{\bullet}=P D
$$

The molecular diffusion coefficient, $D$, is the more fundamental parameter and is the diffusion coefficient required in the flux equations developed by Rogers et al. (1984). Therefore, the effective diffusion coefficient was adjusted to obtain the molecular diffusion coefficients in the air-filled porous medium

$$
D_{s}=\frac{1.0 \times 10^{-2} \mathrm{~cm}^{2} \mathrm{~s}^{-1}}{0.46}-2.0 \times 10^{-2} \mathrm{~cm}^{2} \mathrm{~s}^{-1}
$$




\section{A3.12 Parameter Selection}

These parameter values were used for the $R \mathbf{n}-222$ flux calculations:

$$
\begin{aligned}
& \rho=1.66 \mathrm{~g} \mathrm{~cm}^{3} \text { (Oblath 1986), } \\
& E=0.2 \text { (Rogers et al. 1984), } \\
& \lambda=2.1 \times 10^{-6} \mathrm{~s}^{-1} \\
& x_{s}=730 \mathrm{~cm} \text { (the height of a monolith), } \\
& P_{0}=0.46 \text { (porosity of saltstone assumed, and }
\end{aligned}
$$

\section{A.3.13 Rn-2222 Flux Calculations}

The flux of Rn-222 from bare saltstone was calculated from Eq. A.3.1. This flux, for completely exposed and unsaturated material, was determined to be $7.3 \times 10^{-1} \mathrm{pCi}$ $\mathrm{m}^{-2} \mathrm{~s}^{-1}$, assuming secular equilibrium of Ra-226 with U-234 and no leaching of either radionuclide from the saltstone. This flux is well below the limit of $20 \mathrm{pCi} / \mathrm{m}^{2} \mathrm{~s}$, given in 40 CFR 61. These are extremely maximizing conditions because it is believed that the saltstone will be very near complete saturation (i.e., 80 to $90 \%$ ), thus lowering the diffusion coefficient and flux of $\mathrm{Rn}-222$; leaching of the parent radionuclides will occur over time, thus depleting the source of Rn-222.

\section{A32 Analysis of Maximum H-3 and C-14 Dose Potential}

Volatile releases of H-3 and C-14 were estimated using initial concentrations of these radionuclides in saltstone. The chemical forms of the radionuclides are assumed to be HTO and $\mathrm{CO}_{2}$. The speciation of tritium, between HTO and HT in the saltstone is not known. The high $\mathrm{pH}$ environment in the vaults would prevent the release of $\mathrm{CO}_{2}$ because farbon is present as a carbonate. The saltstone monoliths and vaults are believed to essentially remain saturated (Sect. A 1.2.2), necessitating aqueous diffusion of the radionuclides upward from the vaults before gas-phase diffusion volatilization in the unsaturated soil can occur.

\section{A.3.21 H-3 and C-14 Flux Equation}

The flux rates of $\mathrm{H}-3$ and $\mathrm{C}-14$ were determined using the following relationship (U.S.EPA 1988):

$$
J_{1}=D_{1} C_{s 1}\left(P_{t}\right)^{4 / 3} \frac{M_{1}}{d_{a c}}
$$


where

$J_{i}=$ flux of radionuclide component $\mathrm{i}\left(\mathrm{g} \mathrm{cm}^{-2} \mathrm{~s}^{-1}\right)$,

$D_{i}=$ diffusion coefficient of radionuclide component $i$ in air $\left(\mathrm{cm}^{2} \mathrm{~s}^{-1}\right)$,

$C_{d}=$ saturation vapor concentration of radionuclide component $\mathrm{i}\left(\mathrm{g} \mathrm{cm}^{-3}\right)$,

$P_{1}=$ total soil porosity,

$\dot{M}_{i}=$ mole fraction of radionuclide component $i$ in the waste (gmole gmole ${ }^{-1}$ ), and

$d_{\infty}=$ effective depth of soil cover $(\mathrm{cm})$.

The mole fraction of each radionuclide component $i$ was determined from (U.S.EPA 1988)

$$
M=\frac{B \times F}{F(B-E)+(1000 R \times E)}
$$

where

$M=$ mole fraction of radionuclide component $\mathrm{i}$ in the waste (gmole gmole ${ }^{-1}$ ),

$B=$ molecular weight of solvent,

$F=$ grams of solute per liter of solute,

$E$ = molecular weight of solute, and

$R=$ density of solution $\left(\mathrm{g} \mathrm{cm}^{-2}\right)$.

The saturation vapor pressure was determined from (U.S.EPA 1988)

$$
C_{a 1}=\frac{P M W_{1}}{R_{c} T}
$$

where

$C_{\boldsymbol{A}} \quad=$ saturation vapor pressure of radionuclide component $\mathbf{i}\left(\mathrm{g} \mathrm{cm}^{-3}\right)$,

$p=$ vapor pressure of radionuclide component $\mathrm{i}(\mathrm{mm} \mathrm{Hg})$,

$M W_{i}=$ molecular weight of radionuclide component $\mathrm{i}(\mathrm{g} / \mathrm{mol})$,

$\boldsymbol{R}_{c}=$ molar gas constant $\left(62,361 \mathrm{~mm} \mathrm{Hg} \mathrm{cm}^{3} / \mathrm{mol}^{\circ} \mathrm{K}\right)$, and

$T=$ absolute temperature $\left({ }^{\circ} \mathrm{K}\right)$. 


\section{A322 Parameter Selection}

These parameter values were used for H-3:

D $=0.239 \mathrm{~cm}^{2} \mathrm{~s}^{-1}$ (CRC 1981),

$P_{1}=0.46$,

$d_{x}=15 \mathrm{~cm}$ (assumed 6 inches of soil cover),

$B=18 \mathrm{~g} / \mathrm{mol}$ for $\mathrm{H}_{2} \mathrm{O}$,

$F=4.2 \times 10^{-10} \mathrm{~g} \mathrm{l}^{-1}$,

$E=10 \mathrm{~g} / \mathrm{mol}$ for HTO,

$R=1 \mathrm{~m} \mathrm{~cm}^{-3}$,

$p=18 \mathrm{~mm} \mathrm{Hg}$ (CRC 1981),

$M W=20 \mathrm{~g} / \mathrm{mol}$,

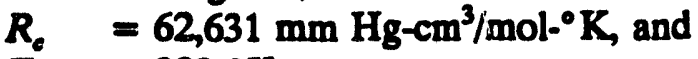

$T=293^{\circ} \mathrm{K}$

These parameter values were used for C-14:

$$
\begin{aligned}
& D=0.139 \mathrm{~cm}^{2} \mathrm{~s}^{-1} \text { in air (CRC 1981), } \\
& P_{1}=0.46 \text {, } \\
& d_{x}=15 \mathrm{~cm} \text { (assumed } 6 \text { inches of soil cover), } \\
& B=18 \mathrm{~g} / \mathrm{mol} \text { for } \mathrm{H}_{2} \mathrm{O} \text {, } \\
& F=2.2 \times 10^{-13} \mathrm{~g} \mathrm{l}^{-1} \text {, } \\
& E \cdot=44 \mathrm{~g} / \mathrm{mol} \text { for } \mathrm{CO}_{2} \\
& R=1 \mathrm{~g} \mathrm{~cm}^{-3} \text {, } \\
& p=42.95 \mathrm{~mm} \mathrm{Hg} \text { (CRC 1981), } \\
& M W=44 \mathrm{~g} / \mathrm{mol} \text {, } \\
& R_{c}=62,631 \mathrm{~mm} \mathrm{Hg}-\mathrm{cm}^{3} / \mathrm{mol}-{ }^{\circ} \mathrm{K} \text {, and } \\
& T=293^{\circ} \mathrm{K}
\end{aligned}
$$

\section{A3223 H-3 and C-14 Flux Calculations}

The mole fractions, represented by $M$, were determined from Eq. A.3.12 to be $8 \times 10^{-13}$ and $9 \times 10^{-17} \mathrm{gmol} / \mathrm{gmol}$ for HTO and ${ }^{14} \mathrm{CO}_{2}$, respectively. The saturation vapor pressures, represented by $\mathrm{C}_{\mathrm{s},}$, were determined from Eq. A.3.13 to be $2 \times 10^{-5}$ and $1 \times 10^{-4} \mathrm{~g} \mathrm{~cm}^{3}$ for HTO and ${ }^{14} \mathrm{CO}_{2}$. These parameters resulted in fluxes for HTO and ${ }^{14} \mathrm{CO}_{2}$ according to Eq. A.3.4 of $8 \times 10^{-4}$ and $1 \times 10^{-10} \mathrm{pCi} \mathrm{cm} \mathrm{cm}^{-1}$, respectively. 


\section{A324 Intruder Dose Calculations}

The dose to the intruder from the inhalation pathway was calculated by assuming that the intruder resides for $8760 \mathrm{~h} / y e a r$ in the basement of a house located directly on top of the disposal unit. The individual is assumed to reside in a room which is $3.7 \mathrm{~m}$ by $3.7 \mathrm{~m}$ by $2.3 \mathrm{~m}$ in height. The individual has a breathing rate of $0.9 \mathrm{~m}^{3} \mathrm{hr}^{-1}$. Fifteen centimeters of cover soil was assumed in the model along with the porosity of saltstone $(0.46)$ to simulate, very conservatively, a $15 \mathrm{~cm}$ concrete slab in the floor of the house. The concrete would have a much lower porosity $(0.08)$, which is directly proportional to the llux.

The conceptual model of the basement room was based on the steady state concentration of the radionuclide concentration, $Q_{\infty}$ in the room given by

$$
Q_{e e}=\frac{R}{K_{z}+K_{v}}
$$

where

$$
\begin{aligned}
& R=\text { radionuclide input rate }\left(\mathrm{pCi} \mathrm{s}^{-1}\right), \\
& \boldsymbol{K}_{\mathbf{V}}=\text { radionuclide decay constant }\left(\mathrm{s}^{-1}\right), \text { and } \\
& \boldsymbol{K}_{v}=\text { room ventilation rate constant }\left(\mathrm{s}^{-1}\right) .
\end{aligned}
$$

The value for $\boldsymbol{R}$ was obtained from the radionuclide flux rates and the area of the basement floor. The value of $K_{v}$ was determined from the ventilation rate of the room, assumed to be one air exchange per hour, and the volume of the room.

- The individual's inhalation dose was determined from the following relationship

$$
D=Q * I * T * D C F
$$

where

$$
\begin{aligned}
& \left.D \quad=\text { inhalation dose (mrem } \mathrm{yr}^{-1}\right), \\
& Q \quad=\text { steady state air concentration }\left(\mathrm{pCi} \mathrm{m}^{-3}\right), \\
& I \quad=\text { inhalation rate }\left(\mathrm{m}^{3} \mathrm{hr}^{-1}\right) \\
& T \quad=\text { occupancy time }\left(\mathrm{hr}^{-1}\right) \text {, and } \\
& \left.D C F=\text { dose conversion factor (mrem } \mathrm{pCi}^{-1}\right) .
\end{aligned}
$$

The dose conversion factors for the inhalation pathway of $\mathrm{H}-3$ and $\mathrm{C}-14$ were determined to be $9.4 \times 10^{-5}$ and $2.4 \times 10^{-5} \mathrm{rem} \mu \mathrm{Ci}^{-1}$, respectively (U.S.DOE 1988b). The dose from tritiated vapor was increased by $50 \%$ to account for the skin absorption pathway. Intruder inhalation doses for H-3 and C-14 were determined to be 10 and $4 \times 10^{-7}$ mrem, respectively. These doses are well below the standards for the intruder 
of 100 mrem. The assumption that the intruder is located in the house $24 \mathrm{~b} /$ day, 365 days per year is considered to bound the all pathways intruder model. Therefore, the external and ingestion pathways are not considered.

\section{A.325 Off-Site Individual Doce Calculation:}

The off-site individuals dose from $\mathrm{H}-3$ and $\mathrm{C}-14$ would be much lower than that obtained for the intruder. Therefore, the off-site individuals dose has not been calculated. The effective dose equivalents determined for the intruder would be diluted further by the atmospheric dispersion and would be below the off-site public limit of 10 mrem per year. In addition, the assumption that there was $15 \mathrm{~cm}$ of cover soil with a porosity equivalent to saltstone $(0.46)$ is considered very conservative since the actual soil cover thickness will be much greater and potentially have lower porosities.

\section{A4 DOSE ANALYSIS FOR OFFSITE INDIVIDUALS AND INADVERTENT INTRUDERS}

\section{A4.1 Introduction}

This appendix presents the models and data bases used to estimate dose equivalents to members of the public per unit concentration of radionuclides in the environment following disposal of LLW in the SDF. The dose analysis considers two critical groups of exposed individuals:

- off-site individuals, i.e., members of the public who reside beyond the boundary of the disposal facility; and

- inadvertent intruders, i.e., individuals who come onto the disposal site following loss of active institutional control.

Off-site individuals may receive exposures from radionuclides released from the disposal facility at any time after disposal. During the period of active institutional control over the disposal facility, which is assumed to last for 100 years after facility closure (U.S.DOE 1988a), off-site individuals are assumed to be restricted to locations beyond the present boundary of the SRS. However, after the period of active institutional control, off-site individuals could be located anywhere beyond the boundary of the disposal facility, which is assumed to be no more than $100 \mathrm{~m}$ from the disposal units. Inadvertent intrusion onto the disposal site is assumed to be precluded by active institutional control until 100 years after facility closure. No credit is taken in this analysis for any passive institutional controls (e.g., physical marker systems at the disposal site and public records of land use) that could prevent inadvertent intrusion for some time after the period of active institutional control. 
The performance assessment for the SDF assumes that releases of radionuclides to groundwater following infiltration of precipitation through disposal units is the principal mechanism for transport of radionuclides to off-site locations. Potential doses to off-site individuals resulting from airborne releases of radionuclides also were considered (see Appendix A.3) but were found to be unimportant.

The dose analysis for inadvertent intruders considers two types of exposure scenarios. The first involves direct intrusion into disposal units or into contaminated soil next to disposal units, and three different scenarios involving direct intrusion into solid waste are evaluated. The second type of scenario involves exposure to contaminated groundwater within the boundary of the disposal site.

The following sections discuss the exposure scenarios and exposure pathways assumed for off-site individuals or inadvertent intruders and the models and parameter values used in calculating annual effective dose equivalents to these groups of individuals for each exposure pathway. For exposures to contaminated groundwater, the results of the dose analysis are summarized in the form of annual effective dose equivalents per unit concentration of radionuclides in water. For exposures resulting from direct intrusion into disposal units or into contaminated soil next to disposal units, the results are summarized in the form of annual effective dose equivalents per unit concentration of radionuclides in solid waste at the time intrusion is assumed to occur.

\section{A.42 Radionuclides of Importance for Dose Analyses}

As shown in Table C.1-1, LLW in the SDF contains a large number of radionuclides. However, only a few radionuclides are potentially important in the dose analyses for off-site individuals or inadvertent intruders. Most of the radionuclides either occur only in very low concentrations or are sufficiently short-lived that they would decay to innocuous levels before off-site transport via the groundwater pathway or inadvertent intrusion onto the disposal site could occur.

The radionuclides which have been considered in the dose analyses, either for offsite individuals or for inadvertent intruders, are listed in Table A.4-1. These radionuclides were selected on the basis of very conservative screening analyses for exposures of off-site individuals via the groundwater pathway and for exposures of inadvertent intruders, as described in Sects. 3.2.3.4 and 3.2.4.4, respectively. The exposure scenarios which have been considered for each radionuclide are indicated in the table and are described in Sect. A.4.3. All other radionuclides listed in Table C.1-1 can be neglected in the dose analyses for off-site individuals and inadvertent intruders, because their concentrations are sufficiently low that they could not result in doses that exceed a very small fraction of the applicable limits for either group of individuals. 
Table A.4-1. Radionuclides considered in dose analyes for off-site individuals or inadvertent intruders

\begin{tabular}{lrlc}
\hline Radionuclide & Half-life $^{b}$ & Applicable scenarios $^{\circ}$ \\
\hline H-3 & 12.28 & y & $1,2,4$ \\
C-14 & 5730 & y & 1,2 \\
Ni-63 & 100.1 & y & 2,4 \\
Se-79 & $6.5 \times 10^{4}$ & y & $1,2,4$ \\
Sr-90 & 28.6 & y & $1,2,4$ \\
$\quad$ Y-90 (1.0) & 64.1 & b & \\
Tc-99 & $2.13 \times 10^{5}$ & y & $1,2,4$ \\
Sn-121m & 55 & y & 2,4 \\
Sn-126 & $1.0 \times 10^{5}$ & y & $1,2,3,4$ \\
\multicolumn{1}{c}{ Sb-126m (1.0) } & 19.0 & m & \\
Sb-126 (0.14) & 12.4 & d & \\
I-129 & $1.57 \times 10^{7}$ & y & $1,2,3,4$ \\
Cs-137 & 30.17 & y & $1,2,3,4$ \\
\multicolumn{1}{c}{ Ba-137m (0.946) } & 2.552 & m & \\
Sm-151 & 90 & y & 2,4 \\
Pu-238 & 87.75 & y & $1,2,4$ \\
Pu-239 & 24131 & y & 1,2 \\
Am-241 & 432.2 & y & $1,2,3,4$ \\
\hline
\end{tabular}

- Indented entries are radiologically significant short-lived decay products of parent radionuclide listed. With each decay product, branching fraction in decay of parent radionuclide is given in parentheses.

- Values from Kocher (1981).

- 1 = drinking water pathway, off-site individuals;

2 = agriculture scenario, inadvertent intruders;

3 = resident scenario, inadvertent intruders;

4 = post-drilling scenario, inadvertent intruders.

Rov. 0 
As indicated in Table A.4-1, some radionuclides included in the dose analyses decay to short-lived radionuclides that are potentially important for at least one exposure pathway. For any exposure pathway, the doses from a parent radionuclide and its shortlived decay products are combined by assuming that the decay products are in secular equilibrium with the parent, and the activity concentrations of the decay products take into account the decay branching fractions given in Table A.4-1.

\section{A.4.3 Assumed Exposure Scenarios and Exposure Pathways}

This section briefly describes the exposure scenarios and exposure pathways assumed in the dose analyses for off-site individuals and inadvertent intruders. A more detailed description of the assumed exposure scenarios, including the justification for neglecting other scenarios in the dose analyses, is given in Sects. 3.2.3 and 3.2.4. The model equations and parameter values for each exposure pathway are presented in Sect. A.4.5.

\section{A.43.1 Exposure Scenarios and Pathways for Off-Site Individuals}

The performance assessment for the SDF assumes that radionuclides are transported to off-site locations principally via the groundwater pathway. Off-site transport via atmospheric releases also was considered (see Appendix A.3) but found to be unimportant.

As described in Sect. 3.2.3, off-site individuals are assumed to use contaminated water for domestic purposes, and the following exposure pathways involving use of contaminated water are assumed to occur: 1) direct ingestion of contaminated drinking water, 2) ingestion of milk and meat from dairy and beef cattle that drink contaminated water, and 3) ingestion of vegetables grown in garden soil irrigated with contaminated water. Irrigation of pasture grass consumed by dairy and beef cattle is assumed to be unimportant, because irrigation of pasture is not widely practiced near the SRS. The relative importance of the different pathways considered is summarized below.

As described in Sect. 3.2.3.1 and 3.2.3.2, off-site releases of radionuclides via the groundwater patbway are assumed to be subject to two dose limits that are consistent with the performance objectives for LLW disposal (U.S.DOE 1988a): 1) a limit on effective dose equivalent of 25 mrem per year from all exposure pathways and 2) a limit on effective dose equivalent of $4 \mathrm{mrem}$ per year from consumption of $2 \mathrm{~L} /$ day of drinking water from a contaminated source. The latter performance objective is used to limit concentra-tions of radionuclides in groundwater at locations beyond the boundary of the disposal site, i.e., at distances greater than $100 \mathrm{~m}$ from any disposal units.

In Sect. 3.2.3.3, an analysis was performed to compare the importance of the two performance objectives for off-site releases of radionuclides listed above. The analysis showed that, at the SRS, the performance objective for protection of groundwater should be more restrictive for any radionuclide than the performance objective for exposures of 
off-site individuals from all exposure pathways. That is, if the lower dose limit from direct consumption of contaminated groundwater is met, then the higher dose limit from all exposure pathways will also be met without the need for further analysis of the exposure pathways other than direct consumption of drinking water.

Therefore, in the dose analysis for off-site individuals, only the following exposure pathway needs to be cunsidered:

- direct ingestion of contaminated drinking water from a source of groundwater beyond the boundary of the disposal site.

This exposure pathway must be considered at any time after disposal.

\section{A432 Exposure Scenarios and Pathways for Inadvertent Intruders}

In estimating doses to inadvertent intruders after the period of active institutional control (i.e., at any time beyond 100 years after closure of the disposal facility), it is assumed that such individuals could establish a permanent homestead on the site. Furthermore, it is assumed that an intruder has no a priori knowledge of waste disposal activities at the site. Inadvertent intruders are assumed to receive radiation exposures from use of contaminated groundwater obtained from a well on the disposal site and from direct intrusion into waste disposal units or contaminated soil next to disposal units.

Exposures of inadvertent intruders to radionuclides in contaminated groundwater are assumed to occur in conjunction with any of the scenarios involving direct intrusion into waste disposal units or contaminated soil described below, and the exposure pathways, involving use of contaminated groundwater are assumed to be the same as those listed in Sect. A.4.3.1 for off-site individuals. However, because the requirements for protection of groundwater beyond the boundary of the disposal site (i.e., the limit on effective dose equivalent of 4 mrem per year from direct consumption of groundwater) is much more stringent than the dose limits for protection of inadvertent intruders taking into account all exposure pathways (i.e., limits on effective dose equivalent of 100 mrem per year for chronic exposures and 500 mrem for occasional exposures), exposures to contaminated groundwater can be neglected in the dose analysis for inadvertent intruders (see Sect. 3.2.4.1).

For direct intrusion into disposal units or contaminated soil next to disposal units after loss of active institutional control, exposures are assumed to occur according to one of three scenarios, which are called the agriculture, resident, and post-drilling scenarios. Other scenarios which were considered but shown to be less important are discussed in Sect. 3.24. The three scenarios considered in this analysis and their associated exposure pathways are described as follows. 
In the agriculture scenario, an intruder is assumed to build a home directly on top of the disposal facility, and the foundation is assumed to extend either into disposal units or into contaminated soil above disposal units. Radioactive wastes exhumed during excavation for the foundation are assumed to be indistinguishable from native soil, and some of the exhumed waste is assumed to be mixed with native soil in the intruder's vegetable garden. The following pathways involving exposure to radionuclides in solid waste then are assumed to occur:

- ingestion of vegetables grown in contaminated garden soil;

- direct ingestion of contaminated soil, primarily in conjunction with intakes of vegetables from the garden;

- external exposure to contaminated soil while working in the garden or residing in the home on top of the disposal facility; and

- inhalation of radionuclides attached to soil particles that are suspended into air from contaminated soil while working in the garden or residing in the home.

Inhalation of volatile radionuclides, principally $\mathrm{H}-3, \mathrm{C}-14$, and isotopes of $\mathrm{Rn}$, while working in the garden or residing in the home also was considered in the dose analysis (see Appendix A.3), but this pathway was found to be unimportant compared with the pathways listed above.

In the resident scenario, an intruder also is assumed to excavate at the location of the disposal facility but is assumed to encounter an intact engineered barrier (i.e, a reinforced concrete roof or saltstone monolith) used in constructing the disposal units which cannot readily be penetrated by the types of excavation equipment normally used near the SRS. Therefore, instead of excavating into the waste, the intruder is assumed to build a home immediately on top of the intact engineered barrier. Since wastes in the disposal facility are not directly accessed during excavation, due to the assumed impenetrability of the engineered barriers, the only exposure pathway of concern for this scenario is external exposure to photon-emitting radionuclides in the saltstone while residing in the home. Any exposure to contaminated soil next to disposal units is taken into account in the agriculture scenario described above.

In the post-drilling scenario, an intruder is assumed to access solid waste by drilling either through a disposal unit or through contaminated soil next to a disposal unit, e.g., for the purpose of constructing a well for the intruder's domestic water supply. However, as discussed in Sect. 3.2.4.1, only drilling through contaminated soil next to a disposal unit is assumed to be relevant for the performance assessment for the SDF, because it is assumed that the agriculture scenario involving direct excavation into disposal units first becomes credible at the same time after disposal as the post-drilling scenario involving drilling directly through a disposal unit and the agriculture scenario always results in higher doses per unit concentration of radionuclides in solid waste. This assumption is believed to be valid because the types of drilling equipment normally used near the SRS could not easily penetrate an intact saltstone monolith. Only if all of the saltstone weathered into soil-equivalent material before a significant amount of the cover 
material for the disposal facility were removed by erosion could the post-drilling scenario for intrusion into a disposal unit be relevant; but, on the basis of the estimated weathering rate for saltstone and erosion rate for the cover material given in Sect. 3.2.4.1, such an occurrence seems extremely unlikely.

During drilling through contaminated soil next to a disposal unit, a small volume of radioactive waste is brought to the surface, and all of the drilling waste is assumed to be mixed with native soil in the intruder's vegetable garden. The following pathways involving exposure to radionuclides in the solid waste then are assumed to occur:

- ingestion of vegetables grown in contaminated soil;

- direct ingestion of contaminated soil, primarily in conjunction with intakes of vegetables from the garden;

- external exposure to contaminated soil while working in the garden; and

- inhalation of radionuclides attached to soil particles that are suspended into air from contaminated soil while working in the garden.

As in the agriculture scenario, inhalation of volatile radionuclides while working in the garden was found to be relatively unimportant.

The pathways listed above for the post-drilling scenario correspond to some of the pathways assumed for the agriculture scenario. However, in the post-drilling scenario, external and inhalation exposures while residing in the home are not relevant, because all of the drilling waste is assumed to be mixed with soil in the intruder's vegetable garden.

\section{A.4.4 Dose Conversion Factors for Internal and External Exposure}

From the descriptions of the assumed exposure scenarios and pathways given in Sect. A.4.3, doses to off-site individuals and inadvertent intruders are assumed to result from ingestion and inhalation of radionuclides and from external exposure to photonemitting radionuclides. This section presents the factors used in the dose analyses to convert intakes of radionuclides via ingestion and inhalation to internal doses and to convert concentrations of radionuclides in the environment to external dose rates.

The internal dose conversion factors for ingestion and inhalation of radionuclides are given in Tables A.4-2 and A.4-3, respectively. These factors give 50-year committed effective dose equivalents per unit activity intake of each radionuclide. The entries for any short-lived decay products of a longer-lived radionuclide do not take into account the branching fraction in the decay of the parent radionuclide; i.e., the values for each decay product assume the same unit intake of activity $(1 \mu \mathrm{Ci})$. The internal dose conversion factors, which apply to reference adults, are those currently recommended for use by the U.S.DOE (1988b) in assessing radiation doses to the public. 
Table A.42 Internal dose conversion factors for ingestion of radionuclides

\begin{tabular}{llc}
\hline Radionuclide $^{b}$ & $\mathrm{f}_{i}{ }^{e}$ & Rem $/$ MCi ingested \\
\hline H-3 & 1.0 & $6.3 \times 10^{-5}$ \\
C-14 & 1.0 & $2.1 \times 10^{-3}$ \\
Ni-63 & 0.05 & $5.4 \times 10^{-4}$ \\
Se-79 & 0.8 & $8.3 \times 10^{-3}$ \\
Sr-90 & 0.3 & $1.3 \times 10^{-1}$ \\
\multicolumn{1}{c}{ Y-90 } & 0.0001 & $1.0 \times 10^{-2}$ \\
Tc-99 & 0.8 & $1.3 \times 10^{-3}$ \\
Sn-121m & 0.02 & $1.3 \times 10^{-3}$ \\
Sn-126 & 0.02 & $1.7 \times 10^{-2}$ \\
\multicolumn{1}{c}{ Sb-126 } & 0.1 & $9.0 \times 10^{-3}$ \\
I-129 & 1.0 & $2.8 \times 10^{-1}$ \\
Cs-137 & 1.0 & $5.0 \times 10^{-2}$ \\
Sm-151 & 0.0003 & $3.4 \times 10^{-4}$ \\
Pu-238 & 0.001 & 3.8 \\
Pus239 & 0.001 & 4.3 \\
Am-241 & 0.001 & 4.5 \\
\hline
\end{tabular}

- Values adopted by U.S.DOE (1988b) give 50-year committed effective dose equivalents per unit activity ingested.

- Indented entries are radiologically significant short-lived decay products of parent radionuclide listed. Dose-rate conversion factors for decay products do not take into account branching fraction in decay of parent.

- Fraction of ingested radionuclide absorbed into blood from GI tract. 
Table A4-3. Internal dose conversion factors for inhalation of radionuclides

\begin{tabular}{lcc}
\hline Radionuclide $^{b}$ & Clearance class $^{c}$ & Rem/ $\mu \mathrm{Ci}$ inhaled \\
\hline H-3 & & $6.3 \times 10^{-5}$ \\
C-14 & & $2.1 \times 10^{-3}$ \\
Ni-63e & D & $3.0 \times 10^{-3}$ \\
Se-79 & W & $8.9 \times 10^{-3}$ \\
Sr-90 & Y & 1.3 \\
Tc-99 & W & $7.5 \times 10^{-3}$ \\
Sn-121m & D & $5.8 \times 10^{-3}$ \\
Sn-126 & D & $8.6 \times 10^{-2}$ \\
Sb-126 & D & $4.6 \times 10^{-3}$ \\
Cs-137 & D & $3.2 \times 10^{-2}$ \\
Sm-151 & W & $2.9 \times 10^{-2}$ \\
Pu-238 & W & $4.6 \times 10^{2}$ \\
Pu-239 & W & $5.1 \times 10^{2}$ \\
Am-241 & W & $5.2 \times 10^{2}$ \\
\hline
\end{tabular}

- Values adopted by U.S.DOE (1988b) give 50-year committed effective dose equivalents per unit activity inhaled.

- Indented entries are radiologically significant short-lived decay products of parent radionuclide listed. Dose-rate conversion factors for decay products do not take into account branching fraction in decay of parent.

- Clearance from respiratory passages for radionuclides in particulate form in a matter of days (D), weeks (W), or years (Y).

Radionuclide is assumed to be in organic form.

- Radionuclide is assumed to be in inorganic form. 
For some radionuclides, more than one dose conversion factor for ingestion or inhalation has been tabulated by the U.S.DOE (1988b). Whenever ingestion dose conversion factors are given for two GI-tract absorption fractions, the value corresponding to the higher absorption fraction is adopted in Table A.4-2, because radionuclides that are transported in water or through terrestrial foodchains should be in relatively soluble form and more easily absorbed in the GI tract. This procedure does not always give the higher dose conversion factor, but the value corresponding to the lower GI-tract absorption fraction differs from the adopted value in such cases by less than $10 \%$. If inhalation dose conversion factors are given for more than one lung clearance class, the clearance class giving the highest value is adopted in Table A.4-3, except all isotopes of Sn are assumed to be Class D for consistency.

Dose conversion factors for external exposure give dose-equivalent rates per unit concentration of radionuclides in the environment. These factors depend on the distribution of radionuclides in the source region, the amount of self-shielding provided by material in the source region, and the shielding provided by any material between the source region and the location of an exposed individual. Therefore, separate sets of dose conversion factors are required for the assumed pathways involving external exposure to 1) activity in contaminated soil while working in the vegetable garden (i.e., in the agriculture and post-drilling scenarios), 2) activity in exposed waste while residing in the home at the disposal site (i.e., in the agriculture and resident scenarios), and 3) activity in waste shielded by intact engineered barriers while residing in the home at the disposal site (i.e., in the resident scenario).

For external exposure to radionuclides in disposal units or in soil, the source region is assumed to be a uniformly contaminated slab of infinite lateral extent. Depending upon the particular exposure scenario and pathway, the slab is assumed to have either finite or infinite thickness, and the shielding provided by uncontaminated material between the source and receptor locations is taken into account. The idealized distributions of radionuclides in the source region assumed in the dose analysis are reasonable, because only about $1 \mathrm{~m}$ of soil-equivalent material between the source and receptor locations provides essentially complete shielding (Kocher and Sjoreen 1985).

In all calculations of external dose, an exposed individual is assumed to be located at a distance of $1 \mathrm{~m}$ above ground. In all cases, the shielding provided by $1 \mathrm{~m}$ of air is negligible compared with the shielding provided by the material in the source region itself or by the thickness of uncontaminated material (e.g., an intact concrete roof) between the source and receptor locations.

For external exposure while working in the vegetable garden, the source region is assumed to be a uniformly contaminated slab of soil with a thickness of $15 \mathrm{~cm}$, which is a typical depth of a plowed layer. The external dose-rate conversion factors for this case are given in Table A.4-4. 
Table A.44. External dose-rate conversion factors for radionuclides uniformbly distributed in $15 \mathrm{~cm}$ of surface soir

\begin{tabular}{cc}
\hline Radionuclide $^{b}$ & $\begin{array}{c}\text { Dose-rate factor } \\
\left(\text { rem/y per } \mu \mathrm{Ci} / \mathrm{m}^{3}\right)\end{array}$ \\
\hline Sn-126 & $8.6 \times 10^{-5}$ \\
Sb-126m & $6.7 \times 10^{-3}$ \\
Sb-126 & $1.2 \times 10^{-2}$ \\
I-129 & $1.8 \times 10^{-5}$ \\
Cs-137 & - \\
Ba-137m & $2.6 \times 10^{-3}$ \\
Am-241 & $2.7 \times 10^{-5}$ \\
\hline
\end{tabular}

- Values give effective dose-equivalent rates from external exposure per unit activity concentration in soil at distance of $1 \mathrm{~m}$ from source region and are based on calculations for monoenergetic photon sources (Kocher and Sjoreen 1985) and energies and intensities of photons emitted in decay of radionuclides (Kocher 1981).

- Indented entries are radiologically significant short-lived decay products of parent radionuclide listed. Dose-rate conversion factors for decay products do not take into account branching fraction in decay of parent. 
For external exposure while residing in the home in the agriculture scenario, the source region is assumed to be a slab of soil-equivalent material of essentially infinite thickness, with no shielding assumed between the source region and the receptor location other than that provided by the material in the source region itself. Shielding provided by the walls of the home during indoor residence is taken into account in the dose analysis itself. The external dose-rate conversion factors for this case are given in the column in Table A.4-5 labeled "No shielding".

For external exposure while residing in the home in the resident scenario, the source region also is assumed to be a slab of soil-equivalent material of infinite thickness. As described in Sect. 3.2.4.2, the maximum external dose in the resident scenario can be bounded by considering two limiting cases. The first is exposure to shorter- and longerlived photon-emitting radionuclides at the time active institutional control ceases at 100 years after facility closure when an intact concrete roof plus the layer of uncontaminated grout on top of the saltstone provides $75 \mathrm{~cm}$ of shielding between the source and receptor locations. The second case is exposure to longer-lived photonemitting radionuclides only at a time long after disposal when the concrete roof has lost its physical integrity, the layer of uncontaminated grout has weathered to soil, and exposure to an unshielded saltstone monolith could occur. Furthermore, as described in Sect. 3.2.4.4, a screening analysis for the resident scenario identified only four radionuclides t/at possibly could be of concern - namely, shorter-lived Cs-137 and longerlived Sn-126, I-129, and Am-241. For the first case of saltstone shielded by intact engineered barriers, the external dose-rate conversion factors for Sn-126, Cs-137, and their short-lived decay products are given in the column in Table A.4-5 labeled 75-cm shielding". The photon energies from decay of I-129 and Am-241 are too low to be of concern for this amount of shielding. For the second case of unshielded saltstone, the external dose-rate conversion factors for all radionuclides of concern are given in the column in the same table labeled "No shielding". Again, shielding provided by the walls of the home during indoor residence is taken into account in the dose analysis itself.

The external dose-rate conversion factors in Tables A.4-4 and A.4-5 are obtained from calculations of absorbed dose rates in air from monoenergetic photon sources in soil (Kocher and Sjoreen 1985) and the spectrum of photons emitted in the decay of each radionuclide (Kocher 1981). The entries for any short-lived decay products of a longer-lived radionuclide do not take into account the branching fraction in the decay of the parent radionuclide; i.e., the values for each decay product assume exposure to the same unit activity concentration $\left(1 \mu \mathrm{Ci} / \mathrm{m}^{3}\right)$. In all calculations, absorbed doses in air are converted to effective dose equivalents by multiplying by a factor of 0.8 . This is a reasonable approximation for all photon energies above $0.1 \mathrm{MeV}$ and provides a conservative overestimate of effective dose equivalents at lower photon energies which are less important in calculations of external dose.

Rev. 0 
Table A45. External dose-rate conversion factors for radionuclides uniformly distributed in infinite thickness of soil-equivalent materiar

\begin{tabular}{|c|c|c|}
\hline \multirow{2}{*}{ Radionuclide ${ }^{b}$} & \multicolumn{2}{|c|}{$\begin{array}{l}\text { Dose-rate factor } \\
\text { (rem/y per } \mu \mathrm{Ci} / \mathrm{m}^{3} \text { ) }\end{array}$} \\
\hline & No shielding & 75-cm shielding \\
\hline Sn-126 & $8.7 \times 10^{-5}$ & - \\
\hline Sb-126m & $7.9 \times 10^{-3}$ & $2.3 \times 10^{-6}$ \\
\hline $\mathrm{Sb}-126$ & $1.4 \times 10^{-2}$ & $4.9 \times 10^{-6}$ \\
\hline I-129 & $1.8 \times 10^{-5}$ & - \\
\hline Cs-137 & - & - \\
\hline Ba-137m & $3.0 \times 10^{-3}$ & $8.8 \times 10^{-7}$ \\
\hline Am-241 & $2.7 \times 10^{-5}$ & - \\
\hline
\end{tabular}

- Values give effective dose-equivalent rates from external exposure per unit activity concentration in soil at distance of $1 \mathrm{~m}$ from source region and are based on calculations for monoenergetic photon sources (Kocher and Sjoreen 1985) and energies and intensities of photons emitted in decay of radionuclides (Kocher 1981).

- Indented entries are radiologically significant short-lived decay products of parent radionuclide listed. Dose-rate conversion factors for decay products do not take into account branching fraction in decay of parent.

Rov. 0 


\section{A.45 Modek and Parameter Values for Exposure Pathways}

This section presents the models used to calculate doses to off-site individuals and inadvertent intruders for the various exposure pathways considered in this analysis that involve use of contaminated water or direct intrusion into disposal units or contaminated soil next to disposal units. In each case, the parameter values assumed in implementing the models also are presented. For each exposure pathway, the results are presented in summary tables which give annual effective dose equivalents per unit concentration of radionuclides in the appropriate environmental medium. The unit concentrations to which the dose estimates are normalized are the concentrations at the time exposures are assumed to occur, rather than the concentrations at the time of disposal.

\section{A.45.1 Exposure Pathways for Off-Site Individuals}

As discussed in Sect. 3.2.3.3 and A.4.3.1, direct consumption of drinking water from a source of contaminated groundwater is the only exposure pathway that needs to be considered in the dose analysis for off-site individuals, because the assumed limit on effective dose equivalent of $\mathbf{4}$ mrem per year from the drinking water pathway only is expected to be more restrictive for any radionuclide than the limit on effective dose equivalent of 25 mrem per year from all exposure pathways.

The annual effective dose equivalent (rem per year) from direct ingestion of radionuclide $i$ in drinking water $(w)$ is given by

$$
H_{i w}=C_{w} U_{w} D_{b}
$$

where

$\mathrm{C}_{\mathrm{w}}=$ concentration of radionuclide $\mathrm{i}$ in drinking water $(\mu \mathrm{Ci} / \mathrm{L})$,

$U_{w}=$ annual consumption of drinking water (L/year), and

$D_{i}=$ dose conversion factor for ingestion of radionuclide $i(\mathrm{rem} / \mu \mathrm{Ci})$.

In implementing the model, a daily consumption of contaminated drinking water of $2 \mathrm{~L}$, i.e., an annual consumption of $730 \mathrm{~L}$, is assumed.

The model for estimating dose from the drinking water pathway is summarized in Table A.4-6. The radionuclides listed in this table are those selected on the basis of a screening analysis for the groundwater pathway described in Sect. 3.23.4. The annual dose per unit concentration of a radionuclide in water is obtained by multiplying the assumed annual consumption of drinking water by the ingestion dose conversion factor given in Table A.4-2. 
Table A46. Annual effective doce equivalents from drinking water pathway per unit concentration of radionuclides in water

\begin{tabular}{lc}
\hline Radionuclide & $\begin{array}{c}\text { Annual effective dose equivalent } \\
\text { (rem/y per } \mu \mathrm{Ci} / \mathrm{L} \text { ) }\end{array}$ \\
\hline H-3 & $4.6 \times 10^{-2}$ \\
C-14 & 1.5 \\
Se-79 & 6.1 \\
Sr-90 + d & $1.0 \times 10^{2}$ \\
Tc-99 & $9.5 \times 10^{-1}$ \\
Sn-126 + d & $1.3 \times 10^{1}$ \\
I-129 & $2.0 \times 10^{2}$ \\
Cs-137 & $3.7 \times 10^{1}$ \\
Pu-238 & $2.8 \times 10^{3}$ \\
Am-241 & $3.3 \times 10^{3}$ \\
\hline
\end{tabular}

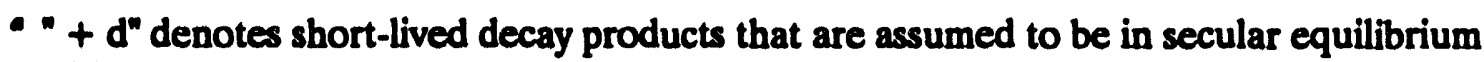
with parent radionuclide; see Table A-1 for decay products and branching fractions.

Rev. 0 


\section{A4.5.2 Exposure Pathways for Inadvertent Intruders}

As described in Sects. 3.2.4 and A.4.3.2, exposures of inadvertent intruders resulting from direct intrusion into disposal units or into contaminated soil next to disposal units are assumed to occur according to the agriculture, resident, or post-drilling scenarios. This section presents the models and parameter values used to estimate doses to inadvertent intruders for each of these scenarios.

\section{Agriculture Scenario}

In the agriculture scenario, exposures of inadvertent intruders are assumed to result when an intruder exhumes waste from disposal units or from soil next to disposal units while excavating to build a foundation for a home on top of the disposal facility, and some of the exhumed waste is mixed with native soil in a vegetable garden. The exposure pathways assumed for this scenario then include: 1) ingestion of vegetables grown in contaminated soil, 2) direct ingestion of contaminated soil, 3) external exposure to contaminated soil while working in the garden and residing in the home on top of the disposal facility, and 4) inhalation of suspended activity in particulate form while working in the garden and residing in the home. The model for each pathway is described below. The radionuclides included in the dose analysis for the agriculture scenario were selected on the basis of a screening analysis described in Sect. 3.2.4.4.

The annual effective dose equivalent (rem per year) from ingestion of radionuclide $i$ in vegetables $(v)$ is given by where

$$
H_{4 v}=C_{k v} U_{v} D_{i v}
$$

- $\mathrm{C}_{\mathrm{w}}=$ concentration of radionuclide $\mathrm{i}$ in vegetables ( $\left.\mu \mathrm{Ci} / \mathrm{kg}\right)$,

$\mathrm{U}_{\mathrm{v}}=$ annual consumption of vegetables (kg fresh weight per year), and

$D_{i}=$ dose conversion factor for ingestion of radionuclide $i(r e m / \mu \mathrm{Ci})$.

Radionuclides are assumed to be transferred to vegetables via root uptake from the contaminated garden soil, and the radionuclide concentrations in vegetables are given by

$$
\begin{aligned}
C_{w v} & =B_{w} C_{i v} / \rho_{s} \\
& =B_{w w} C_{i} / P_{w}
\end{aligned}
$$

where

$B_{k v}=$ plant-to-soil concentration ratio for radionuclide $i(\mu \mathrm{Ci} / \mathrm{kg}$ fresh weight in vegetation per $\mu \mathrm{Ci} / \mathrm{kg}$ dry weight in soil),

$C_{i b}=$ concentration of radionuclide $i$ in soil in vegetable garden $\left(\mu \mathrm{Ci} / \mathrm{m}^{3}\right)$,

$p_{1}=$ density of soil $\left(\mathrm{kg} / \mathrm{m}^{3}\right)$,

$C_{i t}=$ concentration of radionuclide $i$ in exhumed waste $\left(\mu \mathrm{Ci} / \mathrm{m}^{3}\right)$, and

$\mathbf{f}_{\mathbf{f}}$ = dilution factor for mixing of radionuclides in exhumed waste into soil in vegetable garden. 
In implementing the model, the assumed plant-to-soil concentration ratios in vegetables are given in Table A.4-7. Except for Tc, which is discussed below, the adopted values for all elements are based entirely on published data, evaluations, and compilations which are generic in nature; i.e., the concentration ratios are not based on data from the SRS. Thus, selection of these concentration ratios for use at the SRS is clearly judgmental, but the adopted values are intended to represent reasonable average values, rather than the maximum values reported in any compilation.

The adopted plant-to-soil concentration ratio for Tc in Table A.47 is based on the following considerations. The generic value adopted by $\mathrm{Ng}$ et al (1982) is $\mathrm{B}_{\mathrm{v}}=5$. This value presumably applies to the highly soluble pertechnetate form $\left(\mathrm{TcO}_{4}\right)$ which is readily available for root uptake by plants. In one lysimeter study of root uptake from soil at the SRS (Murphy 1990), saltstone containing Tc placed in soil did not contain slag as in the final formulation of saltstone for waste disposal (see Sect. 2.3). In this study, Tc in saltstone was found to be highly soluble and readily available for root uptake, and the estimated plant-to-soil concentration ratio was consistent with the value adopted by $\mathrm{Ng}$ et aL (1982) given above and with other similar reported values (Vandecasteele et al. 1989). However, in a second lysimeter study at the SRS (Clark and Wilhite 1991), the saltstone contained slag as in the final formulation for disposal. In this case, Tc in saltstone presumably is in the relatively insoluble sulfide form ( $\left.\mathrm{TC}_{2} \mathrm{~S}_{7}\right)$ and, thus, is less available for root uptake. Indeed, in the second study, the average concentration of Tc collected in sump water from the lysimeter was a factor of 0.012 less than the average concentration in sump water obtained in the first lysimeter study. Although Tc in vegetation was not measured in the second study, the amount of Tc that would be transferred to vegetation by root uptake presumably is directly proportional to the amount of Tc transferred from saltstone into soil water. Therefore, we conclude from the two lysimeter studies that a reasonable value of $\mathrm{B}_{v}$ for $\mathrm{Tc}$ in saltstone for soil at the SRS is approximately $5 \times 0.012=0.06$, and this value is adopted for use in this analysis.

The other parameter values assumed in the model for the vegetable pathway are as follows: a dilution factor for mixing of radionuclides in exhumed waste into native soil in the vegetable garden of 0.2 (Napier et al. 1984), a soil density of $1,400 \mathrm{~kg} / \mathrm{m}^{3}$ (Baes et al. 1984), and an annual consumption of contaminated vegetables of $90 \mathrm{~kg}$ on a freshweight basis. The assumed dilution factor for mixing of exhumed waste with native soil in a vegetable garden of 0.2 is based on the reasonable assumption that only a relatively small fraction of the soil in the vegetable garden could contain exhumed waste in order for the garden to be productive, particularly when the exhumed waste is saltstone itself. The assumed yearly consumption of vegetables of $90 \mathrm{~kg}$ is based on data obtained near the SRS (Hamby 1992), which indicate a total yearly consumption of all vegetables by an average adult of $180 \mathrm{~kg}$, and the assumption that half of an intruder's total intake of vegetables is obtained from the home garden. An assumption that an intruder's entire intake of all vegetables would be obtained from the home garden is regarded as unreasonably conservative. 
Table A47. Elemental plant-to-eil concentration ratios in vegetables

\begin{tabular}{|c|c|c|}
\hline Element & $\mathbf{B}_{-}^{-}$ & Reference \\
\hline $\mathbf{H}$ & 4.8 & U.S.NRC (1977) \\
\hline C & $3.3 \times 10^{-1}$ & Sheppard et al. $(1991)^{b, e}$ \\
\hline $\mathbf{N i}$ & $3.3 \times 10^{-2}$ & Ng et al. (1982) \\
\hline Se & $6.3 \times 10^{-3}$ & Bacs et al (1984) \\
\hline Sr & $1.6 \times 10^{-1}$ & Ng et al. (1982) \\
\hline $\mathbf{Y}$ & $2.4 \times 10^{-2}$ & Ng et al. (1982) \\
\hline Tc & $6.0 \times 10^{-2}$ & See footnote $f$ \\
\hline Sn & $7.5 \times 10^{-3}$ & Baes et al. $(1984)^{b}$ \\
\hline Sb & $5.0 \times 10^{-2}$ & Bacs et al. $(1984)^{b}$ \\
\hline $\mathbf{I}$ & $1.4 \times 10^{-2}$ & Ng et al (1982) \\
\hline Cs & $9.5 \times 10^{-3}$ & Ng et al. (1982)d \\
\hline Sm & $4.8 \times 10^{-3}$ & Ng et al (1982) \\
\hline Pu & $1.1 \times 10^{-4}$ & Baes et al $(1984)^{b}$ \\
\hline Am & $1.4 \times 10^{-3}$ & Baes et al. $(1984)^{b}$ \\
\hline
\end{tabular}

- $\mu \mathrm{Ci} / \mathrm{kg}$ fresh weight in vegetation per $\mu \mathrm{Ci} / \mathrm{kg} \mathrm{dry}$ weight in soil.

- Value reported on basis of dry weight of vegetation is converted to fresh-weight basis by multiplying by factor of 0.25 (U.S.NRC 1977).

- Value based on measurements in acidic soil with low organic-matter content.

Arithmetic mean of reported measurements.

- Value is factor of ten higher than arithmetic mean of reported measurements for Ce.

$f$ Value based on concentration ratio for $\mathrm{Tc}$ adopted by $\mathrm{Ng}$ et al (1982) and results of lysimeter studies of leaching of Tc from saltstone waste forms at SRS by Murphy (1990) and Clark and Wilhite (1991); see text for further discussion.

- Value is factor of two higher than arithmetic mean of reported measurements for Ce. 
The model for estimating dose from the vegetable pathway is summarized in Table A.4-8. The annual dose per unit concentration of a radionuclide in exhumed waste at the time intrusion occurs is based on the model and parameter values described above and the ingestion dose conversion factors given in Table A.42.

The annual effective dose equivalent (rem per year) from direct ingestion of radionuclide $i$ in contaminated soil (s) is given by

$$
H_{\text {is }}=C_{i s} U_{s} D_{i}
$$

where

$\mathrm{C}_{\mathrm{b}}=$ concentration of radionuclide $\mathrm{i}$ in soil in vegetable garden $(\mu \mathrm{Ci} / \mathrm{kg})$,

$U_{3}=$ annual consumption of contaminated soil (kg/year), and

$D_{i}=$ dose conversion factor for ingestion of radionuclide $i(r e m / \mu \mathrm{Ci})$.

Ingestion of contaminated soil is assumed to occur primarily as a result of incomplete washing of vegetables from the garden before consumption. At a humid site with extensive vegetation, as at the SRS, direct ingestion of contaminated soil from sources other than the garden should be relatively unimportant for an average adult. Radionuclide concentrations in soil in the vegetable garden are given by

$$
C_{i n}=f_{i} C_{i d} / \rho_{v}
$$

where

$C_{i t}=$ concentration of radionuclide $i$ in exhumed waste $\left(\mu \mathrm{Ci} / \mathrm{m}^{3}\right)$,

$f_{i}=$ dilution factor for mixing of radionuclides in exhumed waste into soil in vegetable garden, and

$p_{\text {s }}=$ density of soil $\left(\mathrm{kg} / \mathrm{m}^{3}\right)$.

In implementing the model, a dilution factor for mixing of radionuclides in exhumed waste into native soil in the vegetable garden of 0.2 and a soil density of $1,400 \mathrm{~kg} / \mathrm{m}^{3}$ are assumed, as in the model for the vegetable pathway. A daily consumption of contaminated soil from the vegetable garden of $0.1 \mathrm{~g}$, i.e., an annual consumption of $0.037 \mathrm{~kg}$, also is assumed (EG\&G Idaho 1986).

The model for estimating dose from the soil ingestion pathway is summarized in Table A.4-9. The annual dose per unit concentration of a radionuclide in exhumed waste at the time intrusion occurs is based on the model and parameter values described above and the ingestion dose conversion factors given in Table A.4-2. 
Table A48. Annual effective dose equivalents from vegetable pathway per unit concentration of radionuclides in eshumed waste for agriculture scenario

\begin{tabular}{lc}
\hline Radionuclide & $\begin{array}{c}\text { Annual effective dose equivalent } \\
\left(\text { rem/y per } \mu \mathrm{Ci} / \mathrm{m}^{3}\right)\end{array}$ \\
\hline H-3 & $3.9 \times 10^{-6}$ \\
C-14 & $8.9 \times 10^{-6}$ \\
Ni-63 & $2.3 \times 10^{-7}$ \\
Se-79 & $6.7 \times 10^{-7}$ \\
Sr-90 + d & $2.7 \times 10^{-4}$ \\
Tc-99 & $1.0 \times 10^{-6}$ \\
Sn-121m & $1.3 \times 10^{-7}$ \\
Sn-126+d & $2.4 \times 10^{-6}$ \\
I-129 & $5.0 \times 10^{-5}$ \\
Cs-137 & $6.1 \times 10^{-6}$ \\
Sm-151 & $2.1 \times 10^{-8}$ \\
Pu-238 & $5.4 \times 10^{-6}$ \\
Pu-239 & $6.1 \times 10^{-6}$ \\
Am-241 & $8.1 \times 10^{-5}$ \\
\hline
\end{tabular}

- " $+\mathrm{d}^{n}$ denotes short-lived decay products that are assumed to be in secular equilibrium with parent radionuclide; see Table A.4-1 for decay products and branching fractions. 
Table A49. Annual effective dose equivalents from soil ingestion pathway per unit concentration of radionuclides in exhumed waste for agriculture scenario

\begin{tabular}{lc}
\hline Radionuclide & $\begin{array}{c}\text { Annual effective dose equivalent } \\
\text { (rem/y per } \mu \mathrm{Ci} / \mathrm{m}^{3} \text { ) }\end{array}$ \\
\hline H-3 & $3.3 \times 10^{-10}$ \\
C-14 & $1.1 \times 10^{-8}$ \\
Ni-63 & $2.9 \times 10^{-9}$ \\
Se-79 & $4.4 \times 10^{-5}$ \\
Sr-90 + d & $7.4 \times 10^{-7}$ \\
Tc-99 & $6.9 \times 10^{-9}$ \\
Sn-121m & $6.9 \times 10^{-9}$ \\
Sn-126 + d & $9.7 \times 10^{-8}$ \\
I-129 & $1.5 \times 10^{-6}$ \\
Cs-137 & $2.6 \times 10^{-7}$ \\
Sm-151 & $1.8 \times 10^{-9}$ \\
Pu-238 & $2.0 \times 10^{-5}$ \\
Pu-239 & $2.3 \times 10^{-5}$ \\
Am-241, & $2.4 \times 10^{-5}$ \\
\hline
\end{tabular}

- " $+\mathrm{d}$ " denotes short-lived decay products that are assumed to be in secular equilibrium with parent radionuclide; see Table A.4-1 for decay products and branching fractions. 
For external exposure (e) to contaminated soil while working in the vegetable garden, the annual effective dose equivalent (rem per year) from radionuclide $i$ is given by

$$
H_{60}=C_{2} U_{8} D_{b}
$$

where

$C_{i}=$ concentration of radionuclide $i$ in soil in vegetable garden $\left(\mu \mathrm{Ci} / \mathrm{m}^{3}\right)$,

$\mathrm{U}_{\mathrm{g}}=$ fraction of the year during which external exposure to contaminated soil in vegetable garden occurs, and

$D_{h}=$ dose-rate conversion factor for external exposure to radionuclide $i$ in garden soil $\left(\mathrm{rem} / \mathrm{y}\right.$ per $\left.\mu \mathrm{Ci} / \mathrm{m}^{3}\right)$.

As in the models for the vegetable and soil ingestion pathways, the radionuclide concentrations in soil in the vegetable garden are given by

$$
C_{i b}=f_{3} C_{i b}
$$

where

$C_{i t}=$ concentration of radionuclide $i$ in exhumed waste $\left(\mu \mathrm{Ci} / \mathrm{m}^{3}\right)$, and

$f_{\mathbf{f}}=$ dilution factor for mixing of radionuclides in exhumed waste into soil in vegetable garden.

In implementing the model, a dilution factor for mixing of radionuclides in exhumed waste into native soil in the vegetable garden of 0.2 is assumed, as in the models for the vegetable and soil ingestion pathways. The fraction of the year during which exposure while working in the garden occurs is assumed to be 0.01 (Oztunali et al. 1981); i.e., the assumed exposure time is about $100 \mathrm{~h} / \mathrm{year}$.

The model for estimating external dose while working in the garden is summarized in Table A.4-10. The annual dose per unit concentration of a radionuclide in exhumed waste at the time intrusion occurs is based on the model and parameter values described above and the external dose-rate conversion factors given in Table A.4-4.

For external exposure during residence in a home on top of exposed disposal units or on contaminated soil above disposal units, the annual effective dose equivalent (rem per year) from radionuclide $i$ is given by

$$
H_{i e}=C_{i n} U_{b} D_{i n} S \text {, }
$$


Tabls, A.4-10. Annual effective dose equivalents from external exposure in vegetable garden per unit concentration of radionuclides in chimed waste for agriculture scenario

\begin{tabular}{lc} 
Radionuclide & $\begin{array}{c}\text { Annual effective dose equivalent } \\
\text { (rem/y per } \mu \mathrm{Ci} / \mathrm{m}^{3} \text { ) }\end{array}$ \\
\hline Sn-126+d & $1.7 \times 10^{-5}$ \\
$\mathrm{I}-129$ & $3.6 \times 10^{-8}$ \\
Cs-137 + d & $4.9 \times 10^{-6}$ \\
Am-241 & $5.4 \times 10^{-8}$ \\
\hline
\end{tabular}

- " $+\mathrm{d}$ " denotes short-lived decay products that are assumed to be in secular equilibrium with parent radionuclide; see Table A.4-1 for decay products and branching fractions. 
where

$\mathrm{C}_{\mathbf{n}}=$ concentration of radionuclide $\mathrm{i}$ in disposal units or contaminated soil above disposal units $\left(\mu \mathrm{Ci} / \mathrm{m}^{3}\right)$,

$U_{k}$ = fraction of the year during which external exposure while residing in the home occurs,

$D_{\mathfrak{k}}=$ dose-rate conversion factor for external exposure to radionuclide $\mathrm{i}$ in saltstone or soil (rem/y per $\mu \mathrm{Ci} / \mathrm{m}^{3}$ ), and

$\mathbf{S}=$ shielding factor for radionuclides during indoor residence.

The shielding factor takes into account the reduction in external dose provided by the walls and floor of the home.

In implementing the model, the fraction of the year during which exposure in the home is assumed to occur is 0.5 (Oztunali et al. 1981); i.e., the assumed exposure time is about $4,000 \mathrm{~h} / y e a r$. A shielding factor during iudoor residence of 0.7 is assumed for all radionuclides (U.S.NRC 1977).

The model for estimating external dose during indoor residence is summarized in Table A.4-11. The annual dose per unit concentration of a radionuclide in the disposal units or in contaminated soil above disposal units at the time intrusion occurs is based on the model and parameter values described above and the external dcse-rate conversion factors for scurces uniformly distributed in an infinite thickness of soilequivalent material given in the column in Table A.4-5 labeled "No shielding".

While working in the vegetable garden or residing in the home, the annual effective dose equivalent (rem per year) from inhalation of radionuclide $i$ suspended into air (a) in particulate form is given by

$$
H_{i \mathbf{a}}=C_{i n} f_{a} U_{a} D_{i} \text {, }
$$

where

$C_{i n}=$ concentration of radionuclide $i$ in air $\left(\mu \mathrm{Ci} / \mathrm{m}^{3}\right)$,

$f_{a}=$ fraction of the year during which inhalation exposure occurs,

$U_{2}=$ annual air intake ( $\mathrm{m}^{3} /$ year $)$, and

$D_{i}=$ dose conversion factor for inhalation of radionuclide $i(r e m / \mu C i)$. 
Table A.411. Annual effective dose equivalents from external exposure in home per unit concentration of radionuclides in soil at bomesite for agriculture scenario"

\begin{tabular}{lc}
\hline Radionuclide $^{b}$ & $\begin{array}{c}\text { Annual effective dose equivalent } \\
\left(\text { rem/y per } \mu \mathrm{Ci} / \mathrm{m}^{3}\right)\end{array}$ \\
\hline Sn-126 + d & $3.5 \times 10^{-3}$ \\
$\mathrm{I}-129$ & $6.3 \times 10^{-6}$ \\
Cs-137 + d & $1.0 \times 10^{-3}$ \\
Am-241 & $9.5 \times 10^{-6}$ \\
\hline
\end{tabular}

- Results apply to radionuclide concentrations in exposed disposal units or in soil above disposal units.

- " $+\mathrm{d}$ " denotes short-lived decay products that are assumed to be in secular equilibrium vith parent radionuclide; see Table A.4-1 for decay products and branching fractions. 
Concentrations of suspended radionuclides in air are estimated using a mass-loading model (Anspaugh et al. 1975), which is based on observations of airborne concentrations of naturally occurring materials, such as uranium and thorium, relative to their concentrations in surface soils. In this model, airborne concentrations of radionuclides are given by

$$
C_{\text {in }}=C_{\text {in }} L_{d} / \rho_{0}
$$

where

$C_{i}=$ concentration of radionuclide $i$ in surface soil $\left(\mu \mathrm{Ci} / \mathrm{m}^{3}\right)$,

$L_{\mathbf{a}}=$ atmospheric mass loading of surface soil $\left(\mathrm{kg} / \mathrm{m}^{3}\right)$, and

$p_{1}=$ density of soil $\left(\mathrm{kg} / \mathrm{m}^{3}\right)$.

For inhalation exposure while working in the vegetable garden, the concentration of radionuclide $i$ in soil again is given by

$$
C_{i=}=E_{i b}
$$

where

$C_{i t}=$ concentration of radionuclide $i$ in exhumed waste $\left(\mu \mathrm{Ci} / \mathrm{m}^{3}\right)$, and

$\mathrm{f}_{\mathbf{f}}=$ dilution factor for mixing of radionuclides in exhumed waste into soil in vegetable garden.

In implementing the model, a dilution factor for mixing of radionuclides in exhumed waste into native soil in the garden of 0.2 , a soil density of $1,400 \mathrm{~kg} / \mathrm{m}^{3}$, and a fraction of the year during which exposure while working in the garden occurs of 0.01 (about $100 \mathrm{~h}$ /year) again are assumer, and the annual air intake is assumed to be $8,000 \mathrm{ml}^{3}$ (U.S.NRC 1977). Finally, the atmospheric mass loading of contaminated soil whil: working in the garden is assumed to be $10^{-7} \mathrm{~kg} / \mathrm{m}^{3}$.

The assumed atmospheric mass loading of contaminated soil while woiking in the vegetable garden of $10^{-7} \mathrm{~kg} / \mathrm{m}^{3}$ is a somewhat conservative approximation of the average background value for nonurban locations in the U.S. of about $4 \times 10^{-8} \mathrm{~kg} / \mathrm{m}^{3}$ (Anspaugh et al. 1975) and, furthermore, is in good agreement with an average dust loading of $6 \times 10^{-5} \mathrm{~kg} / \mathrm{m}^{3}$ measured above two agricultural fields at the SRS (Shinn et al. 1982). The choice of an atmospheric mass loading for this exposure pathway is based on these data and the following considerations. Although some gardening activities presumably would increase atmospheric concentrations of suspended soil above background levels, it probably is unreasonable to assume that the average concentration during all gardening activities would be substantially above the average background level in the U.S. First, the average background level of suspended soil originating from the SRS should be substantially lower than the average level in the U.S., because of the high annual 
precipitation, extensive vegetation, and low average wind speed at the site. Second, at any location, airborne concentrations of suspended surface soil consist of material originating from a wide area, not just from the particular location where exposures occur. Finally, the model assumes that all suspended soil particles are respirable; but, particularly during more vigorous gardening activities that result in higher than average atmospheric mass loadings, some particles are likely to be too large to be respirable. Taking into account all of these factors, the choice of $10^{-7} \mathrm{~kg} / \mathrm{m}^{3}$ to represent the average mass loading during gardening activities at the SRS seems reasonable.

The model for estimating inhalation dose while working in the vegetable garden is summarized in Table A.412. The annual dose per unit concentration of a radionuclide in exhumed waste at the time intrusion occurs is based on the model and parameter values described above and the inhalation dose conversion factors given in Table A.4-3.

For inhalation exposure while residing in the home, the airborne concentration of radionuclide $i$ is given by

$$
C_{b}=C_{i r} I / P_{0}
$$

where

$$
\begin{aligned}
& C_{i t}=\text { concentration of radionuclide } \mathrm{i} \text { in disposal units or contaminated soil next to } \\
& \text { disposal units }\left(\mu \mathrm{Ci} / \mathrm{m}^{3}\right) \text {, } \\
& \mathrm{L}_{\mathbf{2}}=\text { atmospheric mass loading of surface soil }\left(\mathrm{kg} / \mathrm{m}^{3}\right) \text {, and } \\
& \rho_{\mathbf{1}}=\text { density of soil }\left(\mathrm{kg} / \mathrm{m}^{3}\right) \text {. }
\end{aligned}
$$

In implementing the model, a fraction of the year during which exposure in the home occurs of 0.5 (i.e., about $4,000 \mathrm{~h} /$ year), a soil density of $1,400 \mathrm{~kg} / \mathrm{m}^{3}$, and an annual air intake of $8,000 \mathrm{~m}^{3}$ again are assumed. The atmospheric mass loading of contaminated soil at the location of the disposal facility is assumed to be $10^{-8} \mathrm{~kg} / \mathrm{m}^{3}$, which is approximately one-fourth of the average background value in the U.S. (Anspaugh et al. 1975). On the basis of the previous discussion of the atmospheric mass loading while working in the vegetable garden, it seems unreasonable to assume that the atmospheric mass loading of largely undisturbed surface soil at the SRS would be as high as the average value in the U.S. The assumption that the atmospheric mass loading of contaminated soil at the disposal site is about one-fourth of the average background level in the U.S. is intended to take into account the abundant precipitation, extensive vegetation, and low average wind speed at the site, as well as the presence of uncontaminated soil suspended from other locations and the possibility that some suspended soil particles may not be respirable. In addition, the model for inhalation exposure indoors does not take into account the possibility that indoor concentrations of suspended soil particles may be somewhat less than the concentrations outdoors. 
Table A412 Annual effective dose equivalents from inhalation exposure in vegetable garden per unit concentration of radionuclides in cochumed waste for agriculture scenario

\begin{tabular}{lc}
\hline Radionuclide & $\begin{array}{c}\text { Annual effective dose equivalent } \\
\text { (rem/y per } \mu \text { Ci/m } \text { m }^{*}\end{array}$ \\
\hline H-3 & $7.2 \times 10^{-14}$ \\
C-14 & $2.4 \times 10^{-12}$ \\
Ni-63 & $3.4 \times 10^{-12}$ \\
Se-79 & $1.0 \times 10^{-11}$ \\
Sr-90 & $1.5 \times 10^{-9}$ \\
Tc-99 & $8.6 \times 10^{-12}$ \\
Sn-121m & $6.6 \times 10^{-12}$ \\
Sn-126 + d & $9.9 \times 10^{-11}$ \\
I-129 & $2.1 \times 10^{-10}$ \\
Cs-137 & $3.7 \times 10^{-11}$ \\
Sm-151 & $3.3 \times 10^{-11}$ \\
Pu-238 & $5.3 \times 10^{-7}$ \\
Pu-239 & $5.8 \times 10^{-7}$ \\
Am-241 & $5.9 \times 10^{-7}$ \\
\hline
\end{tabular}

- " $d$ " denotes short-lived decay products that are assumed to be in secular equilibrium with parent radionuclide; see Table A.4-1 for decay products and branching fractions. 
The model for estimating inhalation dose during indoor residence is summarized in Table A.4-13. The annual dose per unit ancentration of a radionuclide in the disposal units or in contaminated soil above disposal units at the time intrusion occurs is based on the model and parameter values described above and the inhalation dose conversion factors given in Table A.4-3.

For the agriculture scenario, the annual dose from all exposure pathways per unit concentration of radionuclides in the disposal units or in contaminated soil above disposal units at the time intrusion occurs is summarized in Table A.4-14. The total dose is the sum of the doses from the vegetable, soil ingestion, external exposure, and inhalation pathways given in Tables A.4-8 through A.4-13.

Given the models and parameter values assumed in dose analysis for the agriculture scenario, the most important exposure pathways depend on the particular radionuclide. For most of the fission and activation products, the vegetable pathway is by far the most important. However, for the photon-emitting radionuclides Sn-126 and Cs-137, external exposure while residing in the home is the only important pathway. This pathway also contributes to the total dose for I-129. For several of the fission and activation products, the soil ingestion pathway is a minor contributor to the total dose, but the inhalation pathways are never important. For the transuranic radionuclides, the vegetable and soil ingestion pathways and inhalation exposure while residing in the home are important contributors to the total dose. For Am-241, external exposure during indoor residence also is a minor contributor. For Pu-238 and Pu-239, which are assumed to have a low plant-to-soil concentration ratio, the soil ingestion pathway is more important than the vegetable pathway.

The models for the exposure pathways involving mixing of exhumed waste with native soil in a vegetable garden may be somewhat conservative for radionuclides that are highly mobile in surface soil, because the models assume that the concentration in soil during the first year after mixing is not reduced as a result of leaching and transport to deeper soil layers by infiltrating precipitation. Thus, for mobile radionuclides, the average concentration in surface soil during the first year after mixing, which is the appropriate concentration for calculating the maximum annual dose to an intruder, could be substantially less than the initial concentration after mixing, and the annual dose per unit concentration in exhumed waste could be correspondingly overestimated.

The radionuclides for which leaching from surface soil in a vegetable garden by infiltrating precipitation could reduce the annual dose per unit concentration in exhumed waste include H-3, C-14, Tc-99, and I-129. In each case, a leaching model described in Sect. 3.2.3.3 (Baes and Sharp 1983) could be used to estimate the average concentration in surface soil during the first year after mixing of exhumed waste with native soil. However, for the following reasons, a correction to the dose estimates based on this leaching model has not been applied in this analysis. 
Table A.4-13. Annual effective dose equivalents from inhalation exposure in home per unit concentration of radionuclides in soil at bomesite for agriculture scenariof

\begin{tabular}{lc}
\hline Radionuclide & $\begin{array}{c}\text { Annual effective dose equivalent } \\
\left.\text { (rem/y per } \mu \mathrm{Ci} / \mathrm{m}^{3}\right)\end{array}$ \\
\hline H-3 & $1.8 \times 10^{-12}$ \\
C-14 & $6.0 \times 10^{-11}$ \\
Ni-63 & $8.6 \times 10^{-11}$ \\
Se-79 & $2.5 \times 10^{-10}$ \\
Sr-90 & $3.7 \times 10^{-3}$ \\
Tc-99 & $2.1 \times 10^{-10}$ \\
Sn-121m & $1.7 \times 10^{-10}$ \\
Sn-126 + d & $2.5 \times 10^{-9}$ \\
I-129 & $5.1 \times 10^{-9}$ \\
Cs-137 & $9.1 \times 10^{-10}$ \\
Sm-151 & $8.3 \times 10^{-10}$ \\
Pu-238 & $1.3 \times 10^{-5}$ \\
Pu-239 & $1.5 \times 10^{-5}$ \\
Am-241 & $1.5 \times 10^{-5}$ \\
\hline
\end{tabular}

- Results apply to radionuclide concentrations in exposed disposal units or in soil above disposal units.

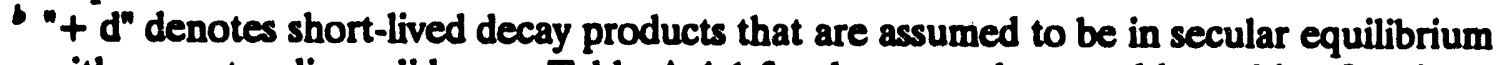
with parent radionuclide; see Table A.4-1 for decay products and branching fractions.

Rev. 0 
Table A4-14. Annual effective dose equivalents per unit concentration of radionuclides from all exposure pathways for agriculture scenario"

\begin{tabular}{lc}
\hline Radionuclide & $\begin{array}{c}\text { Annual effective dose equivalent } \\
\text { (rem/y per } \mu \mathrm{Ci} / \mathrm{m}^{3} \text { ) }\end{array}$ \\
\hline H-3 & $3.9 \times 10^{-6}$ \\
C-14 & $8.9 \times 10^{-6}$ \\
Ni-63 & $2.3 \times 10^{-7}$ \\
Se-79 & $7.1 \times 10^{-7}$ \\
Sr-90 + d & $2.7 \times 10^{-4}$ \\
Tc-99 & $1.0 \times 10^{-6}$ \\
Sn-121m & $1.4 \times 10^{-7}$ \\
Sn-126 + d & $3.5 \times 10^{-3}$ \\
I-129 & $5.8 \times 10^{-5}$ \\
Cs-137 + d & $1.0 \times 10^{-3}$ \\
Sm-151 & $2.4 \times 10^{-8}$ \\
Pu-238 & $3.9 \times 10^{-5}$ \\
Pu-239 & $4.5 \times 10^{-5}$ \\
Am-241. & $1.3 \times 10^{-4}$ \\
\hline
\end{tabular}

- Results are sum of doses in Tables A.4-8 through A.4-13 and apply to radionuclide concentrations in exposed disposal units or in soil above disposal units.

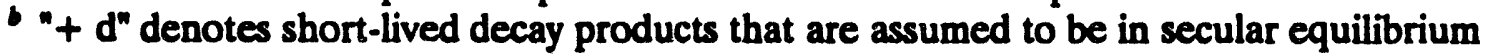
with parent radionuclide; see Table A.4-1 for decay products and branching fractions.

Rev. 0 
For H-3, which is expected to be removed from the soil root zone (i.e., the first $30 \mathrm{~cm}$ of surface soil) at the same rate as infiltrating water, the leaching correction described above would reduce the annual dose per unit concentration in exhumed waste by about a factor of five. However, the uncorrected dose per unit concentration in Table A.4-14 combined with the maximum concentration in the disposal facility at 100 years after disposal, as obtained from Table C.1-1, yields an upper bound for the effective dose equivalent of only about 0.4 mrem per year. Thus, H-3 could not contribute a significant dose to an intruder and the leaching correction can be ignored.

For the other radionuclides listed above (i.e., C-14, Tc-99, and I-129), the assumption of a small but non-zero distribution coefficient $\left(K_{d}\right)$ in surface soil would reduce the annual dose per unit concentration in exhumed waste by less than a factor of two. Thus, the leaching correction undoubtedly is considerably less than the uncertainty in the plant-to-soil concentration ratio $\left(B_{v}\right)$, which is the most important parameter in determining the dose from these radionuclides in the agriculture scenario. Furthermore, there is considerable evidence, based on data from the SRS, that the usual assumption of a low distribution coefficient for Tc-99 and I-129 may overestimate considerably the removal rate from the soil root zone for a substantial fraction of the activity initially mixed into surface soil (Clark and Wilhite 1991; Kocher 1991). Therefore, application of a leaching correction may not be valid for these radionuclides.

\section{Resident scenario}

In the resident scenario, exposures of inadvertent intruders are assumed to result when an intruder encounters an intact and impenetrable engineered barrier (i.e., a concrete roof or saltstone monolith) while excavating to build a foundation for a home at the disposal site. An intruder is assumed to build the home immediately on top of the intact engineered barrier and receives an external exposure while residing in the home. Ingestion and inhalation exposures are precluded when the waste is assumed to be inaccessible during excavation.

External dose in the resident scenario is estimated using the model given in Eq. (A.4-8). In implementing the model, the fraction of the year for indoor residence is assumed to be 0.5 and the shielding factor during indoor residence is assumed to be 0.7, as in implementing Eq. (A.4-8) for the agriculture scenario. The dose-rate conversion factor for each radionuclide is the external effective dose-equivalent rate per unit concentration in the disposal units taking into account the shielding provided by the material in the source region (i.e., saltstone) and by a concrete roof and layer of uncontaminated grout if the latter are assumed to be intact.

As described in Sect. 3.2.4.1 and A.4.4, only two bounding cases need to be considered in evaluating potential doses in the resident scenario. The first is exposure to $\mathrm{Cs}-137$ and $\mathrm{Sn}-126$ in the saltstone at 100 years after disposal when the concrete roof and layer of uncontaminated grout beneath the roof are assumed to be intact. At this time, the engineered barriers provide $75 \mathrm{~cm}$ of shielding. The second case is exposure 

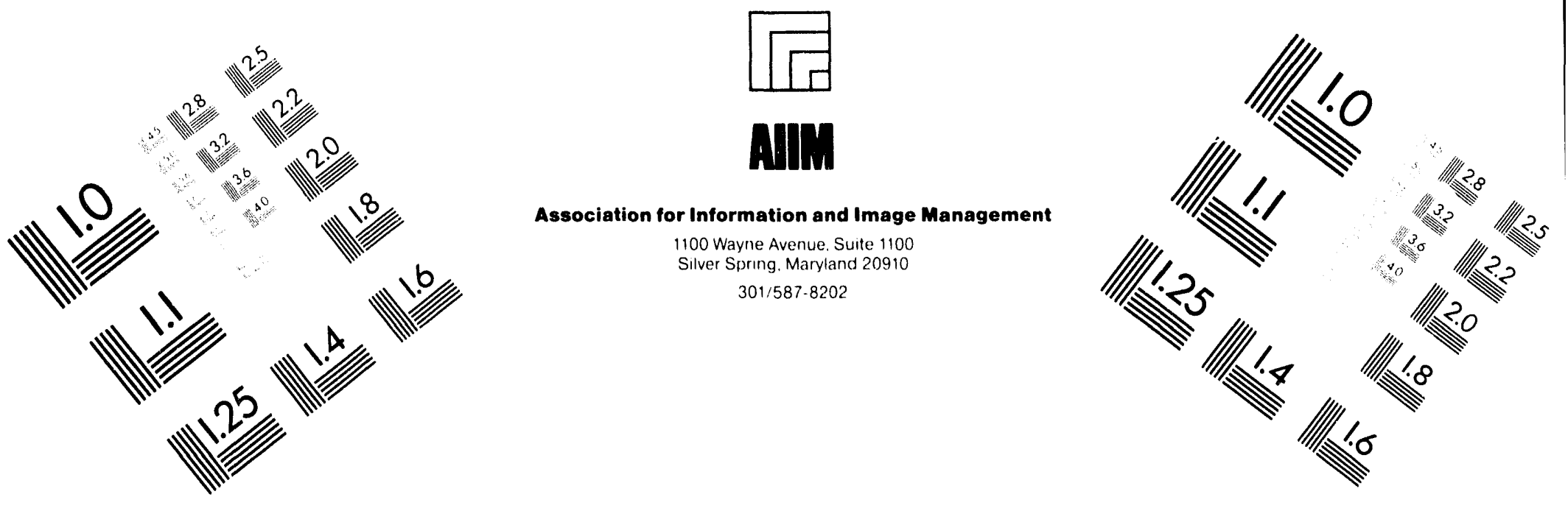

\section{Centimeter}

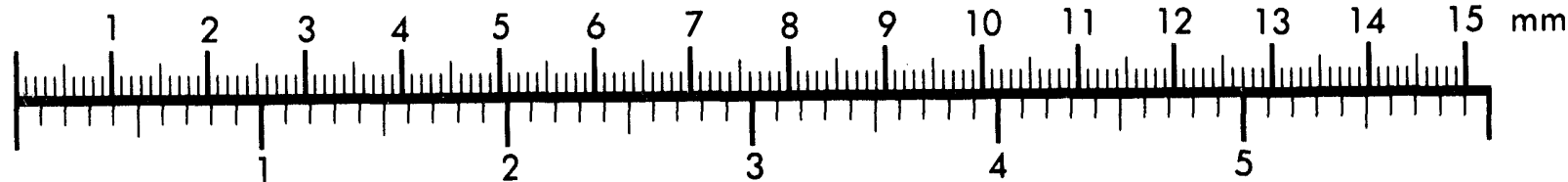

Inches
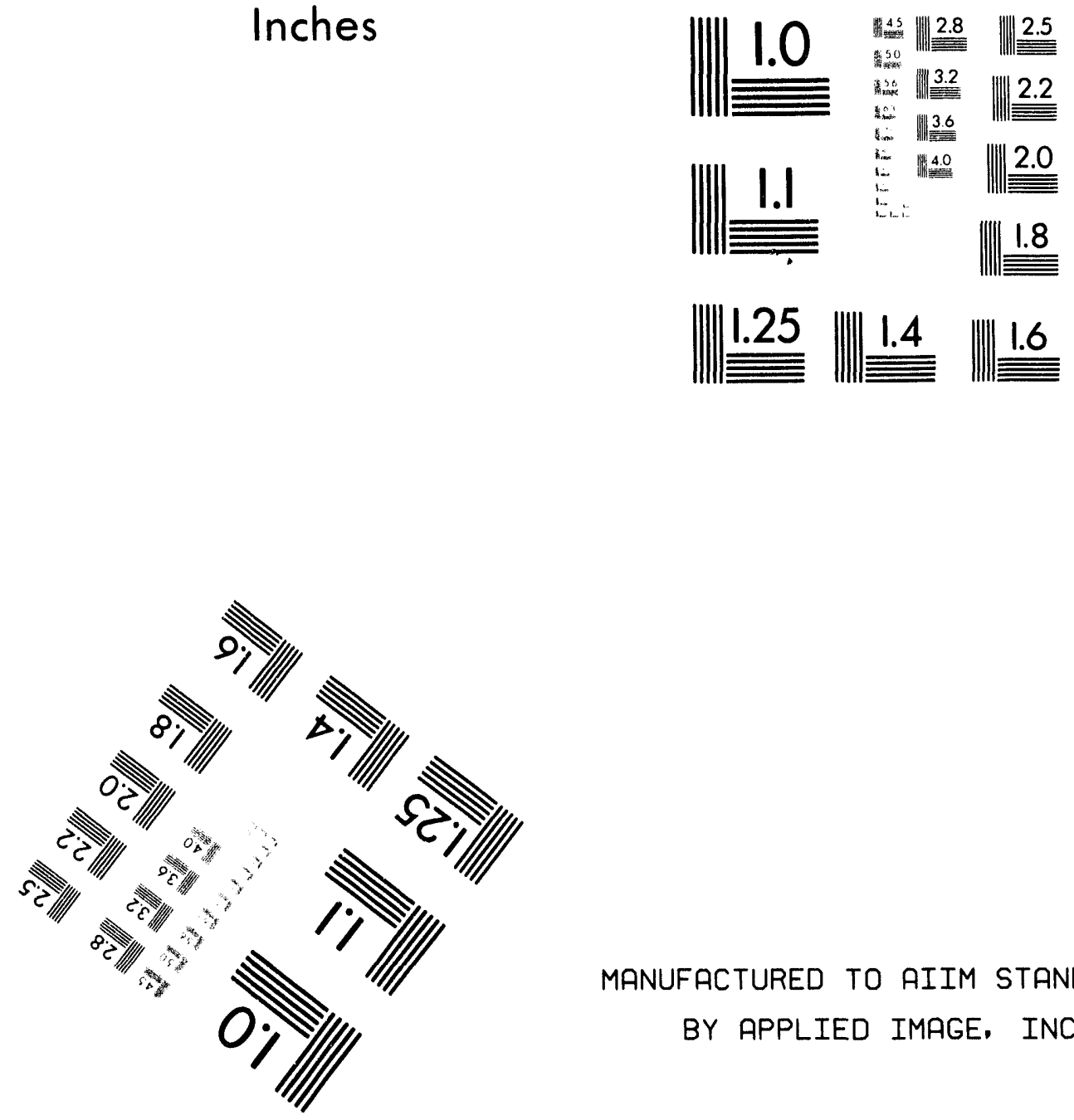

MANUFACTURED TO AIIM STANDARDS

BY APPLIED IMAGE, INC.

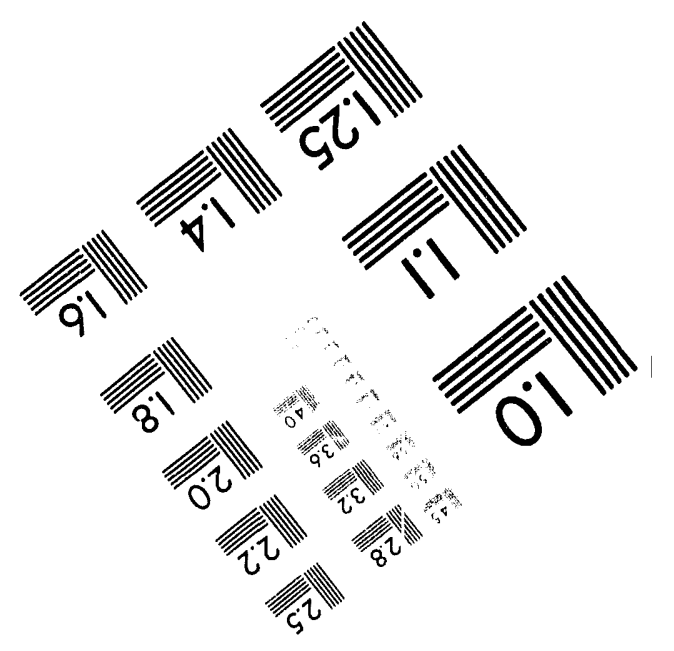



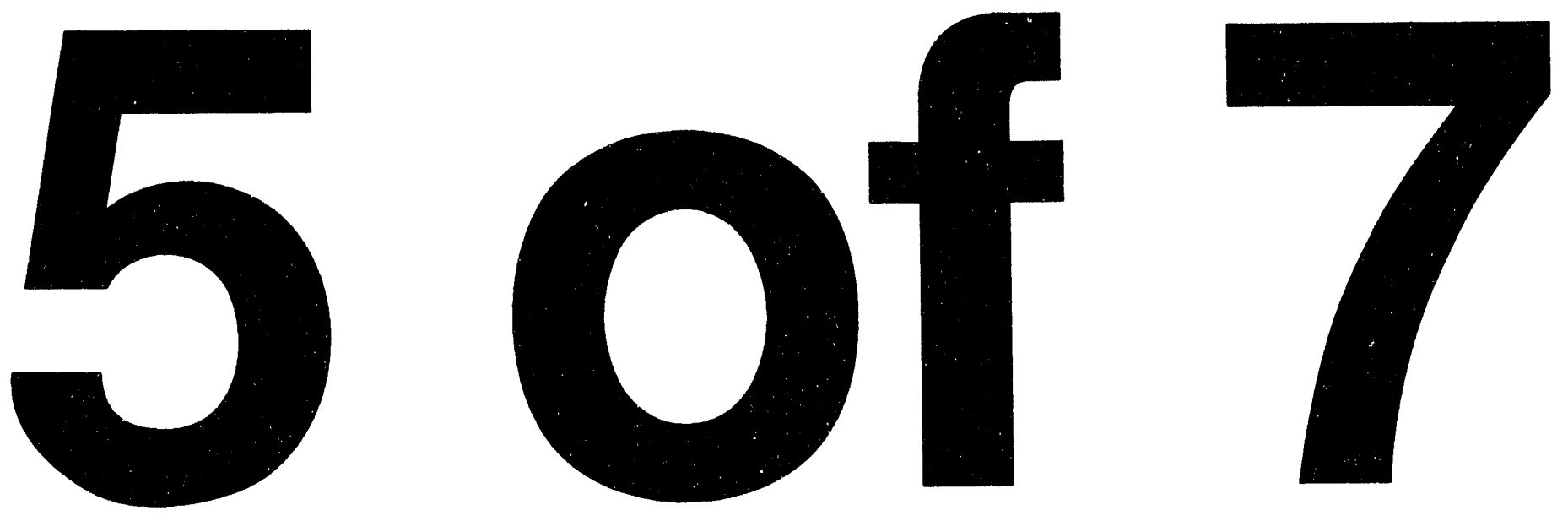
to Sn-126, I-129, and Am-241 in unshielded saltstone at a time long after disposal when the concrete roof has lost its physical integrity, the layer of uncontaminated grout has weathered to soil, and the Cs-137 has decayed to innocuous levels.

The model for estimating external dose in the resident scenario is summarized in Table A.4-15, which gives the annual dose per unit concentration of radionuclides in the disposal units at the time intrusion occurs for the two bounding cases of intact or nonexistent engineered barriers described above. The results are obtained from the assumed exposure time and shielding factor during indoor residence and the external dose-rate conversion factors for the radionuclides of concern given in the two columns in Table A.4-5. For the case of external exposure to unshielded saltstone, it is evident that I-129 and Am-241 would be of concern only if their concentrations in saltstone are much greater than those for Sn-126.

\section{Post-drilling scenario}

In the post-drilling scenario, exposures of inadvertent intruders are assumed to result when an intruder drills through contaminated material, e.g., for the purpose of constructing a well for a domestic water supply. As described in Sect. 3.2.4.1 and A.4.3.2, the post-drilling scenario is assumed to be relevant only for drilling through contaminated soil next to disposal units. The entire amount of drilling waste is assumed to be mixed with native soil in a vegetable garden, and the exposure pathways assumed for this scenario then include: 1) ingestion of vegetables grown in contaminated garden soil, 2) direct ingestion of contaminated soil in conjunction with vegetable intakes, 3 ) external exposure to contaminated soil while working in the garden, and 4) inhalation of suspended activity in particulate form while working in the garden. The radionuclides included in the dose analysis for the post-drilling scenario were selected on the basis of a screening analysis described in Sect. 3.2.4.4.

The exposure pathways for the post-drilling scenario are similar to those for the agriculture scenario described previously, except external and inhalation exposures during indoor residence do not occur in the post-drilling scenario since all of the exhumed waste is assumed to be mixed with native soil in the vegetable garden and the intruder's home is not located on top of exposed disposal units. Therefore, the models given by Eqs. (A.4-2) and (A.4-3) for the vegetable pathway, Eqs. (A.4-4) and (A.4-5) for the soil ingestion pathway, Eqs. (A.4-6) and (A.4-7) for external exposure while working in the garden, and Eqs. (A.4-9) through (A.4-11) for inhalation exposure while working in the garden also apply to the post-drilling scenario. 
Table A.415. Annual effective dose equivalents per unit concentration of radionuclides in disposal units for resident scenario

\begin{tabular}{lcc}
\hline & \multicolumn{2}{c}{$\begin{array}{c}\text { Annual effective dose equivalent } \\
\left(\mathrm{rem} / \mathrm{y} \text { per } \mu \mathrm{Ci} / \mathrm{m}^{3}\right)\end{array}$} \\
\cline { 2 - 3 } Radionuclide & No shielding $^{6}$ & $75-\mathrm{cm}^{6}$ shielding \\
\hline Sn-126+d & $3.5 \times 10^{-3}$ & $1.0 \times 10^{-6}$ \\
$\mathrm{I}-129$ & $6.3 \times 10^{-6}$ & - \\
Cs-137+d & - & $2.9 \times 10^{-7}$ \\
Am-241 & $9.5 \times 10^{-6}$ & - \\
\hline
\end{tabular}

- " $+\mathrm{d}$ " denotes short-lived decay products that are assumed to be in secular equilibrium with parent radionuclide; see Table A.4-1 for decay products and branching fractions.

- Results apply at times long after disposal when engineered barriers are assumed to have lost their physical integrity and residence on unshielded saltstone is assumed to occur.

- Results apply at 100 years after facility closure when engineered barriers are assumed to be intact and residence on unshielded saltstone is precluded. 
In implementing the models for the different exposure pathways, most of the parameter values for the post-drilling scenario would be the same as the values assumed for the agriculture scenario. The one important exception is the dilution factor for mixing of radionuclides in exhumed waste with native soil in the vegetable garden, which is denoted by $\mathrm{f}_{r}$. For all exposure pathways in the post-drilling scenario, the dose per unit concentration of a radionuclide in exhumed waste is directly proportional to this dilution factor.

In this scenario, the volume of contaminated drilling waste is assumed to be $0.5 \mathrm{~m}^{3}$ (Kennedy et al. 1983), and this material is assumed to be mixed to a depth of $15 \mathrm{~cm}$ in a vegetable garden of area about $200 \mathrm{~m}^{2}$. The assumed area of the garden reasonably could provide half of the entire yearly intake of all vegetables by an intruder, which is the value assumed in this analysis. Therefore, the volume of soil in the garden into which the drilling waste is mixed is about $30 \mathrm{~m}^{3}$, and the resulting dilution factor is about 0.02. The assumed dilution factor for the post-drilling scenario thus is a factor of ten less than the value 0.2 assumed for the agriculture scenario. Therefore, for any exposure pathway in the post-drilling scenario, the dose per unit concentration of a radionuclide in exhumed waste is a factor of ten less than the corresponding value for the same pathway in the agriculture scenario.

For the post-drilling scenario, the annual dose from all exposure pathways per unit concentration of radionuclides in exhumed waste at the time intrusion occurs, as obtained from the models and parameter values described above, is summarized in Table A.4-16. The dose per unit concentration from the vegetable, soil ingestion, external exposure, and inhalation pathways again is one-tenth of the corresponding values for the agriculture scenario in Tables A.4-8 through A.4-10 and A.412, respectively.

Since all of the exposure pathways for the post-drilling scenario involve mixing of exhumed waste into surface soil in a vegetable garden, the leaching correction for highly mobile radionuclides discussed previously with the agriculture scenario also could be applied in this case. However, for the reasons previously discussed; a leaching correction is not applied in the dose analysis for the post-drilling scenario.

\section{A.4.6 Summary}

This appendix has presented the models and data bases used in estimating annual effective dose equivalents to 1) off-site individuals resulting from exposure to radionuclides in contaminated groundwater and 2) inadvertent intruders resulting from direct intrusion into the SDF. In each case, particular exposure scenarios and associated exposure pathways have been assumed. The scenarios and pathways chosen for analysis and the radionuclides selected for the dose analysis for each scenario were based on considerations discussed in Sect. 3.2.3 and 3.2.4. Other scenarios, pathways, and radionuclides that might be considered in the dose analyses were shown to be insignificant. For each exposure pathway, simple models for estimating dose have been developed, and annual doses per unit concentration of radionuclides in groundwater or 
Table A4-16. Annual effective dose equivalents per unit concentration of radionuclides in exhumed waste for post-drilling scenario"

\begin{tabular}{lc}
\hline Radionuclide ${ }^{b}$ & $\begin{array}{c}\text { Annual effective dose equivalent } \\
\text { (rem/y per } \mu \mathrm{Ci} / \mathrm{m}^{3} \text { ) }\end{array}$ \\
\hline H-3 & $3.9 \times 10^{-7}$ \\
Se-79 & $7.1 \times 10^{-8}$ \\
Sr-90 + d & $2.7 \times 10^{-5}$ \\
Tc-99 & $1.0 \times 10^{-7}$ \\
Sn-126 + d & $1.9 \times 10^{-6}$ \\
I-129 & $5.2 \times 10^{-6}$ \\
Cs-137 + d & $1.1 \times 10^{-6}$ \\
Sm-151 & $2.3 \times 10^{-9}$ \\
Pu-238 & $2.6 \times 10^{-6}$ \\
Am-241 & $1.1 \times 10^{-5}$ \\
\hline
\end{tabular}

- Values are one-tenth the sum of doses for agriculture scenario in Tables A.4-8 through A.4-10 and A.4-12.

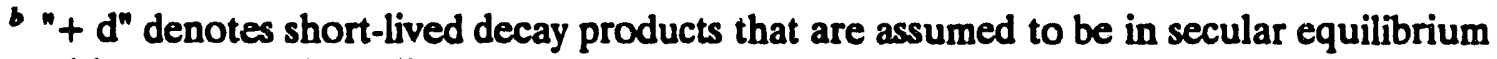
with parent radionuclide; see Table A.4-1 for decay products and branching fractions. 
in solid waste have been estimated on the basis of assumed parameter values for the particular pathway models.

For each exposure scenario, the annual doses per unit concentration of a radionuclide for each exposure pathway have been combined to obtain the total dose per unit concentration from all pathways. The following summary tables give the total dose per unit concentration at the time intrusion occurs for the different exposure scenarios:

- Table A.4-6, exposure of off-site individuals to radionuclides in contaminated groundwater via the drinking water pathway;

- Table A.4-14, agriculture scenario for exposure of inadvertent intruders to radionuclides in disposal units or in contaminated soil above disposal units;

- Table A.4-15, resident scenario for exposure of inadvertent intruders to photonemitting radionuclides in disposal units; and

- Table A.4-16, post-drilling scenario for exposure of inadvertent intruders to radionuclides in contaminated soil next to disposal units.

The dose analyses for each exposure scenario and exposure pathway were based on certain model parameters, some of which are radionuclide- or element-specific and others of which are independent of radionuclide. The radionuclide- or element-specific parameter values are given in Tables A.4-2 through A.4-5 and A.4-7. The parameter values that are independent of radionuclide are summarized in Table A.4-17.

For the three scenarios involving direct intrusion into the SDF, the radionuclide concentrations in the disposal units or in contaminated soil next to disposal units to which the annual doses obtained in this analysis are normalized are the concentrations at the time intrusion is assumed to occur, rather that the concentrations at the time of disposal. That is, the dose analysis for these scenarios presented in this appendix does not include any assumptions about the time after disposal at which intrusion occurs, except in the case of the resident scenario where bounding calculations based on intrusion at 100 years after disposal or at times long after disposal were performed. In most cases, assumptions about the time intrusion occurs are applied when the results of the intruder dose analyses in this appendix are combined with the results of the performance assessments for the disposal facility, which yield predictions of the concentrations of radionuclides remaining in the disposal units or in the environment near disposal units as a function of time after disposal. 
Table A4-17. Summary of radionuclide-independent parameter values used in dose analyses for off-site individuals and inadvertent intruders

\begin{tabular}{|c|c|c|}
\hline Parameter description & Symbol & Parameter value \\
\hline Consumption of contaminated drinking water & $\mathrm{U}_{w}$ & 730 L/year \\
\hline Consumption of contaminated vegetables ${ }^{b}$ & $\mathbf{U}_{\mathbf{v}}$ & $\begin{array}{l}90 \mathrm{~kg} \text { (fresh weight) per } \\
\text { year }\end{array}$ \\
\hline Density of soil & P. & $1,400 \mathrm{~kg} / \mathrm{m}^{3}$ \\
\hline $\begin{array}{l}\text { Dilution factor for mixing of exhumed waste } \\
\text { with native soil in vegetable garden }\end{array}$ & f. & $\begin{array}{l}0.2^{2} \\
0.02^{d}\end{array}$ \\
\hline Consumption of contaminated soil ${ }^{b}$ & $U_{0}$ & $0.037 \mathrm{~kg} /$ year \\
\hline $\begin{array}{l}\text { Exposure times - } \\
\text { working in garden } \\
\text { residing in home }\end{array}$ & $\begin{array}{l}U_{g} \\
U_{k}\end{array}$ & $\begin{array}{l}1 \% \text { per year } \\
50 \% \text { per year }\end{array}$ \\
\hline $\begin{array}{l}\text { Shielding factor for external exposure during } \\
\text { indoor residence }\end{array}$ & $\mathbf{S}$ & 0.7 \\
\hline Air intake (breathing rate) ${ }^{b}$ & U. & $8,000 \mathrm{~m}^{3} /$ year \\
\hline $\begin{array}{l}\text { Atmospheric mass loading of contaminated } \\
\text { surface soil - } \\
\text { working in garden } \\
\text { residing in home }\end{array}$ & $\mathbf{L}_{\mathbf{2}}$ & $\begin{array}{l}10^{-7} \mathrm{~kg} / \mathrm{m}^{3} \\
10^{-8} \mathrm{~kg} / \mathrm{m}^{3}\end{array}$ \\
\hline
\end{tabular}

- Parameter applies to exposure of off-site individuals.

- Parameter applies to agriculture and post-drilling scenarios for inadvertent intruders.

- Parameter applies to agriculture scenario for inadvertent intruders.

d Parameter applies to post-drilling scenario for inadvertent intruders.

- Parameter applies to agriculture and resident scenarios for inadvertent intruders. 


\section{APPENDIX A REFERENCES}

Allard, B. 1985. Radionuclide Sorption on Concrete. NAGRA-NTB-85-21, November 1985.

Anspaugh, L. R., J. H. Shinn, P. L. Phelps, and N. C. Kennedy. 1975. Resuspension and Redistribution of Plutonium in Soils. Health Phys. 29:571.

Baes, C. F. III, and R. D. Sharp. 1983. A Proposal for Estimation of Soil Leaching Constants for Use in Assessment Models. J. Environ. Qual. 12:17.

Baes, C. F. III, R. D. Sharp, A. L. Sjoreen, and R. W. Shor. 1984. A Review and Analysis of Parameters for Assessing Transport of Environmentally Released Radionuclides Through Agriculture. ORNL-5786. Oak Ridge National Laboratory.

Christiansen, E. J., and D. E. Gordon. 1983. Technical Summary of Groundwater Quality Protection Program at Savannah River Plant. DPST-83-829, Vol. 1. E. I. du Pont de Nemours \& Company, Inc., Savannah River Laboratory, Aiken, SC.

Clark, S. B., and E L. Wilhite. 1991. Low-Level Liquid Waste Disposal at the Savannah River Site: A Large Scale Demonstration of Saltstone. Waste Management '91. Vol. II, ed. by R. G. Post, University of Arizona, Tucson, Ariz, pp. 603-609.

Cook, J. R., C. A. Langton, S. B. Oblath, H. C. Wolf, and G. T. Wright. 1984. Saltstone Landfill System: A Method for Disposal of Hazardous Industrial Chemicals.

DPST-84-521. E. I. du Pont de Nemours \& Company, Inc., Savannah River Laboratory, Aiken, SC.

CRC Press, Inc. 1981. CRC Handbook of Chemistry and Physics. Robert C. Weast and Melvin J. Astle, editors. Baca Raton, Florida 33431.

de Marsily, G. 1986. Quantitative Hydrogeology. Academic Press, Inc., New York, NY.

Dennehy, K. F., and P. B. McMahon. 1987. Water Movement in the Unsaturated Zone at a Low-Level Radioactive-Waste Burial Site Near Barmwell, South Carolina. U. S. Geological Survey Open-File Report 87-46, p.66.

Dennehy, K. F., D. C. Prowell, and P. B. McMahon. 1989. Reconnaissance Hydrological Investigation of the Defense Waste Processing Facility and Vicinity. Water-Resources Investigations Report 88-4221. U. S. Geological Survey. 
EG\&G Idaho, Inc. 1986. Development of Threshold Guidance. DOE/LLW-40T.

Freeze, R. A, and J. A. Cherry. 1979. Groundwater. Prentice-Hall, Inc., NJ.

Gruber, P. 1980. A Hydrologic Study of the Unsaturated Zone Adjacent to a RadioactiveWaste Disposal Site at the Savannah River Plant, Aiken, South Carolina. M.S. Thesis, University of Georgia, Athens, Georgia.

Hamby, D. M. 1992. Site-Specific Parameter Values for the Nuclear Regulatory Commission's Food Pathway Dose Model. Health Phys. 62:136.

Hoeffner, S. L. 1984. Radionuclide Sorption on SRP Burial Ground Soil: A Summary and Interpretation of Laboratory Data, Internal Report DPST-84-799, E. I. du Pont de Nemours \& Co., Savannah River Laboratory, Aiken, SC, September.

Hubbard, J. E, and M. Engelhardt. 1987. Calculation of Groundwater Recharge at the Old SRP Burial Ground Using the CREAMS Model (1961-1986). July 31, 1987, Memorandum from J. E. Hubbard and M. Englehardt, Department of Earth Sciences, State University of New York, College at Brockport, New York.

INTERA 1986. Validation of Unsaturated Flow Models Using Tank 24 Lysimeter Data. INTERA Technologies report H01203R005. INTERA Technologies, Inc., Austin, Texas.

INTERA 1989. Comparison of Unsaturated Flow and Transport Models with Volume and Nitrate Measurements from a Pilot-Scale, In-Situ Lysimeter with Different Geometry Low Level Radioactive Waste Designs. INTERA Technologies report - H01203R014. INTERA Technologies, Inc., Austin, Texas.

Kathren, R. L. 1984. Radioactivity in the Environment: Sources, Distribution, and Surveillance. Harwood Academic Publishers, P. O. Box 786, Cooper Station, New York, NY 10276.

Kennedy, W. E. Jr., B. A. Napier, and J. K. Soldat. 1983. Advanced Disposal Systems for Transuranic Waste: Preliminary Disposal Criteria for Plutonium-239 at Hanford. Nucl. Chem. Waste Manage. 4:103.

Kline, N. W., A. K. Runchal, and R. G. Baca. 1983. PORFLOW Computer Code: Users Guide. RHO-BW-CR-138, Rockwell Hanford Operations, Richland, Wash.

Kocher, D. C. 1981. Radioactive Decay Data Tables. DOE/TIC-11026, U. S. Department of Energy. 
Kocher, D. C., and A. L. Sjoreen. 1985. Dose-Rate Conversion Factors for External Exposure to Photon Emitters in Soil. Health Phys. 48:193.

Kocher, D. C. 1991. A Validation Test of a Model for Long-Term Retention of ${ }^{129} \mathrm{I}$ in Surface Soils. Health Phys. 60-523.

Langton, C. A 1985. Physical Properties of Saltstone: A Savannah River Waste Form, E. I. du Pont de Nemours and Co., Savannah River Company, Material Research Society Symposium Proceedings, Vol, 44, pp. 860-864.

Lerman, A 1988. Geochemical Processes: Water and Sediment Environments, Robert Krieger Publishing Co., Inc., Malabar, Florida.

Looney, B. B., M. W. Grant and C. M. King. 1987. Estimation of Geochemical Parameters for Assessing Subsurface Transport at the Savannah River Site, Environmental Information Document, DPST-85-904, E. I. du Pont de Nemours \& Co., Savannah River Laboratory, Aiken, South Carolina, March.

McIntyre, P. F. 1988. Sorption Properties of Carbon-14 on Savannah River Plant Soil, Internal Report DPST-88-900, E. I. du Pont de Nemours \& Co., Savannah River Laboratory, Aiken, SC, October.

Mualem, Y. 1976. A New Model for Predicting the Hydraulic Conductivity Unsaturated Porous Media. Water Resources Reseanch, 12(3):518-522.

Murphy, C. E, Jr. 1990. Lysimeter Study of Vegetative Uptake from Saltstone. WSRC-RP-90-421. Westinghouse Savannah River Company; Savannah River Site, Aiken, SC.

NEA Sorption Data Base. 1989. Version 2.0, B. Ruegger, Radiation Protection and Waste Management, NEA, Paris, France, September.

Napier, B. A, R. A. Peloquin, W. E. Kennedy, Jr., and S. M. Neuder. 1984. Intruder Dose Pathway Analysis for the Onsite Disposal of Radioactive Waste: The ONSITE/MAXI1 Computer Program. NUREG/CR-3620, PNL-4054. Pacific Northwest Laboratory.

Ng, Y. C., C. S. Colsher, and S. E. Thompson. 1982. Soil-to-Plant Concentration Factors for Radiological Assessments. NUREG/CR-2975, UCID-19463. Lawrence Livermore National Laboratory.

Oblath, S. B. 1986. Leach Test of 107 Liter Saltstone Blocks at Brookhaven National Laboratory. SRL Memorandum, DPST-86-442. 
Oztunali, O. I., G. C. Re, P. M. Moskowitz, E. D. Picazo, and C. J. Pitt. 1981. Data Base for Radioactive Waste Management. NUREG/CR-1759, Vol. 3. Dames and Moore, Inc.

Parizek, R. R. and R. W. Root. 1986. Development of a Ground-Water Velocity Model for the Radioactive Waste Management Facility, Savannah River Plant, South Carolina. College of Earth and Mineral Sciences, Pennsylvania State University, University Park, Penn.

Powers, T. C. 1960. Physical Properties of Hardened Portland Cement Paste. Portland Cement Association Research Department, Bulletin \#154.

Rasmuson, A, and I. Neretnieks. 1981. Migration of Radionuclides in Fissured Rock: The Influence of Micropore Diffusion and Longitudinal Dispersion. Journal of Geophysical Research, 86(B5):3749-3758.

Rogers, V. C., Nielson, K. K, and D. R. Kalkwarf. 1984. Radon Attenuation Handbook for Uranium Mill Tailings Cover Design. NUREG/CR-3533, U. S. Nuclear Regulatory Commission.

Sheppard, M. I., S. C. Sheppard, and B. D. Amiro. 1991. Mobility and Plant Uptake of Inorganic ${ }^{14} \mathrm{C}$ and ${ }^{14} \mathrm{C}$-Labelled PCB in Soils of High and Low Retention. Health Phys. 61:481.

Shinn, J. H., D. N. Homan, and D. D. Gay. 1982. Plutonium Aerosol Fluxes and Pulmonary Exposure Rates During Resuspension from Bare Soils Near a Chemical Separation Facility, p. 1131 in Precipitation Scavenging, Dry Deposition, and - Resuspension. Vol. 2 Ed. by H. R. Pruppacher, R. G. Semonin, and W. G. N. Slinn. Elsevier Science Publishing Co., New York, NY.

Stone, H. L. 1973. Estimation of Three-Phase Relative Permeability and Residual Oil Data. Joumal of Canadian Petroleum Technology, October - December.

Thompson, D. G. 1991. RE: Vault Closure Concept for Saltstone Vaults (u). Internal report OPS-DTZ-91-0002. Westinghouse Savannah River Co., Savannah River Site, Aiken, SC.

U.S.DOE. 1986. Construction Pennit Application for the Proposal Z-Area Saltstone Industrial Wastewater Treatment Facility. Savannah River Operations Office, U. S. Department of Energy, Aiken, SC.

U.S.DOE. 1988a. Management of Low-Level Waste, Chapter III in Radioactive Waste Management. Order 5820.2A, U. S. Department of Energy. 
U.S.DOE. 1988b. Internal Dose Conversion Factors for Calculation of Dose to the Public. DOE/EH-0071, U. S. Department of Energy.

U.S.EPA. 1988. Superfund Exposure Assessment Manual. EPA/540/1-88/001 U. S. Environmental Protection Agency.

U.S.NRC. 1977. Regulatony Guide 1.109. Calculation of Annual Doses to Man from Routine Releases of Reactor Effluents for the Purpose of Evaluating Compliance with 10 CFR Part 50, Appendix I. U. S. Nuclear Regulatory Commission.

van Genuchten, M. Th. 1978. Calculating the Unsaturated Hydraulic Conductivity with a New Closed-Form Analytic Model. Report 78-WR-08, Water Resources Program, Department of Civil Engineering, Princeton University, Princeton, NJ.

van Genuchten, M. Th. 1988. RETC,F77 FORTRAN Code, June 1988.

Vandecasteele, C. M., J. P. Dehut, S. Van Laer, D. Deprins, and C. Myttenaere. 1989. Long-Term Availability of Tc Deposited on Soil after Accidental Releases, Health Phys. 57:247.

Wang, H. F., and M. P. Anderson. 1982. Introduction to Groundwater Modeling, W. H. Freeman \& Co., San Francisco, Calif.

Walton, J. C. 1991. Fluid Flow and Placement of Concrete Vaults in the Saturated or Unsaturated Zone, Waste Management, 11:3-10.

Walton J. C., and R. R. Seitz. 1991. Performance of Intact and Partially Degraded Cohcrete Barriers in Limiting Fluid Flow. NUREG/CR-5614, EGG-2614, U. S. Nuclear Regulatory Commission, Washington, D. C.

Wilhite, E. L, and H. C. Wolf. 1986. Unsaturated Properties - Clay Cap Material. DPST-86-228, Technical Division, Savannah River Laboratory, Aiken, SC.

Yates, S. R. 1988. Seepage in a Saturated-Statified Aquifer with Recharge, Soil Sci Soc. Am. J., 52:356-363.

40 CFR 61. 



\section{B.1. CODE SELECTION CRITERIA AND CONSIDERATIONS}

Listed below are criteria that were considered in selecting computer codes for use in the RPA of the SDF at the Savannah River Plant. The first list, which follows directly, consists of absolute requirements for any code (1R = \#1, Required); any code not meeting any one of these requirements was rejected.

1R. The theoretical framework of the selected computer code(s) should be based on appropriate fundamental principles of chemistry and physics (e.g., conservation of mass, momentum, and energy) and well established constitutive equations (e.g., Darcy's law, Fick's law, etc.).

2R. The selected code(s) should be verified (i.e., simulation results compared against known analytical solutions of the underlying equations) to demonstrate correctness of the source code. Such verification should be fully documented in a technical report made available, at a minimum, to SRS and the Peer Review Panel.

3R. The selected code should be documented in a technical report and contain descriptions of: 1) model theory, governing equations and assumptions, 2) computational techniques and algorithm, and 3) example applications.

4R. All simulation codes(s) selected for use in the performance assessments must be maintained under a software QA and management program that assures that modifications and updates are traceable, auditable and documented, and that all production versions have been verified and validated.

This second list contains criteria describing attributes of computer codes that, though desirable, may not be presently attainable $(1 \mathrm{~S}=\# 1$, Suggested). Consideration was given to these criteria, and justification for using a code not meeting them is given in this appendix.

1S. The code(s) should allow site- and facility-specific applications; i.e., be capable of simulating the hydrologic, geologic and/or geochemical setting of the site, as well as specific design features of the facility over time.

2S. A contaminant transport code should be capable of: 1) tracking waste inventory over time, including radioactive daughter products, and 2) computing the contaminant fluxes at designated locations as a function of driving hydrologic processes and mass transport phenomena.

3S. The code(s) should be validated (e.g., simulation results compared with field data) for a system similar to that being modeled whenever possible. Benchmarking (i.e., code-to-code comparisons) is also useful in demonstrating code capabilities. 
4S. The degree of complexity of the compuler code(s) should be consistent with the quantity and quality of data, and the objectives of the computation. Screening calculations and sensitivity analyses should be used to simplify conceptual models, and ultimately direct code selection.

5S. Hardware requirements for the selected code should not be exotic (i.e., codes should run on readily accessible mainframe, mini, or personal computers (PC); convertibility is highly desirable).

6S. Proprietary codes should be used only if they provide a distinct advantage over public domain codes and only if the author(s)/custodian(s) allow inspection and verification of the source code. If a proprietary code is used, it must be made available by lease or purchase to WSRC-IWT.

7S. Consideration must be given to the ease of interfacing code output with other codes. For example, it is often desirable to use a groundwater code that simulates unsaturated and saturated flow, as well as mass transport, as coupling of output from each simulation type has already been accomplished.

8S. Familiarity with the code(s) should also be a consideration in selection, in light of time constraints that may be imposed for completion of a given Performance Assessment, and the need to revise the code if problems arise.

\section{B2 GEOCHEMICAL COMPUTER CODE}

The composition of saltstone pore fluids have been measured by Malek et al. (1987). Because the release rate of contaminants from saltstone is governed by aqueous concentration gradients in the saltstone pore fluids, potential geochemical controls on saltstone pore fluid composition were calculated. The analysis was done using the MINTEQ geochemical code and the measurements and observations of Malek et al. (1987).

\section{Code Description - MINTEQ}

Purpose and Scope: MINTEQ is a geochemical computer code used to predict and evaluate the equilibrium behavior of inorganic pollutants in a variety of geochemical environments. The code can model complex equilibrium relationships that exist among soluble species, insoluble solids, gases, and adsorbed species. The code can also be used to calculate the consequences of equilibrium mass transfer between aqueous and solid phases. However, the code does not have the capability to calculate reaction path models nor can it calculate reaction kinetics. MINTEQ is useful for calculating the source term concentrations and speciation of inorganic contaminants. In addition, MINTEQ contains algorithms that predict the sorption of contaminants on soils and sediments. The sorption algorithms include: activity $\mathbf{K}_{d}$, Langmuir isotherm, Freundlich isotherm, ion exchange, and surface complexation models. The code incorporates a 
Newton-Raphson iteration scheme to solve the set of mass-action and mass-balance expressions.

Development History: The MINTEQ code was originally developed at Pacific Northwest Laboratory (Felmy et al. 1984a) by combining the mathematical structure of the MINEQL and the geochemical attributes of the WATEQ geochemical codes. MINTEQ was developed to solve geochemical equilibria problems by applying fundamental principles of thermodynamics. Changes to the code since its creation have been confined to improving ease of input and the flexibility of the output. Additional thermodynamic data has also been added to the database.

Code Attributes: The code is written in FORTRAN 77 programming language and includes several input data files containing data necessary for the operation of the code, such as: thermodynamic data, component identification numbers, ion charge and size, and formula weights.

Computer Requirements: Many applications of MINTEQ can be performed effectively and efficiently on a PC with a 286 central processor unit (cpu). More complex calculations will be more efficiently processed on a PC with a $386 \mathrm{cpu}$ or on a work station. MIINTEQ can also be run on mainframe computer systems.

Restrictions: The MINTEQ code was developed by Pacific Northwest Laboratory for the U.S. NRC and the EPA; the code is public domain software. The code is documented in Felmy et al. (1984a), Brown and Allison (1987), and Peterson et al. (1987).

\section{Code Selection Basis}

General Critique: MNTEQ is one of several computer codes that have been developed to calculate equilibrium aqueous speciation and mineral mass transfer. Mechanistic adsorption models are included in the MINTEQ code, a major advantage over other geochemical codes such as EQ3/EQ6. The fundamental limitation of MINTEQ and other equilibrium based geochemical codes is that equilibrium conditions are often not obtained in low temperature systems. Furthermore, metastable conditions may persist for long periods of times in experimental systems, and experimentally observed concentrations may differ from those predicted by the code.

Code Verification: MINTEQ calculates the equilibrium speciation for an aqueous composition. Verification can be performed by using the MINTEQ output and hand calculations to evaluate equilibrium. In addition, the MNNTEQ code was verified during its development by comparison calculations against WATEQ4 (Felmy et al. 1984a, b) 
Code Benchmarking: The code has been benchmarked using the river water test case of Nordstrom et. al. (1979; see Peterson et al. 1987). In addition, the code was benchmarked against WATEQ4 during development (Krupka and Morrey 1985).

Code Validation: The MINTEQ code has been partially validated for aqueous systems containing $\mathrm{Cu}$ (II), $\mathrm{Pu}$, and $\mathrm{U}$ (Krupka and Morrey 1985). The code has not been validated for highly saline high-pH conditions found in saltstone pore fluids.

\section{Theoretical Framewort}

Governing Equation and Assumptions: The MINTEQ code calculates equilibrium speciation of aqueous phases. Speciation is defined as the chemical form of an element in an aqueous solution. The code solves mass balance expressions for each component ion (e.g., $\mathrm{Ca}_{1}{ }^{2+}, \mathrm{HCO}_{3}{ }^{-}, \mathrm{Na}^{+}$, etc.) using mass action relationships and equilibrium constants relating each species (such as $\mathrm{CO}_{3}{ }^{2-}$, a species of the $\mathrm{HCO}_{3}{ }^{\circ}$ component) to MINTEQ components. Equilibrium constants for species are provided in the THERMO.DAT data base for calculations at a reference temperature of $25^{\circ} \mathrm{C}$ and infinite dilution. For temperatures that differ from $25^{\circ} \mathrm{C}$, equilibrium constants are calculated either by using the Van't Hoff equation and enthalpies of reaction included in the data base or from analytical expressions relating equilibrium constants to temperature (Smith 1988). The concentration dependence of equilibrium constants are derived from individual ion activity coefficients calculated from the modified Debye-Huckel equation (Trusdell and Jones 1974), the Davies equation (Trusdell and Jones 1974), or the B-dot equation (Smith 1988).

Initial Conditions: The algorithm used in MINTEQ requires estimated starting values for the activities of component species. If these activity estimates are too far from the true values, the algorithm may fail to converge.

Numerical Techniques: MINTEQ uses a Newton-Raphson iteration method to simultaneously solve the non-linear mass balance equations.

\section{Code Inputs and Outputs}

Input Data Structure: To execute the MUNTEQ computer code, an input data file is prepared for each problem. The data file consists of

- title or run identifier,

- analytical units and temperature,

- run-specific user options,

- component identification and concentrations, and

- component modifications (e.g., concentration of $\mathrm{H}^{+}$fixed by $\mathrm{pH}$ ). 
Output Options: The MINTEQ code outputs the following:

- Echo of the data file input

- progress of the Newton-Raphson iterations

- full speciation of the input water composition

- charge balance and ionic strength for the aqueous composition

- saturation state of the water with respect to minerals in the data base

The user can also specify that the thermodynamic data base be printed. Debugging printing options are supported.

\section{B.3 VAULT DEGRADATION COMPUTER CODE}

\section{Code Description - Concrete Degradation and Steel Reinforcement Corrosion}

Purpose and Scope: The code used to estimate concrete degradation and rebar corrosion is designed to model the important degradation processes that can affect the long-term performance of concrete barriers. The processes modeled include:

(1 concrete attack by sulfate and magnesium, 2) concrete leaching (both concrete and geologically controlled), 3) carbonation, and 4) rebar corrosion.

Development History: The current model consists of analytical solutions for concrete degradation processes. These solutions were selected as the best available means of predicting long-term concrete barrier performance.

Code Attributes: The code is written in Mathematica programming language (Wolfram 1988) and consists of four separate modules. Three of the modules are used to estimate concrete degradation and one is used to predict corrosion of steel reinforcement.

Sulfate and magnesium attack on concrete is described by an empirical relationship determined by Atkinson and Hearne (1984). Leaching of concrete components is described by a shrinking core model, in the case of concrete-controlled leaching, and by diffusional mass transport for geologic-controlled leaching (Atkinson and Hearne 1984). Walton et al. (1990) derived a shrinking core model to describe concrete carbonation. Rebar corrosion is described by an empirical correlation to determine time to onset of corrosion from chloride attack (Clear 1976) and a one dimensional diffusion calculation for actual corrosion (Walton et al. 1990). 
Computer Requirements: The code was developed on an Apple Macintosh IIcx and has also been run using a NEXT workstation. The code will run on any workstation, mainframe or PC that runs Mathematica. The degradation code will run on any system running the Mathematica software package. The Macintosh version 1.2.2 recommends a minimum of 4 megabytes of RAM.

Restrictions: The code has been developed in the Mathematica software package and is therefore restricted by the purchase of the software.

\section{Code Selection Basis}

General Critique: The code is a compilation of analytical solutions for important concrete degradation processes (Clear 1976; Atkinson and Hearne 1984; Walton et al. 1990) selected based on the work of Walton et al. (1990). These analytical solutions are considered to be the best available means of predicting concrete degradation. The equations that are used to represent the degradation processes are based on observed conditions (i.e., sulfate, magnesium, chloride and dissolved oxygen concentrations in groundwater, etc.). However, in some cases the conditions encountered in a performance assessment are very different from the conditions on which the empirical relationships are based. Also, the observations that form the basis of the equation are for much shorter periods of time (tens of years) than is needed for performance assessments (thousands of years).

Code Verification: The Mathematica version of the code has been verified against the results of Walton et al. 1990.

Code Benchmarking: The code is made up of analytical solutions, therefore the benchmarking process does not apply.

Code Validation: The code is made up of analytical solutions, therefore the validation process does not apply.

\section{Theoretical Framewort}

\section{Governing Equation and Assumptions:}

Sulfate and Marnesium Attack. The equations that form the basis for the calculations are based on chemical reactions between concrete and rebar with chemical constituents from the monolith and/or the geologic media surrounding the vault. Sulfate attack on concrete is the result of reactions of sulfate with hydrated tricalcium aluminate $\left(\mathrm{C}_{3} \mathrm{~A}\right)$ and portlandite $\left[\mathrm{Ca}(\mathrm{OH})_{2}\right]$ to form compounds of larger volume leading to expansion and disruption of the concrete. The reactions between sulfate and cement 
compounds can be written as

Gypsum:

$\mathrm{Ca}(\mathrm{OH})_{2}+\mathrm{SO}_{4}^{2-}+2 \mathrm{H}_{2} \mathrm{O}==\mathrm{CaSO}_{4} \cdot 2 \mathrm{H}_{2} \mathrm{O}+2 \mathrm{OH}^{-}$

Monosulphoaluminate:

$3 \mathrm{CaO} \cdot \mathrm{Al}_{2} \mathrm{O}_{3} \cdot 6 \mathrm{H}_{2} \mathrm{O}+\mathrm{CaSO}_{4}+6 \mathrm{H}_{2} \mathrm{O}==3 \mathrm{CaO} \cdot \mathrm{Al}_{2} \mathrm{O}_{3}\left(\mathrm{CaSO}_{4}\right) \cdot 12 \mathrm{H}_{2} \mathrm{O}$

Ettringite:

$3 \mathrm{CaO} \cdot \mathrm{Al}_{2} \mathrm{O}_{3}\left(\mathrm{CaSO}_{4}\right) \cdot 12 \mathrm{H}_{2} \mathrm{O}+2 \mathrm{CaSO}_{4}+2 \mathrm{H}_{2} \mathrm{O}==>3 \mathrm{CaO} \cdot \mathrm{Al}_{2} \mathrm{O}_{3} \cdot 3\left(\mathrm{CaSO}_{4}\right)$ $32 \mathrm{H}_{2} \mathrm{O}$

An example of a reaction between cement paste and magnesium sulfate is

Brucite:

$$
\begin{aligned}
& 3 \mathrm{CaO} \cdot 2 \mathrm{SiO}_{2}+3 \mathrm{MgSO}_{4} \cdot 7 \mathrm{H}_{2} \mathrm{O}==3 \mathrm{CaSO}_{4} \cdot 2 \mathrm{H}_{2} \mathrm{O}+3 \mathrm{Mg}(\mathrm{OH})_{2}+2 \mathrm{SiO}_{2}+ \\
& 2 \mathrm{H}_{2} \mathrm{O}
\end{aligned}
$$

The low solubility of $\mathrm{Mg}(\mathrm{OH})_{2}$ causes the reaction to proceed to completion, making the attack more severe.

The depth of sulfate and magnesium attack is described by the equation

$$
x=0.55 \mathrm{C}_{1}\left(\mathrm{Mg}^{2+}+\mathrm{SO}_{4}{ }^{2-}\right) \mathrm{t}
$$

where

X. = depth of deterioration (cm),

$C_{1}=$ weight percent of $C_{3} A$ in non-hydrated cement,

$\mathrm{Mg}^{2+}=$ concentration of magnesium in the bulk solution $(\mathrm{mol} / \mathrm{L})$,

$\mathrm{SO}_{4}{ }^{2-}=$ concentration of sulfate in the bulk solution (molll), and

$\mathrm{t}=$ time (years).

Assumptions: The rate of attack is proportional to sulfate and magnesium concentration in the solution and $C_{3} A$ content of the cement.

Limitations: Correlations are only valid over the time/system parameters tested. Application outside this range is highly questionable.

The empirical correlation does not include the impacts of advective transport and/or the known importance of water cement ratio (WCR) on durability. Application of the model is not clearly conservative.

Rov. 0 
Concrete-Controlled Leaching of Calcium Hydroxide. Cement components will be leached from concrete in environments in contact with water and have significant percolation rates. The alkalis are the first components to be leached followed by calcium hydroxide. The leaching of calcium hydroxide from the cement is described by

$$
\mathrm{Ca}(\mathrm{OH})_{2}==>\mathrm{Ca}^{2+}+2 \mathrm{OH}^{-}
$$

The equation that describes concrete controlled leaching is

$$
x=\left[2 D_{1}\left\{\left(C_{1}-C_{s m}\right) / C_{1}\right\} t\right]^{1 / 2}
$$

where

$x \quad=$ depth of leaching (cm),

$D_{1}=$ intrinsic diffusion coefficient of $\mathrm{Ca}^{2+}$ in concrete solid $\left(\mathrm{mol} / \mathrm{cm}^{3}\right)$,

$\mathrm{C}_{1}=$ concentration of $\mathrm{Ca}^{2+}$ in concrete pore water $\left(\mathrm{mol} / \mathrm{cm}^{3}\right)$,

$C_{m=}=$ concentration of $\mathrm{Ca}^{2+}$ in the groundwater or soil moisture $\left(\mathrm{mol} / \mathrm{cm}^{3}\right)$,

$\mathrm{C}_{1}=$ bulk concentration of $\mathrm{Ca}^{2+}$ in the concrete solid $\left(\mathrm{mol} / \mathrm{cm}^{3}\right)$, and

$\mathrm{t}=$ time (s).

Assumptions: The rate of calcium removal from the exterior of the concrete is assumed to be rapid relative to the movement of calcium ions through the concrete. Therefore, diffusion controls the transport rate of the calcium.

Limitations: Diffusional mass transport is considered, but advection through and around the concrete is not considered.

- $D_{1}$ for the leached portion of the concrete will be substantially higher than $D_{1}$ for intact concrete. Permeability of the concrete will increase as leaching proceeds leading to greater flow rates through the leached area. Diffusional control may no longer be valid under these conditions.

Geology-Controlled Leaching of Calcium Hydroxide. Geology-controlled leaching occurs as a result of the diffusion being controlled by the geologic material surrounding the concrete. The resulting equation is

$$
x=2 \text { phi }\left[\left(C_{1} \cdot C_{g w} / C_{b}\right]\left[\left(R_{d} D_{E} t\right) / p i\right]^{1 / 2}\right.
$$

where

$$
\begin{aligned}
& x=\text { depth of leaching }(\mathrm{cm}) \text {, } \\
& \text { phi = porosity of the geologic material }\left(\mathrm{cm}^{3} \text { voids } / \mathrm{cm}^{3}\right. \text { total), } \\
& \mathrm{C}_{1}=\text { concentration of } \mathrm{Ca}^{2+} \text { in concrete pore water }\left(\mathrm{mol} / \mathrm{cm}^{3}\right) \text {, } \\
& \mathrm{C}_{\mathrm{sw}}=\text { concentration of } \mathrm{Ca}^{2+} \text { in the groundwater or soil moisture }\left(\mathrm{mol} / \mathrm{cm}^{3}\right) \text {, } \\
& \mathrm{C}_{\mathrm{b}}^{\mathrm{m}}=\text { concentration of } \mathrm{Ca}^{2+} \text { in the bulk concrete }(\text { solid +pore })\left(\mathrm{mol} / \mathrm{cm}^{3}\right) \text {, }
\end{aligned}
$$

Rev. 0 
$\mathbf{R}_{\mathbf{d}}$ = retardation factor for $\mathrm{Ca}^{2+}$ in the geologic material,

$\mathrm{D}_{\mathrm{B}}$ = effective dispersivity/diffusivity of $\mathrm{Ca}^{2+}$ in geologic material $\left(\mathrm{cm}^{2} / \mathrm{s}\right)$, and $t \quad=$ time (s).

Assumptions: Diffusion into the surrounding geologic material controls leaching. Leaching is highest in low calcium concentration environments.

Limitations: Parameters for geologic material are needed $\left(R_{d}, D_{B}, p h i\right)$.

Concrete Carbonation. Carbonation is typically thought of as the reaction between calcium hydroxide and carbon dioxide as represented by

$$
\mathrm{Ca}(\mathrm{OH})_{2}+\mathrm{CO}_{2}==>\mathrm{CaCO}_{3}+\mathrm{H}_{2} \mathrm{O}
$$

Carbonation can occur only as rapidly as dissolved carbonate can diffuse through the concrete. Carbonation rate is dependent on the moisture content of the concrete and the relative humidity of the ambient medium and the concentration of $\mathrm{CO}_{2}$ in the ambient medium. If diffusion in the concrete is too slow, an equilibrium is reached where the diffusion of $\mathrm{CO}_{2}$ and carbonation are stopped or severely reduced.

Carbonation rate is dependent on the moisture content of the concrete. As relative humidity changes from 0 to $100 \%$, the rate of carbonation passes through a maximum.

25

Because the $\mathrm{pH}$ in concrete is high $(>12)$, the carbonation reaction actually occurs

$$
\mathrm{Ca}(\mathrm{OH})_{2}+\mathrm{CO}_{3}^{2-}=\Rightarrow \mathrm{CaCO}_{3}+2 \mathrm{OH}^{-}
$$

The relationship between carbonation depth and groundwater concentration, portlandite in the concrete, and intrinsic diffusion coefficient of calcium is:

$$
x=\left[2 D_{1}\left(C_{-} / C_{s}\right) t\right]^{1 / 2}
$$

where

$$
\begin{aligned}
& x=\text { depth of carbonation }(\mathrm{cm}), \\
& D_{i}=\text { intrinsic diffusion coefficient of } \mathrm{Ca}^{2+} \text { in concrete }\left(\mathrm{cm}^{2} / \mathrm{s}\right), \\
& C_{j=}=\text { concentration of total inorganic carbon in the groundwater }\left(\mathrm{mol} / \mathrm{cm}^{3}\right), \\
& C_{1}=\text { bulk concentration of } \mathrm{Ca}(\mathrm{OH})_{2} \text { in the concrete solid }\left(\mathrm{mol} / \mathrm{cm}^{3}\right), \text { and } \\
& t \quad=\text { time }(\mathrm{s}) .
\end{aligned}
$$

Assumptions: Concrete is saturated with water. 
Limitations: The type of cement ultimately affects the depth of carbonation. This relationship becomes increasingly invalid as the relative humidity of the concrete decreases from $100 \%$ to $50 \%$; below this level, the reaction rates decline rapidly resulting in a reduction in carbonation rate.

Reinforcement Corrosion/Chloride Attack The alkaline environment of the concrete and the isolation it provides from external corrosive agents protects the steel reinforcement from corrosion by forming a protective oxide layer on the metal surface. The passive oxide layer may undergo attack by corrosive agents as the concrete deteriorates. Historically, aqueous chloride is the corrosive agent associated with the break up of the passive layer.

Reinforcement corrosion may also be associated with reduction of concrete alkalinity in the absence of elevated chloride levels. Carbonation and leaching can cause a decrease in the concrete $\mathrm{pH}$ with eventual loss of passivity.

Chloride attack is modeled in two stages (a) time to breakup of the passive layer and initiation of corrosion and (b) corrosion rate subsequent to breakup of the passive layer. An empirical correlation for the time to passive layer breakup is

$$
t_{c}=\left(129 x_{i}^{1.22}\right) /\left(W C R C^{0.42}\right)
$$

where

$t_{c} \quad=$ time to onset of corrosion (years),

$x_{c} \quad=$ thickness of concrete over the rebar (in.),

- WCR = water to cement ration (by mass), and

Cl = chloride ion concentration in groundwater (ppm).

Assumptions: The time to onset of corrosion is related to the water to cement ratio, depth of cement cover, and chloride concentration in groundwater.

Limitations: Applicability to conditions outside the observed chloride concentrations on which the equation is based is questionable.

The simplest method of estimating the corrosion rate subsequent to initiation of corrosion is a one dimensional diffusion calculation assuming limitation of the corrosion rate by oxygen diffusion. The percent of reinforcement remaining at any time is given by

$\%$ remaining $=100\left[\left(4^{*} 9.4 \quad s D_{i} C_{s w} t\right) /(\right.$ pi d delta $\left.x)\right]$

Rev. 0 
where

$$
\begin{aligned}
& \text { = spacing between reinforcement bars }(\mathrm{cm}), \\
& D_{1}=\text { intrinsic diffusion coefficient of } \mathrm{O}_{2} \text { in concrete }\left(\mathrm{cm}^{2} / \mathrm{s}\right), \\
& C_{\mathrm{fu}} \quad \text { concentration of oxygen in the groundwater }\left(\mathrm{mol} / \mathrm{cm}^{3}\right), \\
& \text { delta } x=\text { depth of reinforcement below surface }(\mathrm{cm}), \text { and } \\
& t \quad=\text { time }(\mathrm{s}) .
\end{aligned}
$$

Assumptions: The corrosion rate is limited by oxygen diffusion.

Limitations: Applicable only if oxygen diffusion controls corrosion.

Initıal Conditions: Not applicable.

Numerical Techniques: Not applicable.

\section{Code Inputs and Outputs}

Input Data Structure: Input for the calculations is contained in the Mathematica file for degradation calculations. The values may be changed from within Mathematica and the file is evaluated as needed.

Qutput Options: Output can be in the form of numeric values, tables, two- or three-dimensional plots, and contour plots. Mathematica allows many forms of output to be displayed within the package and exported for use in other graphics packages.

\section{B.4 SATURATED/UNSATURATED FLOW AND TRANSPORT CODE}

\section{General Code Description}

Purpose and Scope. The PORFLOW-3D computer code was selected and applied to predict the isolation performance of the saltstone vaults in the vadose zone, to predict transport of radionuclides released to the underlying aquifer, and to predict contaminant transport in the aquifer. Specifically, the computer code was used to model water flow through the backfill, gravel-clay barrier, vault structure, and saltstone waste form. The code was then used to model the release of contaminants from the waste form, migration through the vault structure, surrounding soils and underlying formations. The simulation results generated by the PORFLOW-3D code were then post-processed to obtain predictions of

- water pathlines and travel times to the aquifer,

- contaminant plume distributions in the vadose zone,

- contaminant fluxes to the aquifer, and

- contaminant plume distributions in the aquifer's saturated zone. 
These results are then used to characterize the isolation performance of the SDF.

Development History. The original version of the PORFLO code (Runchal et al. 1985) was developed to analyze the isolation performance of deep geologic repositories. This early version was limited to saturated conditions and two-dimensional porous domains, and was extensively verified and benchmarked by Eyler and Budden (1984). The code was later extended to model variably saturated flow in three-dimensions and was therefore renamed PORFLO-3, version 1.0 (Sagar and Runchal 1990). Version 1.0 of the three-dimensional computer code was independently verified and benchmarked by Magnuson et al. (1990) against FEMWATER, FLASH, TRACR3D, and MAGNUM2D for some applications. The code has been used in practical applications at the Hanford Site to model various waste disposal problems (Smoot and Sagar 1990), at an experimental waste trench site in Las Cruces, NM to evaluate the solute transport simulation capabilities (Rockhold and Wurstner 1991), and at the DNEL to model a large organic vapor plume (Baca et al. 1988).

A newer version of PORFLO-3 (version 2.3) was recently developed which has a number of enhancements and new options. For example, one of the new features of version 2.3 is the capability to model multiphase flow. The commercial version of PORFLO-3 which was used to model the saltstone performance in the vadose and saturated zones is PORFLOW-3D, version 24 (Runchal and Sagar, 1992). This later version has not been verified and benchmarked to the same degree as the previous one. However, the Fortran source code has been checked using the INEL's KRAFT and FORWARN software QA programs (which identify coding errors and suspect programming), and benchmarking has been completed using test files from the earlier verification and benchmarking work (Magnuson et al. 1990).

Code Attributes. The PORFLOW-3D, version 2.4 computer code is written in Fortran 77 programming language. Some of the unique attributes of this version are

- capability to model either single or multiphase flow,

- applicable to one-, two-, or three-dimensional geometries in Cartesian or cylindrical coordinate systems,

- alternate solver techniques (such as point successive over relaxation, Cholesky decomposition, Gauss elimination, and reduced system conjugate gradient) can be selected,

- multiple porosity representations can be used, and

- discrete features (such as fractures) can be represented by line or plate elements.

The computer program is relatively portable and can be run on personal computers, workstations and mainframe computers. 
Computer Requirements. Practical applications of the PORFLOW-3D code to realistic multidimensional flow and transport problems require the availability of a high performance workstation or mainframe computer. The vault and vadose zone simulations presented in this report were performed on an IBM workstation. Complex simulation problems such as those performed for the saltstone vault often require double precision, and are cumbersome for personal computers. For saturated flow, a PC with a 486 processor was sufficient to simulate the flow and mass transport regime.

Restrictions. Version 2.3 of PORFLO-3 was originally developed for the U.S. DOE and is therefore in the public domain. All versions of the PORFLO-3 code are copyright protected. Commercial versions of the code, PORFLOW-3D, which include updates of the version 2.3 are available from Analytic and Computational Research, Inc., Los Angeles, California.

\section{Code Selection Basis}

The code selection criteria put forth in Sect. B.1 of this appendix were used to select PORFLOW-3D for use in the SDF RPA. The procedure followed was to identify several codes meeting requirements $1 R-4 R$, and subsequently evaluate those codes in terms of the remaining eight desirable criteria (1S - 8S). Table B.4.1 summarizes the results of this procedure. A more detailed explanation is given below.

General Critique. At present, there are relatively few general computer codes that have the capability to adequately simulate variably-saturated flow and transport in a multidimensional system. Such codes are scarce because the governing equations for flow in the unsaturated zone are highly nonlinear, and very difficult to solve. In addition to nonlinearity, this numerical difficulty is caused by such factors as:

- large contrasts in soil-hydraulic properties,

- high recharge rates and broad range of saturation conditions,

- contrasting thicknesses of soil strata, and

- advection dominated mass transport.

Advanced computational techniques (Celia et al. 1990 and Fletcher 1988) can overcome some of these difficulties; however, obtaining stable and accurate numerical solutions on a routine basis is still a modeling goal.

A number of computer codes with a demonstrated capability to model flow and transport were considered for application to the SDF study. The principal codes considered were: 1) PORFLOW-3D (Runchal and Sagar 1989 and 1992), 2) FEMWATER/FEMWASTE (Yeh and Ward 1979; Yeh and Ward 1981; Yeh 1987), 3) FLASH (Baca and Magnuson 1992), 4) SUTRA (Voss 1984), 5) TRACR3D (Travis 1985), and 6) VAM3D-CG (Huyakorn and Panday 1990). All of these codes, with the possible exception of FEMWATER/FEMWASTE meet the first four requirements (1R$4 R$, see Table B4.1). The availability of documentation of the most recent version of

Rev. 0 
Table B.4.1. Evaluation of identified alternative subsurface flow and transport codes

\begin{tabular}{|c|c|c|c|c|c|c|}
\hline \multirow{2}{*}{$\begin{array}{l}\text { Selection } \\
\text { Criteria } \\
\text { (by number) }\end{array}$} & \multicolumn{6}{|c|}{ Code Meets Criterion? } \\
\hline & $\begin{array}{l}\text { PORFLO } \\
\text { W-3D' }\end{array}$ & $\begin{array}{l}\text { FEMWAT } \\
\text { ERFEMW } \\
\text { ASTE }^{-}\end{array}$ & $\begin{array}{l}\text { FLAS } \\
\mathbf{H}^{d}\end{array}$ & $\begin{array}{l}\text { SUTR } \\
A^{*}\end{array}$ & $\begin{array}{l}\text { TRACR3 } \\
D^{\prime}\end{array}$ & $\begin{array}{l}\text { VAM3D- } \\
\text { CG }\end{array}$ \\
\hline 1R & yes & yes & yes & yes & yes & yes \\
\hline $2 \mathbf{R}$ & yes & yes & yes & yes & yes & yes \\
\hline 3R & yes & no & yes & yes & yes & yes \\
\hline $4 \mathbf{R}^{\prime}$ & yes & yes & yes & yes & yes & yes \\
\hline $1 S$ & yes & yes & yes & yes & yes & yes \\
\hline $2 S$ & yes & no & yes & yes & yes & $\begin{array}{l}\text { not } \\
\text { known }\end{array}$ \\
\hline $3 S$ & yes & $\begin{array}{c}\text { not } \\
\text { known }\end{array}$ & yes & $\begin{array}{c}\text { not } \\
\text { known }\end{array}$ & yes & $\begin{array}{c}\text { not } \\
\text { known }\end{array}$ \\
\hline 45 & yes & yes & yes & yes & yes & yes \\
\hline SS & yes & yes & yes & yes & yes & yes \\
\hline 6S & yes & yes & yes & $\begin{array}{c}\text { not } \\
\text { known }\end{array}$ & yes & $\begin{array}{l}\text { not } \\
\text { known }\end{array}$ \\
\hline 75 & yes & yes & yes & yes & yes & yes \\
\hline 85 & yes & no & yes & no & no & no \\
\hline
\end{tabular}

- Described in Appendix B-1.

- Runchal, A K and B. Sagar 1992.

- Yeh, G. T. 1987; Yeh, G. T. and D. S. Ward 1981.

- Baca, R. G. and S. O. Magnuson 1992.

- Voss, C. I. 1984

f Travis, B. J. 1985.

- Huyakorn, P. S. and S. Panday 1990.

"Satisfying this criteria ensured by user. 
FEMWATER was in question, as was support by the primary developer of the code. Thus, this code was not considered further.

The remaining codes were evaluated with respect to their probability of satisfying the eight suggested criteria (1S - 8S, Sect. B-1). Reviews of available computer codes useful to performance assessments (Kozak et al. 1989, Case et al. 1989) were consulted to assess this probability. The results are summarized in Table B.4.1. From this table, the lack of familiarity with SUTRA, TRACR3D, and VAM3D-CG is the only distinguishing characteristic between these codes and FLASH and PORFLOW-3D. Because of time constraints, this latter criteria was deemed important to code selection.

The PORFLOW-3D computer code was ultimately selected over FLASH for these reasons:

- previous successful applications to modeling waste sites (Smoot and Sagar 1990);

- quality and completeness of code documentation (Runchal and Sagar 1989 and 1991; Sagar and Runchal 1990);

- favorable results of independent verification and benchmark testing of an earlier version (Magnuson et al. 1990);

- Ilexibility of the code, computational efficiency and ease of use;

- rigorous testing the source code has undergone using Fortran analyzers.

Applicability to Saltstone Vaults. The hydrogeologic setting at the SRS is uniquely characterized by relatively high recharge rates, drainable soils, and a shallow vadose, or unsaturated, zone. In contrast, the vauit and barrier components are typically low permeability. The PORFLOW-3D computer code allows for consideration of heterogeneity and anisotropy, and employs various numerical techniques to enhance stability under the diverse conditions encountered. PORFLOW -3D also has options for considering planar geologic features such as fractures, which is important to evaluating the possibility of vault failure during the time for which performance is being assessed.

Code Verification. Version 1.0 of the PORFLOW-3D computer code has been verified by comparing the numerical solutions against known analytical solutions. In particular, the unsaturated flow component of the code has been verified against the Philip's (1957) analytical solutions for unsaturated flow in vertical and horizontal soil columns. In a like manner, the mass transport component has been verified against a number of analytical solutions for contaminant movement in steady-state flow fields. Results of the code verification are documented in Magnuson et al. (1990).

Code Benchmarking. Version 1.0 of the PORFLOW-3D code has been benchmarked by making code-to-code comparison for various flow and transport simulations. A number of hypothetical flow and transport situations were postulated and were simulated with PORFLOW-3D and other independent computer codes. The hypothetical test problems were formulated to be representative of typical waste sites

Rev. 0 
with realistic hydrogeologic settings. The PORFLOW-3D code has been benchmark tested against such codes as TRACR3D (Travis 1985), FEMWATER (Yeh and Ward 1979), SUTRA (Voss 1984), and FLASH (Baca 1991). Results of the benchmark testing is documented in Magnuson et al. (1990).

Code Validation. At the present time, the PORFLOW-3D code has not been validated by comparison to laboratory or field data. There is a definite need to perform such comparisons against experimental data collected at the SRS.

\section{Theoretical Framework}

Governing Equations and Assumptions. The governing equations solved in the PORFLOW-3D code are based on the conservation principles of continuum mechanics. These equations describe fluid flow and mass transport processes in a heterogeneous and anisotropic porous medium. The equations are well accepted mathematical representations and are found in such texts as Bear and Bachmat (1990), Freeze and Cherry (1979), and Huyakorn and Pinder (1983). The specific partial differential equation solved in PORFLOW-3D for isothermal fluid flow around and through the saltstone vault is

$$
s_{\bullet} \frac{\partial H}{\partial t}=\frac{\partial}{\partial x_{1}}\left[K_{1 y}\left(\frac{\partial H}{\partial x_{y}}-\delta_{13}\right)\right]+m_{v}
$$

where

- $S_{f_{\text {. }}}$ is the fluid storage term (i.e., specific storage or moisture capacity term),

$H$ is the total or hydraulic head,

$\boldsymbol{K}_{i j}$ is the hydraulic conductivity tensor,

$\delta_{i 3}$ is the buoyancy vector, and

$m_{v}$ is the fluid source or sink term,

$t$ is time, and

$x_{i}$ is distance in the ith direction.

The quantity $H$ is defined by:

$$
\begin{aligned}
& H=h+z-z^{*} \quad \text { where } \\
& h=\text { pressure head, } \\
& z=\text { elevation head, and } \\
& z^{*}=\text { reference datum. }
\end{aligned}
$$


and the quantity $S_{e}$ is defined by

$$
S_{\bullet}=S\left(\alpha_{\varepsilon}+\theta_{\Sigma} \alpha_{t}\right)+\theta_{z} \frac{\partial S}{\partial H}
$$

where

$$
\begin{aligned}
& S \quad=\text { the saturation level, } \\
& \alpha_{s} \text { and } \alpha_{s}=\text { the solid and fluid compressibilities normalized by the specific weight } \\
& \text { of the fluid, and } \\
& \theta_{E} \quad=\text { the effective porosity. }
\end{aligned}
$$

Some of the basic assumptions made in the above mathematical formulations are:

- fluid flow is laminar, slightly compressible, and single phase;

- fluid flow obeys Darcy's law for porous flow, where specific discharge is proportional to the hydraulic gradient;

- fluid viscosity is a function of temperature only;

- hydraulic properties of the porous continuum are volume averages; and

- osmotic effects (associated with salts in the waste form) are negligible.

In general, these assumptions are satisfied in the hydrogeologic environment of saltstone vaults.

Thespecific partial differential equation solved in PORFLOW-3D for contaminant transport from saltstone vault is

$$
R_{D} \phi_{D} \frac{\partial C}{\partial t}+\frac{\partial}{\partial x_{1}}\left(V_{1} C\right)=\frac{\partial}{\partial x_{1}}\left[\Gamma_{1 j}^{C} \frac{\partial C}{\partial x_{y}}\right]-\phi_{D} R_{D} \lambda C+S_{C}+\sum_{D} \phi_{D} R_{D}^{p} \sigma^{P} \lambda P_{C}
$$

where

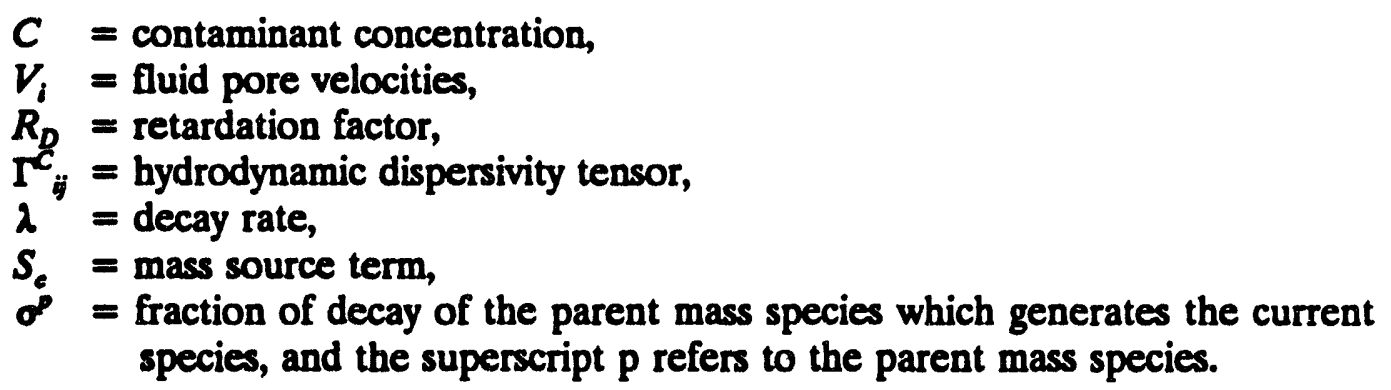


The last term in equation B4.4 represents ingrowth of mass species. The quantity $R_{D}$ is defined by:

$$
R_{D}=\left[1+\frac{\left(1-\theta_{T}\right) \rho_{d} k_{d}}{\phi_{D}}\right] .
$$

where

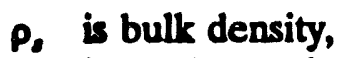

$\theta_{T}$ is total porosity,

$\phi_{D}$ is water filled diffusive porosity, and

$\boldsymbol{k}_{d}$ is sorption coefficient,

and $\Gamma_{i j}$ is defined by,

$$
\Gamma_{1 y}=\phi_{D} \tau_{1 y} D_{K}+\phi_{\delta} D_{1{ }^{\prime}}
$$

where

$\phi_{E}$ is the effective pore space saturated with water,

$\tau_{i j}$ is the tortuosity tensor,

$D_{M}$ is the molecular diffusion coefficient, and

$D_{i j}$ is the mechanical dispersion tensor.

All other coefficients are as previously defined.

Some of the key assumptions that limit the applicability of the above formulation are as follows:

- contaminant concentrations are low enough that the fluid flow is independent of mass transport, i.e., concentrations do not affect the density or viscosity of the fluid;

- diffusion of the contaminants through the fluid obeys Fick's first law, where mass flux is proportional to the concentration gradient with the constant of proportionality being the diffusion coefficient;

- mechanical dispersion is described by Scheidegger's equation, (Scheidegger 1961);

- adsorption (and desorption) of contaminants onto the porous medium is an equilibrium process described by a linear isotherm.

The model formulation is applicable to both unsaturated and saturated flow conditions.

Rov. 0 
Initial and Boundary Conditions. The PORFLOW-3D code accommodates the specification of standard mathematical boundary conditions. These include: 1) Dirichlet, i.e., fixed head or concentration), 2) Neumann, i.e., specified flux, and 3) Robin, i.e., mixed, boundary conditions. Detailed information on boundary condition options is given in Runchal and Sagar (1989 and 1992).

Numerical Techniques. In the PORFLOW-3D code, the governing equations for flow and transport are solved using a method referred to as the Nodal Point Integration, a variation of the finite volume or integrated finite difference technique (Runchal and Sagar 1991). In this method, the difference approximations to the governing equations are derived on a staggered grid system. The state variables are computed at the grid nodes whereas the fluid velocities and fluxes are computed at the cell faces (located midway between adjacent grid nodes). Three discretization schemes, or basis functions to be integrated, are provided. The user may select which of the three schemes is to be used to maximize accuracy and stability.

The system of algebraic equations produced by the finite volume method are solved in the PORFLOW-3D code using any one of five techniques

- Point successive over relaxation (Bear and Verruijt 1987),

- Alternating direction implicit (Peaceman and Rachford 1955),

- Cholesky decomposition (de Marsily 1986),

- Gauss elimination (Remson et al. 1970), or

- Reduced system conjugate gradient method (Hestenes and Stiefel 1952).

The nonlinearity of the governing equation for variably saturated flow is solved using a Picard iteration method.

IV. Code Inputs and Outputs

Input Data Structure. Input data files for the PORFLOW-3D code are relatively easy to prepare and check. The code uses a free-form input which allows the user to document the input data deck. The input file uses a keyword approach to define primary input data groups. For typical flow and transport simulations, the data groups consist of

- Title card and comments,

- Finite difference grid specification, i.e., number of grid nodes in each direction,

- Lists of grid node coordinates,

- Zone definitions that specify the grid locations of distinct strata,

- Rock and hydraulic property specifications,

- Convergence and iteration parameters,

- Initial pressures and concentrations,

Rev. 0 
- Boundary values and/or fluxes,

- Mass properties including effective diffusion coefficients and Kds,

- Source specifications, and

- Time step and output specifications.

Simulations of multidimensional flow and transport can be performed in either steady-state or time-dependent mode.

Output Options. Results from the PORFLOW-3D simulation consist of total head, saturation, contaminant concentration, and Darcy velocities for each grid block in the computational grid. The user can select to print out any or all of the output variables. Each of these variables can be post-processed to produce graphical output.

Post-Processor Programs. A number of post-processor programs have been written by EG\&G Idaho, Inc. which may be used to graph the simulation results. These post-processor programs are DISSPLA based routines that plot profiles, contours, streamlines and travel times, and time histories. These programs have been used extensively by EG\&G Idaho on various projects. However, no formal documentation currently exists. Analytic and Computational Research, Inc. also distributes a PLOT88based post-processor for use with the 486 PC versions of PORFLOW-3D, documented by Runchal (1991).

Documentation of Users Instructions. The PORFLOW-3D, version 2.4, is documented in Runchal and Sagar (1992). This report describes the mathematical theory and numerical techniques of this version, serves as a user's manual, and provides detailed information on the code organization, selection of computational grids and time steps, input structure and keyword definitions. 


\section{APPENDIX B REFERENCES}

Atkinson, A, and J.A. Hearne. 1984. An Assessment of the Long-Term Durability of Concrete in Radioactive Waste Repositories. AERE-R11465, Harwell, U.K.

Baca, R. G. J. C. Walton, and A. S. Rood. 1988. Organic Contaminant Release from a Mixed Waste Disposal Site: Analysis of Vapor Transport through the Vadose Zone and Site Remediation. Proceedings of Tenth Annual DOE Low-Level Waste Management Conferince. Denver, Colo.

Baca, R. G. and S. O. Magnuson. 1992. FLASH - Finite Element Computer Code for Variably Saturated Flow. EGG-GEO-10274. EG\&G Idaho, Inc., Idaho Falls, ID.

Bear, J., and A. Verruijt. 1987. Modeling Groundwater Flow and Pollution. D. Reidel Publishing Co., Boston, Mass.

Bear, J., and Y. Bachmat. 1990. Introduction to Modeling of Transport Phenomena in Porous Media. Kluwer Academic Publishers, Boston, Mass.

Brown, D. S., and J. D. Allison. 1987. MINTEQA1. An Equilibrium Metal Speciation Model: User's Manual. EPA-600/3-87/012. U. S. Environmental Protection Agency, Athens, GA.

Case, M. J., S. J. Maheras, M. D. Otis, and R. G. Baca. 1989. A Review and Selection of Computer Codes for Establishing of the Performance Assessment Center. DOE/LLW-83. EG\&G Idaho, Inc.

Celia, M. A, E. T. Bouloutas, and R. L. Zarba. 1990. A General Mass-Conservative Numerical Solution for the Unsaturated Flow Equation. Water Resources Research, 26(7):1483-1496.

Clear, K.C. 1976. Time to Corrosion of Reinforcing Steel in Concrete Slabs, Vol. 3. Performance After 830 Daily Salt Applications. Federal Highway Administration Report No. FHWA-RD-76-70, NTIS PB-258 446.

de Marsily, G. 1986. Quantitative Hydrogeology. Academic Press, Inc., New York, NY.

Eyler, L. L, and M. J. Budden. 1984. Verification and Benchmarking PORFLO: An Equivalent Porous Continumm Code for Repository Scale Analysis. PNL-5044. Pacific Northwest Laboratory, Richland, Wash.

Felmy, A. R., D. C. Girvin, and E A. Jenne. 1984a. MINTEQ: A Computer Program for Calculating Aqueous Geochemical Equilibria. (NTIS PB84-157148) EPA-600/3-84-032. National Technical Information Service, Springfield, VA. 
Felmy A. R., S. M. Brown, Y. Onishi, S. B. Yabusaki, and R. S. Argo. $1984 b$. MEXAMS--The Metals Exposure Analysis Modeling System. EPA-600/3-84-031 (NTIS PB84-157155). U. S. Environmental Protection Agency, Athens, GA.

Fletcher, C. A. J. 1988. Computational Techniques for Fluid Dynamics. Vols I \& II, Springer-Verlag, New York, NY.

Freeze, R. A and J. A. Cherry. 1979. Groundwater. Prentice-Hall, Inc. Englewood Clife, NJ.

Hestenes, M. R, and E. Stiefel. 1952. Methods of conjugate gradients for solving linear systems. NBS J. Res., 49:409-436.

Huyakorn, P. S., and G. F. Pinder. 1983. Computational Methods in Subsurface Flow. Academic Press, Inc., New York, NY.

Huyakorn, P. S., and S. Panday. 1990. VAM3D-CG - Variably Saturated Analysis Model in Three-dimensions with Preconditioned Conjugate Gradient Matrix Solvers, Documentation and User's Guide, Vession 2.1. HGL89-02, Hydrogeologic, Inc., Herndon, VA.

Kozak, M. W., M. S. Y. Chu, C. P. Harlan, and P. A. Mattingly. 1989. Identification and Recommendation of Computer Codes for Low-Level Waste Performance Assessment. Subtasks 3.0 and 4.1 of the Final Letter Report to the USNRC (August).

Krupka, K. M., and J. R. Morrey. 1985. MINTEQ Geochemical Reaction Code: Status and Applications. Proceedings of a Conference on the Application of Geochemical models to High-Level Nuclear Waste Repository Assessment. G.K. Jacobs, and S. K. - Whatley, Eds. NUREG/CP-0062 U.S. Nuclear Regulatory Commission, Washington, D.C.

Magnuson, S. O., R. G. Baca, and A. J. Sondrup. 1990. Independent Verification and Benchmark Testing of the PORFLO-3 Compuser Code, Version 1.0. EGG-BG-9175. EG\&G Idaho, Inc., ID.

Malek, R. I. A., P. H. Licastro, D. M. Roy. 1987. Saltstone Pore Solution Analyses. A Report to E. I. DuPont De Nemours, Savannah River Plant, Aiken, SC.

Nordstrom, D. K, L. N. Plummer, T. M. L. Wigley, T. J. Wolery, J. W. Ball, E. A. Jenne, R. L. Basset, D. A. Crerarm, T. M. Forence, B. Fritz, M. Morel, M. M. Reddy, G. Sposito, and J. Thrailkill. 1979. A Comparison of Computerized Chemical Models foe Equilibrium Calculations in Aqueous Systems. Chemical Modeling in Aqueous Systems. E. A. Jenne, Ed. (ACS Symp. Series 93, American Chemical Society, Washington D.C.), pp. 857-892. 
Peaceman, D. W., and H. H. Rachford, Jr. 1955. The numerical solution of parabolic and elliptic differential equations. J. Soc. of Industrial and Applied Mathematics. 3.28-41.

Peterson, S. R., C. J. Hostetler, W. J. Deutsch, and C. E. Cowan. 1987. MINTEQ User's Manual. (NUREG/CR-4808) PNL-6106. U.S. Nuclear Regulatory Commission, Washington, D.C.

Philip, J. R. 1957. Numerical Solution of Equations of the Diffusion Type with Diffusivity Concentration-Dependent II. Australian Joumal of Physics, 10(2):29-42.

Remson, I., G. M. Hormberger, and R. F. Molz 1971. Numerical Methods in Sugsurface Hydrology. Wiley-Interscience, New York, NY.

Rockhold, M. L, and S. K. Wurstner. 1991. Simulation of Unsaturated Flow and Solute Transport at the Las Cruces Trench Site Using the PORFLO-3 Computer Code. PNL 7562. Pacific Northwest Laboratory, Richland, Wash.

Runchal, A. K, B. Sagar, R. G. Baca, and N. W. Kline. 1985. PORFLO - A Continuum Model for Fluid Flow, Heat Transfer, Mass Transport in Porous Media. RHO-BW-CR-150P. Rockwell Hanford Operations, Richland, Wash.

Runchal, A. K, and B. Sagar. 1989. PORFLO-3: A Mathematical Model for Fluid Flow, Heat and Mass Transport in Variably Saturated Geologic Media, Users Manual, Version 1.0. WHC-EP-0042. Westinghouse Hanford Operations, Richland, Wash.

Runchal, A. K. 1991. acrPLOT - A General Puppose Plotting Package, User's Manual Version 8.00. ACRiv14/Rev. A. Analytic and computational Research, Inc., Los Angeles, Calif.

Runchal, A. K, and B. Sagar. 1992. PORFLOW: A Model for Fluid Flow, Heat and Mass Transport in Multifluid, Multiphase Fractured or Porous Media, Users Manual, Version 2.4. ACRi/016/Rev. G, Analytic and Computational Research, Inc., Los Angeles, Calif.

Sagar, B., and A. K. Runchal. 1990. PORFLO-3: A Mathematical Model for Fluid Flow, Heat and Mass Transport in Variably Saturated. Geologic Media, Theory and Numerical Methods, Version 1.0. WHC-EP-0042. Westinghouse Hanford Operations, Richland, Wash.

Scheidegger, A. E. 1961. General Theory of Dispersion in Porous Media. J. Geophys. Res. $66(10): 3273-3278$.

Rev. 0 
Smith, R. W. 1988. Calculation of Equilibria at Elevated Temperatures Using the MINTEQ Geochemical Code. PNL-6700. Pacific Northwest Laboratory, Richland, Wash.

Smoot, J. L, and B. Sagar. 1990. Three-dimensional Contaminant Plume Dynamics in the Vadose Zone: Simulation of the 241-T.106 Single-Shell Tank Leak at Hanford. PNL-7221. Pacific Northwest Laboratories, Richland, Wash.

Travis, B. 1985. TRACR3D: A Model of Flow and Transport in Ponous Media. LA-9667-MS. Los Alamos National Laboratory, Los Alamos, NM.

Trusdell, A. H., and B. F. Jones. 1974. WATEQ, a Computer Program for Calculating Chemical Equilibria of Natural Waters." J. Research U.S. Geol Survey, 2:233-348.

Voes, C. I. 1984. A Finite-Element Simulation Model for Saturated-Unsaturated, Fluid-Density-Dependent Ground-Water Flow and Energy Transpon or Chemically-Reactive Single-Species Solute Transport. U. S. Geological Survey, Reston, VA.

Walton, J. C., L. E. Plansky, and R. W. Smith. 1990. Models for Estimation of Service Life of Concrete Barriers in Low-Level Redioactive Waste Dispasal. Prepared for Division of Engineering Office of Nuclear Regulatory Research, U.S. Nuclear Regulatory Commission, Washington, DC 20555, NRC FIN A6858, NUREG/CR-5542, EGG-2597, RW,CC, 38 p.

Wolfram, S. 1988. Mathematica: A System for Doing Mathematics by Computer. Addison-Wesley Publishing Company, Inc., USA, 749 p.

Yeh, G. T., and D. S. Ward. 1979. FEMWATER: A Finite-Element Model of Water Flow Through Saturated-Unsaturated Porous Media. ORNL-5567. Oak Ridge National Laboratory, Oak Ridge, Tenn.

Yeh, G. T., and D. S. Ward. 1981. FEMWASTE: A Finite-Element Model of WASTE, Transport Through Saturated-Unsaturated Porous Media. ORNL-5601. Oak Ridge National Laboratory, Oak Ridge, Tenn.

Yeh, G. T. 1987. FEMWATER: a Finite-Element Model of WATER Flow Through Saturated-Unsaturated Porous Media - First Revision". ORNL-5567/R1. Oak Ridge National Laboratory, Oak Ridge, Tenn. 


\section{C1 RADIONUCLIDE INVENTORY}

The radionuclide content of the waste streams and the Saltstone Disposal Facility assumed for the RPA are listed in Table C.1-1. 
Table C.1-1. Approximate radionuclide content of the waste streams and the Saltstone Disposal Facility

\begin{tabular}{|c|c|c|c|c|c|c|}
\hline Nuclide & Half-ife & $\begin{array}{l}\text { Time } \\
\text { Units }\end{array}$ & $\begin{array}{c}\text { In-Tank } \\
\text { Precipitation } \\
\text { Waste Stream } \\
\text { Chiter }\end{array}$ & $\begin{array}{c}\text { Effluent } \\
\text { Treatment Facility } \\
\text { Waste Streamb } \\
\text { Cinter } \\
\end{array}$ & $\begin{array}{c}\text { Nominal } \\
\text { Blend } \\
\text { Culiter }\end{array}$ & $\begin{array}{c}\text { Facility } \\
\text { Inventory } \\
\mathbf{a}\end{array}$ \\
\hline Te-99 & 213000 & years & $1.0 \times 10^{-4}$ & & $8.9 \times 10^{-5}$ & $6.5 \times 10^{4}$ \\
\hline$R u-106+d$ & 368 & days & $5.0 \times 10^{-5}$ & $5.0 \times 10^{6}$ & $4.5 \times 10^{-5}$ & $3.3 \times 10^{5}$ \\
\hline$C-137+d$ & 30.2 & years & $3.0 \times 10^{-5}$ & $6.0 \times 10^{6}$ & $27 \times 10^{-5}$ & $20 \times 10^{4}$ \\
\hline H-3 & 123 & years & $20 \times 10^{5}$ & $7.0 \times 10^{-5}$ & $2.6 \times 10^{5}$ & $1.9 \times 10^{4}$ \\
\hline $\mathrm{Sb}-125$ & $2 \pi$ & years & $1.0 \times 10^{-5}$ & $6.0 \times 10^{-6}$ & $8.9 \times 10^{6}$ & $6.5 \times 10^{3}$ \\
\hline Pm-147 & 2.62 & years & $6.0 \times 10^{6}$ & $5.0 \times 10^{7}$ & $5.4 \times 10^{6}$ & $3.9 \times 10^{3}$ \\
\hline Sm-151 & 90 & years & $3.0 \times 10^{6}$ & & $27 \times 10^{6}$ & $2.0 \times 10^{3}$ \\
\hline Sr-90 + d & 28.6 & years & $1.0 \times 10^{6}$ & $4.0 \times 10^{7}$ & $9.3 \times 10^{-7}$ & $6.8 \times 10^{2}$ \\
\hline Eu-154 & 8.8 & years & $1.0 \times 10^{6}$ & & $8.9 \times 10^{-7}$ & $6.5 \times 10^{2}$ \\
\hline Se-79 & 65000 & years & $5.0 \times 10^{-7}$ & & $4.4 \times 10^{-7}$ & $3.2 \times 10^{2}$ \\
\hline Eu-155 & 4.96 & years & $5.0 \times 10^{-7}$ & & $4.4 \times 10^{7}$ & $3.2 \times 10^{2}$ \\
\hline Co-60 & 5.27 & years & $3.0 \times 10^{-7}$ & $1.0 \times 10^{-7}$ & $28 \times 10^{-7}$ & $20 \times 10^{2}$ \\
\hline Te-125m & 58 & days & $3.0 \times 10^{-7}$ & $6.0 \times 10^{6}$ & $27 \times 10^{7}$ & $20 \times 10^{2}$ \\
\hline$S n-126+d$ & 100000 & years & $2.0 \times 10^{-7}$ & & $1.8 \times 10^{-7}$ & $1.3 \times 10^{2}$ \\
\hline Am-241 & 432 & years & $20 \times 10^{7}$ & & $1.8 \times 10^{-7}$ & $1.3 \times 10^{2}$ \\
\hline $\mathrm{C}_{5-134}$ & 2.06 & years & $1.0 \times 10^{-7}$ & & $8.9 \times 10^{-5}$ & $6.5 \times 10^{1}$ \\
\hline Pu-238 & 87.8 & years & $7.0 \times 10^{-8}$ & $4.0 \times 10^{8}$ & $6.7 \times 10^{8}$ & $4.9 \times 10^{1}$ \\
\hline $\mathrm{Pu}-241$ & 14.4 & years & $5.0 \times 10^{6}$ & & $4.4 \times 10^{6}$ & $3.2 \times 10^{1}$ \\
\hline
\end{tabular}


Table C.1-1. (continued)

\begin{tabular}{|c|c|c|c|c|c|c|}
\hline Nuclide & Haik-ife & $\begin{array}{l}\text { Tine } \\
\text { Unies }\end{array}$ & $\begin{array}{c}\text { In-Tant } \\
\text { Precipitation } \\
\text { Wacte Stream } \\
\text { Chiter } \\
\end{array}$ & $\begin{array}{c}\text { Efiluent } \\
\text { Treatment Facility } \\
\text { Warte Steamb } \\
\text { Cinter }\end{array}$ & $\begin{array}{l}\text { Nominat } \\
\text { Blend } \\
\text { Chiter }\end{array}$ & $\begin{array}{c}\text { Fecility } \\
\text { Inventory } \\
\text { a }\end{array}$ \\
\hline Sn-121m & 55 & years & $4.0 \times 10^{-1}$ & \multirow{5}{*}{$27 \times 10^{2}$} & $3.6 \times 10^{8}$ & $26 \times 10^{1}$ \\
\hline Ni-63 & 100 & years & $3.0 \times 10^{6}$ & & $27 \times 10^{0}$ & $2.0 \times 10^{1}$ \\
\hline I-129 & $1.5 \times 10^{7}$ & years & $27 \times 10^{3}$ & & $2.7 \times 10^{-6}$ & $20 \times 10^{1}$ \\
\hline Sb-126 & 124 & days & $20 \times 10^{6}$ & & $1.8 \times 10^{-6}$ & $1.3 \times 10^{1}$ \\
\hline C-14 & 5730 & years & $1.0 \times 10^{-0}$ & & $8.9 \times 10^{\circ}$ & 6.5 \\
\hline Eu-152 & 13.6 & years & $9.0 \times 10^{-9}$ & \multirow{5}{*}{$1.0 \times 10^{3}$} & $8.0 \times 10^{-0}$ & 5.8 \\
\hline Ce-144 & 284 & days & $5.0 \times 10^{-9}$ & & $4.4 \mathrm{E} \times 10^{\circ}$ & 3.2 \\
\hline Pu-239 & 24100 & years & $7.0 \times 10^{-10}$ & & $1.7 \times 10^{-9}$ & 1.2 \\
\hline Cm-244 & 18.1 & years & $1.0 \times 10^{-9}$ & & $8.9 \times 10^{-10}$ & $6.5 \times 10^{-1}$ \\
\hline$A_{8}-110 m$ & 250 & days & $9.0 \times 10^{-10}$ & & $8.0 \times 10^{-10}$ & $5.8 \times 10^{-1}$ \\
\hline Pu-240 & 6540 & years & $5.0 \times 10^{-10}$ & & $4.4 \times 10^{-10}$ & $3.2 \times 10^{-1}$ \\
\hline Zr-93 & 1530000 & years & $4.0 \times 10^{-10}$ & & $3.6 \times 10^{-10}$ & $2.6 \times 10^{-1}$ \\
\hline U-234 & 245000 & years & $4.0 \times 10^{-10}$ & \multirow{6}{*}{. } & $3.6 \times 10^{-10}$ & $2.6 \times 10^{-1}$ \\
\hline Ni-59 & 75000 & years & $3.0 \times 10^{-10}$ & & $27 \times 10^{-10}$ & $20 \times 10^{2}$ \\
\hline Ce-142 & $5 \times 10^{16}$ & years & $3.0 \times 10^{-10}$ & & $27 \times 10^{-10}$ & $2.0 \times 10^{-1}$ \\
\hline Th-231 & 25.5 & bours & $20 \times 10^{-10}$ & & $1.8 \times 10^{-10}$ & $1.3 \times 10^{-1}$ \\
\hline Am-242m & 152 & years & $1.0 \times 10^{-10}$ & & $8.9 \times 10^{-11}$ & $6.5 \times 10^{-2}$ \\
\hline Am-242 & 16 & hours & $1.0 \times 10^{-10}$ & & $8.9 \times 10^{-11}$ & $6.5 \times 10^{-2}$ \\
\hline
\end{tabular}


Table C.1-1. (continued)

\begin{tabular}{|c|c|c|c|c|c|c|}
\hline Nuclide & Half-ife & $\begin{array}{l}\text { Time } \\
\text { Units }\end{array}$ & $\begin{array}{c}\text { In-Tank } \\
\text { Precipitation } \\
\text { Waste Stream } \\
\text { Ciliter } \\
\end{array}$ & $\begin{array}{c}\text { Effluent } \\
\text { Treatment Facility } \\
\text { Waste Steamb } \\
\text { CViter }\end{array}$ & $\begin{array}{l}\text { Nominal } \\
\text { Blende } \\
\text { Chiter }\end{array}$ & $\begin{array}{c}\text { Facility } \\
\text { Inventory } \\
\text { a }\end{array}$ \\
\hline $\mathrm{Cm}-242$ & 163 & days & $1.0 \times 10^{-10}$ & & $8.9 \times 10^{-11}$ & $6.5 \times 10^{-2}$ \\
\hline Np-237 + d & 2140000 & years & $9.0 \times 10^{-11}$ & & $8.0 \times 10^{-11}$ & $5.8 \times 10^{-2}$ \\
\hline $\operatorname{Ra}-224+d$ & 3.62 & days & $7.0 \times 10^{-11}$ & & $6.2 \times 10^{-11}$ & $4.5 \times 10^{2}$ \\
\hline U.232 & 72 & years & $7.0 \times 10^{-11}$ & & $6.2 \times 10^{-11}$ & $4.5 \times 10^{-2}$ \\
\hline Am-243 & 7380 & years & $6.0 \times 10^{-11}$ & . & $5.3 \times 10^{-11}$ & $3.9 \times 10^{-2}$ \\
\hline Ca-135 & 2300000 & years & $6.0 \times 10^{-11}$ & & $5.3 \times 10^{-11}$ & $3.9 \times 10^{-2}$ \\
\hline Pr-144m & 7.2 & minutes & $5.0 \times 10^{-11}$ & & $4.4 \times 10^{-11}$ & $3.2 \times 10^{-2}$ \\
\hline $\mathrm{Cm}-243$ & 28.5 & years & $4.0 \times 10^{-11}$ & & $3.6 \times 10^{-11}$ & $26 \times 10^{-2}$ \\
\hline Pd-107 & 6500000 & years & $3.0 \times 10^{-11}$ & & $2.7 \times 10^{-11}$ & $2.0 \times 10^{-2}$ \\
\hline $\mathbf{P a - 2 3 4}$ & 6.7 & hours & $6.0 \times 10^{-12}$ & & $5.3 \times 10^{-12}$ & $3.9 \times 10^{-3}$ \\
\hline U-233 & 159000 & years & $4.0 \times 10^{-12}$ & & $3.6 \times 10^{-12}$ & $2.6 \times 10^{3}$ \\
\hline U-238 & $4.47 \times 10^{\circ}$ & years & $3.0 \times 10^{-12}$ & & $2.7 \times 10^{-12}$ & $20 \times 10^{-3}$ \\
\hline Th-234 & 24.1 & days & $3.0 \times 10^{-12}$ & & $27 \times 10^{-12}$ & $20 \times 10^{-3}$ \\
\hline Th-228 & 1.91 & years & $2.0 \times 10^{-12}$ & & $1.8 \times 10^{-12}$ & $1.3 \times 10^{-3}$ \\
\hline Pu-236 & 285 & years & $6.0 \times 10^{-13}$ & & $5.3 \times 10^{-13}$ & $3.9 \times 10^{-4}$ \\
\hline Pu-242 & 376000 & years & $6.0 \times 10^{-13}$ & & $5.3 \times 10^{-13}$ & $3.9 \times 10^{-4}$ \\
\hline U-235 & $7.04 \times 10^{8}$ & years & $5.0 \times 10^{-13}$ & & $4.4 \times 10^{-13}$ & $3.2 \times 10^{-4}$ \\
\hline Th-230 & 77000 & years & $1.0 \times 10^{-13}$ & & $8.9 \times 10^{-14}$ & $6.5 \times 10^{-5}$ \\
\hline
\end{tabular}



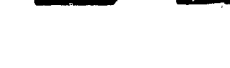

Table C1-1. (continued)

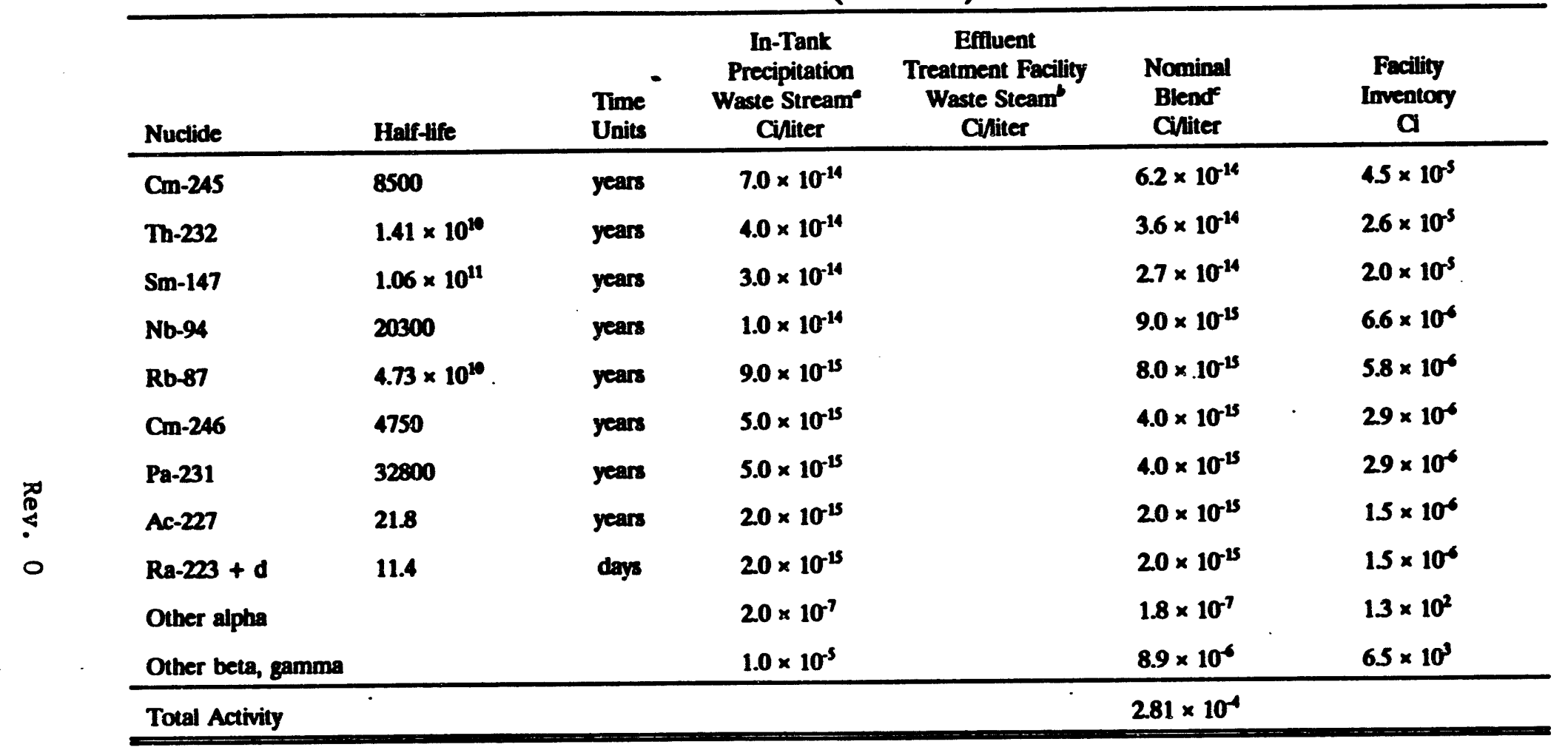

- Source: Fowler 1982a.

- Source: Hectrote 1988.

- Nominal Blend (NB) refers to blend ration of 8:1 by volume of ITP: ETF feed solution.

Note: Curie values were computed based on an assumed production mix with 15 years of decay. 


\section{C2 PORFLOW INPUT FILES}

The input files used for the near-field and groundwater flow and mass transport simulations are given in Fig. C.2-1 through C.2-6.

Rev. 0 
TITLE TwO-d Saltstone Monolith (Attempt 6)

GRIO 63 by 124

SCALE 30.4800

COOROINATE $x$

$\begin{array}{llllllllll}-50.1 & -49.9 & -40.0 & -30.0 & -20.0 & -10.0 & 0.0000 & 8.5814 & 15.7039 & 21.6156\end{array}$ $26.522430 .594933 .973236 .780839 .1094 \quad 41.042242 .646643 .977945 .083046 .0003$ $46.761647 .3935 \quad 47.9180 \quad 48.353348 .7146 \quad 49.0145 \quad 49.2634 \quad 49.470049 .6415 \quad 49.7838$ 49.902050 .000050 .125050 .250050 .375050 .500050 .625050 .750050 .875051 .0000 51.125051 .250051 .375051 .500051 .722151 .999652 .346652 .780353 .322454 .0000

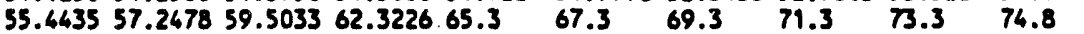
$\begin{array}{lll}76.0 & 76.4 & 76.6\end{array}$

1

SCALE 30.4800

COOROINATE Y

1

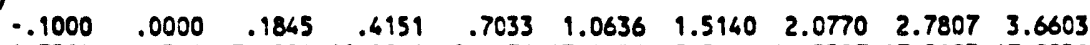
$\begin{array}{llllllllll}4.7599 & 6.1344 & 7.8526 & 10.0000 & 12.1476 & 13.8656 & 15.2401 & 16.3397 & 17.2193 & 17.9230\end{array}$ $18.486018 .936419 .2967 \quad 19.584919 .815520 .000020 .125020 .250020 .375020 .5000$ 20.625020 .750020 .875021 .000021 .125021 .250021 .375021 .500021 .625021 .7500 $21.875022 .000022 .166622 .366522 .606422 .8942 \quad 23.239723 .6542 \quad 24.151624 .7485$ 25.464826 .324327 .355828 .593530 .078831 .861234 .000036 .238638 .096639 .6388 $40.918841 .981242 .863043 .594944 .2024 \quad 46.706645 .125145 .472445 .760746 .0000$ $46.250046 .500046 .750047 .0000 \quad 47.2500 \quad 47.5000 \quad 47.750048 .000048 .250048 .5000$

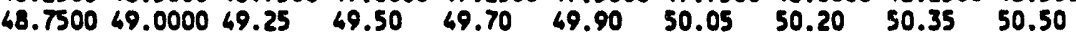
$\begin{array}{llllllllll}50.6 & 50.7 & 50.8 & 50.88 & 50.95 & 51.00 & 51.05 & 51.10 & 51.15 & 51.22\end{array}$

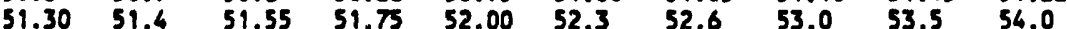

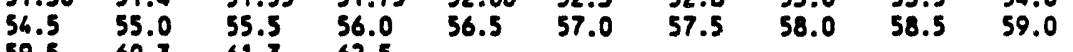
$\begin{array}{llll}59.5 & 60.3 & 61.3 & 62.5\end{array}$

READ 1 st record from 'end. 0 '

ZONE 1 is from $(1,1)$ to $(63,126)$ s BACXFILL

zONE 2 is from $(1,27)$ to $(44,82)$ s CONCRETE

2ONE 3 is from $(1,43)$ to $(32,70)$ s SALTSTONE

2ONE 4 is from $(1,71)$ to $(44,82) \&$ LOU $K$ CONCRETE CAP

ZONE 5 is from $(1,83)$ to $(63,90)$ \& CLAY

2ONE 6 is from $(1,91)$ to $(63,96)$ s GRAVEL

DATUm $=0.0$

GRAVIty components are: $0.02,-1$.

DENSity of fluid is constant and equal to 1 . om/ce

1

FOR zone 1 SBACKFILL

ROCK matrix density $2.6 \mathrm{gm} / c e$ meff $=0.64$ ntot $=0.64$ ndif $=0.64$

HYDRaulic prop ss=1.e-3 $\quad \mathrm{K}=315 \quad \mathrm{Ky}=315 \mathrm{~cm} / \mathrm{Yr}$

TRANsport for $C \mathrm{kd}=0 \quad \mathrm{D}=158 \quad \mathrm{al}=10$ ot: $2 \mathrm{~s} \mathrm{C}$ is NO3

IRANsport for $C 2 \mathrm{kd}=0 \quad \mathrm{D}=158 \quad$ ol 10 at: $25 \mathrm{C}$ is $\mathrm{H}-3$

TRANsport for C3 kd= $0.36 \quad 0=158 \quad$ ol $=10$ at= 2 \& $\mathrm{C}$ is TC-99

TRAMsport for Ch kd= $0.6 \quad 0=158 \quad l=10$ at= 2 \& is $1-129$

MulTiphase flow: tabular option, 79 points

1 saturation matric potential in $\mathrm{cm}$

$\begin{array}{rr}0.22 & 378.3312 \\ 0.23 & 366.3198 \\ 0.26 & 354.5856 \\ 0.25 & 343.125 \\ 0.26 & 331.9344 \\ 0.27 & 321.0102 \\ 0.28 & 310.3488 \\ 0.29 & 299.9466 \\ 0.3 & 289.8 \\ 0.31 & 279.9056 \\ 0.32 & 270.2592 \\ 0.33 & 260.8578 \\ 0.34 & 251.6976 \\ 0.35 & 242.775 \\ 0.36 & 234.0864 \\ 0.37 & 225.6282 \\ 0.38 & 217.3968 \\ 0.39 & 209.3886 \\ 0.4 & 201.6 \\ 0.41 & 196.0274 \\ 0.42 & 186.6672 \\ 0.43 & 179.5158 \\ 0.46 & 172.5696 \\ 0.45 & 165.825 \\ 0.46 & 159.2784 \\ 0.47 & 152.9262 \\ 0.48 & 146.7648 \\ 0.49 & 140.7906\end{array}$

Fig. C.2-1. PORFLON-3D input file for near-field flow and transport simulations. 


\begin{tabular}{|c|c|}
\hline $\begin{array}{l}0.5 \\
0.51 \\
0.52 \\
0.53 \\
0.54 \\
0.55 \\
0.56 \\
0.57 \\
0.58 \\
0.59 \\
0.6 \\
0.61 \\
0.62 \\
0.63 \\
0.64 \\
0.65 \\
0.66 \\
0.67 \\
0.68 \\
0.69 \\
0.7 \\
0.71 \\
0.72 \\
0.73 \\
0.76 \\
0.75 \\
0.76 \\
0.77 \\
0.78 \\
0.79 \\
0.8 \\
0.81 \\
0.82 \\
0.83 \\
0.86 \\
0.85 \\
0.86 \\
0.87 \\
0.88 \\
0.89 \\
0.9 \\
0.91 \\
0.92 \\
0.93 \\
0.94 \\
0.95 \\
0.96 \\
0.97 \\
0.98 \\
0.99 \\
\end{array}$ & $\begin{array}{r}135 \\
129.3894 \\
123.9552 \\
118.6938 \\
113.6016 \\
108.675 \\
103.9104 \\
99.3042 \\
94.8528 \\
90.5526 \\
86.4 \\
82.3914 \\
78.5232 \\
74.7918 \\
71.1936 \\
67.725 \\
64.3824 \\
61.1622 \\
58.0608 \\
55.0746 \\
52.2 \\
49.4334 \\
46.7712 \\
44.2098 \\
41.7456 \\
39.375 \\
37.0944 \\
34.9002 \\
32.7888 \\
30.7566 \\
28.8 \\
26.9154 \\
25.0992 \\
23.3478 \\
21.6576 \\
20.025 \\
18.4464 \\
16.9182 \\
15.4368 \\
13.9986 \\
12.6 \\
11.2376 \\
9.9072 \\
8.6058 \\
7.3296 \\
6.075 \\
4.8384 \\
3.6162 \\
2.4048 \\
1.2006 \\
0.0000\end{array}$ \\
\hline
\end{tabular}

Multiphese flow: COWD tabular aption, 79 points

1 saturation relative conductivity

$0.220 .0000 E+00$

$0.23 \quad 2.7016 E-08$

$0.26 \quad 4.3226 E-07$

$0.25 \quad 2.1823 E \cdot 06$

$0.26 \quad 6.9161 E-06$

0.27 1.6885E-05

$0.28 \quad 3.5013 E-05$

$0.29 \quad 6.4865 E-05$

$0.3 \quad 1.10665 \cdot 04$

$0.31 \quad 1.7725 E \cdot 04$

0.32 2.7016E-04

0.33 3.9554E-04

$0.36 \quad 5.60205 .04$

$0.357 .7960 E-04$

$0.36 \quad 1.0378 E \cdot 03$

0.37 1.3677E-03

$0.38 \quad 1.7705 E .03$

$0.392 .2564 E \cdot 03$

$0.4 \quad 2.8360 \mathrm{E} \cdot 03$

$0.413 .5208 E-03$

$0.42 \quad 4.3226 E \cdot 03$

$0.43 \quad 5.25418 .03$

0.46 6.3287E-03

$0.457 .5602 E-03$

$0.46 \quad 8.9633 E-03$

$0.67 \quad 1.0553 E-02$

$0.481 .2366 E-02$

Fig. C.2-1. (continued). 


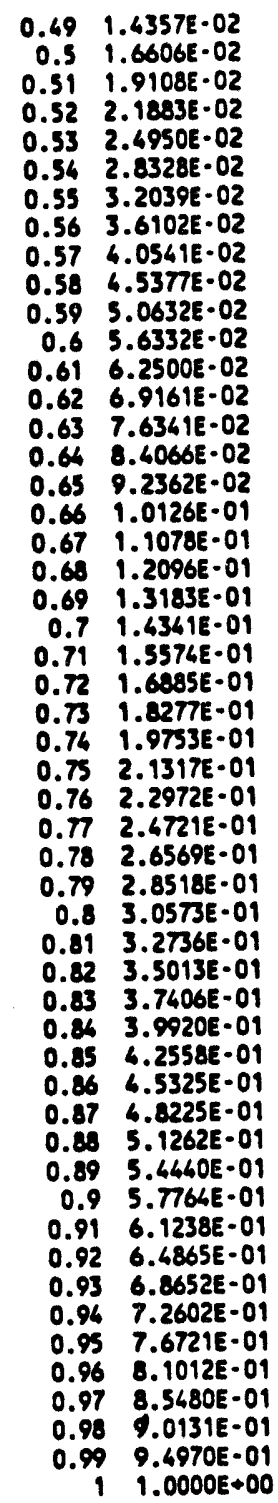

1

FOR zON 2 SCONCRETE

ROCK bulk den 2.1 gm/ee nef $f=0.08$ ntot $=0.08$ ndif $=0.08$

HYOReul ic prop. $38=1 . e-4, \quad k x=3.154 e-3 \quad K y=3.156 e-3$

WULtiphese flow: VAN $n=1.57$ alphe=7.5e-7 swr=0.8

TRANsport for $C$ kd= $0.0 \quad 0=0.315$ its $a t=1$ \& $C$ is NO3

TRAMsport for C2 kd= 0.0 D=0.315 at=5 ot=1 \& C2 is $\mathrm{H}-3$

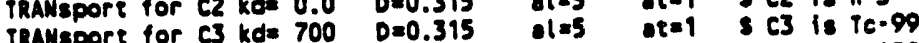

TRANsport for C4 $k d=30 \quad 0=0.315$ il=5 $\quad t=1$ \& $\quad$ is 1.129

FOR zone 3 SSALTSTONE

ROCX bulk den 2.1 onvec, neff $=.46$, ntot $=0.46$, ndi $f=0.46$

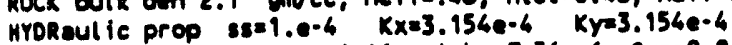

MULTiphase flow: VAN n=4.41 alpha=7.36e-6 Sur=0.8

PRANsport for $C \mathrm{kd}=0.0 \quad 0=0.158$ al=5 at $=1$ \& $C$ is nO3

TRANsport for C2 kd= 0.2 D=0.158 al=5 ot $=1$ \& $\mathrm{C2}$ is $\mathrm{H-3}$

TRAMsport for C3 kd= 700 D=0.158 ol=5 ot $=1$ s $C 3$ is TC-99

TRAKsport for Ch kda 30 D=0.158 ol=5 ot = 1 \& $C 4$ is 1.129

1

POR zONE 4 SCONCRETE ROOF

ROCK bulk den 2.1 on/ce neff $=0.08$ ntot $=0.08$ ndif $=0.08$

HYDR ulic prop. ss=1.e-4, $k x=3.1540-3 \quad k y=3.154 e-3$

MulTiphase flow: VAN $n=1.57$ alphas $=7.5 e-7$ Sur $=0.8$

IRANspore for $C$ kd= $0.0 \quad 0=0.315$ ol $=5$ ot $=1$ \& $C$ is nO3

TRAMsport for C2 kd= $0.0 \quad 0=0.315 \quad$ al $=5$ at $=1$ \& $C 2$ is $\mathrm{H}=3$

TRAMsport for C3 kde 700 0=0.315 al as at=1 \& C3 is Te-99

TRAMsport for C4 kde 30 Do 0.315 ol $=5$ ot $=1$ C4 is 1.129

I

Fig. C.2-1. (continued). 


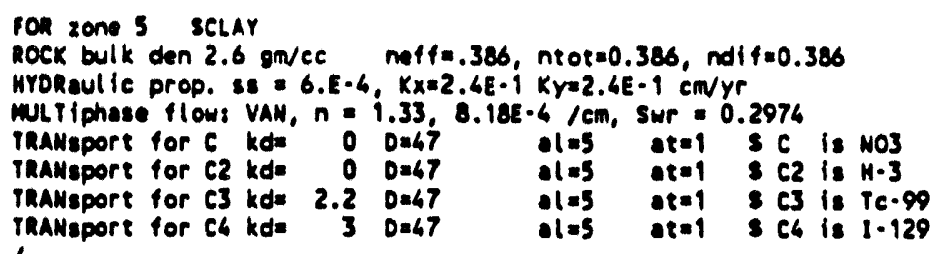


BLUX BALA for Ch trm $(1,29)$ so $(42,80)$ every 200 stops

1

History for C C2 C3 C4 $(3,84)(46,43)(3,57)$ every 200 steps in 'time.his'

I

I (3,84) above concrete roof in clay at center of 200 width of vault

I $(46,43)$ out from sidewall of vault in soll, level w/ base of saltstone max pt

I $(3,57)$ at vaule centrold, for intruder scenario

1 operational control

1

phoporty for $P$ and $c$ is MARM mean

MarRix in $X$ and $Y$ directions for $P$ and $C$ in 3 awoepe waing $A D I$

couvergence for $P$ LOCAl mode; value $=1.00-04$, max of 20 iterations

Ditanenstle node for $V$ and $C(46,43)$ every 3 steps

MINDOW $(2,2)$ to $(2,2)$

OUPPut P every 100000

/solv for $P \quad 1$ init 1.0 .3 ine $1.005 \max 0.05$ min 1.0 .41 .1100000

ISAVE UVPS NOW in 'end.0

solv for P C C2 C3 C6 4 init 0.001 inc $1.005 \max 0.015 \mathrm{~min} 1.0 .41 .1100000$ sAve U VPC C2 C3 C4 s MOW in 'end.1'

1

solv for P C C2 C3 C4 5 init 0.015 ine $1.005 \max 0.02$ min 1.0 .41 .1100000 SAVE U V P C C2 C3 C6 8 NOW in 'end.1"

1

solv for P C C2 C3 C4 10 init 0.02 ine $1.005 \max 0.03$ min 1.0 .41 .1100000 SAVE U V P C C2 C3 Ch 5 MOW in 'end.1' 1

solv for P C C2 C3 Ch 20 init 0.03 ine $1.005 \max 0.04 \mathrm{~min} 1.8 .41 .1100000$ SAVE U V P C C2 C3 C4 5 MON in 'end.2'

solv for P C C2 C3 C4 30 init 0.04 ine 1.000 max 0.05 min 1.0 .41 .1100000 SAVE U V P C C2 C3 C4 s MOW in 'end.2'

solv for P C C2 C3 C6 30 init 0.05 ine $1.005 \max 0.06$ min 1.0 .41 .1100000 SAVE U V P C C2 C3 C4 S MOW in 'end.2'

solv for P C2 C3 C4 100 inie 0.06 ine 1.005 max 0.08 min 1.0 .41 .1100000 SAVE U V P C C2 C3 C4 $S$ NOW in ' and.3'

1

solv for P C C2 C3 C4 100 init 0.09 ine 1.000 max 0.09 min 1.0 .41 .1100000 SAVE U V P C C2 C3 C4 S NOW in 'end.3'

1

souv for P C C2 C3 C4 100 init 0.09 ine 1.005 max 0.09 min $1.0-41.1100000$ SAVE U V P C C2 C3 C4 S NOW in 'end.3'

sotv for P C C2 C3 C4 100 init 0.09 ine 1.000 max 0.09 min $1.0-41.1100000$ SAVE U VIP C C2 C3 C4 S MOW in 'end.4'

solv for P C C2 C3 C4 100 inis 0.09 ine 1.000 max 0.10 min 1.0 .41 .1100000 SAVE U V P C C2 C3 C4 S NOW in 'end. 4 '

solv for P C C2 C3 C4 100 init 0.10 ine $1.000 \max 0.11$ min $1 . e-41.1100000$ SAVE U V P C C2 C3 C4 5 MON in ' and. 4 "

solV for P C C2 C3 C4 300 init 0.11 ine $1.005 \max 0.13$ min 1.0 .41 .1100000 SAVE U V P C C2 C3 C4 5 MOW in 'end.5' 1

I solution to 1000 years

I

DISA RLOW

solv FOR C C2 C3 Ch for 500 init 0.13 ine 1.005 max 0.3 min 1.0 .41 .1100000 SOLV FOR C C2 C3 C4 for 500 init 0.3 ine $1.005 \max 0.5$ min $1.0-41.1100000$ 1

1 solution to 2000 years

solv rOR C C2 C3 C4 to 1000 init 0.5 ine $1.005 \max 0.75 \min 1 . e-41.1100000$ SOLV FOR C C2 C3 C4 fo 2000 init 0.75 ine 1.005 max 1.00 min $1 . e-41.1100000$ SAVE C C2 C3 C4 HOW in 'end.6' I

SOLV FOR C C2 C3 C4 fo 5000 init 1.00 inc $1.005 \max 1.50 \mathrm{~min} 1.0-41.1100000$ SAVE C C2 C3 C4 in 'end.6'

END

Pig. C.2-1, (continued). 
TITL Development of an UNSAT flow model File UNSAT72.DAT

/Analysis of transit time below a fractured block of saltstone GRID 80 by 60

Coordinate $x$

Sdimensions in centimeters

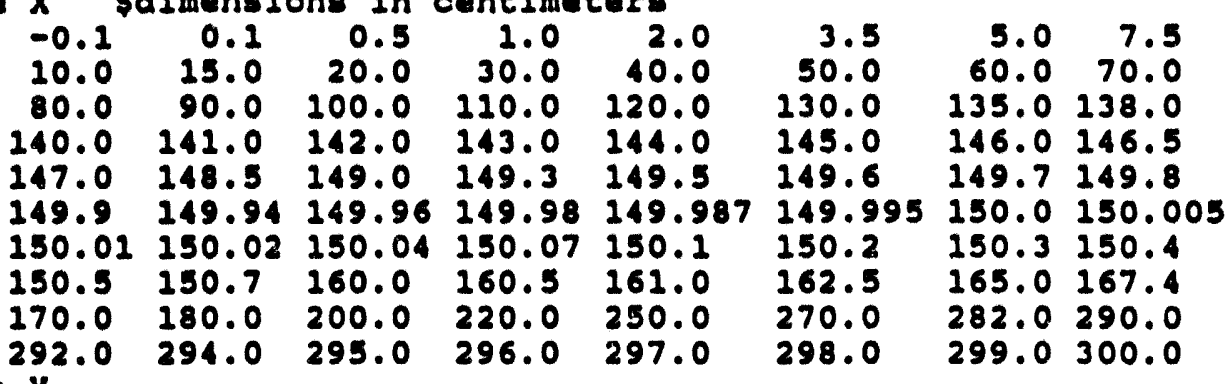
coordinate $Y$

$\begin{array}{rrrrrrrrrr}-0.1 & 0.1 & 0.2 & 0.4 & 0.8 & 1.4 & 2.0 & 5.0 & 10.0 & 20.0 \\ 30.0 & 40.0 & 60.0 & 80.0 & 100.0 & 120.0 & 140.0 & 160.0 & 180.0 & 200.0 \\ 220.0 & 240.0 & 260.0 & 280.0 & 300.0 & 320.0 & 340.0 & 360.0 & 380.0 & 400.0 \\ 420.0 & 440.0 & 460.0 & 480.0 & 500.0 & 520.0 & 540.0 & 560.0 & 580.0 & 590.0 \\ 600.0 & 601.0 & 602.0 & 603.0 & 604.0 & 605.0 & 606.0 & 607.0 & 608.0 & 609.0 \\ 609.3 & 609.5 & 609.6 & 609.7 & 609.8 & 609.9 & 609.95 & 609.98 & 609.99 & 610.0\end{array}$

(

DATUM 0., 0 .

1

ZONE 1 18 from $(1,1)$ to $(80,60)$

/

GRAVity $0 .,-9.864 \mathrm{E}+17 \mathrm{~cm} / \mathrm{Yr} / \mathrm{Yr}$

1 PROPerty ARIThmet1c mean option

1

INITial $P$ everywhere $\$(4 * 0)$ gradx $=0$, grady $=1$

INITial $s$ is 0.7 everywhere

/ lat type boundary conditions are prescribed in terms of total head

1

Boundary for $P:$ index -1 , FIUX $=0$

Boundary for $P$ : index +1 , FLUX $=0$

Boundary for $P$ : Index +2 , FLUX $=-40.0 \mathrm{~cm} / \mathrm{yr}$

Boundary for $P$ : index -2 , INTE $=0$

1

FOR zone 1 SGruber Unsat characteristics

ROCK density 1.0 , porosity $=0.30,0.40,0.30$

HYDRaulic properties: $88=1 . E-7,(\mathrm{kx}, \mathrm{ky}) \rightarrow 2 * 4625 \mathrm{~cm} / \mathrm{Yr}$

MUITlifuid option: TABU molsture curve, 15 values

/Pressure va. Saturation

/Degree of Pressure

/Saturation Cm of $\mathrm{H2O}$

$9.99 \mathrm{E}-01 \quad 0.0 \mathrm{E}+00$

$9.98 \mathrm{E}-01 \quad 1.0 \mathrm{E}+00$

9.96E-01 2.3E+01

9.92E-01 $\quad 4.0 E+01$

$9.89 \mathrm{E}-01 \quad 7.5 \mathrm{E}+01$

8.48E-01 $2.0 E+02$

8.28E-01 2.0E+02

8.18E-01 $3.1 \mathrm{E}+02$

8.08E-01 5.1E+02

$7.00 E-01 \quad 5.5 E+02$

6.50E-01 6.0E+02

6.00E-01 6.5E+02

5.50E-01 7.0E+02

Fig. C.2-2. PORFLOW-3D Input file for estimating travel time beneath fractured saltstone. 


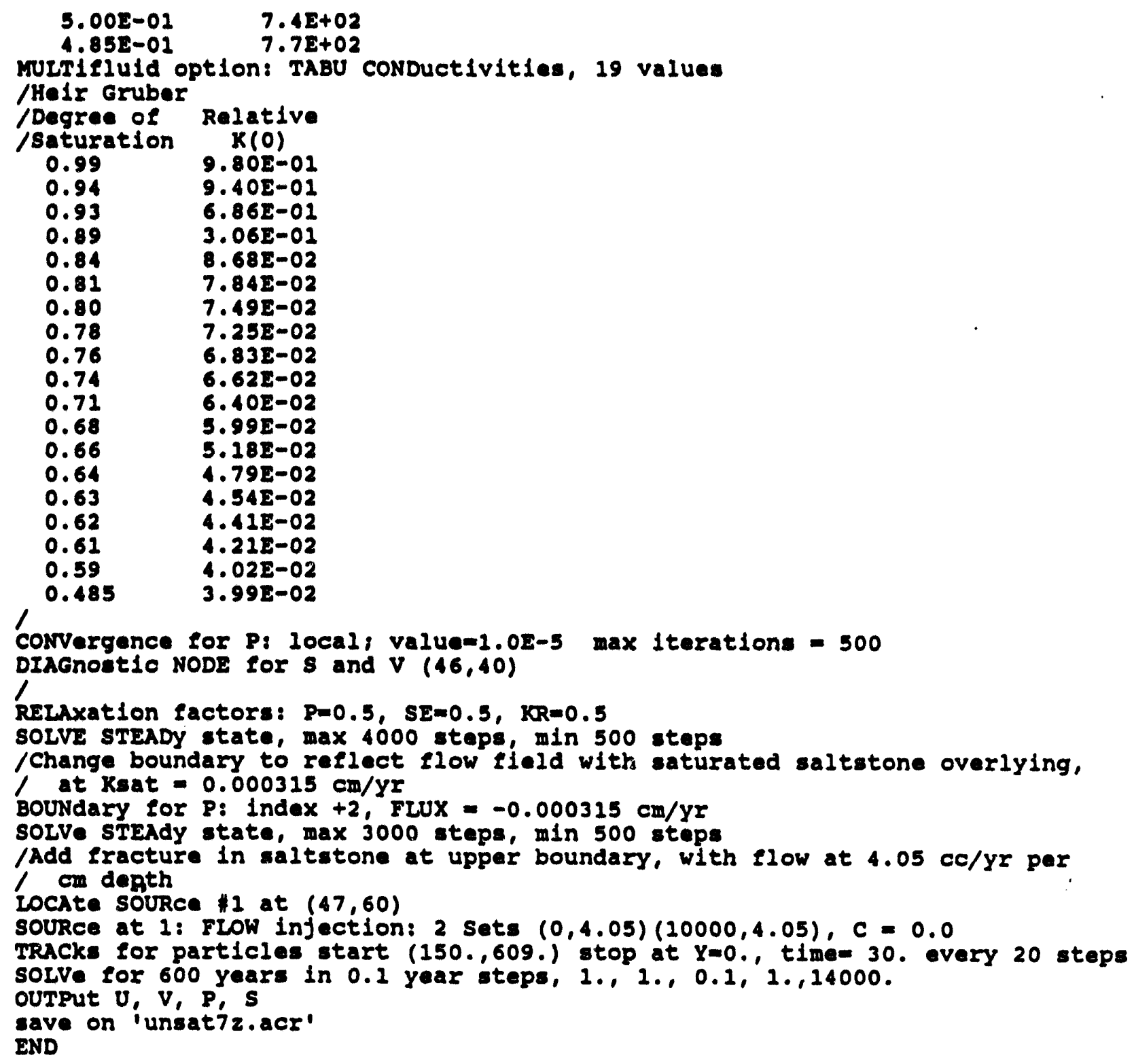

Fig. C.2-2. (continued). 
TITL FLW PORTION OF THE CONTAMINANT TRANSPORT CODE 1F11. 250M.DAT June 2, 1992

This version will be used as the basis for contaminant transport modeling land the calculation of fluxes along the boundary. This version will be /used for PORFLOW Version 2.40 with source data from INEL at z-Area. This /110 establishes the flow field in the absence of the saltstone Disposal Tracility, with $40 \mathrm{~cm} / \mathrm{yr}$ infiltration. GRID 48 by 49 by 13

\begin{tabular}{|c|c|c|c|c|c|c|}
\hline oordir & $\begin{array}{l}-30.48 \\
128016 \\
132400 \\
170688 \\
188976 \\
207264 \\
228600 \\
257251.2\end{array}$ & $\begin{array}{l}12192 \\
134112 \\
155448 \\
173736 \\
192024 \\
210312 \\
231648 \\
262128\end{array}$ & $\begin{array}{l}23774.4 \\
138531.6 \\
158496 \\
176784 \\
195072 \\
213360 \\
235610.4 \\
265176\end{array}$ & $\begin{array}{l}47853.6 \\
143256 \\
161544 \\
179832 \\
198120 \\
218846.4 \\
240792 \\
268224\end{array}$ & $\begin{array}{l}78638.4 \\
146304 \\
164592 \\
182880 \\
201168 \\
222504 \\
243840 \\
277215.6\end{array}$ & $\begin{array}{l}108051.6 \\
149352 \\
167640 \\
185928 \\
204216 \\
225552 \\
249936 \\
288432.2\end{array}$ \\
\hline coordinate $y$ & $\begin{array}{l}-30.48 \\
79248 \\
97536 \\
115824 \\
134112 \\
152400 \\
173736 \\
198912\end{array}$ & $\begin{array}{l}18897.6 \\
82296 \\
100584 \\
118872 \\
137160 \\
155448 \\
176784 \\
210312\end{array}$ & $\begin{array}{l}45537.12 \\
85344 \\
103632 \\
121920 \\
140208 \\
158496 \\
179832 \\
219456\end{array}$ & $\begin{array}{l}62605.92 \\
88392 \\
106680 \\
124968 \\
143256 \\
161544 \\
182880 \\
228600\end{array}$ & $\begin{array}{l}72725.28 \\
91440 \\
109728 \\
128016 \\
146304 \\
167579 \\
185928 \\
237744\end{array}$ & $\begin{array}{l}76200 \\
94488 \\
112776 \\
131064 \\
149352 \\
170688 \\
192024 \\
255209\end{array}$ \\
\hline COORdInate 2 & $\begin{array}{l}1524 \\
4876.8 \\
9144\end{array}$ & $\begin{array}{l}1828.8 \\
5486.4\end{array}$ & $\begin{array}{l}3048 \\
5791.2\end{array}$ & $\begin{array}{l}67.2 \\
96\end{array}$ & .8 & \\
\hline
\end{tabular}

1

The following lixed commands specify nodes at which pressure is fixed /throughout the simulation, 1.e., at the streams.

l

FIXEd P from $(34,3,10)$ to $(35,3,10)$

FIXEd $P$ from $(36,3,10)$ to $(36,4,10)$

FIXEd P from $(37,4,10)$ to $(39,4,10)$

FIXEd f from $(39,5,10)$ to $(39,5,10)$

FIXEd P from $(40,5,10)$ to $(41,5,10)$

FIXEd P from $(42,5,9)$ to $(42,14,9)$

FIXed P erom $(43,14,9)$ to $(43,25,9)$

FIXEd P from $(43,26,9)$ to $(45,26,9)$

FIXed $p$ from $(45,27,8)$ to $(45,34,8)$

FIXEd P from $(45,35,8)$ to $(47,35,8)$

FIXEd P erom $(47,36,8)$ to $(47,37,8)$

FIXEd P from $(48,37,8)$ to $(48,40,8)$

FIXed P from $(48,41,8)$ to $(48,42,8)$

FIXEd $P$ from $(48,43,7)$ to $(48,45,7)$

FIXEd P from $(47,45,7)$ to $(47,47,7)$

FIXEd P from $(2,7,9)$ to $(2,15,9)$

FIXEd $P$ from $(1,15,9)$ to $(1,20,9)$

FIXEd $P$ from $(1,21,8)$ to $(1,27,8)$

FIXEd $P$ from $(1,28,8)$ to $(2,28,8)$

FIXEd P rom $(2,29,8)$ to $(2,32,8)$

FIXEd $P$ from $(2,33,8)$ to $(2,37,8)$

FIXEd P from $(2,38,8)$ to $(2,40,8)$

FIXEd $P$ from $(2,41,7)$ to $(2,42,7)$

FIXEd $P$ from $(2,43,7)$ to $(2,43,7)$

FIXEd $P$ from $(2,44,7)$ to $(2,44,7)$

FIXEd $P$ from $(2,45,6)$ to $(2,45,6)$

Fig. C.2-3. PORFLOW-3D input file for saturated groundwater flow simulations ( $40 \mathrm{~cm} /$ year infiltration through $\mathrm{Z}$-Area without SDF). 


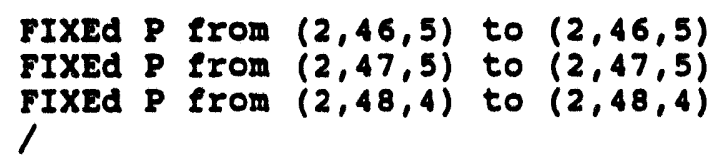

$$
\text { INITial } P \text { is } 7.9203 \mathrm{~cm} \text { from }(1,1,7) \text { to }(1,1,13)
$$

1

BouNdary $P$ for -2 FLUX $=0.0$ SDrainage Divide Boundary P AT -2 FLUX $=1.50 e 2 \mathrm{~cm}$ per year from $(1,1,1)$ to $(48,1,4)$ \$zone $5 \mathrm{a}$ BOUNdary $P$ at +3 FLUX $=-4.00 e 1 \mathrm{~cm}$ per year \$Recharge from precipitation BOUNdary $P$ at -3 FLUX $=0.0$ \$Impermeable boundary through Zone 4 (Ellenton) BoUNdary $P$ at -1 FLUX $=0.0$ \$ No llow boundary BouNdary $P$ at +1 FLUX $=0.0$ \$ No slow boundary BOUNdary $P$ at -1 NODE $=5.85$ ej from $(1,15,9)$ to $(1,20,9)$ sconstant head-2one $6 / 7$ BouNdary $P$ at -1 NODE $=5.73 e 3$ from $(1,21,8)$ to $(1,27,8)$ \$Constant head-2one $6 / 7$ BOUNdary $P$ at -1 NODE $=5.66 e 3$ from $(1,28,8)$ to $(2,28,8)$ \$Constant Head-zone $6 / 7$ Boundary $P$ at +1 NODE $=5.24 e 3$ from $(48,37,8)$ to $(48,40,8)$ SConstant head-2one 6 BouNdary $P$ at +1 NODE $=5.12 e 3$ from $(48,41,8)$ to $(48,42,8)$ \$Constant head-zone 6 Boundary $P$ at +1 NODE $=4.9663$ from $(48,43,7)$ to $(48,43,7)$ \$Constant head-zone 6 /

Fig. C.2-3. (continued). 
/Hydraulic parameters: storativity (ss) and hydraulic conductivity (Ki) / HYDRAULIC $s s=0.0001, \mathrm{KX}=1.89 \mathrm{e}, \mathrm{KY}=1.89 \mathrm{e}, \mathrm{Kz}=1.12 \mathrm{e} \mathrm{cm}$ per year for $\mathrm{zONE} 1$ HYDRaulic $\mathrm{ss}=0.0001, \mathrm{KX}=1.11 \mathrm{e}, \mathrm{KY}=1.11 \mathrm{e2}, \mathrm{Kz}=11$ for ZONE 2 HYDRaulic $s s=0.001, \mathrm{KX}=1.89 \mathrm{e}, \mathrm{KY}=1.89 \mathrm{e}, \mathrm{Kz}=1.89 \mathrm{e}$ for $2 \mathrm{ONE} 3$ corvergence for P GLOBAl mode: value= 0.00001 , 0 iterations DIAGnostic for $P$ and $U$ at node $(22,19,12)$ l MATRIX $P=3$ 1 sOLVe in STEAdy state mode: maximum steps 1000 1 ouTPut for $P, W$ SAVE on 'zout.ACR' END

Tig. C,2-3. (continued). 
TITLE FLOW PORTION OF THE CONTAMINANT TRANSPORT CODE

File 251b.DAT October 22, 1992

This version will be used as the basis for contaminant transport modeling land the calculation of fluxes along the boundary. This version will be /used for PORFLOW Version 2.40 with source data from INEL at z-Area.

/Only $0.175 \mathrm{~cm}$ of recharge occurs under the facility.

GRID 48 by 49 by 13

READ 'zout.acr' \$read established flow fleld at $40 \mathrm{~cm}$ per year infiltration /length units are in cm, time is in years

\begin{tabular}{|c|c|c|c|c|c|c|}
\hline ordinate $x$ & $\begin{array}{l}-30.48 \\
128016 \\
152400 \\
170688 \\
188976 \\
207264 \\
228600 \\
257251.2\end{array}$ & $\begin{array}{l}12192 \\
134112 \\
155448 \\
173736 \\
192024 \\
210312 \\
231648 \\
262128\end{array}$ & $\begin{array}{l}23774.4 \\
138531.6 \\
158496 \\
176784 \\
195072 \\
213360 \\
235610.4 \\
265176\end{array}$ & $\begin{array}{l}47853.6 \\
143256 \\
161544 \\
179832 \\
198120 \\
218846.4 \\
240792 \\
268224\end{array}$ & $\begin{array}{l}78638.4 \\
146304 \\
164592 \\
182880 \\
201168 \\
222504 \\
243840 \\
277215.6\end{array}$ & $\begin{array}{l}108051.6 \\
149352 \\
167640 \\
185928 \\
204216 \\
225552 \\
249936 \\
288432.2\end{array}$ \\
\hline coordinate $Y$ & $\begin{array}{l}-30.48 \\
79248 \\
97536 \\
115824 \\
134112 \\
152400 \\
173736 \\
198912\end{array}$ & $\begin{array}{l}18897.6 \\
82296 \\
100584 \\
118872 \\
137160 \\
155448 \\
176784 \\
210312\end{array}$ & $\begin{array}{l}45537.12 \\
85344 \\
103632 \\
121920 \\
140208 \\
158496 \\
179832 \\
219456\end{array}$ & $\begin{array}{l}62605.92 \\
88392 \\
106680 \\
124968 \\
143256 \\
161544 \\
182880 \\
228600\end{array}$ & $\begin{array}{l}72725.28 \\
91440 \\
109728 \\
128016 \\
146304 \\
167579 \\
185928 \\
237744\end{array}$ & $\begin{array}{l}76200 \\
94488 \\
112776 \\
131064 \\
149352 \\
170688 \\
192024 \\
255209\end{array}$ \\
\hline ORdinate 2 & $\begin{array}{l}1524 \\
4876.8 \\
9144\end{array}$ & $\begin{array}{l}2828.8 \\
5486.4\end{array}$ & $\begin{array}{l}3048 \\
5791.2\end{array}$ & $\begin{array}{l}4267.2 \\
5096\end{array}$ & $\begin{array}{l}4724 \\
6705\end{array}$ & .4 \\
\hline
\end{tabular}

/The following fixed commands specify nodes at which pressure is fixed /throughout the simulation, i.e., at the streams.

/

FIXEd $P$ from $(34,3,10)$ to $(35,3,10)$

FIXEd $P$ from $(36,3,10)$ to $(36,4,10)$

FIXEd $P$ from $(37,4,10)$ to $(39,4,10)$

FIXEd $P$ from $(39,5,10)$ to $(39,5,10)$

FIXEd $P$ from $(40,5,10)$ to $(41,5,10)$

FIXEd $P$ from $(42,5,9)$ to $(42,14,9)$

FIXEd P from $(43,14,9)$ to $(43,25,9)$

FIXEd $P$ from $(43,26,9)$ to $(45,26,9)$

FIXEd P from $(45,27,8)$ to $(45,34,8)$

FIXEd P from $(45,35,8)$ to $(47,35,8)$

FIXEd $P$ from $(47,36,8)$ to $(47,37,8)$

FIXEd P from $(48,37,8)$ to $(48,40,8)$

FIXEd $P$ from $(48,41,8)$ to $(48,42,8)$

FIXEd $P$ from $(48,43,7)$ to $(48,45,7)$

FIXEd $P$ from $(47,45,7)$ to $(47,47,7)$

FIXEd $P$ from $(2,7,9)$ to $(2,15,9)$

FIXEd P from $(1,15,9)$ to $(1,20,9)$

FIXEd 8 from $(1,21,8)$ to $(1,27,8)$

FIXEd P from $(1,28,8)$ to $(2,28,8)$

FIXEd $P$ from $(2,29,8)$ to $(2,32,8)$

FIXEd $P$ from $(2,33,8)$ to $(2,37,8)$

FIXEd $P$ from $(2,38,8)$ to $(2,40,8)$

FIXEd $P$ from $(2,41,7)$ to $(2,42,7)$

FIXEd $P$ from $(2,43,7)$ to $(2,43,7)$

FIXEd $P$ from $(2,44,7)$ to $(2,44,7)$

FIXEd $P$ from $(2,45,6)$ to $(2,45,6)$

Fig. C.2-4. PORFLON-3D input file for saturated groundwater flow simulations $(0.175 \mathrm{~cm} /$ year infiltration through $\mathrm{SDF}, 40 \mathrm{~cm} /$ year elsewhere. 
FIXEd $P$ from $(2,46,5)$ to $(2,46,5)$

FIXEd $P$ from $(2,47,5)$ to $(2,47,5)$ FIXEd $P$ from $(2,48,4)$ to $(2,48,4)$

1

ZONE 1

\$zone 6/7/8, Barnwell-McBean

ZONE 2 from $(1,1,5)$ to $(48,49,6)$ \$zone $5 \mathrm{~b}$, Green Clay

ZONE 3 from $(1,1,1)$ to $(48,49,4)$ \$zone $5 a$, Congaree

$1 /$

/INITial $P$ is $7.92 \mathrm{e} 3 \mathrm{~cm}$ from $(2,2,2)$ to $(47,48,12)$ GRAD $X=0, Y=-0.01, Z=0$

/INITial $p$ is $5.88 \mathrm{em} \mathrm{cm}$ from $(1,1,1)$ to $(48,49,4)$ GRAD $x=0 \quad y=-.0047, z=0$

/INITial $P$ is $4.42 e 3 \mathrm{~cm}$ from $(1,49,1)$ to $(48,49,13)$ GRAD $x=0.0001 y=0, z=0$

INITial $P$ is $6.22 \mathrm{e} 3 \mathrm{~cm}$ from $(34,3,10)$ to $(35,3,10)$

INITIal $P$ is $6.16 e 3$ cm from $(36,3,10)$ to $(36,4,10)$

INITial $P$ is $6.10 \mathrm{em} \mathrm{cm}$ from $(37,4,10)$ to $(39,4,10)$

INITial $P$ is $6.04 e 3 \mathrm{~cm}$ from $(39,5,10)$ to $(39,5,10)$

INITial $P$ is $5.97 e 3 \mathrm{~cm}$ from $(40,5,10)$ to $(41,5,10)$

INITial $P$ is $5.91 \mathrm{e}$ cm from $(42,5,9)$ to $(42,14,9)$

INITial $p$ is $5.82 \mathrm{e} \mathrm{cm}$ from $(43,14,9)$ to $(43,25,9)$

INITial $P$ is $5.67 \mathrm{e} 3 \mathrm{~cm}$ from $(43,26,9)$ to $(45,26,9)$

INITial $P$ is $5.55 \mathrm{e}$ am from $(45,27,8)$ to $(45,34,8)$

INITial $P$ is $5.46 e 3 \mathrm{~cm}$ from $(45,35,8)$ to $(47,35,8)$

INITIal $P$ is $5.30 \mathrm{e} 3 \mathrm{~cm}$ from $(47,36,8)$ to $(47,37,8)$

INItial $P$ is $5.24 e 3 \mathrm{~cm}$ from $(48,37,8)$ to $(48,40,8)$

INItial $P$ is $5.1283 \mathrm{~cm}$ from $(48,41,8)$ to $(48,42,8)$

INITIal $P$ is 4.97 e3 $\mathrm{cm}$ from $(48,43,7)$ to $(48,45,7)$

INITial $P$ is $4.85 e 3 \mathrm{~cm}$ from $(47,45,7)$ to $(47,47,7)$

INITial $P$ is $6.04 \mathrm{em}^{\mathrm{cm}}$ from $(2,7,9)$ to $(2,15,9)$

INITlal $P$ is $5.85 e 3 \mathrm{~cm}$ from $(1,15,9)$ to $(1,20,9)$

INITial $P$ is $5.73 \mathrm{e} \mathrm{cm}$ from $(1,21,8)$ to $(1,27,8)$

INITial $P$ is 5.67 es $\mathrm{cm} \operatorname{from}(1,28,8)$ to $(2,28,8)$

INITial $P$ is $5.61 e 3 \mathrm{~cm}$ from $(2,29,8)$ to $(2,33,8)$

INITlal $P$ is $5.49 e 3 \mathrm{~cm}$ from $(2,33,8)$ to $(2,37,8)$

INITial $P$ is 5.24 es cm from $(2,38,8)$ to $(2,40,8)$

INITial $P$ is 5.12 es cm from $(2,41,7)$ to $(2,42,7)$

INITial $P$ is $5.00 \mathrm{e} 3 \mathrm{~cm}$ from $(2,43,7)$ to $(2,43,7)$

INITial $P$ is $4.88 \mathrm{e} \mathrm{cm}$ from $(2,44,7)$ to $(2,44,7)$

INITial $P$ is $4.75 \mathrm{e} \mathrm{cm}$ from $(2,45,6)$ to $(2,45,6)$

INITial $P$ is $4.60 \mathrm{e} \mathrm{cm}$ from $(2,46,5)$ to $(2,46,5)$

INITial $P$ is $4.51 e 3 \mathrm{~cm}$ from $(2,47,5)$ to $(2,47,5)$

INITial $p$ is 4.33 em from $(2,48,4)$ to $(2,48,4)$

/

/INITial $P$ is $7.92 e 3 \mathrm{~cm}$ from $(1,1,7)$ to $(1,1,13)$

/INITial $P$ is $7.92 e 3 \mathrm{~cm}$ from $(48,1,7)$ to $(48,1,13)$

,

/

BouNdary $P$ for -2 FLUX $=0.0$ SDrainage Divide

Boundary P AT -2 FLUX $=1.50 e 2 \mathrm{~cm}$ per year from $(1,1,1)$ to $(48,1,4)$ \$zone 5 a

BoUndary $P$ at +3 FLUX = $-4.00 \mathrm{el} \mathrm{cm}$ per year \$Recharge from precipitation

Boundary $P$ at +3 FLUX $=-0.1750000 \mathrm{~cm}$ per year from $(14,7,13)$ to $(30,22,13)$

Boundary $P$ at +3 FLUX $=-0.1750000 \mathrm{~cm}$ per year erom $(22,24,13)$ to $(29,32,13)$

BouNdary $P$ at -3 FLUX $=0.0$ \$Impermeable boundary through zone 4 (Elienton)

BouNdary $P$ at -1 FLUX $=0.0$ \$ No flow boundary

Bousdary $P$ at +1 FLUX $=0.0$ \$ No flow boundary

BoUidary $P$ at -1 NODE $=5.85 e 3$ from $(1,15,9)$ to $(1,20,9)$ \$Constant head-zone $6 / 7$ BoUNdary $P$ at -1 NODE $=5.73 e 3$ from $(1,21,8)$ to $(1,27,8)$ \$Constant head-2one $6 / 7$ Boundary $P$ at -1 NODE $=5.66 e 3$ from $(1,28,8)$ to $(2,28,8)$ sconstant Head-zone $6 / 7$ BOUNdary $P$ at +1 NODE $=5.24$ e3 from $(48,37,8)$ to $(48,40,8)$ sConstant head-2one 6 BouNdary $P$ at +1 NODE $=5.12$ e3 from $(48,41,8)$ to $(48,42,8)$ \$Constant head-zone 6

Fig. C.2-4. (continued). 
Boundary $P$ at +1 NODE $=4.96 \mathrm{e}$ from $(48,43,7)$ to $(48,43,7)$ sconstant head-zone 6 1 /Hydraulic parameters: storativity (ss) and hydraulic conductivity (Ki) / HYDRAULIC ss=0.0001, $\mathrm{KX}=1.89 \mathrm{e}, \mathrm{Ky}=1.89 \mathrm{e}, \mathrm{Kz}=1.12 \mathrm{e} \mathrm{\textrm {cm }}$ per year for $\mathrm{ZONE} 1$ HYDRaulic $s s=0.0001, K x=1.11 \mathrm{e2}, \mathrm{Ky}=1.11 \mathrm{e2}, \mathrm{Kz}=11$. for $20 \mathrm{KE} 2$ HYDRaulic $s s=0.001, \mathrm{Kx}=1.89 e 5, \mathrm{Ky}=1.89 \mathrm{e}, \mathrm{Kz}=1.89 \mathrm{e} 4$ for $\mathrm{zONE} 3$ CONVergence for $P$ GLOBAl mode: value= 0.00001 , 0 iterations DIAGnostic for $P$ and $U$ at node $(22,19,12)$ 1 $\operatorname{MATR} L X=3$ 1 SOLVe in STEAdy state mode: maximum steps 1000 OUTPut for $P, W$ SAVE on 'Zoutlb.ACR' SFlow flle for subseguent mass transport calculations END

Fig. C.2-4. (continued). 
TITLE CONTAMINANT TRANSPORT EXPANDED GRID /File 253Ni.DAT NOV 11, 1992 /Contaminant transport modeling for NITRATE; $0.175 \mathrm{~cm}$ recharge /Intact vaults/saltstone /Update for Phase 111 modeling on $3 / 19 / 92$ by pmk /ekr / Units are in em per year GRID 48 by 49 by 13

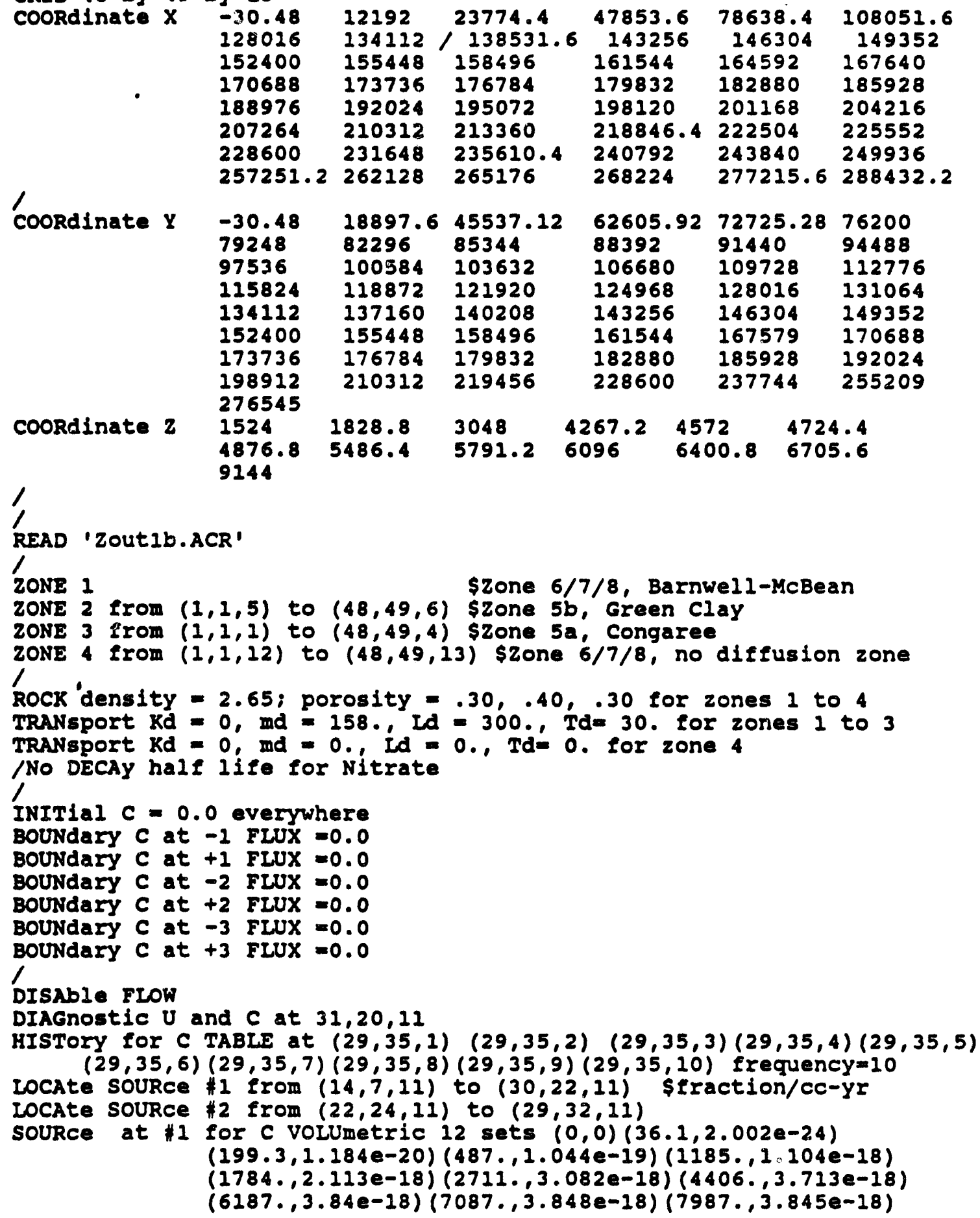

Fig. C.2-5. Example PORFLOW-3D input file for mass transport simulation In groundwater (nitrate-intact saltstone case). 


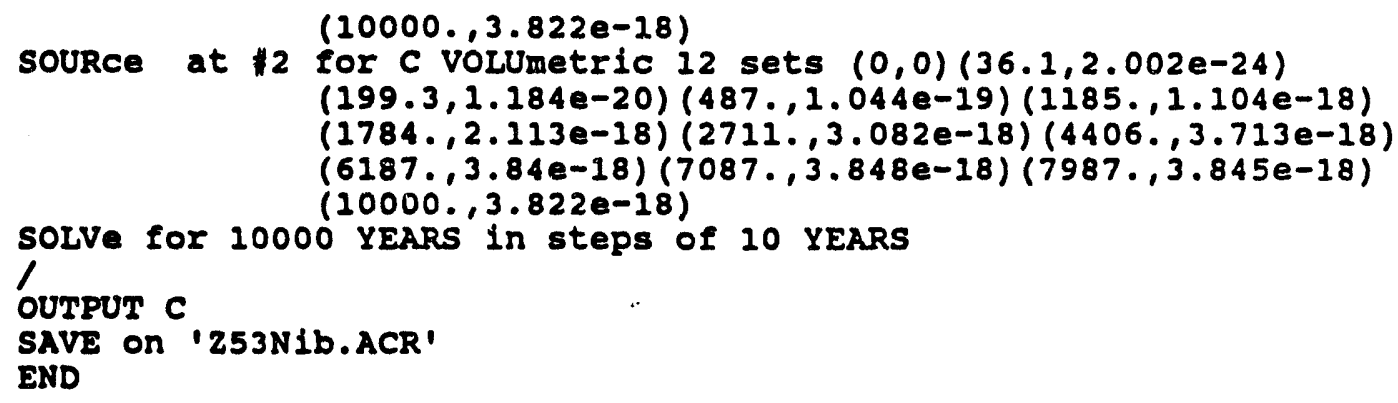

Fig. C.2-5, (continued). 
TITLO CONTAMINANT TRANSPORT EXPANDED GRID File Z53Ne.DAT Nov 13, 1992

/Contaminant transport modeling for NITRATE; $0.175 \mathrm{~cm}$ recharge /Fracture case

/Update for Phase 111 modeling on $3 / 19 / 92$ by pmk /ekr / Units are in $\mathrm{cm}$ per year GRID 48 by 49 by 13

\begin{tabular}{|c|c|c|c|c|c|c|}
\hline Dordinate & $\begin{array}{l}-30.48 \\
128016 \\
152400 \\
170688 \\
188976 \\
207264 \\
228600 \\
257251.2\end{array}$ & $\begin{array}{l}12192 \\
134112 \\
155448 \\
173736 \\
192024 \\
210312 \\
231648 \\
262128\end{array}$ & $\begin{array}{l}23774.4 \\
138531.6 \\
158496 \\
176784 \\
195072 \\
213360 \\
235610.4 \\
265176\end{array}$ & $\begin{array}{l}47853.6 \\
143256 \\
161544 \\
179832 \\
198120 \\
218846.4 \\
240792 \\
268224\end{array}$ & $\begin{array}{l}78638.4 \\
146304 \\
164592 \\
182880 \\
201168 \\
222504 \\
243840 \\
277215.6\end{array}$ & $\begin{array}{l}108051.6 \\
149352 \\
167640 \\
185928 \\
204216 \\
225552 \\
249936 \\
288432.2\end{array}$ \\
\hline & & & & & & \\
\hline cooRdinate $Y$ & $\begin{array}{l}-30.48 \\
79248 \\
97536 \\
115824 \\
134112 \\
152400 \\
173736 \\
198912 \\
276545\end{array}$ & $\begin{array}{l}18897.6 \\
82296 \\
100584 \\
118872 \\
137160 \\
155448 \\
176784 \\
210312\end{array}$ & $\begin{array}{l}45537.12 \\
85344 \\
103632 \\
121920 \\
140208 \\
158496 \\
179832 \\
219456\end{array}$ & $\begin{array}{l}62605.92 \\
88392 \\
106680 \\
124968 \\
143256 \\
161544 \\
182880 \\
228600\end{array}$ & $\begin{array}{l}72725.28 \\
91440 \\
109728 \\
128016 \\
146304 \\
167579 \\
185928 \\
237744\end{array}$ & $\begin{array}{l}76200 \\
94488 \\
112776 \\
131064 \\
149352 \\
170688 \\
192024 \\
255209\end{array}$ \\
\hline Rdinate $\mathbf{z}$ & $\begin{array}{l}1524 \\
4876.8 \\
9144\end{array}$ & $\begin{array}{l}8 \\
4\end{array}$ & $\begin{array}{l}048 \\
791.2\end{array}$ & 57.2 & 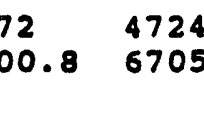 & 4 \\
\hline
\end{tabular}

1

READ 'ZOUTIB.ACR'

ZONE 1

2ONE 2 from $(1,1,5)$ to $(48,49,6)$ \$zone 5b, Green Clay

ZONE 3 from $(1,1,1)$ to $(48,49,4)$ szone $5 a$, Congaree

zONE 4 from $(1,1,12)$ to $(48,49,13)$ \$zone $6 / 7 / 8$, no diffusion zone

ROCK' density $=2.65$; porosity $=.30, .40, .30$ for zones 1 to 4

TRANsport $\mathrm{Kd}=0, \mathrm{md}=158 \ldots, \mathrm{Id}=300 ., \mathrm{Td}=30$. for zones 1 to 3

TRANsport $\mathrm{Kd}=0$, ind $=0$., Id $=0 ., \mathrm{Td}=0$. for zone 4

/No DECAY half life for Nitrate

INITial $C=0.0$ everywhere

Boundary $c$ at -1 FLUX $=0.0$

Boundary $C$ at +1 FIUX $=0.0$

BoUNdary C at -2 FLUX $=0.0$

Boundary $C$ at +2 FLUX $=0.0$

Boundary $C$ at -3 FIUX $=0.0$

Boundary $C$ at +3 FLUX $=0.0$

DISAbIe FIOW

DIAGnostic $U$ and $C$ at $31,20,11$

HISTOry for C TABLE at $(29,35,1)(29,35,2)(29,35,3)(29,35,4)(29,35,5)$ $(29,35,6) \quad(29,35,7) \quad(29,35,8)(29,35,9) \quad(29,35,10)$ frequency $=10$

Locate source \#1 from $(14,7,11)$ to $(30,22,11)$ \$g/cc-yr

LOCAte sOURce $\$ 2$ from $(22,24,11)$ to $(29,32,11)$

souRce at $\# 1$ for $C$ volumetric 15 sets $(0,0)(1190,0)(1200,3.47 \mathrm{E}-06)$

$(1300,3.46 E-06)(1400,3.46 E-06)(1500,3.43 E-06)$

$(1600,3.38 E-06)(1700,3.30 E-06)(2200,2.89 E-06)$

$(2700,2.55 E-06)(3200,2.30 E-06)(5200,1.70 E-06)$

Fig. C.2-6. Example PORFLOW-3D input file for mass transport simulation in groundwater (nitrate-fractured saltstone case). 
$(7200,1.39 E-06)(9200,1.19 E-06)(11200,1.05 E-06)$

source at $\| 2$ for $C$ volumetric $15 \operatorname{sets}(0,0)(1190,0)(1200,3.47 E-06)$

$(1300,3.46 \mathrm{E}-06)(1400,3.46 \mathrm{E}-06)(1500,3.43 \mathrm{E}-06)$

$(1600,3.38 E-06)(1700,3.30 E-06)(2200,2.89 E-06)$

$(2700,2.55 E-06)(3200,2.30 E-06)(5200,1.70 E-06)$

sOLVe for 11950 YEARS in steps of 10 YEARS

$(7200,1.39 E-06)(9200,1.19 E-06)(11200,1.05 E-06)$

OUTPUT $c$

SAVE on ' $253 N F b . A C R$ '

END

Tig, C, 2-6, (contimued). 


\section{C3 ZAREA STREAM FLOW DATA}

The gauging results for SRS creeks in the vicinity of Z-Area are presented in Table C.3-1. In Fig. C.3-1, the location of stream flow measurements supporting these results is shown.

Rev. 0 
Table C3-1. Stream gauging results for SRS creets in the vicinity of Z-Area (field measurements made on November 12 - 14, 1991 by Peter M. Rearl)

\begin{tabular}{|c|c|c|}
\hline $\begin{array}{l}\text { Location } \\
\text { No. }\end{array}$ & $\begin{array}{l}\text { Location description } \\
\text { (refer to Fig. C.2-1) }\end{array}$ & $\begin{array}{l}\text { Flow } \\
\text { (cfs) }\end{array}$ \\
\hline 1 & Crouch, upstream of Upper Three Runs & 1.9 \\
\hline 2 & Crouch, upstream of E-Area Tributary & 1.6 \\
\hline 3 & E-Area Tributary, upstream of Crouch & 0.29 \\
\hline 4 & Crouch Branch, at Road 4 & 0.090 \\
\hline 5 & Crouch Branch Tributary, at Road 4 & 0.016 \\
\hline 6 & Z-Area Tributary to Upper Three Runs & 0.039 \\
\hline 7 & McQueen Branch at F Road & 0.84 \\
\hline 8 & Tributary to McQucen Branch & 1.0 \\
\hline 9 & Tributary to McQueen Branch below dam & 0.35 \\
\hline 10 & McQueen Branch upstream of Tinker Creek & 3.7 \\
\hline 11 & Upper Three Runs, upstream of Tinker Creek & 130.0 \\
\hline 12 & Tinker Creek, upstream of Upper Three Runs & 45.0 \\
\hline 13. & McQueen Branch at Z-Area Road & 2.1 \\
\hline
\end{tabular}

- Weather prior to gauging had been dry, with the exception of a $3 \mathrm{~cm}$ rain storm 3 days before gauging. 


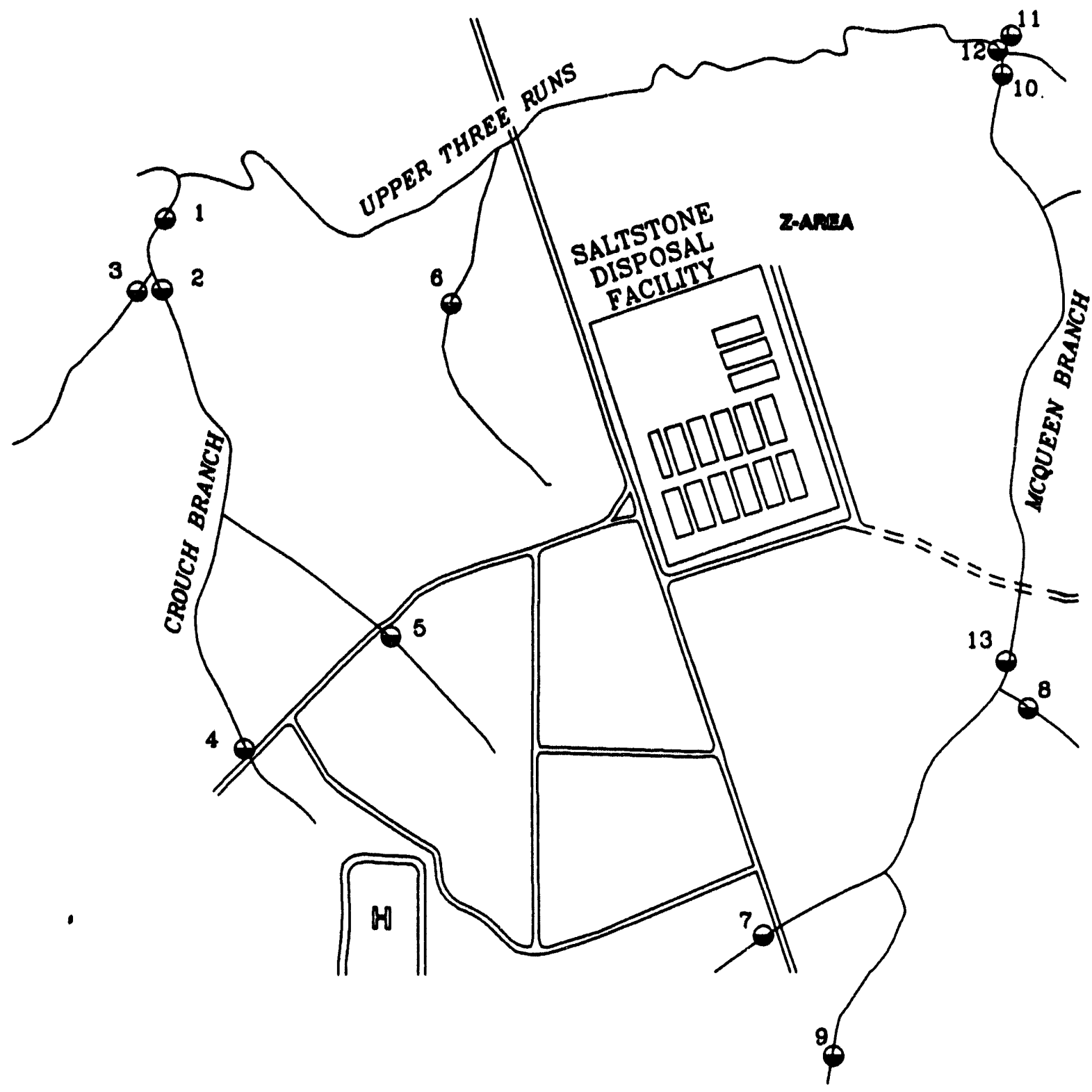

- STREAM GAGING LOCATION

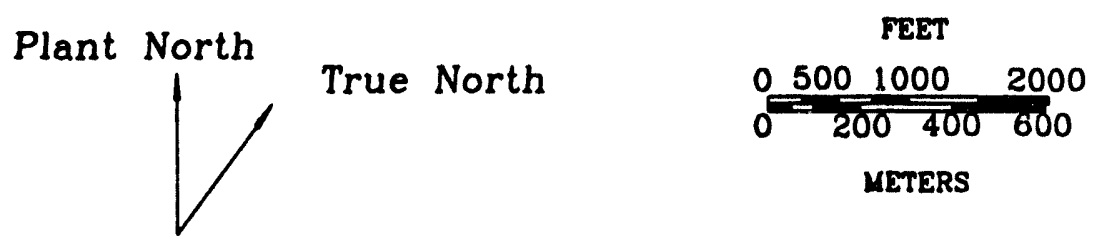

Fig. C.3-1. Location of stream flow measurements on November $12-14,1991$ at SRS.

Rev. 0 


\section{C.4 RESULTS}

\section{C.4.1 Fluses to Water Table}

Figures C.4-1 through C.4-11 show the time histories of fluxes to the water table for nitrate and the ten radionuclides of concern with respect to groundwater resource protection standards in this RPA. The fluxes are given in fraction of original inventory per year release to the water table under the Z-Area facility, and were used in groundwater transport simulations to estimate groundwater concentrations at the compliance point for groundwater protection. 


\section{Fractional Release to Aquifer}

$\mathrm{H}-3$

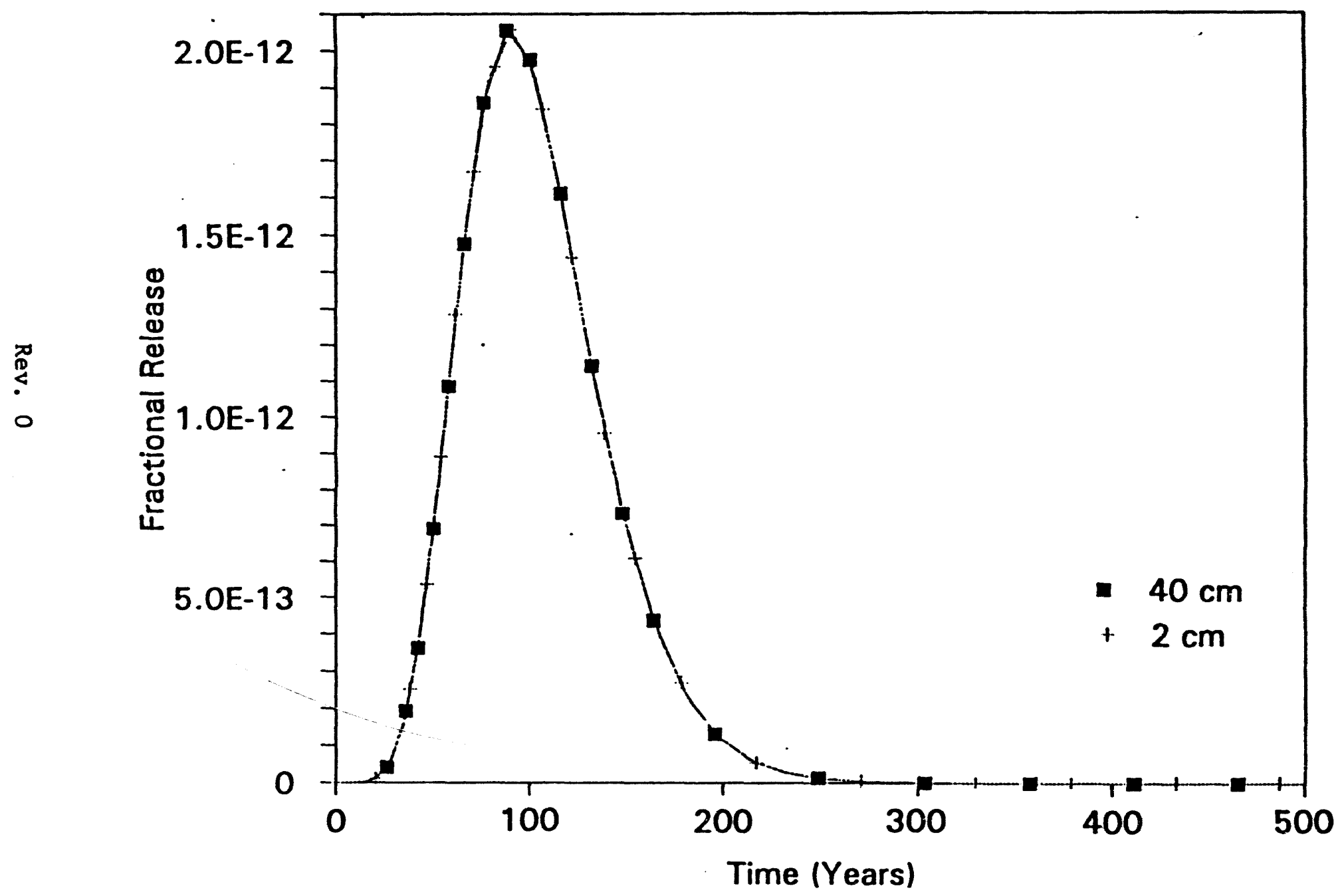

Fig. C.4-1. Fractional flux of II-3 from the SDF to the water table estimated from near-field simulations for intact saltstone and vaults. 
Fractional Release to Aquifer

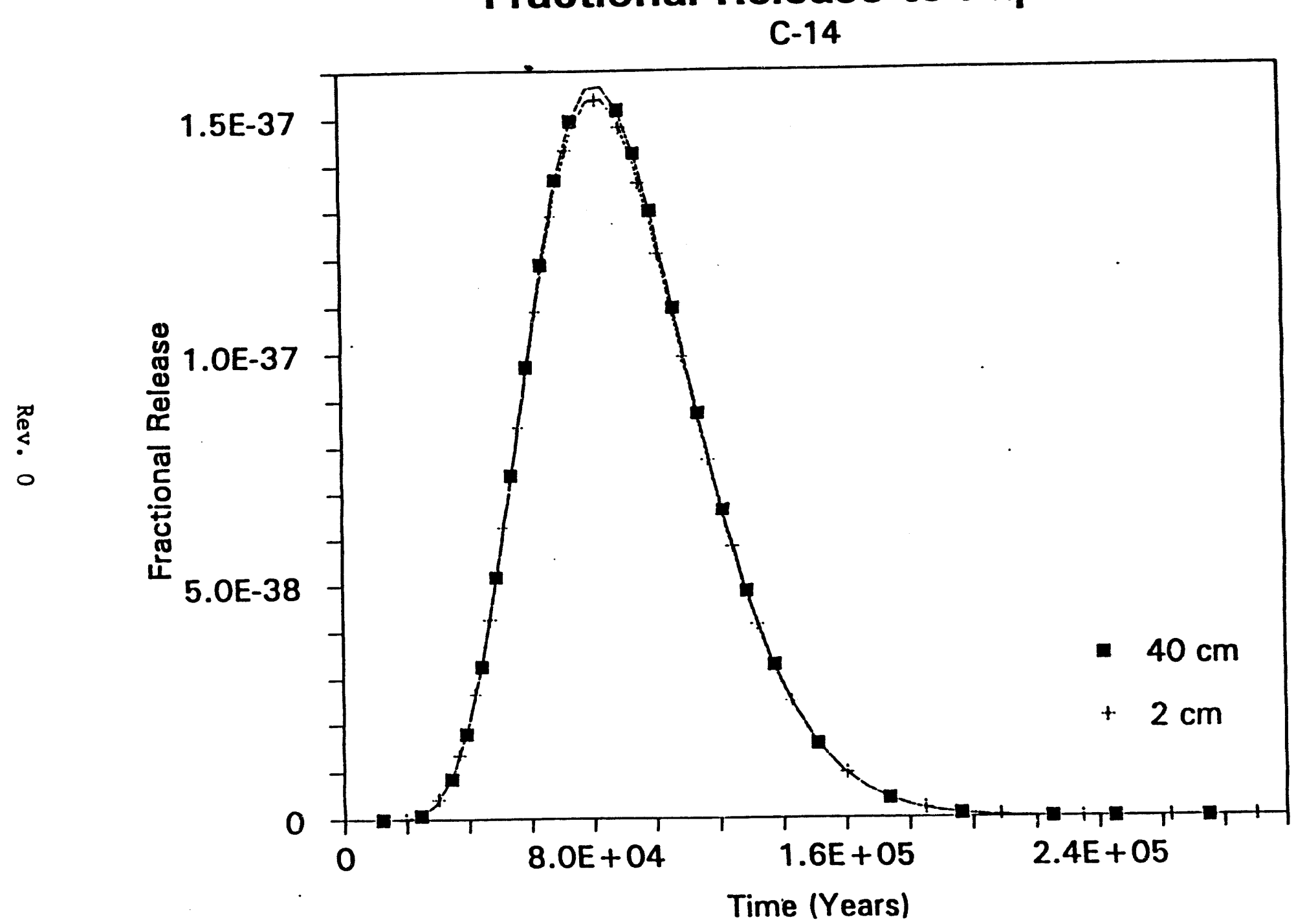

Fig. C.4-2. Fractional flux of $\mathrm{C}-14$ from the SDF to the water table estimated from near-field simulations for intact saltstone and vaults. 


\section{Fractional Release to Aquifer}

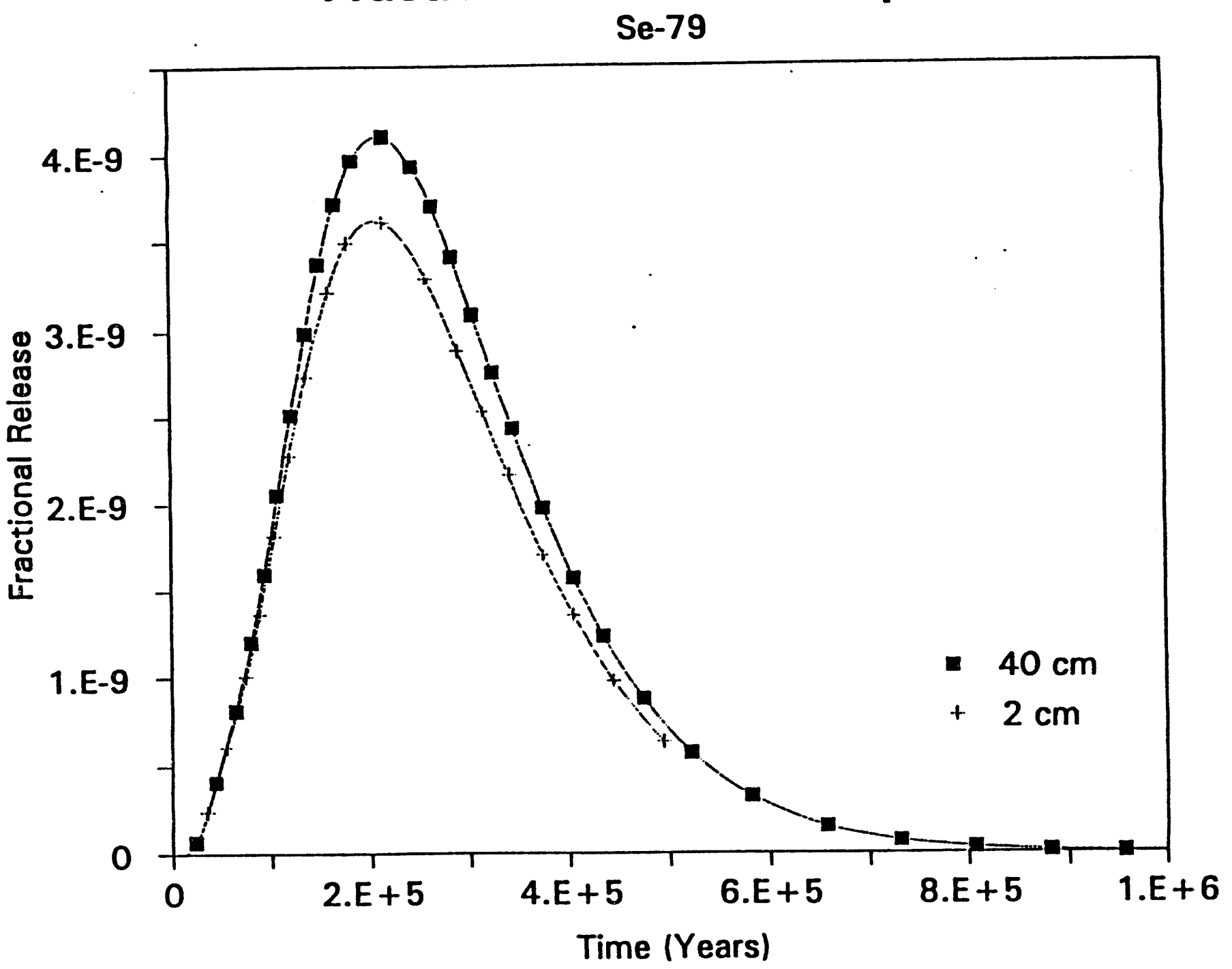

F1g. C.1-3. Fractional flux of Se-79 from the SDF to the water table estimated from near-field simulations for intact saltstone and vaults. 
Fractional Release to Aquifer

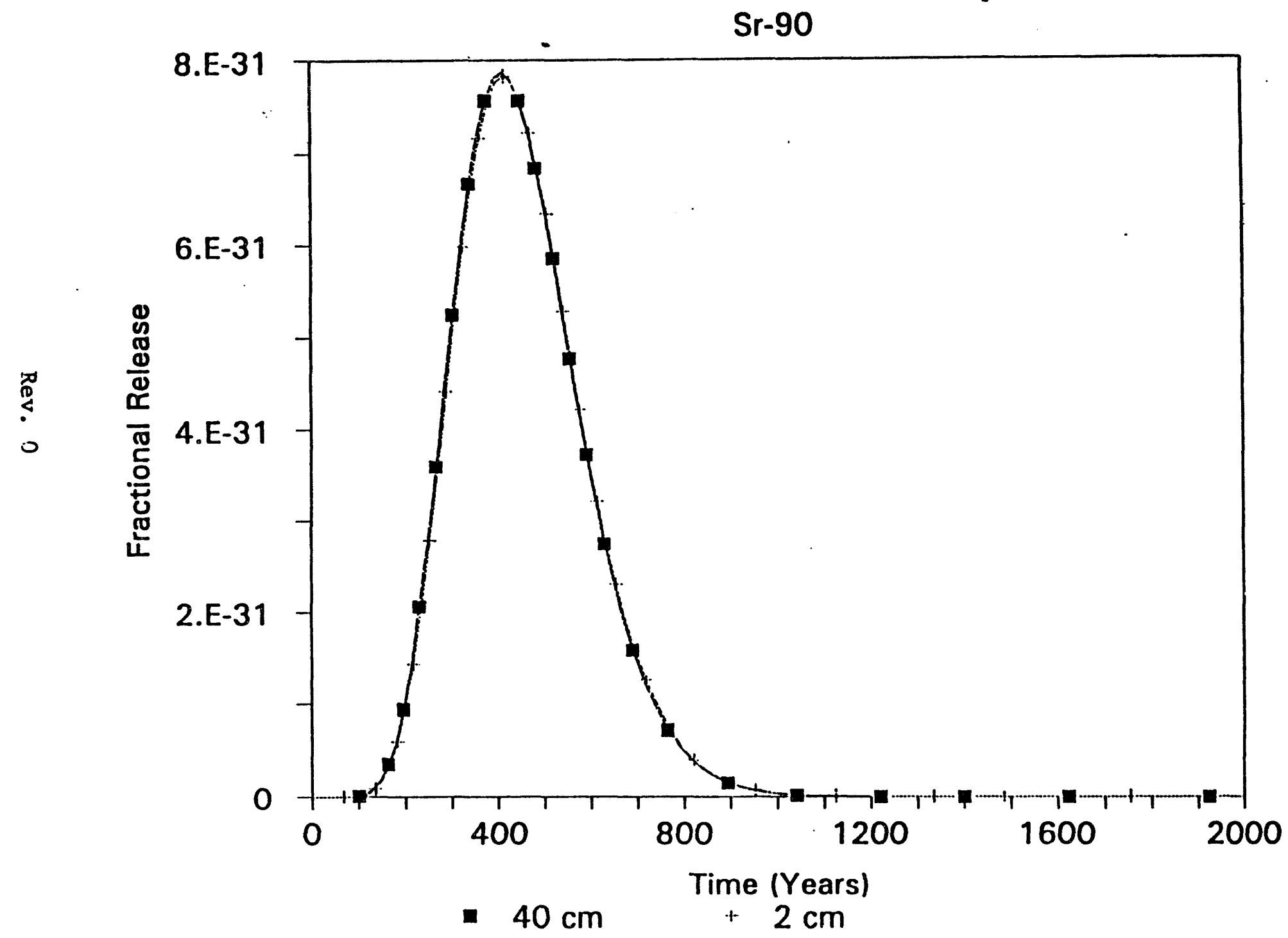

Fig. C.4-4. Fractional flux of $\mathrm{Sr}-90$ from the SDF to the water table estimated from near-field simulations for intact saltstone and vaults. 


\section{Fractional Release to Aquifer}

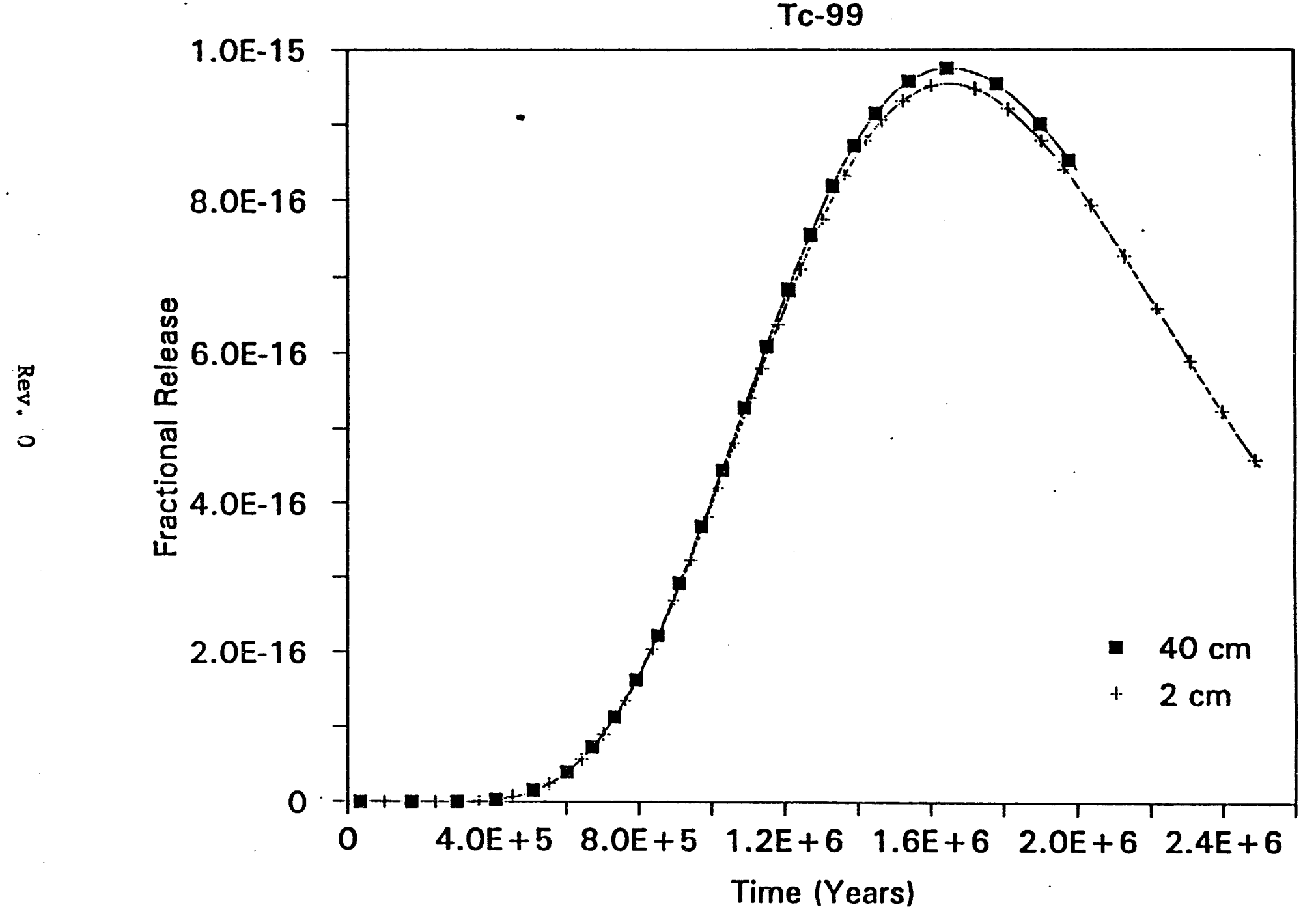

Fig. C.4-5. Fractional flux of Tc 99 from the SDF to the water table estimated from the near-field simulations for intact saltstone and vaults. 


\section{Fractional Release to Aquifer}

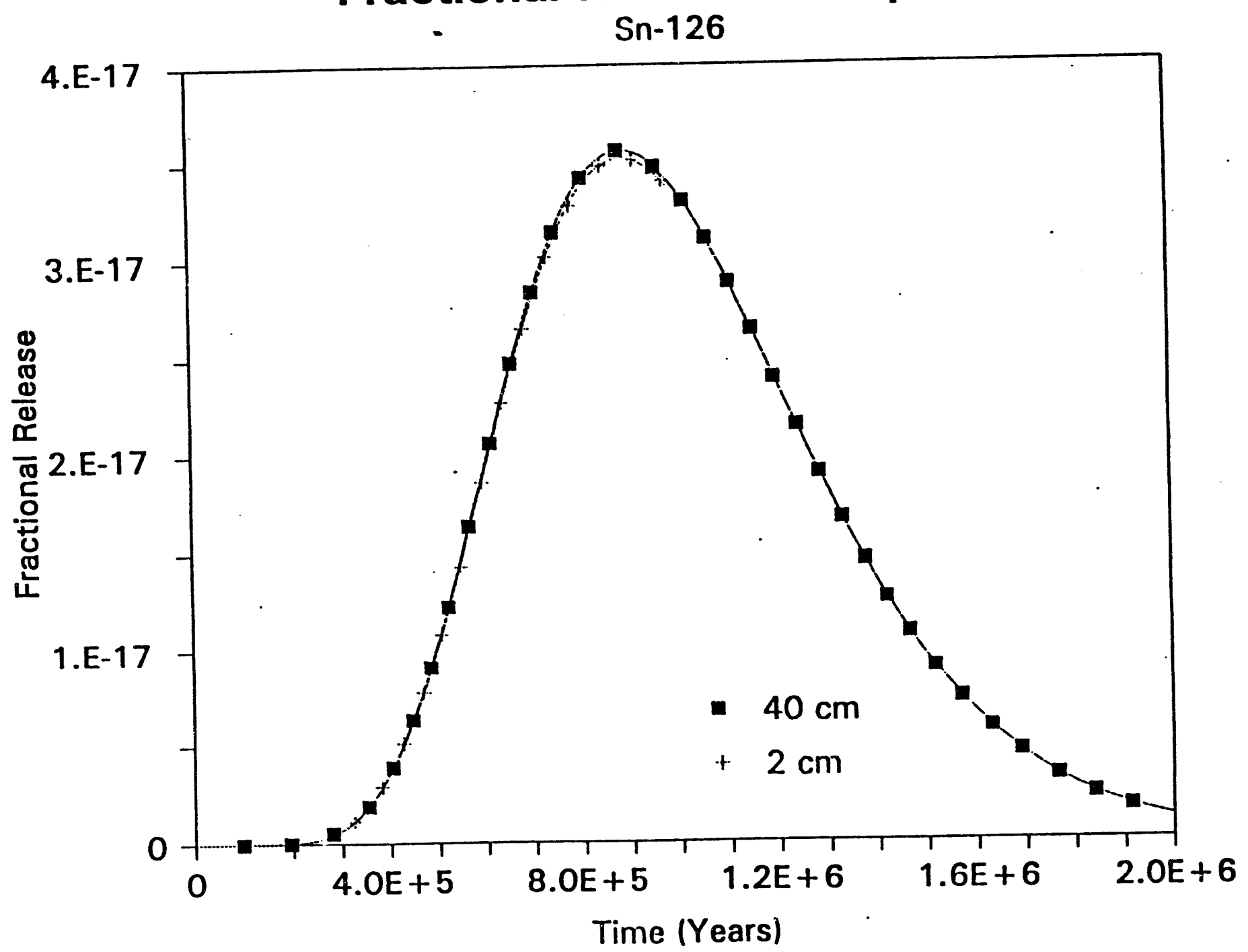

Fig. C.4-6. Fractional flux of $\mathrm{Sn-126}$ from the SDF to the water table estimated from near-field simulations for intact saltstone and vaults. 


\section{Frạctional Release to Aquifer}

1-129

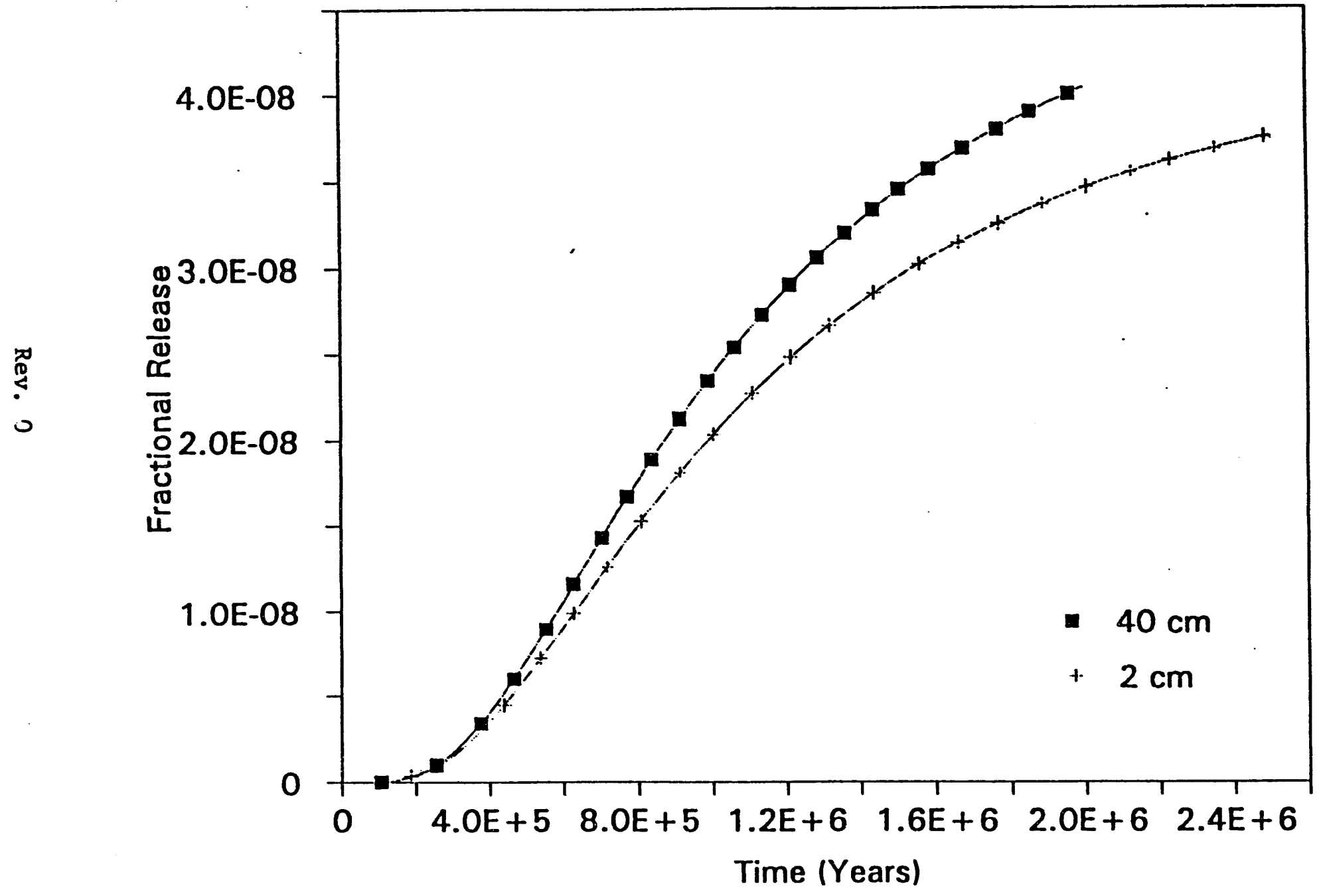

Fig. C.4-7. Fractional flux of I-129 from the SDF to the water table estimated from near-field simulations for intact saltstone and vaults. 



\section{Fractional Release to Aquifer}

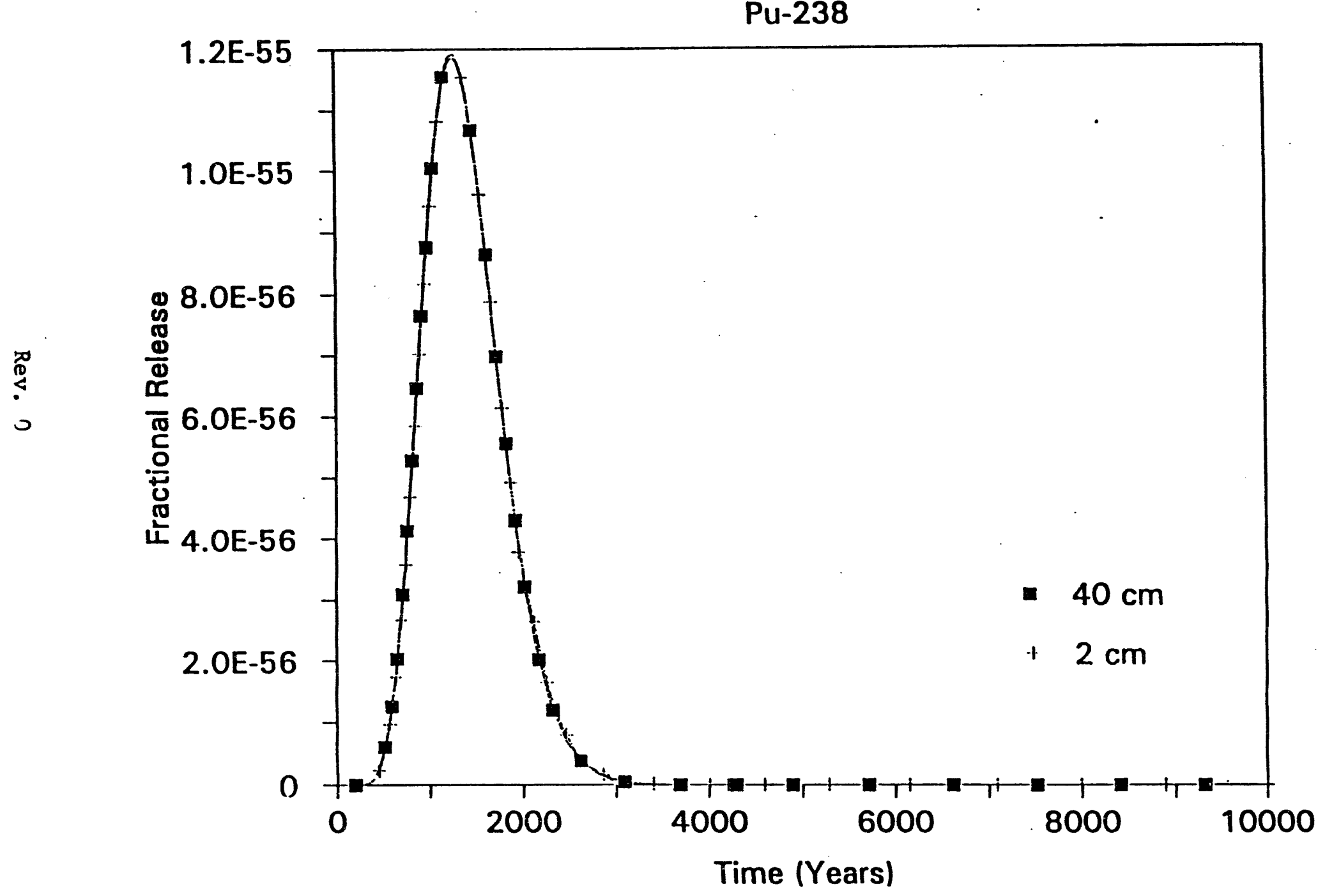

Fig. C.4-9. Fractional flux of Pu-238 from the SDF to the water table estimated from near-field simulations for intact saltstone and vaults. 


\section{Fractional Release to Aquifer}

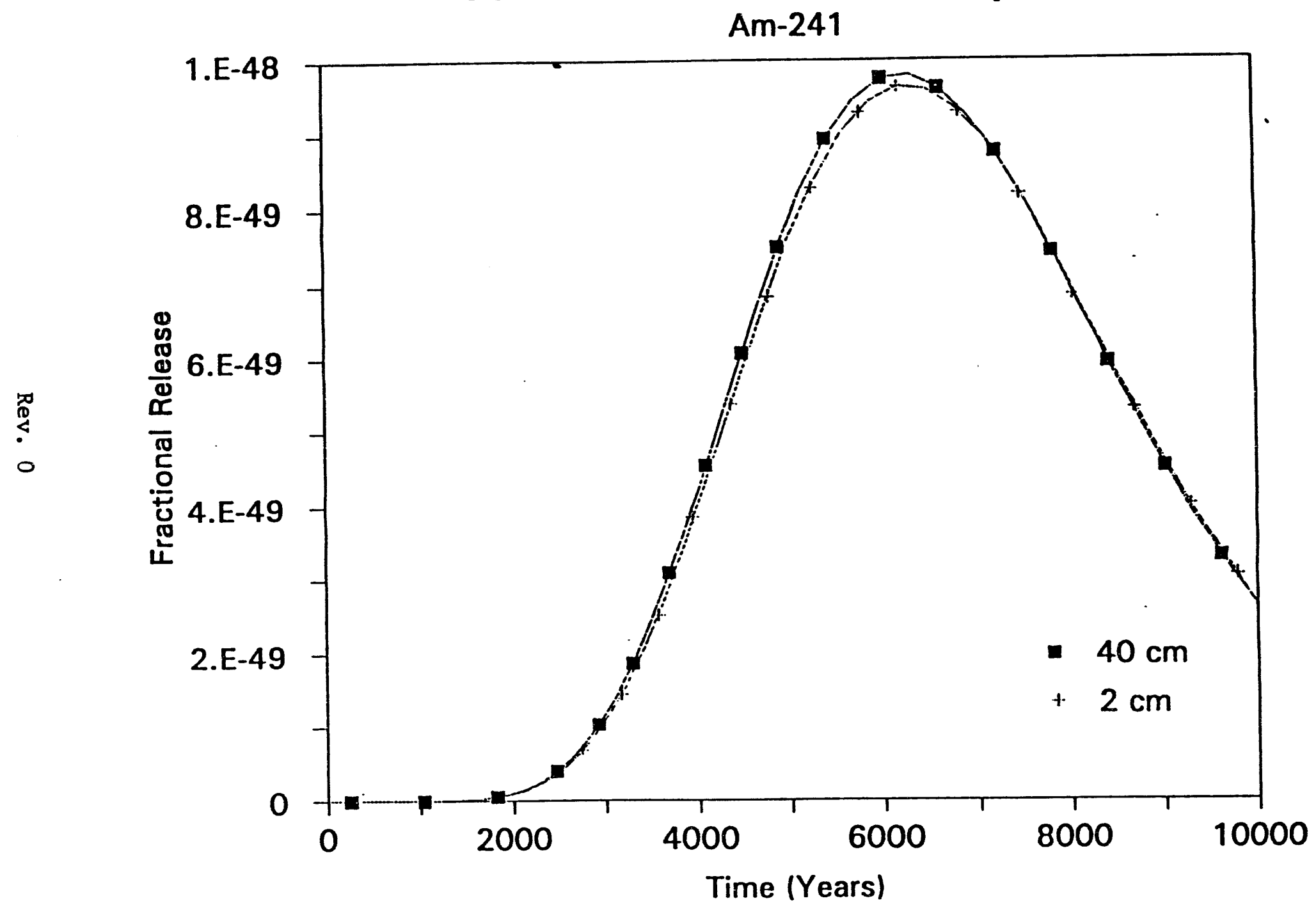

Fig. C.4-10. Fractional flux of $A \mathrm{~m} 241$ from the SDF to the water table estimated from near-field simulations for intact saltstone and vaults 


\section{Fraetional Release to Aquifer}

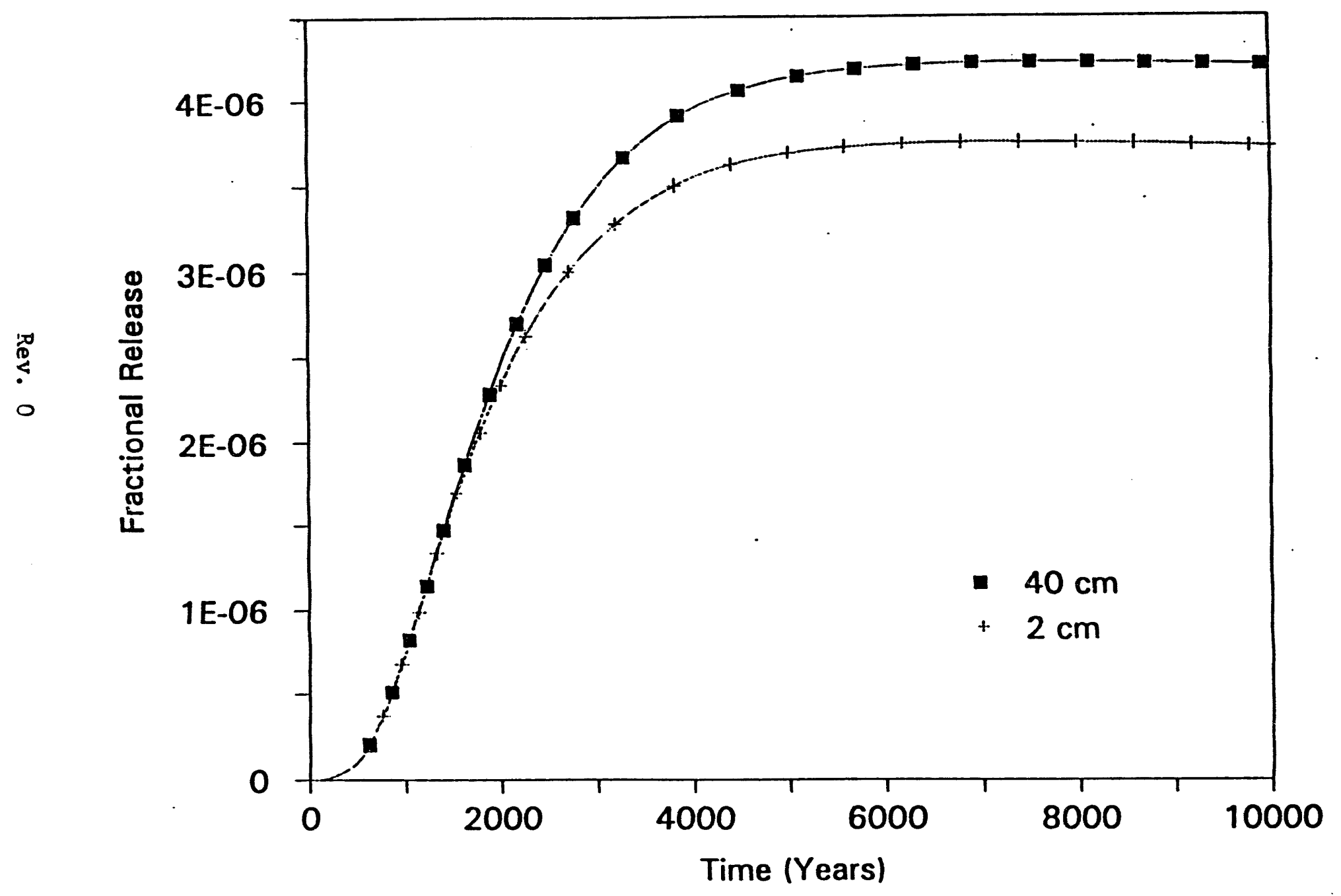

Fig. C.4-11. Fractional flux of nitrate from the SDF to the water table estimated from near-field simulations for intact saltstone and vaults. 
Table C.4-1. Fractional flux of $\mathrm{H}-3$ from fractures in the degraded scenario H-3 Fractional Flux to Water Table from Fractures

\begin{tabular}{|c|c|}
\hline Half-life $=12.3$ years & $\mathrm{Kd}=0$ \\
\hline $\begin{array}{l}\text { Arrival } \\
\text { Time } \\
\end{array}$ & Fractional Flux \\
\hline at Water & to Water Table \\
\hline $\begin{array}{l}\text { Table } \\
\text { (years) }\end{array}$ & $(y x)$ \\
\hline 1200 & $1.71 e-35$ \\
\hline 1220 & $5.56 e-36$ \\
\hline 1240 & $1.80 e-36$ \\
\hline$\$ 260$ & $5.83 e-37$ \\
\hline 1280 & $1.89 \mathrm{e}-37$ \\
\hline 1300 & $6.11 e-38$ \\
\hline 1320 & $1.98 \mathrm{e}-38$ \\
\hline 1340 & $6.43 e-39$ \\
\hline 1360 & $2.08 e-39$ \\
\hline 1380 & $6.75 e-40$ \\
\hline 1400 & $2.19 e-40$ \\
\hline 1420 & $7.07 e-41$ \\
\hline 1440 & $2.30 e-41$ \\
\hline 1460 & $7.44 e-42$ \\
\hline 1480 & $2.41 e-42$ \\
\hline 1500 & $7.81 e-43$ \\
\hline 1520 & $2.53 e-43$ \\
\hline 1540 & $8.18 \mathrm{e}-44$ \\
\hline 1560 & $2.65 e-44$ \\
\hline 1580 & $8.59 e-45$ \\
\hline 1600 & $2.79 e-45$ \\
\hline 1620 & $9.05 e-46$ \\
\hline 1640 & $2.93 e-46$ \\
\hline 1660 & $9.46 e-47$ \\
\hline 1680 & $3.07 e-47$ \\
\hline 1700 & $9.97 e-48$ \\
\hline
\end{tabular}

Fraction/yr $=\left[\right.$ Fracture Conc. $(\mathrm{pCi} / \mathrm{cc}) \times(.0135 \mathrm{~cm} / \mathrm{yr}) \times\left(0.49 \mathrm{~cm}^{2}\right.$ saltstone $) \times\left(3.2 \times 10^{9} \mathrm{~cm}^{2}\right.$ facility $\left.) \times\left(\mathrm{e}^{-2 \mathrm{tl}}\right)\right]+(\mathrm{pCi})$ 
Table C.4-2. Fractional fiux of $\mathrm{C}-14$ from fractures in the degraded scenario for the SDF

C-14 Fractional Flux to Water Table from Fractures

Half-life $=5730$ years $\quad \mathrm{Kd}=2.4(\mathrm{cc} / \mathrm{g})$

\begin{tabular}{|c|c|}
\hline $\begin{array}{l}\text { Arrival } \\
\text { Time }\end{array}$ & Fractional Flux \\
\hline $\begin{array}{l}\text { at Water } \\
\text { Table }\end{array}$ & at Water Table \\
\hline (yrs) & (tyr) \\
\hline 5779.2 & $1.2 e-09$ \\
\hline 5879.2 & $1.1 \mathrm{e}-09$ \\
\hline 5979.2 & $1.1 e-09$ \\
\hline 6079.2 & $1.1 \mathrm{e}-09$ \\
\hline 6179.2 & $1.1 \mathrm{e}-09$ \\
\hline 6279.2 & $1.1 \mathrm{e}-09$ \\
\hline 6779.2 & $1.0 \mathrm{e}-09$ \\
\hline 7279.2 & $9.7 e-10$ \\
\hline 7779.2 & $9.1 \mathrm{e}-10$ \\
\hline 9779.2 & $7.1 \mathrm{e}-10$ \\
\hline 11779.2 & $5.6 \mathrm{e}-10$ \\
\hline 13779.2 & $4.4 e-10$ \\
\hline 15779.2 & $3.5 e-10$ \\
\hline
\end{tabular}

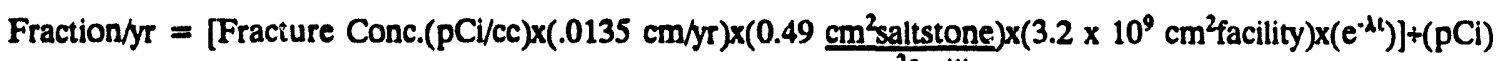
$\mathrm{cm}^{2}$ facility 
Table C.4-3. Fractional flux of Se-79 from fractures in the degraded scenario for the SDF

Se-79 Fractional Flux to Water Table from Fractures

Half-life $=6.5 \mathrm{E}+4$ years $\quad \mathrm{Kd}=5(\mathrm{cc} / \mathrm{g})$

\begin{tabular}{|c|c|}
\hline $\begin{array}{l}\text { Arrival } \\
\text { Time }\end{array}$ & Fractional Flux \\
\hline at Water & to Water Table \\
\hline $\begin{array}{l}\text { Table } \\
\text { (years) }\end{array}$ & $(/ y r)$ \\
\hline 10740 & $1.43 e-06$ \\
\hline 10840 & $1.43 e-06$ \\
\hline 10940 & $1.43 e-06$ \\
\hline 11040 & $1.43 e-06$ \\
\hline 11140 & $1.43 e-06$ \\
\hline 11240 & $1.42 e-06$ \\
\hline 11740 & $1.42 \mathrm{e}-06$ \\
\hline 12240 & $1.41 \mathrm{e}-06$ \\
\hline 12740 & $1.40 \mathrm{e}-06$ \\
\hline 14740 & $1.37 e-06$ \\
\hline 16740 & $1.35 \mathrm{e}-06$ \\
\hline 18740 & $1.32 \mathrm{e}-06$ \\
\hline 20740 & $1.29 e-06$ \\
\hline
\end{tabular}

Fraction/yr $=\left[\right.$ Fracture Conc. $(\mathrm{pCi} / \mathrm{cc}) \times(.0135 \mathrm{~cm} / \mathrm{yr}) \times\left(0.49 \mathrm{~cm}^{2}\right.$ saltstone $) \times\left(3.2 \times 10^{9} \mathrm{~cm}^{2}\right.$ facility $\left.) \times\left(\mathrm{e}^{-\lambda t}\right)\right] \div(\mathrm{pCi})$ $\mathrm{cm}^{2}$ facility

Rey. Q 
Table C.4-4. Fractional flux of $\mathrm{Cs}-137$ from fractures in the degraded scenario for the SDF

Cs-137 Fractional Flux to Water Table from Fractures

Half-life $=30.2$ years

$\mathrm{Kd}=100(\mathrm{cc} / \mathrm{g})$

\begin{tabular}{|c|c|}
\hline $\begin{array}{l}\text { Arrival } \\
\text { Time }\end{array}$ & Fractional Flux \\
\hline at Water & to Water Table \\
\hline $\begin{array}{l}\text { Table } \\
\text { (years) }\end{array}$ & $(/ y r)$ \\
\hline 192000 & $<<1.0 \times 10^{.200}$ \\
\hline 192030 & $<<1.0 \times 10^{-200}$ \\
\hline 192060 & $<<1.0 \times 10^{-200}$ \\
\hline 192090 & $<<1.0 \times 10^{-200}$ \\
\hline 192120 & $<<1.0 \times 10^{-200}$ \\
\hline 192150 & $<<1.0 \times 10^{-200}$ \\
\hline 192180 & $<<1.0 \times 10^{-200}$ \\
\hline 192210 & $<<1.0 \times 10^{.200}$ \\
\hline 192240 & $<<1.0 \times 10^{-200}$ \\
\hline 192270 & $<<1.0 \times 10^{-200}$ \\
\hline 192300 & $<<1.0 \times 10^{-200}$ \\
\hline 192330 & $<<1.0 \times 10^{-200}$ \\
\hline 192360 & $<<1.0 \times 10^{-200}$ \\
\hline 192390 & $<<1.0 \times 10^{.200}$ \\
\hline 192420 & $<<1.0 \times 10^{-200}$ \\
\hline 192450 & $<<1.0 \times 10^{-200}$ \\
\hline 192480 & $<<1.0 \times 10^{-200}$ \\
\hline
\end{tabular}

Fraction/yr = [Fracture Conc. $(\mathrm{pCi} / \mathrm{cc}) \times(.0135 \mathrm{~cm} / \mathrm{yr}) \times\left(0.49 \mathrm{~cm}^{2}\right.$ saltstone $) \times\left(3.2 \times 10^{9} \mathrm{~cm}^{2}\right.$ facility $\left.) \times\left(\mathrm{e}^{-\lambda t}\right)\right]+(\mathrm{pCi})$ $\mathrm{cm}^{2}$ facility 
Table C.4-5. Fractional flux of Sr-9n from fractures in the degraded scenario for the SDF

Sr-90 Fractional Flux to Water Table from Fractures

$$
\text { Half-life }=28.6 \text { years } \quad \mathrm{Kd}=10(\mathrm{cc} / \mathrm{g})
$$

\begin{tabular}{||l|c|}
\hline $\begin{array}{l}\text { Arrival } \\
\text { Time }\end{array}$ & Fractional Flux \\
\hline at Water & to Water Table \\
\hline $\begin{array}{l}\text { Table } \\
\text { (years) }\end{array}$ & $($ /yr) \\
\hline 20280 & $2.0 \times 10^{-220}$ \\
\hline 20310 & $9.6 \times 10^{-221}$ \\
\hline 20340 & $4.7 \times 10^{-22}$ \\
\hline 20370 & $2.3 \times 10^{-221}$ \\
\hline 20400 & $1.1 \times 10^{-221}$ \\
\hline 20430 & $5.5 \times 10^{-22}$ \\
\hline 20460 & $2.7 \times 10^{-22}$ \\
\hline 20490 & $1.3 \times 10^{-222}$ \\
\hline 20520 & $6.4 \times 10^{-223}$ \\
\hline 20550 & $3.1 \times 10^{-223}$ \\
\hline 20580 & $1.5 \times 10^{-223}$ \\
\hline 20610 & $7.5 \times 10^{-224}$ \\
\hline 20640 & $3.7 \times 10^{-224}$ \\
\hline 20670 & $1.8 \times 10^{-224}$ \\
\hline 20700 & $8.8 \times 10^{-225}$ \\
\hline 20730 & $4.3 \times 10^{-225}$ \\
\hline 20760 & $2.1 \times 10^{-225}$ \\
\hline
\end{tabular}

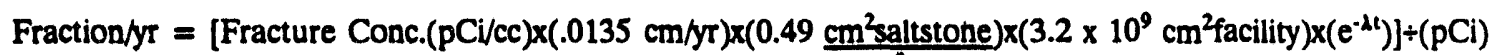
$\mathrm{cm}^{2}$ facility 
Table C.4-6. Fractional flux of Tc-99 from fractures in the degraded scenario for the SDF

Tc-99 Fractional Flux to Water Table from Fractures

Half-life $=2.13 \mathrm{E}+5$ years $\quad \mathrm{Kd}=0.36(\mathrm{cc} / \mathrm{g})$

\begin{tabular}{||l|c|}
\hline $\begin{array}{l}\text { Arrival } \\
\text { Time }\end{array}$ & Fractional Flux \\
\hline at Water & to Water Table \\
\hline $\begin{array}{l}\text { Table } \\
\text { (years) }\end{array}$ & \begin{tabular}{c} 
(hyr) \\
\hline 1887
\end{tabular} \\
\hline 1987 & $1.66 \mathrm{e}-08$ \\
\hline 2087 & $1.66 \mathrm{e}-08$ \\
\hline 2187 & $1.66 \mathrm{e}-08$ \\
\hline 2287 & $1.66 \mathrm{e}-08$ \\
\hline 2387 & $1.66 \mathrm{e}-08$ \\
\hline 2887 & $1.66 \mathrm{e}-08$ \\
\hline 3387 & $1.66 \mathrm{e}-08$ \\
\hline 3887 & $1.66 \mathrm{e}-08$ \\
\hline 5887 & $1.65 \mathrm{e}-08$ \\
\hline 7887 & $1.64 \mathrm{e}-08$ \\
\hline 9887 & $1.63 \mathrm{e}-08$ \\
\hline 11887 & $1.62 \mathrm{e}-08$ \\
\hline & $1.61 \mathrm{e}-08$ \\
\hline
\end{tabular}

Fraction/yr = [Fracture Conc. $(\mathrm{pCi} / \mathrm{cc}) \times(.0135 \mathrm{~cm} / \mathrm{yr}) \times\left(0.49 \frac{\mathrm{cm}^{2} \text { saltstone }}{\mathrm{cm}^{2} \text { facility }} ;\left(3.2 \times 10^{9} \mathrm{~cm}^{2}\right.\right.$ facility $\left.) \times\left(\mathrm{e}^{-2 \mathrm{t}}\right)\right]+(\mathrm{pCi})$ Rev. 0 
Table C.4-7. Fractional flux of Sn-126 from fractures in the degraded scenario for the SDF

Sn-126 Fractional Flux to Water Table from Fractures

$$
\text { Half-life }=1.00 \mathrm{E}+5 \text { years } \quad \mathrm{Kd}=100(\mathrm{cc} / \mathrm{g})
$$

\begin{tabular}{||l|r||}
\hline $\begin{array}{l}\text { Arrival } \\
\text { Time }\end{array}$ & Fractional Flux \\
\hline at Water & to Water Table \\
\hline $\begin{array}{l}\text { Table } \\
\text { (years) }\end{array}$ & (/yr) \\
\hline 192000 & $7.44 \mathrm{e}-09$ \\
\hline 192100 & $7.44 \mathrm{e}-09$ \\
\hline 192200 & $7.39 \mathrm{e}-09$ \\
\hline 192300 & $7.39 \mathrm{e}-09$ \\
\hline 192400 & $7.39 \mathrm{e}-09$ \\
\hline 192500 & $7.39 \mathrm{e}-09$ \\
\hline 193000 & $7.39 \mathrm{e}-09$ \\
\hline 193500 & $7.33 \mathrm{e}-09$ \\
\hline 194000 & $7.33 \mathrm{e}-09$ \\
\hline 196000 & $7.22 \mathrm{e}-09$ \\
\hline 198000 & $7.11 \mathrm{e}-09$ \\
\hline 200000 & $6.99 \mathrm{e}-09$ \\
\hline 202000 & $6.94 \mathrm{e}-09$ \\
\hline
\end{tabular}
Fraction/yr $=\left[\right.$ Fracture Conc. $(\mathrm{pCi} / \mathrm{cc}) \times(.0135 \mathrm{~cm} / \mathrm{yr}) \times\left(0.49 \frac{\mathrm{cm}^{2} \text { saltstone }}{\mathrm{cm}^{2} \text { facility }}\right) \times\left(3.2 \times 10^{9} \mathrm{~cm}^{2}\right.$ facility $\left.) \times\left(\mathrm{e}^{-\lambda t}\right)\right] \div(\mathrm{pCi})$

Rev. 0 
Table C.4-8. Fractional flux of I-129 from fractures in the degraded scenario for the SDF

I-129 Fractional Flux to Water Table from Fractures

Half-life $=1.5 \mathrm{E}+7$ years $\quad \mathrm{Kd}=0.6(\mathrm{cc} / \mathrm{g})$

\begin{tabular}{|c|c|}
\hline $\begin{array}{l}\text { Arrival } \\
\text { Time }\end{array}$ & Fractional Flux \\
\hline at Water & to Water Table \\
\hline $\begin{array}{l}\text { Table } \\
\text { (years) }\end{array}$ & $($ tyr) \\
\hline 2344.8 & $3.50 \mathrm{e}-07$ \\
\hline 2444.8 & $3.50 \mathrm{e}-07$ \\
\hline 2544.8 & $3.50 \mathrm{e}-07$ \\
\hline 2644.8 & $3.50 \mathrm{e}-07$ \\
\hline 2744.8 & $3.50 \mathrm{e}-07$ \\
\hline 2844.8 & $3.50 \mathrm{e}-07$ \\
\hline 3344.8 & $3.50 \mathrm{e}-07$ \\
\hline 3844.8 & $3.50 \mathrm{e}-07$ \\
\hline 4344.8 & $3.50 \mathrm{e}-07$ \\
\hline 6344.8 & $3.50 \mathrm{e}-07$ \\
\hline 8344.8 & $3.50 \mathrm{e}-07$ \\
\hline 10344.8 & $3.50 \mathrm{e}-07$ \\
\hline 12344.8 & $3.50 \mathrm{e}-07$ \\
\hline
\end{tabular}

Fraction/yr $=\left[\right.$ Fracture Conc. $(\mathrm{pCi} / \mathrm{cc}) \times(.0135 \mathrm{~cm} / \mathrm{yr}) \times\left(0.49 \mathrm{~cm}^{2}\right.$ saltstone $) \times\left(3.2 \times 10^{9} \mathrm{~cm}^{2}\right.$ facility $\left.) \times\left(e^{-2 t}\right)\right] \div(\mathrm{pCi})$ $\mathrm{cm}^{2}$ facility

Rev: 0 
Table C.4-9. Fractional flux of Pu-233 from fractures in the degraded scenario for the SDF

Pu-238 Fractional Flux to Water Table from Fractures
\begin{tabular}{||l|c||}
\hline \begin{tabular}{|l|l|} 
Arrival \\
Time
\end{tabular} & Fractional Flux \\
\hline at Water & to Water Table \\
\hline \begin{tabular}{||l|} 
Table \\
(years)
\end{tabular} & (/yr) \\
\hline 192000 & $<<1.0 \times 10^{-200}$ \\
\hline 192100 & $<<1.0 \times 10^{-200}$ \\
\hline 192200 & $<<1.0 \times 10^{-200}$ \\
\hline 192300 & $<<1.0 \times 10^{-200}$ \\
\hline 192400 & $<<1.0 \times 10^{-200}$ \\
\hline 192500 & $<<1.0 \times 10^{-200}$ \\
\hline 192600 & $<<1.0 \times 10^{-200}$ \\
\hline 192700 & $<<1.0 \times 10^{-200}$ \\
\hline 192800 & $<<1.0 \times 10^{-200}$ \\
\hline 192900 & $<<1.0 \times 10^{-200}$ \\
\hline 193000 & $<<1.0 \times 10^{-200}$ \\
\hline
\end{tabular}

Fraction/yr $=$ Fracture Conc. $(\mathrm{pCi} / \mathrm{cc}) \times(.0135 \mathrm{~cm} / \mathrm{yr}) \times\left(0.49 \mathrm{~cm}^{2}\right.$ saltstone $) \times\left(3.2 \times 10^{9} \mathrm{~cm}^{2}\right.$ facility $\left.) \times\left(\mathrm{e}^{-\lambda t}\right)\right] \div(\mathrm{pCi})$ $\mathrm{cm}^{2}$ facility

Rev. 0 
Table C.4-10. Fractional flux of Am-241 from fractures in the degraded scenario for the SDF

Am-241 Fractional Flux to Water Table from Fractures

\begin{tabular}{|c|c|}
\hline Half-life $=432$ years & $\mathrm{Kd}=150(\mathrm{cc}$ \\
\hline Arrival Time & Fractional Flux \\
\hline at Water & to Water Table \\
\hline Table (years) & $(h t)$ \\
\hline 287400 & $1.7 \times 10^{.209}$ \\
\hline 287500 & $1.4 \times 10^{.209}$ \\
\hline 287600 & $1.2 \times 10^{.209}$ \\
\hline 287700 & $1.0 \times 10^{-309}$ \\
\hline 287800 & $8.8 \times 10^{.210}$ \\
\hline 287900 & $7.5 \times 10^{.210}$ \\
\hline 288400 & $3.4 \times 10^{.210}$ \\
\hline 288900 & $1.5 \times 10^{.210}$ \\
\hline 289400 & $6.8 \times 10^{-211}$ \\
\hline 259900 & $3.0 \times 10^{-211}$ \\
\hline 290400 & $1.4 \times 10^{.211}$ \\
\hline 290900 & $6.1 \times 10^{-212}$ \\
\hline 291400 & $2.7 \times 10^{.212}$ \\
\hline 291900 & $1.2 \times 10^{.212}$ \\
\hline 292400 & $5.5 \times 10^{-2.13}$ \\
\hline 292900 & $2.5 \times 10^{.213}$ \\
\hline 293400 & $1.2 \times 10^{.213}$ \\
\hline 293900 & $5.0 \times 10^{-214}$ \\
\hline 294400 & $2.2 \times 10^{-214}$ \\
\hline 294900 & $1.0 \times 10^{.214}$ \\
\hline 295400 & $4.5 \times 10^{.215}$ \\
\hline 29.5900 & $2.0 \times 10^{.215}$ \\
\hline 296400 & $9.1 \times 10^{-216}$ \\
\hline 296900 & $4.1 \times 10^{.216}$ \\
\hline 297400 & $1.8 \times 10^{-216}$ \\
\hline
\end{tabular}

Fraction/yr $=$ [Fracture Conc. $(\mathrm{pCi} / \mathrm{cc}) \times(.0135 \mathrm{~cm} / \mathrm{yr}) \times\left(0.49 \mathrm{~cm}^{2}\right.$ saltstone $) \times\left(3.2 \times 10^{9} \mathrm{~cm}^{2}\right.$ facility $\left.) \times\left(e^{-2 t}\right)\right]+(\mathrm{pCi})$ $\mathrm{cm}^{2}$ facility

Rev. 0 
Table C.4-11. Fractional flux of nitrate from fractures in the degraded scenario for the SDF

Nitrate Fractional Flux to Water Table from Fractures

\begin{tabular}{|c|c|}
\hline \multicolumn{2}{|c|}{$\mathrm{Kd}=0(\mathrm{cc} / \mathrm{g})$} \\
\hline $\begin{array}{l}\text { Arrival } \\
\text { Time }\end{array}$ & Fractional Flux \\
\hline at Water & to Water Table \\
\hline $\begin{array}{l}\text { Table } \\
\text { (years) }\end{array}$ & $(/ \mathrm{yr})$ \\
\hline 1200 & $2.60 \mathrm{e}-05$ \\
\hline 1300 & $2.60 \mathrm{e}-05$ \\
\hline 1400 & $2.60 \mathrm{e}-05$ \\
\hline 1500 & $2.58 \mathrm{e}-05$ \\
\hline 1600 & $2.53 e-05$ \\
\hline 1700 & $2.48 \mathrm{e}-05$ \\
\hline 2200 & $2.17 \mathrm{e}-05$ \\
\hline 2700 & $1.91 \mathrm{e}-05$ \\
\hline 3200 & $1.72 \mathrm{e}-05$ \\
\hline 5200 & $1.27 e-05$ \\
\hline 7200 & $1.04 \mathrm{e}-05$ \\
\hline 9200 & $8.96 \mathrm{e}-06$ \\
\hline 11200 & $7.91 \mathrm{e}-06$ \\
\hline
\end{tabular}

Fraction/yr $=\left[\right.$ Fracture Conc. $(\mathrm{pCi} / \mathrm{cc}) \times(.0135 \mathrm{~cm} / \mathrm{yr}) \times\left(0.49 \mathrm{~cm}^{2}\right.$ saltstone $) \times\left(3.2 \times 10^{9} \mathrm{~cm}^{2}\right.$ facility $\left.) \times\left(\mathrm{e}^{-\lambda \mathrm{l}}\right)\right] \div(\mathrm{pCi})$ $\mathrm{cm}^{2}$ facility

Rev, 0 


\section{C42 Concentration in Soil Around Vaults}

Figures C.4-12 through C.4-21 show the time histories of radionuclide concentration in soil and saltstone at three nodes in the simulation domain. The node locations, shown in Fig. A.1-9, are as follows:

- NODE 1: just above the concrete vault near the left boundary which corresponds to a location centered above a complete $200 \mathrm{ft}$ vault,

- NODE 2: just out from the concrete sidewall at an elevations level with the base of the saltstone, and

- NODE 3: inside the vault at the left boundary at an elevation midway between the top and bottom of the saltstone which corresponds to the centroid of a 200 ft vault.

The concentration histories for NODE 1 and NODE 2 were used to estimate inadvertent intruder doses from the agriculture scenario involving intrusion into contaminated soil above the vaults, and the post-drilling scenario. 



\section{Carbon (C-14) Time History}

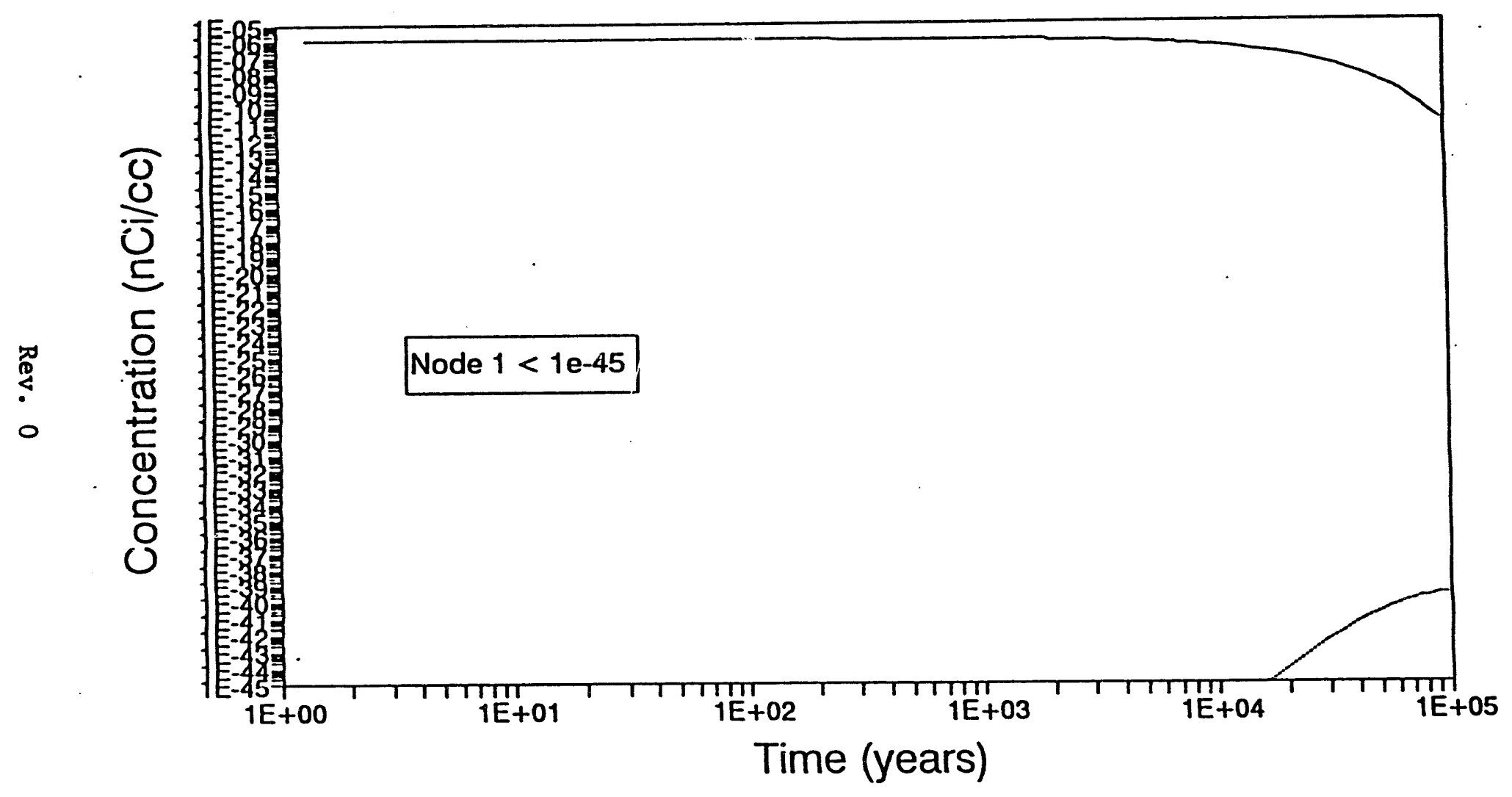

Fig. C.4-13. Time history pore water concentrations for $\mathrm{C}-14$ in soil above the vault (Node 1), in soil to the side of the vault near the base of the saltstone (Node 2), and in saltstone at the cnetroid of the monolith (Node 3 ). 


\section{Selenium (Se-79) Time History}

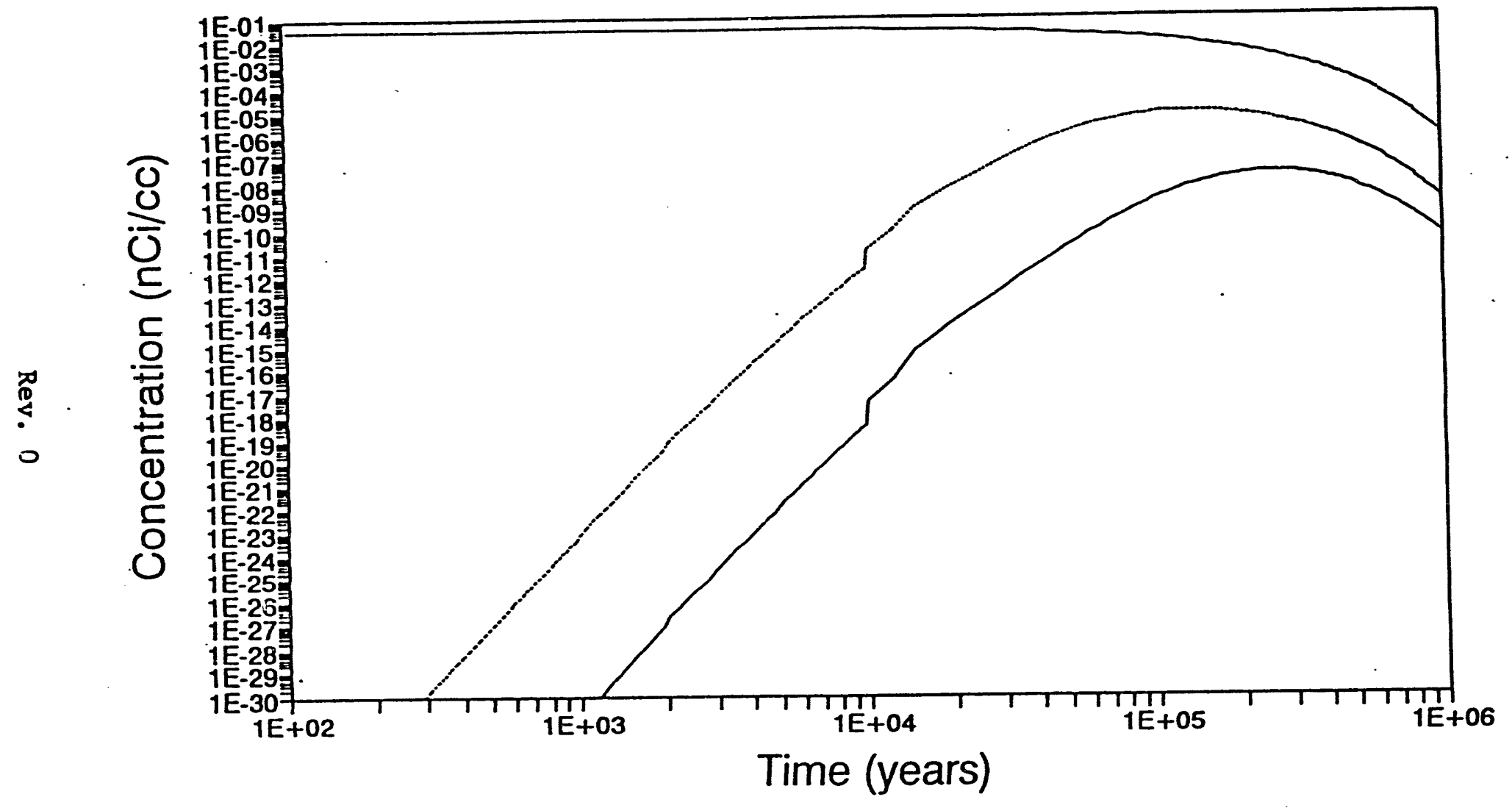

Fig. C.li-14. Time history pore water concentrations for Se-79 in soll above the vault (Node 1), in soil to the side of the vault near the base of the saltstone (Node 2), and in saltstone at the centroid of the monolith (Node 3 ). 


\section{Strontium (Sr-90) Time History}

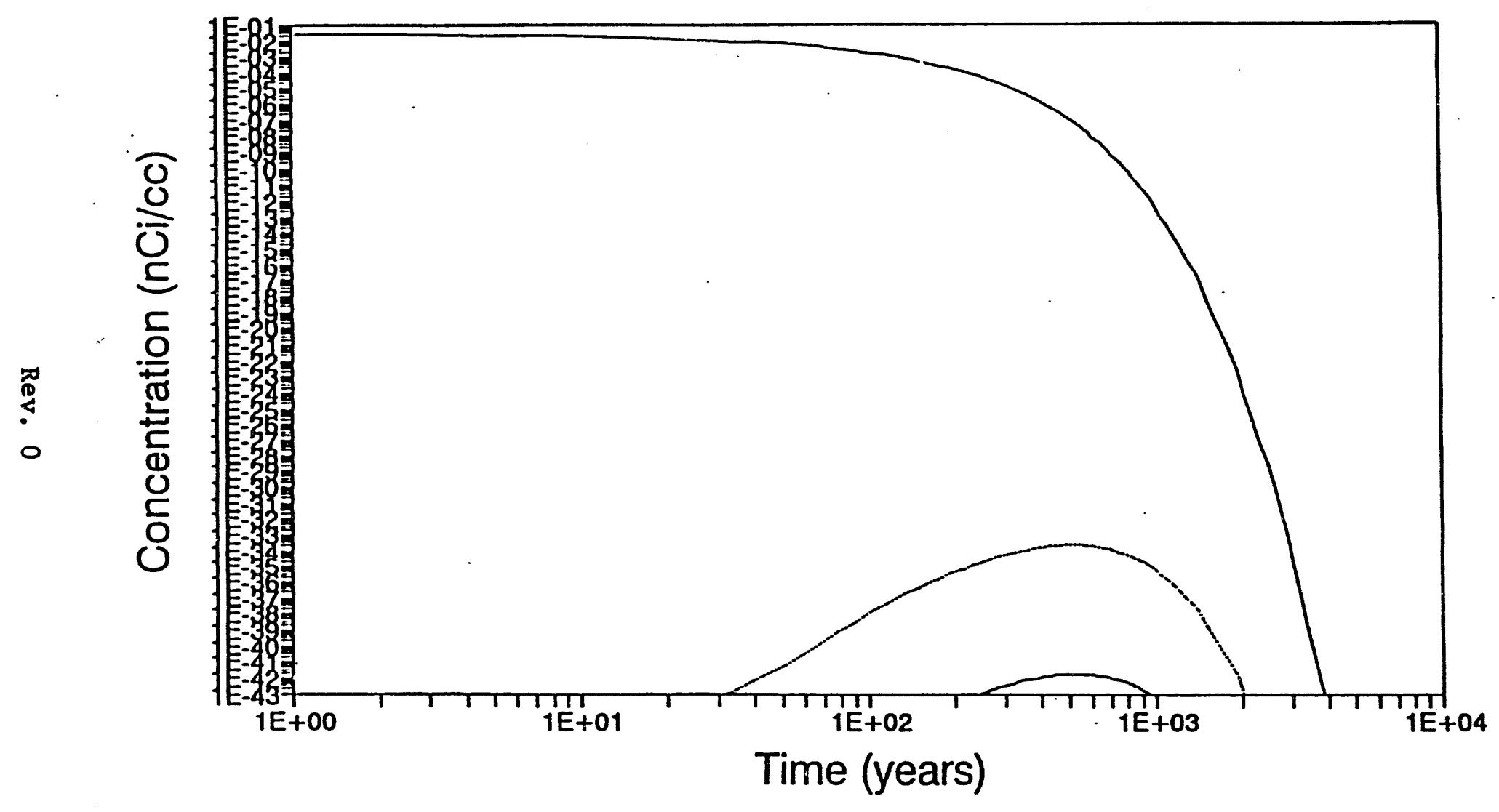

Fig. C.4-15. Time history pore water concentrations for Sr-90 in soil above the vault (Node 1), in soil to the side of the vault near the base of the saltstone (Node 2), and in saltstone at the centroid of the monolith (Node 3). 



\section{Tin (Sn-126) Time History}

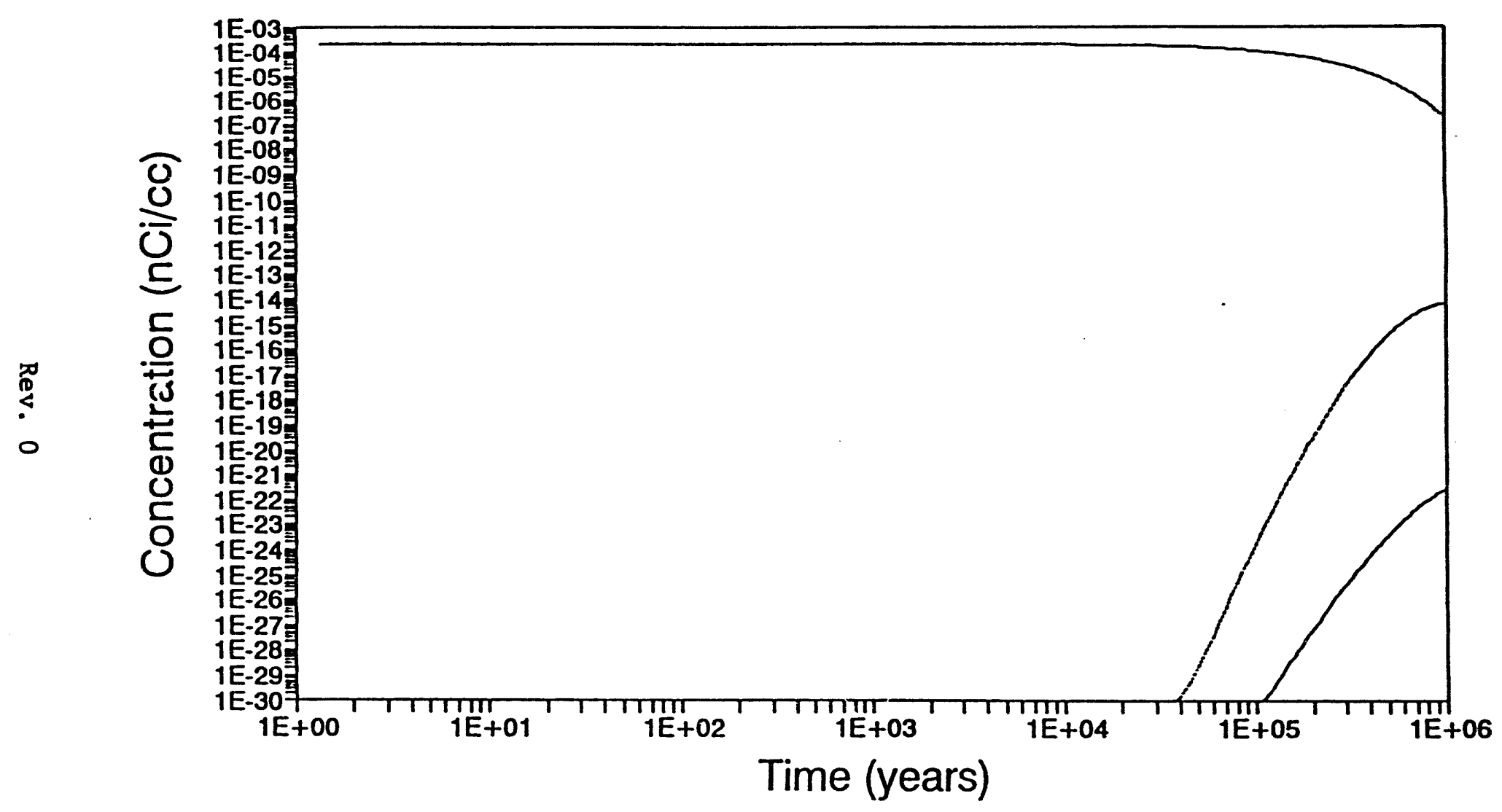

Fig. C.4-17. Time history pore water concentrations for Sn-126 in soil above the vauit (Node 1), in the soil to the side of the vault near the base of the saltstone (Node 2), and in saltstone at the centroid of the monolith (Node 3 ). 


\section{lodine (I-129) Time History}

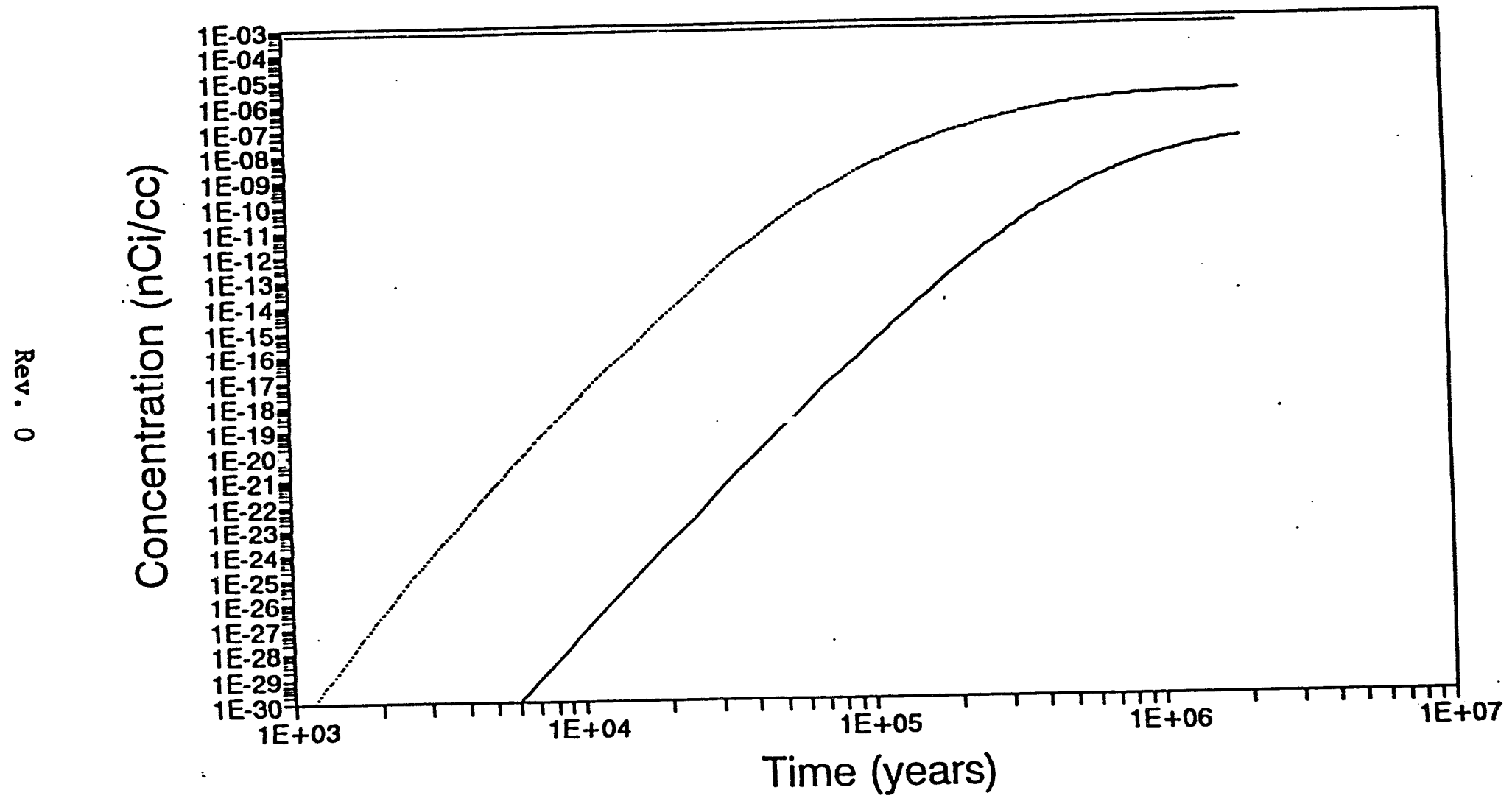

Fig. C.4-18. Time history pore water concentrations for I-129 in soil above the vault (Node 1), in the soil to the side of the vault near the base of the saltstone (Node 2), and in saltstone at the centroid of the monolith (Node 3 ). 


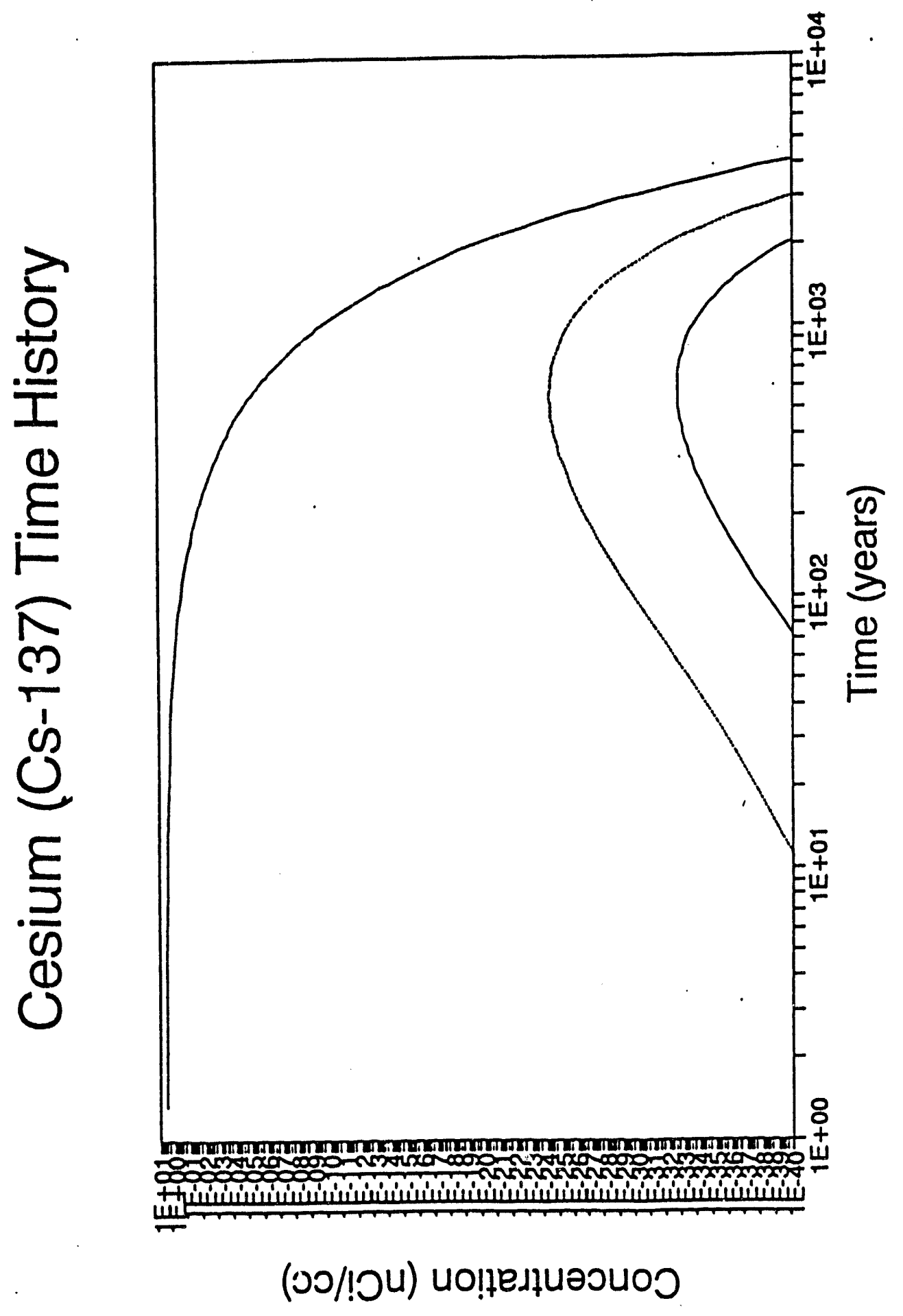

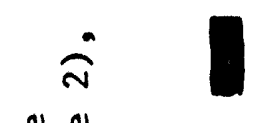

苋

ปั

式

.

대

ले

ำ

के

늉

这

ธั

击

芯造

藏

演

ठํ $\stackrel{\pi}{>}$

ช

H气

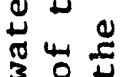

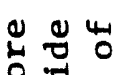

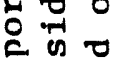

둥형

ป

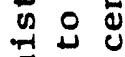

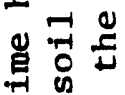

in

. $5 \pi$

$\stackrel{9}{1}$

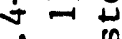

ن 욤

क 艾

$\rightarrow=$

is +5 亗 

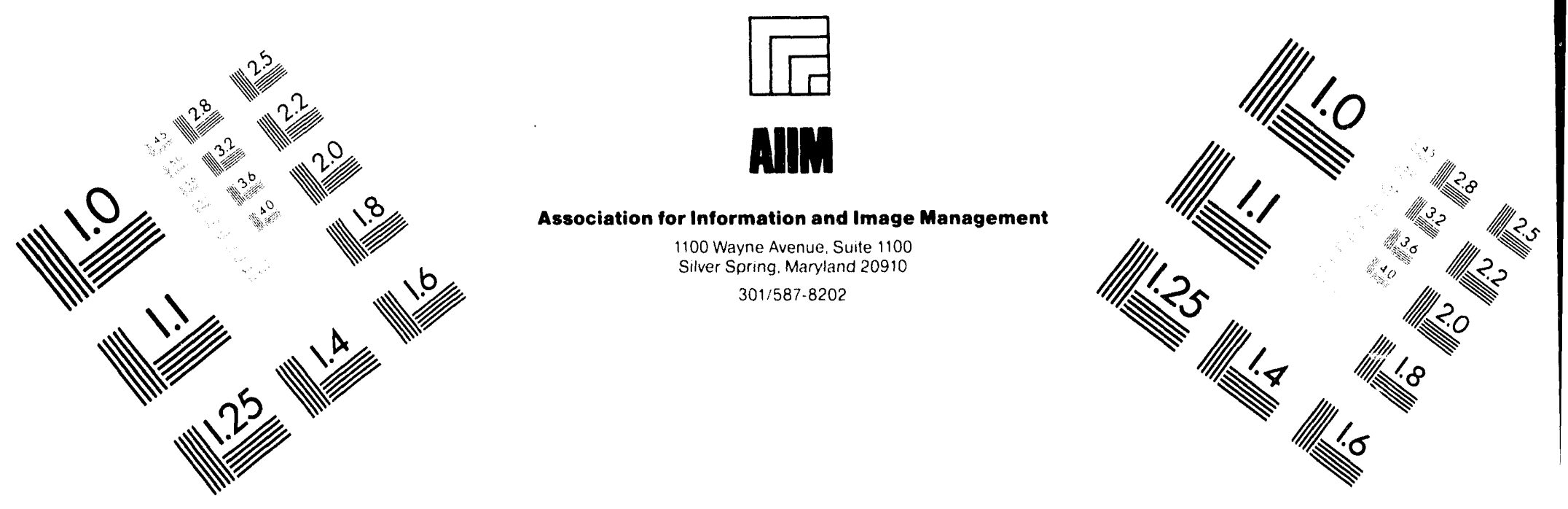

\section{Centimeter}

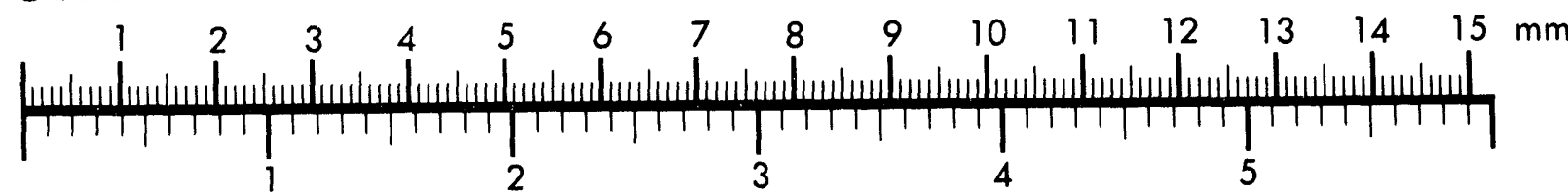
Inches
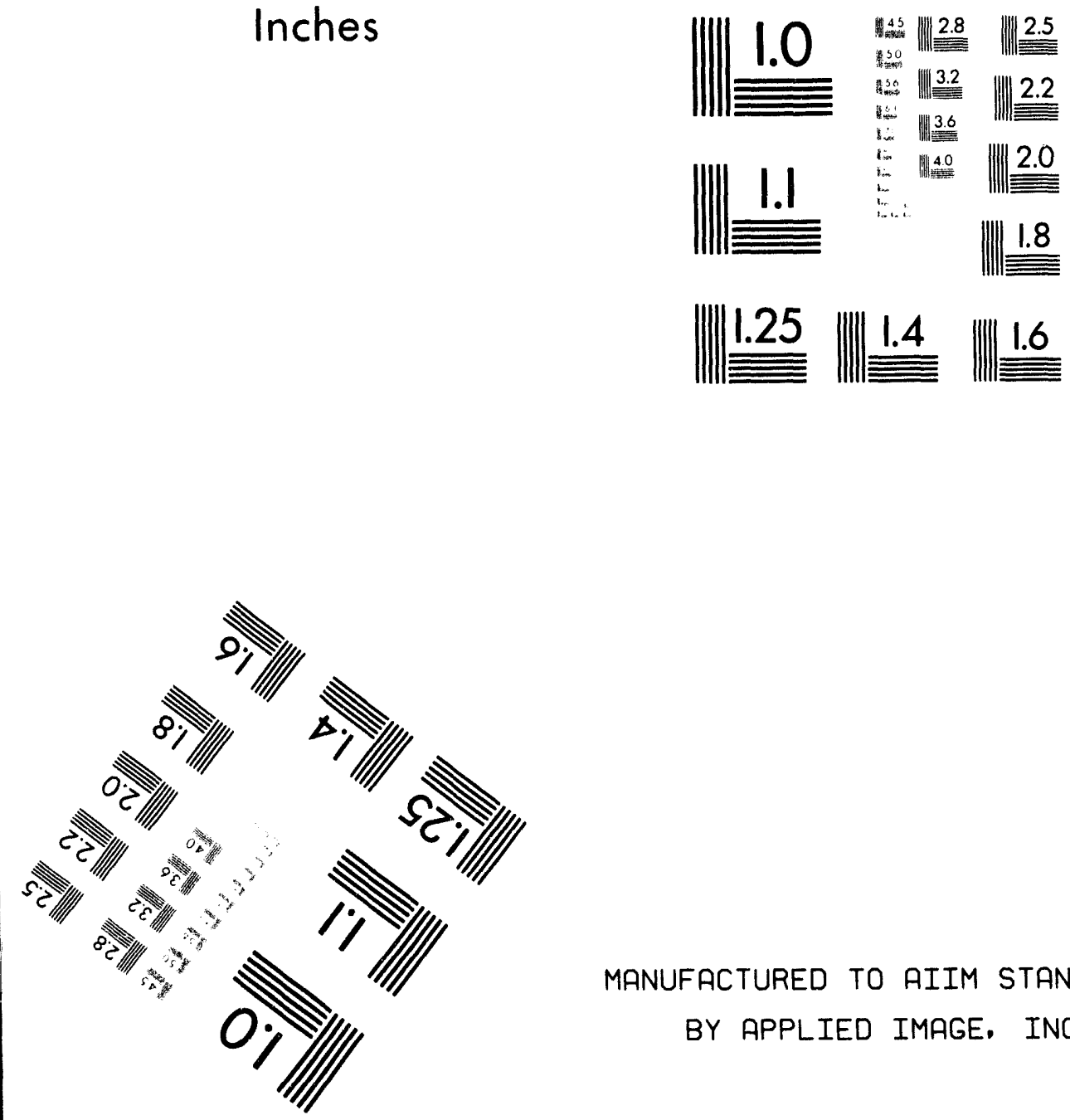

MANUFACTURED TO AIIM STANDARDS

BY APPLIED IMAGE, INC.

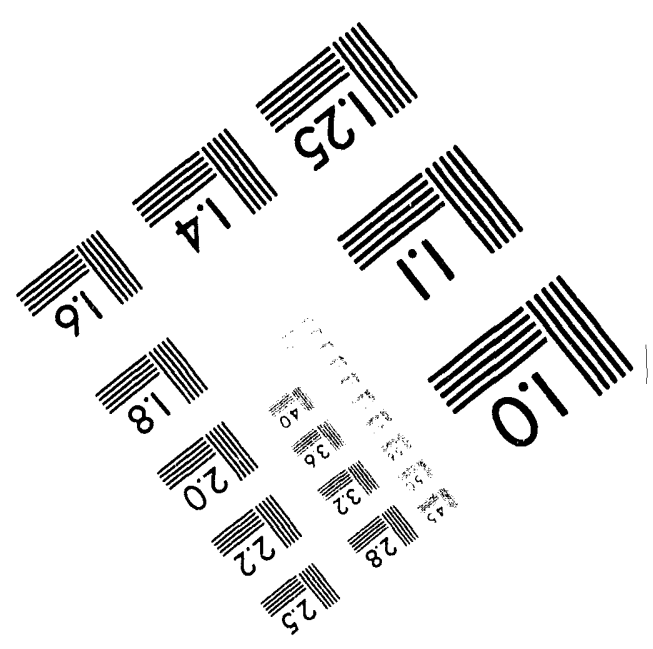



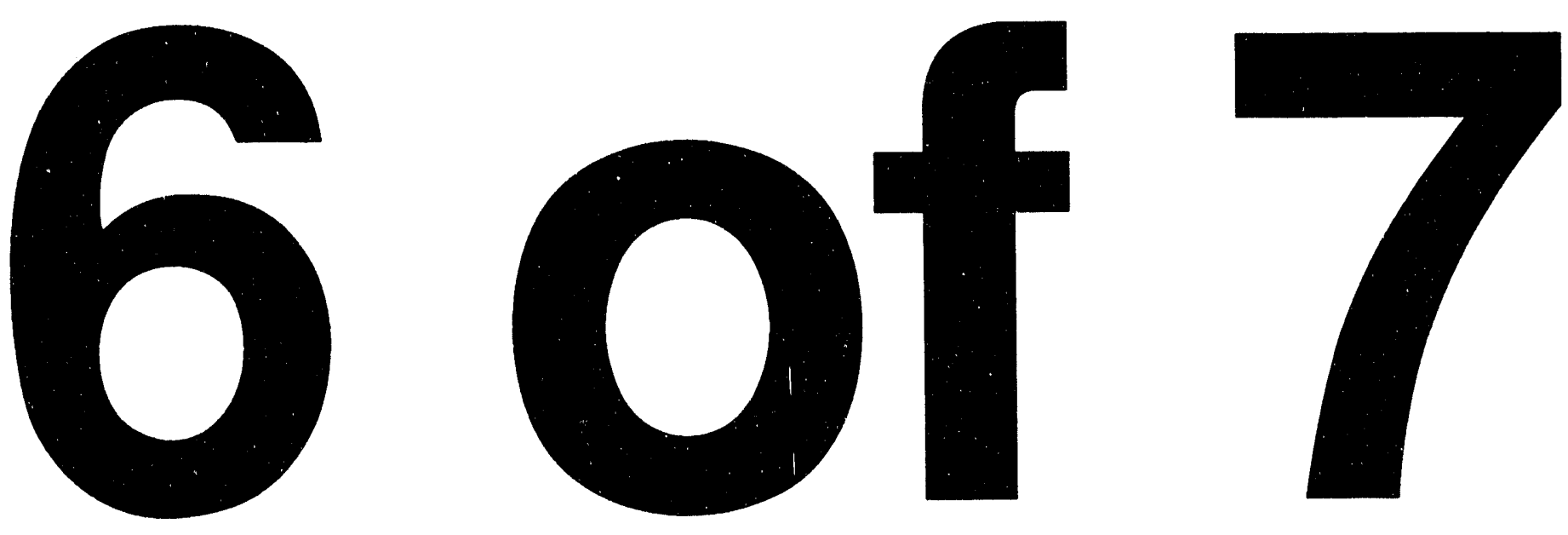


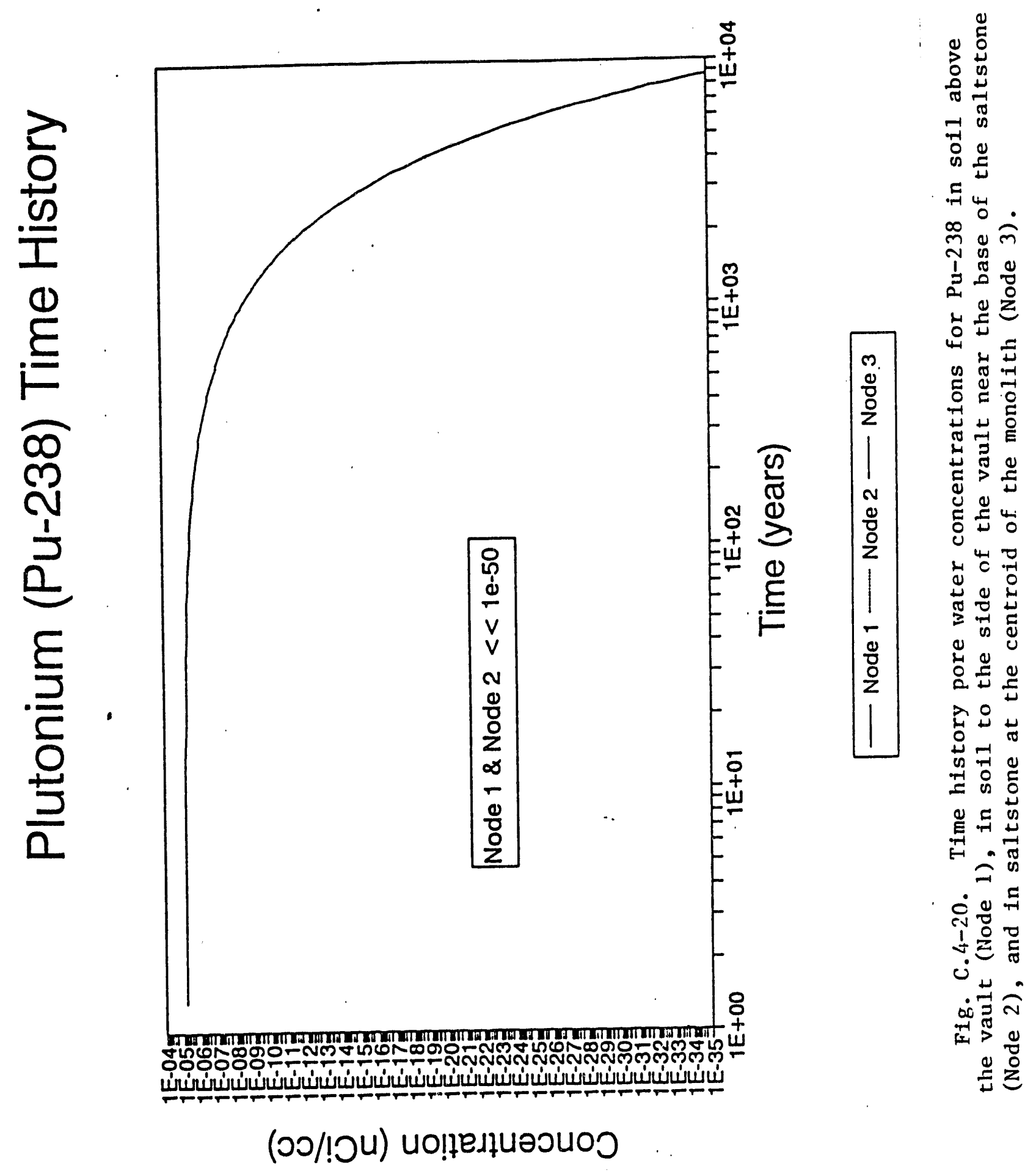

Rev. 0 


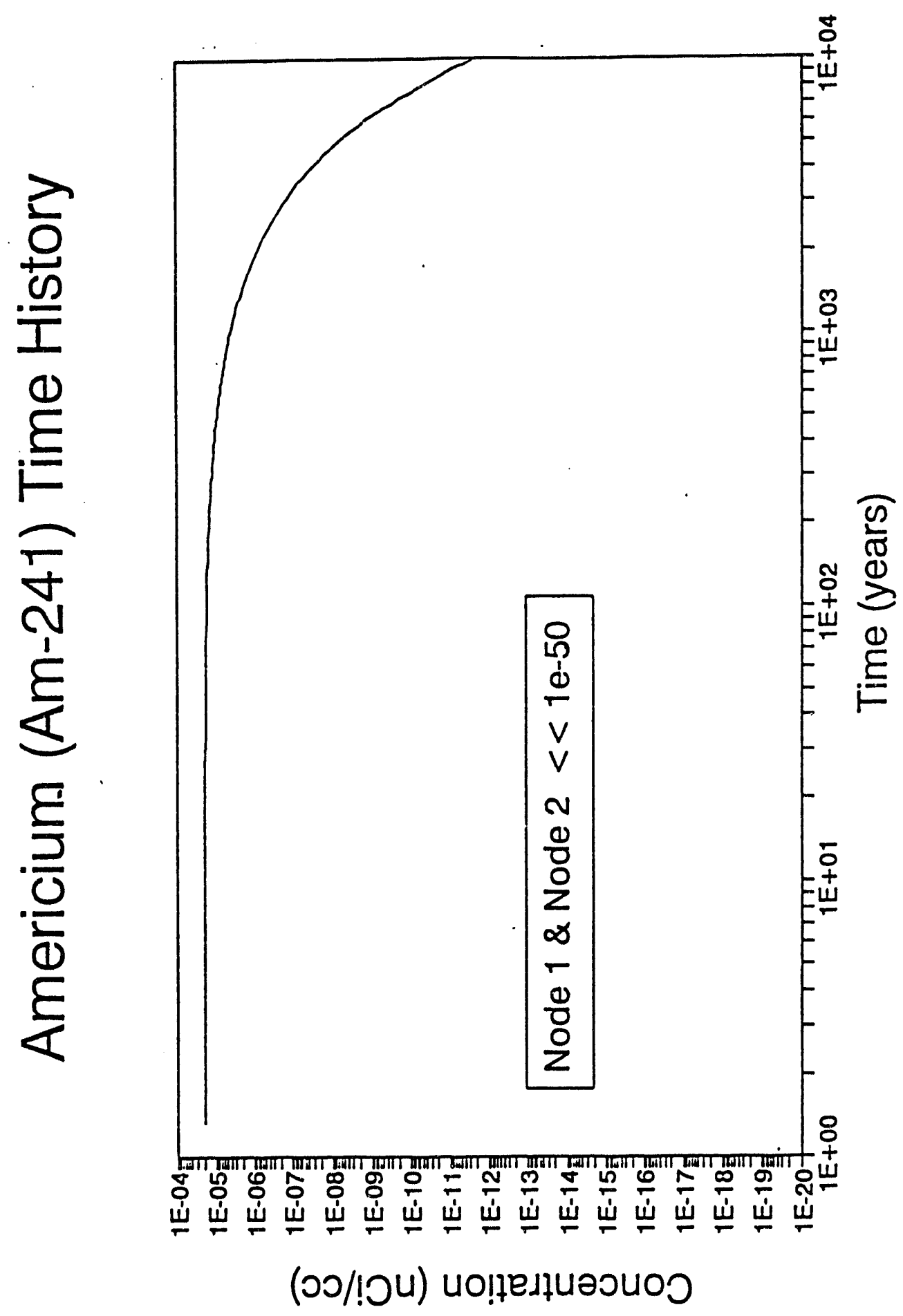

$\Rightarrow$

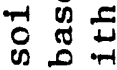

든

$\overline{5}$

พี

是步方

넝

잉

$\rightarrow>0$

$\Xi \nsubseteq$

政

बै

$\leftarrow 0$

艺卷

हैं

$u$

它至

峁造

$3=$

궁

is

의

당둥

ํำ

की

ม่ลิ

רิ E .

तो

힌

i 年 क

ac $\frac{\pi}{0}$

in

مَّ

Rev. 0 


\section{C.43 Groundwater Concentrations}

Figures C.4-22 through C.4-28 show the time history concentrations of nitrate and the ten radionuclides of concern in groundwater at the compliance point for groundwater resource protection. The table at the bottom of these figures indicates the maximum concentration in the three hydrologic units which were simulated. 


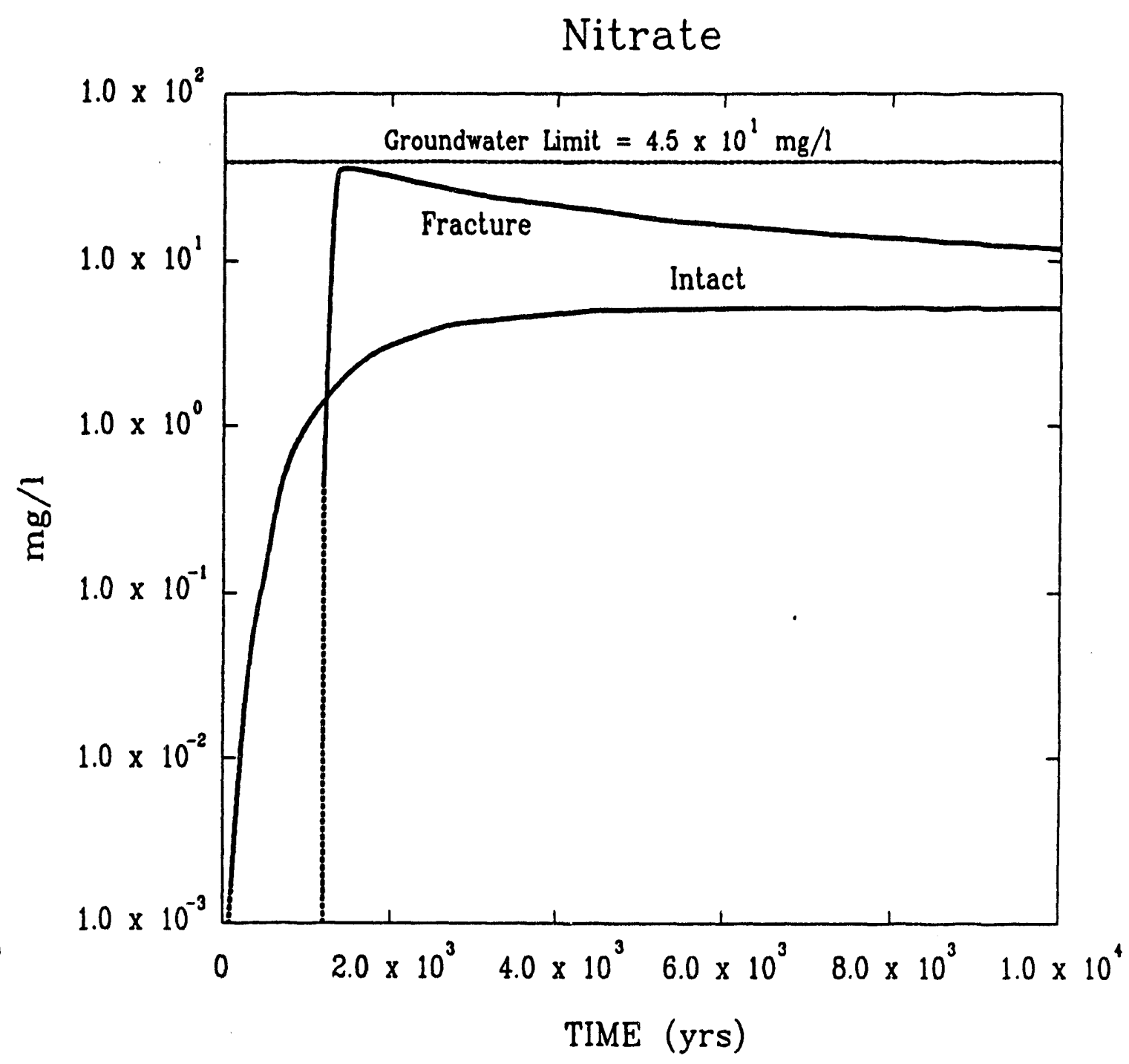

Maximum Concentrations ( $\mathrm{mg} / \mathrm{l}$ )

\begin{tabular}{|l|l|l|}
\hline \multicolumn{1}{|c|}{ Hydrologic Unit } & \multicolumn{1}{c|}{ Intact } & Fracture \\
\hline Barnwell/McBean $100 \mathrm{~m}$ & $8.7 \times 10^{-1}$ at $7.1 \times 10^{3} \mathrm{yrs}$ & 6.0 at $1.4 \times 10^{3} \mathrm{yrs}$ \\
\hline Green Clay $100 \mathrm{~m}$ & 2.8 at $7.0 \times 10^{3} \mathrm{yrs}$ & 19 at $1.4 \times 10^{3} \mathrm{yrs}$ \\
\hline Congaree $100 \mathrm{~m}$ & 5.2 at $7.1 \times 10^{3} \mathrm{yrs}$ & 36 at $1.4 \times 10^{3} \mathrm{yrs}$ \\
\hline
\end{tabular}

Fig. C.4-22. Predicted groundwater concentrations of nitrate as a function of time, resulting from releases from fractures and intact saltstone and vaults.

Rev. 0 


\section{Tritium}

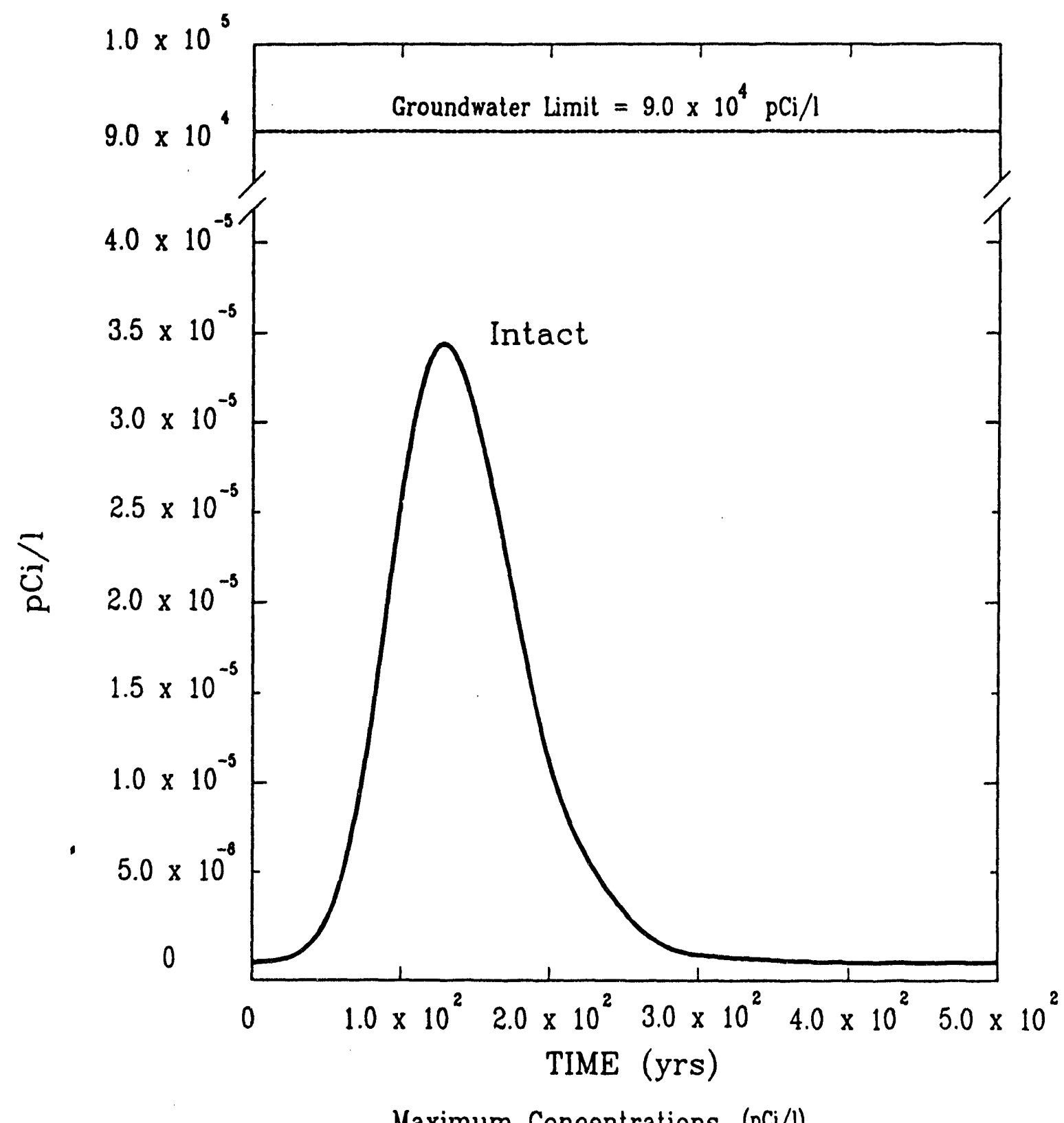

Maximum Concentrations ( $\mathrm{pCi} / \mathrm{l})$

\begin{tabular}{|l|l|l|}
\hline \multicolumn{1}{|c|}{ Hydrologic Unit } & Intact & Fracture \\
\hline Barnwell/McBean $100 \mathrm{~m}$ & $4.7 \times 10^{-8}$ at $1.4 \times 10^{2} \mathrm{yrs}$ & $\ll 1.0 \times 10^{-12}$ \\
\hline Green Clay $100 \mathrm{~m}$ & $1.7 \times 10^{-6}$ at $1.2 \times 10^{2} \mathrm{yrs}$ & $\ll 1.0 \times 10^{-12}$ \\
\hline Congaree $0100 \mathrm{~m}$ & $3.5 \times 10^{-5}$ at $1.2 \times 10^{2} \mathrm{yrs}$ & $\ll 1.0 \times 10^{-12}$ \\
\hline
\end{tabular}

Fig. C.4-23. Predicted groundwater concentrations of H-3 as a function of time, resulting from releases from fractures and intact saltstone and vaults. 
Carbon-14

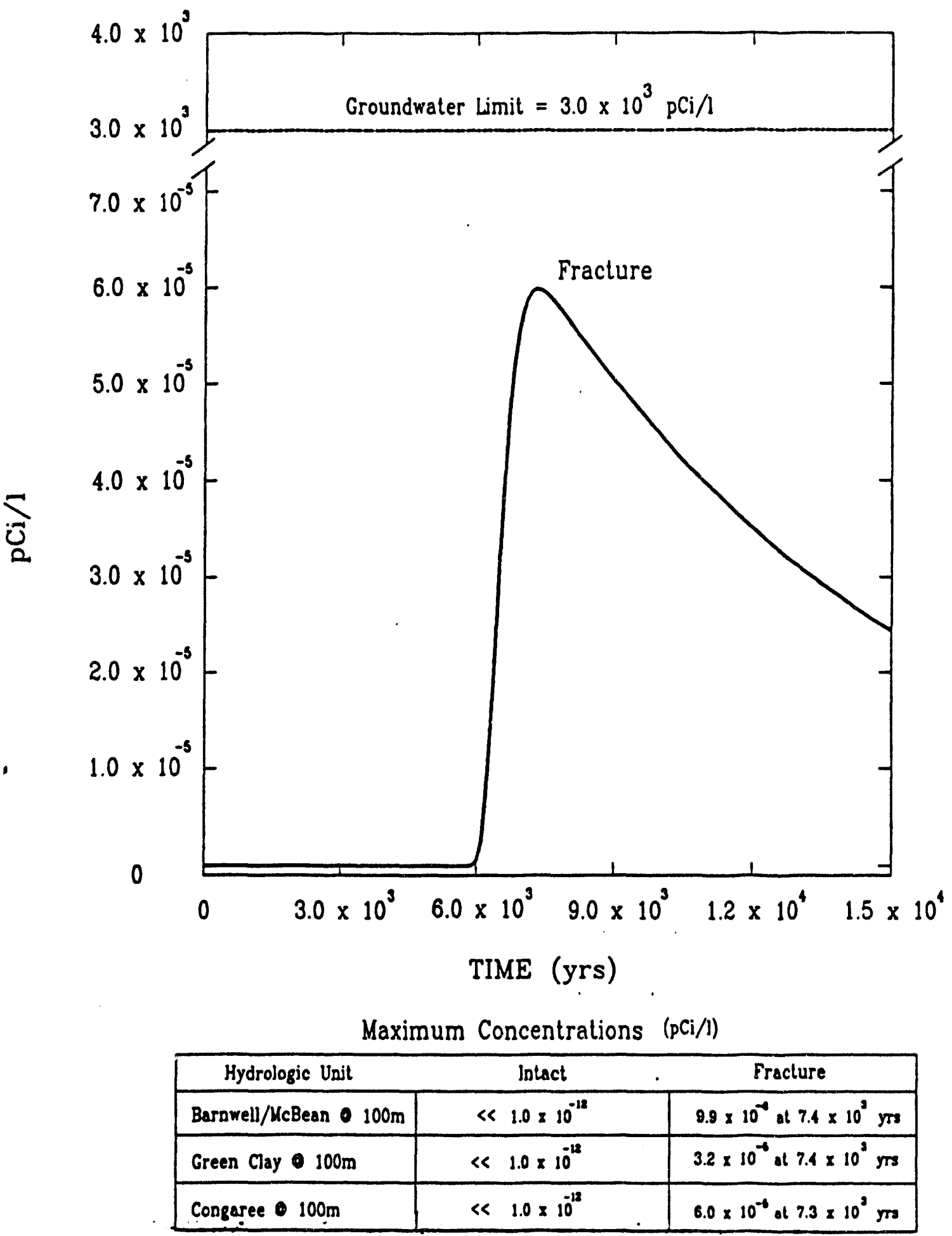

Fig. C.424. Predicted groundwater concentrations of C-14 as a function of time, resulting from releases from fractures and intact saltstone and vaults. 


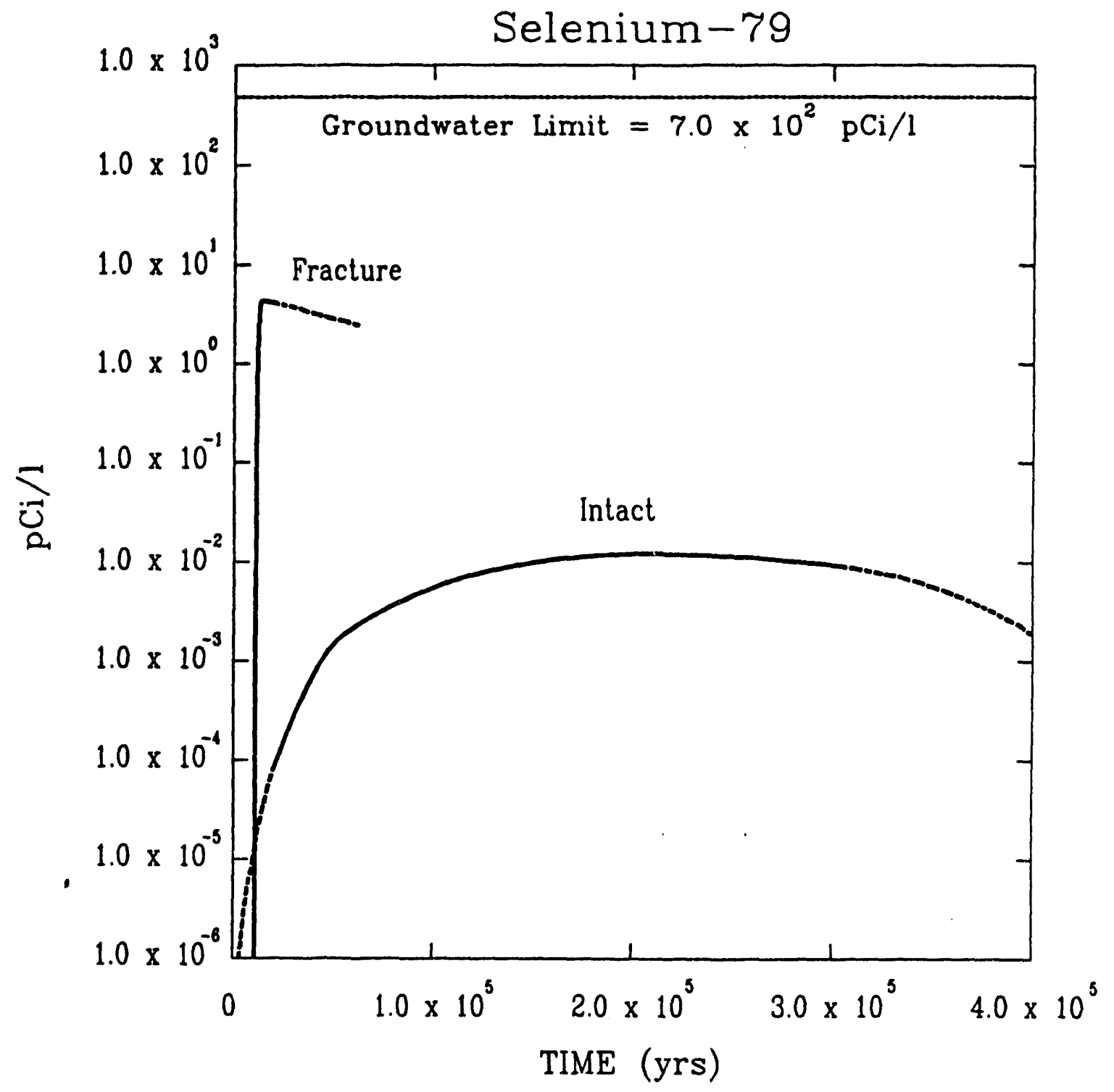

Maximum Concentrations (pCi/l)

\begin{tabular}{|l|l|l|}
\hline \multicolumn{1}{|c|}{ Hydrologic Unit } & \multicolumn{1}{c|}{ Intact } & Fracture \\
\hline Barnwell/McBean $100 \mathrm{~m}$ & $2.1 \times 10^{-3}$ at $2.1 \times 10^{5} \mathrm{yrs}$ & $7.3 \times 10^{-1}$ at $1.5 \times 10^{4} \mathrm{yrs}$ \\
\hline Green Clay $100 \mathrm{~m}$ & $6.7 \times 10^{-9}$ at $2.1 \times 10^{5} \mathrm{mrs}$ & 2.4 at $1.5 \times 10^{6} \mathrm{yrs}$ \\
\hline Congaree $100 \mathrm{~m}$ & $1.2 \times 10^{-2}$ at $2.1 \times 10^{5} \mathrm{yrs}$ & 4.4 at $1.4 \times 10^{4} \mathrm{yrs}$ \\
\hline
\end{tabular}

Fig. C.4-25. Predicted groundwater concentrations of Se-79 as a function of time, resulting from releases from fractures and intact saltstone and vaults. 


\section{Technetium-99}

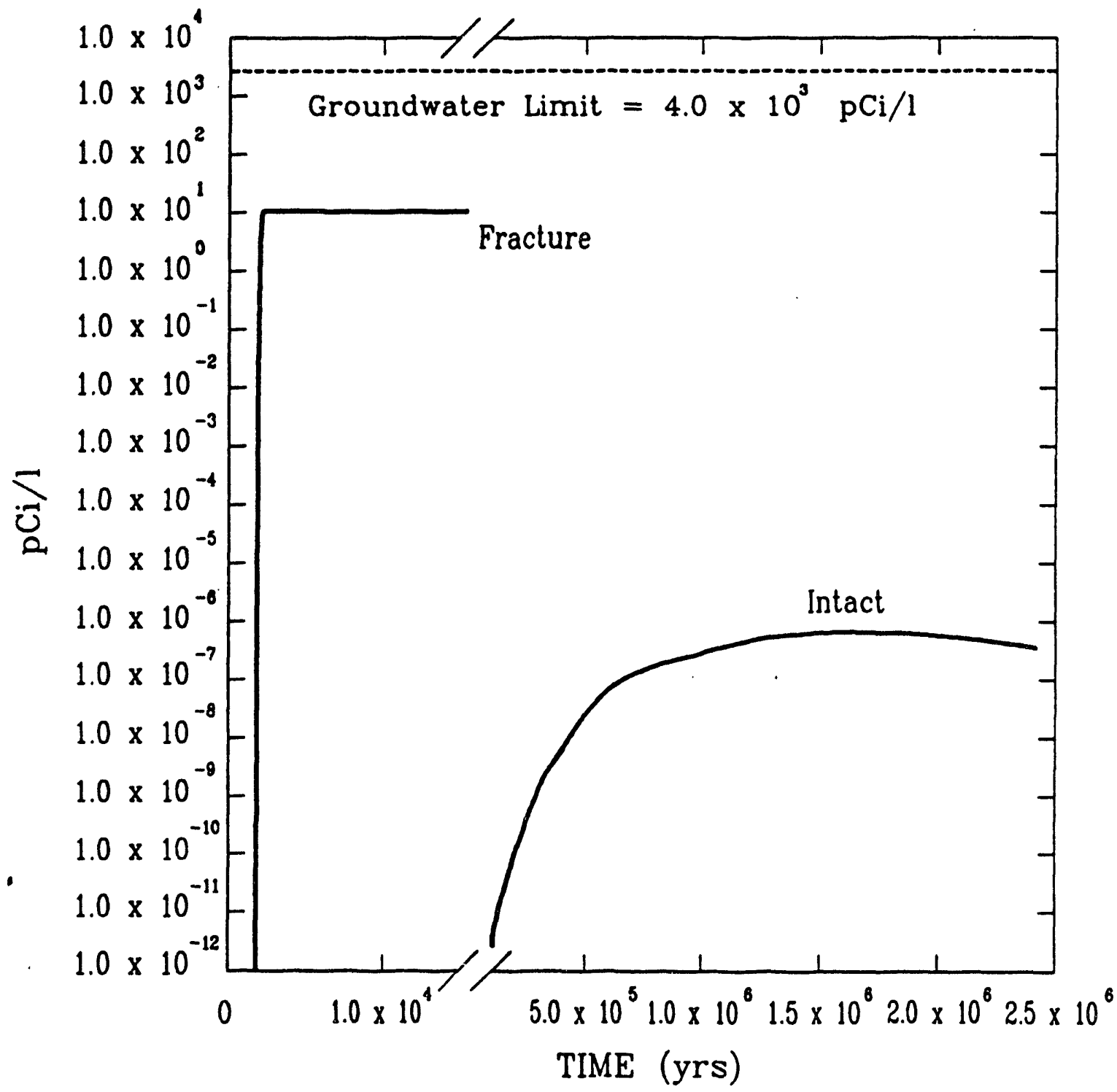

Maximum Concentrations ( $\mathrm{pCi} / \mathrm{l})$

\begin{tabular}{|l|l|c|}
\hline \multicolumn{1}{|c|}{ Hydrologic Unit } & Intact & Fracture \\
\hline Barnwell/McBean $100 \mathrm{~m}$ & $1.1 \times 10^{-7}$ at $1.6 \times 10^{6} \mathrm{yrs}$ & 1.8 at $2.5 \times 10^{3} \mathrm{yrs}$ \\
\hline Green Clay $100 \mathrm{~m}$ & $2.2 \times 10^{-7}$ at $1.6 \times 10^{6} \mathrm{yrs}$ & 5.7 at $2.6 \times 10^{3} \mathrm{yrs}$ \\
\hline Congaree $0100 \mathrm{~m}$ & $6.7 \times 10^{-7}$ at $1.6 \times 10^{6} \mathrm{yrs}$ & 11 at $2.4 \times 10^{3} \mathrm{yrs}$ \\
\hline
\end{tabular}

$\operatorname{sisen}$

Fig. C.4-26. Predicted groundwater concentrations of Tc-99 as a function of time, resulting from releases from fractures and intact saltstone and vaults. 


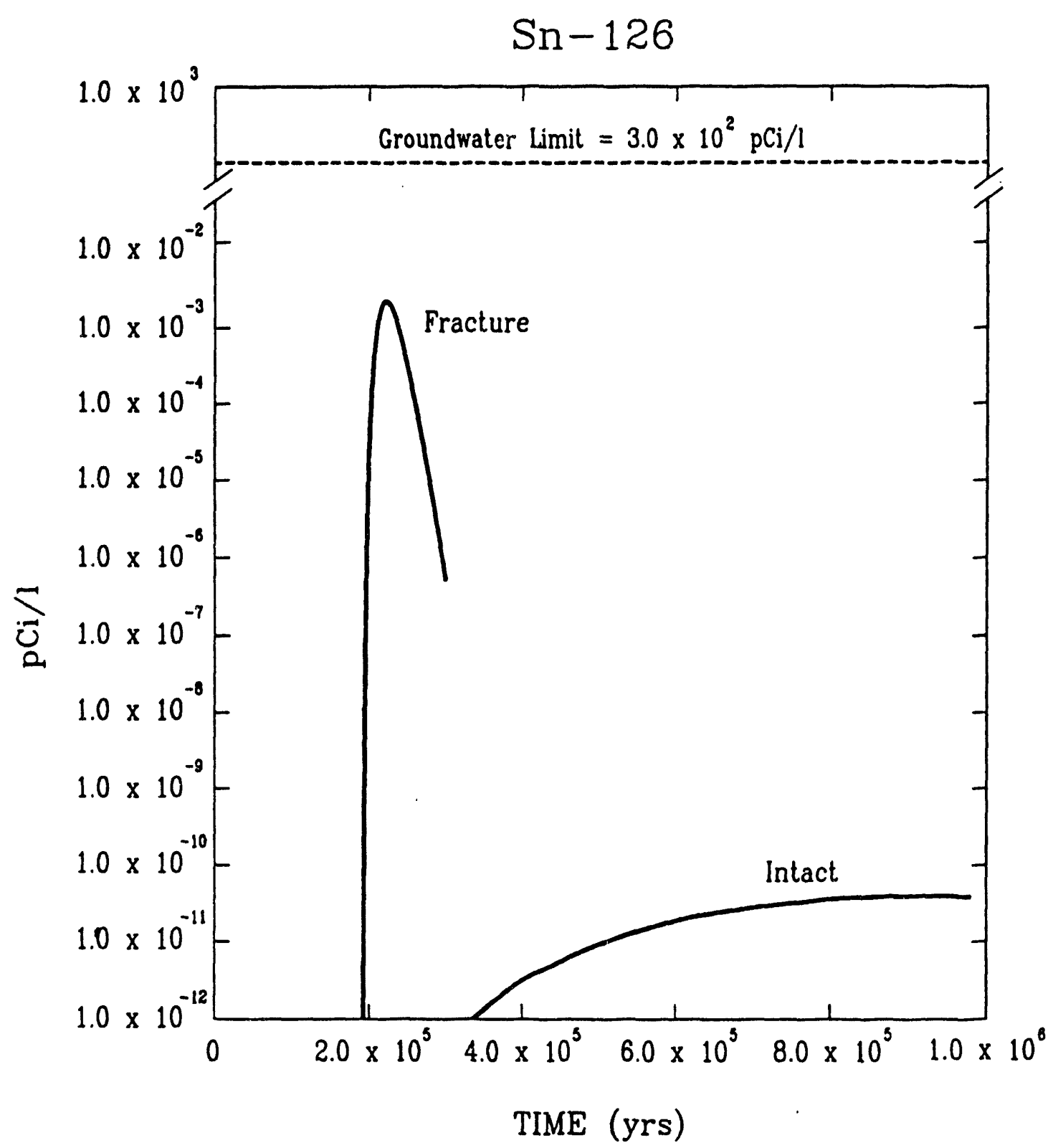

Maximum Concentrations (pCi/l)

\begin{tabular}{|l|l|c|}
\hline \multicolumn{1}{|c|}{ Hydrologic Unit } & Intact & Fracture \\
\hline Barnwell/YcBean $0100 \mathrm{~m}$ & $6.5 \times 10^{-12}$ at $9.2 \times 10^{6} \mathrm{mrs}$ & $3.4 \times 10^{-4}$ at $2.2 \times 10^{5} \mathrm{yrs}$ \\
\hline Green Clay $100 \mathrm{~m}$ & $2.1 \times 10^{-11}$ at $9.2 \times 10^{5} \mathrm{yrs}$ & $1.2 \times 10^{-9}$ at $2.2 \times 10^{5} \mathrm{grs}$ \\
\hline Congaree $100 \mathrm{~m}$ & $4.0 \times 10^{-11}$ at $9.2 \times 10^{5} \mathrm{mrs}$ & $2.2 \times 10^{-9}$ at $2.2 \times 10^{5} \mathrm{yrs}$ \\
\hline
\end{tabular}

Fig. C.4-27. Predicted groundwater concentrations of Sn-126 as a function of time, resulting from releases from fractures and intact saltstone and vaults. 


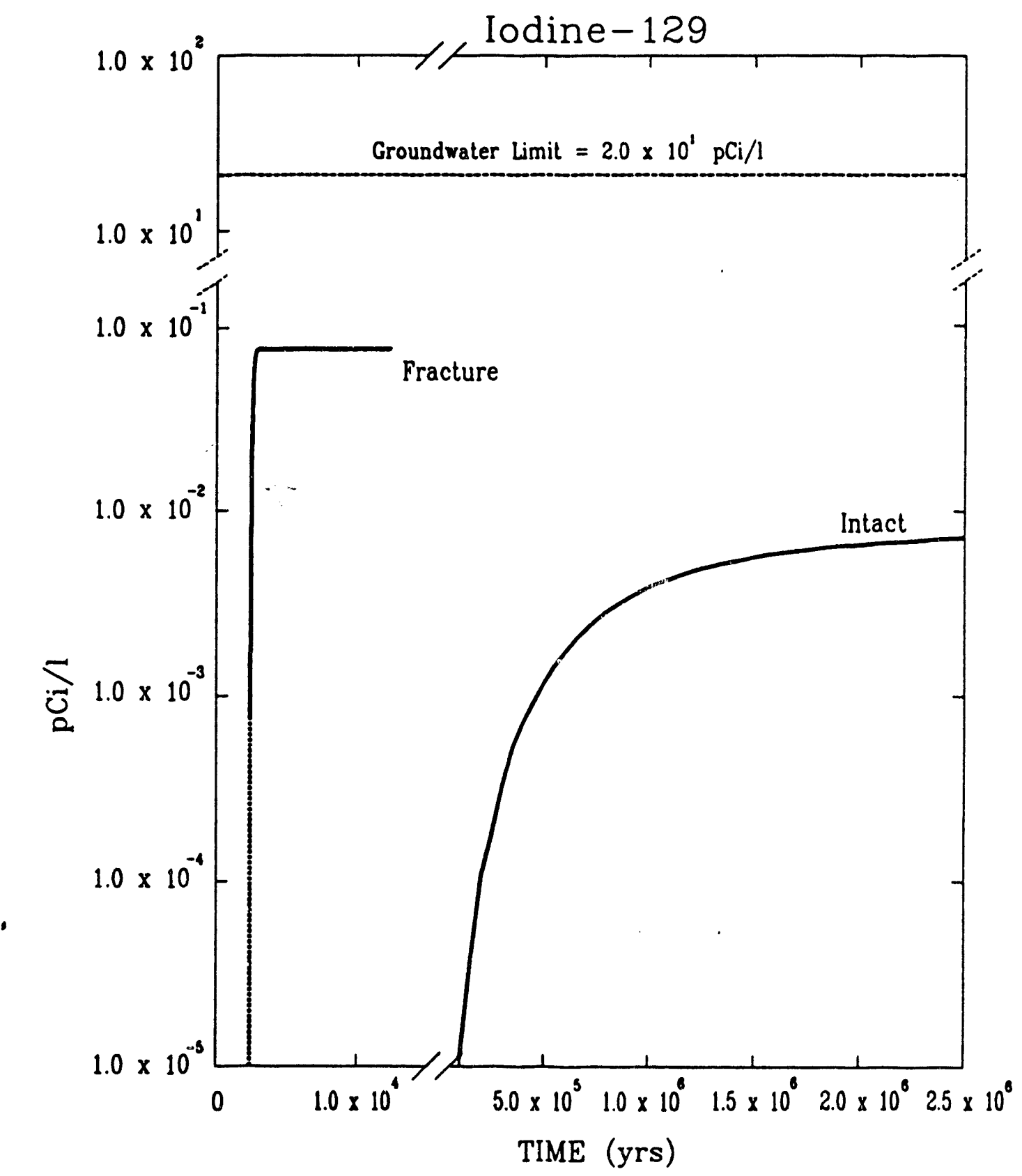

Maximum Concentrations $>(\mathrm{pCi} / \mathrm{l})$

\begin{tabular}{|l|l|l|}
\hline \multicolumn{1}{|c|}{ Hydrologic Unit } & \multicolumn{1}{c|}{ Intact } \\
\hline Barmwell/NcBean $100 \mathrm{~m}$ & $1.2 \times 10^{-3}$ at $2.5 \times 10^{\circ} \mathrm{yrs}$ & $1.2 \times 10^{-2}$ at $3.1 \times 10^{3} \mathrm{rrs}$ \\
\hline Green Clay $100 \mathrm{~m}$ & $3.9 \times 10^{-3}$ at $2.5 \times 10^{\circ} \mathrm{yrs}$ & $4.0 \times 10^{-2}$ at $3.2 \times 10^{3} \mathrm{yrs}$ \\
\hline Congaree $0100 \mathrm{~m}$ & $7.2 \times 10^{-3}$ at $2.5 \times 10^{\circ} \mathrm{yrs}$ & $7.4 \times 10^{-2} \mathrm{at} 3.2 \times 10^{3} \mathrm{yrs}$ \\
\hline
\end{tabular}

Fig. C.4-28. Predicted groundwater concentrations of I-129 as a function of time, resulting from releases from fractures and intact saltstone and vaults. 



\section{D.1 INTRODUCTION}

One of the most important input paranneters to the flow models used to simulate transport of contaminants from the Saltstione Production and Disposal Facility (Z-Area) vaults to the nearest point of compliance is the determination of a representative pollutant source term. The most representative source term for this purpose is the resultant concentration of pollutants in the pore fluid within the saltstone grout matrix following the geochemical interactions that occur after the wastewater feed solution and the cementitious materials (cement, slag, and fly-ash) are mixed together. The predominant transport pathway from the saltstone to the nearest point of compliance is downward migration via fluids which have passed through the waste form and concrete vaults and through the vadose zone into the saturated zone. The most representative source term for this transport pathway is the concentration of pollutants in the interstitial fluids within the vadose zone immediately surrounding the saltstone vaults. This latter source term estimate is based on the geochemical interactions that occur between the saltstone pore fluid and the soil (sediments) immediately surrounding the Z-Area vaults.

This appendix provides an estimate of selected pollutant concentrations in the saltstone pore fluid obtained by using the MINTEQ computer code. Pollutant concentration in interstitial fluids within the vadose zone are also estimated using the MINTEQ code.

The MINTEQ code was selected for this geochemical evaluation because it is well documented and generally accepted within the technical community. The MINTEQ code was installed and tested on computers at both EG\&G Idaho, Inc. and Westinghouse Hanford Company. EG\&G Idaho, Inc. studied the evolution of the pollutant contamination within the saltstone pore fluid while Westinghouse Hanford Company studied the pollutant contamination within the interstitial fluids in the vadose zone. The same thermodynamic properties of chemical compounds and mineral species, published saltstone properties, and sediment composition at the Savannah River Site were used as the data base for calculations conducted by both contractors.

Kaolinite, quartz, and iron compounds were assumed to be the major constituents in the sediments surrounding the Z-Area vaults with which the saltstone pore fluid will react.

The pollutants selected for the initial source term evaluation are technetium-99, tritium, and nitrate ion. There are other pollutants of interest present in the feed solution which are candidates for future evaluation. These are iodine-129, tin-126, selenium-79, americium-241, and carbon-14. 


\section{D.12 Background}

The large concentration of dissolved solids in the feed solution $(>300,000 \mathrm{mg} / \mathrm{L})$ are beyond solution concentrations normally used when the MINTEQ code is used to calculate appropriate activity coefficients and solubilities. Initial test runs were made to evaluate the sensitivity of the MINTEQ code to these high concentrations. The code was used to calculate appropriate activity coefficients and solubilities of the pore fluid in the saltstone grout matrix at the time the feed solution and the dry additives were mixed. Results from the test runs showed that the MINTEQ code could be used with reliability to determine the composition of pore fluids. Further, that activity coefficients and solubility data are not as sensitive as previously thought to the high concentrations of dissolved solids.

Movement of pore fluids through the saltstone matrix is controlled by advection and diffusion. Leaching occurs both at the outermost surface of the saltstone matrix and along the surface of cracles and fractures within the saltstone matrix. The data indicate that the most significant leach rates will occur along the cracks and fractures in the saltstone where the influx of water has the shortest residence time.

\section{D2 SUMMARY AND CONCLUSION}

The nominal concentration of technetium-99 in the waste form is projected to be $25,000 \mathrm{pCi} / \mathrm{g}$. Upon mixing with the cementitious materials a significant portion of the technetium is partitioned between the solid matrix $(40,700 \mathrm{pCi} / \mathrm{g})$ and the pore fluid

$(46.3 \mathrm{pCi} / \mathrm{mL})$. An estimated $\mathrm{Kd}$ of $880 \mathrm{~mL} / \mathrm{g}$ was calculated for technetium in the saltstone. The reaction of pore fluids with the sediments did not influence the technetium concentration.

Results show that elemental sulfur present in blast furnace slag will react to form sulfide species during the hydration of the saltstone. the sulfide is available to react with technetium to form insoluble technetium sulfide $\left(\mathrm{Tc}_{2} \mathrm{~S}_{7}\right)$ which significantly reduces the technetium concentrations in the pore fluid from $46,300 \mathrm{pCi} / \mathrm{L}$ to $2.4 \times 10^{-8} \mathrm{pCi} / \mathrm{L}$. For each 10 fold increase of HS $^{-}$in the pore fluid the technetium concentration decreases by a factor of 3,200 . Results also show that a decrease of 1 unit in pH results in an decrease in rechnetium in the pore fluid by a factor of 32,000 .

Initial tritium concentration in the waste form is projected to be $7,000 \mathrm{pCi} / \mathrm{g}$. Upon mixing with the cementitious materials the concentration of water in the pore fluid is $0.825 \mathrm{~g} / \mathrm{mL}$ and the concentration of water in the hydrated cement is $0.177 \mathrm{~g} / \mathrm{g}$ which gives a calculated $\mathrm{K}_{d}$ of 0.2 for tritium in the saltstone. The tritium concentration in the pore fluid is $16,000,000 \mathrm{pCi} / \mathrm{L}$. The tritium concentration in the interstitial fluid within the vadose zone was reduced slightly because some of the insoluble minerals that are precipitated from solution are hydrated. 
The total nitrogen (as $\mathrm{NO}_{3}{ }^{-}$) in the waste water feed solution exceeds $150,000 \mathrm{mg} / \mathrm{L}$. The loss of water into the saltstone from hydration causes the nitrate concentration in the pore fluid to increase to more than $200,000 \mathrm{mg} / \mathrm{L}$. The nitrate concentration in the interstitial fluid within the vadose zone will decrease primarily due to the dilution of the interstitial fluid by naturally occurring waters present in the vadose zone.

\section{D3 PORE FLUID COMPOSITION WITHIN SALTSTONE}

The partitioning of contaminants between the aqueous phase (pore fluid) and solid matrix (hydrated cement) must be understood in order to understand the release of contaminants from a saltstone waste form. The term sorption describes the partitioning processes and is mathematically represented by the use of a distribution coefficient $\left(\mathbf{K}_{\mathrm{d}}\right)$. However, sorption does not occur by a single mechanism. The three mechanisms important to calculating the hydration and pore fluid composition for saltstone are

1) Adsorption - The contaminant is partitioned between the solid surface and the pore fluid. At low concentrations this adsorption can be linear and reversible allowing the use of $a \mathrm{~K}_{d}$ to represent partitioning.

2) Precipitation - The contaminant forms a separate solid phase or coprecipitates into an existing solid phase. The aqueous concentration is controlled by the solubility of this solid phase (i.e., the pore fluid concentration is independent of the solid concentration). Typically the solid phase has a very low solubility; therefore, the contaminants are effectively immobilized in the solid waste form. The relationship between aqueous and solid concentration for coprecipitated contaminants are related by kinetic and thermodynamic considerations (Murphy and Smith 1989). However, at low contaminant concentrations multiphase thermodynamic equilibrium can be mathematically represented by a K (Smith and Walton 1992).

3) Absorption - This mechanism is important when calculating a source term for tritium. During the hydration of cement water is taken up into the cement paste, removing tritium from solution in proportion to the total amount of water transferred into the solid phase.

In addition to contaminants, the release of ions such as sulfate from the saltstone waste form may lead to the degradation of the concrete vault. These releases need to be understood in order to evaluate long-term contaminant release performance. To quantify the saltstone pore fluid composition, hydration calculations have been conducted to 1) determine the distribution of water between pore fluid and hydrated cement and 2) estimate the composition of the pore fluid. In addition, the distribution of water between pore fluid and solid matrix can be used to estimate a distribution coefficient 
$\left(\mathrm{K}_{\mathbf{q}}\right)$ for tritium. The results of hydration calculations are summarized below.

\section{D3.1 Hydration Calculation}

The saltstone mix is composed of $3 \%$ Class II cement, 25\% blast furnace slag, $25 \%$ Class F fly ash , and 47\% Nominal Blend Salt Solution Feed (Heckrotte 1988). The compositions of the four components of saltstone are given in Table D.3-1. As the concrete waste form cures, water is taken up from the salt solution feed and incorporated into the cement mix by hydration, forming the solid matrix of the waste form. A portion of the initial free water is incorporated into the solid matrix of the waste form; the remaining water occurs as pore fluid. Ions that are not incorporated into the solid matrix (e.g., nitrate, nitrite), are concentrated in the pore fluids. Table D.3-2 documents the hydration of $100 \mathrm{~g}$ of the cement mixture. The compositions of the solid phases were taken from Table 4 of Malek et al. (1985). The maximum extent of hydration was estimated by assuming that

- $\mathrm{SiO}_{2}$ and $\mathrm{TiO}_{2}$ do not consume water during hydration,

- $\mathrm{Al}_{2} \mathrm{O}_{3}$ and $\mathrm{Fe}_{2} \mathrm{O}_{3}$ consume 3 mol of water per mol of oxide,

- $\mathrm{SO}_{3}$ reduces hydration by $1 \mathrm{~mol}$ of water per mol of oxide,

- $\mathrm{Na}_{2} \mathrm{O}$ and $\mathrm{K}_{2} \mathrm{O}$ dissolve into the pore fluid, and

- All other oxides consume $1 \mathrm{~mol}$ of water per mol of oxide.

The hydration process results in a $15.8 \mathrm{~g}(16 \%)$ increase in the mass of the solid matrix. This value is consistent with the range given in Neville (1981). The total amount of salt feed solution per $100 \mathrm{~g}$ of cement mixture is $88.7 \mathrm{~g}$ (28.4\% total dissolved solids), of which $63.5 \mathrm{~g}$ are free water and $25.2 \mathrm{~g}$ are salt. The hydration process results in the transfer of $15.8 \mathrm{~g}$ of the free water into the solid matrix leaving $47.7 \mathrm{~g}$ of free water in the pore fluid. The loss of free water results in an increase in the salt concentration in the pore fluid to $34.6 \%(25.2 \mathrm{~g} / 72.9 \mathrm{~g})$ total dissolved solids. The final distribution of water is as follows: $47.7 \mathrm{~g}$ of free water in the pore fluids and $20.5 \mathrm{~g}$ of hydration water in the solid matrix ( $4.7 \mathrm{~g}$ initially in the cement mixture plus $15.8 \mathrm{~g}$ from the salt feed solution).

The density of the pore fluid is estimated to be $1.26 \mathrm{~g} / \mathrm{mL}$ (34\% sodium nitrate, CRC Press (1987). Using this density the total volume of pore fluid per $100 \mathrm{~g}$ of cement mixture (115.8 $\mathrm{g}$ hydrated cement) is calculated to be $57.8 \mathrm{~mL}(72.9 \mathrm{~g} / 1.26 \mathrm{~g} / \mathrm{mL})$. The concentration of water in the pore fluid is $0.825 \mathrm{~g} / \mathrm{mL}(47.7 \mathrm{~g} / 57.8 \mathrm{~mL})$. The concentration of water in the hydrated cement is $0.177 \mathrm{~g} / \mathrm{g}(20.5 \mathrm{~g} / 115.8 \mathrm{~g})$. A distribution coefficient $\left(\mathrm{K}_{\mathrm{d}}\right)$ of $0.2 \mathrm{~mL} / \mathrm{g}[(0.177 \mathrm{~g} / \mathrm{g}) /(0.825 \mathrm{~g} / \mathrm{mL})]$ was estimated for tritium based on the hydration calculations and the assumptions that tritium occurs as tritiated water and that the isotope fractionation effects (i.e., exchange of ${ }^{1} \mathrm{H}$ for ${ }^{3} \mathrm{H}$ ) are small.

Rev. 0 
Table D3-1. Composition of starting material for saltstone formation in weight percent

\begin{tabular}{|c|c|c|c|c|c|c|}
\hline & $\begin{array}{l}\text { Hydration } \\
\text { factor }\end{array}$ & $\begin{array}{c}\text { Formulab } \\
\text { weight }\end{array}$ & Slag & $\begin{array}{l}\text { Fly } \\
\text { ash }\end{array}$ & $\begin{array}{c}\text { Portland } \\
\text { Cement }\end{array}$ & $\begin{array}{l}\text { Salt Feed } \\
\text { Solution } \\
\end{array}$ \\
\hline $\mathrm{SiO}_{2}$ & 0 & 60.09 & 34.70 & 52.17 & 21.10 & \\
\hline $\mathrm{A}_{12} \mathrm{O}_{3}$ & 3 & 101.96 & 10.70 & 27.60 & 4.66 & \\
\hline $\mathrm{TiO}_{2}$ & 0 & 79.90 & 0.51 & 1.98 & 0.23 & \\
\hline $\mathrm{Fe}_{2} \mathrm{O}_{3}$ & 3 & 159.69 & 0.41 & 4.36 & 4.23 & \\
\hline $\mathrm{MgO}$ & 1 & 40.30 & 11.90 & 0.61 & 1.21 & \\
\hline $\mathrm{CaO}$ & 1 & 56.08 & 39.37 & 0.96 & 64.55 & \\
\hline $\mathrm{MnO}$ & 1 & 70.94 & 0.54 & 0.01 & 0.16 & \\
\hline $\mathrm{BaO}$ & 1 & 153.34 & 0.05 & 0.10 & 0.02 & \\
\hline $\mathrm{Na}_{2} \mathrm{O}$ & & 61.98 & 0.25 & 0.26 & 0.11 & \\
\hline $\mathrm{K}_{2} \mathrm{O}$ & & 94.20 & 0.55 & 1.53 & 0.34 & \\
\hline $\mathrm{SO}_{3}$ & -1 & 80.06 & & 0.33 & 250 & \\
\hline $\mathbf{S}$ & & 32.06 & 1.34 & & & \\
\hline $\mathrm{LOI}\left(\mathrm{H}_{2} \mathrm{O}\right)$ & -1 & 18.02 & & 9.92 & 0.86 & 71.60 \\
\hline Salt & & & & & & 28.40 \\
\hline Total & & & 100.32 & 99.83 & 99.97 & 100.00 \\
\hline
\end{tabular}

- Composition of solids for Malek et al. (1985). Composition of salt feed solution for Heckrotte (1988). Hydration factor and formula weights were used to calculate hydration as described in text.

- g/mol. 
Table D3-2 Summary of saltstone hydration calculations for a mixture of $47 \%$ salt feed and $53 \%$ cement mix. Composed of $47.17 \%$ cach of alag and thy ash and $5.66 \%$ of Portland cement. Normalized to $100 \mathrm{~g}$ of cement mix

\begin{tabular}{|c|c|c|c|c|}
\hline & $\begin{array}{l}\text { Salt feed } \\
\text { solution }\end{array}$ & $\begin{array}{c}\text { Cement } \\
\text { mix }\end{array}$ & $\begin{array}{c}\text { Hydrated } \\
\text { cement }\end{array}$ & $\begin{array}{l}\text { Pore } \\
\text { fluid }\end{array}$ \\
\hline $\mathrm{SiO}_{2}$ & & 42.14 & 42.14 & \\
\hline $\mathrm{Al}_{2} \mathrm{O}_{3}$ & & 18.32 & 28.03 & \\
\hline $\mathrm{TiO}_{2}$ & & 1.19 & 1.19 & \\
\hline $\mathrm{Fe}_{2} \mathrm{O}_{3}$ & & 2.49 & 3.33 & \\
\hline $\mathrm{MgO}$ & & 5.97 & 8.63 & \\
\hline $\mathrm{CaO}$ & & 22.66 & 29.94 & \\
\hline $\mathrm{MnO}$ & & 0.27 & 0.34 & \\
\hline $\mathrm{BaO}$ & & 0.07 & 0.08 & \\
\hline $\mathrm{Na}_{2} \mathrm{O}$ & & 0.25 & 0.25 & \\
\hline $\mathbf{K}_{2} \mathbf{O}$ & & 1.00 & 1.00 & \\
\hline $\mathrm{SO}_{3}$ & & 0.30 & 0.23 & \\
\hline $\mathbf{S}$ & & 0.63 & 0.63 & \\
\hline $\mathrm{LOI}\left(\mathrm{H}_{2} \mathrm{O}\right)$ & 63.49 & 4.72 & & 47.71 \\
\hline Salt & 25.18 & & & 25.18 \\
\hline \multirow[t]{2}{*}{ Total } & 88.68 & 100.00 & 115.79 & 72.89 \\
\hline & $47 \%$ & $53 \%$ & $61.4 \%$ & $38.6 \%$ \\
\hline
\end{tabular}

- Compositions are from Table D-1. 
Given that the initial tritium loading of the saltstone is $7,000 \mathrm{pCi} / \mathrm{g}$, the concentration of ${ }^{3} \mathrm{H}$ in the solid matrix and the pore fluid can be calculated. A total of $1,320,000 \mathrm{pCi}$ of ${ }^{3} \mathrm{H}$ occur in $188.7 \mathrm{~g}$ of saltstone (115.8 $\mathrm{g}$ hydrated cement $+72.9 \mathrm{~g}$ pore fluid). The partitioning of ${ }^{3} \mathrm{H}$ is given by:

$$
\begin{aligned}
& \text { Total }=M_{1} \times C_{2}+V_{1} \times C_{1}, \\
& C_{2}=C_{1} \times K_{d,} \\
& \text { Total }=C_{1}\left(K_{d} \times M_{1}+V_{1}\right) \\
& C_{1}=\text { Total } /\left(K_{d} \times M_{1}+V_{1}\right), \\
& C_{1}=16,000 \mathrm{pCi} / \mathrm{mL}^{2}=16,000,000 \mathrm{pCi} / \mathrm{L} \text {, and } \\
& C_{1}=3,300 \mathrm{pCi} / \mathrm{g} .
\end{aligned}
$$

where

Total is the total ${ }^{3} \mathrm{H}(1,320,000 \mathrm{pCi})$,

$\mathrm{M}_{\text {, is }}$ that mass of the hydrated cement $(115.8 \mathrm{~g})$,

$\mathrm{C}_{\mathrm{b}}$ is the concentration of ${ }^{3} \mathrm{H}$ in the hydrated cement $(\mathrm{pCi} / \mathrm{g})$,

$V_{1}$ is the volume of pore fluid $(57.8 \mathrm{ml})$, and

$\mathrm{G}$ is the concentration of ${ }^{3} \mathrm{H}$ in the pore fluid ( $\mathrm{pCi} / \mathrm{mL}$ ).

\section{D.32 Concentration of Technetium-99 and Nitrate in Saltstone Pore Fluids}

Previous screening suggested that technetium and nitrate are the two contaminants most likely to determine the overall performance of saltstone. For this reason, geochemical calculations were conducted to estimate the pore fluid concentrations of technetium, nitrate, and nitrite. The computer code MINTEQ was used to calculate an equilibrium solution speciation and to evaluate degree of saturation with respect to concrete,minerals. Activity coefficients for aqueous species were calculated using the B-dot method documented in Helgeson (1969). Thermodynamic data for complexes of nitrate were taken from Smith and Martell (1976). Thermodynamic data for cement phases were obtained from the compilation of Crisentia and Serne (1990). Modified salt feed solution composition was calculated from the salt feed solution composition (Heckrotte 1988) and the hydration calculations described above. The modified salt feed solution composition was used as input for MINTEQ to calculate pore fluid composition. Additionally, the aqueous $\mathrm{NaAl}(\mathrm{OH})_{4}$ was allowed to react via:

$$
\mathrm{NaAl}(\mathrm{OH})_{4,}=\mathrm{Al}(\mathrm{OH})_{3, s}+\mathrm{NaOH}_{2 q}
$$

$\mathrm{Al}(\mathrm{OH})_{3}$, refers to fully hydrated $\mathrm{Al}_{2} \mathrm{O}_{3}$ in the solid matrix and not to a particular pure phase aluminum hydroxide. This adjustment to the pore fluid is based on the very low aluminum concentration in saltstone pore fluids reported by Malek et al. (1987).

Equilibrium between the pore fluid and calcite, $\mathrm{C}_{3} \mathrm{AH}_{6}, \mathrm{C}-\mathrm{S}-\mathrm{H}$ gel, and $\mathrm{C}_{3} \mathrm{FH}_{6}$ was assumed in the MINTEQ calculations. 
where

$$
\begin{aligned}
& \mathrm{C}=\mathrm{CaO}, \\
& \mathrm{A}=\mathrm{Al}_{2} \mathrm{O}_{3}, \\
& \mathrm{H}=\mathrm{H}_{2} \mathrm{O}, \\
& \mathrm{S}=\mathrm{SiO}_{2} \text { and } \\
& \mathrm{F}=\mathrm{Fe}_{2} \mathrm{O}_{3} \text { (standard cement nomenclature). }
\end{aligned}
$$

The solid phases chosen for these calculations were identified by $x$-ray diffraction in the slag containing cement mixes (Malek et al. 1987). The pH value was determined from the hydroxide concentration and charge balance.

Calculations showed the pore fluid to be undersaturated with any aluminum sulfate phase and with portlandite, and significantly undersaturated with aluminum and calcium nitrates. Furthermore, hydration calculations similar to those described above conducted for the 84-48 saltstone mix of Malek et al. (1987) indicate that, within experimental uncertainties, all nitrate and nitrite in saltstone occurs within the pore fluids. These calculations differ from the $x$-ray diffraction analysis of Malek et al. (1987) who found solid hydrated aluminum and calcium nitrates. A possible explanation for the difference between the calculated results and the observations of Malek et al. (1987) may be in their preparation of saltstone samples for $x$-ray diffraction. If the saltstone samples were dried before analysis, the precipitation of soluble nitrate salts in the saltstone would be expected.

The aluminum concentration of the pore fluid was buffered at extremely low concentrations by equilibrium with the solid phases. As a result, the pore fluids are essentially $\mathrm{NaOH}-\mathrm{NaNO}_{3}-\mathrm{NaNO}_{2}$ mixtures with a very high $\mathrm{pH}$ of 13.8 to 14.0 (see reaction 1). The resulting composition for the pore fluid is presented in Table D.3-3. Additionally, a $\mathrm{NO}_{3}^{-}$concentration is reported based on the stoichiometric oxidation of $\mathrm{NO}_{2}^{-}$to $\mathrm{NO}_{3}$ :

Under oxidizing conditions, aqueous technetium occurs in the heptavalent oxidation state as the pertechnetate ion $\left(\mathrm{TcO}_{4}\right)^{\circ}$. Many heptavalent technetium solids have high solubilities leading to potentially elevated aqueous concentrations. In addition, as a monovalent anion, $\mathrm{TcO}_{4}$ is only weakly sorbed by cementitious solids. The combination of high solubility and low sorption can result in the release of significant amounts of technetium from cementitious waste forms. To decrease release, a reducing agent, blast furnace slag, was added to the saltstone formulation to immobilize $\mathrm{TcO}_{4}^{*}$ as a precipitated solid. Thermodynamic calculations using the MINTEQ code indicate that in slag cement, technetium is immobilized as a Tc (VII) sulfide. During the hydration of blast furnace slag-cement, elemental sulfur in the slag (Angus and Glasser 1985) reacts to form reduced aqueous sulfur species such as sulfide. The aqueous sulfide reacts with $\mathrm{TcO}^{-}$to form $\mathrm{Tc}_{2} \mathrm{~S}_{7()^{\circ}}$. The over all reaction is given by

$$
6 \mathrm{TcO}_{4}^{-}+28 \mathrm{~S}_{3}+8 \mathrm{OH}^{-}=3 \mathrm{Tc}_{2} \mathrm{~S}_{7,}+7 \mathrm{SO}_{4}^{2-}+4 \mathrm{H}_{2} \mathrm{O}
$$

Rev. 0 
Table D3-3. Calculated saltstone pore fluid composition using MINTEQ, the results of the hydration calculations and equilibrium with calcite, $\mathrm{C}_{3} \mathrm{AH}_{6}, \mathrm{CS}-\mathrm{H}$ gel, and $\mathrm{C}_{3} \mathrm{FH}_{6}$ "Tc is calculated by asuming equilibrium with $T_{2} S_{1}$, as described in the teat

\begin{tabular}{|c|c|c|c|}
\hline Species & $\mathrm{mg} / \mathrm{L}$ & HS (mg/L) & ${ }^{99} \mathrm{Tc}(\mathrm{pCi} / \mathrm{L})$ \\
\hline $\mathrm{Na}^{+}$ & 139,000 & & \\
\hline $\mathrm{CO}_{3}^{2-}$ & 12,800 & & \\
\hline $\mathrm{SO}_{4}^{2-}$ & 15,000 & & \\
\hline $\mathrm{NO}_{2}^{-}$ & 36,800 & & \\
\hline $\mathrm{NO}_{3}^{-}$ & 159,000 & & \\
\hline $\mathrm{OH}^{-}$ & 32,900 & & \\
\hline $\mathrm{Ca}^{2+}$ & 1 & & \\
\hline $\mathrm{SiO}_{2 \times 9}$ & 1 & & \\
\hline $\mathrm{Al}^{3+}$ & 11 & & \\
\hline $\mathbf{K}^{+}$ & 9,800 & & \\
\hline $\mathrm{NH}^{4+}$ & 400 & & \\
\hline pH & 13.97 & & \\
\hline Total $\mathrm{N}$ as $\mathrm{NO}_{3}{ }^{-}$ & 209,000 & & \\
\hline Density' & 1.26 & & \\
\hline High sulfide & & 10 & $2.4 \times 10^{-8}$ \\
\hline Stoichiometric & & 0.003 & 46,300 \\
\hline
\end{tabular}

Rev. 0 
The $\mathrm{Tc}_{2} \mathrm{~S}_{7}$, phase is very insoluble, limiting the $\mathrm{TcO}_{4}^{-}$concentration in pore fluids to very low concentrations. To calculate the concentration of $\mathrm{TcO}_{4}^{-}$in the pore fluid, the concentration of HS' is needed. Angus and Glasser (1985) report aqueous sulfide concentration for slag cement ore fluids of up to $1100 \mathrm{mg} / \mathrm{L}$ for a mixture containing 97.5\% slag. For a mixture containing $50 \%$ slag (similar to the saltstone mix) $12 \mathrm{mg} / \mathrm{L}$ sulfide was reported (Angus and Glasser 1985). This value was used in conjunction with the pore fluid to calculate concentrations of technetium. Additionally, a technetium concentration was calculated by assuming that technetium and sulfide occurred in solution in stoichiometric proportions (i.e., 2:7). The second concentration of technetium is higher, and the total sulfide concentration is much lower. The resulting concentrations of sulfide and technetium are presented in Table D.3-3.

Using the higher $\mathrm{TcO}_{4}$ concentration from Table $\mathrm{D} .3-3, \mathrm{~K}_{\mathrm{d}}$ values for technetium can be calculated. The total loading of ${ }^{2 \%} \mathrm{Tc}$ in saltstone is $25,000 \mathrm{pCi} / \mathrm{g}$. From the hydration calculations the volume of pore fluid per gram of saltstone is $0.306 \mathrm{~mL}$ $(57.8 \mathrm{~mL} / 188.7 \mathrm{~g})$. A total of $14 \mathrm{pCi}(46,000 \mathrm{pCi} / \mathrm{L} \times 0.000306 \mathrm{~L})$ of technetium occurs in the $0.306 \mathrm{~mL}$ of pore fluid. The remaining $24,986 \mathrm{pCi}$ occurs in the $0.614 \mathrm{~g}$ of the solid matrix, with a concentration of $40,700 \mathrm{pCi} / \mathrm{g}$. Although the technetium concentration is limited by the solubility of $\mathrm{Tc}_{2} \mathrm{~S}_{7,}$, the solid and aqueous concentration can be used to estimate a $\mathrm{K}_{d}$ of $880 \mathrm{~mL} / \mathrm{g}[(40,700 \mathrm{pCi} / \mathrm{g}) /(46.3 \mathrm{pCi} / \mathrm{mL})]$ for ${ }^{90} \mathrm{Tc}$ in saltstone.

Technetium concentrations are insensitive to the variations in the total salt concentration or to the selection of solid cement phases used in the equilibrium calculations. The sensitivity of technetium concentration to $\mathrm{pH}$ and sulfide concentration can be evaluated by examining the stoichiometry of the dissolution reaction

$$
\begin{gathered}
\mathrm{Tc}_{2} \mathrm{~S}_{1_{1}}+8 \mathrm{H}_{2} \mathrm{O}=2 \mathrm{TcO}_{4}^{-}+7 \mathrm{HS}^{-}+9 \mathrm{H}^{+} \\
\log \left[\mathrm{TcO}_{4}\right]=0.5 \log \mathrm{Q}-3.5 \log \left[\mathrm{HS}^{-}\right]+4.5 \mathrm{pH}
\end{gathered}
$$

where $\log \mathbf{Q}$ is a conditional equilibrium quotient (constant at constant ionic strength) and brackets denote molal concentration. Examination of the coefficients in equation (4) indicates that the concentration of $\mathrm{TcO}_{4}^{-}$decreases by a factor of 3,200 for each 10 fold increase in HS concentration. An increase of $\mathrm{pH}$ by 1 unit results in an increase in $\mathrm{TcO}_{4}$ concentration by a factor of 32,000 .

For the case in which technetium and sulfur are related by stoichiometry, $\log \left[\mathrm{TcO}_{4}\right]$ is directly proportional to $\mathrm{pH}$. Because the aqueous concentration of $\mathrm{TcO}_{4}$ is proportional to $\mathrm{pH}$, the value of $\mathrm{K}_{\mathrm{d}}$ for ${ }^{99} \mathrm{Tc}$ in saltstone calculated above will also be dependent on $\mathrm{pH}$. The dependency is calculated using this proportional relationship and the $\mathrm{K}_{\mathrm{d}}$ of 880 in $\mathrm{mL} / \mathrm{g}$ and is given by:

$$
\log \mathrm{Kd}=16.94 \cdot \mathrm{pH}
$$


Hence, the $\mathrm{K}_{\mathrm{d}}$ of $880 \mathrm{~mL} / \mathrm{g}$ is conservative because the pore fluid $\mathrm{pH}$ will decrease over time as $\mathrm{NaOH}$ is leached from the saltstone. In response to decreasing $\mathrm{pH}$ the $\mathrm{K}_{\mathrm{d}}$ will become larger.

The results of these calculations for technetium indicate that the concentration of technetium in the pore fluid, and hence the release, is very sensitive to the presence of aqueous sulfide. Because no direct measurements of sulfide are available for saltstone pore fluids, these calculations are subject to a great amount of uncertainty. In addition, the thermodynamic solubility data for $T c_{2} S_{7}$, are highly uncertain. If credit is to be taken for formation of technetium sulfide, measurements should be made of sulfur speciation in saltstone pore fluids; if possible, the solubility of $\mathrm{Te}_{2} \mathrm{~S}_{7,}$ should be measured in strongly alkaline solutions. However, the tentative results presented bere indicate that even in the more conservative case, greater than $99.9 \%$ of the technetium in the saltstone waste form is initially present in the solid matrix.

\section{D.4 FLUID COMPOSIIONS IN SEDIMENTS OUTSIDE THE VAULT}

The behavior of the saltstone fluid composition outside the vault was evaluated using the MINTEQ geochemical code. Pore fluid compositions were reacted with the unsaturated sediments surrounding the saltstone vaults. This model considers only equilibrium geochemical reactions, not transport and flow of the saltstone fluids.

\section{D.4.1 Modeling Steps}

Geochemical modeling was carried out by simulating the reactions between the pore fluid calculated above and the unsaturated sediments surrounding the saltstone vaults. All modeling was done at a temperature of $25^{\circ} \mathrm{C}$; pertinent details of the modeling conditions follow.

1) Solution is reacted with $\mathrm{CO}_{2}$ gas at atmospheric pressure (10.35 atm.). This is the only gas likely to be present in this environment, because of the reducing environment created in sediments by organic activity.

2) React solution with a sediment representative of that found in the Savannah River Z-Area. Individual sediment components used were quartz, kaolinite, gibbsite, and an iron oxide phase.

3) Fine-tune results by eliminating saturated phases which are geologically unreasonable. This last step should not bias the results if a competent geologist or mineralogist evaluates the phases with respect to the probability of formation at surface conditions. 
Results from the final solutions using the steps outlined above are shown below..

\section{D.42 Interactions with the Sediment}

The composition of the pore fluid in equilibrium with the grout phases, as described in Sect. D.j, was reacted with mineral phases in the unsaturated zone. Reaction of the evolved pore solution (Table D.3-3) with $\mathrm{CO}_{2}$ in the unsaturated zone reduces the $\mathrm{pH}$ from 13.78 to 7.32

The pore fluid changed very little after reacting with the soil minerals. A small amount of diaspore was precipitated, reducing the aluminum concentration in the interstitial fluid. Presence of an iron oxide or iron hydroxide phase has very little effect on the precipitated phases or intensive parameters (i.e., $\mathrm{pH}, \mathrm{Eh}$ ). Further, the specific composition of the iron phase did not substantially change the composition of the reacted solution or the composition or quantity of the precipitated minerals. A small amount of the iron phase dissolved, adding iron to the reacted solution. This is present almost totally as ferric iron. The amount of dissolved iron varies according to what iron phase is chosen.

The composition of the pore solution after reacting with unsaturated zone minerals and $\mathrm{CO}_{2}$ is presented in Table D.41, along with the amount of the precipitated phase. Speciation of the pore solution is presented in Table D.4-2.

In summary, reaction with iron minerals increased the concentration of iron in solution from nearly zero to $3 \mathrm{ppb}$. The concentration of the three primary pollutants, 99 Tc, tritium, and nitrate do not substantially change in the interstitial fluid during communication with the unsaturated zone minerals. The precipitation of diaspore $\left(\mathrm{AlO}{ }^{*} \mathrm{OH}\right)$, would attenuate tritium to a small degree, but the amount is insignificant. The concentration of all three pollutants will decrease in the interstitial fluid due to the dilution by naturally occurring water present in the vadose zone. 
Table D.41. Composition of interstitual fluid after reaction with unsaturated zone minerak, and type and amount of precipitated solids

\begin{tabular}{|c|c|c|c|}
\hline Species & $\mathrm{mg} / \mathrm{L}$ & $\mathrm{HS}^{\circ}(\mathrm{mg} / \mathrm{L})$ & $\begin{array}{c}\text { 99Tc } \\
(\mathrm{pCi} / \mathrm{L})\end{array}$ \\
\hline $\mathrm{Na}^{+}$ & 139,000 & & \\
\hline $\mathrm{CO}_{3}^{2-}$ & 12,800 & & \\
\hline $\mathrm{SO}_{4}^{2 .}$ & 15,000 & & \\
\hline $\mathrm{NO}_{2}^{-}$ & 36,800 & & \\
\hline $\mathrm{NO}_{3}$ & 159,000 & & \\
\hline $\mathrm{OH}^{-}$ & 32,900 & & \\
\hline $\mathrm{Ca}^{2+}$ & 1 & & \\
\hline $\mathrm{SiO}_{249}$ & 1 & & \\
\hline $\mathbf{A l}^{3+}$ & $4.4 \times 10 \mathrm{E}-04$ & & \\
\hline $\mathbf{K}^{+}$ & 9,800 & & \\
\hline $\mathrm{NH}^{4+}$ & 400 & & \\
\hline pH & 7.32 & & \\
\hline Total $\mathbf{N}$ as $\mathrm{NO}_{3}{ }^{-}$ & 209,000 & & \\
\hline Density & 1.26 & & \\
\hline High sulfide & & 10 & $2.4 \times 10^{-8}$ \\
\hline & & 0.003 & 46,300 \\
\hline \multicolumn{4}{|l|}{ Stoichiometric } \\
\hline Precipitate & $\begin{array}{c}\text { Concentration } \\
(m g / L)\end{array}$ & & \\
\hline Diaspore & 25 & & \\
\hline
\end{tabular}

Rev. 0 
Table D.4-2 Percentage distribution of components in reacted interstitial fluid

\begin{tabular}{|c|c|c|c|c|c|}
\hline Component & Percentage & Species & Component & Percentage & Species \\
\hline $\mathbf{N a}$ & $\begin{array}{r}89.5 \\
7.8 \\
2.6\end{array}$ & $\begin{array}{l}\mathrm{Na} \\
\mathrm{NaNO}_{3} \\
\mathrm{NaSO}_{4}\end{array}$ & $\begin{array}{l}S \\
\text { Al }\end{array}$ & $\begin{array}{l}100 \\
100\end{array}$ & $\begin{array}{l}\mathbf{S} \\
\mathrm{Al}(\mathrm{OH})_{4}\end{array}$ \\
\hline $\mathbf{K}$ & $\begin{array}{r}98.1 \\
1.9\end{array}$ & $\begin{array}{l}\mathrm{K} \\
\mathrm{KSO}_{4}\end{array}$ & $\mathrm{NO}_{3}$ & $\begin{array}{l}83.4 \\
16.6\end{array}$ & $\begin{array}{l}\mathrm{NO}_{3} \\
\mathrm{NaNO}_{3,29}\end{array}$ \\
\hline $\mathrm{H}_{4} \mathrm{SiO}_{4}$ & $\begin{array}{r}98.3 \\
1.7\end{array}$ & $\begin{array}{l}\mathrm{H}_{4} \mathrm{SiO}_{4} \\
\mathrm{H}_{3} \mathrm{SiO}_{4}^{-}\end{array}$ & $\mathrm{CO}_{3}$ & $\begin{array}{l}60.3 \\
37.9\end{array}$ & $\begin{array}{l}\mathrm{NaHCO}_{3,29} \\
\mathrm{HCO}_{3}^{-}\end{array}$ \\
\hline $\mathrm{SO}_{4}^{2-}$ & $\begin{array}{r}32.4 \\
65.5 \\
1.9\end{array}$ & $\begin{array}{l}\mathrm{SO}_{4}^{2-} \\
\mathrm{NaSO}_{4} \\
\mathrm{KSO}_{4}\end{array}$ & $\mathrm{Ca}$ & $\begin{array}{l}97 \\
1.6\end{array}$ & $\begin{array}{l}\mathrm{CaCO}_{3,29} \\
\mathrm{CaSO}_{4,29}\end{array}$ \\
\hline $\mathrm{NH}_{4}$ & $\begin{array}{r}97.1 \\
2.7\end{array}$ & $\begin{array}{l}\mathrm{NH}_{4} \\
\mathrm{NH}_{4} \mathrm{SO}_{4}^{-}\end{array}$ & $\mathrm{Fe}^{+3}$ & $\begin{array}{r}1.4 \\
33.1 \\
65.5\end{array}$ & $\begin{array}{l}\mathrm{FeOH}_{4} \\
\mathrm{FeOH}_{2} \\
\mathrm{FeOH}_{3}\end{array}$ \\
\hline $\mathrm{NO}_{2}$ & 100 & $\mathrm{NO}_{2}$ & $\mathrm{Fe}^{+2}$ & $\begin{array}{r}97.5 \\
2.4 \\
\end{array}$ & $\begin{array}{l}\mathrm{Fe}^{+2} \\
\mathrm{FeSO}_{4,29}\end{array}$ \\
\hline
\end{tabular}

Rev. 0 


\section{APPENDIX D REFERENCES}

Angus, M. J., and F. P. Glasser. 1985. The chemical environment in cement matrices. Mat. Res. Soc. Symp. Proc., 50:547-556.

CRC Press, Inc. 1987. CRC Handbook of Chernisty and Physics. 68th Edition, R. C. Weast, M. J. Astle, W. H. Beyer, Eds. CRC Press, Inc., Boca Raton, Florida.

Crisentia, L, and R. J. Serne. 1990. Thermodynamic modeling of cement/groundwater interaction as a tool for long term performance assessment. Mat. Res. Soc. Symp. Proc. 176:81-89.

Heckrotte, R. W. 1988. Project-1780-Savarnah River Plant-200-S-area Defense Waste Processing Facility - sludge plant request to Modify the DWPF Saltstone Industrial Solid Waste Permit. memo PP-001183 (January).

Helgeson, H. C. 1969. Thermodynamics of hydrothermal systems at elevated temperatures and pressures. Am. J. Sci, 267:729-804.

Malek, R. I. A, P. H. Liscastro, and C. A Langton. 1985. Saltstone Starting Materials Characterization. E. I. du Pont de Nemours \& Co., Inc.

Malek, R. I. A, P. H. Liscastro, and D. M. Roy. 1987. Saltstone Pore Solution Analyses. Materials Research Laboratory, The Pennsylvania State University, University Park, Penn.

Murphy, W. M., and R. W. Smith. 1089. Irreversible dissolution of solids solutions: a kinetic and stoichiometric mojel. Radiochim. Acta, 44/45:395-401.

Neville, A M. 1981. Properties of Concrete. 3rd Edition, John Wiley \& Sons, New York, NY.

Smith, R. M., and A E Martell. 1976. Critical Stability Constants Volume 4: Inorganic Complexes. Plenum Press, New York, NY.

Smith, R. W., and J. C. Walton. 1992 The effects of calcite solid solution formation on the transient release of radionuclides from concrete barriers. Mat. Res. Soc. Symp. Proc. 212:547-556. 


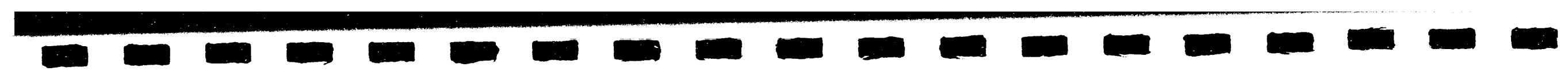

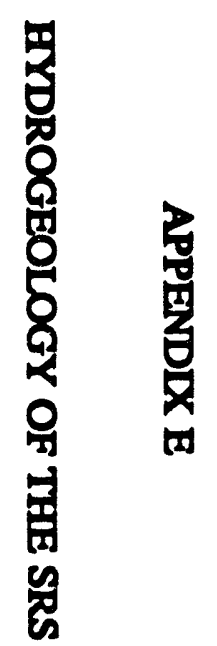




\section{E1 GEOLOGY}

The surface of the Upper Atlantic Coastal Plain on which SRS is located slopes gently seaward. The province is underlain by a seaward dipping wedge of unconsolidated and semi-consolidated sediments that extends from the Fall Line to the seaward edge of the continental shelf. Sediment thickness increases from zero at the Fall Line, where the crystalline Piedmont province gives way to the Coastal Plain, to more than $1.2 \mathrm{~km}$ near the coast of South Carolina. The SRS is underlain by about 180 to $370 \mathrm{~m}$ of Coastal Plain sediments. The Coastal Plain sediments vary in age from Late Cretaceous to Recent. The Coastal Plain sediments are divided into several groups based principally on age and lithology. These groups are described briefly below. An in-depth treatment of the stratigraphy of the SRS is given in the Replacement Tritium Facility Draft Safety Analysis Report (WSRC 1992).

\section{E1.1 Late Cretaceous Lumbee Group}

The Late Cretaceous sediments constitute the Lumbee Group, which includes, from oldest to youngest, the Cape Fear, Middendorf, Black Creek, and Peedee Formations (Fig. E.1-1). This group has also been referred to as the Tuscaloosa Formation (Intera 1986). The thickness of the Lumbee Group varies across SRS from $120 \mathrm{~m}$ in the northwest to more than $230 \mathrm{~m}$ near the southeastern boundary.

The Cape Fear Formation is composed of poorly sorted silty-to-clayey quartz sands and interbedded clays. Bedding thicknesses range from 1.5 to $6 \mathrm{~m}$, with sand beds being thicker than clay beds. The formation is about $9 \mathrm{~m}$ thick at the northwestern boundary of SRS, and it increases to more than $55 \mathrm{~m}$ near the southeastern boundary. This formation has not been observed to outcrop in the vicinity of the SRS.

The Middendorf Formation, which overlies the Cape Fear Formation, is composed mostly of medium and coarse quartz sand that is cleaner and less indurated than the underlying sediments. Clay casts and pebbly zones occur in several places in the Middendorf Formation. A clay zone up to $24 \mathrm{~m}$ thick forms the top of this formation over much of the SRS. In total, the Middendorf Formation ranges from approximately 40 to $55 \mathrm{~m}$ thick from the northwestern to south-eastern boundary of the SRS. Outcrops of this formation have been identified northwest of the SRS.

The Black Creek Formation consists of quartz sands, silts and clays. The lower section consists of fine- to coarse-grained sands, with layers of pebbles and clay casts. The upper section changes in composition as it crosses the SRS from northwest to southeast; from massive clay to silty sand with interbeds of clay. Thickness of the Black Creek Formation under the SRS ranges from $34 \mathrm{~m}$ in the northwest to $76 \mathrm{~m}$ in the southeast. Outcropping in the vicinity of the SRS has not been confirmed. 


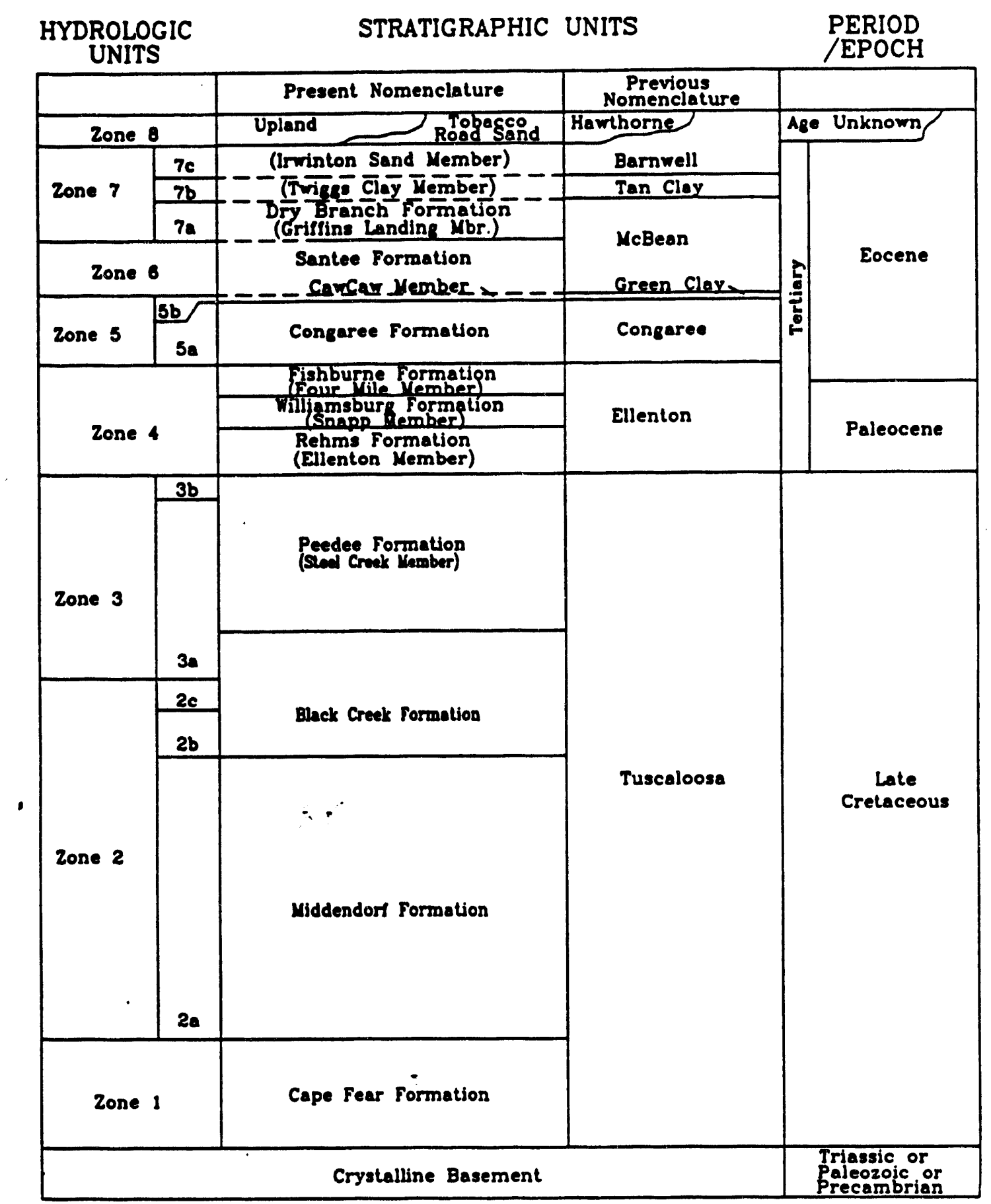

Fig. E.1-1. Hydrologic and stratigraphic units underlying the SRS.

$$
\text { Rev. } 0
$$


The uppermost formation in the Lumbee Group is the Peedee Formation, which consists of fine-grained sandstone and siltstone with marine fossils. This formation is subtitled as the Steel Creek Member in Fig. E.1-1 to distinguish this formation from the Peedee Formation in southwestern South Carolina that is comparable in age, but lithologically distinct. The lower portion of this formation consists of fine- to coarsegrained quartz sand and silty sand, with a pebble-rich zone at its base. Pebbly zones and clay casts are common throughout the lower portion of the Peedee Formation. The upper portion of this formation is a clay that varies from more than $15 \mathrm{~m}$ to less than $1 \mathrm{~m}$ in thickness at the SRS. The Peedee Formation is about $34 \mathrm{~m}$ thick at the northwestern SRS boundary, and about $\mathbf{4 0} \mathrm{m}$ thick at the southeastern boundary. No nearby outcropping has been identified.

\section{E12 Paleocene-Eocene Black Mingo Group}

The Paleocene-Early Eocene sediments make up the Black Mingo Group. This group consists of the Early Paleocene Rhems Formation, the Late Paleocene Williamsburg Formation, and the Early Eocene Fishburne Formation (Fig. E.1-1). This group is about $21 \mathrm{~m}$ thick at the northwestern SRS boundary, thickens to about $46 \mathrm{~m}$ near the southeastern boundary, and is about $210 \mathrm{~m}$ thick at the coast.

The Rhems Formation has also been called the Ellenton Formation (Intera 1986), but is now believed to be the time-equivalent to the Rhems Formation with some lithological differences in the vicinity of SRS. Thus, it is now designated as the Ellenton Member of the Rhems Formation (Fig. E.1-1). The Ellenton Member consists mostly of gray, poorly sorted, micaceous, lignitic, silty and clayey quartz sand interbedded with gray clays. It is approximately $12 \mathrm{~m}$ thick at the northwestern boundary of the SRS and thickens to about $30 \mathrm{~m}$ near the southeastern boundary. This formation outcrops about four miles northwest of the SRS.

The deposits near the SRS that are time equivalent to the Williamsburg Formation differ frum the type Williamsburg and are designated as the Snapp Member of the Williamsburg Formation. The sediments are typically silty, medium- to coarse-grained quartz sand interbedded with clay. The Snapp Member is about $9 \mathrm{~m}$ thick at the northwestern SRS boundary and thickens to about $15 \mathrm{~m}$ near the southeastern boundary. Sediments of this formation have not been identified to outcrop northwest of the SRS. Although the Fishburne Formation exists in southwestern South Carolina, only one Early Eocene fossil assemblage has been found at the SRS. The distribution of any Fishburne equivalent at the SRS is not known at this time. 


\section{E13 Middle Eocene Orangeburg Group}

The Middle Eocene sediments make up the Orangeburg Group, which consists of the lower Middle Eocene Congaree Formation and the upper Middle Eocene Santee Limestone Formation. The sediments thicken from about $30 \mathrm{~m}$ at the northwestern SRS boundary to about $49 \mathrm{~m}$ near the southeastern boundary. The dip of the upper surface of this formation is about $.002 \mathrm{~m} / \mathrm{m}$ to the southeast across the site. The Orangeburg Group is about $100 \mathrm{~m}$ thick at the coast. The group outcrops at lower elevations in many places near and on the SRS.

The Congaree Formation consists of fine to coarse quartz sands. Thin clay laminae oceur throughout with pebbly layers, clay casts, and glauconite present in places. A glauconitic clay encountered in some wells on the SRS may be at or near the base of this formation. In many places at the SRS, the upper part of the Congaree Formation is cemented with silica, while in other places it is slightly calcareous. The well-sorted sands, glauconite, and a few fossils indicate that the Congaree is a shallow marine deposit. The formation is about $18 \mathrm{~m}$ thick at the northwestern boundary of the SRS and about $26 \mathrm{~m}$ thick near the southeastern boundary.

The Santee Limestone Formation consists of carbonates, calcareous quartz sands, quartz sands, glauconitic sands, and clays. The sediments comprising this formation have been referred to in the past as the McBean and Lisbon Formations. However, more recently (WSRC 1992), these sediments are considered to be one of three members of the Santee Limestone Formation. A fine-grained sandstone occurs at the base of the Santee Limestone Formation at several locations across the SRS. This sandstone is referred to as the Warley Hill Member. Green clay, which also occurs near the base of this formation, is referred to as the Caw Caw Member of the Santee Limestone. The remainder of the Santee Limestone Formation is assigned to the McBean Member, which dominates the formation and is made up of micritic, calcarenitic, and shelly limestone, calcareous quartz sand, and noncalcareous, generally fine-grained quartz sand. Previous investigations in the vicinity of Z-Area indicate that the green clay is not a discrete clay bed, but rather a series of thin clays interlayered with sandy clays (Dennehy et al. 1989). Therefore, the green clay tends to thicken and thin, and grade laterally into the sands of the overlying McBean Member (Dennehy et al. 1989). A soil boring at Z-Area (well SDS-7, Cook 1986) suggests the heterogeneity of the green clay may be a result of deposition which is indicated by the gradational nature of the overlying and underlying setiments.

Above the green clay, the McBean Member is comprised of $13 \mathrm{~m}$ of poorly sorted multi-colored clayey sand with clay lenses. Below the green clay the SDS-7 boring describes the interlayered fine-grained gray sands and clays of the Congaree Formation. Calcareous components of the McBean Member are rare in the northwestern part of the SRS, more abundant in central portions, and increase to the southeast across the SRS where they are widespread and thick. Siple (1967) noted that voids and loosely compacted sediments were encountered during well drilling and mentioned that large 
amounts of cement grout were used to stabilize the subsurface before construction of heavy structures, suggesting that dissolution of calcareous material in the Santee Limestone has occurred at the SRS. The Formation is about $12 \mathrm{~m}$ thick at the northwestern boundary and thickens to more than $24 \mathrm{~m}$ near the southeastern boundary. All three members of the Santee Limestone Formation outcrop within the SRS boundary.

\section{E1.4 Late Eocene Barmwell Group}

The Late Eocene sediments make up the Barnwell Group, which consists of the Clinchfield, Dry Branch, and Tobacco Road Sand Formations (Fig. E.1-1). The Clinchfield Formation, the oldest of the three, is made up of quartz sand and has been identified only when the contrasting carbonates of the Dry Branch and Santee Limestone Formations are present, with the sand of the Clinchfield Formation sandwiched between them. It has been identified at several areas within the SRS, where it is up to $8 \mathrm{~m}$ thick, but it cannot be mapped with available data.

The Dry Branch Formation consists of three distinguishable members: the Griffins Landing Member, the Irwinton Sand Member and the Twiggs Clay Member. The latter member does not appear to be mappable within the SRS, but lithologically similar clay is present at various levels within this formation. This clay, referred to as "tan clay" in previous documents (Intera 1986), is up to $4 \mathrm{~m}$ thick in SRS wells, but is not continuous over long distances. Review of available geologic data for Z-Area suggest the tan clay is a heterogeneous hydrostratigraphic unit with numerous low permeability clay lenses that are intercalated with more sandy sedimentary rock (Cook 1986). The composition of the tan clay at Z-Area as described in borings completed by Cook (1986), varies from a dark brown to tan clayey sand to a red to dark brown sandy clay. There is no geologic evidence suggesting a discrete clay layer for the Twiggs Clay Member. Rather, this member is apparently a series of intercalated clay and sand layers.

The carbonate of the Griffins Landing Member is up to $14 \mathrm{~m}$ thick in the southeastern part of the SRS. This member consists mostly of calcilutite and calcarenite, calcareous quartz sand, and slightly calcareous clay. It occurs sporadically at the SRS and is not known to be present northwest of Tinker Creek and Upper Three Runs Creek within the SRS boundaries. The Griffins Landing Member has previously been considered to be part of the "McBean Formation" (Siple 1967; Intera 1986). The remainder of the Dry Branch Formation within the SRS is made up of the Irwinton Sand Member, which is composed of moderately sorted quartz sand, with interlaminated clays abundant in places. The Dry Branch formation is about $15 \mathrm{~m}$ thick at the northwestern SRS boundary, and thickens to $24 \mathrm{~m}$ near the southeastern boundary. It outcrops in many places around and within the SRS. 
The Tobacco Road Sand overlies the Dry Branch Formation. The base of this unit is marked by a coarse layer that can contain flat quartz pebbles. The rest of the formation is made up of moderately to poorly sorted quartz sands. The sediments have the characteristics of a shallow marine deposit. The upper surface of this formation is irregular due to an incision that accompanied deposition of the overlying "Upland" unit and later erosion. The thickness is variable as a result of erosive processes, but is at least $15 \mathrm{~m}$ in places. The Tobacco Road Sand of Barnwell Group (Intera 1986), is widely exposed at the SRS. The combined thickness of the Dry Branch and Tobacco Road formations at the coast is almost $120 \mathrm{~m}$.

\section{E1.5 "Upland Unit"}

The "Upland Unit" is an informal stratigraphic term applied to terrestrial deposits that occur at higher elevations in some places in the southwestern South Carolina Coastal Plain. This unit occurs at the surface at higher elevations in many places around and within the SRS, but it is not present at all higher elevations. The sediments are poorly sorted, clayey-to-silty sands, with lenses and layers of conglomerates, pebbly sands, and clays. Clay casts are abundant. The "Upland" unit is up to $21 \mathrm{~m}$ thick in parts of the SRS. Much of this unit corresponds to the Hawthorne Formation and the Tertiary alluvial gravels identified in previous documents (Intera 1986).

\section{E1.6 Quaternary Deposits}

Cooke (1936) identified seven marine terraces in the region near the SRS, although the highest three are extensively eroded and are not easily recognized. The terrace deposits are a few tens of feet thick. The origin of these deposits is not definitive. Recent alluvium occurs in the main and tributary channels of the Savannah River and other streams in the vicinity of the SRS.

\section{E2 GROUNDWATER HYDROLOGY}

Three distinct geologic and hydrologic systems underlay the SRS: Paleozoic metamorphic and igneous rocks; lithified mudstones, sandstones, and conglomerates of Triassic age; and unconsolidated Coastal Plain sediments of Late Cretaceous and Tertiary age. The geology and hydrology of these systems is described in detail in Sect. E.1. Beneath Z-Area, the Coastal Plain sediments rest directly on the Paleozoic bedrock The Triassic sediments are absent in this region.

Two kinds of fractures have been identified in the Paleozoic bedrock. The first consists of minute fractures that pervade the entire rock mass, but transmit water slowly. Rocks with this kind of fracture are "virtually inpermeable" (WSRC 1992). The second kind of fractures have larger openings, and rocks with these larger fractures are considered "hydraulically transmissive".

Rev. 0 
A hydraulic conductivity of $1.4 \times 10^{-10} \mathrm{~m} \mathrm{~s}^{-x}$ has been reported for the virtually impermeable rocks, and $3.8 \times 10^{-7} \mathrm{~m} \mathrm{~s}^{-1}$ for the transmissive rocks. Well tests indicated a fracture porosity of $0.08 \%$ in a hydraulically transmissive fracture zone. Laboratory analyses of cores indicated an average porosity of $0.13 \%$.

Inside the SRS boundaries, the Paleozoic bedrock is not utilized as a source of water. However, north of the Fall Line, within the Piedmont province, and in an area immediately to the south of it, Paleozoic rocks can serve as a source of domestic water.

Although groundwater occurs in the primary porosity of the Triassic clastic units in the central and southern portions of the SRS, the hydraulic conductivity of this sedimentary rock ranged from $4.7 \times 10^{-11}$ to $4.7 \times 10^{-14} \mathrm{~m} \mathrm{~s}^{-1}$ in field tests. The average total porosity was $8 \%$ for sandstones and $3.3 \%$ for mudstones. Average effective porosity was $7 \%$ for sandstones and $0.53 \%$ for mudstones.

Water is not pumped from the Triassic sediments due to its extremely low hydraulic conductivity, poor quality and great depth. The water quality is poor, due to a high concentration of dissolved solids, most of which is sodium chloride.

The Coastal Plain sediments constitute a multilayered hydrologic system in which low permeability beds are interlayered with beds that transmit water more readily. Groundwater flow is governed by the hydraulic properties and geometry of each unit, and the distribution of recharge and discharge areas. A scheme for designating hydrologic units has been adopted that identifies each unit according to its hydrologic characteristics, rather than according to its stratigraphic name. Eight units, designated Zone 1 through Zone 8, are identified (Fig. E1-1). For the Tertiary sediments (Zones 4 through 8), the hydrologic unit identification was based on subsurface data in the vicinity of Z-Area. The hydrologic unit scheme is applicable only in a very local sense, because hydrologic characteristics change rapidly northward toward the Fall Line. A summary of the range in measured hydraulic conductivity for each unit is given in Table E.2-1.

\section{E21 Hydrology of Coastal Plain Sediments - Zone 1}

Zone 1 is the lowermost hydrologic unit of the Coastal Plain. It corresponds to the Cape Fear Formation and consists of clay layers and semiconsolidated, clayey-silty sands. Vertical hydraulic conductivities for Zone 1 are reported to range from $1 \times 10^{\text {s }}$ to $6 \times 10^{-8} \mathrm{~m} \mathrm{~s}^{-1}$ (Table E.2-1), with a porosity of 38\%. For the saprolite overlying the bedrock beneath Zone 1, the vertical hydraulic conductivity averages $2 \times 10^{-9} \mathrm{~m} \mathrm{~s}^{-1}$, with an average porosity of $30 \%$. Water levels within Zone 1 are not monitored. 
Table E2-1 Summary of hydraulic conductivities reported for hydrologic units of the Costal Plain Sediments (borizontal uniess Otherwise stated)

\begin{tabular}{|c|c|c|c|c|}
\hline $\begin{array}{l}\text { Hydrologic } \\
\text { Units }\end{array}$ & $\begin{array}{l}\text { Sub- } \\
\text { Units }\end{array}$ & $\begin{array}{l}\text { Field-determined } \\
\text { Hydraulic Conductivity } \\
\left(\mathbf{m} \mathbf{s}^{-1}\right)\end{array}$ & $\begin{array}{l}\text { Hydraulic Conductivity } \\
\text { determined from Soil } \\
\text { Cores } \\
\left(m s^{-1}\right)\end{array}$ & $\begin{array}{c}\text { Hydraulic } \\
\text { Conductivity } \\
\text { determined from } \\
\text { Sieve Analysis } \\
\left(m \mathrm{~s}^{-1}\right)\end{array}$ \\
\hline Zone 8 & & - & $10^{-5}$ & - \\
\hline \multirow{3}{*}{ Zone 7} & $7 c$ & $2 \times 10^{-7}-10^{-4}$ the & $10^{6}$ ad & - \\
\hline & $7 \mathbf{b}$ & $\begin{array}{c}2 \times 10^{-9}-8 \times 10^{-9} e \\
\text { (vertical) }\end{array}$ & $10^{-4}$ & $\infty$ \\
\hline & $7 \mathrm{a}$ & $10^{-5}-10^{-t h a n}$ & - & - \\
\hline Zone 6 & & $6 \times 10^{-7}-2 \times 10^{-5}$ we & - & $\infty$ \\
\hline \multirow[t]{2}{*}{ Zone 5} & Sb & $\begin{array}{c}1 \times 10^{-9}-2 \times 10^{-1} 1 \\
\text { (vertical) }\end{array}$ & - & - \\
\hline & $5 \mathbf{a}$ & $10^{-7}-5 \times 10^{-4}$ bee & $-\infty$ & $3 \times 10^{-5}-2 \times 10^{-3}$ \\
\hline Zone 4 & & - & $\begin{array}{c}1 \times 10^{-10}-4 \times 10^{-9} 8 \\
\text { (vertical) }\end{array}$ & $2 \times 10^{-5}-3 \times 10^{-4}$ \\
\hline \multirow{2}{*}{ Zone 3} & 36 & $=$ & - & $\infty$ \\
\hline & $3 \mathbf{a}$ & - & - & $3 \times 10^{-4}$ \\
\hline \multirow{3}{*}{ Zone 2} & $2 c$ & \multirow{3}{*}{ - } & \multirow{3}{*}{-} & \multirow{3}{*}{$4 \times 10^{-41}$} \\
\hline & $2 b$ & & & \\
\hline & $2 a$ & & & \\
\hline Zone 1 & & - & $\begin{array}{c}2 \times 10^{-9}-6 \times 10^{-6} \\
\text { (vertical) }\end{array}$ & - \\
\hline
\end{tabular}

'Dennehy et al. 1989; Z-Area vicinity

'Christensen and Gordon 1983; regional data

Parizek and Root 1986; SRS data, near Z-Area

¿Cook 1986; Z-Area vicinity

INTERA 1986; Z-Area vicinity

'Root 1981; near H-Area

Bledsoe 1987; central and southeastern SRS

"WSRC 1992; regional data 


\section{E22 Fydrology of Costal Plain Sediments - Zone 2}

Zone 2 is comprised of three subzones: 2a, 2b, and 2c (Fig. E.1-1). Zone 2a corresponds to the Middendorf Formation, which consists predominantly of fine to coarse sands. Clay layers occur within Zone 2a. These beds appear to have some lateral continuity, but they are only impervious locally. Thus, Zone $2 \mathrm{a}$ is hydrologically connected to the overlying $Z$ Zone $2 \mathrm{~b}$. Zone $2 \mathrm{c}$ is a clay layer that is confining in some parts of the SRS, but does not form an effective seal in other places.

Groundwater levels measured in January 1988 (WSRC 1992) indicate that water levels in both zones were within one foot in 10 of the 16 wells that monitor Zones $2 \mathrm{a}$ and $2 b$ at the SRS. In the remaining wells, the difference between the water levels varied from two to five feet. These latter variations may be caused by a clay layer that occurs in the upper part of Zone $2 \mathrm{a}$. The potentiometric contours and hydraulic gradients are similar for both zones at equivalent geographic locations, suggesting that they act as a single hydrologic unit. The general pattern indicates flow toward a sink along the Savannah River. A piezometric map of the Upper Cretaceous formations prepared by the United States Geological Survey (Faye and Prowell 1982) also indicated a groundwater sink along the Savannah River. In the southern part of the SRS, the horizontal hydraulic gradient is about $4.0 \times 10^{-4}$, dipping toward the west. In the northern part of the SRS, the slope of the potentiometric surface is $1.5 \times 10^{-3}$ to the south. Near Z-Area, the gradient is $6.0 \times 10^{-4}$ to the southwest.

Hydrologic data for Zone 2 are listed in Table E.2-2. Transmissivity, hydraulic conductivity, and storage coefficients were determined from the results of pumping tests made in 1951 and 1952. The mean hydraulic conductivity for Zone 2 was estimated from Table E.2-2 to be $4 \times 10^{-4} \mathrm{~m} \mathrm{~s}^{-1}$. Using an estimated median porosity of $32 \%$ (WSRC 1992) this corresponds to a Darcy velocity of $2 \times 10^{-6} \mathrm{~m} \mathrm{~s}^{-1}$, based on an estimated 1.5 $\times 10^{-3}$ hydraulic gradient to the south in the northern SRS. Near Z-Area, the Darcy velocity, based on a hydraulic gradient of $6.0 \times 10^{-4}$, is $8 \times 10^{-7} \mathrm{~m} \mathrm{~s}^{-1}$ to the southwest.

\section{E23 Hydrology of Coastal Plain Sediments - Zone 3}

Zone 3 is comprised of two subzones, $3 a$ and $3 b$. The lower sand aquifer (Zone 3a) includes the upper part of the Black Creek Formation and most of the Peedee Formation. Zone 3b is the uppermost part of the Peedee. It is an effective aquitard in many places at the SRS, but at other places, it allows upward or downward flow of groundwater, possibly due to discontinuities or thinning of this zone.

A map of the potentiometric surface for wells screened in Zone 3a (WSRC 1992) are based on groundwater levels measured in January 1988. Data indicate that Zone 3a levels were similar to the Zone $2 \mathrm{~b}$ water levels in most of the SRS. However, they were significantly different in the part of the SRS southeast of L Lake and Pen Branch (Fig. E-2-1). In the vicinity of Z-Area, the head difference between the two zones was generally less than one $\mathrm{ft}$, and the direction of groundwater flow, is to the southwest. 
Table E2-2 Hydrologic data for the upper cretnocous formations and the paloocene blact mingo group

\begin{tabular}{|c|c|c|c|c|c|c|c|c|c|}
\hline Zone & $\begin{array}{c}\text { Date } \\
\text { Sampled }\end{array}$ & Area & $\begin{array}{c}\text { Well } \\
\text { pumped }\end{array}$ & $\begin{array}{c}\text { Well } \\
\text { observed }\end{array}$ & $\begin{array}{l}\text { Average } \\
\text { pumping rate } \\
\text { (gpm) }\end{array}$ & $\begin{array}{l}\text { Sand } \\
\text { thictoness } \\
\text { (fi) }\end{array}$ & $\begin{array}{l}\text { Transmisstvity } \\
\text { (epd/at) }\end{array}$ & $\begin{array}{c}\text { Hydraulic } \\
\text { conductivity } \\
\text { (gpd/nit) }\end{array}$ & $\begin{array}{l}\text { Storage } \\
\text { coefiicient }\end{array}$ \\
\hline $3+4$ & $09 / 20 / 51$ & $\mathbf{P}$ & 25-P & 25-P & 540 & 219 & 63,500 & 290 & - \\
\hline $3+4$ & $11 / 03 / 51$ & $\mathbf{P}$ & 30-P & 30-P & 540 & 144 & 52,000 & 361 & - \\
\hline $3+4$ & 08/10/52 & $\mathbf{R}$ & 27-R & $105-R$ & 440 & 103 & 90,000 & 874 & 0.0004 \\
\hline 3 & $12 / 31 / 51$ & $\mathbf{K}$ & $33-K$ & 33-K & 578 & 154 & 109,000 & 708 & - \\
\hline 3 & $05 / 26 / 52$ & C & S1-C & S1-C & 589 & - & & 95,000 & - \\
\hline 3 & $06 / 16 / 52$ & C & $52-C$ & $52-C$ & 567 & 136 & 140,000 & 1,029 & - \\
\hline 3 & $08 / 03 / 52$ & $\mathbf{P}$ & 25-P & 105-P & 370 & 219 & 46,000 & 210 & 0.0004 \\
\hline 3 & $11 / 28 / 51$ & $\mathbf{L}$ & 29-L & 29-L & 525 & 124 & 71,000 & 573 & - \\
\hline 3 & $04 / 23 / 51$ & $\mathbf{M}$ & $15-M$ & $15-M$ & 450 & 160 & 33,500 & 209 & - \\
\hline 2 & $04 / 28 / 52$ & $\mathbf{F}$ & 49-F & 49-F & 562 & 267 & 105,000 & 393 & - \\
\hline 2 & $11 / 16 / 51$ & $\mathbf{F}$ & 21-F & 24-F & 1,870 & 237 & 252,000 & 1,065 & 0.0007 \\
\hline 2 & $05 / 08 / 52$ & $\mathbf{H}$ & 35-H & $35-\mathrm{H}$ & 1,350 & 273 & 196,000 & 720 & - \\
\hline 2 & $01 / 03 / 52$ & $\mathbf{H}$ & 35-H & $35-\mathrm{H}$ & 560 & 273 & 198,000 & 725 & - \\
\hline 2 & $02 / 23 / 52$ & $\mathbf{H}$ & 43-H & 43-H & 560 & 277 & 204,000 & 736 & - \\
\hline 2 & $05 / 06 / 52$ & $\mathbf{H}$ & 48-H & 48-H & 600 & 260 & 198,000 & 762 & - \\
\hline 2 & $03 / 17 / 52$ & $\mathbf{H}$ & 44-H & 44-H & 570 & 239 & 375,000 & 1,569 & - \\
\hline 2 & $02 / 29 / 52$ & $\mathbf{F}$ & 37-F & $37-F$ & 589 & 213 & 178,000 & 836 & - \\
\hline 2 & $01 / 19 / 52$ & $\mathbf{M}$ & 31-M & $\begin{array}{l}4-M \\
20-M\end{array}$ & 1,500 & 181 & 147,000 & 812 & 0.0003 \\
\hline
\end{tabular}




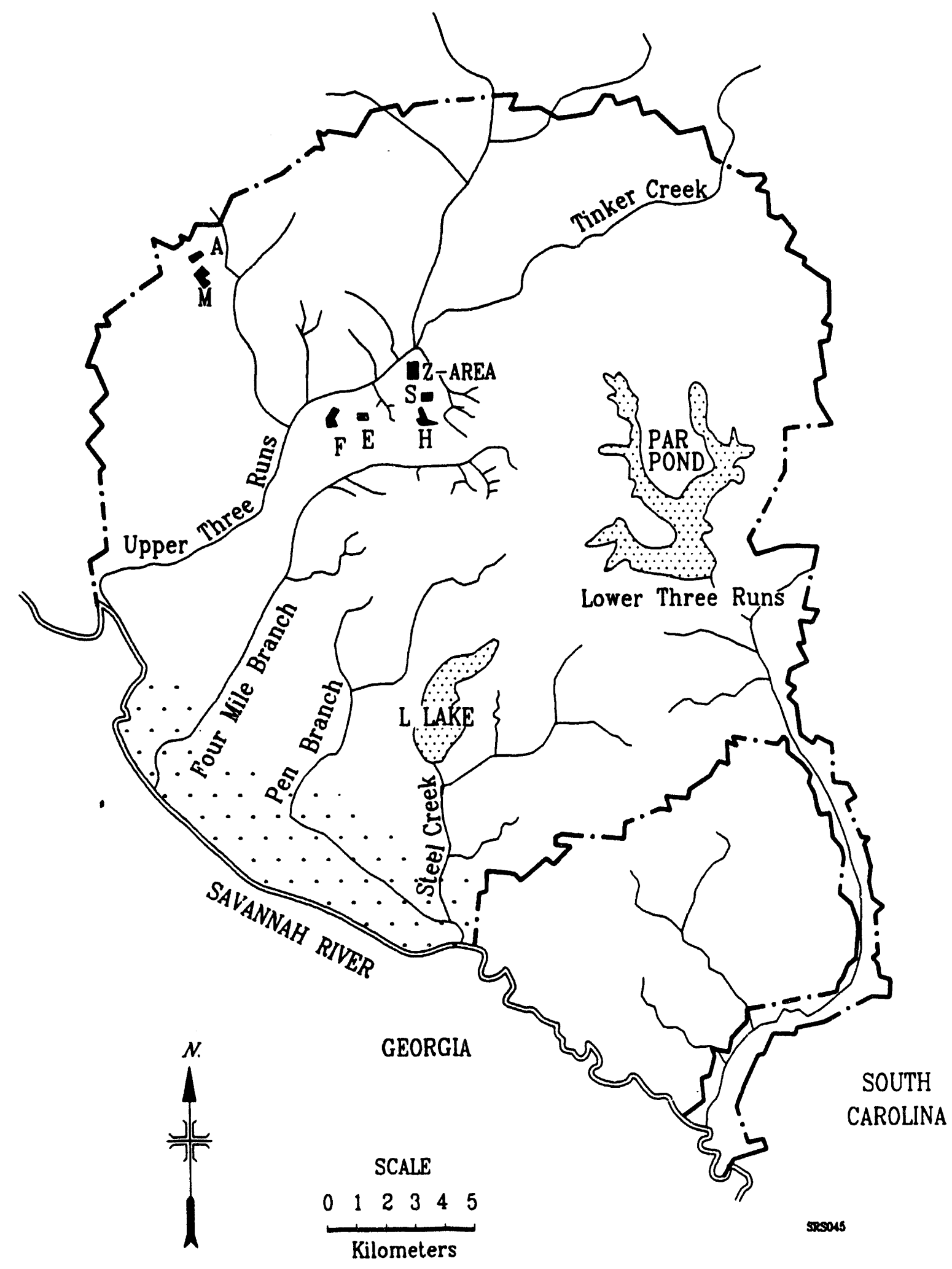

Fig. E, 2-1. Surface drainage map of the SRS. 
In the southeastern portion of the SRS, the potentiometric surface of Zone 3a was significantly lower (1.5 to $4.3 \mathrm{~m}$ lower), the dip of the Zone 3a surface was predominantly to the southwest, while the slope of Zone $2 b$ was to the west.

An average Darcy velocity for Zone 3 in the vicinity of Z-Area was determined using a calculated average hydraulic conductivity for Zone $3\left(3 \times 10^{-1} \mathrm{~m} \mathrm{~s}^{-1}\right)$ from Table E.2-2, an average hydraulic gradient of $6 \times 10^{4}$ near Z-Area, and an estimated porosity of about 0.29 (WSRC 1992). This velocity is estimated to be $5 \times 10^{-7} \mathrm{~m} \mathrm{~s}^{-1}$. Regional potentiometric surface maps for wells screened in the Upper Cretaceous formations (Zones 1, 2, and 3) indicate a flow pattern toward a sink along the Savannah River, which has breached the Cretaceous sediments and is a discharge area for the Cretaceous aquifers in the SRS region. Thus flow beneath the Savannah River into Georgia apparently does not occur in this area (WSRC 1992).

\section{E24 Hydrology of Coastal Plains Sediments - Zone 4}

Zone 4 consists of the Rhems and Williamsburg Formations of the Paleocene Black Mingo Group (Fig. E.1-1). This zone contains lignitic clay interbedded with sand layers. The sand at the base of Zone 4 may be water bearing, but is only a minor part of the unit, the rest of which is virtually impermeable material. In the vicinity of Z-Area, this zone is approximately 15 to $24 \mathrm{~m}$ thick (Dennehy et al. 1989).

Horizontal hydraulic conductivity estimates for the fine and coarse sands of this zone based on sieve analysis data range from $2 \times 10^{-5}$ to $3 \times 10^{-4} \mathrm{~m} \mathrm{~s}^{-1}$ (WSRC 1992). However, vertical hydraulic conductivity measurements of soil cores of clays in zone 4 obtained from wells at the SRS indicate values ranging from $10^{-10}$ to $4 \times 10^{-9} \mathrm{~m} \mathrm{~s}^{-1}$ (Bledsoe 1987), suggesting that clays of Zone 4 can be confining layers. How effective Zone 4 is as an aquitard over the entire SRS is not clear. Few geohydrologic data have been reported for this zone in Z-Area (Dennehy et al. 1989). Near the center of the SRS, Christensen and Gordon (1983) present water level data indicating that Zone 4 is locally confining based on the fact that water levels in the lower unit exceed those in the overlying Zone 5a. Potentiometric surfaces in the vicinity of Z-Area support that indication (WSRC 1992).

\section{E25 Hydrology of Coastal Plains Sediments - Zone 5}

Zone 5 consists of the clastic sediments of the Congaree Formation (Zone 5a) and the glauconite-bearing sands and clays of the lowermost Santee Limestone Formation (Zone $5 \mathrm{~b}$ ). Zone $5 \mathrm{a}$ is an aquifer that consists predominantly of fine-to-coarse quartz sand. Clay laminae occur throughout the formation, but they are too thin and discontinuous to be effective seals except locally. Zone 5b, often called the "green clay", is characterized by rapid facies changes, and the permeability of this layer varies greatly from place to place. Zone $5 \mathrm{a}$, in the vicinity of Z-Area, is about 15 to $21 \mathrm{~m}$ thick (Dennehy et al. 1989). The "green clay" layer, or Zone 5b, near Z-Area averages about $3 \mathrm{~m}$ in thickness.

Rev. 0 
Potentiometric surface maps of Zone 5 at the SRS are shown in Fig. E.2-2 and Fig. E2-3. Figure E2-2 is a potentiometric map from wells located to Z-Area, while Fig. E.2-3 represents a more regional map for the SRS. The dashed potentiometric lines in Fig. E2-2 indicate the uncertainty associated with the lines, because data from only five wells developed in Zone 5 were available. The natural discharge areas of Zone 5 a at the SRS are the swamps and marshes along Upper Three Runs Creek and the Savannah River. These streams dissect the upper part of Zone 5 causing unconfined conditions in the stream valleys. Four Mile Creek, to the southeast of Z-Area

(Fig. 22-1), does not incise Zone 5 (Parizek and Root 1986), and thus does not affect the head in this zone. Away from the creeks and rivers, Zone $5 a$ behaves as a confined to semiconfined aquifer. The hydraulic gradients in Zone 5 near the marshy llood plain of Upper Three Runs Creek are much steeper than they are elsewhere at the SRS, although data are not available near the Savannah River. The horizontal gradient is about $3.8 \times 10^{-3}$ to $7.6 \times 10^{-3}$ toward Upper Three Runs Creek, within one mile from the creek, where Z-Area sits (WSRC 1992).

Field determinations of hydraulic conductivities of the sandy portions of Zone 5 have been reported to range from $10^{-7}$ to $5 \times 10^{-4} \mathrm{~m} \mathrm{~s}^{-1}$ (Christensen and Gordon 1983, Parizek and Root 1986). The large range likely reflects the heterogeneous nature of the formations.

Measurements of vertical hydraulic conductivities through Zone 5b, the "green clay" layer, are not available at Z-Area. Root (1981) reported a vertical hydraulic conductivity range of $1 \times 10^{-9}$ to $2 \times 10^{-6} \mathrm{~m} \mathrm{~s}^{-1}$ at H-Area for the green clay based on pumping test results. The hydraulic head in Zone $5 \mathrm{a}$ is lower than that in both the overlying and underlying formations in the central part of the SRS (Christensen and Gordon 1983). Thus, Zqne Sa is a zone where groundwater tlow converges from above and below, as it moves laterally to a point of discharge. The vertical upward flow direction from undertying zones to Zone 5 a acts as a barrier to migration of contaminants which might originate near the land surface. At Z-Area, the head diffezence between Zones 4 and $5 \mathrm{a}$ is between 5 and $8 \mathrm{~m}$ (Intera 1986). Similarly, the head difference between Zones $5 a$ and 6 averages $25 \mathrm{~m}$ (Intera 1986). This is likely due to the relatively high conductivity of Zone Sa coupled with the limited recharge to the zone brought about by the confining "green clay" layer above.

\section{E26 Hydrology of Coastal Plain Sediments - Zone 6}

Zone 6 consists of clastic and carbonate sediments of the Santee Formation that lie above the "green clay" layer of Zone 5b. Porosity and permeability of Zone 6 strata vary greatly, depending on the dominant lithology and amount of clay present at any particular location. Nowhere on the SRS, however, do the clays form effective aquitards. The thickness of this zone in the Z-Area vicinity is about $9 \mathrm{~m}$ (Dennehy et al. 1989).

Rev. 0 


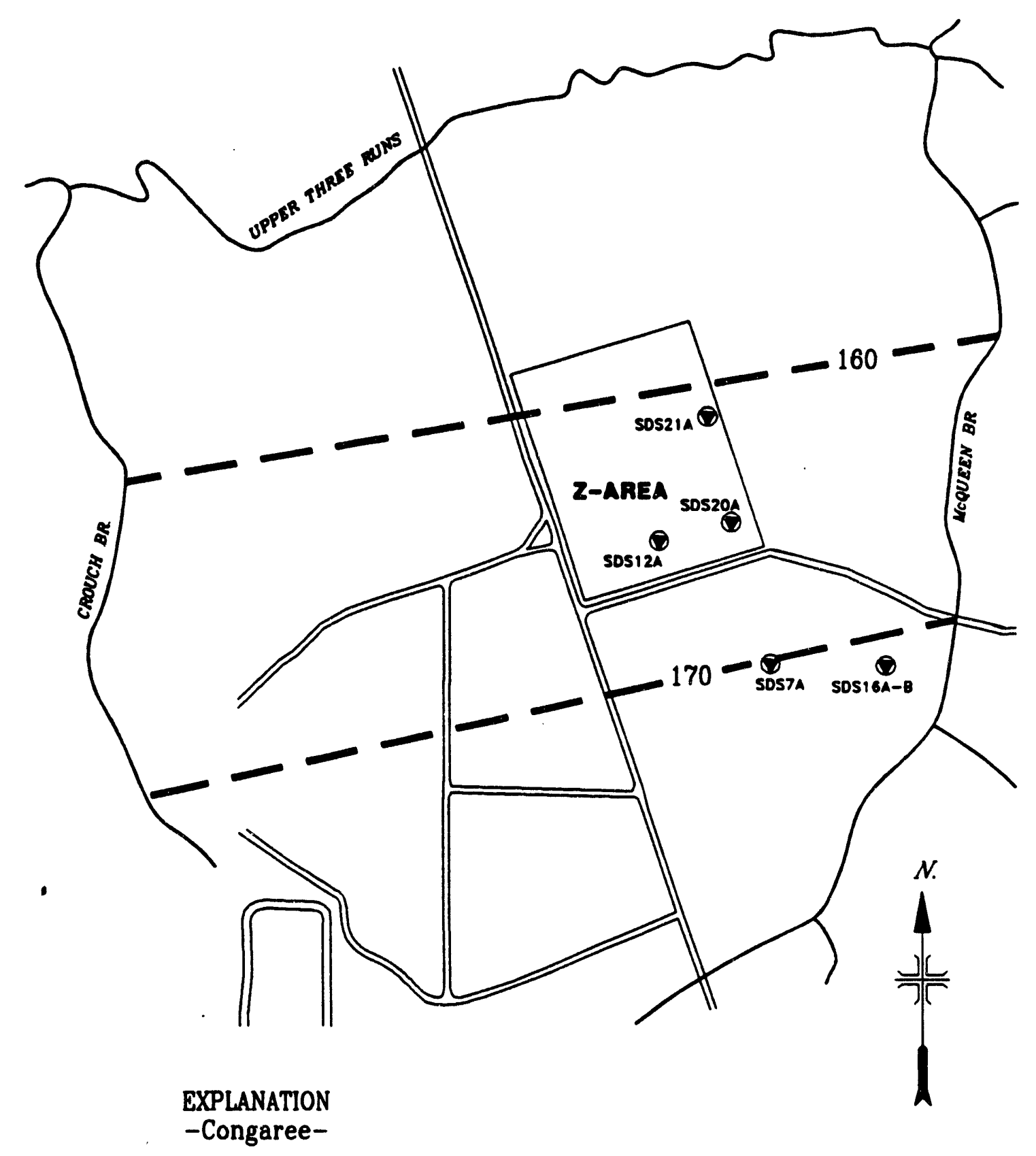

- $140-$ Potentiometric Contour shows elevation ( $\mathrm{ft}$ ) based on actual USGS data.

(1) Monitoring Well Location

Fig. E.2-2. Poteniometric surface of Zone 5a, in Z-Area vicinity.

SRS074 Rev. 0 


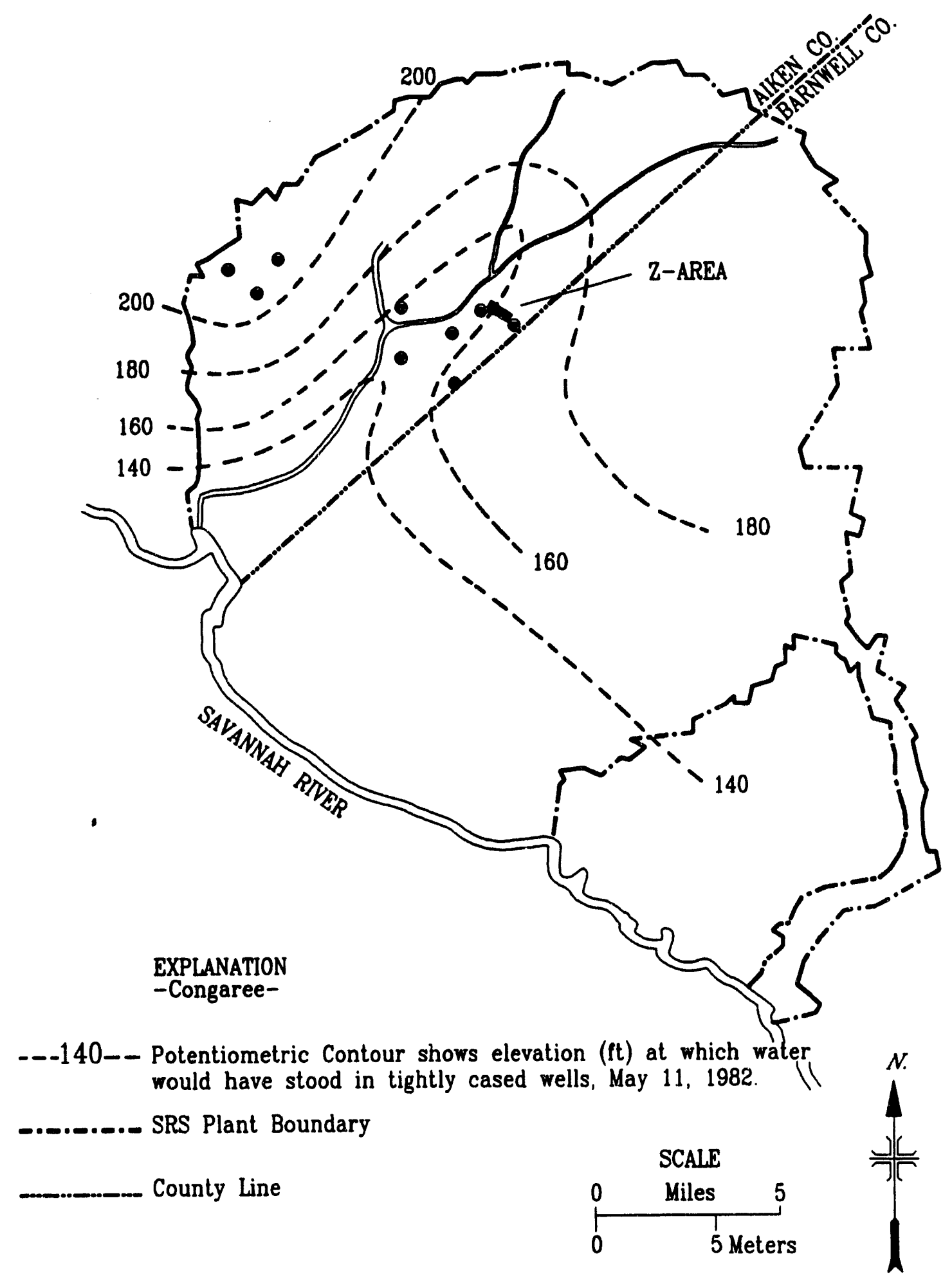

Fig. E.2-3. Regional potentiometric surface of Zone 5a (Christensen and Gordon 1983).

Rev. 0 
Zone 6 is incised by local streams in the vicinity of Z-Area. McQueens and Crouch Branches cut down into the aquifer to varying degrees. North and northwest of Z-Area, Upper Three Runs Creek cuts into this hydrologic unit. A potentiometric surface map (Fig. E.2-4) of Zone 7a, to which Fig. E.2-4 Zone 6 is hydraulically connected, indicate flow in a predominantly northern direction in Z-Area, with lateral components towards either Upper Three Runs Creek or McQueens Branch.

Zone 6 corresponds to the lower portion of the McBean aquifer of previous reports (Dennehy et al. 1989). Measured hydraulic conductivities for Zones 6 range from $6 \times$ $10^{-7}$ to $2 \times 10^{-5} \mathrm{~m} \mathrm{~s}^{-1}$ (Christensen and Gordon 1983, Parizek and Root 1986).

Zone 6 has been found to have large cavities in drilling operations in some areas of the SRS (Dennehy et al. 1989). Instances have occurred when drill pipe fell into these cavities, and drilling fluids were lost in this zone, suggesting that this zone is quite permeable. Aquifer tests done on this zone at Z-Area (Intera 1986), however, indicated a lower hydraulic conductivity than in the overlying sandy layer (Zone 7a), suggesting that either the cavities are not present at Z-Area, or are not interconnected. There is a vertical head difference between the overlying sandy layer and Zone 6 of about $0.6 \mathrm{~m}$, indicating a downward component of groundwater flow at Z-Area (Intera 1986).

\section{E27 Hydrology of Coastal Plain Sediments - Zone 7}

Zone 7 is comprised of three subzones: $7 \mathrm{a}, 7 \mathrm{~b}$, and $7 \mathrm{c}$, which correspond to two members of the Dry Branch Formation and the lower Tobacco Road Sand Formation. Zones 7a (Griffins Landing and Irwinton Sand Members) and 7c (Tobacco Road Sand Formation) are aquifers whereas Zone $7 b$ (Twiggs Clay Member) is locally an aquitard. Zone $7 \mathrm{a}$ acts as an aquifer when the amount of clay and carbonate is low. Zone $7 \mathrm{~b}$ is called the "tan clay" on the SRS. Zone 7c consists of moderately to poorly sorted quartz sand with interlaminated clays abundant in places, and supports a perched water table in areas where the piezometric surface in Zone 7a is below the tan clay (Intera 1986). Zone 7 varies from about $15 \mathrm{~m}$ thick at the northwestern SRS boundary to $24 \mathrm{~m}$ at the southeastern boundary. The "tan clay" varies from 0.6 to $3 \mathrm{~m}$ in thickness where present, although this zone is absent in the northeastern half of Z-Area (Dennehy et al. 1989). As previously discussed in Sect. E.1.3 and E.1.4, the heterogeneity of the Zone 6 and Zone 7 sediments have a measurable effect on the hydraulic head. The variability of these sediments is illustrated in Fig. E2-5 which includes the lithology from well cluster SDS-7 as described by Cook (1986) and water level data from Table 6-5 in the Intera (1986) report. The 0.6-m head differential between wells SDS-7c and SDS-7d, both developed in Zone $6 / 7 \mathrm{a}$, indicated the locally confining influence of the discontinuous clay lenses found throughout Zone 6 and 7. This suggests that even in areas where the tan clay is absent, the presence of other nondescript clay lenses may achieve the same confining ability. 


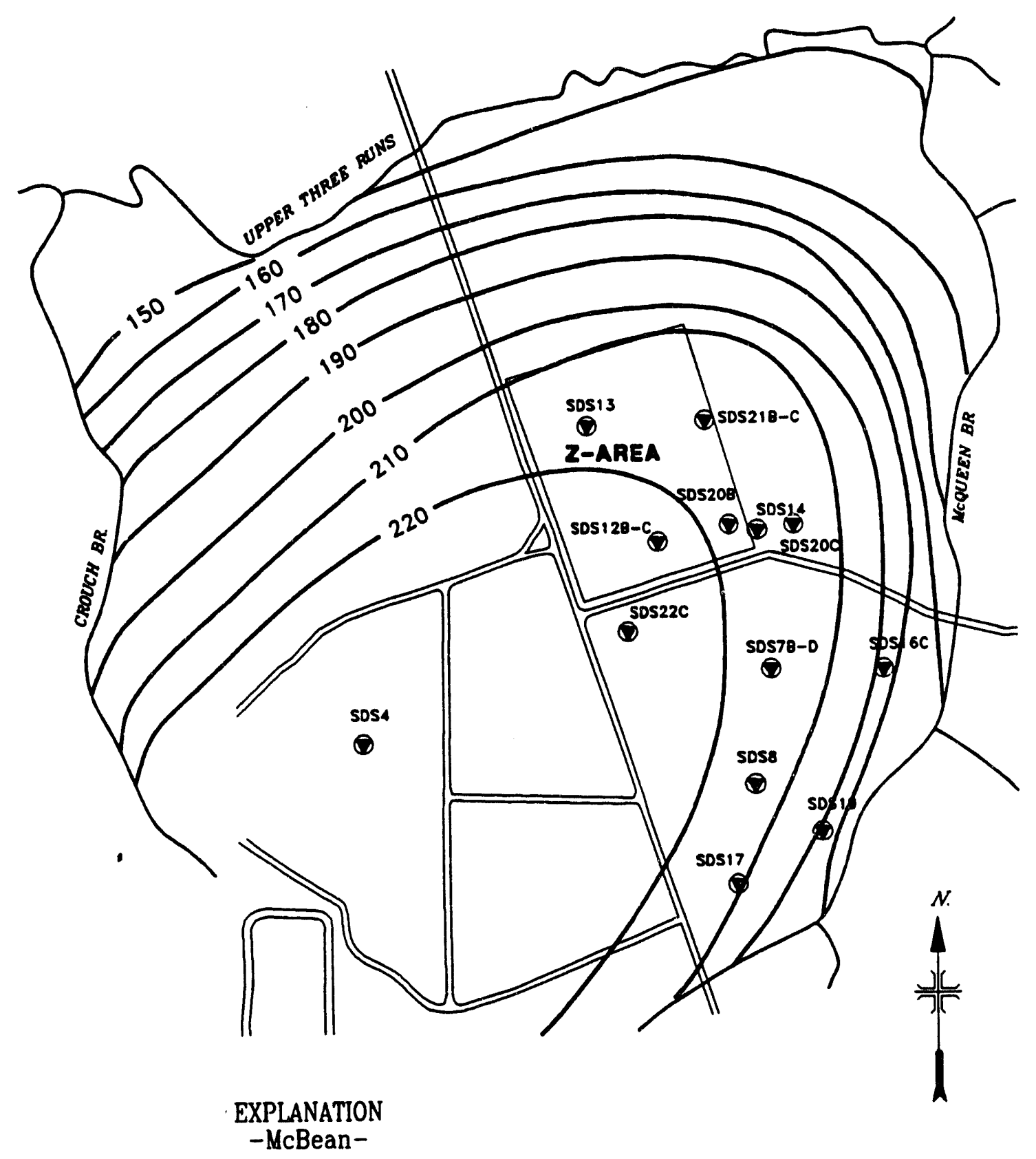

- 140 - Potentionetric Contour shows elevation (ft) based on actual 1987 head data.

(1) Monitoring Well Location

Fig. E.2-4. Potentiometric surface of Zone 7a in Z-Area vicinity.

Rev. 0 


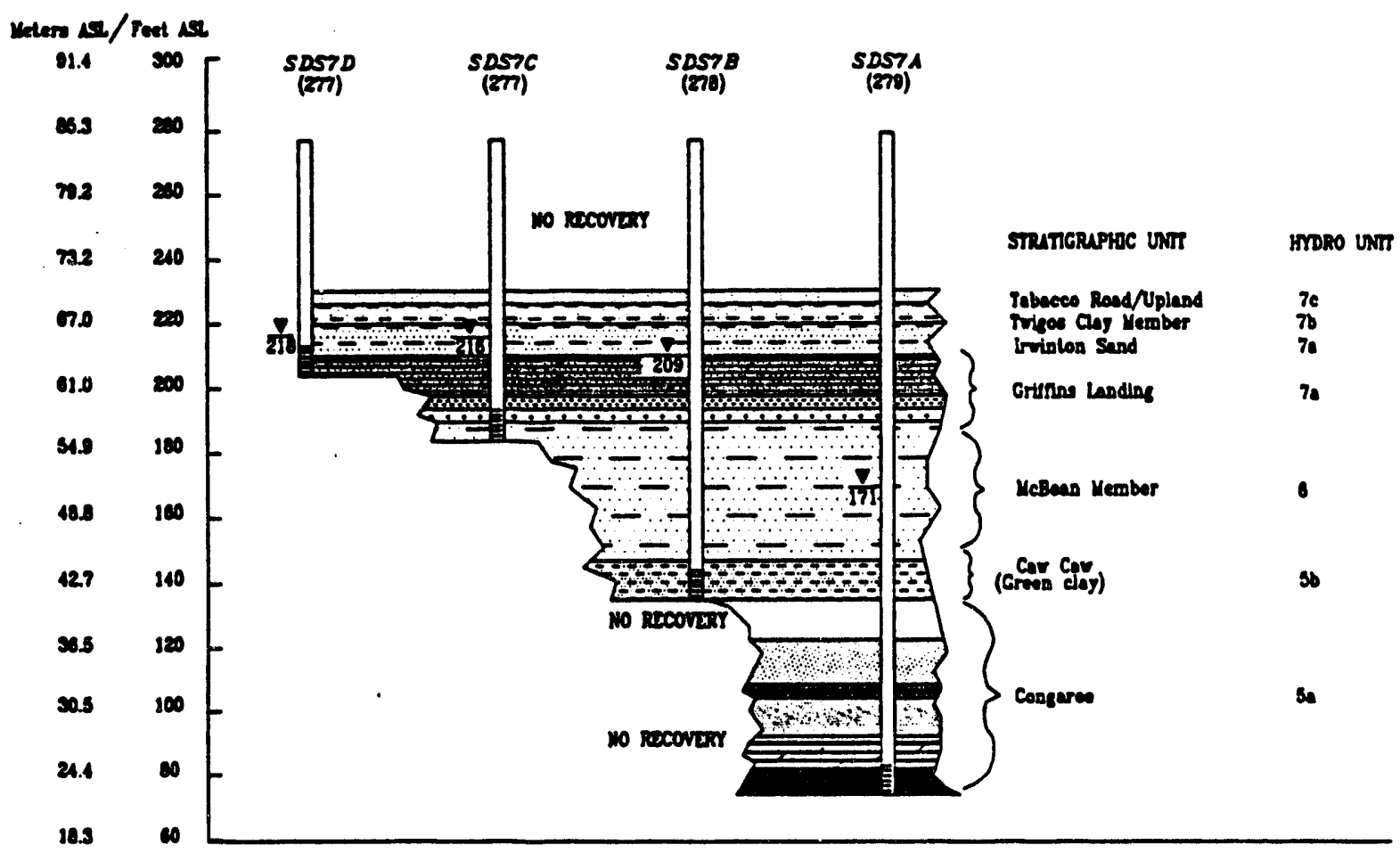

EXPLANATION

SNAD-oranse, tise to coern. trace of graved.

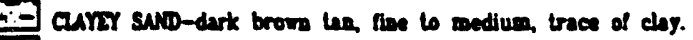

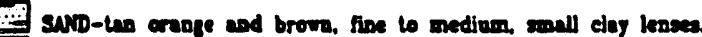
SWD-tas browe and orange, fine to course.

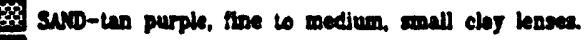

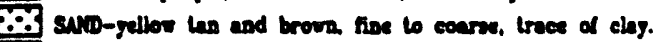

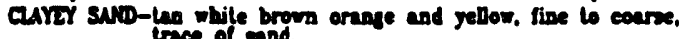

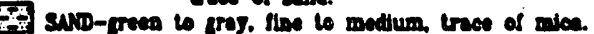

SUND-presen fine to medium.

CuY-dart prey, trace of and

OS SNID-light to dert groy, toe to medium.

curer swid-dart gray, the to modium.

SuNo-light aray ten, thoe to andium.

sos-A vell aumber

(coi) Denotion

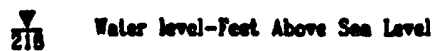
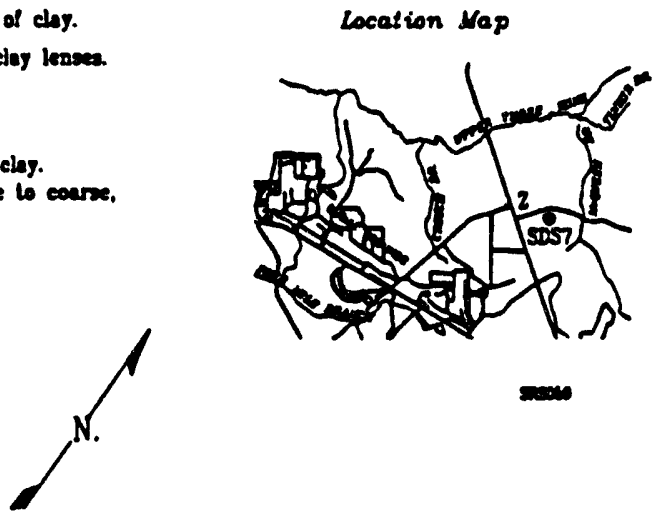

Not to scale

Dele oblained trom D'Appologia boring loye and Drtern mater levels.

FIg. E.2-5. Lithology and water level data for well SDS-7.

R.ev. 0 . 
The median hydraulic conductivity for Zone 7a, which corresponds to the upper portion of the previously designated McBean aquifer, is about $2 \times 10^{-6} \mathrm{~m} \mathrm{~s}^{-1}$ as determined from borehole tests (Intera 1986). As was stated in the previous section, this aquifer is dissected by the creels near Z-Area, and potentiometric surface data indicate How predominantly in the northern direction, although east or west components of flow exist due to the presence of the affecting creels. The horizontal gradient ranges from 0.007 at the center of Z-Area to 0.030 at the western hill slope. The potentiometric surface of Zone 7a is a free water table near the creeks (Intera 1986).

Zone $7 \mathrm{~b}$ is important because it supports perched water in Zone $7 \mathrm{c}$ in areas where the piezometric head in Zone 7a is lower than the elevation of Zone $7 \mathrm{~b}$. Evidence of perched water supported by Zone $7 \mathrm{~b}$ is provided in water level data presented in Table 6-5 of the Intera (1986) report. Vertical head differential across Zone $7 \mathrm{~b}$ varies from 3 to $12 \mathrm{~m}$ at Z-Area. Field data indicate vertical hydraulic conductivities between $2 \times 10^{-9}$ and $8 \times 10^{-9} \mathrm{~m} \mathrm{~s}^{-1}$ for Zone $7 \mathrm{~b}$ (Parizek and Root 1986).

In the northeastern section of Z-Area, Zone 7a is hydraulically connected to Zone 7c, with the "tan clay" layer, or Zone $7 b$, being absent in this section. Perched water can be found within Zone $7 \mathrm{c}$ due to the presence of discontinuous clay lenses. Zone 7c forms the lower portion of what has previously been designated the Barnwell aquifer. Like Zone 7a, Zone $7 \mathrm{c}$ is drained by the creels in the vicinity of Z-Area. A potentiometric surface map of Zone 7c is shown in Fig. E.2-6.

\section{E28 Hydrology of Coastal Plain Sediments - Zone 8}

Zone 8 consists of the upper gravels, sands, and clays of the Tobacco Road Sand and "Upland" unit. Both the Tobacco Road and "Upland" unit contain appreciable clay layers, but these are discontinuous and do not form an effective regional aquitard. The thickness of the Tobacco Road Sand is extremely variable, but can be up to $15 \mathrm{~m}$ thick in places. The "Upland" unit occurs up to $21 \mathrm{~m}$ thick at the SRS, but averages $5 \mathrm{~m}$ in the vicinity of Z-Area.

Zone 8 is commonly water bearing. The water-table often occurs in this zone, at an altitude ranging from 63 to $77 \mathrm{~m}$ above sea level, leaving the "Upland" unit and overlying Quaternary deposits unsaturated. Near the creeks, where Zone 7a is a free water table, the groundwater in Zone 8 must be considered perched. The direction of flow is affected by the creeks, and is generally in a northern direction at Z-Area (Dennehy et al. 1989). The horizontal gradient ranges from 0.002 in the southern part of Z-Area to 0.05 at the northeastern hill slope.

Field tests indicate a saturated hydraulic conductivity ranging from $10^{-6}$ to $10^{4} \mathrm{~m} \mathrm{~s}^{-1}$ for a sand lens in this zone (Christensen and Gordon 1983). Field tests in other portions of the Tobacco Road Sand indicate saturated conductivities varying between $10^{-7}$ to $10^{-5} \mathrm{~m} \mathrm{~s}^{-1}$ (Christensen and Gordon 1983). 


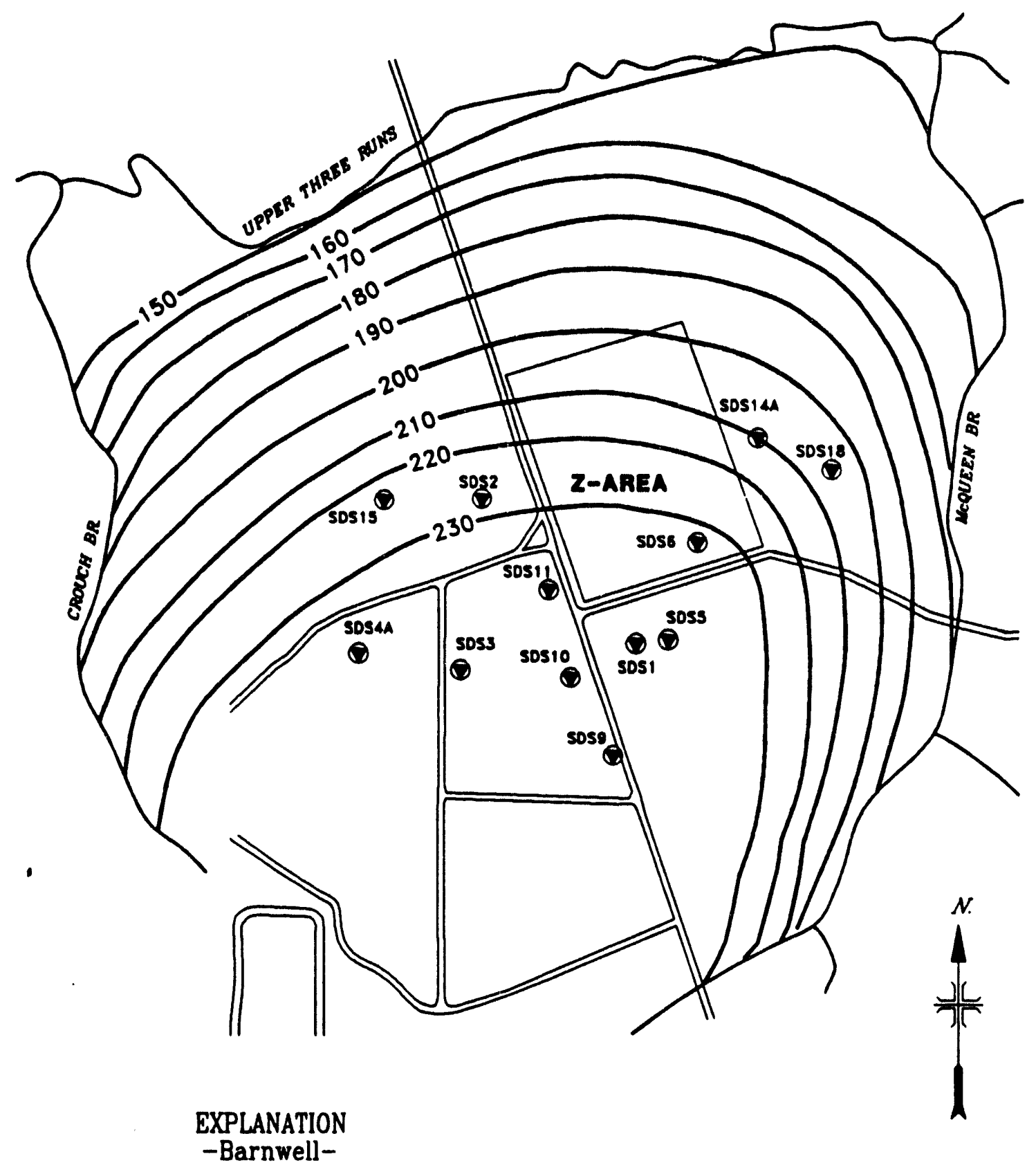

- 140 - Potentiometric Contour shows elevation (ft) based on actual 1987 head data.

- Monitoring Well Location

Fig. E.2-6. Potentiometric surface map of Zone 7c in Z-Area vicinity.

Rev. 0 


\section{B29 Hydrologic Characteristics of the Unsaturated Zone}

Hydraulic characteristics of unsaturated soil in Z-Area were investigated by Quisenberry (1985) and in nearby E-Area, by Gruber (1980). Soil water content - soil water pressure relationships for soil in both areas were developed, as were relationships between hydraulic conductivity and water content. Results for the undisturbed soil in Z-Area are presented in Figs. E.2-7 and E.2-8. A relationship similar to that depicted in Fig. E.2-7 for undisturbed soil cores was found for disturbed soil, with a somewhat steeper gradient as soil water preis:יre spproached zero. For the undisturbed soil cores, at pressures less than $-1 \mathrm{~m}$, little additional decrease in soilwater content was measured as pressures were decreased to $-5 \mathrm{~m}$. Saturated hydraulic conductivity of the Z-Area soils tested was estimated by Quisenberry to be $2 \times 10^{-7} \mathrm{~m} \mathrm{~s}^{-1}$, with a porosity of 0.37 and corresponding bulk density of $1.7 \mathrm{~g} \mathrm{~cm}^{-3}$. It is noted by Quisenberry that the field measurements were made in three well-drained areas. Characteristic curves illustrating the relationship between moisture content and soil pressure head $(m)$, and between moisture content and hydraulic conductivity $\left(\mathrm{m} \mathrm{s}^{-1}\right)$, for soils in E-Area are presented in Fig. E.2-9 and E.2-10. The plotted data were obtained by Gruber for undisturbed soil cores. Saturated hydraulic conductivity of these soils was estimated by Gruber to be on the order of $1 \times 10^{-6} \mathrm{~m} \mathrm{~s}^{-1}$, with porosity on the order of 0.47 to 0.52 , and bulk density on the order of $1.6 \mathrm{~g} \mathrm{~cm}^{-3}$. The difference between both investigator's curves illustrate the heterogeneous nature of soils in the vicinity of Z-Area. 


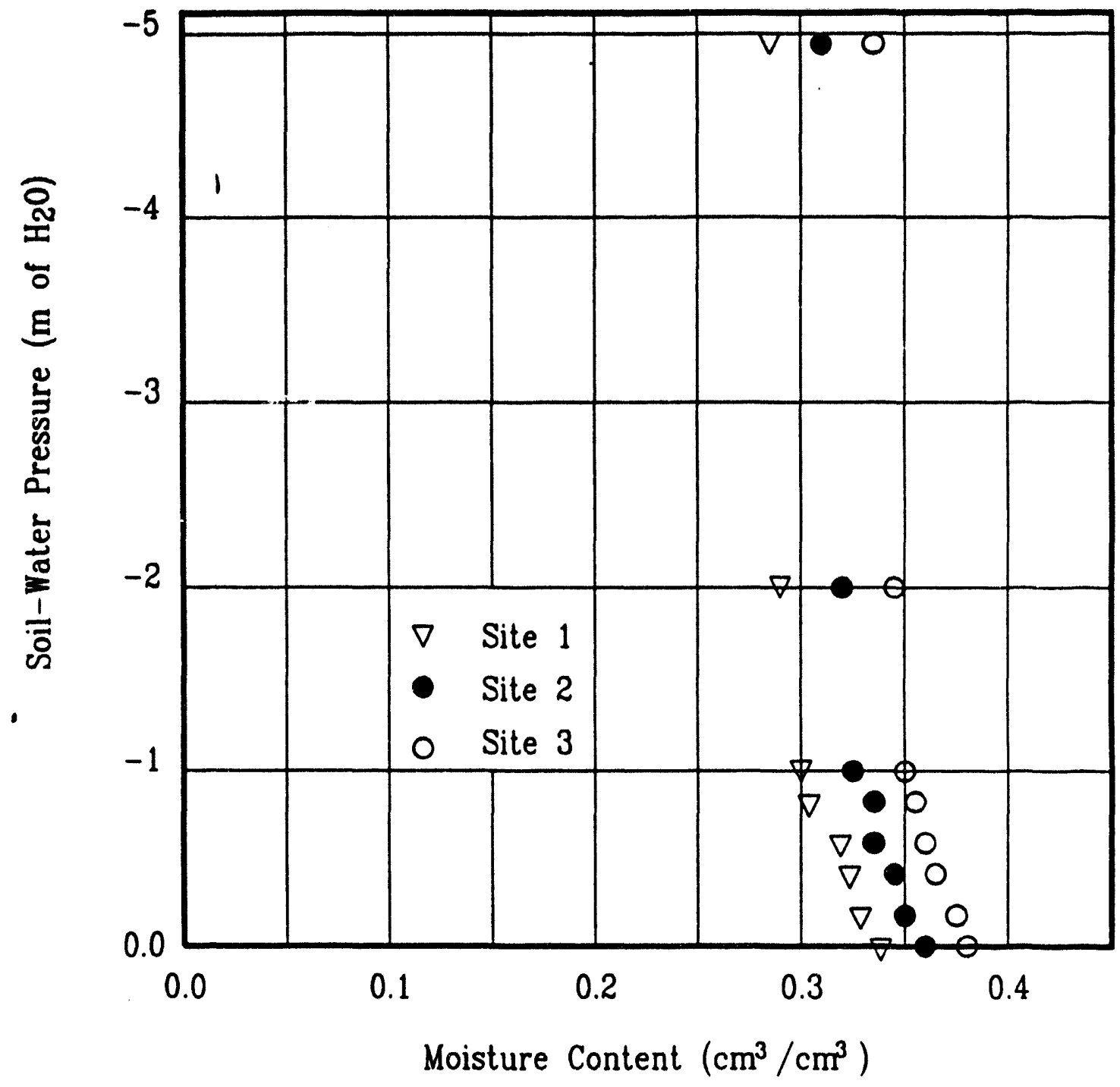

F1g. E.2-7. So11 water content-pressure relationships for undisturbed soils in Z-Area (nuisenberry 1985).

Rev. 0 


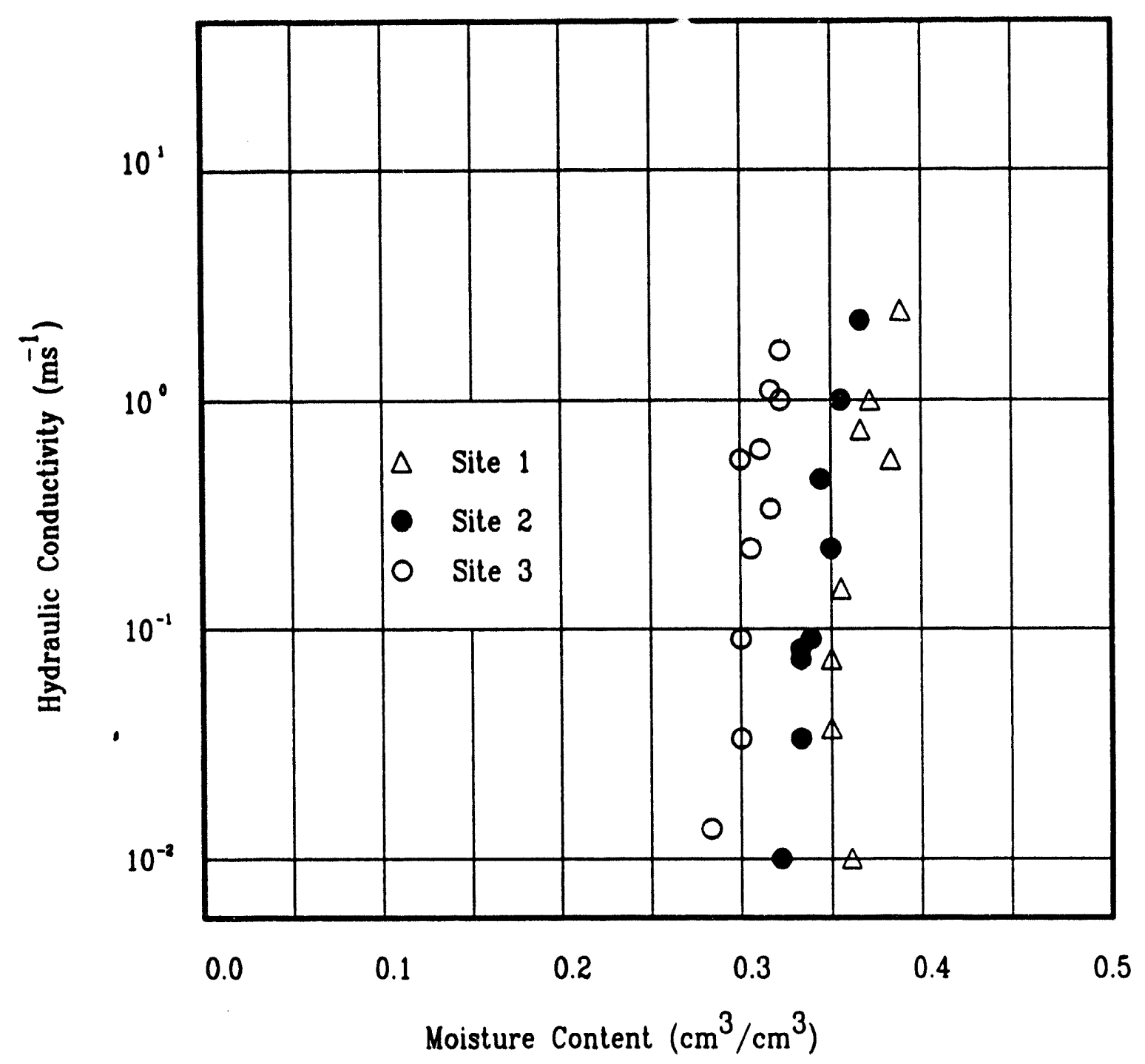

Fig. E.2-8. Unsaturated hydraulic conductiyity as a function of moisture content at Z-Area (Quisenberry 1985),

Rev. 0 


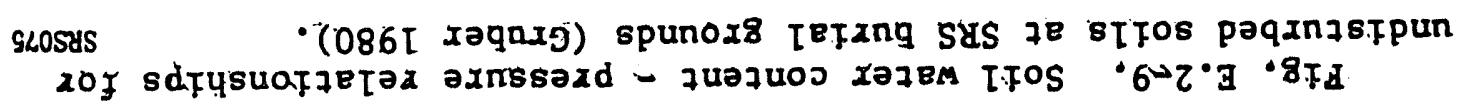

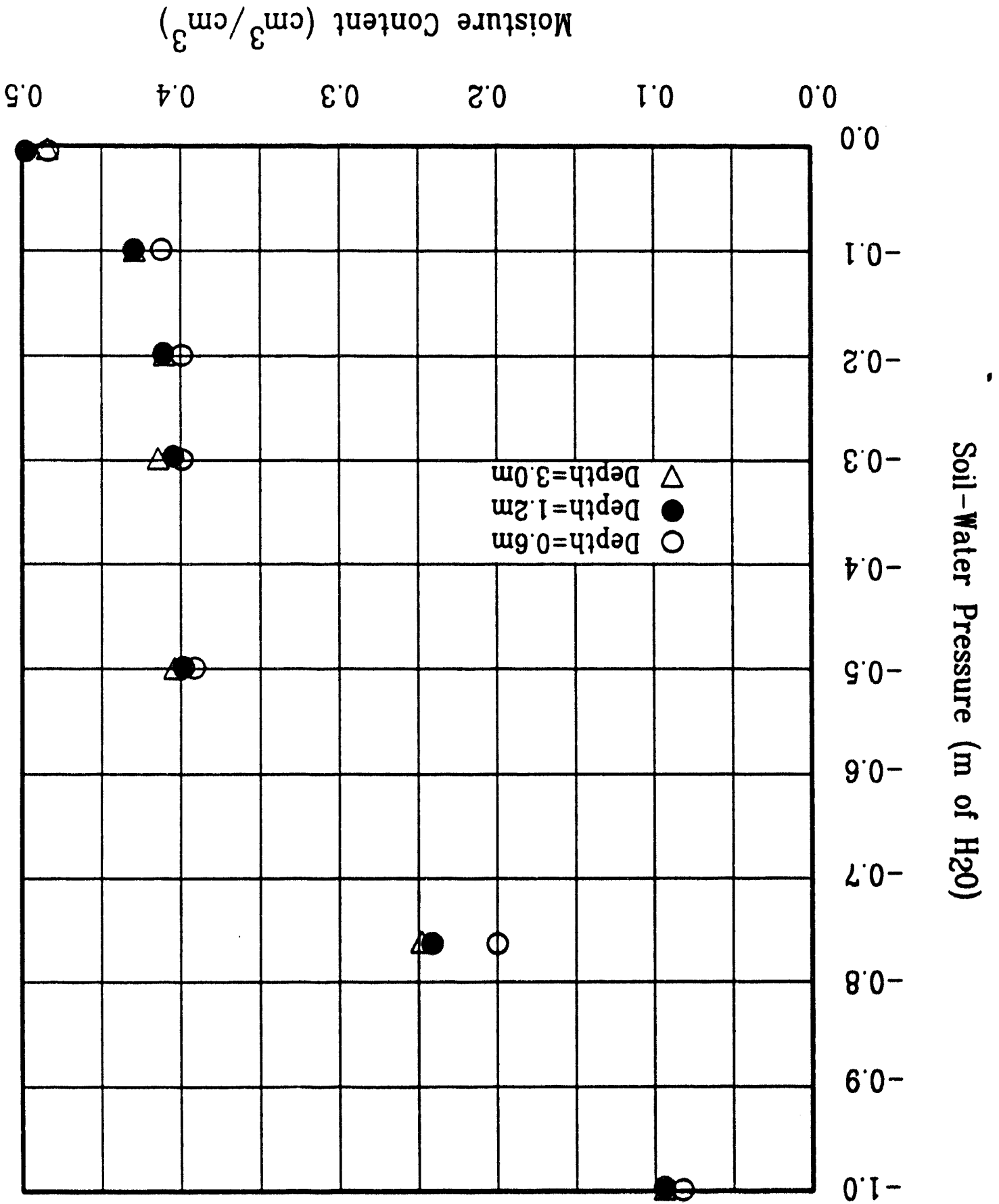




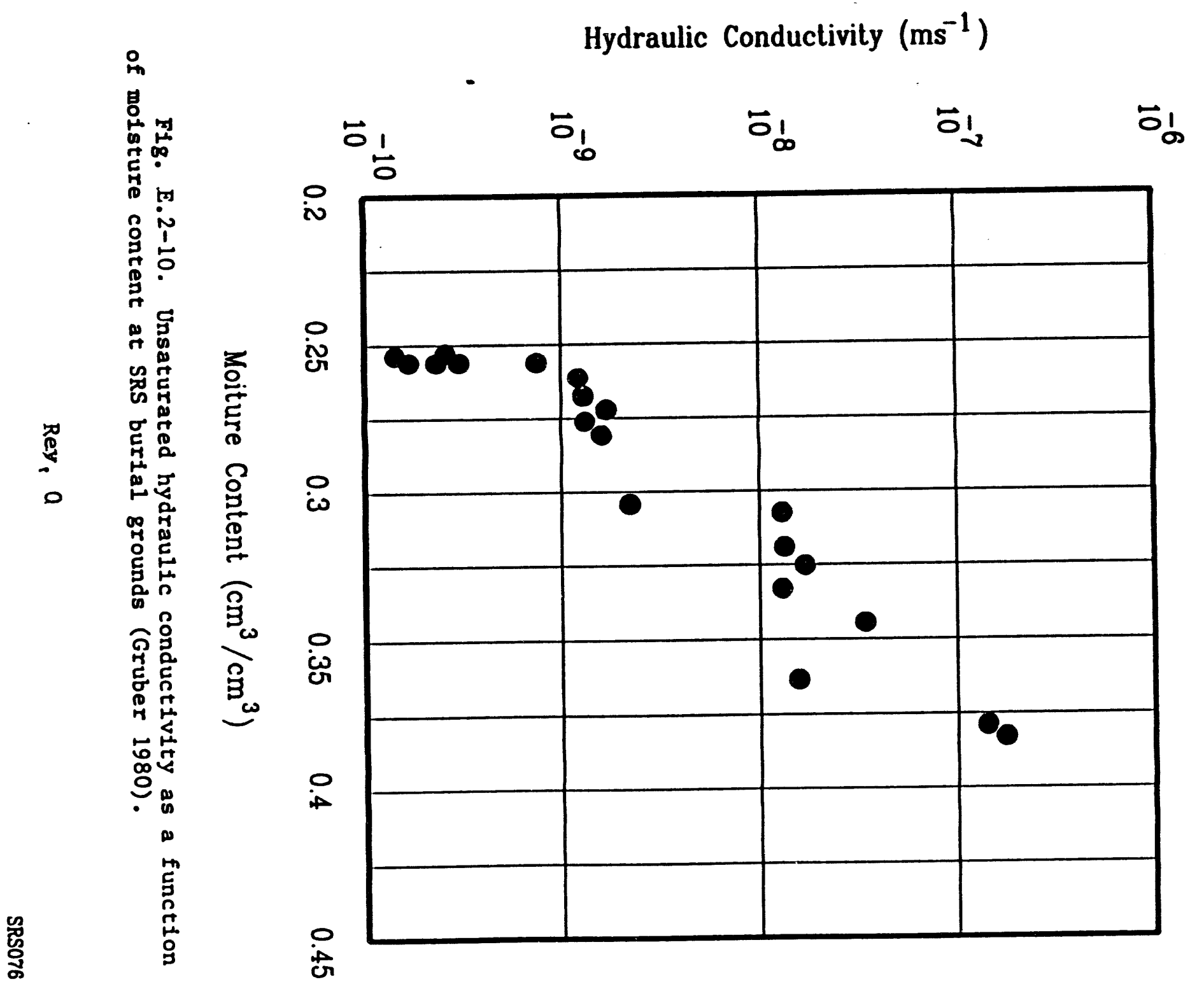




\section{APPENDIX E REFERENCES}

Bledsoe, H. W. 1987. SRP Baseline Hydrogeologic Investigation - Phase II, Savannah River Laboratory. E. I. du Pont de Nemours \& Co., Inc., Aiken, South Carolina.

Christensen, E. J., and D. E. Gordon. 1983. Technical Summary of Groundwater Quality Protection Program at Savannah River Plant, Volume I. DPST-83-829, Savannah River Laboratory, E. I. du Pont de Nemours \& Co., Inc., Aiken, South Carolina.

Cook, J. R. 1986. Hydrogeologic Data from Z-Area. E. I. du Pont de Nemours and Co., Inc., Savannah River Laboratory, Aiken, South Carolina.

Cooke, C. W. 1936. Geology of the Coastal Plain of South Carolina, U. S. Geological Survey Bull. 867, U. S. Geological Survey.

Dennehy, K. F., D. C. Prowell, and P. B. McMahon. 1989. Reconnaissance Hydrological Invesigation of the Defense Waste Processing Facility and Vicinity. E. I. du Pont de Nemours \& Co., Inc., Savannah River Laboratory, Aiken, South Carolina.

Faye, R. E., and D. C. Prowell. 1982. Effects of Late Cretaceous and Cenzoic Faulting on the Geclogy and Hydrology of the Coastal Plain Near the Savannah River, Georgia and South Carolina. U. S. Geological Survey Open-File Report 82-156, Doraville, Georgia.

Gruber, P. 1980. A Hydrologic Study of the Unsaturated Zone Adjacent to a Radioactive- Waste Disposal Site at the Savannah River Plant, Aiken South Carolina. M. S. Thesis, University of Georgia, Athens, Georgia.

INTERA. 1986. Z-Area Site Assessment. INTERA Technologies, Inc., for E I. du Pont de Nemours \& Co., Inc., Savannah Research Laboratory, Aiken, South Carolina.

Parizek, R. R., and R. W. Root. 1986. Development of a Groundwater Velocity Model for the Radioactive Waste Management Facility, Savannah River Plant, South Carolina. Pennysylvania State University, University State Park, Penn.

Quisenberry, V. 1985. Hydraulic Properties of Saltstone and Z-Area Soil. DPST-86-268, Savannah River Laboratory, E I. du Pont de Nemours \& Co., Inc., Aiken, South Carolina.

Root, R. W. 1981. Separations Areas Aquifer Testing Program. DPST-81-551, Savannah River Laboratory, E. L. du Pont de Nemours \& Co., Inc., Aiken, South Carolina. 
Siple, G. E. 1967. Geology and Ground Water of the Savannah River Plant and Vicinity, South Carolina. Geological Survey Water-Supply Paper 1984, U. S. Atomic Energy Commission.

WSRC. 1992. Safety Anahysis 200 Area Replacement Tritium Facility. WSRC-SA-1-1, Savannah River Laboratory, Westinghouse Savannah River Company, Savannah River Laboratory, Aiken, SC. 


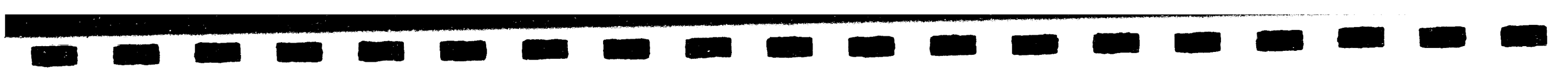

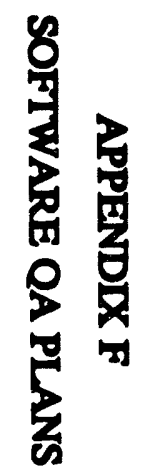


OAK RIDGE NATIONAL LABORATORY/ GRAND JUNCTION OFFICE

\author{
SOFTWARE QUALITY ASSURANCE PLAN FOR PORFLOW-3D
}

\title{
1.0 PURPOSE
}

This plan describes the steps taken by Oak Ridge National Laboratory's (ORNL) Pollutants Assessment Group (PAG) to implement software quality assurance (SQA) procedures, developed with consideration of the ORNL Quality Assurance Manual (ref. 10.1), the Martin Marietta Automated Data Processing Systems Development Methodology (ref. 10.2), and ASME NQA-2a (ref. 10.3) for the acquired computer code PORFLOW-3D (ref. 10.4).

\section{SCOPE}

The SQA plan applies to life cycle phases of PORFLOW-3D as it is used in conducting radiological performance assessments at the Savannah River Site (SRS), including identification and acquisition, installation, testing, operation and maintenance, and retirement of this pre-existing custom software. Configuration control and quality control procedures are also included in the plan.

\subsection{TERMS/DEFINITIONS}

\section{- COMPUTER PROGRAMMING ASSISTANT}

The Computer Programming Assistant assists the Computer Services Manager in assignment and management of software.

\section{COMPUTER SECURMY OFFICER (CSO)}

The Computer Security Officer is the person who ensures computer and software security, and passwords.

\section{COMPUTER SERVICES MANAGER (CSM)}

The Computer Services Manager is the person who oversees procurement and assignment of computer hardware and software, who works to ensure compatibility of existing and newly acquired products, and who ensures systems have adequate backup. 


\section{CONFIGURATION CONTROL}

Configuration control is the process of identifying and defining the configuration items in the PORFLOW-3D software system, controlling the release and change of these items throughout the system life cycle, and recording and reporting the status of configuration items and change requests.

PERFORMANCE ASSESSMENT PRINCIPAL INVESTIGATOR (PI)

The Principal Investigator is the person having overall technical responsibility for the radiological performance assessment (PA) project.

\section{PORFLOW-3D}

PORFLOW-3D is a commercially-available computer code acquired by ORNL for use in simulating unsaturated and saturated flow of mass transport in the subsurface. Simulation results will provide concentrations of radionuclides originating in low-level waste (LLW) facilities in groundwater. By sponsor (Westinghouse Savannah River Company) directive, it is subject to NQA-2a, and thus is considered a Category 4 software, from QA Procedure No. QA-L-19-100 entitled "Software Quality Assurance" in the ORNL QA Program.

\section{SOFTWARE}

Computer programs, procedures, associated procedure manuals, computer source codes and program disks.

CUSTOM SOFTWARE

Software developed to address a specific technical problem, as opposed to commercially-available wide-usage software such as a word processor or database manager.

\section{SOFTWARE VALIDATION}

Validation of software refers to the resting of the software with respect to the accuracy of decisions or assumptions incorporated into the software.

\section{SOFTWARE VERIFICATION}

Verification of software refers to the testing of the software with respect to accuracy of numerical algorithms. 


\subsection{RESPONSIBIITIES FOR SQA}

\section{PERFORMANCE ASSESSMENT PRINCIPAL INVESTIGATOR}

The principal investigator (PI) for the radiological performance assessments for which PORFLOW-3D was acquired is responsible for defining software needs. Upon acquisition, the PI is responsible for overseeing that the software life cycle procedures are correctly implemented and for overseeing configuration control and quality control procedures. The PI is also responsible for maintaining documentation of SQA procedures.

\section{COMPUTER SERVICES MANAGER}

The Computer Services Manager (CSM) is responsible for assisting the PI, when requested, with identifying software needs, as well as determining software compatibility with existing or acquired hardware, the operating system, network system and other software that it may have to interface with.

\section{COMPUTER SECURITY OFFICER}

Software protection measures are defined by and overseen by the Computer Security Officer (CSO).

\subsection{SOFTWARE LIFE CYCLE}

\subsection{Identification of Software Requirements}

The PI shall examine, in detail, the performance assessment problem(s) that necessitate software acquisition, and define the purpose, objectives, scope and constraints of the software need. A feasibility study shall be done to identify alternative pre-existing custom software solutions.

When a code, such as PORFLOW-3D, is identified as a solution, the PI must define all significant requirements of PORFLOW-3D pertinent to its:

1) Function - verifiable simulations to be accomplished,

2) Performance - time efficiency,

3) External Interfaces - interactions with hardware, other software, and available trained operators,

4) Attributes - adequacy of documentation, security, particular attributes specified by sponsor.

Documentation of identified requirements of PORFLOW-3D will be provided in the Procedural Logbook, and in an appendix of the performance assessment report. 


\section{Software Installation}

Because PORFLOW-3D is pre-existing software, installation must be preceded by tests to assure the software is complete and free of viruses that may infect the computer system on which it is installed. Backup copies of the original software shall be made, and used for installation. Installation will take place in accordance with the installation instructions provided by the provider of PORFLOW-3D.

Once installed, the original software and the backup copy is stored and protected from theft, loss and environmental damage. The Configuration Control Logbook shall be initiated, in which date of installation, version installed, and installation notes are recorded. This Logbook shall contain the name and telephone number of the PI responsible for PORFLOW-3D and the name of the performance assessment project for which it was acquired. Source code listing, software documentation and user's manuals will be stored in a location accessible to designated users of the software, and shall not be removed without permission of the PI.

\section{Software Testing}

Testing is required to confirm that PORFLOW-3D satisfies the objectives and requirements defined in Section 5.1, Identification of Software Requirements. Verification testing, described in Section 5.3.1 below, is a demonstration of whether PORFLOW-3D meets the requirements specified regarding function, performance, external interfaces and attributes.

\subsubsection{Verification}

- The capabilities of PORFLOW-3D must be verified by comparing analytical solutions of the desired simulation equations for a defined problem to PORFLOW-3D output to evaluate the accuracy of numerical algorithms. Comparison of software simulation results with results from previously verified versions or codes (termed benchmarking) is acceptable.

\subsection{Validation or Benchmarking}

Validation of PORFLOW-3D requires data from SRS that are not available in sufficient quantity or quality to provide meaningful results. Benchmarking of PORFLOW-3D will therefore be carried out by comparing the results to software that has gained high acceptability by acknowledged experts.

\subsubsection{Documentation of Testing}

Results of verification and benchmarking of PORFLOW-3D shall be recorded in the Procedural Logbook which is initiated when requirements are identified (Sect. 5.1), and in an appendix of the performance assessment report. 


\subsection{Software Operation and Maintenance}

\subsubsection{Operation}

Operation of PORFLOW-3D will be conducted by personnel approved by the PI, who in the PI's judgement, are appropriately trained. These individuals will have access to the user's manual of the code, the Procedural Logbook, and the Configuration Control Logbook.

Operational tests will be performed whenever PORFLOW-3D is installed on a different computer, or when configurational changes are made to the software or hardware system. The results of these tests will be documented in the Configuration Control Logbook.

\subsection{Maintenance}

Maintenance to correct software errors or adapt to changes in requirements or the operating environments will be made only with the PI's approval, documented in the Procedural Logbook. Written requests for maintenance actions will be kept in a specified location by the PI.

\subsection{Software Retirement}

Once the life cycle of PORFLOW-3D is over, it will be retired according to the developer's requirements, in order to assure future use is in accord with applicable licensing agreements. All documents pertaining to the life cycle of PORFLOW-3D will be archived, and a caretaker will be designated by the PI to ensure that the retired software is not made available for unrestricted use. Documentation of retirement procedures followed will be made in the Procedural Logbook.

\subsection{CONIGURATION CONTROL}

\subsection{Configuration Identification}

A configuration baseline shall be defined for PORFLOW-3D, all input data sets including test cases, simulation results, and hardware as the tested and approved configuration. A labeling system will be implemented for each of these components of the system, such that each item is uniquely identified and that configurations resulting from revisions of each item are uniquely identified. 


\section{Configuration Change Control}

Changes to configuration items, including the PORFLOW-3D code, input data sets, simulation results and hardware shall be formally documented under the following guidelines.

\section{Changes to PORFLOW-3D}

Changes to the baseline version of PORFLOW-3D must be approved by the PI. Verification shall be performed to ensure that changes are properly reflected in documentation of the code, and that the changed document is properly archived.

\section{Changes to Mreation of Data Sets and Simulation Results}

Changes to, or creation of new, data sets must be documented in a manner that uniquely identifies each set and corresponding simulation results set.

\section{Changes in Hardware Configuration}

Changes to hardware may affect the operation of PORFLOW-3D. Therefore, such changes shall be reflected in the archiving, or tracking procedure, and in the documentation.

\section{Configuration Control Documentation}

Configuration control documentation shall contain the information needed to manage the PORFLOW-3D configuration and accompanying data sets, simulation results and bardware requirements. This information shall identify the approved configuration (via a well documented naming conventions for software, data sets, and simulation results) and will be kept in the Configuration Control Logbook. This logbook shall be easily decipherable with respect to reflecting modifications made to the various configurations.

\subsection{QUALTY CONTROL}

\subsection{Technical Review of Software}

The PI shall periodically review the approach and key assumptions, and evaluate input data sets to assure that QA procedures have been applied and that proper documentation is being generated throughout the life-cycle of PORFLOW-3D. When necessary, the PI will call on others to review assumptions and input data to verify their appropriateness and accuracy. 


\section{Sign-ofi and Approvals}

The sign-off and formal approvals on key assumptions and input data will be accomplished with cover letters transmitting the information being approved. Individuals whose approval is sought will be identified by the PI, and will include QA personnel from ORNL and from SRS, as well as those with particular knowledge of the specific information from both organizations, and appropriate managers.

\subsection{Quality Control Documentation}

Documentation of Quality Control procedures will be kept in the form of the sign-off and approval cover letters that transmit information that has submitted to these procedures. These signature forms and attached information will be kept in a separate notebook, entitled Quality Control Notebook.

\subsection{PROBLEM REPORTING AND CORRECTIVE ACTION}

A formal procedure of software problems and corrective action reporting shall be established by the PI for PORFLOW-3D errors and failures. The reporting system shall assure that problems and corrective actions taken are promptly reported to affected organizations, such and Idaho National Engineering Laboratory and SRS. Problems and corrective actions shall be reported in the form of letters to affected individuals and organizations, and will be described in the Procedural Logbook.

\subsection{RECORDS}

The following documents will be retained as records:

1) SQA Plan;

2) Procedural Logbook containing information on software requirements, code testing results, maintenance actions, and retirement procedures followed;

3) Configuration Control Logbook containing installation information, results of testing when configurational changes are made, and identification of approved or defined configuration items, including the PORFLOW-3D version, input data sets, simulation results and hardware;

4) Documentation of PORFLOW-3D, including user's manual; and

5) Quality Control Notebook including documentation of approvals on input data and major assumptions made. 


\subsection{REFERENCES}

Oak Ridge National Laboratory. Quality Assurance Manual. Current Edition. Oak Ridge National Laboratory, Oak Ridge, Tenn.

Martin Marietta for Department of Energy. 1987. Automated Data Processing Systems Development Methodology Volume I. KJCSD/INF/86-3, Vol. 1 \& 2, R3, (ADP SDM), August.

ASME NQA-2a. Part 26, Quality Assurance Requirements of Computer Software for Nuclear Facility Applications.

Runchal, A. K, and B. Saggar. 1991. PORFLOW: A Model For Fluid Flow, Heat and Mass Transport in Mustifluid, Multiphase Fractured or Porous Media; User's Manual - Version 234. Analytic and Computational Research, Inc., West Los Angeles, Calif. 
EGG-EELS-003

EG\&G Idaho, Inc.

SOFTWARE QUALITY ASSURANCE PLAN FOR PORFLOW-3D

\author{
Steven J. Maheras
}

1992

Rey. 0 


\subsection{PURPOSE}

The purpose of this plan is to describe the steps taken by the Idaho National Engineering Laboratory (INEL) Subsurface and Environmental Modeling (SEM) Unit to implement software quality assurance (SQA) procedures consistent with the EG\&G Idaho Quality Manual Section QP-21 (Computer Software Configuration Management) and ASME NQA-2a-1990 Part 2.7 (Quality Assurance Requirements of Computer Software for Nuclear Facility Applications) for the computer code PORFLOW-30.

\subsection{SCOPE}

The SQA plan applies to life cycle phases of PORFLOW-3D as it is used in conducting radiological performance assessments at the Savannah River Site (SRS), including acquisition, installation, testing, operation, maintenance, and retirement of this acquired software. Configuration control and quality assurance procedures are also included or referenced in this plan.

\subsection{TERMS/DEFINITIONS}

COMPUTER CODE CUSTODIAN - The designated individual with responsibility for coordinating the control of computer codes and related documentation.

CONFIGURATION CONTROL - Configuration control is the process of identifying and defining the configuration items in the PORFLOW-3D software system, controlling the release and change of these items throughout the system life cycle, and recording and reporting the status of configuration items and change requests.

PERFORMANCE ASSESSMENT PRINCIPAL INVESTIGATOR - The Principal Investigator (PI) is the person having overall technical responsibility for the radiological performance assessment (PA) project. 
PORFLOW-3D - PORFLOW-30 is a commercially-available computer code acquired by the INEL for use in simulating unsaturated and saturated flow and mass transport in the subsurface. Simulation results will provide concentrations of radionuclides originating the low-level waste facilities in ground water. By sponsor [Westinghouse Savannah River Company (WSRC)] directive, it is considered "High Impact" software (QAP-20-1, Rev 1., $10 / 01 / 90)$. This is equivalent to EG\&G Idaho Quality Level B software* .

SOFTWARE - Computer programs, procedures, associated procedure manuals, computer source code, and program disks.

SOFTWARE VALIOATION - Validation of software refers to the testing of the software with respect to the accuracy of decisions or assumptions incorporated into the software.

SOFTWARE VERIFICATION - Verification of software refers to the testing of the software with respect to accuracy of numerical algorithms.

\subsection{RESPONSIBILITIES FOR SQA}

PERFORMANCE ASSESSMENT PRINCIPAL INVESTIGATOR - The principal investigator (PI) for the radiological performance assessments for which PORFLOW-3D was acquired is responsible for software quality assurance. Upon acquisition, the $P I$ is responsible for overseeing that the software life cycle procedures are correctly implemented and for overseeing configuration control and quality control procedures. The PI is also responsible for maintaining documentation of SQA procedures. The PI may delegate the configuration control responsibility to the computer code custodian.

a. Quality Level B software includes software whose failure would degrade the performance or reliability of operations, data acquisition, or deliverables.

$$
\text { Rev. } 0
$$




\subsection{SOFTWARE LIFE CYCLE}

\subsection{Software Installation}

Because PORFLOW-30 is pre-existing, commercially available software, life cycle steps associated with the development of the software are the responsibility of the computer code vendor. Installation will take place in accordance with the installation instructions provided by the vendor of PORFLOW-3D. A backup copy of the original software shall be made and stored under version control. Because PORFLOW-30 is stored under version control on the INEL CRAY, it is protected against theft, loss, and environmental damage.

After installation, PORFLOW-30 will be installed in the INEL Version Control System (VCS) (Miller et al. 1991). VCS provides for automated change control and logging, therefore a separate configuration control logbook is not required.

\subsection{Software Testing}

Testing is required to confirm that PORFLOW-3D functions as the code vendors assert. Once installed, a FORTRAN analyzer is typically run on the code to look for potential programming errors. Marshall and Marwil (1991) contains a description of a typical FORTRAN analyzer. No programming errors were identified in PORFLOW-30.

\subsubsection{Verification}

The capabilities of PORFLOW-30 must be verified by comparing analytical solutions of the desired simulation equations for a defined problem to PORFLOW-30 output to evaluate the accuracy of numerical algorithms. Comparison of software simulation results with results from previously verified versions or codes (termed benchmarking) is acceptable. An independent verification of an earlier version of PORFLOW has been performed (Magnuson et al. 1990).

$$
\text { Rev. } 0
$$




\subsubsection{Validation or Benchmarking}

Validation of PORFLOW-30 requires data from SRS that are not available in sufficient quantity or quality to provide meaningful results. Benchmarking of PORFLOW-3D will therefore be carried out by comparing the results to software that has gained high acceptability by acknowledged experts. An independent benchmarking of an earlier version of PORFLOW has been performed (Magnuson et al. 1990).

\subsubsection{Documentation of Testing}

The results of the verification and benchmarking of PORFLOW-3D are documented in Magnuson et al. (1990). The verification and benchmark testing of PORFLOW was conducted using Version 1. However, the version of PORFLOW used on this project was PORFLOW-3D. The test problems used to verify and benchmark Version 1 have been run using PORFLOW-3D and equivalent results were obtained.

\subsection{Software Operation and Maintenance}

\subsubsection{Operation}

Operation of PORFLOW-30 will be conducted by personnel approved by the PI, who in the PI's judgment, are appropriately trained. These individuals will have access to the user's manual of the code.

Operational tests will be performed whenever PORFLOW-3D is installed on a computer with a different operating system, or when configuration changes are made to the software or hardware system.

\subsubsection{Maintenance}

Maintenance to correct software errors or adapt to changes in requirements or the operating environments will be made only with the PI's approval. However, the PI may delegate this authority to the code custodian. Rev. 0 
The changes will be logged in the Version Control System. Since VCS provides an automated $\log$ of changes to the source code, no separate maintenance log will be required.

\subsection{Software Retirement}

Once the life cycle of PORFLOW-3D is over, it will be retired according to the code developer's requirements, in order to assure future use is in accord with applicable licensing agreements. All documents pertaining to the life cycle of PORFLOW-30 at the INEL will be archived. During the retirement phase of the software lifecycle, the routine use of PORFLOW-30 will be prevented. The retirement procedures followed will be documented.

\subsection{CONFIGURATION CONTROL}

PORFLOW-3D is maintained under configuration control using the INEL VCS system. The Configuration Management Plan (CMP) for PORFLOW-3D is part of a larger CMP documented in Matthews (1992) that meets the requirements of EG\&G Idaho QP-21 (Computer Software Configuration Management).

\subsection{QUALITY ASSURANCE}

The PI shall periodically review the approach and assumptions, and evaluate input data sets to assure that $Q A$ procedures have been applied and that proper documentation is being generated throughout the life-cycle of PORFLOW-3D. When necessary, the PI will call on others to review assumptions and input data to verify their appropriateness and accuracy.

Key assumptions (those critical to the project) will be evaluated by WSRC, ORNL-GJ, and INEL and a consensus on each key assumption will be reached.

Project notebooks will be used to document day-to-day project activities. Formal documentation of analyses conducted using PORFLOW-3D will be accomplished using the EG\&G Idaho Engineering Design File (EDF) format. Rev. 0 
The EDF format provides for formal sign-offs on input data, assumptions, and output by the author, reviewer (technical), and approver (managerial) of the calculations. The EG\&G Idaho Quality Manual [Design Control (QP-3, Section 4.2.15)] describes the elements required in the documentation of a design analysis. The EDF's generated during this project will be transmitted to SRS as part of the project documentation.

\subsection{ERROR REPORTING AND CORRECTIVE ACTION}

Any errors found in the code will be reported to the code author and other affected organizations, such as SRS and ORNL-GJ. The error and its corrective action will be documented in the project logbook maintained by the analyst.

\subsection{RECORDS}

The following documents will be retained as records that will be turned over to WSRC:

(1) SQA PIan

(2) The VCS change log for PORFLOW-30.

(3) Documentation of PORFLOW-3D, including user's manual

(4) Engineering Design Files containing results generated using PORFLOW-3D.

(5) Project notebooks.

\subsection{REFERENCES}

ASME NQA-2a-1990, Part 2.7, Quality Assurance Requirements of Computer Software for Nuclear Facility Applications. 
EG\&G Idaho, 1992, Quality Manual, Sections QP-3 (Design Control) and QP-21 (Computer Software Configuration Management).

Magnuson, S. O., R. G. Baca, and A. J. Sondrup, 1990, Independent Verification and Benchmark Testing of the PORFLO-3 Computer Code, Version 1.0, EGG-BG-9175.

Marshall, N. H. and E. S. Marwil, 1991, Cross Reference Analys is of FORTRAN (CRAFT), EGG-CATT-9198.

Matthews, S. D., 1992, Software Configuration Management Plan for Controlled Code Support System, EGG-CATT-10196.

Miller, G. V., D. G. Barber, and E. S. Marwil, 1991, Software Quality Assurance Plan for the Version Control System. Release 2, EGG-CATT-9821.

Runchal, A. K. and B. Saggar, 1991, PORFlOW: A Model for Fluid Flow, Heat and Mass Transport in Multifluid. Multiphase Fractured or Porous Media; User's Manual - Version 2.34, Analytic and Computational Research, Inc., West Los Angeles, CA.

Rey. a 


\section{APPENDIX G \\ PERFORMANCE ASSESSMENT PEER REVIEW \\ PANEL RECOMMENDATIONS}




\section{G.1 INTRODUCTION}

On August 17 and 18, 1992, a preliminary review of this Performance Assessment (PA) was conducted by the Performance Assessment Peer Review Panel (PRP). Recommendations for improving this assessment were made by the Panel based on a review of an earlier version of the draft of this report and on presentations that were made to the panel during the review. The Panel reached consensus on 16 recommendations which were presented to SRS, and are listed verbatim in Sect. G.2. How those recommendations which suggested action were adopted for improving this report are discussed immediately below each recommendation.

\section{G2 RECOMOMENDATIONS OF PERFORMANCE ASSESSMENT PEER REVIEW PANEL}

\section{Recommendation \#1}

The PRP is very appreciative of the courteous reception; generous hospitality, and openness of discussion provided by DOE's Savannah River Field Office, the Westinghouse Savannah River Company, and all study contributors."

Response: No action requested.

\section{Recommendation \#2}

The PRP would like to commend the fine efforts of Westinghouse Savannah River Company and all of the study preparers in producing the best preliminary draft report we have seen to date. Specifically, we appreciated the focus on establishing and testing a conceptual model; the application of a screening approach to establish the significant radionuclides and pathways; and the long-term research program that supports several aspects of the PA, most notably, the development of the saltstone waste form."

Response: No action requested.

\section{Recommendation \#3}

The PRP applauds the multidisciplinary "teamwork" approach. The willingness to "go to the experts" has resulted in the development of a quality draft. This is a very good approach that the panel would like to see used by other sites in the development of future PA's."

Response: No action requested. 


\section{Recommendation \#4}

The PRP notes that our review suffered from the lack of completeness of this draft. By having no "all pathway" results to review, the Panel was not able to fully evaluate the relative importance of the modeling components, the impacts of design changes, and the likelihood that an acceptable disposal system will result. The PRP could not assess the degree of conservatism (or lack thereof) in the PA."

Response: The lack of completeness of the draft reviewed by the PRP has been addressed by adding Sect 4, RESULTS OF ANALYSTS, and Sect. 5, PERFORMANCE EVALUATION. Specifically, the PRP noted that they could not evaluate the relative importance of the modeling components, the impacts of design changes, and the likelihood that an acceptable disposal system will result. These aspects are now addressed in Sect. 4.2, SENSITIVITY AND UNCERTAINTY ANALYSES, and Sect. 4.3, INTERPRETATION OF RESULTS. Also of concern to the PRP was the lack of information on the degree of conservatism built into the PA. This is also addressed in Sect. 4.3, where consideration of the ranges for sensitive parameters, and the value assumed in generating results, is given.

\section{Recommendation \#5}

"Although the PRP applauds the teamwork approach, we note that this draft lacks synthesis and integration of the components into a fully-described and defendable PA The PRP cautions the preparers that this integration step is essential to the production of an acceptable final PA.

Response: The draft Z-Area PA reviewed by the PRP has been improved with respect to integration and synthesis by adding summary paragraphs to the end of chapters (e.g., Sect. 2.8), highlighting the most significant information provided in that chapter, and describing how that information is used in the subsequent analyses. Several cover-tocover reviews wers, also carried out to identify weak links in information flow in the report, or discrepancies in information between sections.

\section{Recommendation \#6}

" The PRP recommends a better analysis of seismic events, including liquefaction of soils, and the potential impacts (i.e., sensitivity) of stress cracking on waste form performance."

Response: The approach taken to addressing seismic events was enhanced by more completely explaining the consequences of the potential events, rather than relying solely on their probability. In Sect. 2.1 .4 , the statement that liquefaction is not considered a problem based on the URS/Blume report was omitted, and a discussion of liquefaction potential was added to the end of Sect. 2.1.4.3, based on the URS/Blume report. In addition, in Sect. 3.1.3.2, cracking as a result of seismic events is more 
explicitly listed as a form of degradation. Liquefaction is not believed to result in anything other than cracking, and this is noted in Sect. 3.1.3.2. Since results of the degraded case (i.e., cracked vaults and monoliths) analysis are insensitive to crack aperture (Sect. 4.2.1.2), the present degraded vault analysis is believed to encompass seismic effects.

\section{Recommendation \#7}

The PRP notes that the model selection did not seem to be well defended. The logical progression is from simple to more complex models, with justification of why complexity is needed, and how existing data support that progression. By initially selecting complex models, the justification seems weakened. As guidance, the PRP recommends that the simplest defendable model that supports the PA conclusions should be used and that the modeling should be done in a manner consistent with existing data and conditions at the site."

Response: Model selection was based on the code selection criteria described in Appendix B.1. In particular, criteria number $4 S$ states that "the degree of complexity of the computer code should be consistent with the quantity and quality of data, and the objectives of the computation" and that "screening calculations and sensitivity analyses should be used to simplify conceptual models, and ultimately direct code selection". While this particular criteria was adhered to in selecting computational techniques for this RPA, documentation of this adherence is admittedly insufficient in the RPA. The only models used in this RPA that perhaps would be classified as complex are the unsaturated and saturated flow models, implemented in the PORFLOW-3D computer code. The justification for selecting these models was based for the most part on the need to predict the effect of the SDF on flow in the near-field environment and the underlying groundwater. The number of materials (i.e., saltstone, concrete, clay, gravel, backfill) with different hydraulic properties in the SDF, and their complex interrelationships, is a difficult problem, yet all-important from the standpoint of flux of contaminants to the water table. A paragraph was added to Sect. 3.3.1, Near-Field Model, documenting this need.

For analysis of saturated flow, a three-dimensional flow and transport model was necessary to address the affect of the SDF on the flow field in the saturated underlying materials, and the vertical heterogeneity under the SDF. Analytical approaches rely on knowledge of the flow field, which must be predicted in the presence of the SDF for this RPA. The presence of the continous clay layer beneath Z-Area, and the different hydraulic properties of the three zones potentially affected by contaminants released from Z-Area necessitated the three-dimensional approach taken in order to track the contaminant plume, and identify the location of maximum concentration as necessitated by the groundwater protection requirements applicable to this facility. 


\section{Recommendation \#8}

The PRP encourages the Savannah River Site to explore available data to ensure that the models that are selected and developed are representative of site behavior. For example, Fig. A-16 indicates the existence of a large number of wells in the vicinity of the Saltstone Facility. It is not clear that data from these wells have been included in the establishment of the conceptual model."

Response: The data from the Z-Area vicinity wells (well series SDS) were relied upon extensively to develop the conceptual model (e.g., the tan clay was determined not to be continuous, so did not assign a separate zone to that unit) and for calibration of the computer model (comparison of pressure heads to simulated heads allowed adjustment of parameters within the model to achieve an acceptable "fit"). The text has been revised to reflect that usage in the following manner. In Sect. 2.2.2, a map of the Z-Area vicinity wells (or SDS wells) is provided (Fig. 2.2-2), and it is stated that much of the hydrogeologic information used in the RPA came from these wells. Lithologic cross-sections are also added to that section, which were developed from Z-Area well logs, and used in development of the conceptual model. In Appendix A.2.1, the manner in which the Z-Area hydrologic information was used in developing the conceptual model is indicated more explicitly. The discussions in Sect. A.1.2.3, Hydrogeologic Properties, and A.1.2.4, Properties Affecting Mass Transport, indicate the source of values for many of the parameters identified are site-specific hydrologic data.

\section{Recommendation \#9}

"By separating barrier (i.e. cap) from vault simulations, there is a potential difficulty of integration of the component results that makes an analysis of the total system difficult. Artificial and potentially contradictory boundary conditions appear to be imposed. For example, by not allowing upward movement to the perched water there seems to be an omission of a potential mechanism that could affect performance."

Response: The upper moisture barrier simulations were separated from the saltstone and vault simulations because it was determined that there was an insignificant diffusive flux of contaminants upward from the domain containing the vaults and saltstone. Therefore, the difficulty encountered in simulating the entire domain at once was not considered an obstacle in producing defensible results. The domain which includes the vault and saltstone does allow for upward diffusion to the perched water which occurs in the clay layer directly on top of the vault. In the gravel layer above this clay, water runs off laterally to a drain in between the vaults. The majority of the flux of contaminants from the top of the vaults, which is orders of magnitude less than the flux from the bottom and sides, ends up in these drains, which are still within the simulation domain. 


\section{Recommendation \#10}

Transient rainfall-driven events (i.e. storms) are not well accounted for in the present simulations. The PRP cannot determine their importance with information presented. This should be addressed in the final PA."

Response: Transient rainfall events were not explicitly addressed in the RPA for the Z-Area SDF. In terms of effects on contaminant concentrations, there are two scenarios that deserve consideration. First, the instantaneous increase in infiltration through the facility should be addressed; and second, the potential for subsurface runoff of contaminated soil water should be addressed. With respect to increased infiltration, the present RPA considers a clay and gravel drain system that would intercept and remove excess water from a storm event, and thus infiltration through the facility would not occur. In the event of failure of the drain system, however, additional water could conceivably flow down next to the vaults and perch on top. The short-term effect of this would be to increase flow through any fractures, and thus the mass flux from degraded vaults (Sect. A.1.3), and to increase mass flux of contaminants that have diffused to the side of the vaults for the duration of the storm. Flux from the saltstone wasteform is unlikely to increase because the saltstone is essentially saturated under normal conditions, and thus convective or diffusive transport beneath the vaults will not change. The impact of the additional mass flux as a result of such transient events has not been assessed. However, it is important to remember that: 1) increased water flux may raise the water table elevation briefly and provide more dilution water, and 2) the transient events are short-lived and are balanced over the year by the dry periods when flux is reduced below that predicted with an annual average infiltration rate. The fact that the assumed distance to the water table is based on the historic high water table, however, takes into account an elevated water table due to increased flux.

Subsurface stormflow becomes important when the lateral gradient in the shallow subsurface is significant relative to the vertical gradient. The gentle grading of the closure concept for the Z-Area SDF makes this potential scenario less important. The fact that the cover concept provides about $3 \mathrm{~m}$ of cover over the facility further reduces the potential importance of lateral stormflow from the standpoint of contaminant transport. While upward diffusion of contaminants from saltstone may occur, the strong vertical gradient on top of the facility severely limits significant contamination of the overtying cover (Sect. A.1.2.2).

\section{Recommendation \#11}

"The scenarios and results. must be put in context in an interpretation section to ensure that proper risk management decisions can be made."

Response: Sect. 4.3, INTERPRETATION OF RESULTS, has been added, addressing this comment. 


\section{Recommendation \#12}

The effect of the cover at site closure may elevate the water table. The consequences of this potential rise in the water table are appropriate to consider in the PA"

Response: The water table elevation is controlled largely by the amount of infiltration into Z-Area, the surrounding streams to which the groundwater discharges, and hydraulic properties of the saturated units beneath the site. Increases in infiltration can be expected to occur when vegetation is cleared from an area with a concomitant decrease in evapotranspiration. The infiltration analysis in this report (Appendix A.1.1), relied on studies in the SRS burial grounds vicinity, where grass is the predominant cover vegetatiun. (This information was added to Sect. A.1.1) Thus, if bare soil is present at Z-Area at any time in the future, infiltration might be expected to increase to some degree, depending on the relative contribution of transpiration to evaporation. The effect of increasing infiltration in groundwater flow simulations, by four times the assumed value of $40 \mathrm{~cm} / y e a r$ over the entire problem domain (i.e., including the entire region bounded by the creeks), is discussed in Sect. A.2.2.6. The increase in water table elevation was found to be up to $12 \mathrm{~m}$ for this unrealistically large amount of infiltration (i.e., exceeding the average annual precipitation of $124 \mathrm{~cm} / \mathrm{year}$ ). This observation, coupled with the unlikelihood of Z-Area and its vicinity being completely unvegetated, and the fact that the vaults themselves limit the water recharging the groundwater directly beneath them, suggests that the water table is unlikely to reach the bottom of the closest vault, which would require a rise of greater that $8 \mathrm{~m}$.

At site closure, placement of a cover that limits infiltration (clay) and erosion (bamboo) is likely to lower, rather than elevate, the water table under the facility. The effect of this was observed in conducting the preliminary sensitivity analysis for the saturated flow simulations, and is documented in Sect. A.2.2.6, Recharge to the Water Table. Allowing $2 \mathrm{~cm} / y e a r$ to infiltrate under the facility, but allowing the $40 \mathrm{~cm} / y e a r$ infiltration rate in the surrounding regions results in a lowering of the water table under the facility by about $1.5 \mathrm{~m}$. With the clay and gravel drain system immediately on top of the vaults, as simulated for this RPA (Sect. 2.7), infiltration under the vaults is expected to be on the order of $0.2 \mathrm{~cm} / y e a r$, and thus the water level would drop even more than $1.5 \mathrm{~m}$ under the facility.

\section{Recommendation \#13}

The effect of the bamboo cover on evapotranspiration and consequent desiccation of the cap or increased infiltration should be evaluated."

Response: In Sect. 2.7.1, a brief description of the bamboo revegetation concept has been added, which indicates that bamboo evapotranspirates in a climate like that at the SRS all year. Thus, it is expected that bamboo would remove a large amount of moisture from the soil, and decrease infiltration into the facility. However, the actual 
amount of water removed by the bamboo forest, and whether this can lead to desiccation of the upper clay layer, is not known. It should be noted, however, that bamboo is shallow rooted, and there is at least $1.2 \mathrm{~m}$ of backfill and gravel between the surface of the ground and the conceptual upper clay layer making it unlikely that the roots themselves would penetrate the clay layer. Furthermore, there is abundant rainfall at the SRS, suggesting that desiccation of the clay layer would require a tremendous water demand by bamboo. If desiccation were to occur, infiltration would be severely reduced by the bamboo, rather than by the moisture barrier.

The fact that degradation of the upper clay moisture barrier was evaluated in this RPA addresses the eventuality of desiccation of the clay layer. It was postulated that many processes could lead to such degradation, and the SDF performance was evaluated under the condition of a totally degraded moisture barrier with full infiltration without the benefit of bamboo. As the results indicated, loss of effectiveness of this clay layer did not significantly affect the results, in part because of the clay/gravel drain system, but also because the vaults themselves severely limit infiltration into the waste form.

\section{Recommendation \#14}

"A plan for long-term monitoring during the control period should be presented. The PRP understands that there currently are no plans for a near-field monitoring program to confirm PA assumptions and data. This monitoring could include TDR probes and suction lysimeters."

Response: The saltstone disposal facility has a plan for long-term monitoring, as required by the state of South Carolina under existing permits. The plan calls for monitoring of groundwater at the boundary of Z-Area and within Z-Area itself. In addition, several lysimeters have been constructed at the SRS that contain saltstone waste. Continued operation and monitoring of these lysimeters is planned.

\section{Recommendation \#15}

"Consideration of all disposal practices in the saltstone vaults, including the existing materials in vaults 1 and 4 should be included in the PA."

Response: Tables and brief discussions that compare the concentrations of key radionuclides in Cells $A$ and B of Vault 1 and Cell A of Vault 4 to the projected concentrations used in the RPA have been added to Section 2.6. Radionuclide concentrations in these two cells are significantly lower than the concentrations used as the design basis for the disposal site and as a basis for establishing acceptable long-term performance. 
Recommendation \#16

The PRP supports expanded efforts to re-evaluate the waste inventory in light of recent mission-related production changes at the Savannah River Site. An expanded discussion of the wastes should be provided, including their origin, processing steps, the QA program, the waste acceptance program, and potential variations in waste composition that may be encountered."

Reaponse: The projected waste inventory used in this RPA assumed a continuation of the historic nuclear materials production mission at the SRS. Although the long-term mission at SRS is uncertain, the projected inventory used in the RPA is conservative, since discontinued production would reduce the total inventory used as the basis for the RPA. Results of this RPA will be used to validate waste acceptance criteria for the SDF. As a part of the maintenance of the performance assessment that is required by DOE Order $5820.2 \mathrm{~A}$, the total inventory and its composition will be reviewed periodically to provide reasonable assurance that long-term performance goals are met. The discussion in Sect. 25.1 has been expanded to reflect the possible impact of a change in the SRS mission. 


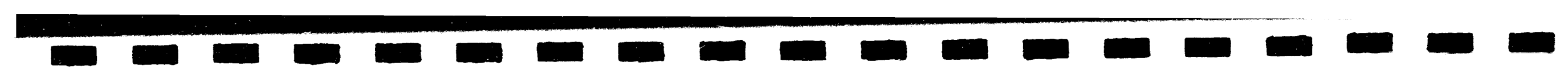

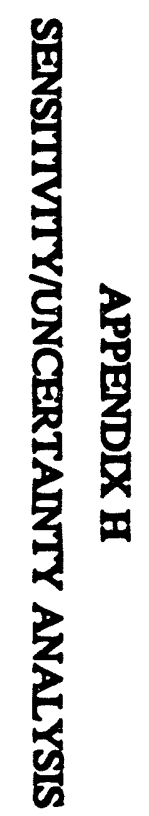

$\Lambda$ 


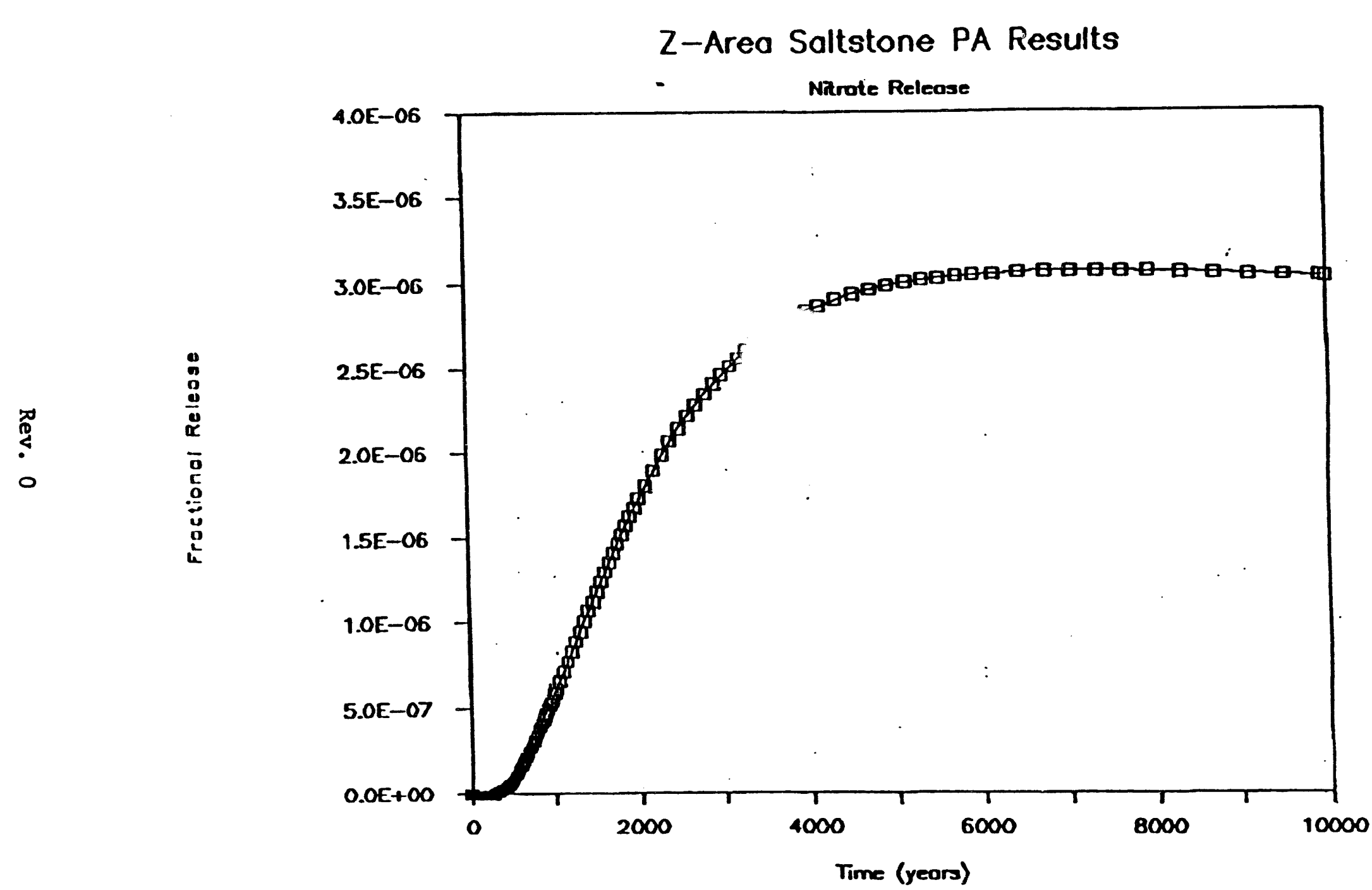

Fig. H.1-1. Fractional nitrate flux release as a function of time for reference run. 


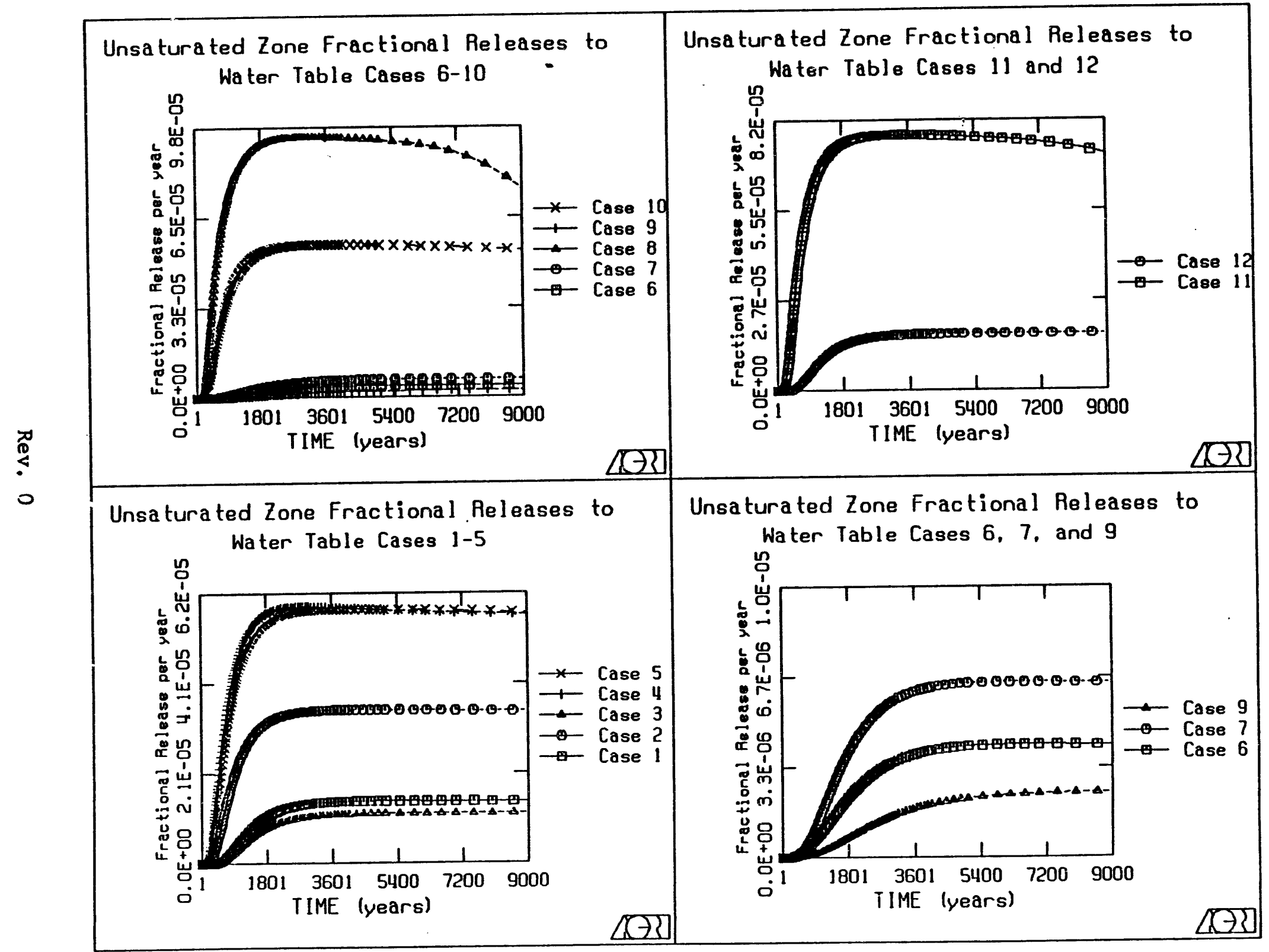

Fig. H.1-2. Fractionan nitrate flux release of a function of time for twelve uncertainty analysis runs. 


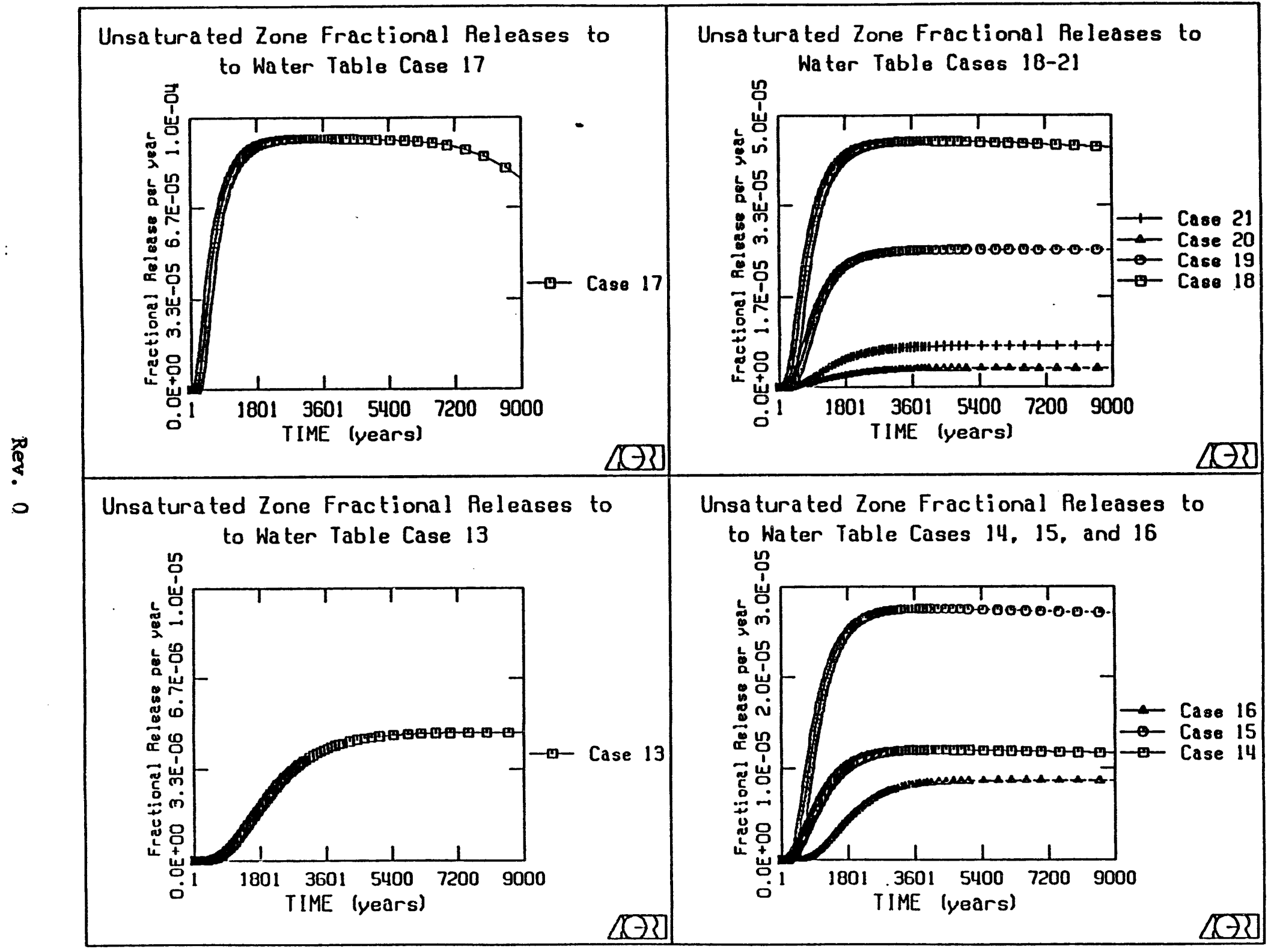

Fig. H.1-3. Fractional nitrate flux release as a function of time for nine uncertainty analysis runs. 


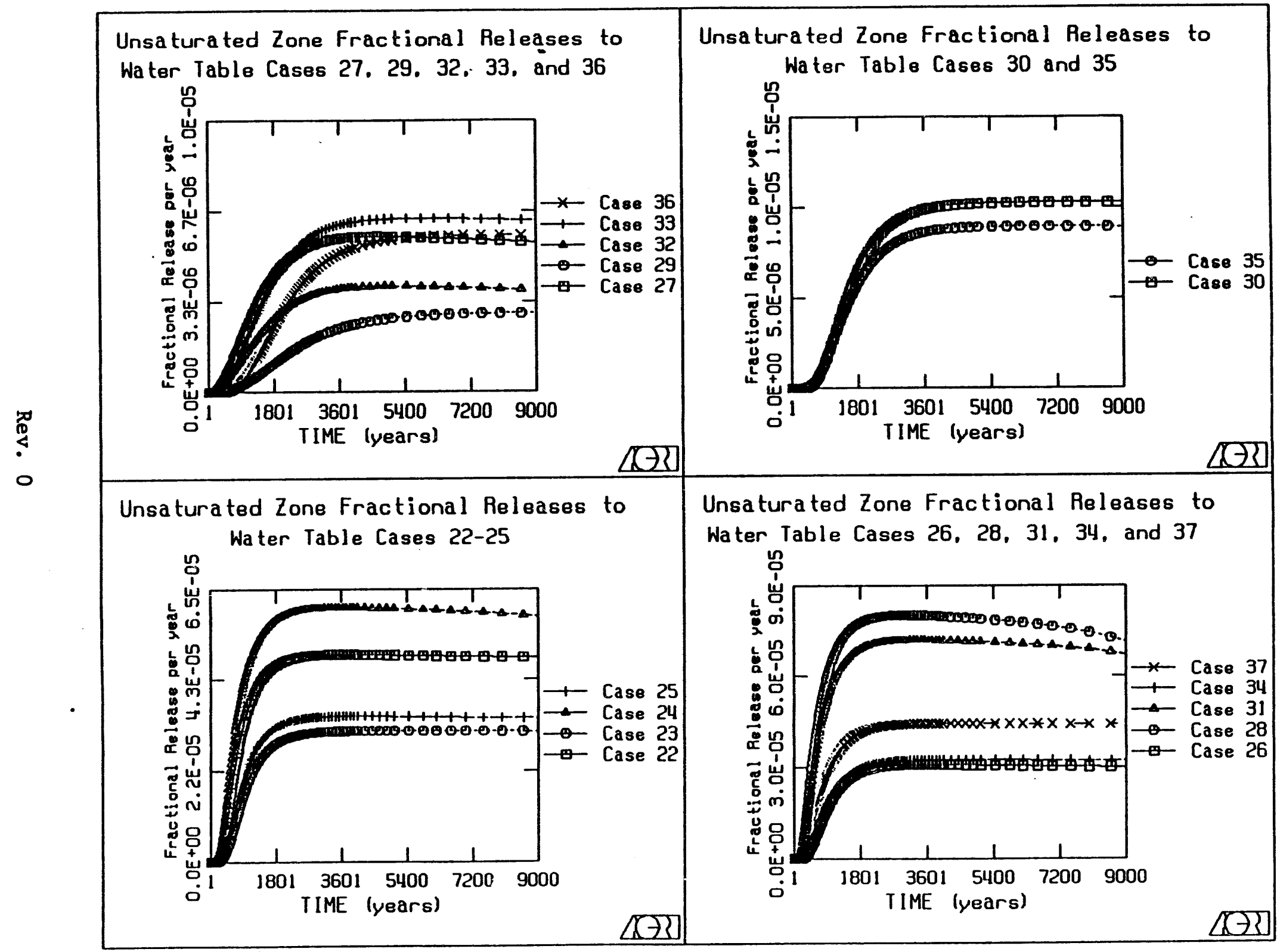

Fig. H.1-4. Fractional nitrate flux release as a function of time for sixteen uncertainty analysis runs. 


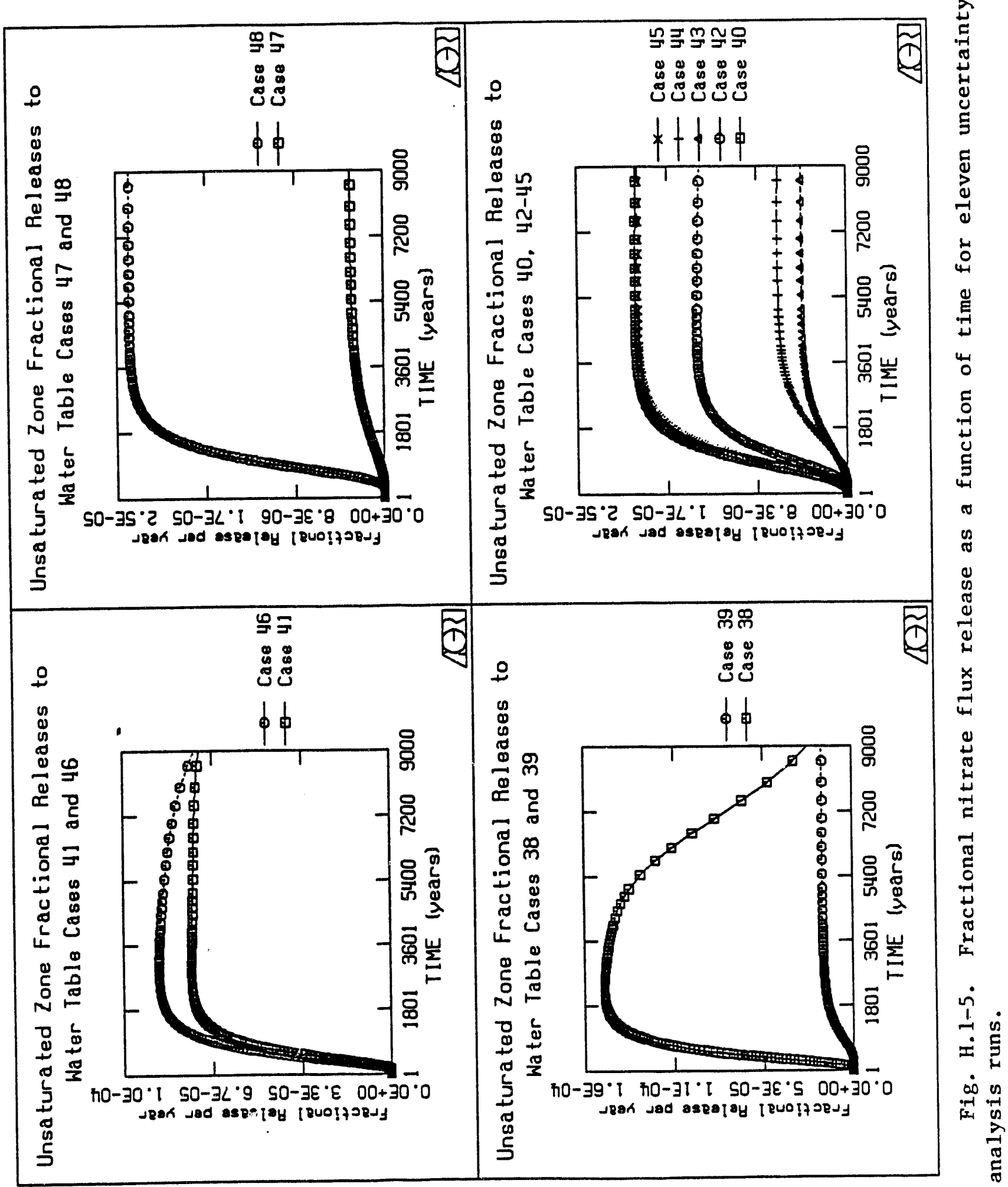

Rey. 0 


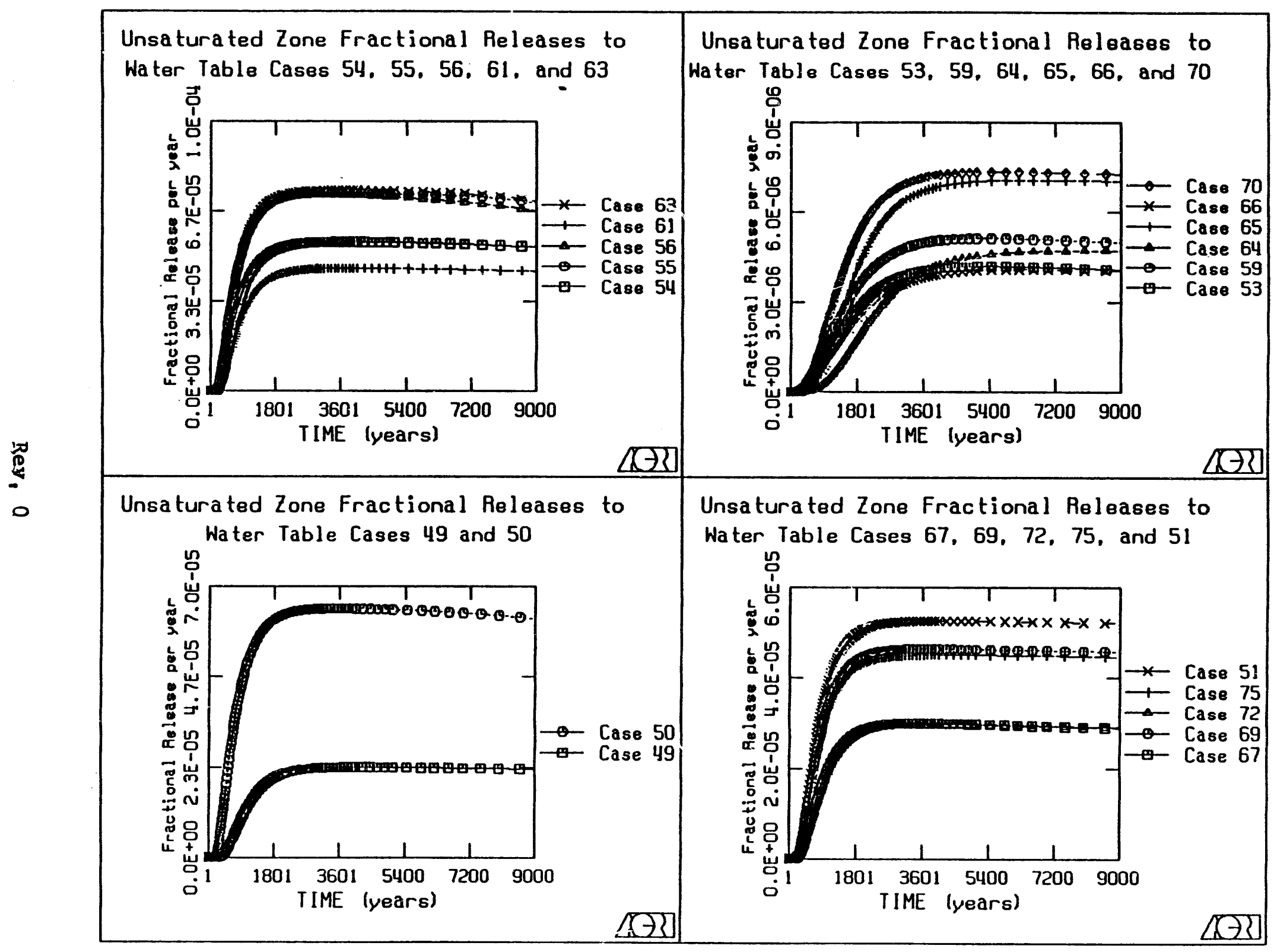

Fig. H.1-6. Fractional nitrate flux release as a function of time for eighteen uncertainty analysis runs. 


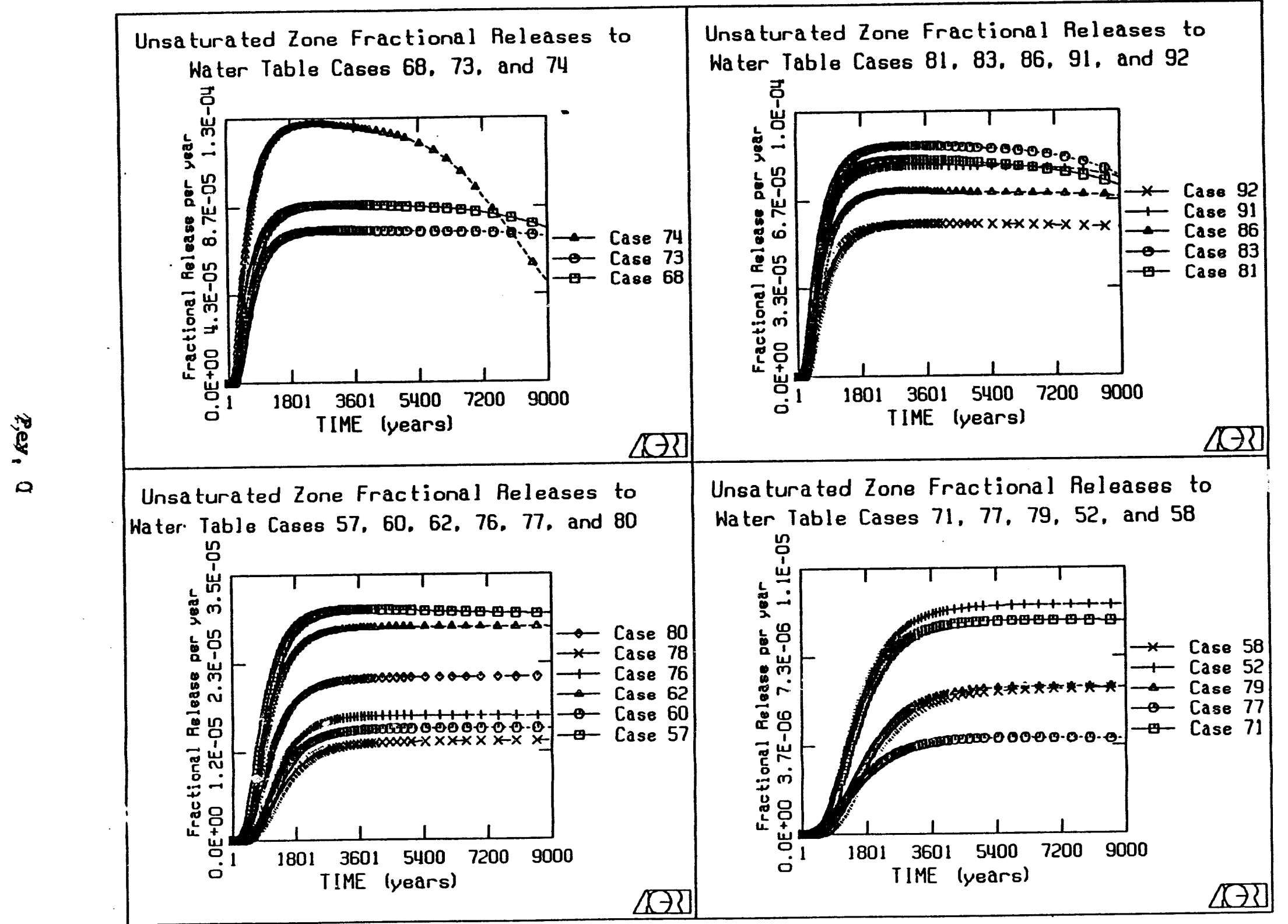

Fig. 11.1-7. Fractional nitrate flux release as a function of time for nineteen uncertainty analysis runs. 


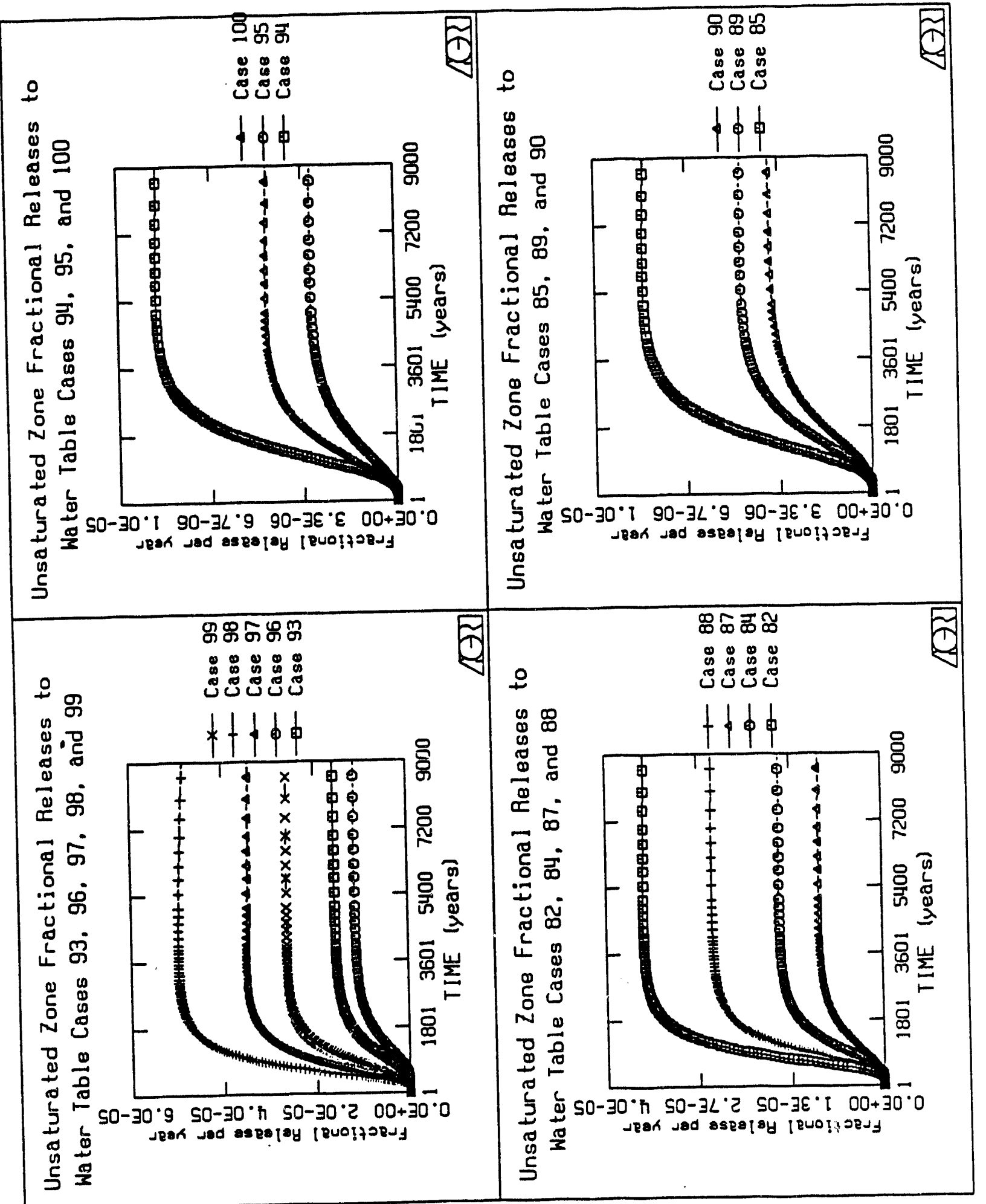

壱

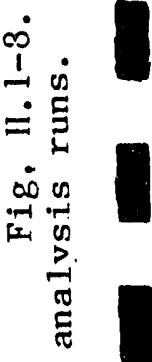

Rey. a 
Table H.1-1. Sampled parameter values for uncertainty analysis of near-field model; results for the 100 runs in terms of calculated peak fractional flux of nitrate to the water table and time of peak

\begin{tabular}{|c|c|c|c|c|c|c|}
\hline Run & $\begin{array}{c}\text { Saltstone } \\
\mathbf{K}_{\mathbf{z}}=\mathrm{K}_{\mathrm{y}} \\
\text { (cm/year) }\end{array}$ & $\begin{array}{c}\text { Saltstone } \\
\mathrm{D}_{\text {eft }} \\
\left(\mathrm{cm}^{2} / \text { year }\right)\end{array}$ & $\begin{array}{c}\text { Concrete } \\
\mathbf{K}_{\mathbf{z}}=\mathbf{K}_{\mathbf{y}} \\
\text { (cm/year) }\end{array}$ & $\begin{array}{c}\text { Concrete } \\
\mathrm{D}_{\text {efi }} \\
\text { (cm²/year) }\end{array}$ & $\begin{array}{l}\text { Peak Flux } \\
\text { (per year) }\end{array}$ & $\begin{array}{c}\text { Time } \\
\text { (years) }\end{array}$ \\
\hline 1 & $3.27 \times 10^{-3}$ & $7.274 \times 10^{-2}$ & $2706 \times 10^{-3}$ & 0.282 & $1.413 \times 10^{.5}$ & 5248 \\
\hline 2 & $3.109 \times 10^{-2}$ & 0.133 & $1.659 \times 10^{-3}$ & 0.683 & $3.518 \times 10^{-5}$ & 4342 \\
\hline$\dot{3}$ & $4.237 \times 10^{-3}$ & 0.225 & $8.513 \times 10^{4}$ & 0.359 & $1.137 \times 10^{-5}$ & 7499 \\
\hline 4 & $1.236 \times 10^{-2}$ & 0.146 & $3.154 \times 10^{-2}$ & 0.490 & $5.904 \times 10^{-5}$ & 2780 \\
\hline 5 & $2.282 \times 10^{-2}$ & 0.209 & $4.572 \times 10^{-3}$ & 0.401 & $5.832 \times 10^{-5}$ & 3996 \\
\hline 6 & $5.872 \times 10^{-4}$ & 0.306 & $6.635 \times 10^{-3}$ & 0.290 & $4.163 \times 10^{-6}$ & 6804 \\
\hline 7 & $1.171 \times 10^{-3}$ & 0.110 & $3.174 \times 10^{-3}$ & 0.333 & $6.469 \times 10^{-6}$ & 6605 \\
\hline 8 & $6.116 \times 10^{-2}$ & 0.188 & $5.215 \times 10^{-3}$ & 0.132 & $9.472 \times 10^{-5}$ & 3041 \\
\hline 9 & $3.154 \times 10^{4}$ & 0.161 & $1.877 \times 10^{-3}$ & 0.204 & $2.388 \times 10^{-6}$ & $9000^{*}$ \\
\hline 10 & 0.147 & 0.120 & $2.173 \times 10^{-3}$ & 0.236 & $5.552 \times 10^{-5}$ & 3541 \\
\hline 11 & $5.605 \times 10^{-2}$ & 0.122 & $4.042 \times 10^{-3}$ & 0.267 & $7.773 \times 10^{-5}$ & 3341 \\
\hline 12 & $7.165 \times 10^{-3}$ & 0.146 & $1.194 \times 10^{-3}$ & 0.375 & $1.717 \times 10^{-5}$ & 6205 \\
\hline 13 & $8.010 \times 10^{-4}$ & 0.222 & $3.153 \times 10^{-3}$ & 0.210 & $4.657 \times 10^{-6}$ & 7999 \\
\hline 14 & $2.122 \times 10^{-3}$ & 0.213 & $7.247 \times 10^{-3}$ & 0.697 & $1.196 \times 10^{-5}$ & 4146 \\
\hline 15 & $6.620 \times 10^{-3}$ & 0.173 & $5.153 \times 10^{-3}$ & 0.295 & $2.756 \times 10^{-5}$ & 3891 \\
\hline 16 & $1.735 \times 10^{-3}$ & 0.180 & $3.262 \times 10^{-3}$ & 0.100 & $8.634 \times 10^{-6}$ & 6405 \\
\hline 17 & $3.084 \times 10^{-2}$ & 0.131 & $9.100 \times 10^{-3}$ & 0.244 & $9.218 \times 10^{-5}$ & 3441 \\
\hline 18 & 0.143 & 0.114 & $1.734 \times 10^{-3}$ & 0.320 & $4.518 \times 10^{-5}$ & 3891 \\
\hline 19 & $1.326 \times 10^{-2}$ & 0.282 & $1.493 \times 10^{-3}$ & 0.448 & $2.524 \times 10^{-5}$ & 5445 \\
\hline 20 & $3.895 \times 10^{-4}$ & $9.919 \times 10^{-2}$ & $2.296 \times 10^{-3}$ & 0.424 & $3.521 \times 10^{-6}$ & 5645 \\
\hline 21 & $1.504 \times 10^{-3}$ & 0.163 & $1.842 \times 10^{-3}$ & 0.428 & $7.591 \times 10^{-6}$ & 5845 \\
\hline 22 & $1.370 \times 10^{-2}$ & 0.133 & $6.600 \times 10^{-3}$ & 0.354 & $4.928 \times 10^{-5}$ & 3541 \\
\hline 23 & $3.372 \times 10^{-2}$ & 0.238 & $1.383 \times 10^{-3}$ & 0.281 & $3.109 \times 10^{-5}$ & 4947 \\
\hline 24 & $5.645 \times 10^{-2}$ & 0.183 & $2.851 \times 10^{-3}$ & 0.346 & $6.055 \times 10^{-5}$ & 3641 \\
\hline
\end{tabular}


$\mathrm{H}-10$

WSRC-RP-92-1360

Table H.1-1. (continued)

\begin{tabular}{|c|c|c|c|c|c|c|}
\hline Run & $\begin{array}{c}\text { Saltstone } \\
\mathbf{K}_{\mathbf{z}}=\mathbf{K}_{\mathbf{y}} \\
\text { (cm/year) }\end{array}$ & $\begin{array}{l}\text { Saltstone } \\
\mathrm{D}_{\text {eff }} \\
\text { (cm²/year) }\end{array}$ & $\begin{array}{c}\text { Concrete } \\
\mathbf{K}_{\mathbf{z}}=\mathrm{K}_{\mathbf{y}} \\
\text { (cm/year) }\end{array}$ & $\begin{array}{c}\text { Concrete } \\
\text { Defu }^{\text {ex }} \\
\left(\mathrm{cm}^{2} / \text { year }\right)\end{array}$ & $\begin{array}{l}\text { Peak Flux } \\
\text { (per year) }\end{array}$ & $\begin{array}{c}\text { Time } \\
\text { (years) }\end{array}$ \\
\hline 25 & $9.476 \times 10^{-3}$ & 0.292 & $4.568 \times 10^{-3}$ & 0.439 & $3.458 \times 10^{-5}$ & 3941 \\
\hline 26 & $6.776 \times 10^{-3}$ & 0.151 & $8.833 \times 10^{-3}$ & 0.152 & $3.079 \times 10^{-5}$ & 3441 \\
\hline 27 & $8.318 \times 10^{4}$ & 0.113 & $4.861 \times 10^{-3}$ & 0.553 & $5.742 \times 10^{-6}$ & 4642 \\
\hline 28 & 0.128 & 0.130 & $3.371 \times 10^{-3}$ & 0.302 & $8.003 \times 10^{-5}$ & 2980 \\
\hline 29 & $4.088 \times 10^{-4}$ & 0.204 & $2.152 \times 10^{-3}$ & 0.226 & $2.904 \times 10^{-6}$ & $9000^{*}$ \\
\hline 30 & $2.894 \times 10^{-3}$ & $9.353 \times 10^{-4}$ & $1.164 \times 10^{-3}$ & 0.245 & $1.027 \times 10^{-5}$ & 8296 \\
\hline 31 & $6.864 \times 10^{-2}$ & 0.212 & $3.369 \times 10^{-3}$ & 0.270 & $7.176 \times 10^{-5}$ & 3341 \\
\hline 32 & $3.927 \times 10^{-4}$ & 0.126 & $9.609 \times 10^{-3}$ & 0.451 & $3.926 \times 10^{-6}$ & 5052 \\
\hline 33 & $1.071 \times 10^{.3}$ & 0.192 & $5.014 \times 10^{-3}$ & 0.371 & $6.407 \times 10^{-6}$ & 5845 \\
\hline 34 & $9.198 \times 10^{-3}$ & 0.231 & $4.010 \times 10^{-3}$ & 0.207 & $3.234 \times 10^{-5}$ & 4342 \\
\hline 35 & $2.147 \times 10^{.3}$ & 0.284 & $1.334 \times 10^{-3}$ & 0.313 & $8.957 \times 10^{-6}$ & 6605 \\
\hline 36 & $1.152 \times 10^{-3}$ & 0.109 & $1.790 \times 10^{-3}$ & 0.193 & $5.790 \times 10^{-6}$ & $9000^{*}$ \\
\hline 37 & $1.906 \times 10^{-2}$ & $9.666 \times 10^{-2}$ & $3.132 \times 10^{-3}$ & 0.318 & $4.432 \times 10^{-5}$ & 4442 \\
\hline 38 & 0.154 & 0.139 & $7.015 \times 10^{-3}$ & 0.240 & $1.484 \times 10^{-4}$ & 2255 \\
\hline 39 & $4,490 \times 10^{-3}$ & 0.169 & $2.567 \times 10^{-3}$ & 0.424 & $1.769 \times 10^{-5}$ & 5052 \\
\hline 40 & $2.825 \times 10^{-2}$ & 0.153 & $8.073 \times 10^{-4}$ & 0.759 & $1.962 \times 10^{-5}$ & 5249 \\
\hline 41 & $1.896 \times 10^{-2}$ & 0.191 & $1.369 \times 10^{-2}$ & 0.335 & $7.471 \times 10^{.5}$ & 2930 \\
\hline 42 & $2.678 \times 10^{-3}$ & 0.156 & $6.533 \times 10^{-3}$ & 0.460 & $1.391 \times 10^{-5}$ & 4642 \\
\hline 43 & $6.057 \times 10^{-4}$ & 0.210 & $1.565 \times 10^{-3}$ & 0.367 & $4.166 \times 10^{-6}$ & 6405 \\
\hline 44 & $1.148 \times 10^{-3}$ & 0.328 & $4.067 \times 10^{-3}$ & 0.208 & $6.391 \times 10^{-6}$ & 6804 \\
\hline 45 & $2.453 \times 10^{-2}$ & 0.125 & $8.234 \times 10^{-4}$ & 0.596 & $1.944 \times 10^{-5}$ & 5845 \\
\hline 46 & 0.142 & 0.251 & $3.656 \times 10^{-3}$ & 0.399 & $8.695 \times 10^{-5}$ & 2905 \\
\hline 47 & $4.066 \times 10^{4}$ & 0.134 & $2.182 \times 10^{-3}$ & 0.288 & $3.086 \times 10^{-6}$ & 7749 \\
\hline 48 & $8.577 \times 10^{-3}$ & 0.102 & $1.995 \times 10^{-3}$ & 0.236 & $2.386 \times 10^{-5}$ & 5645 \\
\hline 49 & $5.372 \times 10^{-3}$ & $9.736 \times 10^{-2}$ & $4.981 \times 10^{-3}$ & 0.260 & $2.333 \times 10^{-5}$ & 3995 \\
\hline 80 & $5.527 \times 10^{-2}$ & 0.170 & $3.107 \times 10^{-3}$ & 0.192 & $6.422 \times 10^{-5}$ & 3591 \\
\hline
\end{tabular}

Rev. 0 
b-11

WSRC-RP-92-1360

Table H.1-1. (continued)

\begin{tabular}{|c|c|c|c|c|c|c|}
\hline Run & $\begin{array}{c}\text { Saltstone } \\
\mathbf{K}_{\mathbf{z}}=\mathbf{K}_{\mathbf{y}} \\
\text { (cm/year) }\end{array}$ & $\begin{array}{c}\text { Saltstone } \\
\mathrm{D}_{\text {eft }} \\
\text { (cm²/year) }\end{array}$ & $\begin{array}{c}\text { Concrete } \\
\mathbf{K}_{\mathbf{z}}=\mathbf{K}_{\mathbf{y}} \\
\text { (cm/year) }\end{array}$ & $\begin{array}{c}\text { Concrete } \\
D_{\text {efl }} \\
\text { (cm²/year) }\end{array}$ & $\begin{array}{l}\text { Peak Flux } \\
\text { (per year) }\end{array}$ & $\begin{array}{c}\text { Time } \\
\text { (years) }\end{array}$ \\
\hline 51 & $1.853 \times 10^{-2}$ & 0.144 & $4.656 \times 10^{-3}$ & 0.294 & $5.254 \times 10^{-5}$ & 4050 \\
\hline 52 & $2.265 \times 10^{-3}$ & $6.444 \times 10^{-2}$ & $1.497 \times 10^{-3}$ & 0.330 & $9.464 \times 10^{-6}$ & 7004 \\
\hline $5 i$ & $4.951 \times 10^{-4}$ & 0.172 & $3.189 \times 10^{-3}$ & 0.443 & $4.192 \times 10^{-6}$ & 5445 \\
\hline 54 & $6.469 \times 10^{-2}$ & 0.319 & $2.446 \times 10^{-3}$ & 0.379 & $5.533 \times 10^{-5}$ & 3791 \\
\hline 55 & $3.671 \times 10^{-2}$ & 0.197 & $4.681 \times 10^{-3}$ & 0.704 & $7.355 \times 10^{-5}$ & 3491 \\
\hline 56 & 0.152 & 0.108 & $2.952 \times 10^{-3}$ & 0.263 & $7.295 \times 10^{-5}$ & 3141 \\
\hline 57 & $7.065 \times 10^{-3}$ & 0.132 & $6.715 \times 10^{-3}$ & 0.167 & $3.042 \times 10^{-5}$ & 3691 \\
\hline 58 & $1.938 \times 10^{-3}$ & 0.179 & $5.048 \times 10^{-4}$ & 0.243 & $6.015 \times 10^{-6}$ & $9000^{*}$ \\
\hline 59 & $7.371 \times 10^{-4}$ & 0.125 & $9.824 \times 10^{-3}$ & 0.425 & $5.123 \times 10^{-6}$ & 5445 \\
\hline 60 & $3.788 \times 10^{-3}$ & 0.222 & $2.095 \times 10^{-3}$ & 0.231 & $1.468 \times 10^{-5}$ & 6025 \\
\hline 61 & 0.106 & 0.189 & $1.796 \times 10^{-3}$ & 0.395 & $4.552 \times 10^{-5}$ & 3891 \\
\hline 62 & $1.814 \times 10^{-2}$ & 0.102 & $1.498 \times 10^{-3}$ & 0.303 & $2.813 \times 10^{-5}$ & 5248 \\
\hline 63 & $4.076 \times 10^{-2}$ & 0.136 & $4.462 \times 10^{.3}$ & 0.210 & $7.448 \times 10^{-5}$ & 3541 \\
\hline 64 & $8.461 \times 10^{-4}$ & 0.128 & $3.043 \times 10^{-3}$ & 0.183 & $4.734 \times 10^{-6}$ & $9000^{*}$ \\
\hline 65 & $1.366^{\prime} \times 10^{-3}$ & 0.327 & $2.211 \times 10^{-3}$ & 0.283 & $7.079 \times 10^{-6}$ & 6605 \\
\hline 66 & $5.546 \times 10^{4}$ & 0.198 & $3.530 \times 10^{-3}$ & 0.354 & $4.083 \times 10^{-6}$ & 6205 \\
\hline 67 & $6.294 \times 10^{-3}$ & 0.165 & $1.021 \times 10^{-2}$ & 0.486 & $2.990 \times 10^{-5}$ & 3441 \\
\hline 68 & $6.082 \times 10^{-2}$ & 0.220 & $4.679 \times 10^{-3}$ & 0.248 & $8.795 \times 10^{-5}$ & 3141 \\
\hline 69 & $1.307 \times 10^{-2}$ & $7.375 \times 10^{-2}$ & $6.022 \times 10^{-3}$ & 0.344 & $4.644 \times 10^{-5}$ & 3641 \\
\hline 70 & $2.123 \times 10^{-3}$ & 0.157 & $6.169 \times 10^{-4}$ & 0.517 & $7.335 \times 10^{-6}$ & 5845 \\
\hline 71 & $1.914 \times 10^{-3}$ & 0.267 & $1.827 \times 10^{-3}$ & 0.294 & $8.826 \times 10^{-6}$ & 6605 \\
\hline 72 & $6.983 \times 10^{-3}$ & 0.108 & $5.904 \times 10^{-3}$ & 0.370 & $2.960 \times 10^{-5}$ & 3741 \\
\hline 73 & $2.009 \times 10^{-2}$ & 0.179 & $1.158 \times 10^{-2}$ & 0.586 & $7.514 \times 10^{-5}$ & 2980 \\
\hline 74 & 0.121 & 0.168 & $6.115 \times 10^{-3}$ & 0.226 & $1.272 \times 10^{-4}$ & 2605 \\
\hline 75 & $2.767 \times 10^{-2}$ & 0.254 & $2.483 \times 10^{-3}$ & 0.444 & $4.505 \times 10^{-5}$ & 4242 \\
\hline 76 & $3.780 \times 10^{-3}$ & 0.156 & $3.356 \times 10^{-3}$ & 0.153 & $1.635 \times 10^{-5}$ & 4947 \\
\hline
\end{tabular}

Rev. 0 
H-12

WSRC-RP-92-1360

Table H.1-1. (continued)

\begin{tabular}{|c|c|c|c|c|c|c|}
\hline Run & $\begin{array}{c}\text { Saltstone } \\
\mathbf{K}_{\mathbf{z}}=\mathbf{K}_{\mathbf{y}} \\
\text { (cm/year) }\end{array}$ & $\begin{array}{c}\text { Saltstone } \\
\text { Dea } \\
\text { (cm²/year) }\end{array}$ & $\begin{array}{c}\text { Concrete } \\
\mathbf{K}_{\mathbf{z}}=\mathrm{K}_{\mathbf{y}} \\
\text { (cm/year) }\end{array}$ & $\begin{array}{c}\text { Concrete } \\
D_{\text {eff }} \\
\text { (cm²/year) }\end{array}$ & $\begin{array}{l}\text { Peak Flux } \\
\text { (per year) }\end{array}$ & $\begin{array}{c}\text { Time } \\
\text { (years) }\end{array}$ \\
\hline 77 & $5.410 \times 10^{-4}$ & $9.351 \times 10^{-2}$ & $2.784 \times 10^{-3}$ & 0.406 & $3.978 \times 10^{-6}$ & 5845 \\
\hline 78 & $5.421 \times 10^{-2}$ & 0.116 & $4.812 \times 10^{-4}$ & 0.278 & $1.303 \times 10^{-5}$ & 8296 \\
\hline 79 & $1.071 \times 10^{-3}$ & 0.206 & $4.650 \times 10^{-3}$ & 0.237 & $6.085 \times 10^{-6}$ & 6804 \\
\hline 80 & $1.139 \times 10^{-2}$ & 0.134 & $1.264 \times 10^{-3}$ & 0.337 & $2.149 \times 10^{-5}$ & 6025 \\
\hline 81 & 0.124 & 0.196 & $3.494 \times 10^{-3}$ & 0.377 & $8.219 \times 10^{-5}$ & 2980 \\
\hline 82 & $3.365 \times 10^{-2}$ & $8.016 \times 10^{-2}$ & $1.591 \times 10^{-3}$ & 0.204 & $3.460 \times 10^{-5}$ & 5845 \\
\hline 83 & $5.623 \times 10^{-2}$ & 0.175 & $4.805 \times 10^{-3}$ & 0.303 & $8.734 \times 10^{-5}$ & 3191 \\
\hline 84 & $4.107 \times 10^{-3}$ & 0.312 & $1.757 \times 10^{-3}$ & 0.432 & $1.497 \times 10^{-5}$ & 5445 \\
\hline 85 & $1.493 \times 10^{-3}$ & 0.147 & $7.239 \times 10^{-3}$ & 0.254 & $8.249 \times 10^{-6}$ & 5845 \\
\hline 86 & $1.903 \times 10^{-2}$ & 0.140 & $1.039 \times 10^{-2}$ & 0.494 & $7.023 \times 10^{-5}$ & 3091 \\
\hline 87 & $2.606 \times 10^{-3}$ & 0.125 & $8.665 \times 10^{-4}$ & 0.582 & $9.149 \times 10^{-6}$ & 5445 \\
\hline 88 & $7.943 \times 10^{-3}$ & 0.158 & $2.415 \times 10^{-3}$ & 0.171 & $2.467 \times 10^{-5}$ & 5445 \\
\hline 89 & $7.273 \times 10^{-4}$ & 0.241 & $3.044 \times 10^{-3}$ & 0.330 & $4.701 \times 10^{-6}$ & 6605 \\
\hline 90 & $5.470 \times 10^{-4}$ & 0.100 & $4.254 \times 10^{-3}$ & 0.282 & $3.656 \times 10^{-6}$ & 7499 \\
\hline 91 & $2579 \times 10^{-2}$ & 0.142 & $8.246 \times 10^{-3}$ & 0.247 & $7.980 \times 10^{-5}$ & 3441 \\
\hline 92 & $4.755 \times 10^{-2}$ & 0.241 & $2.828 \times 10^{-3}$ & 0.506 & $5.777 \times 10^{-5}$ & 3691 \\
\hline 93 & $1.343 \times 10^{-2}$ & 0.178 & $7.419 \times 10^{-4}$ & 0.304 & $1.579 \times 10^{-5}$ & 7749 \\
\hline 94 & $1.656 \times 10^{-3}$ & 0.212 & $3.232 \times 10^{-3}$ & 0.330 & $8.642 \times 10^{-6}$ & 5845 \\
\hline 95 & $3.332 \times 10^{-4}$ & $9.098 \times 10^{-2}$ & $1.414 \times 10^{-3}$ & 0.370 & $3.051 \times 10^{-6}$ & 6405 \\
\hline 96 & $2.522 \times 10^{-3}$ & 0.171 & $2.547 \times 10^{-3}$ & 0.202 & $1.145 \times 10^{-5}$ & 5845 \\
\hline 97 & $9.027 \times 10^{-3}$ & 0.105 & $5.250 \times 10^{-3}$ & 0.568 & $3.485 \times 10^{-5}$ & 3741 \\
\hline 98 & $9.351 \times 10^{-2}$ & 0.125 & $2.016 \times 10^{-3}$ & 0.282 & $4.970 \times 10^{-5}$ & 3791 \\
\hline 99 & $6.646 \times 10^{-3}$ & 0.148 & $4.263 \times 10^{-3}$ & 0.192 & $2.631 \times 10^{-5}$ & 4242 \\
\hline 100 & $6.128 \times 10^{4}$ & 0.272 & $6.636 \times 10^{-3}$ & 0.401 & $4.706 \times 10^{-6}$ & 5445 \\
\hline
\end{tabular}

- Results were only obtained up to 9000 years, but the slope of the plots at that point indicate the values are very near, if not, the peak. 
Table H.2-1. Variable input for the 100 uncertainty runs for the groundwater transport model (see footnote to table for explanation of data entries)

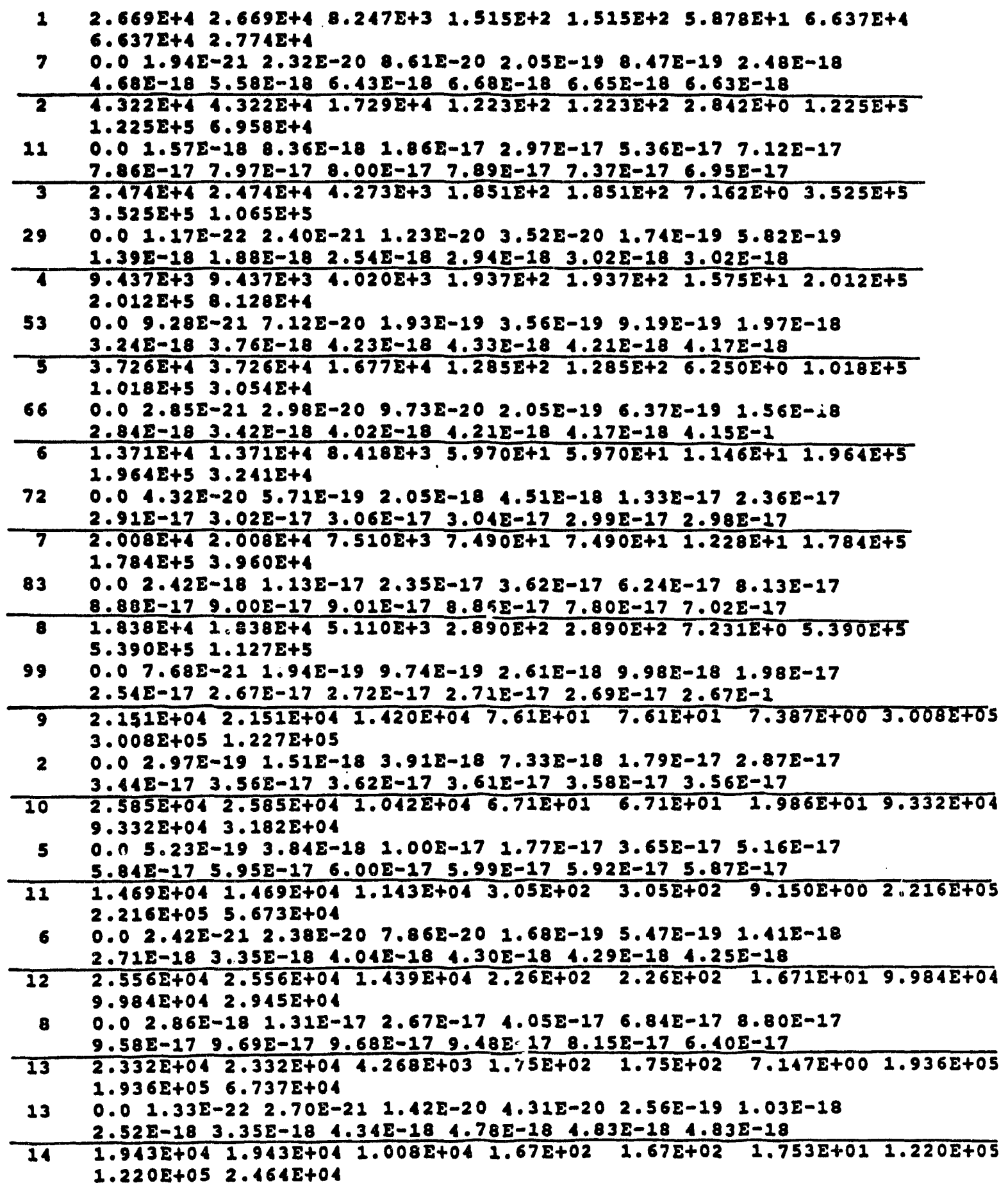

Rev. 0 
Table H.2-1. (continued)

$17 \quad 0.0 \quad 3.00 E-18 \quad 1.29 E-17 \quad 2.60 E-17 \quad 3.93 E-17 \quad 6.68 E-17 \quad 8.63 E-17$

$9.41 E-17 \quad 9.52 E-17 \quad 0.545-17 \quad 9.46 E-17 \quad 8.02 E-17 \quad 6.475-17$

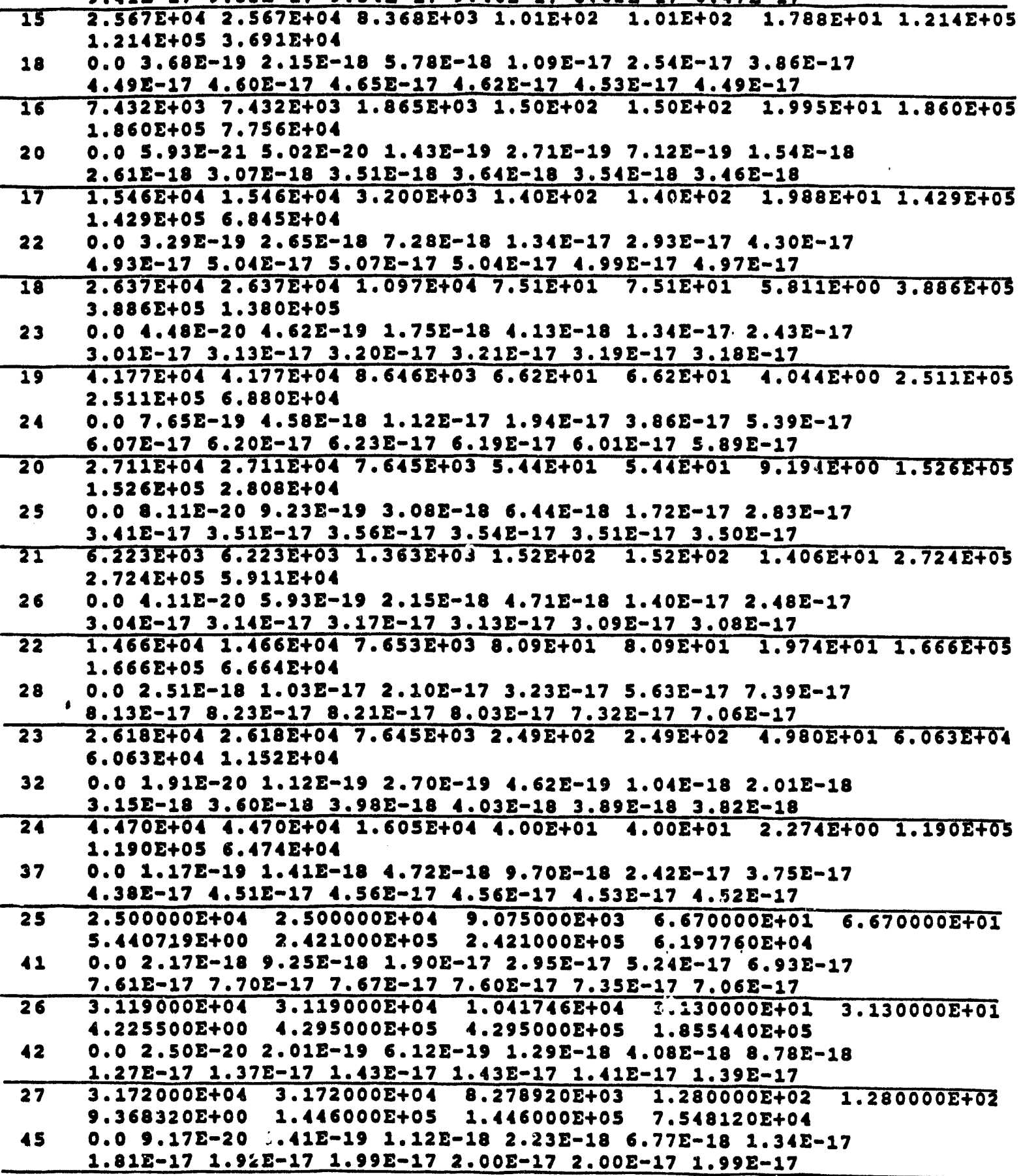

Rev. 0 

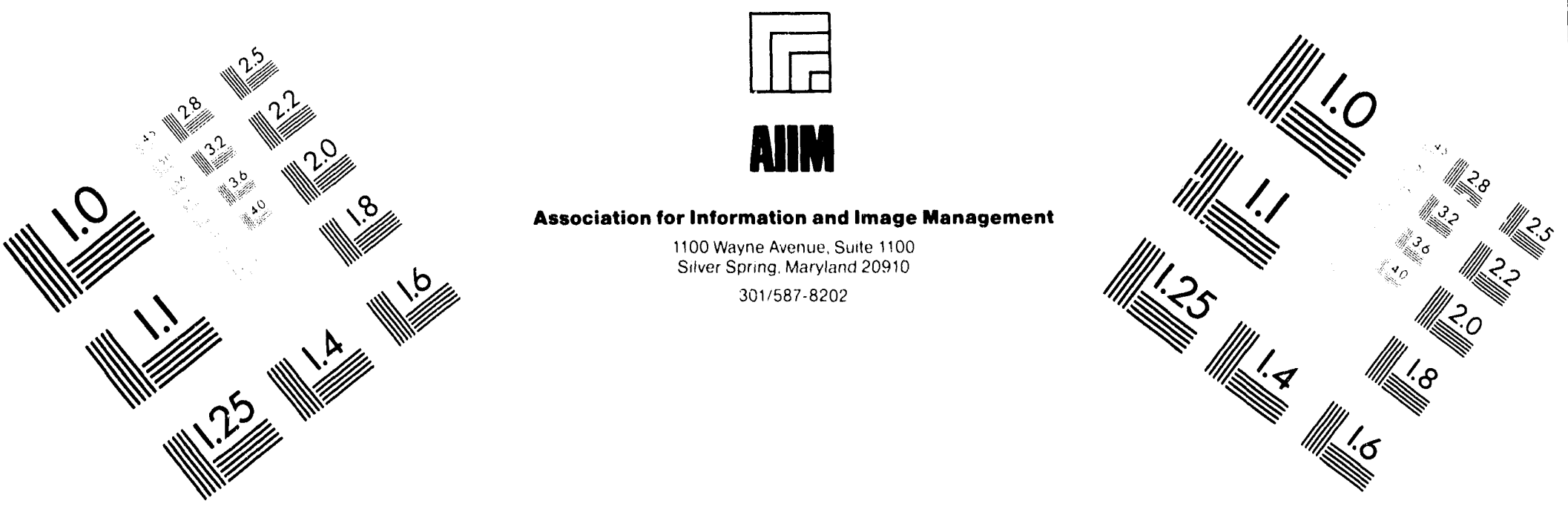

\section{Centimeter}

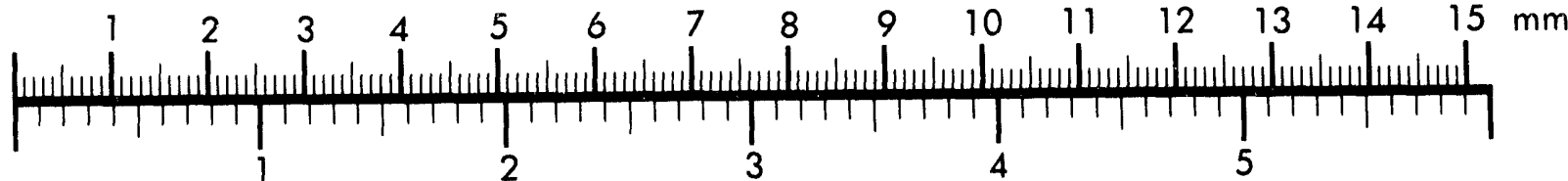

Inches
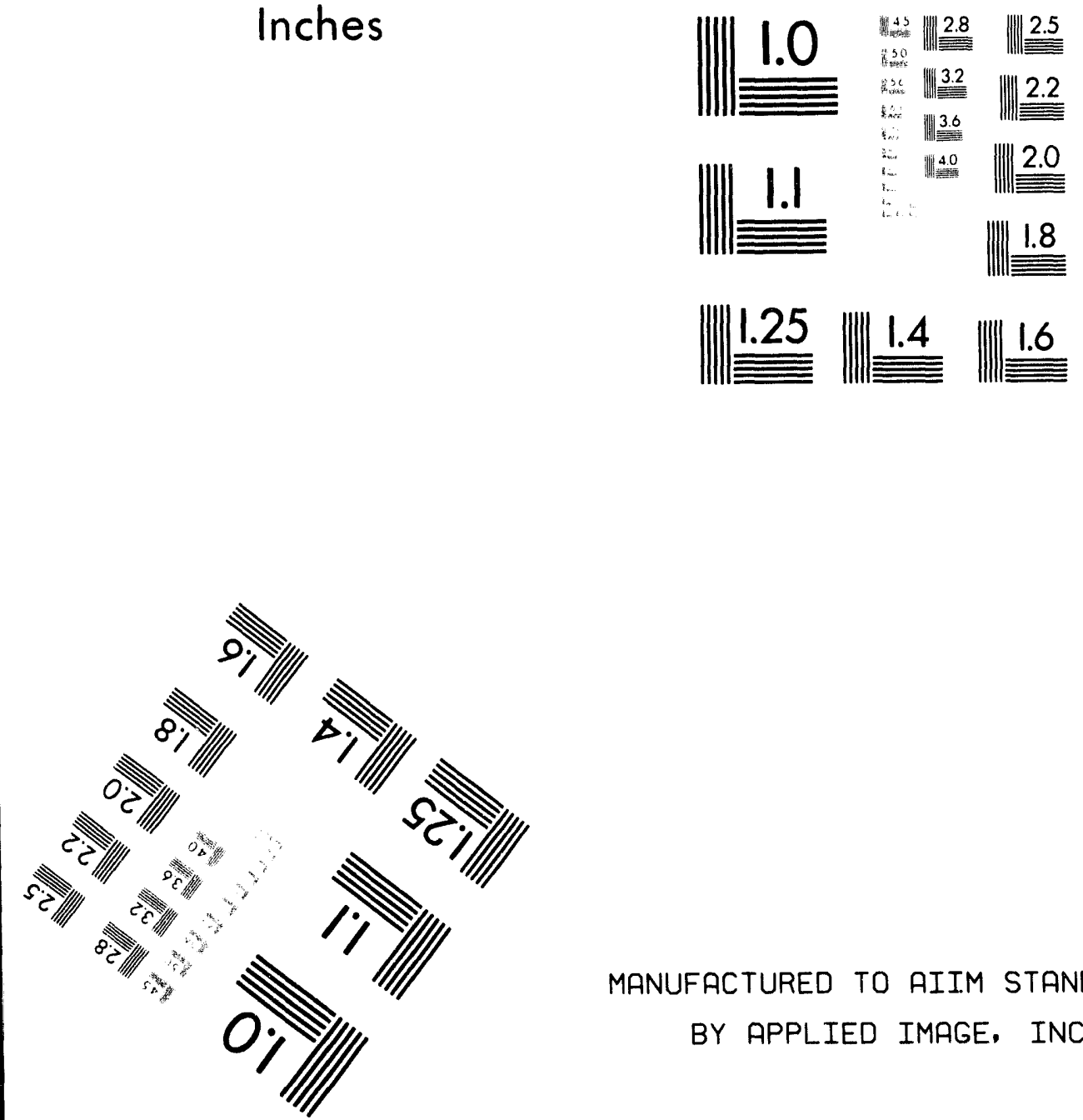

MANUFACTURED TO AIIM STANDARDS

BY APPLIED IMAGE, INC.

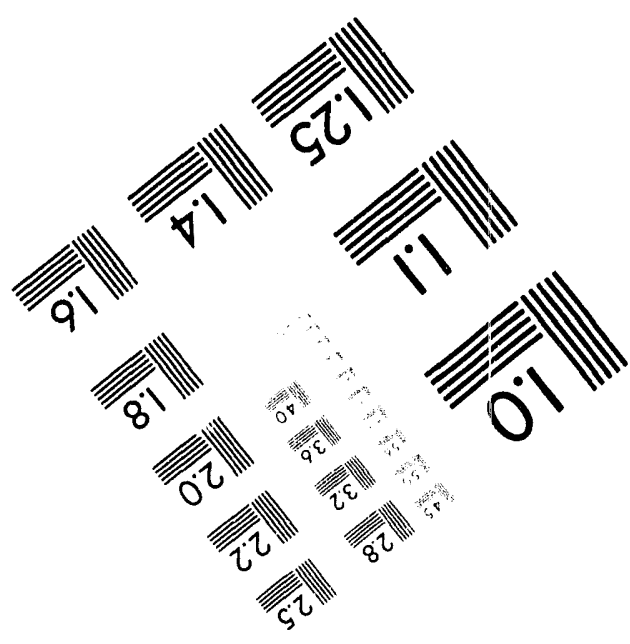



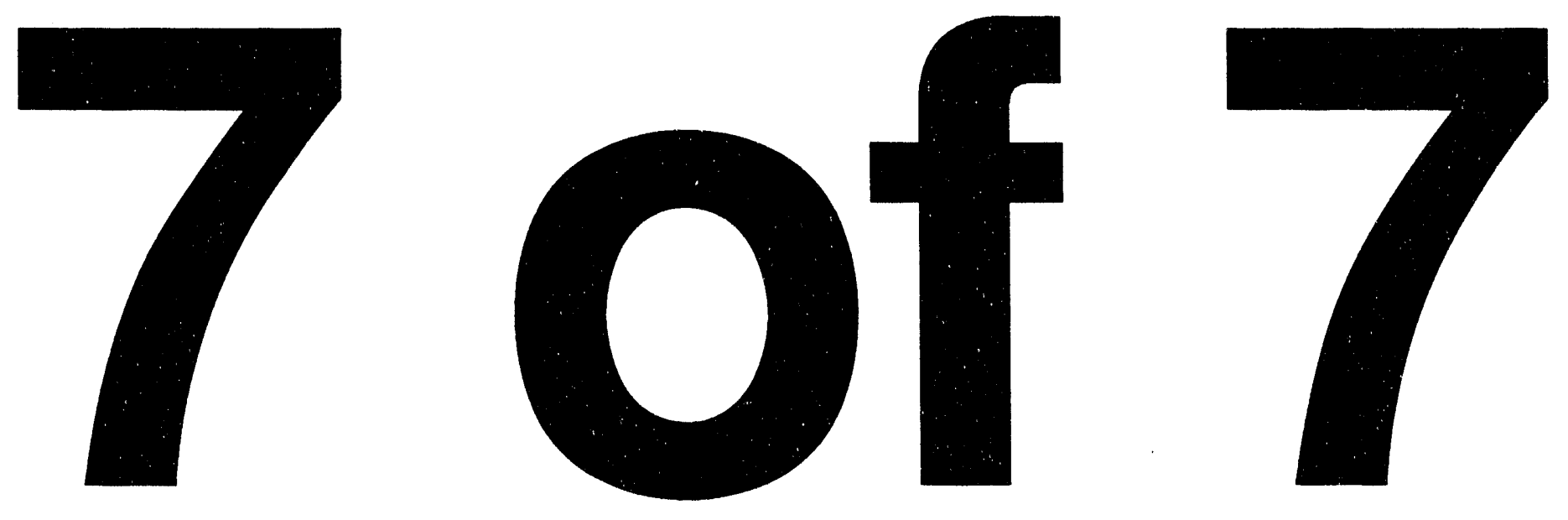
Table H.2-1. (continued)

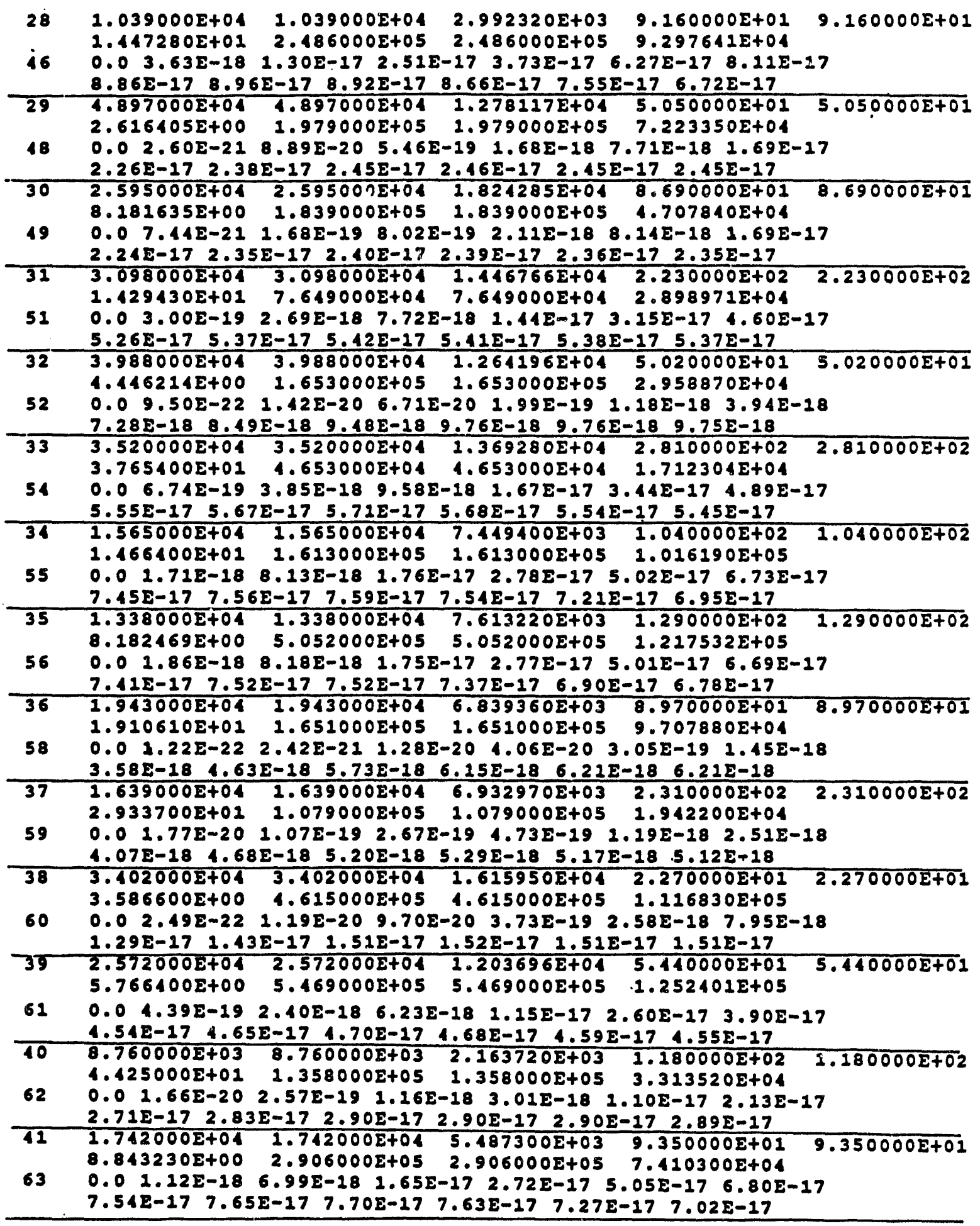

Rev. 0 
Table H.2-1. (continued)

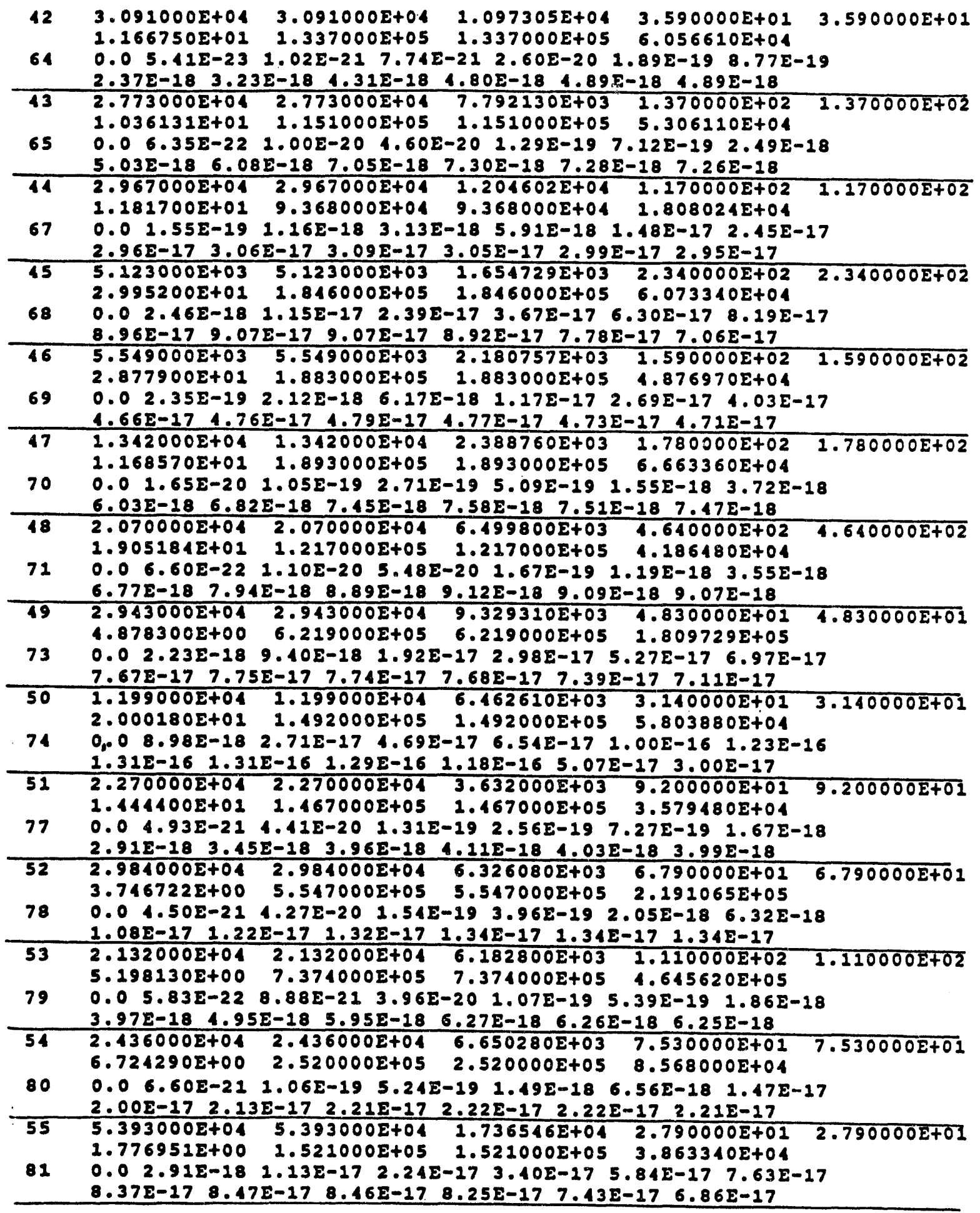

Rev. 0 
Table H.2-1. (continued)

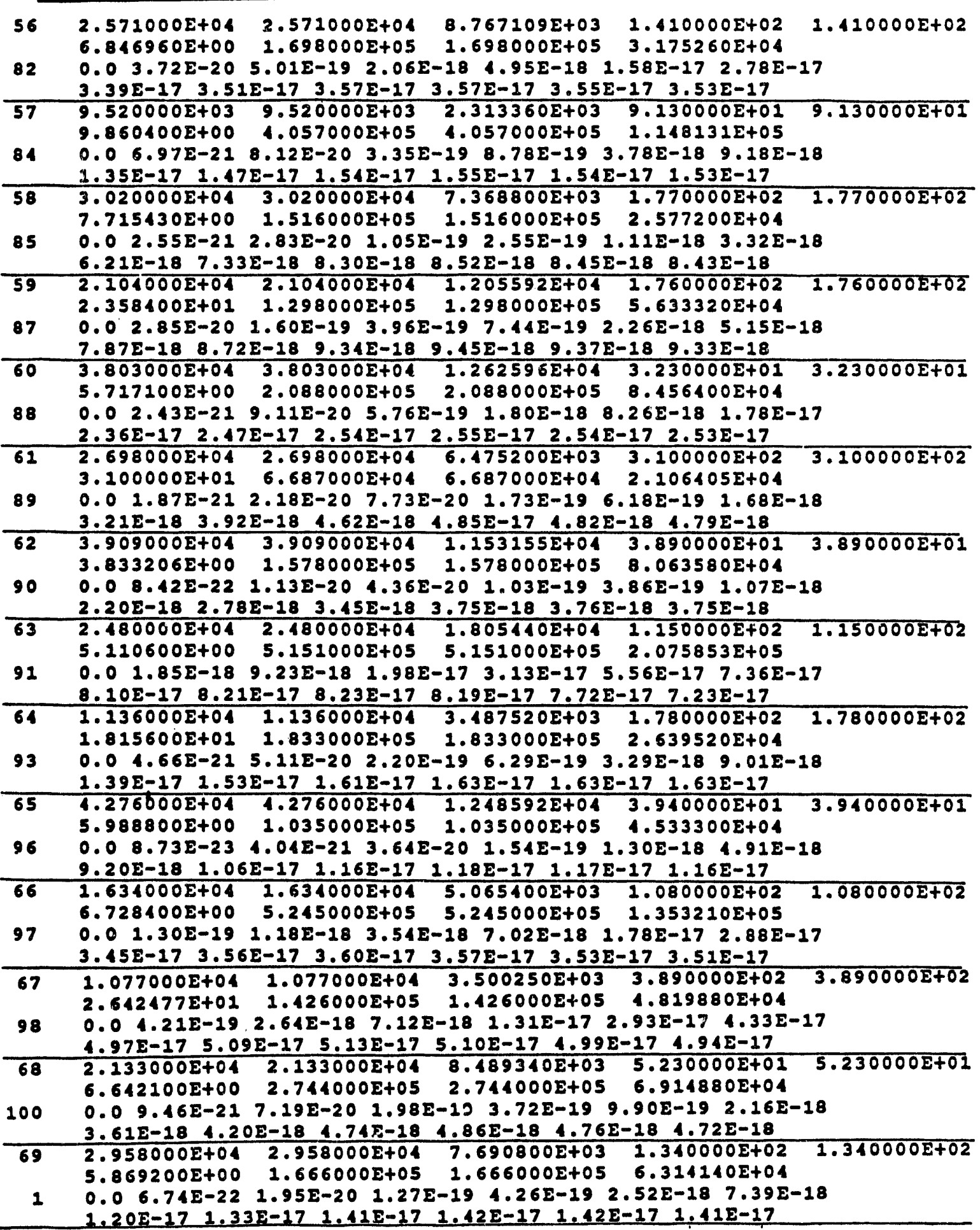


Table H2-1. (continued)

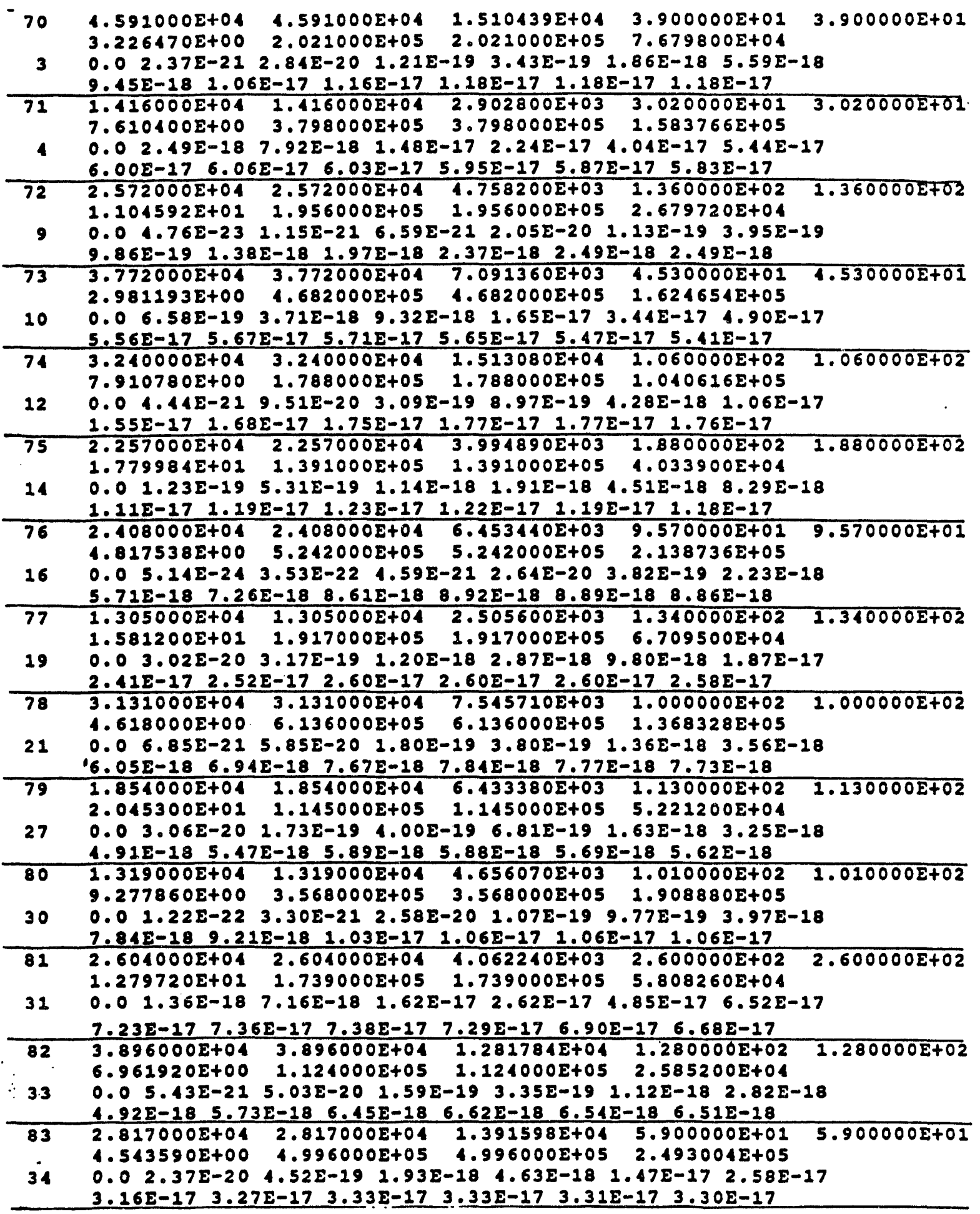


Table H2-1. (continued)

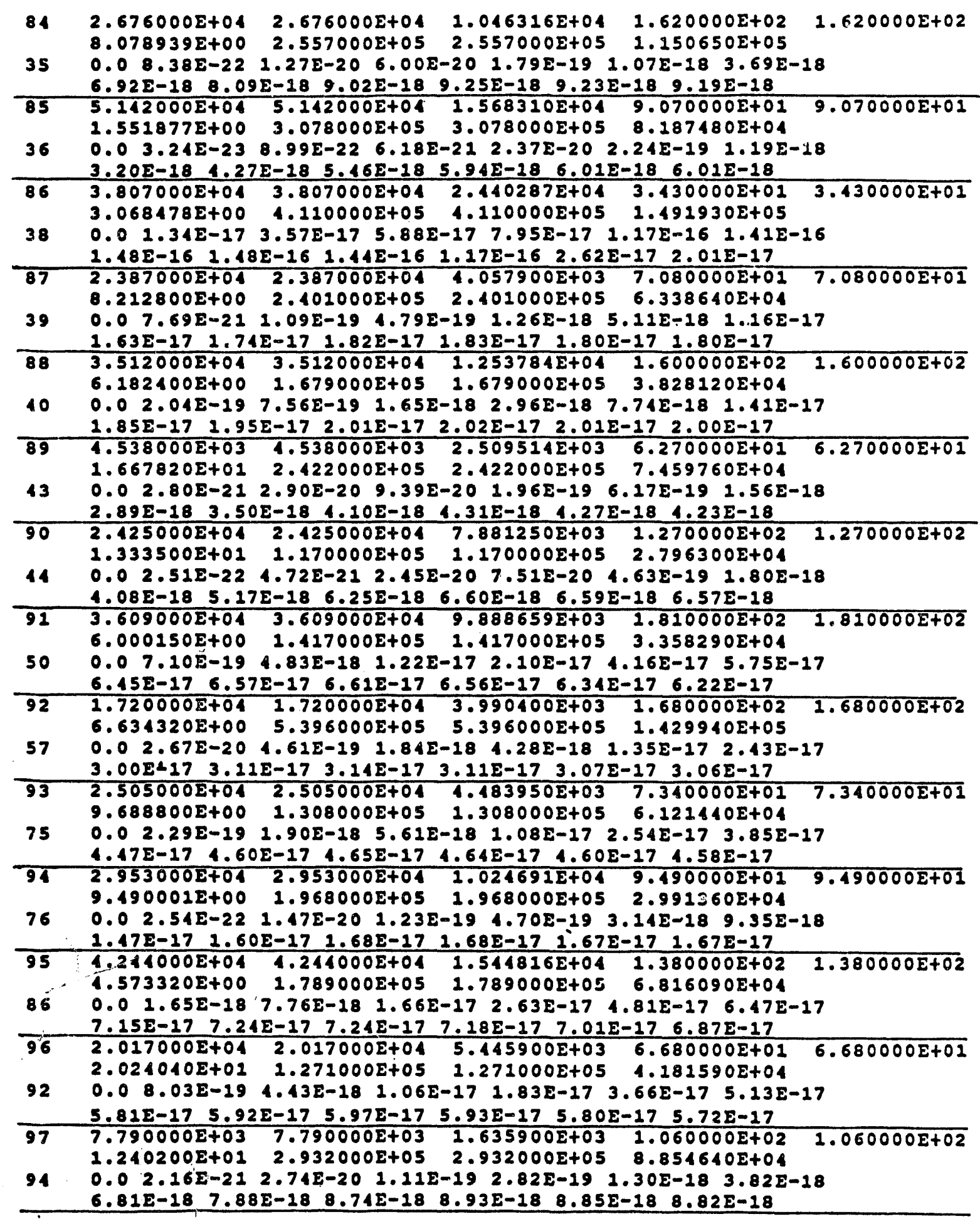

Rev. 0 
Table H.2-1. (continued)

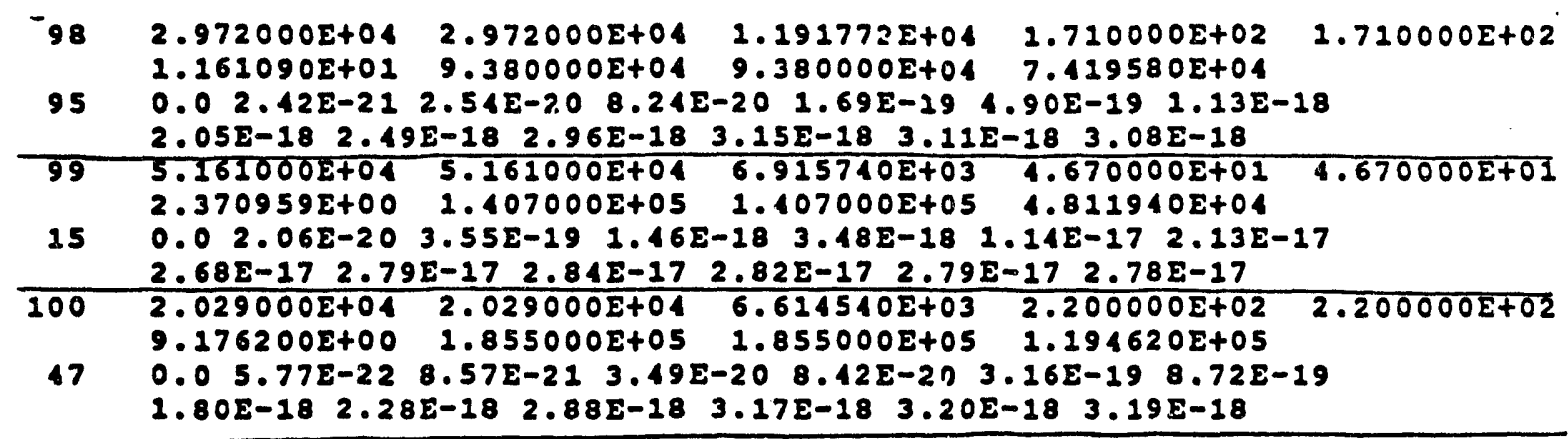

\section{Footnote:}

Table entries are interpreted as follows:

Far left integers represent run number, with saturated flow run 1 paired with run 7 from near-field uncertainty run. To the right of the saturated flow run number are nine numbers, representing, in order, $K_{w} K_{y}$, and $K_{2}$ for Zone $6 / 7 / 8, K_{\diamond}, K_{r}$ and $K_{z}$ for Zone $5 b$, followed by $K_{\infty} K_{y}$ and $K_{2}$ for Zone. $5 \mathrm{a}$. To the right of the near-field uncertainty run number are eleven numbers, representing the eleven nitrate fractional fluxes used for the saturated runs. 
Table H.2-2. Predicted peak nitrate concentrations in groundwater at $100 \mathrm{~m}$ from the SDF, node at which they occur, and time of peak for the 100 uncertainty analysis runs listed in Table H.2-1.

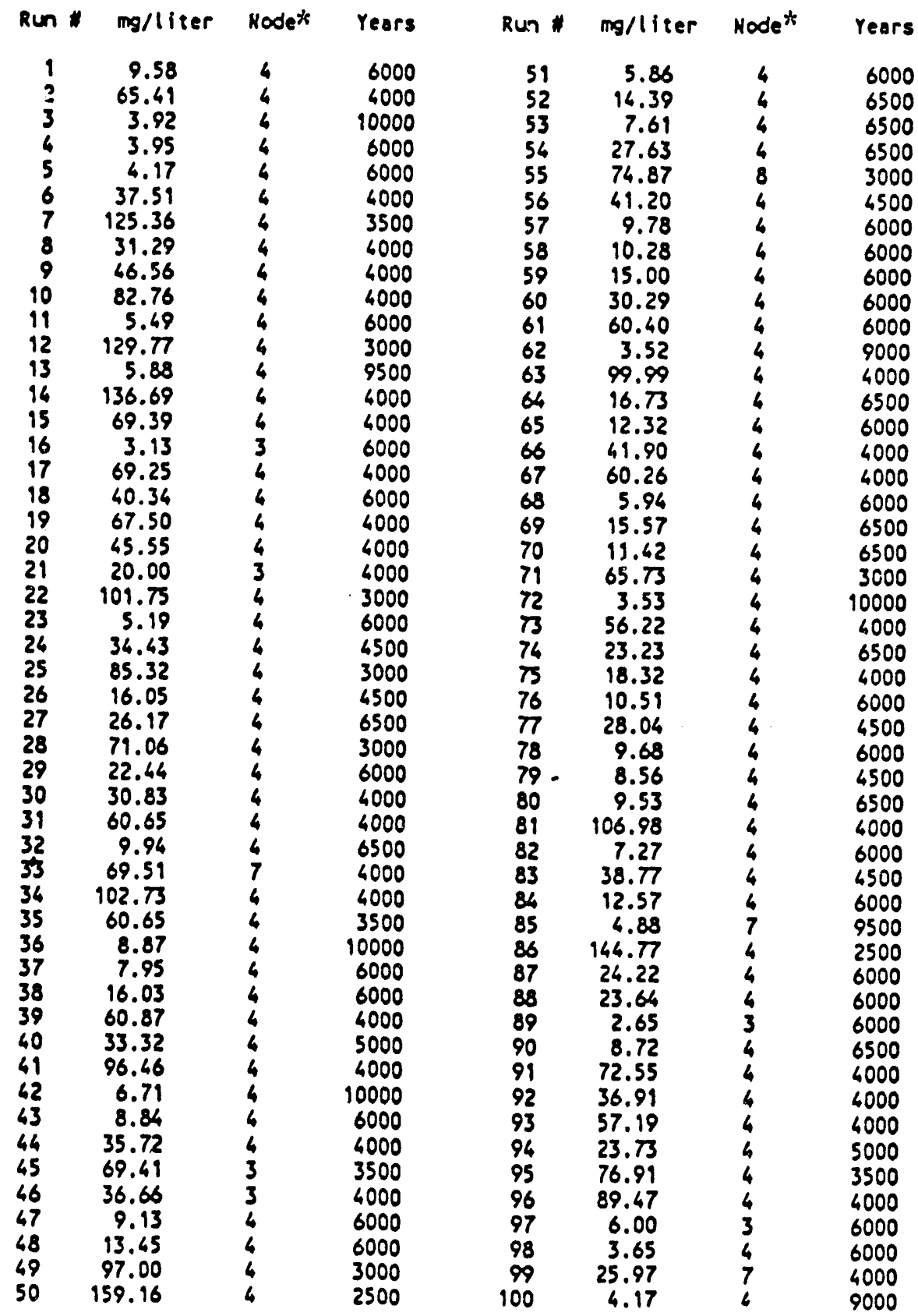

- Nodes 3 and 4 correspond to the Congaree formation, or Zone 5a. Nodes 7 and 8 correspond to the water table aquifer, or Zone $6 / 7 / 8$.

Rev. 0 

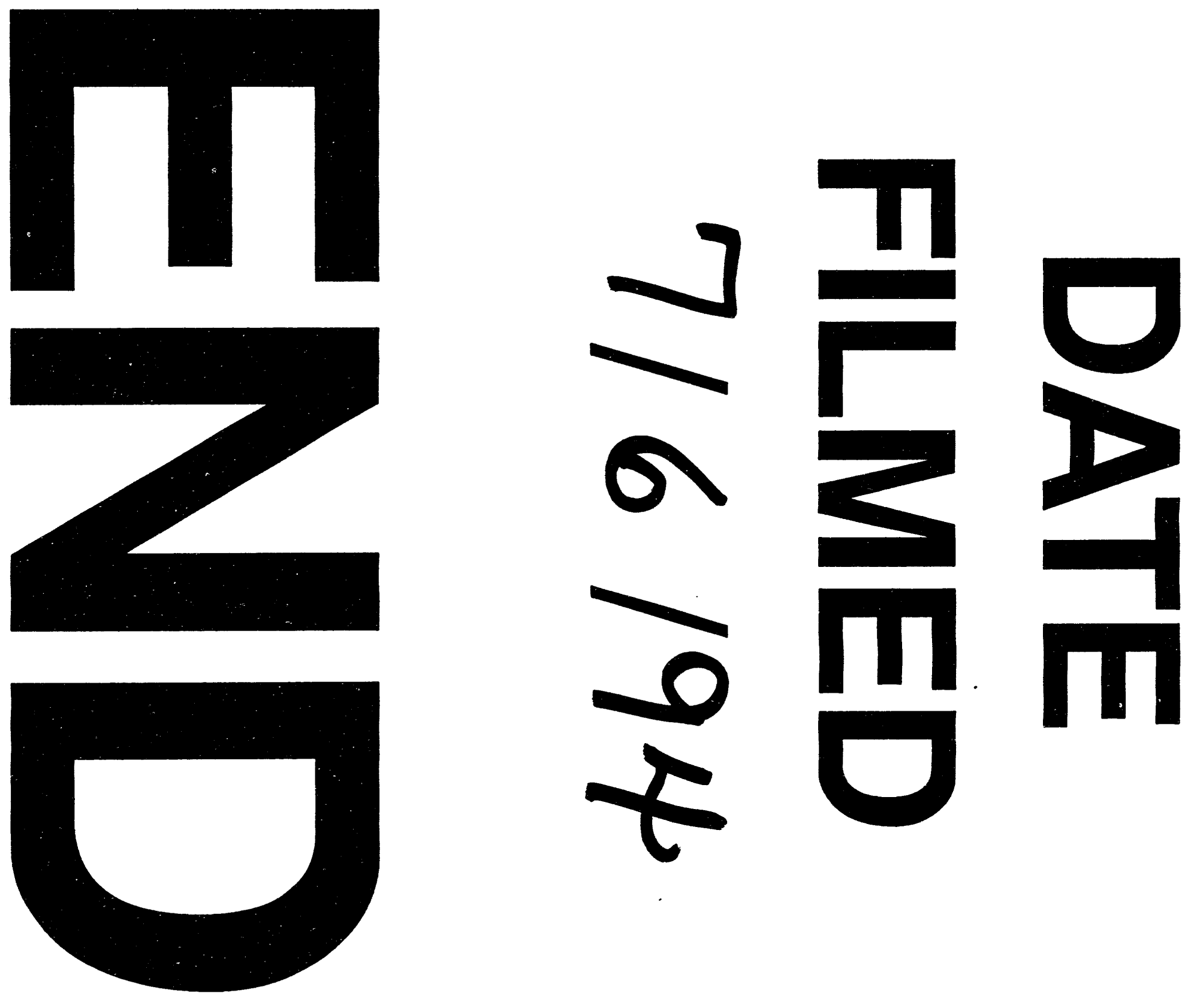


$$
-
$$

$-$<smiles>C1CCC1</smiles>

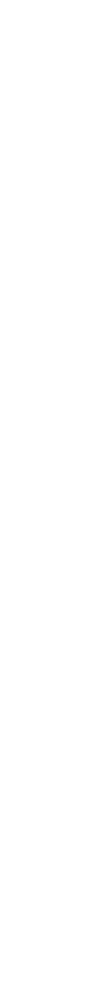

